\title{
HYDROGELS BASED ON SHORT AMPHIPATHIC PEPTIDES: \\ Self-assembly studies and applications
}

\begin{abstract}
PhD Thesis
Marta Tena-Solsona

Castellón, October 2015
\end{abstract}

Supervisors

Beatriu Escuder \& Juan Felipe Miravet 



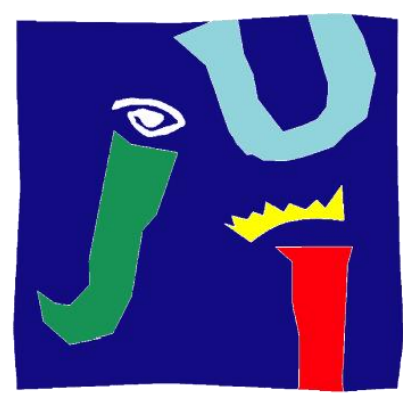

\section{UNIVERSITAT \\ JAUME•I}

DEPARTAMENT De QUímICA INORGÀNICA i ORgÀNICA

\section{HYDROGELS BASED ON SHORT}

\section{AMPHIPATHIC PEPTIDES: SELF-ASSEMBLY STUDIES AND APPLICATIONS}

HIDROGELES BASADOS EN PEQUEÑOS PÉPTIDOS ANFIPÁTICOS: ESTUDIOS DE AUTOENSAMBLAJE Y APLICACIONES

PhD Thesis

Marta Tena-Solsona

Supervisors:

Beatriu Escuder Gil and Juan F. Miravet Celades

Castelló, October 2015 



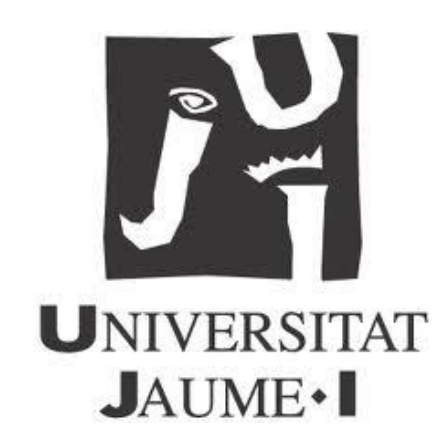

\section{DePARTAMENT De Química INORGÀnICA I ORgÀnICA}

Beatriu Escuder Gil, Associate Professor at the Department of Inorganic and Organic Chemistry, Universitat Jaume I.

Juan Felipe Miravet Celades, Associate Professor at the Department of Inorganic and Organic Chemistry, Universitat Jaume I.

CERTIFY that the PhD thesis entitled "Hydrogels Based on Short Amphipathic Peptides: Self-Assembly Studies and Applications" presented by Marta Tena-Solsona, has been developed under their supervision at the Organic Chemistry Section of the Department of Inorganic and Organic Chemistry, Universitat Jaume I.

Castelló, October 2015

B. Escuder Gil

J. F. Miravet Celades 



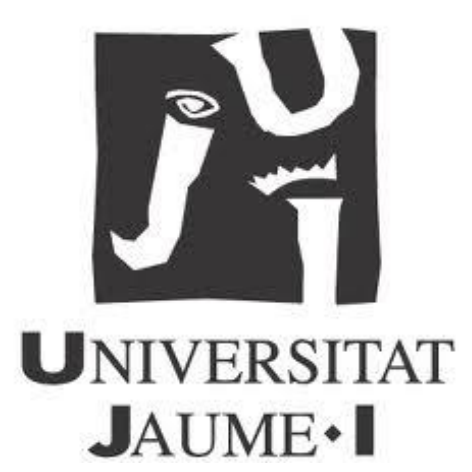

This work has been financed by the Spanish Ministry of Science and Innovation (CTQ2012-37735), and Universitat Jaume I (grant P1.1B2013-57). The Spanish Ministry of Education, Culture and Sports is acknowledged for an FPU predoctoral fellowship (AP2010-4780). Cost Actions CM1005, CM1304 and ISIS Neutron Source are acknowledged for travel and training grants.

The main part of this work has been published up to date in the following papers:

Tetrapeptidic molecular hydrogels: Self-assembly and co-aggregation with Amyloid fragment Aß1-40. M. Tena-Solsona, J. F. Miravet and B. Escuder, Chem. Eur. J., 2013, 20, 1023-1031.

Mechanistic insight into the lability of benzyloxycarbonyl (Z) group in some $\mathrm{N}$-protected peptides under mild basic conditions. M. Tena-Solsona, C. Angulo-Pachón, B. Escuder and J. F. Miravet, Eur. J. Org. Chem. 2014, 3372-3378.

Co-assembly of tetrapeptides into complex pH-responsive molecular hydrogel networks. $\mathrm{M}$. Tena-Solsona, S. Alonso-de Castro, J.F. Miravet and B. Escuder, J. Mater. Chem. B, 2014, 2, 61926197.

Thermodynamic and kinetic study of the fibrillization of a family of tetrapeptides and its application to self-sorting. What takes so long? M. Tena-Solsona, J.F. Miravet, B. Escuder, V. Castelleto, I.W. Hamley and A. Dehsorkhi, Chem. Mater. 2015, 27, 3358-3365.

Emergent catalytic behaviour of self-assembled low molecular weight peptide-based aggregates and hydrogels. M. Tena-Solsona, J. Nanda, A. Chotera, J.F. Miravet, G. Ashkenasy, B. Escuder, 2015, submitted. 



\section{AKNOWLEDGEMENTS}

Si bien no resulta demasiado fácil llevar a cabo una tesis doctoral tampoco resulta sencillo tratar de agradecer en tan breves líneas el inmenso apoyo y comprensión recibido por todas aquellas personas que, sin esperar nada a cambio, han permanecido a mi lado (aguantándome...) durante estos cuatro años.

La primera mención corresponde, claro está, a mis directores de tesis, los doctores Bea Escuder y Juan Felipe Miravet por darme la oportunidad de conocer de primera mano el mundo de la investigación. Su paciencia, sabiduría y buenos consejos han hecho posible poner punto y final a este trabajo que no siempre ha sido tan bonito como me hubiese gustado. Porque creo que han llegado a conocerme a mí y a mi particular tendencia al abismo cuando las cosas no salen bien, les agradezco que siempre hayan estado ahí para rescatarme y dedicarme esas palabras de apoyo que en el fondo uno siempre está esperando escuchar y que sin duda te ayudan a seguir adelante. Gracias en definitiva por vuestro apoyo tanto a nivel profesional como personal que espero encontrar en el futuro allá donde vaya.

Me gustaría agradecer también a todos aquellos que hicieron muy agradable las estancias lejos de mi hábitat en especial a los compañeros de York (Jorge, Vania, Stephen, Dan, Rex, Nicole, Julia, Tunde, Buthaina and Christopher) y al Profesor David Smith por adoptarme durante los tres meses y facilitarme la inmersión en el mundo de la heparina con su particular habilidad para contagiar el gusto por la ciencia. Hacer extensivo además el agradecimiento al Prof. Hamley y al Prof. Ashkenasy por permitirme colaborar con sus grupos y hacerme partícipe de sus proyectos.

No puedo olvidarme por supuesto de aquellos que han compartido laboratorio conmigo y me han escuchado reír, cantar, llorar, gritar e incluso maldecir a veces. A ellos y a su inestimable ayuda va dedicada gran parte de esta tesis. A aquellos que ya se han ido les echo mucho de menos. A Maria Dolores por sus valiosos consejos científicos en mis comienzos y por su inestimable amistad. A Vicent porque con él es una fiesta hasta discutir ecuaciones de termodinámica. A Carlos porque para mí es sin duda, un Supra más y a Silvia y a Alba por compartir vitrina codo con codo y ayudarme en lo que llamamos el 
trabajo duro. Espero haberos dejado un buen recuerdo (difícil de borrar) durante vuestro paso por aquí.

Para los compañeros que todavía siguen dando vueltas por el laboratorio... también tengo unas palabritas. Al Dr. Díaz (Santi para los amigos) le agradezco sobretodo sus consejos orgánico-síntéticos y su ayuda en esta dura recta final. Al Dr. César y a Carles tengo que darles las gracias por esas "salas", a veces en horas intempestivas, y por sus alegres piropos mañaneros que despiertan una sonrisa a cualquiera. Otro al que debería agradecer esos piropos (aunque desafortunadamente algo menos apropiados) es a mi querido portugués, Marco, que espero me invite a comer "bacalao" antes de que se vuelva a su amada tierra. Si de una cosa estoy segura es que esta experiencia no hubiera sido igual de divertida sin el incansable joker man Juanjo y el imparable Nishant, ambos ejemplos de vitalidad y compañerismo. A mi Cris mil gracias, simplemente por estar ahí siempre que te he necesitado. Agradecer también la compañía de nuestros vecinos de pasillo como Andreu, Alicia... a los que les deseo sin duda la mejor de las suertes. Con todos ellos he disfrutado de mi trabajo y también (aunque no menos importante) de festivales nocturnos y paellas dignas de los mejores paladares.

A los amigos que ya tenía (de la Comarca y más allá) así como aquellos que por fortuna han aparecido en mi vida, debo reconocerles su interés por esa cosa extraña que son los geles supramoleculares pero sobretodo agradecerles su comprensión, cariño y apoyo mostrados durante los momentos más duros.

Las palabras más emotivas son finalmente para mi familia sin la que sin duda no hubiera llegado a donde estoy. A mis padres debo darles las gracias por quererme, por apoyarme incondicionalmente y por hacerme tal como soy. Mi madre, Leonor, es sin duda la persona más fuerte y luchadora que jamás he conocido cuyo esfuerzo nos ha permitido salir adelante cuando todo lo dábamos por perdido. Mi padre, Leocadio, era y siempre será el perfecto ejemplo de bondad y generosidad con el que aprendí que la vida siempre merece la pena ser vivida. Mi hermano Lucas, aunque como yo no es hombre de muchas palabras, siempre ha estado ahí en las buenas y sobre todo en las malas por lo que no tengo palabras suficientes para agradecerle lo que eso significa para mí. A mis abuelas, a mis tíos, a mis primos, a mi cuñada Raquel (una más de la familia)...a todos 
gracias. Finalmente unas palabras con especial cariño para mi compañero de batalla, Pablo. Gracias por tu infinita paciencia y especialmente por no desesperar cuando yo lo hago. 

A mi padre

If you can't fly then run.

If you can't run then walk.

If you can't walk then crawl,

but whatever you do, have to keep moving forward.

Martin Luther King 



\section{Abbreviations}

\begin{tabular}{|c|c|}
\hline A, Ala & Alanine \\
\hline ABSMs & Amyloid $\beta$-sheet mimics \\
\hline $\mathrm{ACN}$ & Acetonitrile \\
\hline $\mathrm{AcOH}$ & Acetic acid \\
\hline$A D$ & Alzheimer's disease \\
\hline AFM & Atomic force microscopy \\
\hline ANS & 1-Anilinonaphthalene-8-sulphonate \\
\hline$A \beta$ & Amyloid peptide \\
\hline $\mathrm{B}_{\mathrm{AC} 2}$ & Bimolecular Basic Hydrolysis with Acyl-Oxygen Fission \\
\hline $\mathrm{Boc}_{2} \mathrm{O}$ & di-tert-butyl dicarbonate \\
\hline BOP & (Benzotriazol-1-yloxy)tris(dimethylamino)phosphonium hexafluorophosphate \\
\hline BTB & Bromothymol Blue \\
\hline C, Cys & Cysteine \\
\hline $\mathrm{CD}$ & Circular dichroism \\
\hline Cha & Cyclohexylalanine \\
\hline$d$ & Doublet \\
\hline D, Asp & Aspartic acid \\
\hline DCC & $\mathrm{N}, \mathrm{N}^{\prime}$-dicyclohexylcarbodiimide \\
\hline DCM & Dichloromethane \\
\hline DCU & $\mathrm{N}, \mathrm{N}^{\prime}$-dicyclohexylurea \\
\hline dd & Doble doublet \\
\hline DHAP & Dihydroxyacetone phosphate \\
\hline DIC & N,N'-Diisopropylcarbodiimide \\
\hline DIPEA & N,N-Diisopropylethylamine \\
\hline DME & Ethylene glycol dimethyl ether \\
\hline DMF & $\mathrm{N}, \mathrm{N}$-dimethylformamide \\
\hline DMSO & Dimethyl sulfoxide \\
\hline DNA & Deoxyribonucleic Acid \\
\hline DOSY & Diffusion-ordered spectroscopy \\
\hline E, Glu & Glutamic acid \\
\hline e.e. & Enantiomeric excess \\
\hline $\mathrm{E} 1 \mathrm{cB}$ & Elimination Unimolecular conjugate Base \\
\hline ESI & Electrospray ionisation \\
\hline F, Phe & Phenylalanine \\
\hline Fmoc & Fluorenylmethyloxycarbonyl chloride \\
\hline FTIR & Fourier transform infrared spectroscopy \\
\hline $\mathrm{G}^{\prime \prime}$ & Loss modulus \\
\hline G, Gly & Glycine \\
\hline $\mathrm{G}^{\prime}$ & Storage modulus \\
\hline GdL & $\delta$-D-Gluconolactone \\
\hline $\mathrm{H}$, His & Histidine \\
\hline HBTU & O-Benzotriazol-1-yl-tetramethyluronium \\
\hline
\end{tabular}




\begin{tabular}{|c|c|}
\hline HDGA & Hexadecanedioyl glutamic acid \\
\hline HMPA & Hexamethylphosphoramide \\
\hline HPLC & High performance liquid chromatography \\
\hline HRMS & High resolution mass spectrometry \\
\hline IAPP & Islet amyloid polypeptide \\
\hline IR & Infrared spectroscopy \\
\hline I, lle & Isoleucine \\
\hline K, Lys & Lysine \\
\hline Kapp & Apparent constant \\
\hline Kdim & Dimer formation constant \\
\hline $\mathrm{K}_{\mathrm{s}}$ & Solubility product \\
\hline$K_{\text {tet }}$ & Tetramer formation constant \\
\hline L, Leu & Leucine \\
\hline LMW & Low molecular weigh \\
\hline LVR & Linear viscolastic regime \\
\hline $\mathrm{m}$ & Multiplete \\
\hline M, Met & Methionine \\
\hline m.g.c. & Minimum gelation concentration \\
\hline MB & Methylene Blue \\
\hline MeOD & Deuterated methanol \\
\hline$N$, Asn & Asparagine \\
\hline NMP & N-Methyl-2-pyrrolidone \\
\hline NMR & Nuclear magnetic resonance spectroscopy \\
\hline P, Pro & Proline \\
\hline PA & Peptide amphiphile \\
\hline PB & Phosphate buffer \\
\hline PBS & Phosphate buffer saline \\
\hline PMMA & Poly(methyl methacrylate) \\
\hline РyВOP & benzotriazol-1-yl-oxytripyrrolidinophosphonium hexafluorophosphate \\
\hline q & Quadruplet \\
\hline$Q, G \ln$ & Glutamine \\
\hline $\mathrm{R}, \mathrm{Arg}$ & Arginine \\
\hline RNA & Ribonucleic acid \\
\hline s & Singlet \\
\hline Sar & Sarcosine \\
\hline S, Ser & Serine \\
\hline SANS & Small angle neutron scattering \\
\hline SAXS & Small angle $X$-ray scattering \\
\hline SEM & Scanning electron microscopy \\
\hline SPPS & Solid phase peptide synthesis \\
\hline $\mathrm{t}$ & Triplet \\
\hline T, Thr & Threonine \\
\hline$t-B o c$ & tert-butyloxycarbonyl \\
\hline$t-B u$ & tert-butyl ester \\
\hline
\end{tabular}




$\begin{array}{ll}\text { TCEP } & \text { Tris(2-carboxyethyl)phosphine } \\ \text { TEM } & \text { Transmission electron microscopy } \\ \text { TFA } & \text { Trifluoroacetic acid } \\ \text { TFE } & \text { 2, 2, 2-Trifluoroethanol } \\ \text { THF } & \text { Tetrahydrofuran } \\ \text { ThT } & \text { Thioflavine T } \\ \text { TLC } & \text { Thin layer chromatography } \\ \text { TOF } & \text { Time of flight } \\ \text { UV-Vis } & \text { Ultraviolet-visible spectroscopy } \\ \text { V, Val } & \text { Valine } \\ \text { W, Trp } & \text { Tryptophan } \\ \text { WAXS } & \text { Wide-angle X-ray scattering } \\ \text { Y, Tyr } & \text { Tyrosine } \\ \text { Z } & \text { Benzyloxycarbonyl } \\ \sigma_{y} & \text { Yield stress }\end{array}$





\section{TABle of Contents}

$\begin{array}{lll}\text { Chapter } 1 & \text { INTRODUCTION } & 5\end{array}$

1.1 Molecular self-assembly 5

$\begin{array}{lll}1.2 & \text { Peptide self-assembly } & 8\end{array}$

1.2.1 Amphiphatic peptides alternating polar/non polar amino 11 acids

$\begin{array}{ll}\text { 1.2.2 Lipopeptides } & 15\end{array}$

$\begin{array}{ll}\text { 1.2.3 Peptide co-assembly } & 20\end{array}$

1.3 Peptide fibrillisation and amyloid diseases 23

1.3.1 Kinetics and thermodynamics of fibrillisation 25

1.3.2 Small peptides as a model for amyloid fibril formation 26

1.3.3 Small peptides as inhibitors of amyloid formation 28

$\begin{array}{lll}1.4 & \text { Supramolecular gels } & 31\end{array}$

1.4.1 Peptide-based supramolecular hydrogels 34

1.4.1.1 Stimuli responsive supramolecular hydrogels 36

1.4.1.2 Applications of peptide hydrogels 40

$\begin{array}{lll}1.5 & \text { References } & 47\end{array}$

$\begin{array}{lll}\text { Chapter } 2 & \text { OBJECTIVES OF THE THESIS } & 63\end{array}$

2.1 General objectives of the thesis 63

2.2 Specific objetives $\quad 63$

$\begin{array}{lll}2.3 & \text { References } & 66\end{array}$

$\begin{array}{lll}\text { Chapter } 3 & \text { DESIGN AND SYNTHESIS } & 71\end{array}$

$\begin{array}{ll}3.1 \text { Design of amphipatic peptides } & 71\end{array}$

$\begin{array}{lll}3.2 & \text { Peptide synthesis in solution } & 73\end{array}$

3.2.1 Synthesis of compounds 1-12 77

3.3 Solid phase peptide synthesis (SPPS) 82

3.4 Unexpected deprotection of benzyloxycarbonyl group (Z) 88

$\begin{array}{ll}3.5 & \text { Supplementary information }\end{array}$

$\begin{array}{lll}3.6 & \text { References } & 111\end{array}$ 
Chapter 4 ACIDIC TETRAPEPTIDES CONTAINING L-ASPARTIC (D) AND LPHENYLALANINE (F)

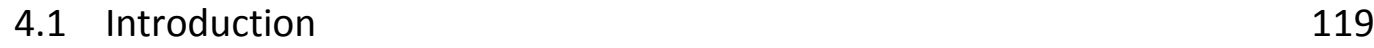

4.2 Hydrogelation with acidic tetrapeptides 119

4.2.1 Determination of m.g.c. and morphological description 120

$\begin{array}{lll}\text { 4.2.2 Structural studies } & 126\end{array}$

$\begin{array}{ll}\text { 4.2.3 Mechanical properties of the hydrogels } & 137\end{array}$

4.3 Thermodynamic and kinetic studies of the fibrillisation process 140

$\begin{array}{lll}\text { 4.3.1 Thermodynamics } & 142\end{array}$

$\begin{array}{lll}4.3 .2 & \text { Kinetics } & 146\end{array}$

4.3.3 Self-sorting of a two-component hydrogel 154

4.4 Interaction of tetrapeptides 1-6 with amyloid peptide A $\beta 1-40 \quad 157$

$\begin{array}{ll}4.5 \text { Conclusions } & 166\end{array}$

$\begin{array}{ll}4.6 & \text { Supplementary information } \\ & 168\end{array}$

$\begin{array}{llr}4.7 & \text { References } & 180\end{array}$

Chapter 5 BASIC TETRAPEPTIDES CONTAINING L-LYSINE (K) AND L- 191 PHENYLALANINE (F)

$\begin{array}{ll}5.1 \text { Introduction } & 191\end{array}$

5.2 Hydrogelation of basic tetrapeptides 7 and 8

5.3 Co-assembly between acidic $(\mathbf{1}, \mathbf{2})$ and basic $(\mathbf{7}, \mathbf{8})$ tetrapeptides at 195 neutral $\mathrm{pH}$

5.3.1 Stoichiometry of the co-assembled mixtures 196

$\begin{array}{ll}\text { 5.3.2 Microscopic and structural studies } & 198\end{array}$

$5.4 \mathrm{pH}$ responsive co-assembled systems 202

5.4.1 Hydrogel formation and characterization 203

5.4.2 Exchange of fibrillar networks by pH tunning 209

5.4.3 Tunable release of loads by pH changes 213

5.5 Kinetically entrapped networks 216

$\begin{array}{lll}5.6 \text { Conclusions } & 218\end{array}$

5.7 Supplementary information 219

$\begin{array}{lll}5.8 & \text { References } & 229\end{array}$ 
Chapter 6 AMPHIPHILIC PEPTIDES CONTAINING L-PROLINE (P) 235

6.1 Introduction 235

6.2 Self-assembly of proline derivatives in phosphate buffer 239

6.3 Catalytic activity of proline peptide amphiphiles in the aldol 244 reaction

6.4 Biomimetic catalysis 251

6.5 Conclusions 253

6.6 Supplementary information 255

$\begin{array}{lll}6.7 & \text { References } & 269\end{array}$

$\begin{array}{llr}\text { Chapter } 7 & \text { CONCLUSIONS } & 277\end{array}$

\section{ANNEXES}

Annex I: Summary in Spanish 283

Annex II: List of compounds 293 

CHAPTER 1

\section{INTRODUCTION}



CHAPTER 1

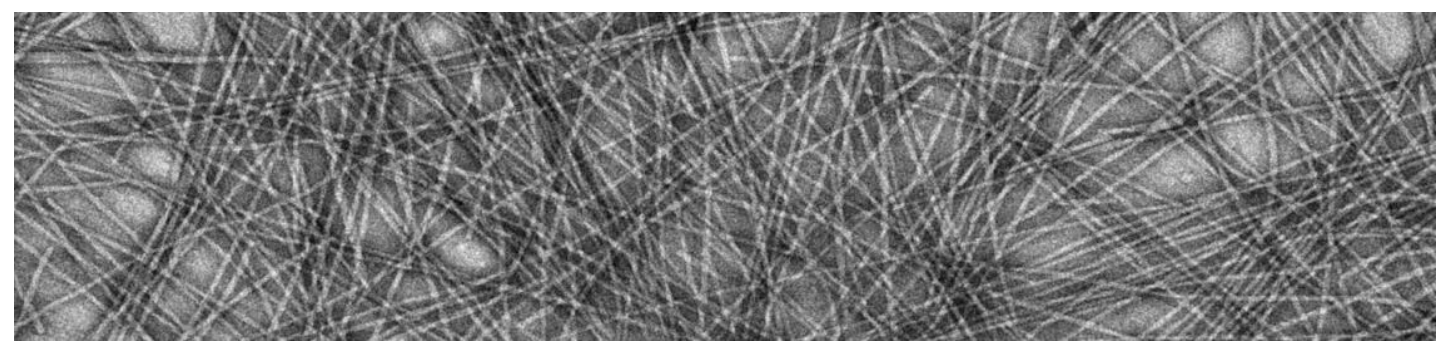

Introduction 



\section{INTRODUCTION}

\subsection{Molecular self-assembly}

Molecular self-assembly is the spontaneous and reversible association of molecules under equilibrium conditions into well-ordered structures as a result of noncovalent intramolecular/intermolecular interactions. ${ }^{1}$ The study of this astonishing phenomenon has been widely explored during the last few decades for many reasons. ${ }^{2}$ One of them for example comes from the inherent attraction humans have to understand and explain how order can appear from disorder. Other important motivation is due to the smallest unit of life that can replicate, the cell. This basic, structural and functional unit of all known organism self-assembles and therefore, the understanding of life will require first of all, the understanding of self-assembly principles. Finally the countless applications that self-assembled systems have in such different fields like materials science, biomedicine or nanotechnology will also promote an intense research on this area for a better knowledge of these systems and substantial improvements of their final properties.

As we know boundaries are very important in our society for economical reasons and also because they define and characterize cities, countries, nations... we cannot even imagine how important the cell boundary formation was for the origin of life. The constitution of the cell membrane leaded to a spatially localized compartment where genetic material can reside and metabolic activities can take place without being lost to the environment. ${ }^{3}$ Leading aside the possible sources of complex prebiotic organic compounds in the earth, the key role of self-assembly processes in the emergence of cell membrane and further self-reproducing molecular systems is almost undeniable and subsequently to understand the principles that rule the self-assembly will enormously clarify the origin of life.

Because cell membrane could be one of the first examples of cell assembly and also because the cell as a whole illustrates a wide variety of natural self-assembled processes (Figure 1.1) it deserves a special mention when we refer to this topic. ${ }^{4}$ 


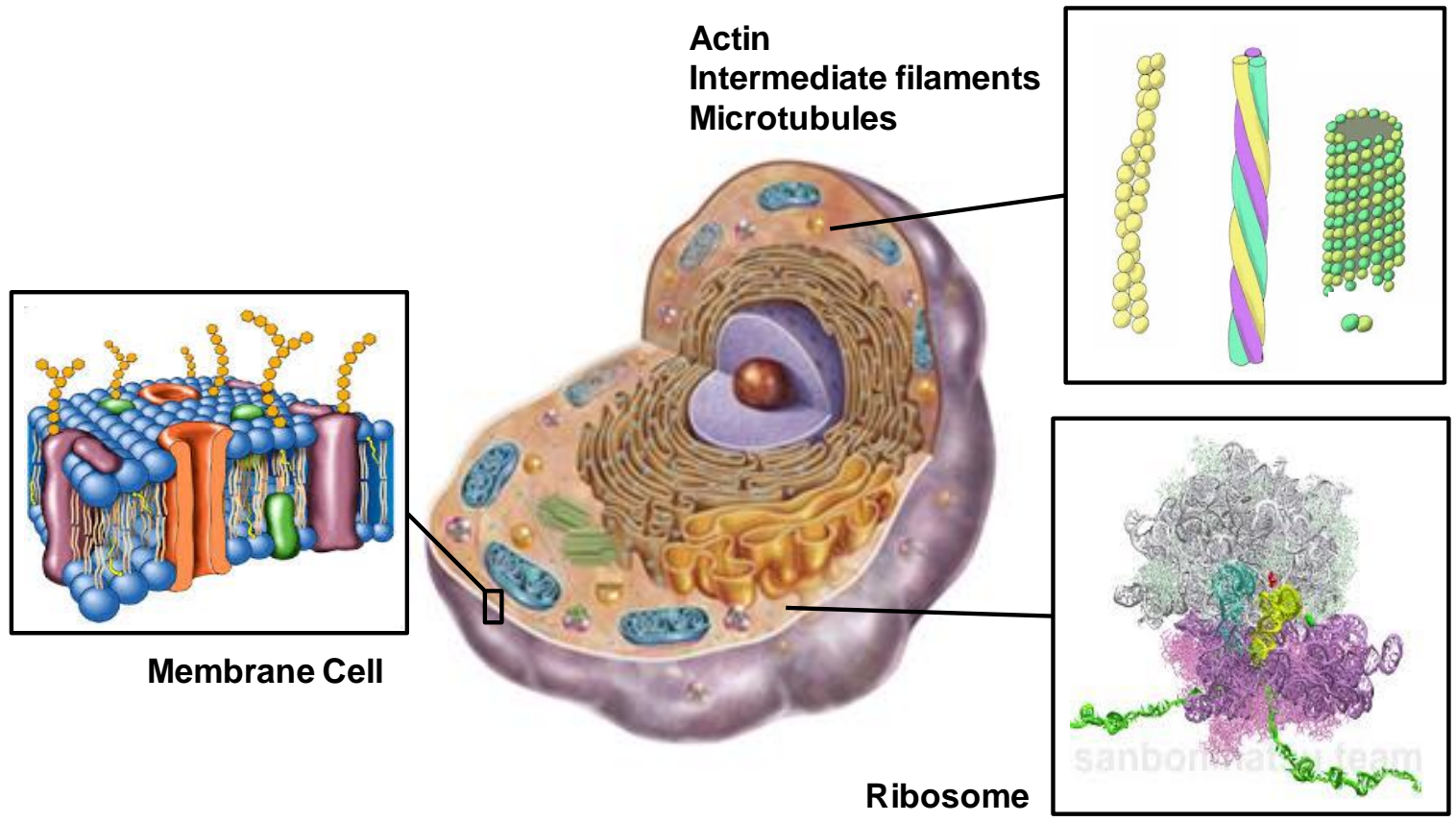

Figure 1.1 Eurcaryotic cell with insets corresponding to membrane cell, cytoskeleton polymers (actin filaments, intermediate filaments and microtubules) and ribosome. Adapted from ref. 4.

The cell membrane is a highly selective permeable barrier consisting of a selfassembled phospholipid bilayer that limits and protects the cell from its surroundings. The membrane is composed of two layers of lipids arranged in a way that their hydrocarbon tails face one another to form a hydrophobic core, while their hydrophilic head groups oriented to the aqueous solutions on either side of the membrane. Other important self-assembly example in the cell can be found in its cytoskeleton. The three main cytoplasmatic supramolecular polymers which are microtubules, actin filaments and intermediate filaments, spontaneously assemble from short monomers into long uniform structures. They participate in such important functions like chromosome segmentation during cell division, linkage between transmembrane and cytoplamasmatic proteins or providing a supporting framework within the cell respectively. The eukariotic ribosome finally is also an extremely complex assembled system containing more than fifty protein subunits and several RNAs.

Those examples among other natural self-assembled systems have inspired scientists leading to the emergence of what is known as Supramolecular Chemistry. This discipline covers the study of not only self-assembly in and between molecules but also the study of the emerging supramolecular structures. ${ }^{5}$ 
From the earliest simple synthetic examples of self-assembly, ${ }^{6}$ increased knowledge of supramolecular interactions has enabled the development of more complex systems with many different building blocks (natural or artificial) that led to a wide variety of topologies, physico-chemical properties and applications. ${ }^{7}$

A

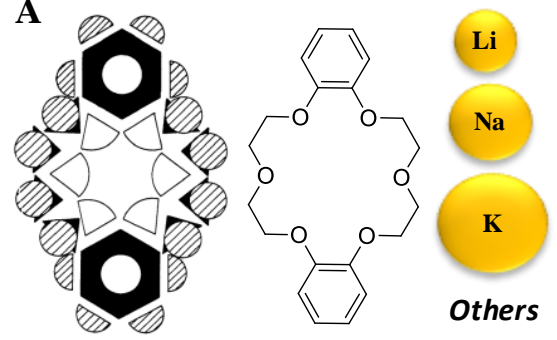

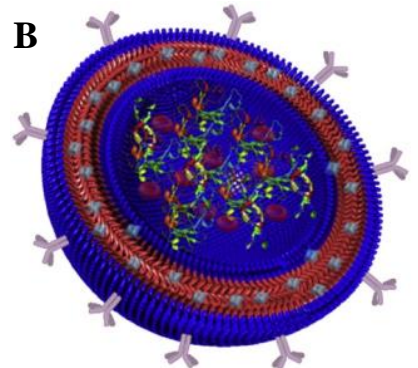

Figure 1.2 a) Simple supramolecular complex described by Pedersen and co-workers in 1967 between cyclic polyethers and metal salts.6 b) An example of supramolecular complex architecture recently reported which consists in a polymersome modified by antibodies containing hydrophilic molecules in the aqueous core and hydrophobic drugs in the bilayer membrane held, all of them, by non-covalent interactions. $^{8}$

As it has been introduced before the process of self-assembly is governed by non-covalent interactions incluiding electrostatic interaccions, hydrogen bonding, $\pi-\pi$ stacking, metal-ligand coordination, van der Waals interactions and solvophobic effects. These interactions are individually weak when compared with covalent bonds but in sufficient number they can generate highly assembled systems and their delicate balance govern the shape and the function of the final system.

Solvophobic effects deserve a special consideration when the self-assembly process takes place in water. In this solvent common non-covalent interactions, such as hydrogen bonding, lose its strength in benefit of the hydrophobic effect and as a consequence the self-assembly is driven by the minimization of the exposed hydrophobic surfaces to water. Hydrophobic effect besides cannot be simply described as one type of non-covalent interaction but rather a combination of enthalpic interactions such as dipole-dipole interactions, hydrogen bonds or van der Waals interactions ${ }^{9}$ together with the gain of entropy associated to water molecules.

In general these reversible non-covalent interactions endow supramolecular selfassembled systems with extraordinary features in comparison with covalent organizations including: $: 4^{\prime} 7^{\mathrm{a}, \mathrm{b}, 10}$ 
- Dynamic behaviour.

- High degrees of structural order.

- Self-healing, adaptation and error correction.

- Smart responsiveness to stimuli. Multiple external stimuli can reversibly switch on/off the structure, morphology and properties of these materials.

- The ease of supramolecular synthesis.

- The possibility to incorporate multiple arrays of different ligands through intermixing of building blocks.

Although the great progress molecular self-assembly materials have undergone during last decades there are several challenges that have not been yet extensively solved. One of the main challenges in Supramolecular Chemistry still includes the development of homogeneous and structurally well-defined architectures with tunable properties to cover a broad range of applications. In order to achieve this final goal an accurate and rational design as well as, a better understanding of the self-assembly rules for the different monomeric building blocks are key features to create smart supramolecular architectures with predictable final properties and functions.

Among the wide variety of building blocks described so far (including natural ${ }^{11}$ or artificial) ${ }^{12}$ peptides are one of the most versatile motifs and their main features and properties will be extensively described in next sections.

\subsection{Peptide self-assembly}

Peptides are one of the most commonly used biological building blocks for the development of self-assembling materials and possess a wide number of advantages that make them especially attractive for this purpose. Proteins and peptides are made up of 20 natural L-amino acids (Figure 1.3). All amino acids are chiral in nature except glycine $(G)$ and have the same basic structure containing an amino and a carboxylic acid group. The only difference between them is the side chain groups $(-R)$ attached to the chiral carbon $\left(\mathrm{C}_{\alpha}\right)$. Peptides adopt specific configurations depending on which R-groups are near one another in peptide chain. The number, type and sequence of amino acids 
can be manipulated to design self-assembling peptides and as a consequence there is a relationship between amino acid sequence and structure.

Amino acids as building blocks show different physicochemical properties depending on the charge, hydrophobicity, size and polarity in the side chain which contribute to their biochemical mode of action and dictates the final self-assembled conformation. For example, aliphatic residues ( $A, I, L, M, V)$ provide a hydrophobic environment while aromatic amino acids $(F, W, Y)$ can become involved in $\pi-\pi$ stacking interactions. Neutral polar residues can be involved in hydrogen bonding through $\mathrm{OH}(\mathrm{S}$, $\mathrm{T})$ and $\mathrm{CONH}_{2}(\mathrm{~N}, \mathrm{Q})$. Peptide sequence can also be endowed with positively $(H, K, R)$ or negatively $(D, E)$ charged residues. These charged residues can be useful to create specific charge-charge interactions between oppositely charged moieties that contribute to form assemblies or they can be used to prevent assembly by charge repulsions. Other amino acids like glycine $(G)$ and proline $(P)$ can modify the flexibility of the peptide chain. $\mathrm{G}$ for instance removes steric hindrance while $\mathrm{P}$ introduces structural ridigity because the side chain is covalently linked to the amino terminus. Amino acids like cysteine (C) can bind gold surfaces and participate in peptide cross-linking by intra and intermolecular disulfide bonds. histidine $(\mathrm{H})$ is also able to bind other compounds like metal cations and finally serine, threonine and tyrosine $(S, T, Y)$ are suitable for chemical or enzymatic modifications. ${ }^{13}$

It is not difficult to see why the rational design of these materials is still so challenging. Considering just a tetrapeptide sequence, $20^{4}$ different combinations can be obtained and the possibilities are nearly endless for longer peptide chains.

This enormous versatility however, can be also considered as an advantage which combined with their relative physicochemical stability and the feasibility to synthesize them in large amounts have promoted peptides as one of the best building blocks for new self-assembled materials. ${ }^{10}$ In addition peptides have become specially useful in medical applications ${ }^{14}$ because of their intrinsic biocompatibility and biodegradability and also because they participate in a wide variety of physiological and biochemical functions. Regarding this topic, the key role of self-assembled peptides in amyloid diseases will be specially considered and discussed later on in this work. 


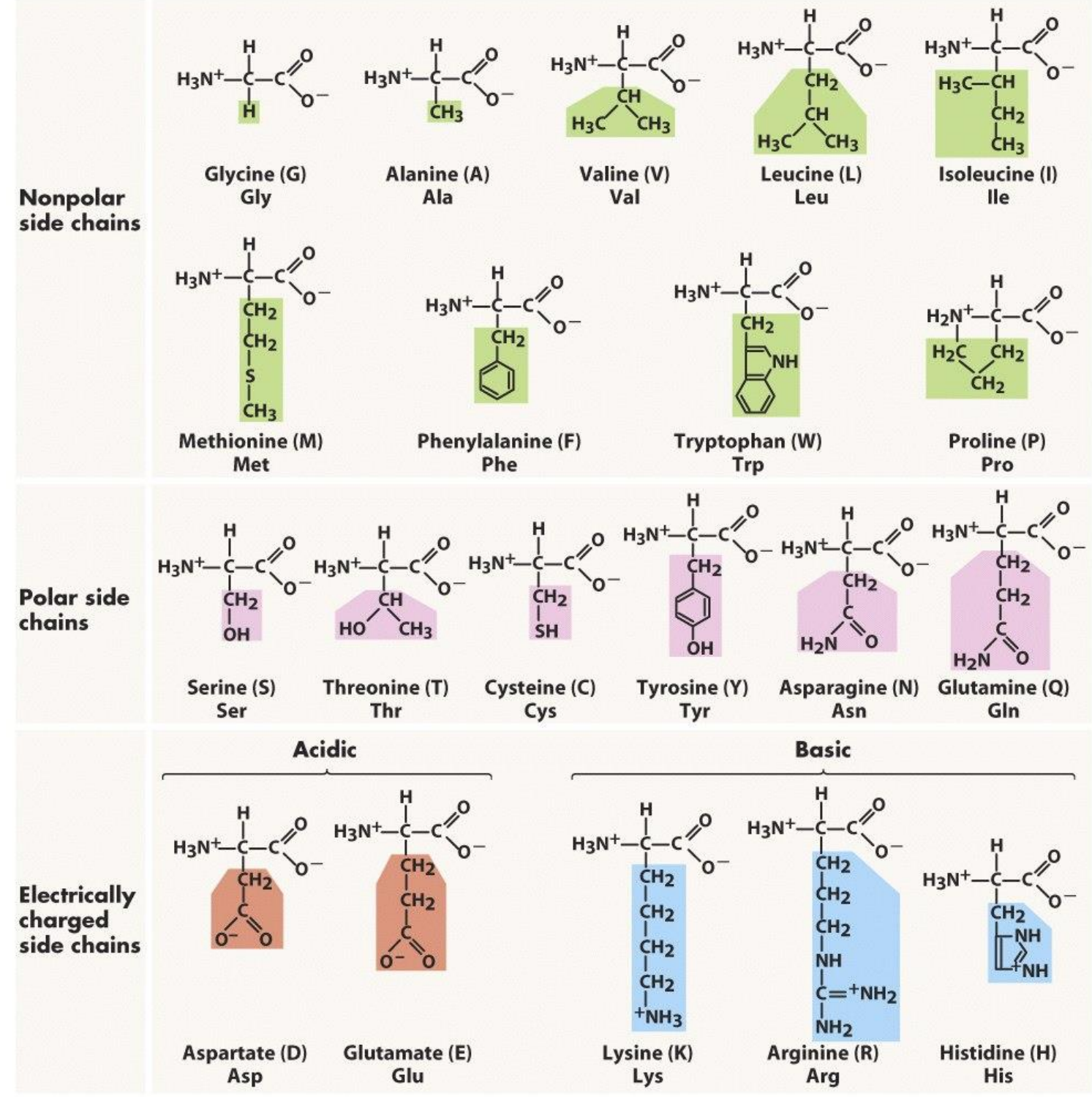

Figure 1.3 Natural amino acids classification considering the chemical properties of the side chain (-R). Adapted from Pearson Prentice Hall 2005, Inc.

The two most common "natural" motifs used for peptide-based materials are the $\alpha$-helix and the $\beta$-sheet. Additionally peptide epitopes can be easily modified chemically or biologically including additional supramolecular interactions and as a result a broad range of self-assembled nanostructures have been reported as for instance nanotubes, nanofibres, nanospheres, nanobelts, hydrogels... ${ }^{15}$ 


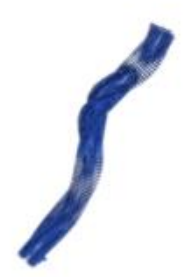

fibre
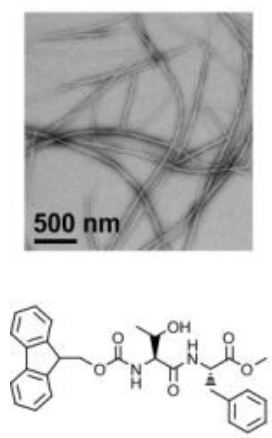

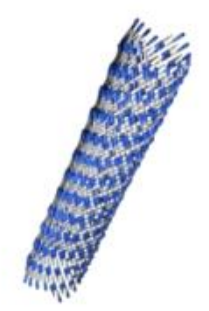

tube
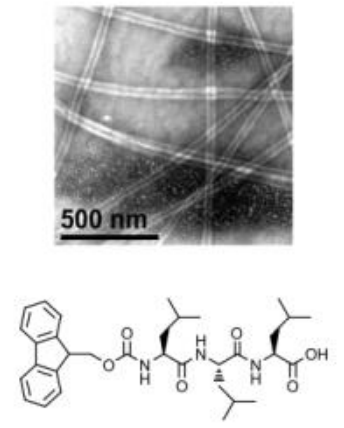

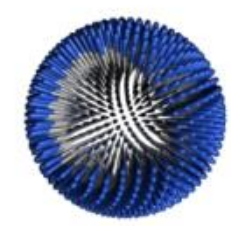

sphere
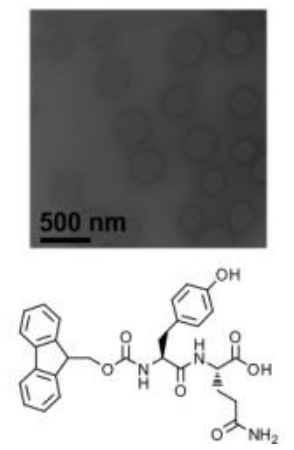

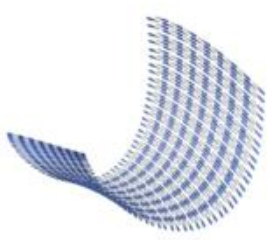

sheet
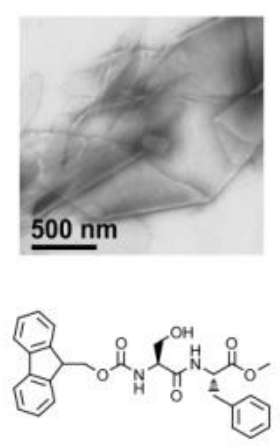

Figure 1.4 Different nanostructures obtained after the self-assembly of di- and tripeptides containing Fmoc. $^{16}$

As it has been mentioned above there is a huge variability of peptide sequences and there are also many classifications of self-assembled peptides considering for example peptide chain composition, secondary interactions involved in the selfassembly process, nanostructure generated after this process and so on. Since it is not possible to cover all of them and because of our particular interest we will focus our attention on the amphipathic peptides and will distinguish between those formed by alternating polar/non polar amino acids and those containing hydrophilic peptides attached to hydrophobic lipid alkyl chain (also known as lipopeptides or simply peptide amphiphiles).

\subsubsection{Amphipathic peptides alternating polar/non polar amino acids}

The amphipathic term commonly refers to molecules which contain simultaneously both polar and non polar residues. First of all we will focus our attention in those formed by alternating polar and non polar amino acids. Generally these amphipathic peptides self-assemble into $\beta$-sheet bilayers in which the hydrophobic residues are buried in the core of the fibril while the hydrophilic moieities are exposed to the aqueous medium (Figure 1.5). 


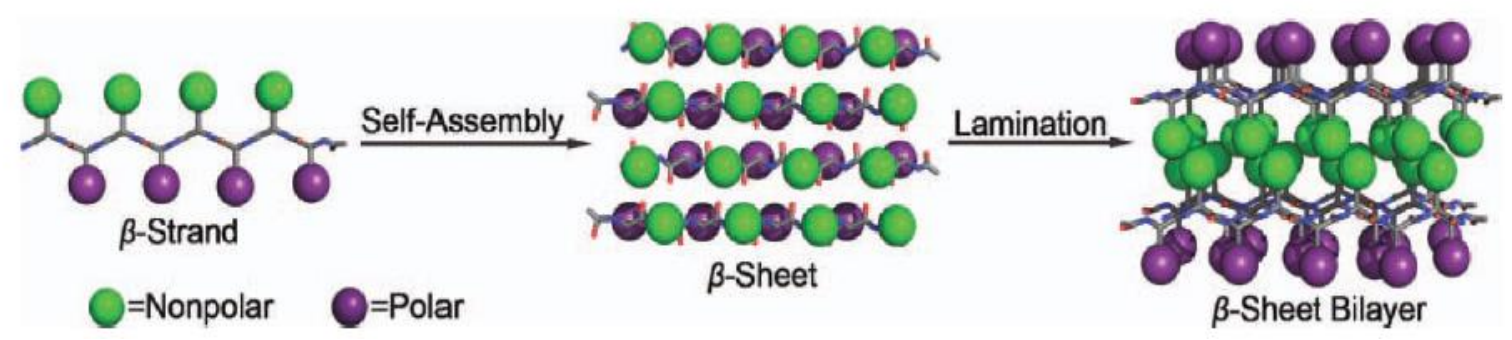

Figure 1.5 Proposed mode of self-assembly for amphipathic peptides into a $\beta$-sheet structure. ${ }^{17}$

Zhang and co-workers discovered in the early $90 \mathrm{~s}^{18}$ that amphipathic peptides such as Ac-(AEAEAKAK) ${ }_{2}-\mathrm{NH}_{2}$ self-assemble into nanofibres by electrostatic interactions between oppositely charged amino acids, hydrophobic interactions involving $A$ and interchained hydrogen bonding. From then until now, the reported variety of amphipathic peptides which give rise to $\beta$-sheet bilayer structures is so large ${ }^{19}$ that the understanding of the relationship between peptide sequence, self-assembly propensity and final properties of the fibrils is still incomplete. In order to elucidate some of these self-assembly principles there have been many detailed studies about sequenceassembling properties correlation based on a systematic approach.

The influence of hydrophobic residues on self-assembly propensity was investigated by many authors using the sequence (FKFE) $\mathrm{n}$ and variants. ${ }^{20}$ Nilsson and coworkers $^{20 \mathrm{~b}}$ for example, modified systematically the initial sequence $\mathrm{Ac}-(\mathrm{FKFE})_{2}-\mathrm{NH}_{2}$ by changing $\mathrm{F}$ residues into $\mathrm{A}, \mathrm{V}, \mathrm{L}$ and cyclohexylalanine (Cha) residues (listed in order of incresing hydrophobicity).

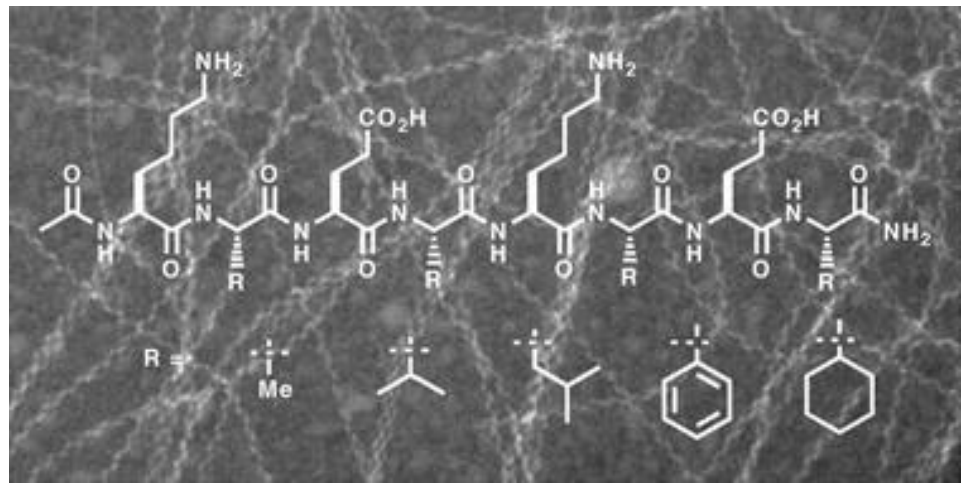

Figure 1.6 Original molecular design of the $\beta$-sheet amphipathic peptide with the corresponding variations attending to hydrophobicity of amino acid side chain. ${ }^{20 b}$ 
They demonstrated the effect of hydrophobicity changes in the rates of nucleation and elongation in self-assembly. It was hypothesized that an increase in peptide hydrophobicity increases the number of nucleation events leading to a greater number of fibrils in solution but reduced lamination of $\beta$-sheet bilayers. In this study it was also shown that aromatic interactions were not essential for self-assembly but they provided unique helical fibril morphologies never formed by the non aromatic derivatives.

The influence of aromatic interactions was also highlighted in a recent work by $\mathrm{Xu}$ and co-workers. ${ }^{21}$ Four different tripeptides FFK, FYK, YFK and YYK were synthesized and the effect of $F$ substitution by $Y$ was analyzed in terms of self-assembly. This subtle structural variation (adding a hydroxyl group to the phenyl ring) results in a big change in molecular self-assembly going from tubular structures for the FFK compound to thinner fibres for monosubstituted derivatives (FYK and YFK) and finally spherical nanostructures for YYK (Figure 1.7). The introduction of hydroxyl groups modifies the aromatic interactions and introduces hydrogen bonding. Due to the high interdependence between all the secondary interactions which drive the self-assembly, changes in aromatic interaction induce a "domino" effect and cause a shift to a new state with significant variations in self-assembly behaviour.

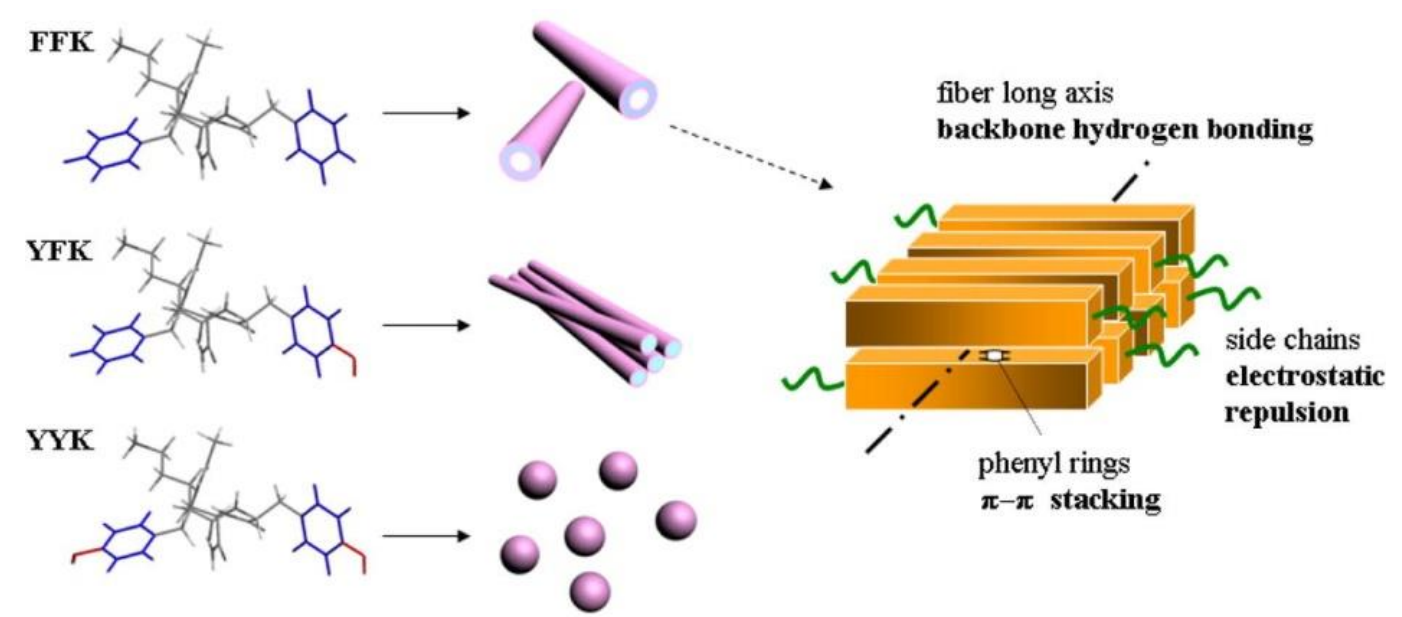

Figure 1.7 Molecular structures of the tripeptides reported by $\mathrm{Xu}$ and co-workers ${ }^{21}$ with the corresponding assemblies in water.

Differences in self-assembly patterns due to amino acid distribution in sequences of isomeric peptides were also reported. Chen P. and co-workers ${ }^{22}$ designed two different isomers, AEAEAKAKAEAEAKAK (EAK16-II) and AEAEAEAEAKAKAKAK (EAK16-IV), 
modifying the charge distribution along the peptide sequence. At neutral $\mathrm{pH}$ the selfassembly behaviour found was completely different for each of them. Compound EAK16-II showed conventional fibrillar aggregates while EAK16-IV developed globular nanostructures. The differences in amino acid sequence were reflected in the surface tension of the peptides resulting in significant differences in the final assembly.

Using a similar approach but varying the traditional alternated hydrophobic/hydrophilic amino acid distribution Nilsson and co-workers ${ }^{23}$ studied the difference in aggregation behaviour between an isomeric family of octapeptides composed by $\mathrm{F}, \mathrm{K}$ and $\mathrm{E}$ (Figure 1.8).

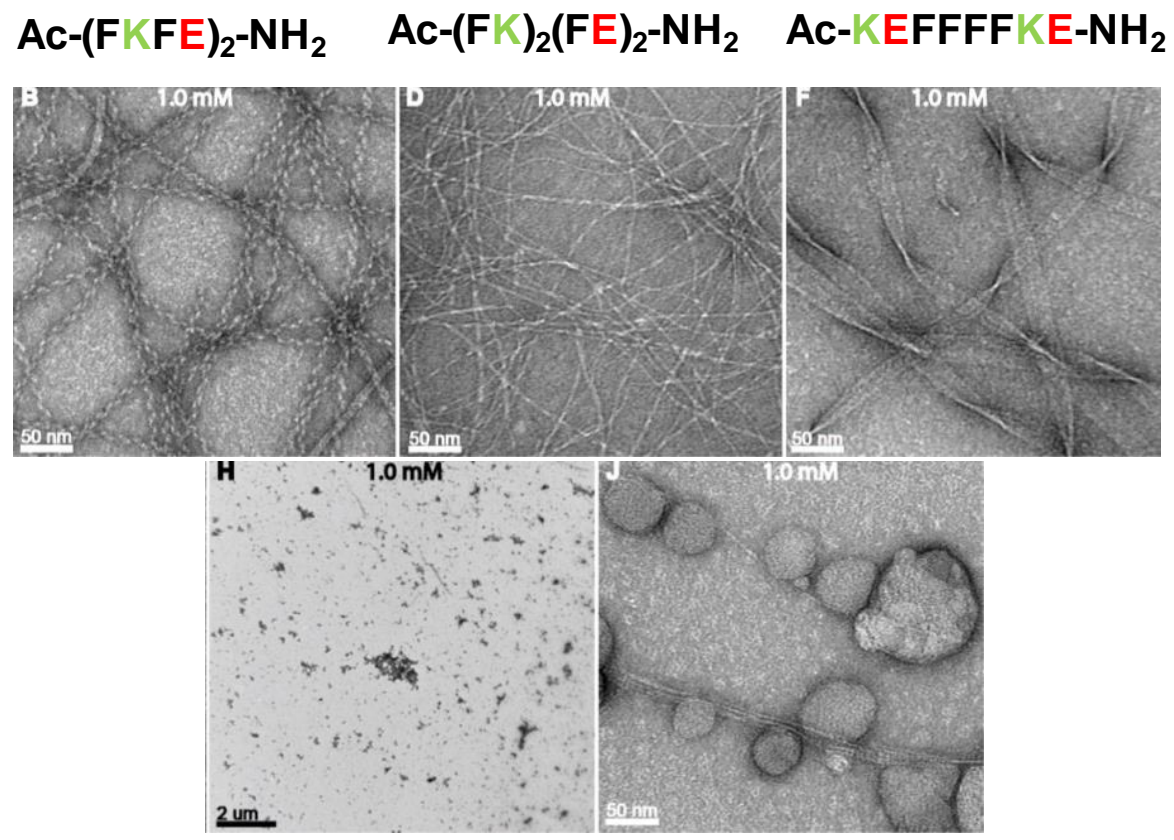

Ac- $(\mathrm{KFFE})_{2}-\mathrm{NH}_{2} \quad$ Ac-FFKEKEFF- $\mathrm{NH}_{2}$

Figure 1.8 Octapeptides containing F,K and $\mathrm{E}$ amino acids reported by Nilsson and co-workers and their self-assembled nanostructures in water. ${ }^{23}$

This study confirmed that the optimal amino acid sequence pattern for promotion of $\beta$-sheet self-assembly of amphipathic peptides is composed of alternating hydrophobic $(\mathrm{X})$ and hydrophilic $(\mathrm{Z})$ amino acids in a general $(\mathrm{XZXZ})_{\mathrm{n}}$ motif. Other modifications in the peptide sequence exhibited in general reduced self-assembly propensity even though the overall hydrophobicity and charge of the related peptides were identical. 
Other factors such as the strand length have also an influence on the $\beta$-sheet stability. ${ }^{20 c, 24}$

An appropriate balance between non-covalent interactions favoring selfassembly versus the interactions disfavoring association (frustrating forces) allowed many authors to finely control final nanostructures. Nanda and co-workers ${ }^{25}$ showed a wide variety of nanostructures going from nanodiscs to fibrillar structures by increasing the number of non polar amino acids with high tendency to $\beta$-sheet formation (Figure 1.9).
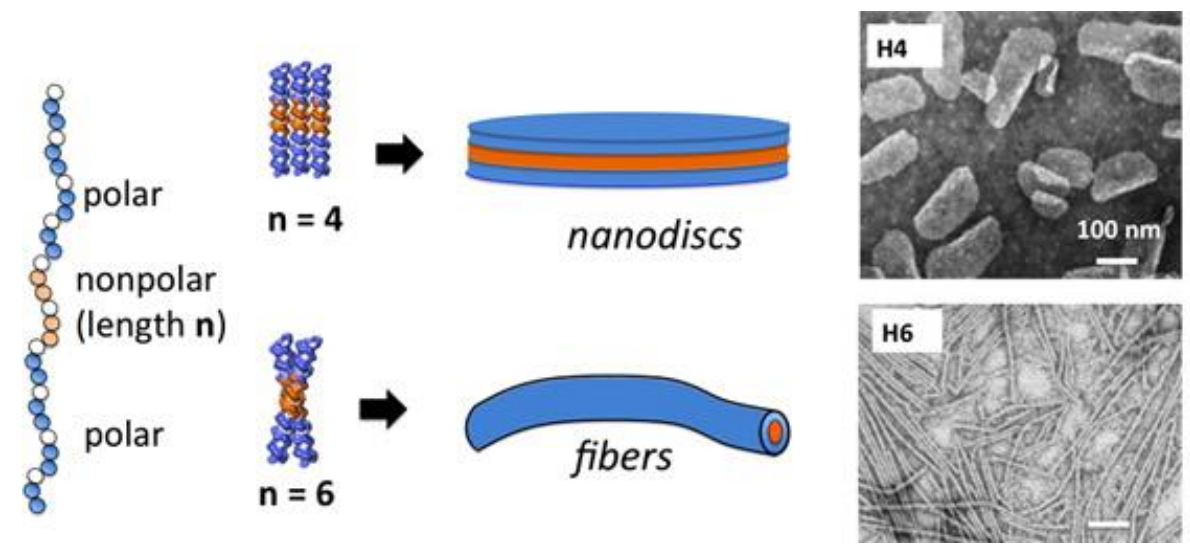

Figure 1.9 Schematic representation of the amphipathic peptides reported by Nanda and co-workers. The number of hydrophobic residues influences the final self-assembled nansostructures. ${ }^{25}$

With the aim of getting further insight into the relationship between peptide sequence and self-assembly, in chapter 4 a family of amphipathic tetrapeptides containing $F$ and $D$ residues have been prepared. In the following sections some definitions and concepts used in that chapter are introduced.

\subsubsection{Lipopeptides}

Lipopeptides, generally known as peptide amphiphiles (PA), are peptide-alkylchain surfactants in which a peptide segment is covalently bound to a very hydrophobic moiety, usually a simple alkyl tail. In aqueous media the aggregation of the hydrophobic tails drives the self-assembly leaving the hydrophilic peptide segment at the periphery and hiding the hydrophobic segment into the core of the assembly. These molecules combine the structural features of amphiphilic surfactants with the functions of bioactive peptides allowing a broad range of different nanostructures and applications specially outstanding in the biomedical field. ${ }^{14 b, 26}$ 
The first example of a PA was reported by Tirrell and co-workers in $1995 .{ }^{27}$ The design consisted in a dialkyl ester tail appended onto a peptide sequence from collagen and the formation of stable assembled monolayers at the air-water interface was demonstrated. A little bit later in $2001^{28}$ Stupp and co-workers presented a novel structure based on an unbranched palmitic acid tail covalently attached to a peptidic sequence (Figure 1.10). After the protonation of acidic residues $(\mathrm{pH}<4)$ cylindrical nanofibres were inmediately observed mainly due to the hydrophobic collapse of the aliphatic chain.

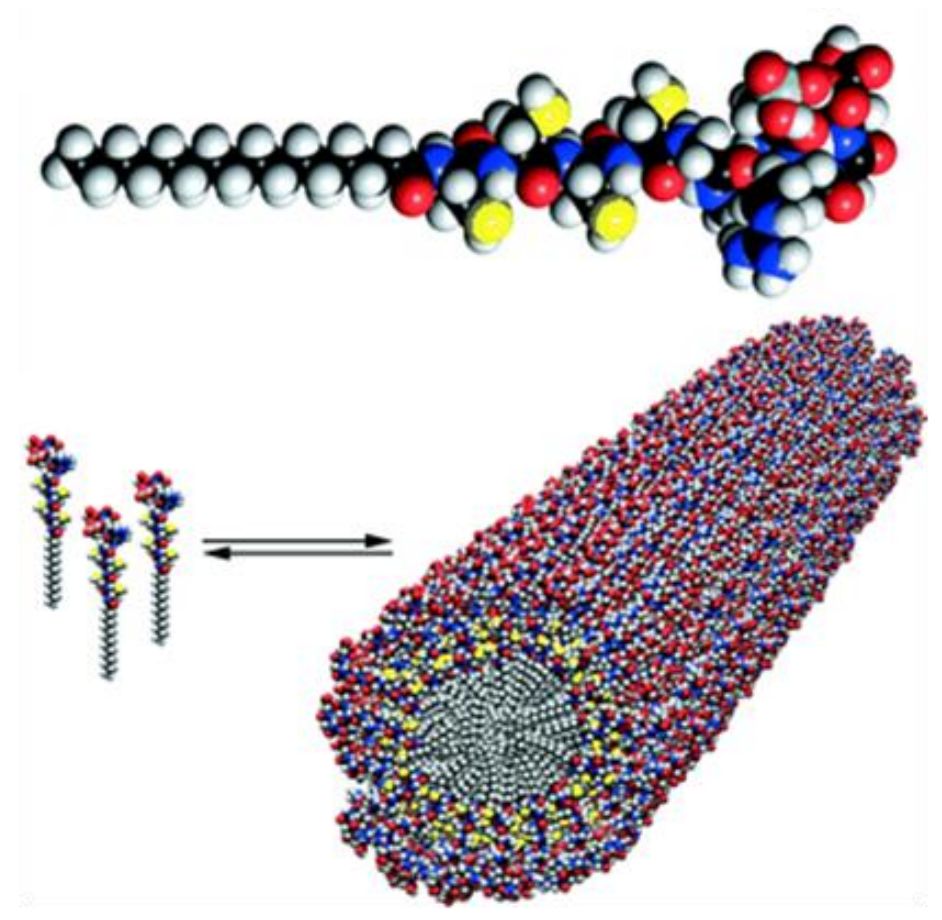

Figure 1.10 Schematic illustration of the PA self-assembly into cylindrical nanofibres. ${ }^{28}$

After these first examples many laboratories have given important contributions trying to understand the self-assembly of lipopetide PAs over the last years. ${ }^{26 a, e, 29}$ Highlighting the work of Stupp and co-workers some key features about PA are summarized below.

Generally four essential domains (Figure 1.11) are needed to develop a fully functional and well-defined supramolecular structure although many variations can be introduced. These domains are i) a hydrophobic region typically consisting of a long alkyl chain and, a peptide sequence divided into ii) a short peptide chain able to form 
hydrogen bonds, iii) charged amino acids for enhanced solubility in water and iv) a functional (bioactive) peptide epitope.

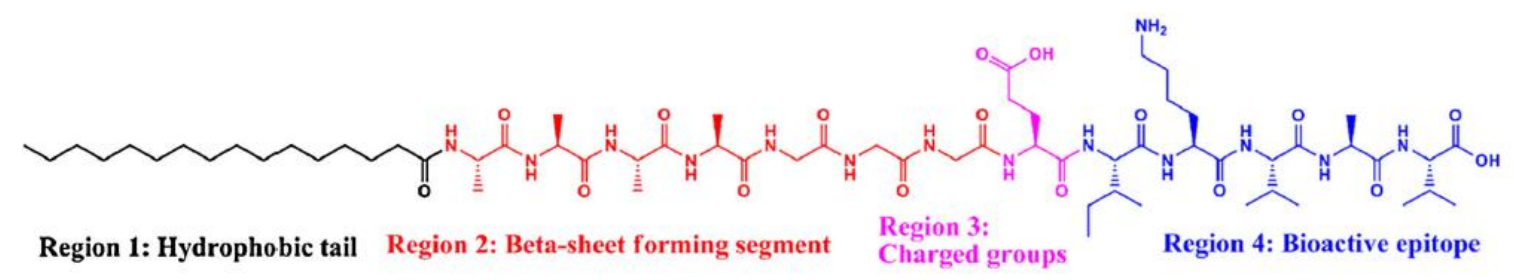

Figure 1.11 Typical PA molecular design reported by Stupp and co-workers including the four characteristics domains. ${ }^{26 a}$

The hydrophobicity of the first domain is the most important element of the design because it drives the self-assembly of the amphiphilic chain leaving the peptide domain exposed at the surface. The hydrophobicity can be modified by using different alkyl chain lengths or by changing the alkyl chain by using other non-polar components such as cholesterol. ${ }^{30}$

The influence of the chain length was explored by Stupp, ${ }^{31}$ van Hest, ${ }^{32}$ and Tirrell $^{33}$ among others showing in general that the presence of hydrophobic tails induces or stabilizes the three-dimensional nanostructures. The longer the tail was the poorer the solubility it has and conversely with decreasing the tail length, the solubility increases and the tendency to aggregate diminish. Decrease in tail lengh however can be balanced by increasing the number of hydrophobic amino acids with tendence to form $\beta$-sheet in the second domain.

Hartgerink and co-workers went an step further and investigated the role of hydrogen bonding in this second domain. The study involved more than 25 lipopeptides ${ }^{34}$ and demonstrated that the four amino acids closest to the core of the nanofibre determine the ability of a PA to form cylindrical nanofibres. In fact the disruption of hydrogen bonds associated to these amino acids converted the nanostructure into spherical micelles. The amino acids located further away from the core are less restricted in their conformation and also play a less important role in stabilizing the nanostructure. In a similar way amino acids close to the nanofibre core can ultimately induce chirality in the hydrophobic tail regions. ${ }^{35}$ 
The distribution of hydrophobic amino acids along the peptide sequence is also important as we previously described for amphipathic peptides alternating polar and non polar amino acids. Stupp and co-workers have reported recently the wide variety of aggregation behaviours for an isomeric tetrapeptide family with identical composition but different amino acid distribution (Figure 1.12). ${ }^{36}$
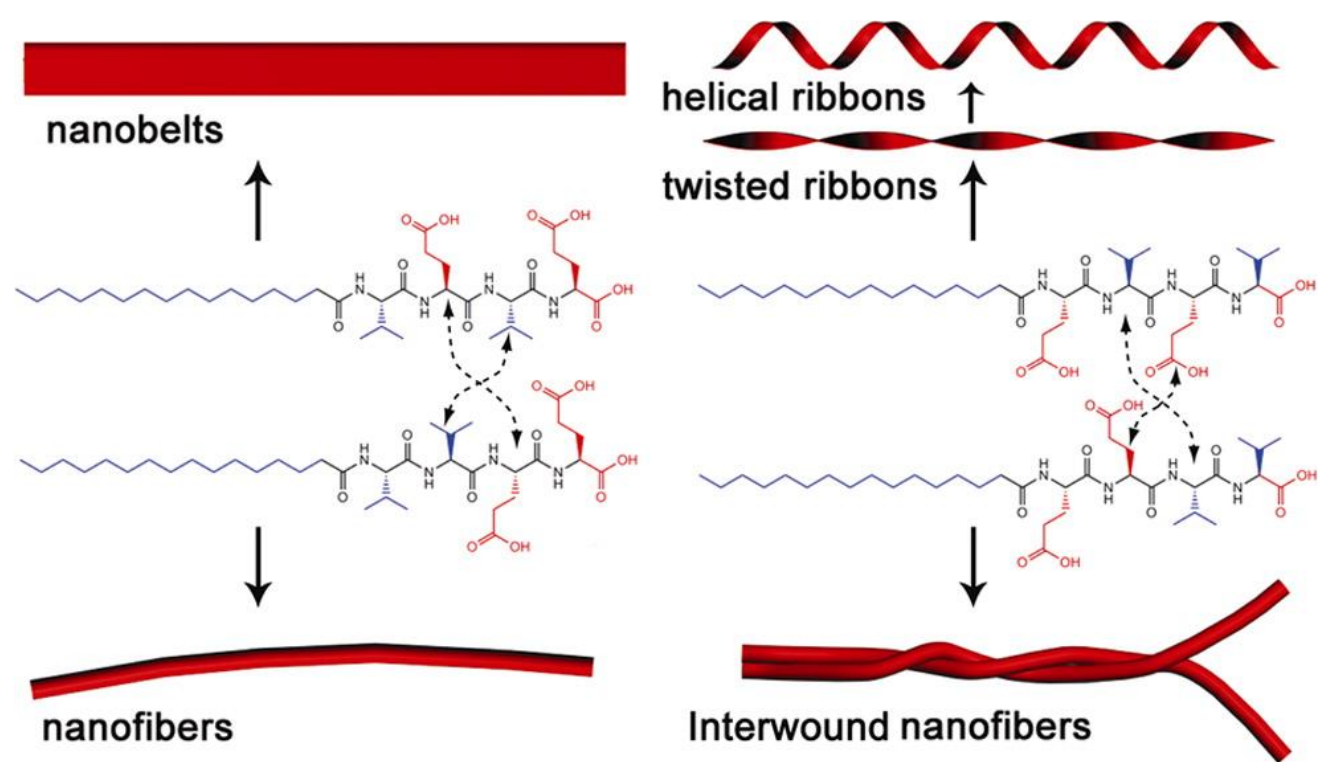

Figure 1.12 Molecular structure for a family of isomeric PAs containing $V$ and $D$ and their corresponding assembled nanostructures in water. ${ }^{36}$

Lipopeptides with a peptide sequence of alternating hydrophobic and hydrophilic amino acids such as VEVE and EVEV self-assembled into flat nanostructures while the non-alternating isomers VVEE and EEVV developed cylindrical nanostructures. Interestingly, it was also shown that when the $\mathrm{E}$ residue is directly attached to the aliphatic tail, the final structures are more internally flexible. These results remark how important the non covalent interactions in this domain are in the final nanoarchitecture.

The third domain corresponds to charged amino acids which provide solubility to the molecule. The number of charged amino acids added should be enough to guarantee solubility but not too many because electrostatic repulsions could disturb the selfassembly process. In addition to solubility the incorporation of ionic or cationic amino acids endows the molecule with sensitivity towards external stimuli such as $\mathrm{pH}$ or ionic strength. The salt and $\mathrm{pH}$ responsive design is critical for biomedical applications in particular those related with injectable therapies. 
Several examples in the literature ${ }^{37}$ include many of the key parameters we have mentioned so far and illustrate how modifications in the hydrophobic domain as well as in the hydrophobic peptide chain composition or even in the number of charges can affect the final self-assembled architecture and therefore their interactions for example with cell membranes. Particularly we will focus our attention in a recent example also reported by Stupp and co-workers. ${ }^{38}$ In this work PA1 (Figure 1.13) was synthesized and systematic variations of the initial structure were performed. The main results are summarized as follows.

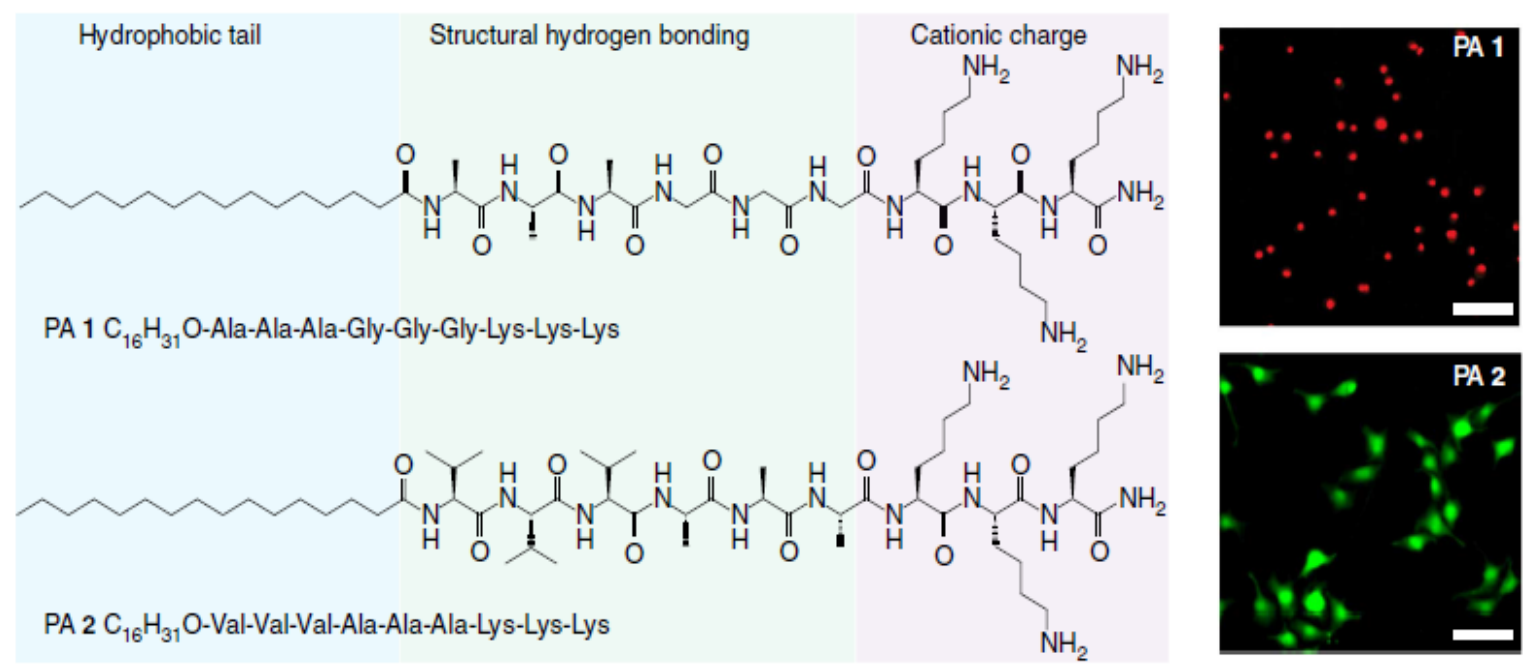

Figure 1.13 Chemical structures of PA1 and PA2 (left) and representative fluorescence images of MC3T3E1 cells that are viable (green) or dead (red) on coatings of each PA after $4 \mathrm{~h}$ of culture.

Compound PA1 showed strong toxicity and rapid cell death. Then variations on the initial structure PA1 were performed systematically starting with decreasing the number of aliphatic carbons from 16 to 12 . Reducing the amphiphilic nature of the molecule resulted in a shape change and promoted cell viability. On the other hand decreasing the number of lysine residues also reduced the toxicity.

Although these variations in hydrophobicity and cationic charge influence the toxicity of the previous assemblies, the most remarkable difference was observed when modifying $\beta$-sheet hydrogen bonding among molecules within the nanostructure by changing the initial $A$ and $G$ amino acid pattern by $A$ and $V$ residues (PA2). Interestingly the cell toxicity was abolished when cells were exposed to PA2 and the authors hypothesized that this is because a greater strength of intermolecular cohesion. In other words less cohesive assemblies rapidly associate with the phospholipid bilayer disrupting 
the cell membrane and causing its death however, cell viability is rescued by increasing intermolecular interactions within the nanostructure.

The fourth domain finally corresponds to the epitope which can be attached for various purposes especially those related with biological activities. Some epitopes such as RGD and IKVAV are commonly used among others for cell adhesion and these and many other examples are reported in literature. ${ }^{26 \mathrm{e}}$

Simplified lipopopeptide analogues have been designed and prepared in Chapter 6 in order to study their aggregation behaviour in aqueous media as well as to explore their functional application in organocatalysis.

\subsubsection{Peptide co-assembly}

Co-assembly of several components is a useful methodology to obtain new materials with enhanced or even emergent properties. ${ }^{39}$

In particular, co-assembly of peptides can be achieved through different noncovalent interactions being electrostatic interactions the most used so far. Several authors have reported the formation of nanofibres by electrostatic co-assembly of two amphipathic peptides with oppositely charged sequences. ${ }^{40}$ Usually these compounds fail to self-assemble individually at neutral $\mathrm{pH}$ values most likely due to charge repulsions. In comparison with traditional self-assembly triggers such as temperature, $\mathrm{pH}$ or salt addition, the co-assembly could be a convenient strategy specially for biomedical applications because it is possible to start from two independent solutions at neutral $\mathrm{pH}$ which undergo self-assembly after mixing them without any external stimuli applied. Besides this approach provides a potential to combine two different bioactive epitopes within a single nanofibre.

Hamley and co-workers reported the co-assembly of $\mathrm{C}_{16}$-ETTES and $\mathrm{C}_{16}$-KTTKS containing oppositely charged amino acids. ${ }^{41}$ Mixtures of both enabled the aggregation into highly extended nanotapes along with enhancement of $\beta$-sheet ordering. Additionally, the aggregation behaviour of this system was easily tuned by changing the composition of the mixtures as evidenced macroscopically or by TEM (Figure 1.14). 


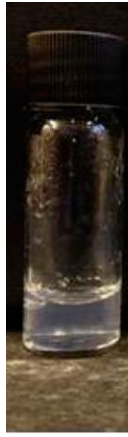

(a)

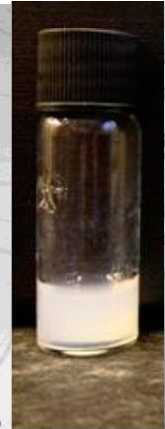

(b)

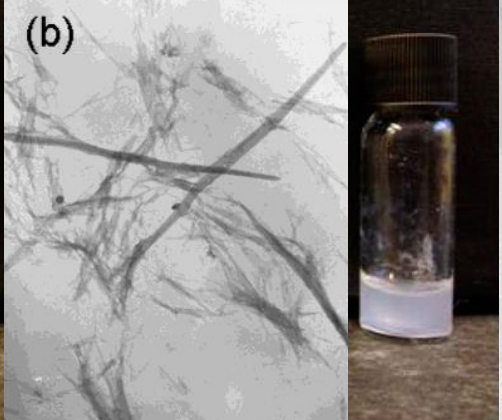

(c)

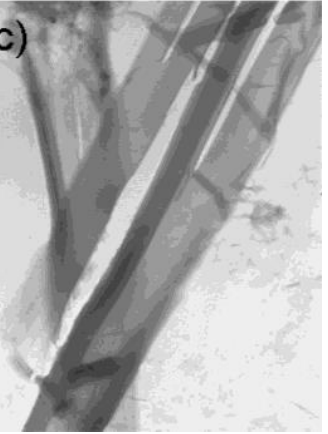

Figure 1.14 Macroscopic aspect and TEM images for samples with C16-KTTKS/C16-ETTES mixtures. (a) 1:0.5, (b) 1:1, and (c) 2:1. The scale bar represents $1 \mu \mathrm{m} .{ }^{41}$

These co-assembled systems are usually responsive to acidic and basic $\mathrm{pH}$ stimuli due to the complementary charged amino acid side chains. ${ }^{42}$ The stability of coassembled systems can be switched on/off for a specific $\mathrm{pH}$ range by adjusting the pKa values of the corresponding monomers as well as other secondary interactions. For instance, Besenius and co-workers have reported recently a pair of complementary monomers based on small $\beta$-sheet syntons that contain complementary sites of interaction (acid/base or cation/anion) and an alternated sequence of hydrophobic/hydrophilic amino acids (Figure 1.15). ${ }^{43}$
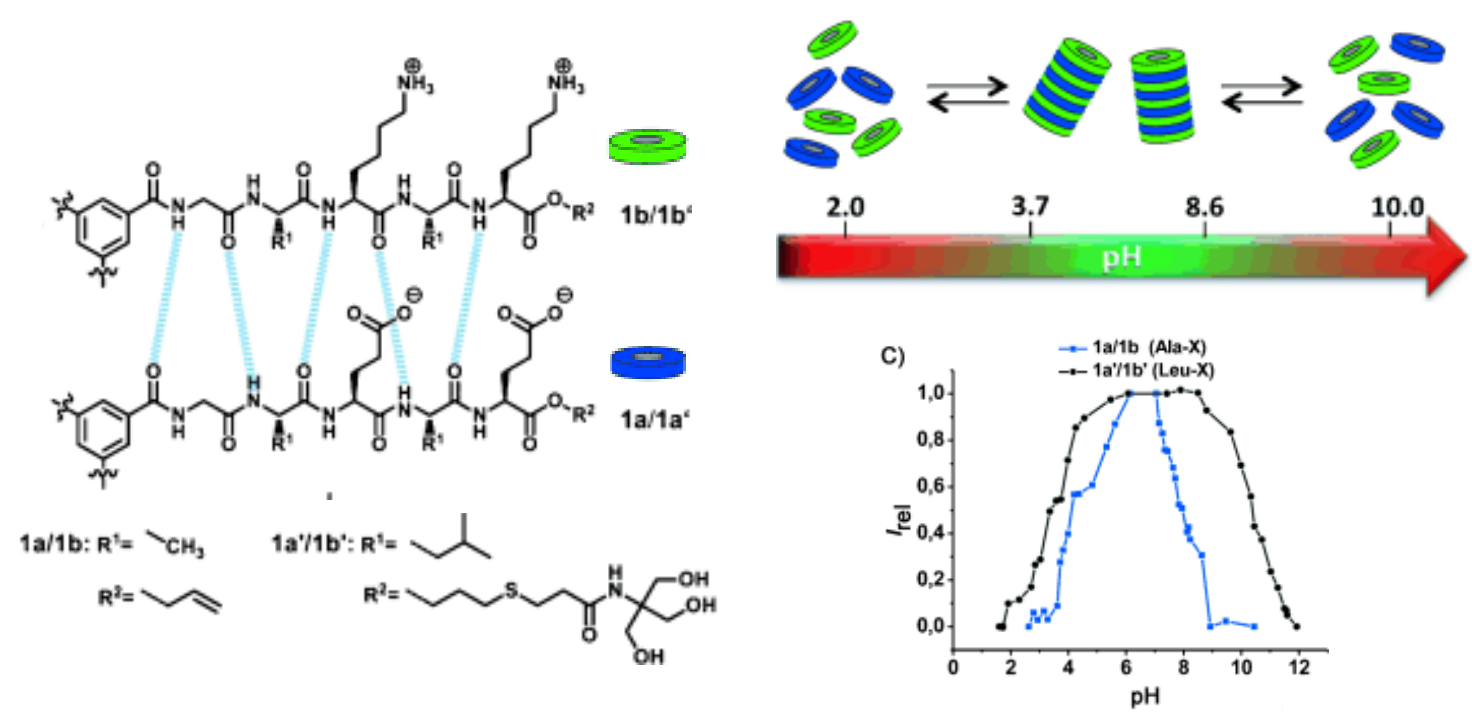

Figure 1.15 Chemical structures for the basic and acidic monomers and suggested interaction between them (left). Schematic representation of the self-assembly behaviour over the $\mathrm{pH}$ range and a $\mathrm{pH}$ window stability determined by CD (right). ${ }^{43}$

Co-monomers $\mathbf{1 a}$ and $\mathbf{1 b}$ separately showed a lack of secondary structure under the buffered conditions used and they were not able to spontaneously self-assemble. However the mixture of both in a 1:1 ratio immediately resulted in a parallel $\beta$-sheet 
architecture. The authors define this process as cooperative because the electrostatic interactions reinforce the parallel $\beta$-sheet encoded hydrogen bonding. The study of aggregation behaviour was extended to a broad range of $\mathrm{pH}$ from 1 to 12 to investigate the dual responsiveness of these co-assemblies. Unlike traditional single-component based on acidic or basic peptide amphiphiles that aggregate when the $\mathrm{pH}$ values are decreased or increased respectively, this co-assembled system is switched on at a physiological $\mathrm{pH}$ range and can be switched off sharply when leaving this $\mathrm{pH}$ window.

Other methodologies have been described to also induce co-assembly of complementary peptides into multicomponent fibrils. Schneider and coworkers ${ }^{44}$ have reported mixtures of short enantiomeric peptides that instead of self-sorting into enantiomeric fibrils composed of all $L$ - and all $D$-peptides, co-assemble into fibrils containing alternating $L$ - and $D$ - peptides. This material showed large, non-additive, synergistic enhancement of the mechanical rigidity of gels prepared from enantiomeric mixtures of self-assembling peptides, with the racemate displaying the greatest degree of enhancement (Figure 1.16).

A

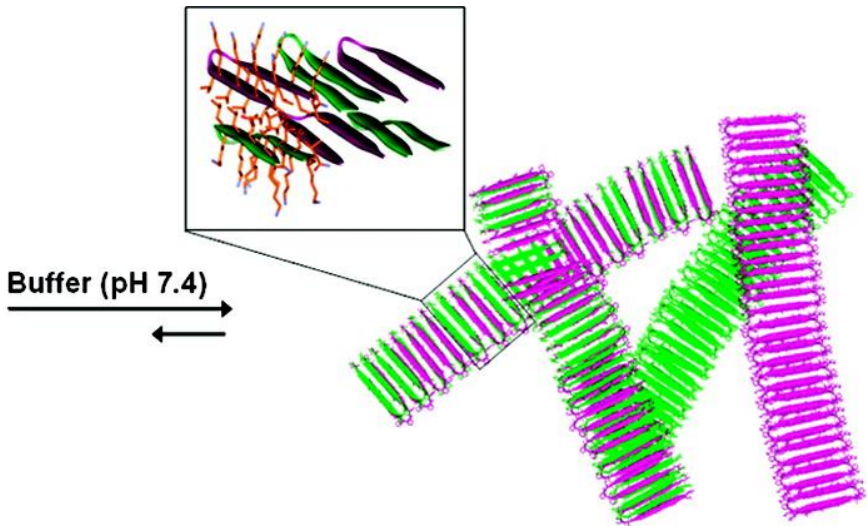

B

\begin{tabular}{|c|l|}
\hline MAX1 & VKVKVKVKV ${ }^{D}$ PPTKVKVKVKV- $\mathrm{NH}_{2}$ \\
\hline DMAX1 & VKVKVKVKVLPPTKVKVKVKV- $\mathrm{NH}_{2}$ \\
\hline Control & IKVKIKVKVDPPTGAKVKIKV- $\mathrm{NH}_{2}$ \\
\hline
\end{tabular}

Figure $\mathbf{1 . 1 6}$ a) Assembly mechanisms for enantiomeric peptides leading to the formation of a fibrillar network, b) Primary sequences of the enantiomers. ${ }^{44}$

Following this work, Nilsson and co-workers reported another example of a system in which two enantiomeric oligopeptides $L / D-A c-(F K F E)_{2}-N_{2}$ showed again a preference for co-assembly. ${ }^{45}$ Isotermal titration calorimetry experiments showed an enthalpic advantage for the enantiomeric co-assembly which could explain this preferred behaviour. Both studies suggest that molecular chirality may represent a new 
tool for the design of new materials and can be used to influence their properties. Besides, recent examples reported the higher resistance to proteolysis of this coassembled enantiomeric amphipathic peptides in comparison with enantiopure selfassembled L-peptides. ${ }^{46}$

\subsection{Peptide fibrillisation and amyloid diseases}

Protein and peptide self-assembly into fibrils is a key event in the pathology of amyloid protein misfolding disorders including Alzheimer's disease (AD), Parkinson's disease and type II diabetes among others. ${ }^{47}$ All of them are characterized by an aberrant aggregation of normally soluble proteins and peptides into amyloid fibrils deposits that correlate highly to disease progression and cell death. Amyloid diseases, mainly $A D$, are the main cause of dementia which affects more than 40 million people worldwide. This number will be increase to an estimated 75.6 million in 2030 and around 135.5 million in $2050 .{ }^{48}$ This trend is due to the increase in aging of the population especially in developed countries. $A D$ and other dementia diseases are neurodegenerative disorders linked to age and because more and more people live longer lives these diseases are becoming a serious concern. Unfortunately, currently available treatments usually provide at best only temporary and incomplete symptomatic relief but they do not arrest or reverse the progression of $A D$, in other words, there is no cure. The limited benefits offered by current therapies highlight the urgent necessity to an intense research activity focused on the development of new treatments for amyloid disorders. In this sense self-assembled peptides play an important role not only because they can be used to model the aggregation of native peptides but also because small peptides can be extremely useful as inhibitors of the amyloidogenic process.

The term amyloid refers originally to protein deposits similar to those first observed for starch (amyloid originally meant starch-like). Currently the term is more specifically associated with proteins or peptides that self-assemble into fibrils based on the cross- $\beta$ structure. In this kind of structure the peptide chain is perpendicularly oriented to the fibre axis. ${ }^{49}$ There is no specific peptide sequence which undergoes fibril formation, for example more than 50 amyloid disorders have been described and for 
each amyloid disease a different protein is involved. In fact it is believed that at infinite time any protein solution above a critical concentration will eventually give rise to fibrillisation. The soluble state of a protein (correctly folded) is considered then a metastable state in a local minimum of energy and the transition through fibril formation may take minutes, days or even years. ${ }^{50}$ This lack of specific sequence makes more difficult to go deeper into the fibrillisation mechanisms and to find new methodologies to reverse or avoid amyloid disorders.

The amyloid fibrils generated from many different proteins have however many common characteristics. ${ }^{47,49,51}$ As it has been mentioned before all of them adopt a common $\beta$-cross pattern in X-ray fibre diffraction. The fibres tend to appear as unbranched filamentous structures around 3-10 $\mathrm{nm}$ in width and usually several micrometres in length. The protofibrils assemble and twist around each other leading mature fibres as it can be seen in Figure 1.17. The high level of kinetic and thermodynamic stability endows amyloids with regions resistant to hydrogen-deuterium exchange and proteases. The presence of amyloid regions is relatively easy to confirm as they are stained by for example Congo Red and Thioflavine T dyes.
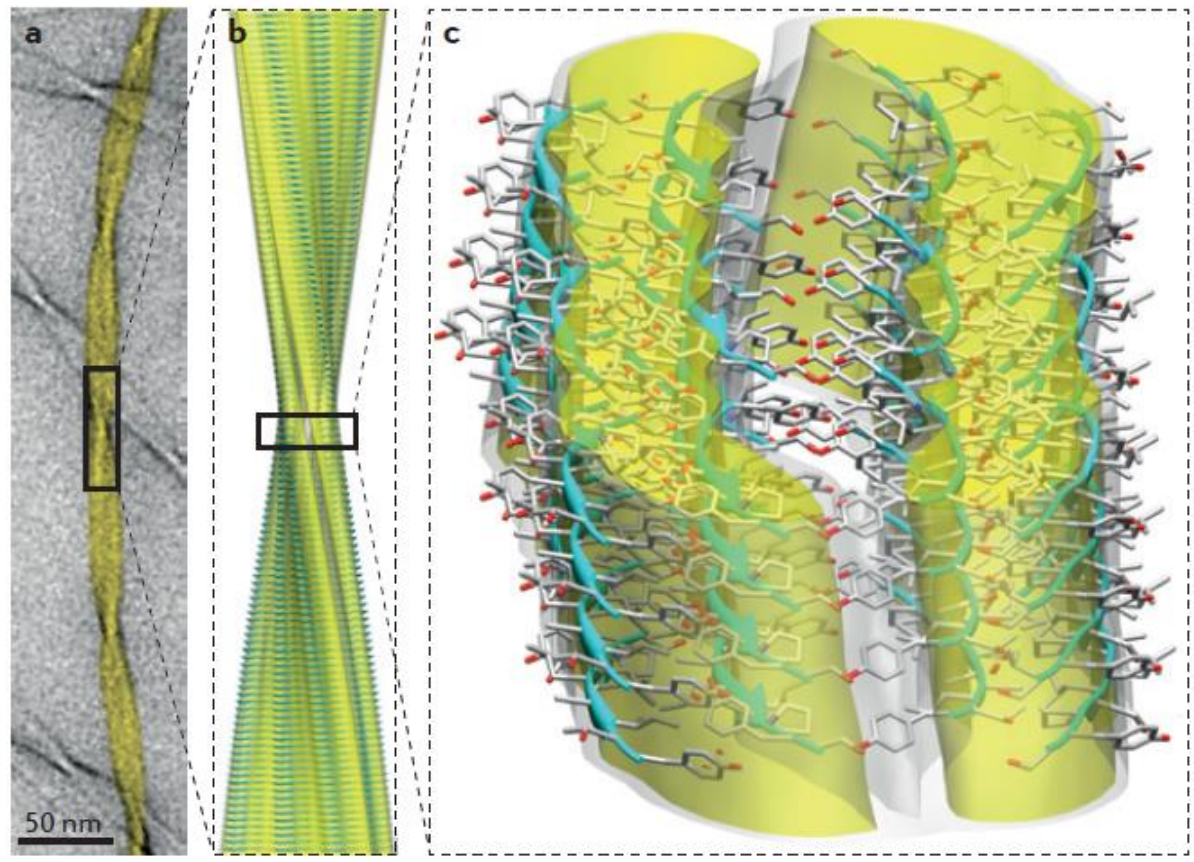

Figure 1.17 Structure of an amyloid fibril at atomic resolution. ${ }^{52}$ 


\subsubsection{Kinetics and thermodynamics of fibrillisation}

As it has been mentioned before the aggregated form of proteins is thought to represent a true global minimum of energy not only for aggregation-prone proteins but also for all proteins in general. ${ }^{47,50}$ In terms of thermodynamics the native state (also called the correctly folded state) will be stable in comparison with the amyloid state if the free energy of the latter is higher. In this situation a protein cannot spontaneously undergoes the transition from a lower energy state to a state of higher energy. Then the conversion into amyloid state will only take place if the final free energy is lower than in the native state. However because the stability of the amyloid state $(\Delta \mathrm{G})$ depends on protein concentration, a critical value (of concentration) exists at which the stability of the native state and the amyloid state are exactly the same. For concentration values above the critical one, proteins can spontaneously transform into amyloid state and they could exist in their native form just if there is a high free energy barrier that delays the transition into the more stable state (Figure 1.18a). Under such circumstances the native state is considered a kinetically trapped metastable state. The exact value of critical aggregation concentration is different from one protein to another and besides it can be modified by changing parameters such as temperature, ionic strength or $\mathrm{pH}$.
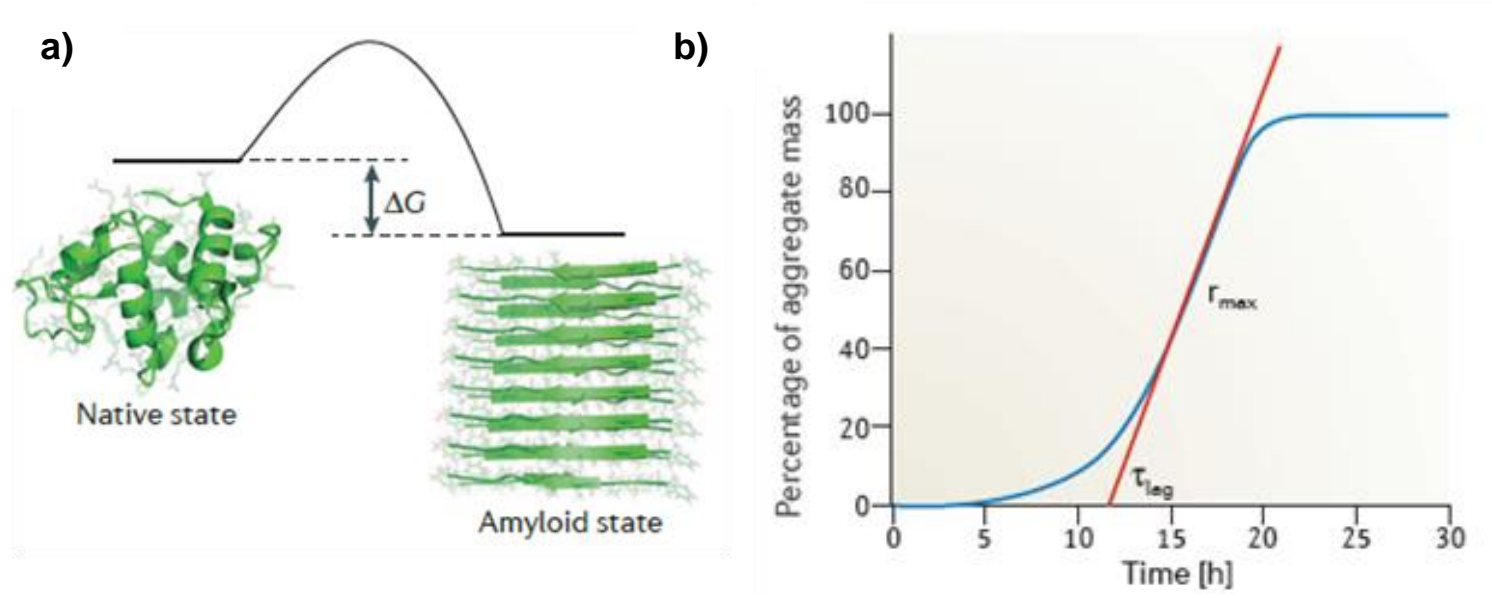

Figure 1.18 a) Energy diagram for a typical protein misfolding where an energy barrier between the native and the amyloid state can be observed; b) Sigmoidal function for a typical kinetic process of amyloid fibril formation which are characterized by a lag time $\left(\tau_{\mathrm{lag}}\right)$ and a maximal growth rate ( $r_{\text {max; }}$ red line). ${ }^{47}$

Thermodynamic parameters of amyloid formation have been scarcely studied most likely due to intrinsic technical difficulties. Recently it has been highlighted that 
isothermal titration calorimetry can be used for such studies and in general for protein folding and misfolding processes. ${ }^{52}$

While thermodynamics can be used to describe if it is possible to go from one state to another spontaneously without any external driving force involved, kinetics focus on how fast such transition will take place. The kinetics of fibrillisation generally follows a nucleation and growth mechanism characterized by a lag time $\left(\tau_{\text {lag }}\right)$ and a maximal growth rate $\left(r_{\max }\right)$ respectively (Figure $\left.1.18 \mathrm{~b}\right)$. Initially the nucleation step generates small oligomers which are very reactive and hence evolve into longer protofibrils and fibres by monomer addition. ${ }^{53}$ The aggregation rate is accelerated in many cases by fibril fragmentation or secondary nucleation during the nucleation process. In a similar way the addition of soluble monomers (nucleation) or aggregated peptides (templating or seeding) can trigger the transition from native structure to amyloid state. ${ }^{54}$

The relationship between thermodynamic and kinetic processes in peptide fibrillisation is not clearly established but it has been pointed out that determinants of both aspects of the process have a similar physicochemical basis. ${ }^{55}$

A particular thermodynamic and kinetic study of fibrillisation process for a family of tetrapeptides will be deeply analysed in chapter 4 .

\subsubsection{Small peptides as a model for amyloid fibril formation}

Experimental evidences have shown that small fragments of proteins are responsible for its amyloidogenic behaviour. Considering besides that small peptidic fragments are easier to design and synthesize than full proteins, short peptides represent currently a more suitable option for investigating amyloid fibril formation. ${ }^{49,55}$ Recent work has been focused on the determination of the smallest peptide sequence able to still exhibit amyloid fibrillisation. Some examples are shown in the next table and it is important to mention how in some cases just three amino acids are needed to yield amyloid-like fibrils in a similar way to a full protein. 
Table 1.1 Typical amyloid fibril formation by remarkably short aromatic peptide fragments. ${ }^{55,47}$

\begin{tabular}{lll}
\hline Name of native protein & Associated amyloid disease & Amyloidogenic sequence \\
\hline Islet amyloid polypeptide & Type II diabetes & NFGAIL / NFLVH \\
Human calcitonin & Thyroid carcinoma & DFNK \\
Human medin & Aortic medial amyloid & NFGSVQ \\
Amyloid $\beta$-peptide & Alzheimer's disease & KLVFFAE \\
PHF6 $(\tau$ protein) & Alzheimer's disease & VYK \\
Gelsolin & Finnish hereditary amyloidosis & SFNNGDCCFILD \\
Serum amyloid & Chronic inflammation amyloidosis & SFFSFLGEAFD \\
B2-microglobulin & Dialysis-associated renal amyloidosis & DWSFYLLYTEFT \\
\hline
\end{tabular}

A more detailed study has been carried out with some of the above proteins like peptide $\beta$-amyloid most likely due to their medical relevance. ${ }^{49,26}$ Hilbich and co-workers demonstrated the importance of the fragment LVFF (residues 17 to 20) for the $\beta$-sheet formation at the beginning of the $90 \mathrm{~s} .{ }^{56}$ Tjernberg and co-workers discovered a little bit later that peptides containing at least five residues (A $\beta$ 16-20) were needed to bind a full-length $A \beta 40$ peptide. ${ }^{57}$ The same group studied the fibrillisation dependence with the fragment size containing the $A \beta(16-20)$ sequence. They found that the shortest sequence able to yield fibril formation was the decapeptide $A \beta$ (14-23). However more recent studies by Meredith ${ }^{58}$ and Hamley ${ }^{59}$ and co-workers demonstrated that the pentapeptide KLVFF is able to fibrillate itself. The self-assembly of larger sequences like the heptapeptide $\mathrm{CH}_{3} \mathrm{CO}-\mathrm{KLVFFAE}-\mathrm{NH}_{2}$ has been described by many authors including Lynn, ${ }^{60}$ Tycko $^{61}$ or Nilsson ${ }^{62}$ among others.

Aromatic amino acids have shown a high propensity to promote the selfassembly of peptides and proteins into cross- $\beta$ amyloid ${ }^{63}$ however, the mechanistic insight into this fibrillisation process remains still under debate. On the one hand the ability of aromatic amino acids to participate directly into $\pi-\pi$ interactions has been reported for example by Serpell and co-workers ${ }^{64}$ for KFFEAAAKKFFE oligopeptide models, by Desamero and co-workers ${ }^{65}$ for the peptide IAPP $_{22-29}$ and by Gazit and coworkers for the dipeptide of minimal sequence FF. Certainly these $\pi-\pi$ interactions exert an influence on the structure and properties of the final amyloid materials but their contribution cannot be applied to all amyloid systems because other modes of action have been described for aromatic amino acids. Recently a wide variety of studies suggest 
that their high tendency to form amyloid fibrils comes from their hydrophobicity, $\beta$ sheet propensity and planar geometry rather than the ability to develop direct $\pi-\pi$ interactions. $^{66}$

\subsubsection{Small peptides as inhibitors of amyloid formation}

Small organic compounds and peptides or peptidomimetics are the two main categories of inhibitors being developed for the prevention of amyloid aggregation. ${ }^{67}$ Comparing both approaches the use of peptides offers several advantages including the ease of synthesis and sequence modifications and their biocompatibility and biomimetic nature.

Although the presence of amyloid fibrils is the most visible evidence of amyloid disorders, precursor oligomeric species are considered to be even more toxic ${ }^{68}$ and they should also be regarded as a target. A full explanation about different targets, peptide inhibitors or binding mechanism is not possible in this short introduction, however some relevant examples from our point of view will be considered right after.

Cyclic peptides have been widely studied during the last five years as amyloid inhibitors ${ }^{69}$ because their structural and biochemical characteristics resemble those reported for amyloid structures. Rahimipour and co-workers developed a cyclic D,L- $\alpha$ peptide that strongly interacted with $A \beta$ and inhibited its aggregation. ${ }^{70}$ The structure of the cyclic peptide and CD/TEM evidences of the inhibition potential are shown in Figure 1.19.
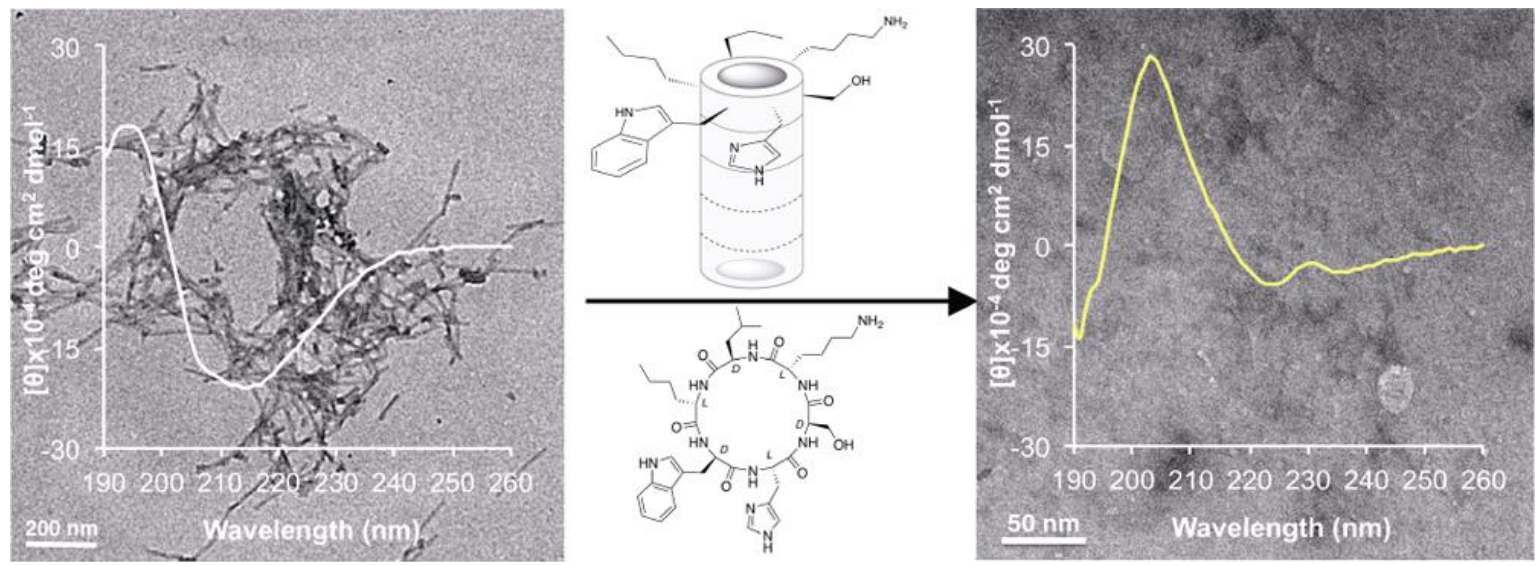

Figure 1.19 TEM and CD of amyloid aggregates (left) and after inhibitor addition (right). Cyclic peptide structure (centre). ${ }^{70}$ 
The inhibition of the formation of $A \beta$ aggregates went together with a complete disassembly of preformed fibrillar $A \beta$ aggregates and fortunately the reported cyclic peptide protected rat pheochromocytoma PC12 cells from $A \beta$ toxicity, without inducing any toxicity by itself.

More sophisticated and complex inhibitors will be described in the next two examples. Mutter and Lashuel developed new switch peptides to disrupt amyloid formation by conformational changes. ${ }^{71}$ The designed switch peptide contains the amyloid sequence $A \beta(14-25)$ connected to a helix inducing template Ncap $(\sigma)$ through a serine derived switch element (S) (Figure 1.20).

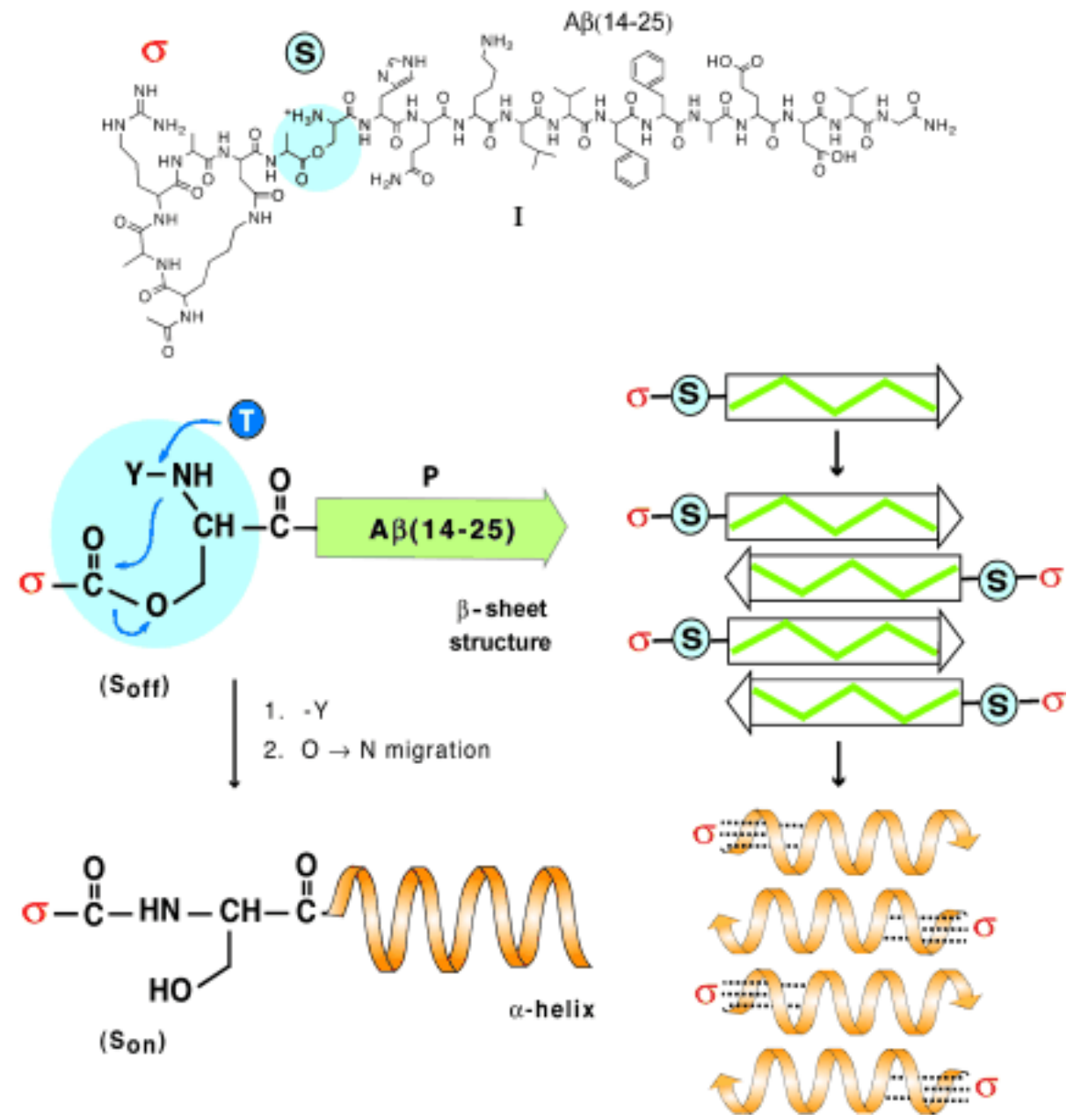

Figure 1.20 Molecular structure of switch peptide (top) and conformational transition from $\beta$-sheet (off state) to $\alpha$ helix (on state) after the $\mathrm{O} \rightarrow \mathrm{N}$ acyl migration (bottom). ${ }^{71}$ Circled $\mathrm{S}$ : a serine derived switch element; Circled T: 2,2,2-trifluoroethanol (TFE)

In off conditions CD experiments revealed a typical $\beta$-sheet secondary conformation for the molecule however when $\mathrm{O} \rightarrow \mathrm{N}$ acyl group migration was activated (on conditions) an unprecedented transition to an $\alpha$-helix conformation was observed in 
less than five minutes at room temperature. Fibrillar assemblies completely disappeared and in such conditions more than $80 \%$ of the compound was detected to be in solution.

The last example corresponds to a recent work reported by Nowick and coworkers. ${ }^{72}$ They design a family of macrocycles called amyloid $\beta$-sheet mimics (ABSMs) formed by: an upper strand containing an heptapeptide sequence derived from amyloid proteins (A $\beta$, tau, IAPP...), a lower strand containing a Hao unit (Hydrazine, 5-Amino-2methoxybenzoic acid, Oxalic acid) flanked by two dipeptides and two linked ornithine fragments as a $\beta$-turn mimics (Figure 1.21a).

The upper strand was designed to recognize and bind their parent amyloid protein. The Hao unit however, is a tripeptide $\beta$-strand mimic that not only serves as a template for intramolecular hydrogen bonding, but also prevents ABSMs aggregation in solution (Hao blocker unit).

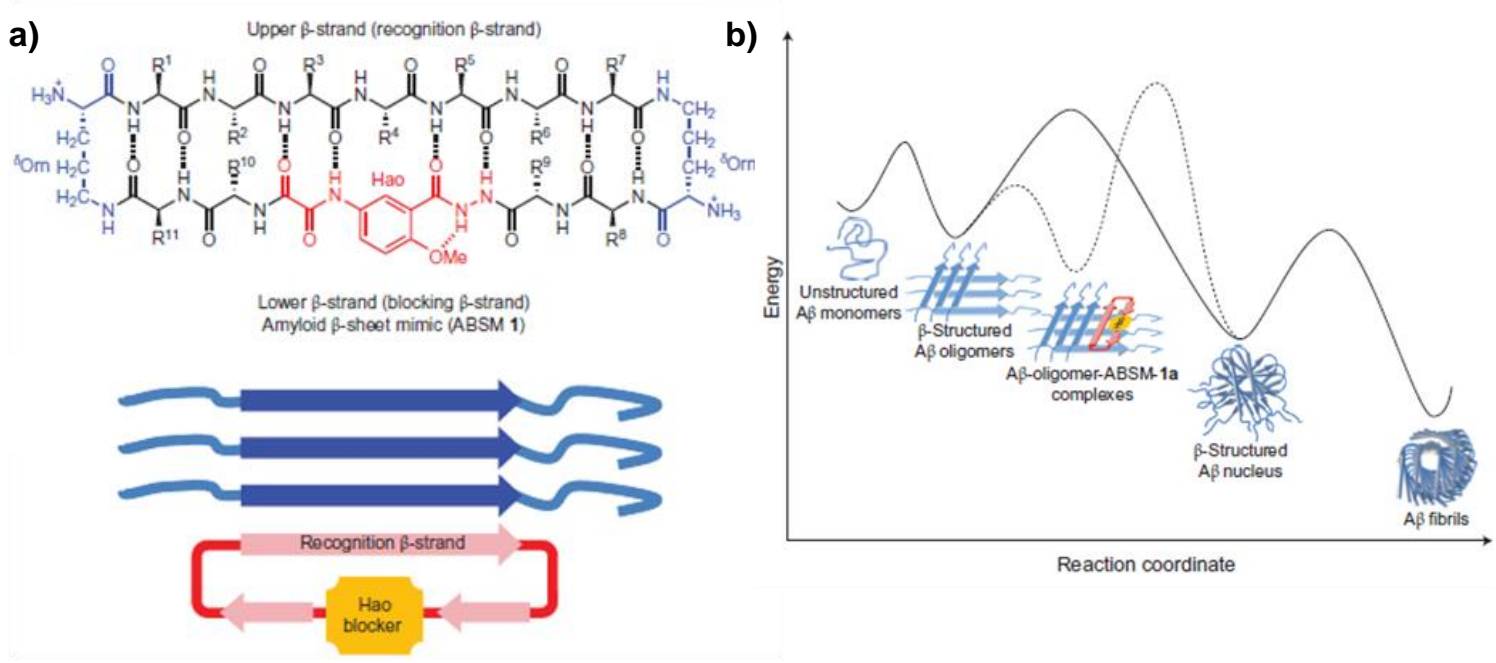

Figure 1.21 a) Representation of ABSM illustrating the upper $\beta$-strand (recognition $\beta$-strand), the linked ornithine (Orn) turn unit and the Hao amino-acid blocker unit (top) and representation of ABSM recognizing and blocking amyloid aggregation through $\beta$-sheet interactions (bottom); b) Proposed model of inhibition of $A \beta$ aggregation by ABSM. The solid curve corresponds to a pathway for $A \beta$ aggregates without $A B S M$. The dashed curve corresponds to an alternative pathway in which $A B S M$ inhibits $A \beta$ aggregation by binding $A \beta$ oligomers. ${ }^{72}$

The rational design of these inhibitors leads to really promising results in terms of amyloid inhibition and subsequently they reduce the toxicity of $A \beta 40$ and $A \beta 42$ in PC-12 cells. The authors hypothesized an inhibition mechanism in which the ABSMs macrocycles bind early $\beta$-structured oligomers and blocked $A \beta$ nucleation. The stabilisation of these complexes creates a higher energy barrier (dash lines) towards 
fibril formation in comparison with the absence of ABSM (black line). This new energetic pathway delays or even halts the final fibril formation.

Having shown that small peptides can be extremely useful as inhibitors for the amyloid aggregation a particular interaction study between isomeric tetrapeptides and amyloid protein $A \beta 40$ will be carried out in Chapter 4 highlighting the importance of amino acid sequence.

\subsection{Supramolecular gels}

Supramolecular gels represent an intriguing case of self-assembly of low molecular weight (LMW) species into nano(micro) fibrillar networks that percolate the solvent and transform it into a viscoelastic material. ${ }^{73}$ In the last 25 years these kind of systems has received great attention not only for academic reasons but also for their potential applications in many different areas including drug release, regenerative medicine, optoelectronics and templating materials or catalysis among others. ${ }^{74}$

The transition from small molecules in solution to the formation of a gel may occur by just adding the solid gelator into the solvent but usually the gelator has to be dissolved in a hot solvent and then the resulting solution is cooled, concentrated, or exposed to a poor solvent to promote the aggregation (Figure 1.22). ${ }^{39 a}$ When the molecules start to aggregate through non-covalent interactions other physical crosslinking phenomena like precipitation or crystallisation can take place which could hinder the formation of the gel. However the gelator-solvent system promotes the anisotropic growth of one dimensional fibres that develop complex fibrillar networks entrapping the solvent and avoiding the characteristic phase separation observed during the crystallization process. As it is represented in Figure 1.22 the crystallization process can occur afterwards and in fact, gel-assemblies usually represent a kinetically entrapped state and not the thermodynamically stable one. As a consequence the fibrillisation process will be generally strongly kinetically dependent ${ }^{75}$ and more than one possible pathway will be possible. Considering this, the final mechanical properties of the gels will be defined not only by the properties of the fibres themselves (thickness, persistence length, etc.) but also by the process whereby the self assembly takes place, usually ignored in many reported examples. 
It is also important to mention that a certain percentage of the gelator remains generally in solution awarding the gel with the characteristic dynamic behaviour due to the gelator exchange between the gel and the sol phase.

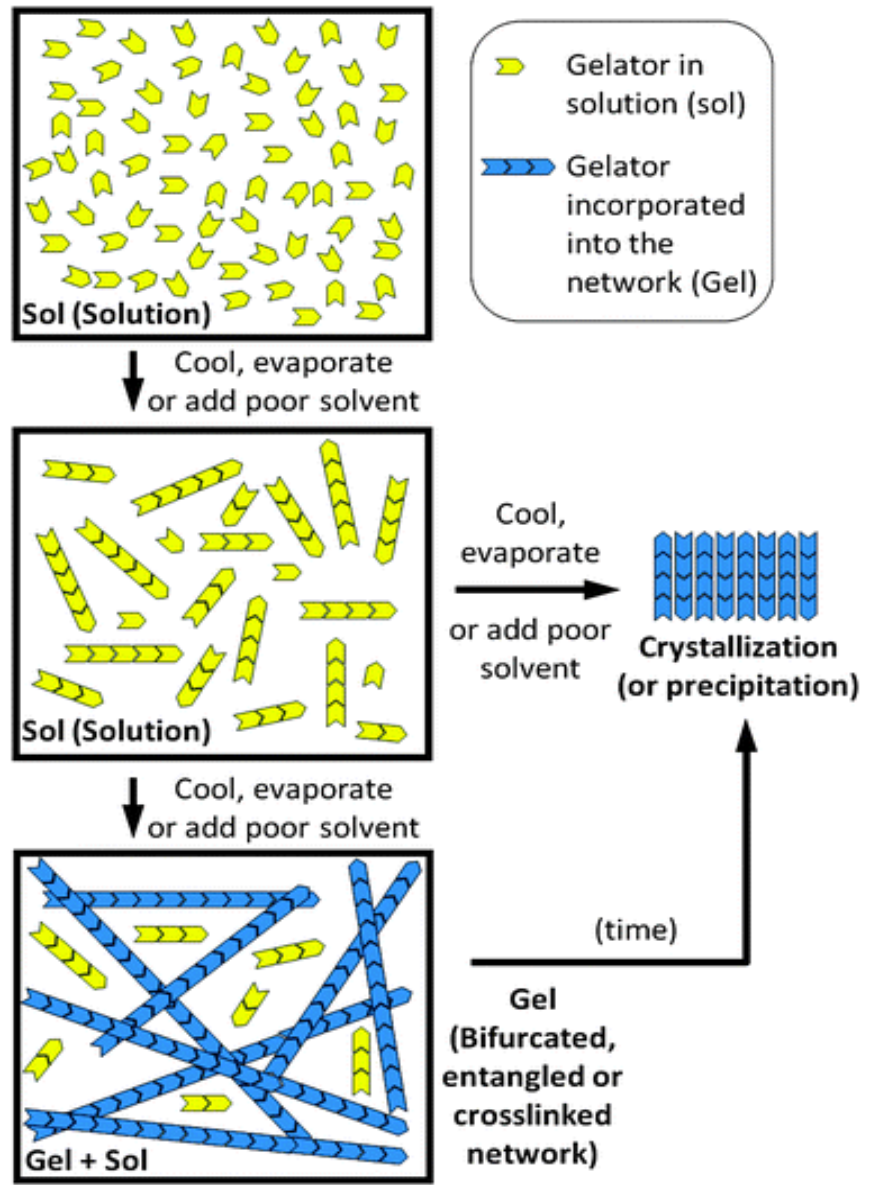

Figure 1.22 Simplified cartoon highlighting the process of supramolecular gelation. ${ }^{39 a}$

The non-covalent interactions that hold supramolecular gels also endow them with particular features which cannot be found in most of the traditional polymeric gels such as precise structural arrangement, reversible shear sensitivity, self-healing ability and of course the facility to respond against external stimuli.

Most of the gelators are found serendipitously and therefore quite often, the design of new molecules is based on the construction of libraries of compounds with few structural modifications of an already known gelator.

The gelation phenomenon is still difficult to predict but a remarkable progression has been made to understand the structural requirements for the gelation to occur and certain functional groups are usually found in gelator molecules as for instance:

(i) Amides (peptides), ureas and hydroxyl groups (carbohydrates) capable of hydrogen bonding. 
(ii) Long aliphatic tails able to participate in van der Waals forces and solvophobic interactions.

(iii) Aromatic residues to develop $\pi$ - $\pi$ stacking interactions.

The design consideration differs widely depending on the solvent used. Supramolecular interactions involved in organogels (gels in organic solvents) will be different from hydrogels due to the particular properties of water previously discussed.

A more ambitious goal is the functionalization of the conventional LMW gelators to develop new materials for a desired application. In this sense, gelators could be carefully endowed with tailor-made functionalities at the molecular level, which will be displayed in the gel material. ${ }^{74 a}$

Undoubtedly, the better the gelation mechanism is understood, the more innovatively these promising materials can be developed. However, it is still difficult for chemists to fully characterise these novel materials due to their dynamic nature. Advances in characterisation techniques provide insights at different levels of the selfassembly process and therefore they offer continuously new tools for the design and development of new and better gelators. ${ }^{76}$

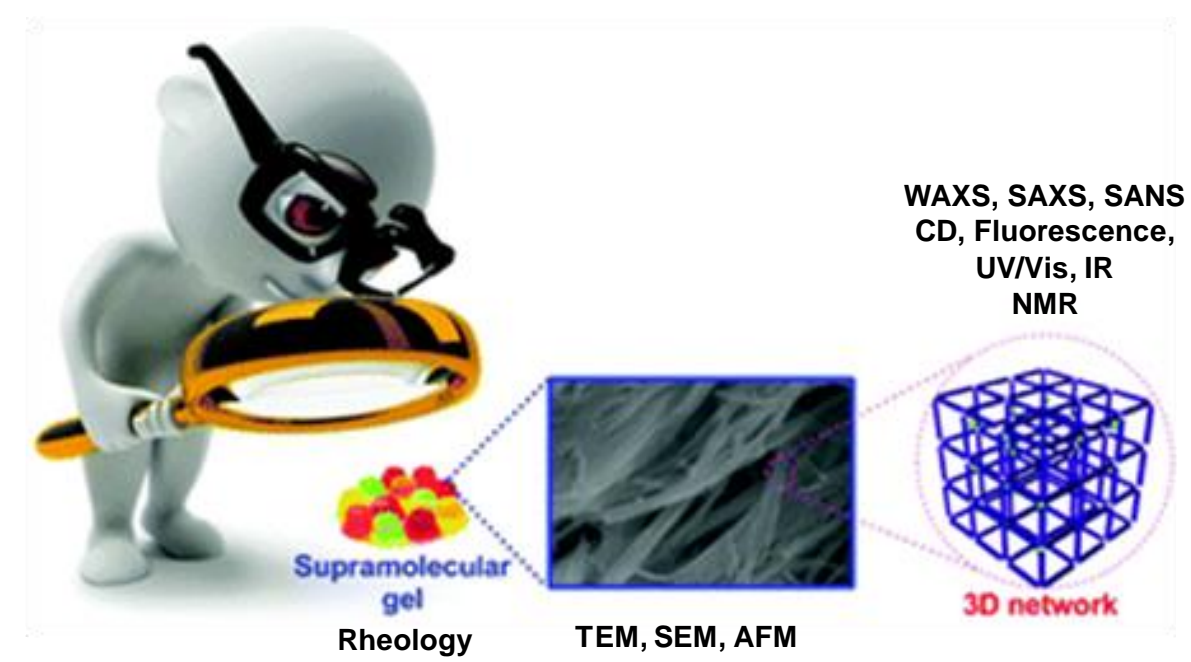

Figure 1.23 Cartoon illustration about different levels of self-assembly including some characterisation techniques for each one. Adapted from reference 76b.

Considering gels as soft materials they can be macroscopically explored by rheological methods which analyze the response of materials to applied stress. Electron microscopy techniques like SEM (scanning electron microscopy) and TEM (transmission electron microscopy) provide valuable information about the aggregate morphologies. Besides, cryo-modes of these techniques as well as AFM (atomic force microscopy) can 
avoid drying effects and have the advantage of not requiring any additional staining. Other complementary techniques such as diffraction techniques can be employed to elucidate the packing mode of the gelator. They are non-destructive and can also reveal information about chemical composition and physical properties of materials. WAXS (wide angle X-ray scattering) or powder diffraction has usually been carried out using dry samples however other diffraction techniques including SAXS (Small-angle X-ray scattering) and SANS (Small-angle neutron scattering) allow performing the experiments directly onto the gel. Further information about the molecular level organization including the nature of intermolecular interactions, concentration critical values and changes in the motion and the conformation of molecules within the aggregates can be obtained by analyzing NMR (nuclear magnetic resonance) data. Concentration, temperature and time dependent experiments by using other spectroscopic techniques including UV/Vis, fluorescence, IR (Infra Red) or CD (circular dichroism) spectroscopy also offer interesting descriptions about the self-assembly process. UV/Vis and fluorescence are especially useful for identifying hydrophobic pockets inside hydrogels or detect changes in the hydrophobicity of the surrounding for a reported group. IR for example is really helpful to confirm the presence of $\mathrm{H}$-bonds and $\mathrm{CD}$ studies can be used to assess the chirality transfer from molecular level to nanoscale.

It is important to know the advantages and disadvantages of each characterisation technique as well as how to combine them considering gelation mechanism and other possible factors of each gelator.

\subsubsection{Peptide-based supramolecular hydrogels}

Among the wide structural diversity of LMW gelators once again short peptides represent an attractive option for the formation of supramolecular hydrogels due to their ease of design and synthesis but especially because of their biocompatibility and also biodegradability. ${ }^{77}$ Peptidic building blocks combine aromatic, amide and hydrophobic fragments which endow peptide molecules with the ability to adopt specific self-assembled structures that are not easily available with traditional organic molecules and polymers. The self-assembly of peptides leading to hydrogelation is a hierarchical process ${ }^{19}$ and can be simplified as illustrated in Figure 1.24: 

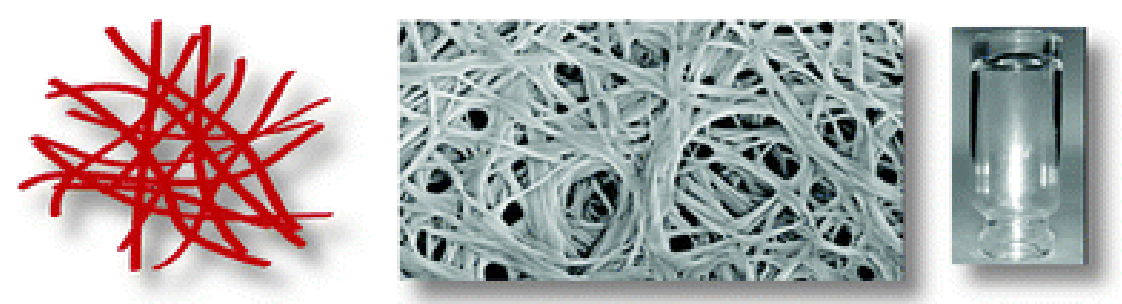

Formation of Hydrogel Network
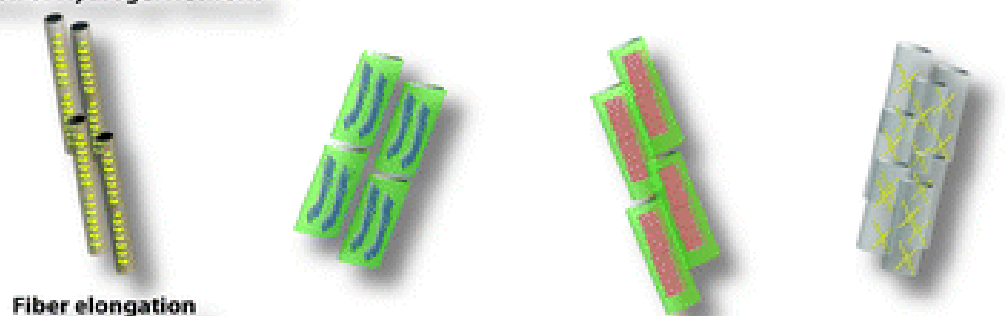

Fiber elongation
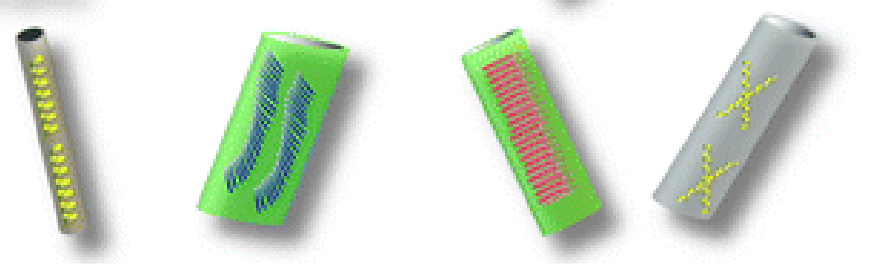

Peptide Self-assembly: Nano-fiber Formation
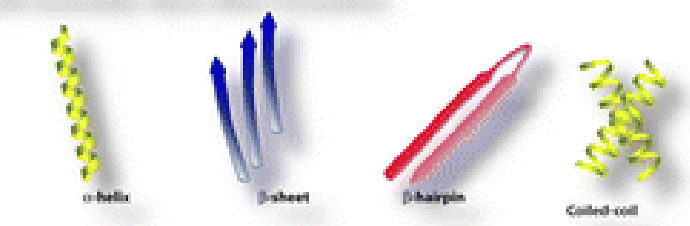

Peptide Secondary Structures

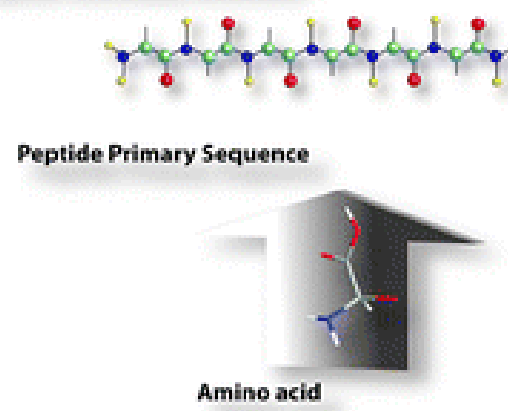

Figure 1.24 Schematic illustration of the hierarchical self-assembly process involved in the formation of a hydrogel from peptides. ${ }^{77 a}$

In solution the peptide primary sequence adopts a secondary structure ( $\alpha$-helix, $\beta$-sheet, $\beta$-harpin, coiled-coil...) and in the presence of an appropriate stimulus the secondary conformation self-assembles to form nanofibres whose elongation allows the formation of a fibrillar network of peptides. This network is capable of entrapping the solvent providing finally a self-supporting hydrogel.

Although simple functionalized amino acids and dipeptides have shown hydrogelation capability, the introduction of other functionalities such as aromatic moieties, electro-conducting residues, enzyme recognition sites or even non-natural 
amino acids has expanded the potential of these systems making them sensitive to many different stimuli as well as useful in a wide range of applications that will be commented in following sections. ${ }^{16,78}$

\subsubsection{Stimuli responsive supramolecular hydrogels}

Probably one of the key properties for the non-covalent based materials to have gained that much interest over the last years is their fast response towards external stimuli. Although temperature and concentration are the most common stimuli employed so far, hydrogelation triggers include a variety of other chemical and physical stimuli ${ }^{79}$ such as changes in ionic strength, $\mathrm{pH}$, metal ions, bond formation or cleavage, light and enzymatic transformation among others (see some reported examples in figure 1.25). For bond formation and cleavage in peptide building blocks, the reduction/oxidation of Cys residues is commonly used to transform a gelator solution into a self-supporting hydrogel. ${ }^{80}$ Light is also a suitable candidate to modulate the state of the hydrogel because it acts in a non-contact and site-specific way and delivers relatively easy and precise control of the irradiation conditions. Short peptidic fragments endowed with azobenzene moiety which undergoes cis/trans conformational change upon irradiation have been recently reported. ${ }^{81}$ Enzymatic regulation in comparison with other physical or more conventional chemical triggering, offers a unique opportunity to modulate the self-assembly in water with high selectivity and specificity. ${ }^{82}$

Our group in particular has recently explored $\mathrm{pH}$ and ionic strength changes to develop new and interesting peptide based hydrogelators. Therefore and because these stimuli are probably the most relevant for the present work a more detailed description for both of them will be considered.

\section{Acid-base sensitive peptide-based hydrogels}

$\mathrm{pH}$ is considered an excellent stimulus for a wide range of biomedical applications. $^{83}$ In living cells and tissues the intra- and extracellular $\mathrm{pH}$ values are stringently regulated but in some cases like in tumour, inflammatory sites or specific cellular compartments the $\mathrm{pH}$ value deviates from the neutrality. 


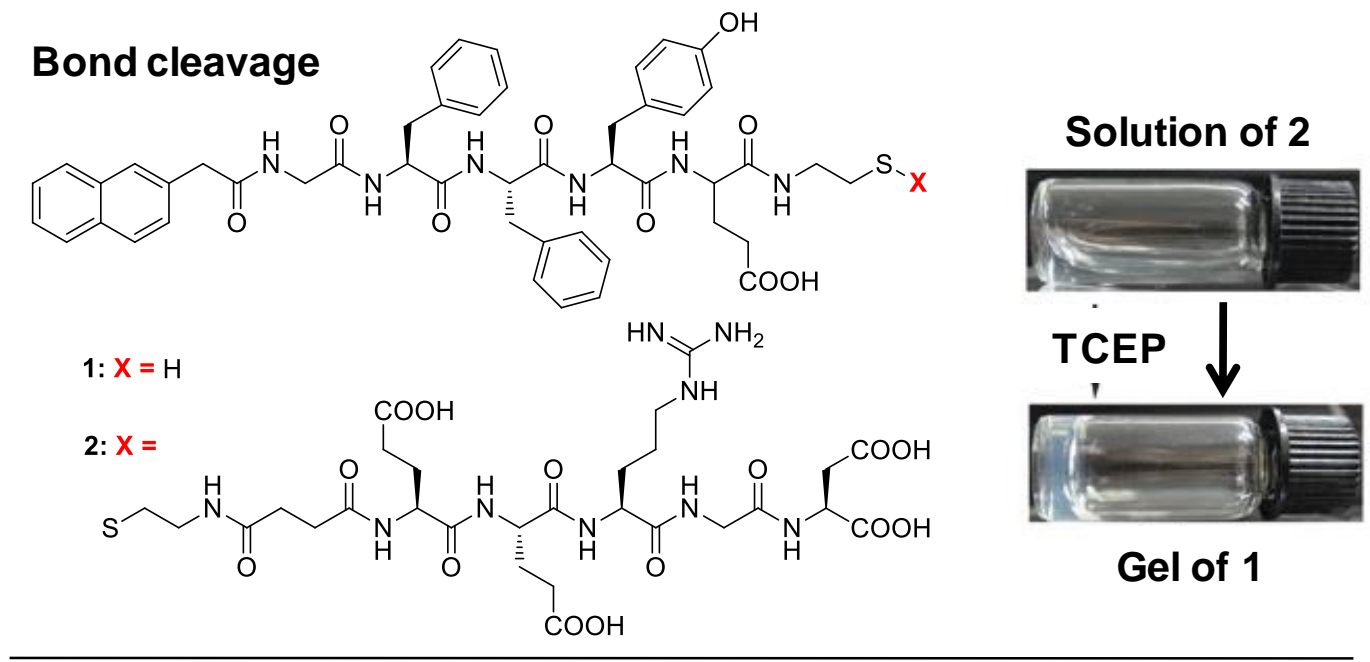

\section{Photoresponsive}
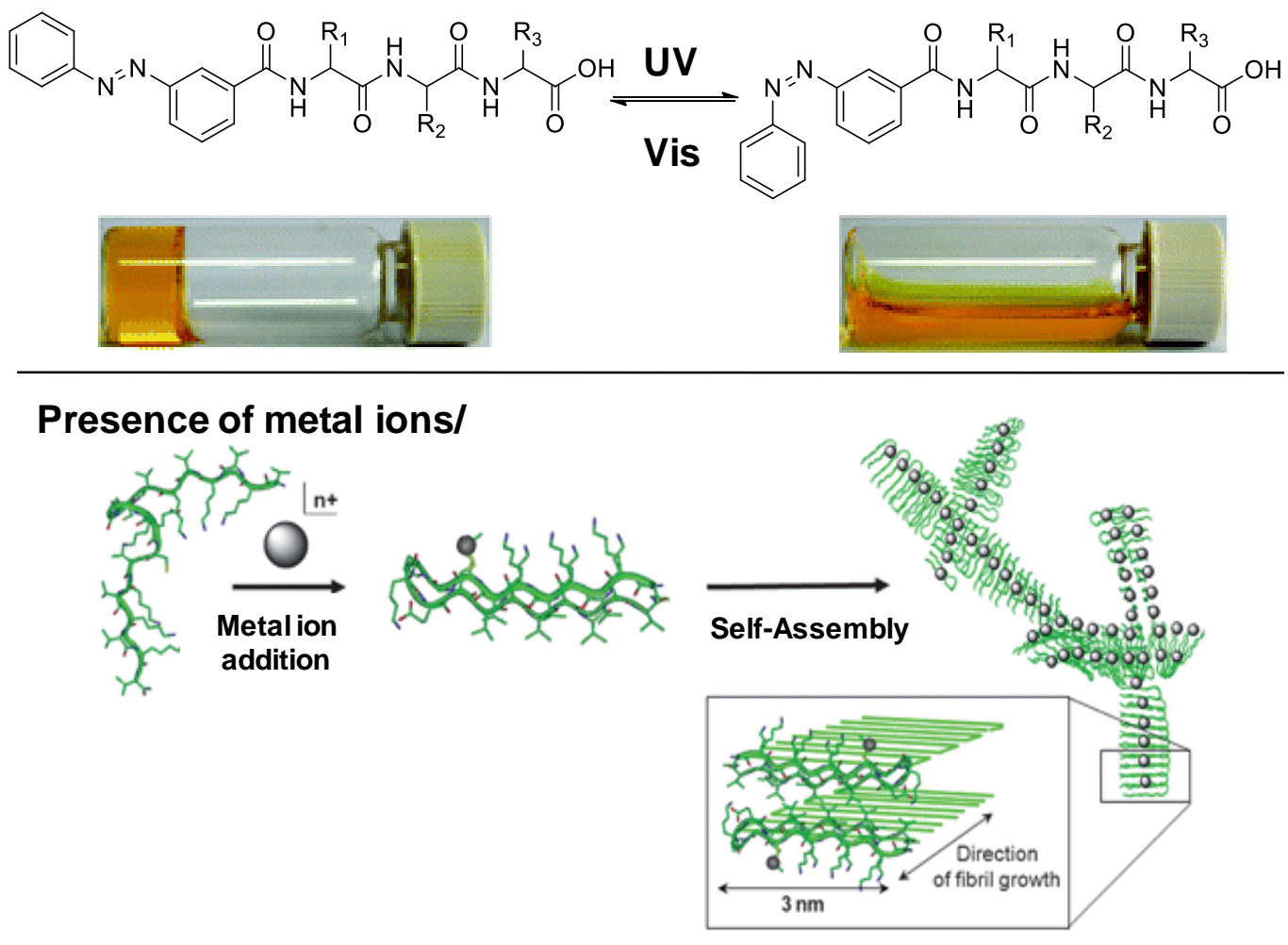

\section{Enzymatic hydrogelation}
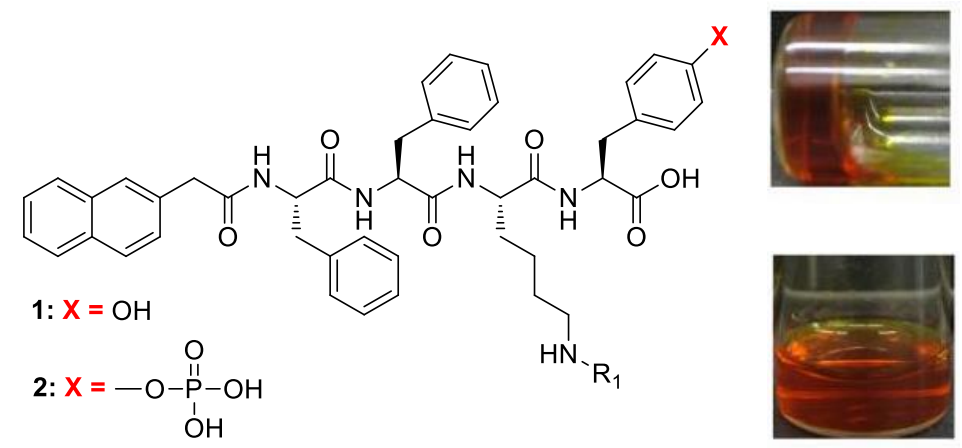

Gel of 1

\section{Solution of 2}

Figure 1.25 Selected examples for different hydrogelation triggers including a) covalent bond cleavage, ${ }^{80}$ b) ions, ${ }^{84}$ c) light ${ }^{85}$ and d) enzymes. ${ }^{82}$ 
These sites are considered then potential targets where $\mathrm{pH}$ sensitive molecules can undergo a programmed response. Amino acids in general are able to respond against $\mathrm{pH}$ changes and besides the possibility to incorporate specific charged amino acids or other ionic functionalities into the building block allows exploring them in a wide range of $\mathrm{pH}$ values.

It is possible to achieve gelation by decreasing ${ }^{86}$ or increasing ${ }^{87}$ the $\mathrm{pH}$ for acidic and basic ionisable groups respectively. The protonation or deprotonation of the gelator will trigger the self-assembly and the $\mathrm{pH}$ at which this process occurs is therefore strongly dependent on its apparent pKa. It has been proposed that this value is dependent on the overall hydrophobicity of the molecule since the hydrophobic effect is known to provoke shifts in the apparent pKa value. ${ }^{89}$

A common problem usually found in the $\mathrm{pH}$ dependant gelation is the difficulty to achieve a uniform $\mathrm{pH}$ in solution before the gelation process stars by acid or base addition. In some cases the kinetics of mixing are slower than the initial kinetics of gelation leading to $\mathrm{pH}$ gradients which finally result into inhomogeneous gels. This problem can be addressed by using for instance smooth diffusion of acidic or basic vapours through the gelator solution as reported by our group for a pyridine bolaamphiphilic derivative ${ }^{88}$ shown in Figure 1.26 .

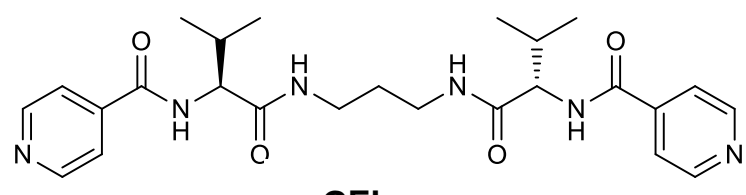

GEL
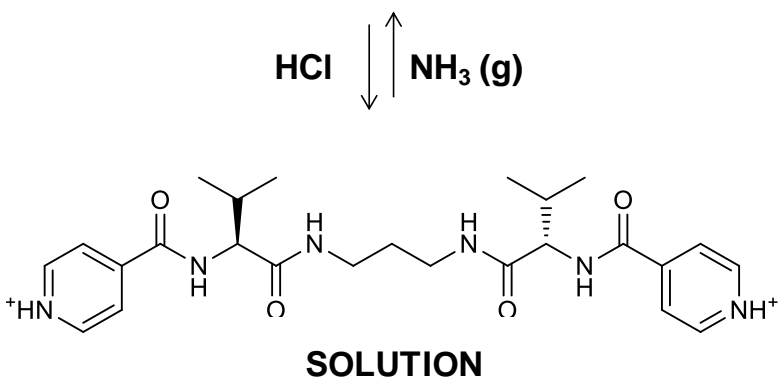

Figure 1.26 Solution-to-gel transition achieved via $\mathrm{pH}$ changes by the diffusion of ammonia vapours.

Another nice approach to obtain homogenous and reproducible hydrogels using $\mathrm{pH}$ changes was reported by Adams and co-workers ${ }^{89}$ who introduced the use of $\delta$-Dgluconolactone (GdL). GdL is known to slowly hydrolyse in water generating D-gluconic 
acid and smoothly decreasing the $\mathrm{pH}$ value as a consequence. The slow GdL hydrolysis also has the advantage of allowing the gelation process to be followed with time and besides the $\mathrm{pH}$ change rate can be modulated by modifying the amount of GdL offering new possibilities for a programmed hydrogelation.

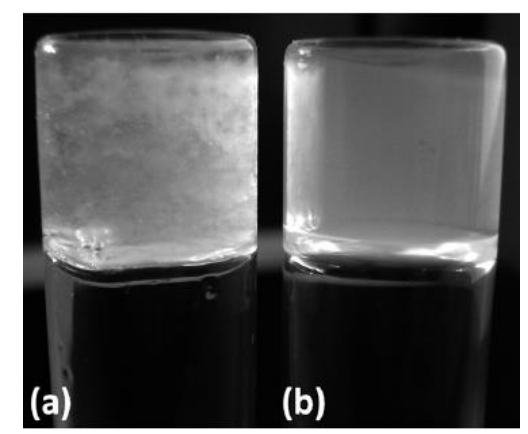

c)<smiles>O=C(O)[C@H](O)[C@@H](O)[C@H](O)CO</smiles>

Figure 1.27 Photographs of hydrogels prepared by addition of a) $\mathrm{HCl}$ and b) GdL. c) Hydrolysis of GdL to Dgluconic acid.

This protocol will be extensively used in this work, especially in Chapter 4 . In chapter 4, pKa shifts associated to the self-assembly process will also be reported and deeply analysed for a family of isomeric tetrapeptides demonstrating the importance of hydrophobic/hydrophilic amino acid distribution.

\section{lonic strength changes by salt addition}

Ionic species represent also a stimulus of particular interest because many applications of molecular gels have to deal with the presence of salts in complex aqueous environments, especially in biomedical applications. Particularly in water the hydrogelator-ion binding equilibrium has a strong competitor with water solvating the salts and therefore the effect of ions on the water behaviour as a solvent can be used to control the gel formation rather than the interaction ion-hydrogelator itself.

In the 1870s, Frank Hofmeister described the relative ability of different salts to decrease (salting-out species or kosmotropes) or increase (salting-in species or chaotropes) the solubility of proteins and some other colloids. Since then ionic strength has been employed to trigger the self-assembly of peptides, ${ }^{90}$ proteins and other systems.

Particularly, a detailed study based on the Hofmeister effect has been recently reported by in our group. Smart supramolecular hydrogels were prepared from a bolaamphiphilic L-valine derivative in aqueous solutions of different salts. ${ }^{91}$ The 
hydrogels responded selectively to different ions and were either reinforced (by kosmotropic anions such as sulfate) or weakened (by chaotropic anions such as perchlorate). Some examples can be seen in Figure 1.28:

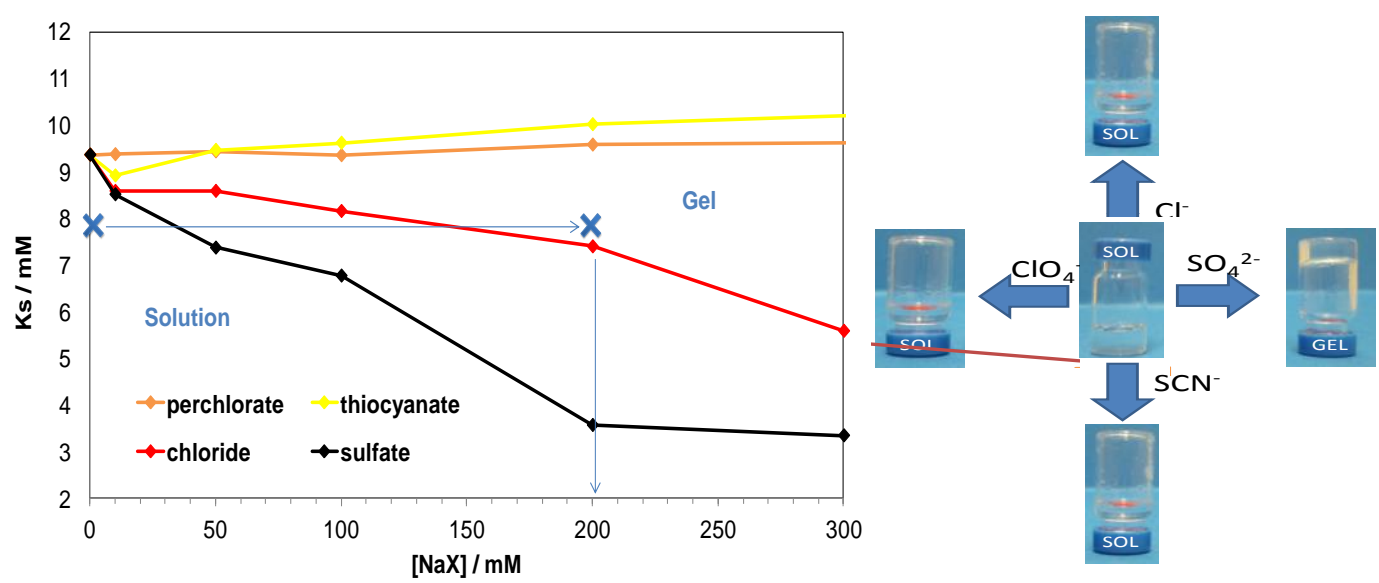

Figure 1.28 Phase diagram illustrating the salt induced hydrogelation process (left) and pictures of the selective gelation induced by different salts (right).

Additionally, the well-known behaviour of this system in the presence of different salts allowed the development of a non-conventional system in which the hydrogel formation was reached upon heating the solution in the presence of guanidinium salt in contrast to the traditional heating-cooling methodology for gel formation.

\subsubsection{Applications of peptide hydrogels}

The gained knowledge in the last years about peptide self-assembly and the improvement of the characterisation techniques have encouraged not only the emergence of countless publications related to this topic but also the development of new applications in such different fields like biomedicine, materials science and catalysis.

The low toxicity as well as the biodegradability and the modular design that peptide building blocks offer have promoted them as one of the best candidates for biomedical applications including drug delivery, cell culture or tissue engineering and regenerative medicine among others. ${ }^{92}$

The conjugation or encapsulation of therapeutic agents like anticancer ${ }^{93}$ drugs into peptide hydrogels have been extensively studied since hydrogels provide a solid 
matrix which allows a selective and controlled release avoiding the contact with healthy tissues and providing advantages in comparison with free drugs.

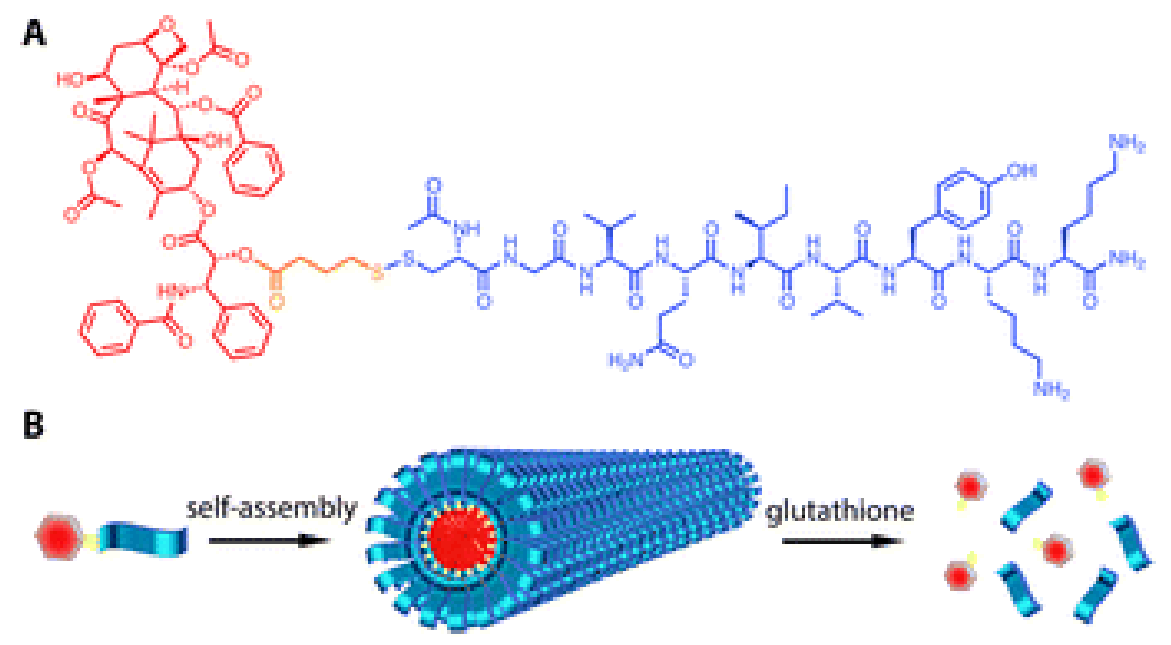

Figure 1.29 a) Chemical design of the paclitaxel-amphiphile drug and b) molecular self-assembly into tubular micelles and drug release in the presence of glutathione. ${ }^{93 a}$

Supramolecular gels are also suited for tissue engineering and regenerative medicine because synthetic biomaterials generally minimize the risk of carrying biological pathogens and contaminants in comparison with naturally derived polymer. Pioneers in this field were the peptide amphiphiles reported by Stupp and co-workers ${ }^{94}$ bearing bioactive epitopes that upon being mixed with cell culture media self-assembled into a three-dimensional network of nanofibres (in the presence of calcium ions) and afforded a hydrogel able to promote neural progenitor cells to rapidly differentiate into neurons. The use of peptide based hydrogels in this field has grown exponentially since then and the main results are reported in several reviews. ${ }^{92}$

For cell culture applications some peptide based hydrogels have reached the market as the known case of PuraMatrix ${ }^{\mathrm{TM}}$. The initial peptide sequence Ac-(RADA) ${ }_{4}-\mathrm{NH}_{2}$ reported by Zhang and co-workers ${ }^{109}$ is soluble at low $\mathrm{pH}$ and osmolarity but undergoes fibril formation under physiological conditions. The high content of water (99\%) and the ability to customize the peptide backbone have yielded successful culturing of neural cells or osteocytes among others. PuraMatrix ${ }^{\mathrm{TM}}$ advantages in terms of synthesis and long term cell culture may displace currently used materials such as Matrigel ${ }^{\mathrm{TM}}$ in many applications.

The hierarchical self-assembly process which defines peptide hydrogel network formation can be also explored as an efficient template for the fabrication of 
nanomaterials with proper control of size and dimensions. ${ }^{95}$ Our group for instance designed a bola-amphiphilic peptide derivative which was used as structure directing agent for preparing nanostructured silica. ${ }^{96}$ Other interesting example was reported by Park and coworkers. They synthesized transition metal phosphate nanotubes for its application as a cathode material for rechargeable lithium (Li) ion batteries by using a peptide hydrogel self-assembled from Fmoc-FF as template. ${ }^{97}$

Aside from applications in biomedicine or materials science, the field of catalysis is also one of the most promising areas in which supramolecular chemistry is involved. ${ }^{98}$ Regarding this topic the combination between intrinsic peptide catalytic activity and supramolecular gels offers unique opportunities for the bottom-up construction of supramolecular catalysts that aim to emulate the efficiency and selectivity of natural enzymes. ${ }^{99}$

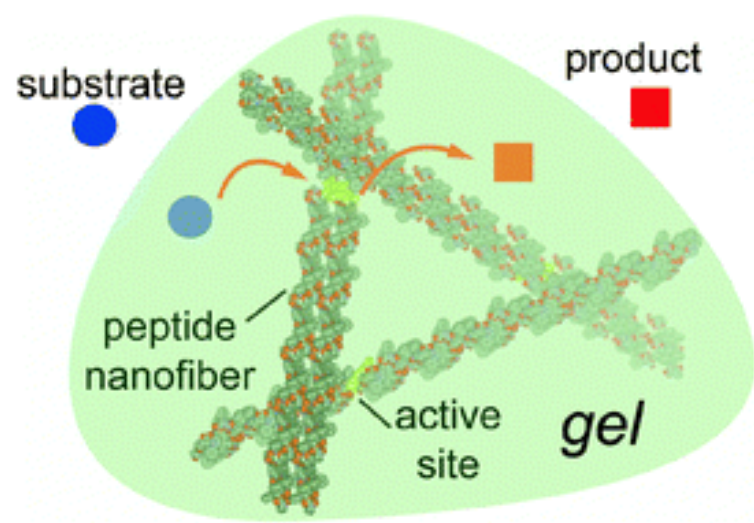

Figure 1.30 Schematic representation of a catalytic reaction performed into a peptidic hydrogel matrix..$^{99 b}$

On the one hand amino acid side chains show functional fragments able to participate (as they do in natural enzymes) in the catalysis of organic reactions including the formation of $\mathrm{C}-\mathrm{C}$ bonds, asymmetric oxidations and reductions, hydrolysis, acylation... ${ }^{100}$ On the other hand the hierarchical self-assembly of peptide sequences into molecular gels provide many advantages. Firstly, supramolecular gels can behave as self-supported catalyst with a large active surface that can be filtered out of the reaction and be reused. Secondly, their reversible formation, usually controlled by temperature and concentration, could result in a tuneable catalytic activity. Finally the precise organization of functional groups in the gel fibres is of great interest because the cooperation of multiple interacting sites can yield new or enhanced catalytic properties. ${ }^{101}$ 
A recent example was reported by Zhang and co-workers. ${ }^{102}$ They designed an artificial hydrolase via self-assembly of short peptides to catalyze ester hydrolysis. The co-assembly of two amphipathic peptides containing histidine (to carry out the hydrolysis reaction) and arginine (to stabilize the transition state of the substrate at the binding site) into peptide nanofibres and hydrogels demonstrated a high catalytic efficiency suggesting that this well-ordered nanostructure is an attractive scaffold for developing new artificial enzymes.

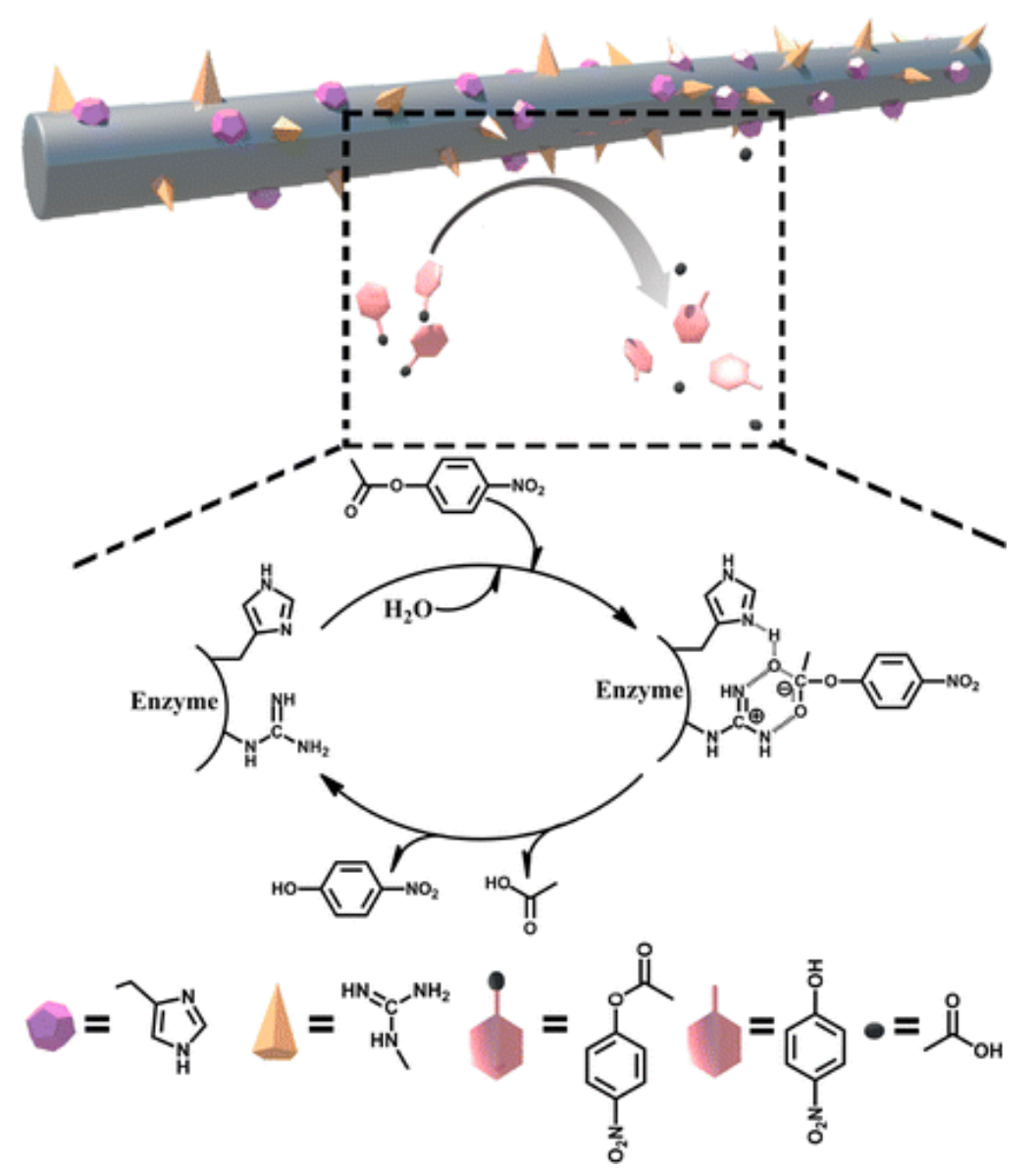

Figure 1.31 Schematic representation of possible mechanisms for p-nitrophenyl acetate hydrolysis catalyzed by nanofibres reported by Zhang and co-workers. ${ }^{102}$

The catalytic role of aldolase type I in nature has been extensively mimicked in artificial catalytic systems by using L-proline amino acid. ${ }^{103}$ In both cases the formation of an enamine represents the key intermediate for the reaction to proceed ${ }^{104}$ (Figure 1.32). 
a)

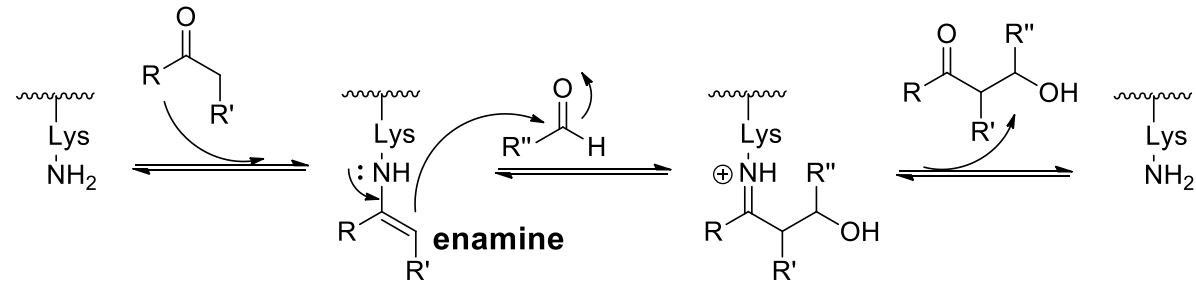

b)

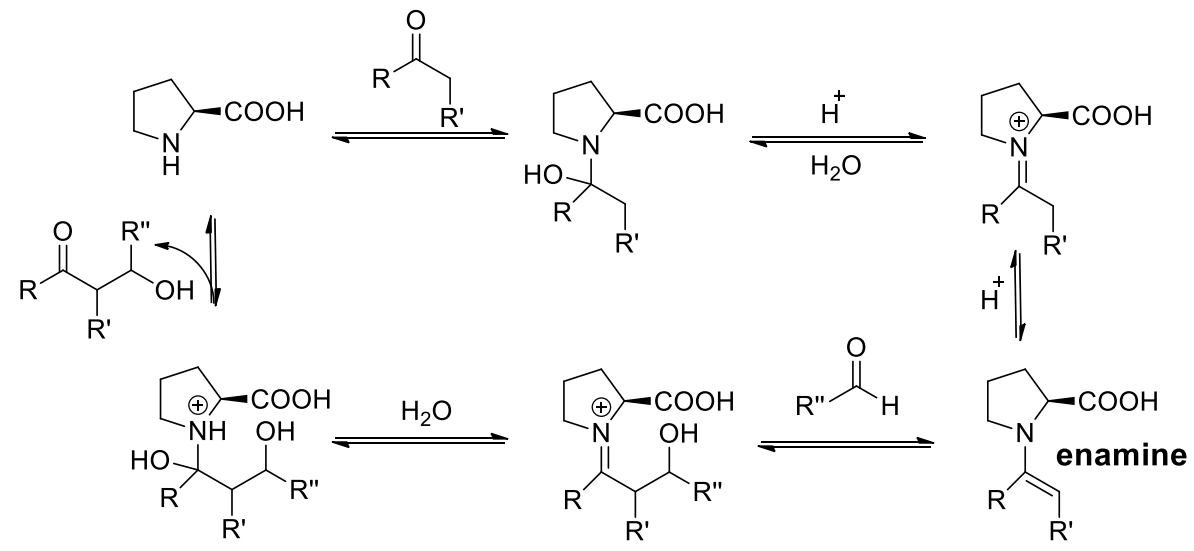

Figure 1.32 a) General mechanism for type I aldolase. b) Detailed mechanism for the direct aldol reaction, using L-proline as the organocatalyst.

Our group has reported the incorporation of an L-proline moiety as a functional group into a self-assembled scaffold and performed catalytic reactions into the gel matrix. ${ }^{105}$ For instance, an amphiphilic dipeptide containing L-proline (PV12 in Figure 1.33) was shown to self-assemble in water forming hydrogels that were tested for the aldol reaction between cyclohexanone and 4-nitrobenzaldehyde. ${ }^{106}$ Reagents were easily added on top of the gel dissolved in toluene and the reaction was quantitatively completed after $24 \mathrm{~h}$ at 5 oc with high stereoselectivity (anti:syn 92:8, 88\% ee). Moreover, the catalytic hydrogel could be reused after decantation of the toluene phase for at least three times with the same efficiency and stereoselectivity.

The same system was studied in more detail and the key role of hydrophobic effect in the catalytic success was demonstrated. ${ }^{107}$ After a systematic study employing different aliphatic ketones a dual role for the hydrophobic effect was hypothesized. First of all it acts as the driving force for hydrogel self-assembly and, secondly, binding substrates close to the catalytic sites. It could be observed that polar ketones such as acetone, 1,3-dihydroxyacetone and butanone did not react after $10 \mathrm{~h}$, medium size ketones such as 2-pentanone, 2-hexanone, 2-heptanone and 2-octanone lead to yields 
below $20 \%$ whereas long alkyl tail ketones (2-nonanone and 2-dodecanone) yielded $70 \%$ of aldol after that period of time.

a)

b)<smiles>CCCCCCCCCCCNC(=O)[C@@H](NC(=O)C1CCCN1)C(C)C</smiles><smiles>O=C1CCCCC1[N+](=O)[O-]</smiles>

c)

\begin{tabular}{l|c|c|c} 
c) & Yield (\%) & anti:syn & ee (\%) \\
\hline Run 1 & 98 & $92: 8$ & 88 \\
\hline Run 2 & $>99$ & $93: 7$ & 87 \\
\hline Run 3 & $>99$ & $92: 8$ & 90
\end{tabular}

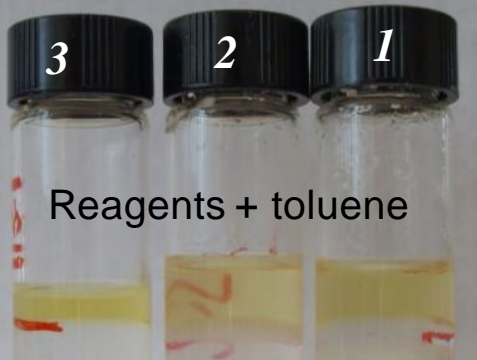

Hydrogel: $0.026 \mathrm{mmol}$ of gelator $(0.2 \mathrm{eq})$ in water $(4 \mathrm{~mL})$; Reagents: $4-$ nitrobenzaldehyde $(1 \mathrm{eq})$, cyclohexanone $(20 \mathrm{eq})$ in toluene $(1 \mathrm{~mL})$. Time: $24 \mathrm{~h}$. $\mathrm{T}=5^{\circ} \mathrm{C}$.

Figure 1.33 a) Chemical structure for PV12, b) aldol reaction performed using hydrogel matrix of PV12 and c) application as reusable catalyst.

a)

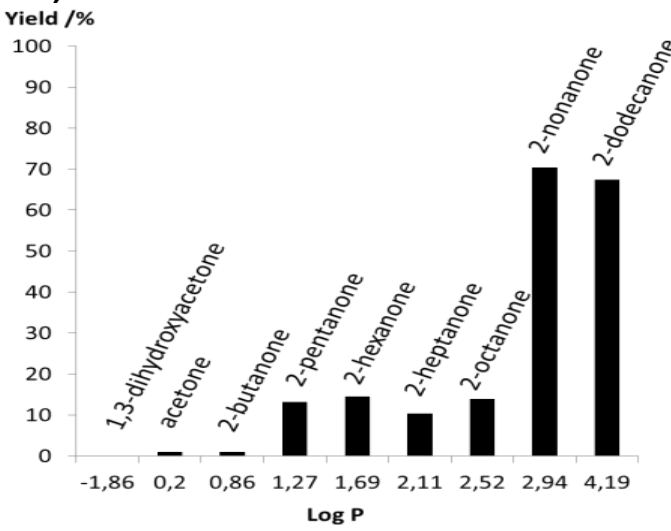

b)

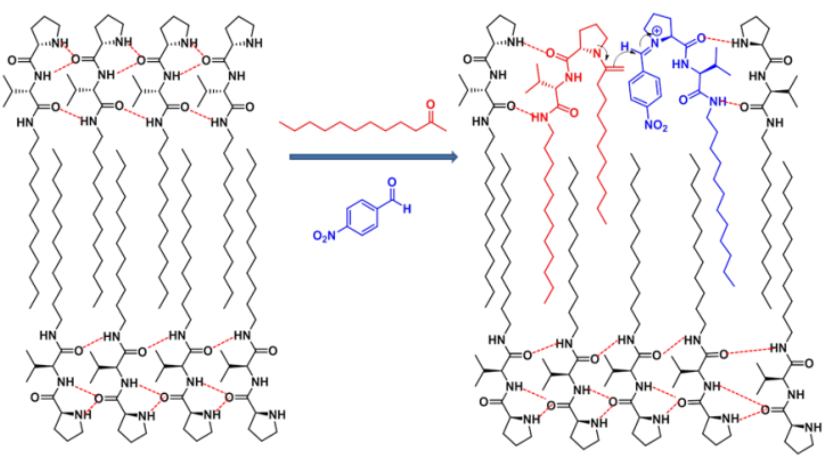

Figure 1.34 a) Yield of aldol product versus $\log \mathrm{P}$ of ketone after $10 \mathrm{~h}$ of reaction and $\mathrm{b}$ ) Proposed scheme for the hydrogel reaction site. 
In a similar way as enzymes use metals as co-factors to perform chemical functions, several systems involving metal coordination to amino acids embedded into a hydrogel matrix have been also reported. Liu and co-workers described the selfassembly of a bolaamphiphilic derivative containing glutamate residues (L-HDGA) in the presence of copper and the formed metallogel was shown to be efficient for Diels-Alder reaction between cyclopentadiene and an aza-chalcone. ${ }^{108}$ Although the enantioselectivity of the reaction was moderate, interestingly it could be reversed by using the opposite enantiomer (D-HDGA) which formed nanotubes of opposite handedness. This work constitutes an example of the transmission of a molecular feature as chirality into the nanoscopic level and the construction of chiral supramolecular catalytic sites.

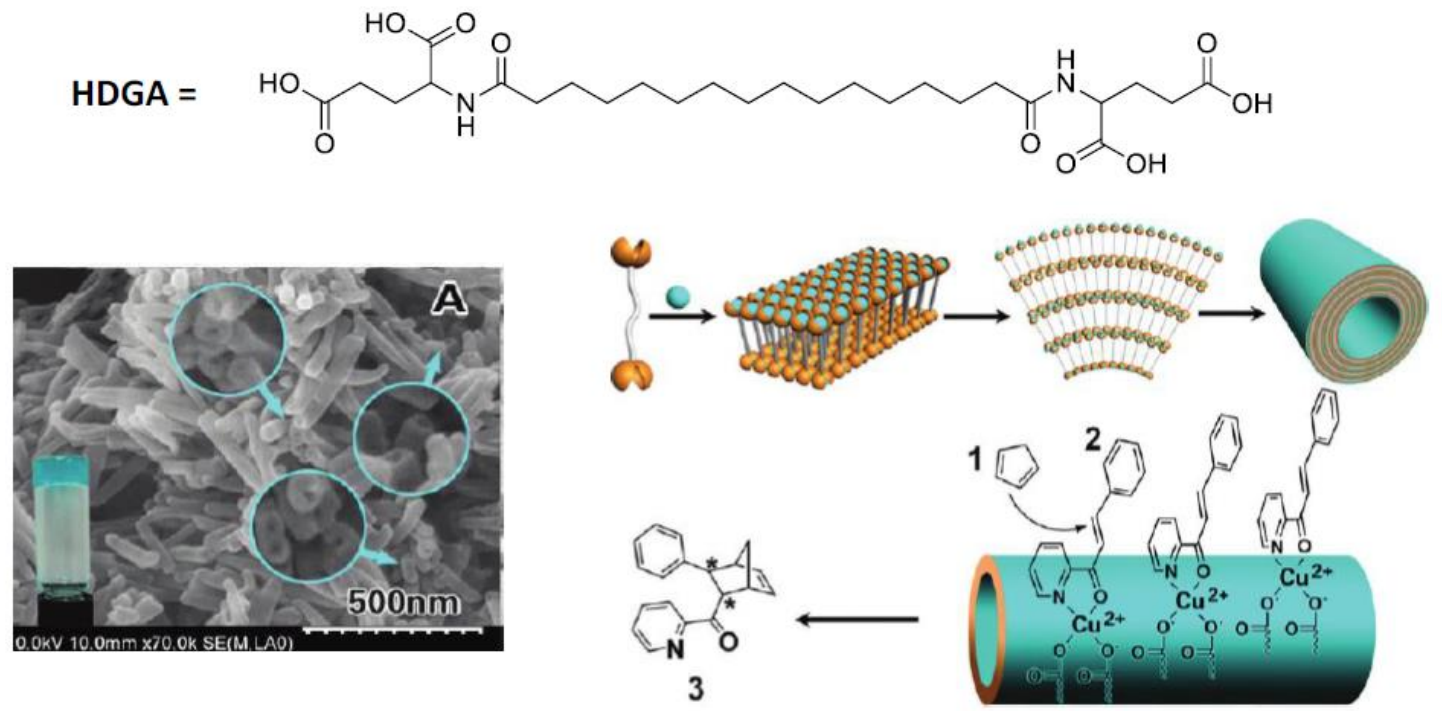

Figure 1.35 Chemical structure of compound HDGA, microscopic and macroscopic structure (left) and schematic representation of the self-assembly process and Diels-Alder reaction (right).

Previously reported examples are just only small evidences of the great potential peptidic hydrogels represent nowadays. In an attempt to contribute for a better understanding of the complex self-assembly phenomena and explore new applications the main results of the present research work will be summarized and deeply analysed in following chapters. 


\subsection{References}

1 a) Lehn, J.-M., Toward complex matter: Supramolecular chemistry and selforganization. Proc. Natl. Acad. Sci. 2002, 99, 4763-4768, b) Lehn, J.-M., Supramolecular Chemistry: Concepts and Perspectives, 1995.

2. Whitesides, G. M.; Grzybowski, B., Self-Assembly at All Scales. Science 2002, 295, 2418-2421.

3. a) Deamer, D. W., Origins of life: How leaky were primitive cells? Nature 2008, 454, 37-38, b) Deamer, D.; Dworkin, J. P.; Sandford, S. A.; Bernstein, M. P.; Allamandola, L. J., The First Cell Membranes. Astrobiology 2002, 2, 371-381, c) Trevors, J. T.; Psenner, R., From self-assembly of life to present-day bacteria: a possible role for nanocells. FEMS Microbiol. Rev. 2001, 25, 573-582.

4. Petkau-Milroy, K.; Brunsveld, L., Supramolecular chemical biology: bioactive synthetic self-assemblies. Org. Biomol. Chem. 2013, 11, 219-232.

5. Lehn, J. M., Supramolecular chemistry-receptors, catalysts and carriers. Science $1985,227,849-856$.

6. Pedersen, C. J., Cyclic polyethers and their complexes with metal salts. J. Am. Chem. Soc. 1967, 89, 7017-7036.

7. a) Dong, R.; Zhou, Y.; Huang, X.; Zhu, X.; Lu, Y.; Shen, J., Functional supramolecular polymers for biomedical applications. Adv. Mater. 2015, 27, 498526, b) Busseron, E.; Ruff, Y.; Moulin, E.; Giuseppone, N., Supramolecular selfassemblies as functional nanomaterials. Nanoscale 2013, 5, 7098-7140, c) Aida, T.; Meijer, E. W.; Stupp, S. I., Functional supramolecular polymers. Science 2012, 335, 813-817, d) Ciferri, A., Supramolecular Polymers, Second Edition. Taylor \& Francis Group 2005.

8. Lee, J. S.; Feijen, J., Polymersomes for drug delivery: Design, formation and characterization. J. Controlled Release 2012, 161, 473-483.

9. Chandler, D., Interfaces and the driving force of hydrophobic assembly. Nature 2005, 437, 640-647.

10. Stephanopoulos, N.; Ortony, J. H.; Stupp, S. I., Self-assembly for the synthesis of functional biomaterials. Acta Mater. 2013, 61, 912-930.

11. Lim, Y.-B.; Moon, K.-S.; Lee, M., Recent advances in functional supramolecular nanostructures assembled from bioactive building blocks. Chem. Soc. Rev. 2009, 38, 925-934.

12. a) Guo, D.-S.; Liu, Y., Calixarene-based supramolecular polymerization in solution. Chem. Soc. Rev. 2012, 41, 5907-5921, b) Liu, Y.; Yang, H.; Wang, Z.; Zhang, X., Cucurbit [8] uril-based supramolecular polymers. Chem. Asian J. 2013, 8, 16261632. 
13. a) Mendes, A. C.; Baran, E. T.; Reis, R. L.; Azevedo, H. S., Self-assembly in nature: using the principles of nature to create complex nanobiomaterials. Wiley Interdisciplinary Reviews: Nanomedicine and Nanobiotechnology 2013, 5, 582612 , b) Ulijn, R. V.; Smith, A. M., Designing peptide based nanomaterials. Chem. Soc. Rev. 2008, 37, 664-675.

14. a) Roy, A.; Franco, O. L.; Mandal, S. M., Biomedical exploitation of self assembled peptide based nanostructures. Curr. Protein Pept. Sci. 2013, 14, 580-587, b) Matson, J. B.; Stupp, S. I., Self-assembling peptide scaffolds for regenerative medicine. Chem. Commun. 2012, 48, 26-33.

15. Mandal, D.; Nasrolahi Shirazi, A.; Parang, K., Self-assembly of peptides to nanostructures. Org. Biomol. Chem. 2014, 12, 3544-3561.

16. Zelzer, M.; Ulijn, R. V., Next-generation peptide nanomaterials: molecular networks, interfaces and supramolecular functionality. Chem. Soc. Rev. 2010, 39, 3351-3357.

17. Bowerman, C. J.; Nilsson, B. L., Self-assembly of amphipathic beta-sheet peptides: Insights and applications. Biopolymers 2012, 98, 169-184.

18. Zhang, S. G.; Holmes, T.; Lockshin, C.; Rich, A., Spontaneous assembly of a selfcomplementary oligopeptide to form stable macroscopic membrane. Proc. Natl. Acad. Sci. 1993, 90, 3334-3338.

19. a) Dong, H.; Paramonov, S. E.; Aulisa, L.; Bakota, E. L.; Hartgerink, J. D., Selfassembly of multidomain peptides: balancing molecular frustration controls conformation and nanostructure. J. Am. Chem. Soc. 2007, 129, 12468-12472, b) Schneider, J. P.; Pochan, D. J.; Ozbas, B.; Rajagopal, K.; Pakstis, L.; Kretsinger, J., Responsive hydrogels from the intramolecular folding and self-Assembly of a designed peptide J. Am. Chem. Soc. 2002, 124, 15030-15037, c) Aggeli, A.; Nyrkova, I. A.; Bell, M.; Harding, R.; Carrick, L.; McLeish, T. C. B.; Semenov, A. N.; Boden, N., Hierarchical self-assembly of chiral rod-like molecules as a model for peptide $\beta$-sheet tapes, ribbons, fibrils, and fibers. Proc. Natl. Acad. Sci. 2001, 98, 11857-11862.

20. a) Bowerman, C. J.; Liyanage, W.; Federation, A. J.; Nilsson, B. L., Tuning $\beta$-sheet peptide self-Assembly and hydrogelation behavior by modification of sequence hydrophobicity and aromaticity. Biomacromolecules 2011, 12, 2735-2745, b) Bowerman, C. J.; Ryan, D. M.; Nissan, D. A.; Nilsson, B. L., The effect of increasing hydrophobicity on the self-assembly of amphipathic $\beta$-sheet peptides. Mol. BioSyst. 2009, 5, 1058-1069, c) Caplan, M. R.; Schwartzfarb, E. M.; Zhang, S.; Kamm, R. D.; Lauffenburger, D. A., Control of self-assembling oligopeptide matrix formation through systematic variation of amino acid sequence. Biomaterials 2002, 23, 219-227, d) Caplan, M. R.; Schwartzfarb, E. M.; Zhang, S. G.; Kamm, R. D.; Lauffenburger, D. A., Effects of systematic variation of amino acid sequence on the mechanical properties of a self-assembling, oligopeptide biomaterial. J. Biomater. Sci. Poly. Ed. 2002, 13, 225-236. 
21. Cao, M.; Cao, C.; Zhang, L.; Xia, D.; Xu, H., Tuning of peptide assembly through force balance adjustment. J. Colloid Interface Sci. 2013, 407, 287-295.

22. Hong, Y.; Legge, R. L.; Zhang, S.; Chen, P., Effect of amino acid sequence and pH on nanofiber formation of self-assembling peptides EAK16-II and EAK16-IV. Biomacromolecules 2003, 4, 1433-1442.

23. Lee, N. R.; Bowerman, C. J.; Nilsson, B. L., Effects of varied sequence pattern on the self-assembly of amphipathic peptides. Biomacromolecules 2013, 14, 32673277.

24. a) Lee, N. R.; Bowerman, C. J.; Nilsson, B. L., Sequence length determinants for self-assembly of amphipathic $\beta$-sheet peptides. Biopolymers 2013, 100, 738-750, b) Freire, F.; Almeida, A. M.; Fisk, J. D.; Steinkruger, J. D.; Gellman, S. H., Impact of strand length on the stability of parallel- $\beta$-Sheet secondary structure. Angew. Chem. Int. Ed. 2011, 50, 8735-8738, c) Stanger, H. E.; Syud, F. A.; Espinosa, J. F.; Giriat, I.; Muir, T.; Gellman, S. H., Length-dependent stability and strand length limits in antiparallel $\beta$-sheet secondary structure. Proc. Natl. Acad. Sci. 2001, 98, 12015-12020.

25. McGuinness, K.; Khan, I. J.; Nanda, V., Morphological diversity and polymorphism of self-assembling collagen peptides controlled by length of hydrophobic domains. ACS Nano 2014, 8, 12514-12523.

26. a) Dehsorkhi, A.; Castelletto, V.; Hamley, I. W., Self-assembling amphiphilic peptides. J. Pept. Sci. 2014, 20, 453-467, b) Webber, M. J.; Berns, E. J.; Stupp, S. I., Supramolecular nanofibers of peptide amphiphiles for medicine. Isr. J. Chem. 2013, 53, 530-554, c) Webber, M. J.; Tongers, J. r.; Newcomb, C. J.; Marquardt, K.-T.; Bauersachs, J.; Losordo, D. W.; Stupp, S. I., Supramolecular nanostructures that mimic VEGF as a strategy for ischemic tissue repair. Proc. Natl. Acad. Sci. 2011, d) Shah, R. N.; Shah, N. A.; Del Rosario Lim, M. M.; Hsieh, C.; Nuber, G.; Stupp, S. I., Supramolecular design of self-assembling nanofibers for cartilage regeneration. Proc. Natl. Acad. Sci.2010, 107, 3293-3298, e) Cui, H.; Webber, M. J.; Stupp, S. I., Self-assembly of peptide amphiphiles: From molecules to nanostructures to biomaterials. Peptide Science 2010, 94, 1-18.

27. Berndt, P.; Fields, G. B.; Tirrell, M., Synthetic lipidation of peptides and amino acids: monolayer structure and properties. J. Am. Chem. Soc. 1995, 117, 95159522.

28. Hartgerink, J. D.; Beniash, E.; Stupp, S. I., Self-assembly and mineralization of peptide-amphiphile nanofibers. Science 2001, 294, 1684-1688.

29. Zhao, X.; Pan, F.; Xu, H.; Yaseen, M.; Shan, H.; Hauser, C. A. E.; Zhang, S.; Lu, J. R., Molecular self-assembly and applications of designer peptide amphiphiles. Chem. Soc. Rev. 2010, 39, 3480-3498.

30. Liu, L.; Xu, K.; Wang, H.; Jeremy Tan, P. K.; Fan, W.; Venkatraman, S. S.; Li, L.; Yang, Y.-Y., Self-assembled cationic peptide nanoparticles as an efficient antimicrobial agent. Nat. Nanotechnol. 2009, 4, 457-463. 
31. Hartgerink, J. D.; Beniash, E.; Stupp, S. I., Peptide-amphiphile nanofibers: A versatile scaffold for the preparation of self-assembling materials. Proc. Natl. Acad. Sci. 2002, 99, 5133-5138.

32. Löwik, D. W. P. M.; Garcia-Hartjes, J.; Meijer, J. T.; van Hest, J. C. M., Tuning secondary structure and self-assembly of amphiphilic peptides. Langmuir 2005, 21, 524-526.

33. Gore, T.; Dori, Y.; Talmon, Y.; Tirrell, M.; Bianco-Peled, H., Self-assembly of model collagen peptide amphiphiles. Langmuir 2001, 17, 5352-5360.

34. Paramonov, S. E.; Jun, H.-W.; Hartgerink, J. D., Self-assembly of peptide-amphiphile nanofibers: The roles of hydrogen bonding and amphiphilic packing. J. Am. Chem. Soc. 2006, 128, 7291-7298.

35. Cui, H.; Muraoka, T.; Cheetham, A. G.; Stupp, S. I., Self-assembly of giant peptide nanobelts. Nano Lett. 2009, 9, 945-951.

36. Cui, H.; Cheetham, A. G.; Pashuck, E. T.; Stupp, S. I., Amino acid sequence in constitutionally isomeric tetrapeptide amphiphiles dictates architecture of onedimensional nanostructures. J. Am. Chem. Soc. 2014, 136, 12461-12468.

37. Anderson, J. M.; Andukuri, A.; Lim, D. J.; Jun, H.-W., Modulating the gelation properties of self-assembling peptide amphiphiles. ACS Nano 2009, 3, 3447-3454.

38. Newcomb, C. J.; Sur, S.; Ortony, J. H.; Lee, O.-S.; Matson, J. B.; Boekhoven, J.; Yu, J. M.; Schatz, G. C.; Stupp, S. I., Cell death versus cell survival instructed by supramolecular cohesion of nanostructures. Nat. Commun. 2014, 5, 3321.

39. a) Buerkle, L. E.; Rowan, S. J., Supramolecular gels formed from multi-component low molecular weight species. Chem. Soc. Rev. 2012, 41, 6089-6102, b) Hirst, A. R.; Smith, D. K., Two-component gel-phase materials - Highly tunable selfassembling systems. Chem. Eur. J 2005, 11, 5496-5508.

40. a) Kyle, S.; Felton, S. H.; McPherson, M. J.; Aggeli, A.; Ingham, E., Rational molecular design of complementary self-assembling peptide hydrogels. Adv. Health. Mater. 2012, 1, 640-645, b) Xu, X.-D.; Chen, C.-S.; Lu, B.; Cheng, S.-X.; Zhang, X.-Z.; Zhuo, R.-X., Coassembly of oppositely charged short peptides into well-defined supramolecular hydrogels. J. Phys. Chem.B. 2010, 114, 2365-2372, c) Behanna, H. A.; Donners, J.; Gordon, A. C.; Stupp, S. I., Coassembly of amphiphiles with opposite peptide polarities into nanofibers. J. Am. Chem. Soc. 2005, 127, 1193-1200.

41. Hamley, I. W.; Dehsorkhi, A.; Castelletto, V., Coassembly in binary mixtures of peptide amphiphiles containing oppositely charged residues. Langmuir 2013, 29, 5050-5059.

42. Aggeli, A.; Bell, M.; Boden, N.; Carrick, L. M.; Strong, A. E., Self-assembling peptide polyelectrolyte beta-sheet complexes form nematic hydrogels. Angew. Chem. Int. Ed. 2003, 42, 5603-5606. 
43. Frisch, H.; Unsleber, J. P.; Lüdeker, D.; Peterlechner, M.; Brunklaus, G.; Waller, M.; Besenius, P., pH-switchable ampholytic supramolecular copolymers. Angew. Chem. Int. Ed. 2013, 52, 10097-10101.

44. Nagy, K. J.; Giano, M. C.; Jin, A.; Pochan, D. J.; Schneider, J. P., Enhanced mechanical rigidity of hydrogels formed from enantiomeric peptide assemblies. J. Am. Chem. Soc. 2011, 133, 14975-14977.

45. Swanekamp, R. J.; DiMaio, J. T. M.; Bowerman, C. J.; Nilsson, B. L., Coassembly of enantiomeric amphipathic peptides into amyloid-inspired rippled $\beta$-sheet fibrils. J. Am. Chem. Soc. 2012, 134, 5556-5559.

46. Swanekamp, R. J.; Welch, J. J.; Nilsson, B. L., Proteolytic stability of amphipathic peptide hydrogels composed of self-assembled pleated $\beta$-sheet or coassembled rippled $\beta$-sheet fibrils. Chem. Commun. 2014, 50, 10133-10136.

47. Knowles, T. P. J.; Vendruscolo, M.; Dobson, C. M., The amyloid state and its association with protein misfolding diseases. Nat. Rev. Mol. Cell Biol. 2014, 15, 384-396.

$48 \quad$ Web page www.alz.co.uk/research/statistics consulted on May 2015.

49. Hamley, I. W., Peptide fibrillization. Angew. Chem. Int. Ed. 2007, 46, 8128-8147.

50. a) Thirumalai, D.; Reddy, G., Protein thermodynamics: Are native proteins metastable? Nature Chem. 2011, 3, 910-911, b) Baldwin, A. J.; Knowles, T. P. J.; Tartaglia, G. G.; Fitzpatrick, A. W.; Devlin, G. L.; Shammas, S. L.; Waudby, C. A.; Mossuto, M. F.; Meehan, S.; Gras, S. L.; Christodoulou, J.; Anthony-Cahill, S. J.; Barker, P. D.; Vendruscolo, M.; Dobson, C. M., Metastability of native proteins and the phenomenon of amyloid formation. J. Am. Chem. Soc. 2011, 133, 1416014163, c) Gazit, E., The "Correctly folded" state of proteins: Is it a metastable state? Angew. Chem. Int. Ed. 2002, 41, 257-259.

51. a) Eisenberg, D.; Jucker, M., The amyloid state of proteins in human diseases. Cell 2012, 148, 1188-1203, b) Luhrs, T.; Ritter, C.; Adrian, M.; Riek-Loher, D.; Bohrmann, B.; Doeli, H.; Schubert, D.; Riek, R., 3D structure of Alzheimer's amyloid-beta (1-42) fibrils. Proc. Natl. Acad. Sci. 2005, 102, 17342-17347.

52. Fitzpatrick, A. W. P.; Debelouchina, G. T.; Bayro, M. J.; Clare, D. K.; Caporini, M. A.; Bajaj, V. S.; Jaroniec, C. P.; Wang, L.; Ladizhansky, V.; Müller, S. A.; MacPhee, C. E.; Waudby, C. A.; Mott, H. R.; De Simone, A.; Knowles, T. P. J.; Saibil, H. R.; Vendruscolo, M.; Orlova, E. V.; Griffin, R. G.; Dobson, C. M., Atomic structure and hierarchical assembly of a cross- $\beta$ amyloid fibril. Proc. Natl. Acad. Sci. 2013, 110, 5468-5473.

53. Arosio, P.; Vendruscolo, M.; Dobson, C. M.; Knowles, T. P. J., Chemical kinetics for drug discovery to combat protein aggregation diseases. Trends Pharmacol. Sci. 2014, 35, 127-135.

54. Jucker, M.; Walker, L. C., Pathogenic protein seeding in Alzheimer disease and other neurodegenerative disorders. Ann. Neurol. 2011, 70, 532-540. 
55. a) Lakshmanan, A.; Cheong, D. W.; Accardo, A.; Di Fabrizio, E.; Riekel, C.; Hauser, C. A. E., Aliphatic peptides show similar self-assembly to amyloid core sequences, challenging the importance of aromatic interactions in amyloidosis. Proc. Natl. Acad. Sci. 2013, 110, 519-524, b) Gazit, E., Self assembly of short aromatic peptides into amyloid fibrils and related nanostructures. Prion 2007, 1, 32-35, c) Gazit, E., Mechanisms of amyloid fibril self-assembly and inhibition. FEBS J. 2005, 272, 5971-5978, d) López de la Paz, M.; Goldie, K.; Zurdo, J.; Lacroix, E.; Dobson, C. M.; Hoenger, A.; Serrano, L., De novo designed peptide-based amyloid fibrils. Proc. Natl. Acad. Sci. 2002, 99, 16052-16057.

56. Hilbich, C.; Kisters-Woike, B.; Reed, J.; Masters, C. L.; Beyreuther, K., Substitutions of hydrophobic amino acids reduce the amyloidogenicity of Alzheimer's disease BA4 peptides. J. Mol. Biol. 1992, 228, 460-473.

57. Tjernberg, L. O.; Näslund, J.; Lindqvist, F.; Johansson, J.; Karlström, A. R.; Thyberg, J.; Terenius, L.; Nordstedt, C., Arrest of amyloid fibril formation by a pentapeptide ligand. J. Biol. Chem. 1996, 271, 8545-8548.

58. Gordon, D. J.; Tappe, R.; Meredith, S. C., Design and characterization of a membrane permeable $\mathrm{N}$-methyl amino acid-containing peptide that inhibits $\mathrm{A} \beta 1-$ 40 fibrillogenesis. J. Pept. Res. 2002, 60, 37-55.

59. Krysmann, M. J.; Castelletto, V.; Kelarakis, A.; Hamley, I. W.; Hule, R. A.; Pochan, D. J., Self-assembly and hydrogelation of an amyloid peptide fragment. Biochemistry 2008, 47, 4597-4605.

60. Lu, K.; Jacob, J.; Thiyagarajan, P.; Conticello, V. P.; Lynn, D. G., Exploiting amyloid fibril lamination for nanotube self-assembly. J. Am. Chem. Soc. 2003, 125, 63916393.

61. Balbach, J. J.; Ishii, Y.; Antzutkin, O. N.; Leapman, R. D.; Rizzo, N. W.; Dyda, F.; Reed, J.; Tycko, R., Amyloid fibril formation by Aß16-22, a seven-residue fragment of the Alzheimer's $\beta$-amyloid peptide, and structural characterization by solid state NMR. Biochemistry 2000, 39, 13748-13759.

62. Senguen, F. T.; Lee, N. R.; Gu, X.; Ryan, D. M.; Doran, T. M.; Anderson, E. A.; Nilsson, B. L., Probing aromatic, hydrophobic, and steric effects on the selfassembly of an amyloid- $\beta$ fragment peptide. Mol. BioSyst. 2011, 7, 486-496.

63 a) Gazit, E., Self assembly of short aromatic peptides into amyloid fibrils and related nanostructures. Prion 2007, 1, 32-35, 64. Makin, O. S.; Atkins, E.; Sikorski, P.; Johansson, J.; Serpell, L. C., Molecular basis for amyloid fibril formation and stability. Proc. Natl. Acad. Sci. 2005, 102, 315-320.

64. Marshall, K. E.; Morris, K. L.; Charlton, D.; O’Reilly, N.; Lewis, L.; Walden, H.; Serpell, L. C., Hydrophobic, aromatic, and electrostatic interactions play a central role in amyloid fibril formation and stability. Biochemistry 2011, 50, 2061-2071. 
65. Profit, A. A.; Felsen, V.; Chinwong, J.; Mojica, E.-R. E.; Desamero, R. Z. B., Evidence of $\pi$-stacking interactions in the self-assembly of hIAPP22-29. Proteins: Struct. Funct. Bioinf. 2013, 81, 690-703.

66. Doran, T. M.; Kamens, A. J.; Byrnes, N. K.; Nilsson, B. L., Role of amino acid hydrophobicity, aromaticity, and molecular volume on IAPP(20-29) amyloid selfassembly. Proteins: Struct. Funct. Bioinf. 2012, 80, 1053-1065.

67. Liu, R.; Su, R.; Liang, M.; Huang, R.; Wang, M.; Qi, W.; He, Z., Physicochemical strategies for inhibition of amyloid fibril formation: An overview of recent advances. Curr. Med. Chem. 2012, 19, 4157-4174.

68. Lashuel, H. A.; Hartley, D.; Petre, B. M.; Walz, T.; Lansbury, P. T., Neurodegenerative disease: Amyloid pores from pathogenic mutations. Nature 2002, 418, 291-291.

69. Luo, J.; Abrahams, J. P., Cyclic peptides as inhibitors of amyloid fibrillation. Chem. Eur. J. 2014, 20, 2410-2419.

70. Richman, M.; Wilk, S.; Chemerovski, M.; Wärmländer, S. K. T. S.; Wahlström, A.; Gräslund, A.; Rahimipour, S., In vitro and mechanistic studies of an antiamyloidogenic self-assembled cyclic D, L- $\alpha$-peptide architecture. J. Am. Chem. Soc. 2013, 135, 3474-3484.

71. Mimna, R.; Camus, M.-S.; Schmid, A.; Tuchscherer, G.; Lashuel, H. A.; Mutter, M., Disruption of amyloid-derived peptide assemblies through the controlled induction of a $\beta$-Sheet to $\alpha$-Helix transformation: Application of the switch concept. Angew. Chem. Int. Ed. 2007, 46, 2681-2684.

72. Cheng, P.-N.; Liu, C.; Zhao, M.; Eisenberg, D.; Nowick, J. S., Amyloid beta-sheet mimics that antagonize protein aggregation and reduce amyloid toxicity. Nature Chem. 2012, 4, 927-933.

73. a) Terech, P.; Weiss, R. G., Low molecular mass gelators of organic liquids and the properties of their gels. Chem. Rev. 1997, 97, 3133-3160, b) Terech, P.; Weiss R. G., Molecular Gels: Materials with Self-Assembled Fibrillar Networks, Springer, New York 2005.

74. a) Weiss, R. G., The past, present, and future of molecular gels. What is the status of the field, and where is it going? J. Am. Chem. Soc. 2014, 136, 7519-7530, b) Escuder, B.; Miravet J. F., Functional Molecular Gels. RSC 2013, c) Hirst, A. R.; Escuder, B.; Miravet, J. F.; Smith, D. K., High-tech applications of self-assembling supramolecular nanostructured gel-phase materials: from regenerative medicine to electronic devices. Angew. Chem. Int. Ed. 2008, 47, 8002-8018.

75. Raeburn, J.; Cardoso, A. Z.; Adams, D. J., The importance of the self-assembly process to control mechanical properties of low molecular weight hydrogels. Chem. Soc. Rev. 2013, 42, 5143-5156.

76. a) Nebot, V. J.; Smith, D. K., Chapter 2: Techniques for the characterisation of molecular gels. Functional Molecular Gels, RSC 2014, b) Yu, G.; Yan, X.; Han, C.; 
Huang, F., Characterisation of supramolecular gels. Chem. Soc. Rev. 2013, 42, 6697-6722.

77. a) Dasgupta, A.; Mondal, J. H.; Das, D., Peptide hydrogels. RSC Advances 2013, 3, 9117-9149, b) Jonker, A. M.; Löwik, D. W. P. M.; van Hest, J. C. M., Peptide- and protein-based hydrogels. Chem. Mater. 2012, 24, 759-773.

78. a) Tomasini, C.; Castellucci, N., Peptides and peptidomimetics that behave as low molecular weight gelators. Chem. Soc. Rev. 2013, 42, 156-172, b) Ryan, D. M.; Nilsson, B. L., Self-assembled amino acids and dipeptides as noncovalent hydrogels for tissue engineering. Polym. Chem. 2012, 3, 18-33.

79. Wang, H.; Yang, Z.; Adams, D. J., Controlling peptide-based hydrogelation. Materials Today 2012, 15, 500-507.

80. Ren, C.; Song, Z.; Zheng, W.; Chen, X.; Wang, L.; Kong, D.; Yang, Z., Disulfide bond as a cleavable linker for molecular self-assembly and hydrogelation. Chem. Commun. 2011, 47, 1619-1621.

81. Sahoo, J. K.; Nalluri, S. K. M.; Javid, N.; Webb, H.; Ulijn, R. V., Biocatalytic amide condensation and gelation controlled by light. Chem. Commun. 2014, 50, 54625464.

82. Gao, Y.; Shi, J.; Yuan, D.; Xu, B., Imaging enzyme-triggered self-assembly of small molecules inside live cells. Nat. Commun. 2012, 3, 1033-1033.

83. Frisch, H.; Besenius, P., pH-Switchable Self-Assembled Materials. Macromol. Rapid Commun. 2015, 36, 346-363.

84. Knerr, P. J.; Branco, M. C.; Nagarkar, R.; Pochan, D. J.; Schneider, J. P., Heavy metal ion hydrogelation of a self-assembling peptideviacysteinyl chelation. J. Mater. Chem. 2012, 22, 1352-1357.

85. Huang, Y.; Qiu, Z.; Xu, Y.; Shi, J.; Lin, H.; Zhang, Y., Supramolecular hydrogels based on short peptides linked with conformational switch. Org. Biomol. Chem. 2011, 9, 2149-2155.

86. Morris, K. L.; Chen, L.; Raeburn, J.; Sellick, O. R.; Cotanda, P.; Paul, A.; Griffiths, P. C.; King, S. M.; O'Reilly, R. K.; Serpell, L. C.; Adams, D. J., Chemically programmed self-sorting of gelator networks. Nat. Commun. 2013, 4, 1480-1480.

87. Lin, B. F.; Megley, K. A.; Viswanathan, N.; Krogstad, D. V.; Drews, L. B.; Kade, M. J.; Qian, Y.; Tirrell, M. V., pH-responsive branched peptide amphiphile hydrogel designed for applications in regenerative medicine with potential as injectable tissue scaffolds. J. Mater. Chem. 2012, 22, 19447-19454.

88. Miravet, J. F.; Escuder, B., Pyridine-functionalised ambidextrous gelators: towards catalytic gels. Chem. Commun. 2005, 5796-5798. 
89. Adams, D. J.; Butler, M. F.; Frith, W. J.; Kirkland, M.; Mullen, L.; Sanderson, P., A new method for maintaining homogeneity during liquid-hydrogel transitions using low molecular weight hydrogelators. Soft Matter 2009, 5.

90. Roy, S.; Javid, N.; Frederix, P. W. J. M.; Lamprou, D. A.; Urquhart, A. J.; Hunt, N. T.; Halling, P. J.; Ulijn, R. V., Dramatic specific-ion effect in supramolecular hydrogels. Chem. Eur. J. 2012, 18, 11723-11731.

91. Nebot, V. J.; Ojeda-Flores, J. J.; Smets, J.; Fernández-Prieto, S.; Escuder, B.; Miravet, J. F., Rational design of heat-set and specific-ion-responsive supramolecular hydrogels based on the Hofmeister effect. Chem. Eur. J. 2014, 20, 14465-14472.

92. a) Boekhoven, J.; Stupp, S. I., 25th Anniversary article: Supramolecular materials for regenerative medicine. Adv. Mater. 2014, 26, 1642-1659, b) Wang, H.; Yang, Z., Short-peptide-based molecular hydrogels: novel gelation strategies and applications for tissue engineering and drug delivery. Nanoscale 2012, 4, 52595267.

93. a) Lin, R.; Cheetham, A. G.; Zhang, P.; Lin, Y.-a.; Cui, H., Supramolecular filaments containing a fixed 41\% paclitaxel loading. Chem. Commun. 2013, 49, 4968-4970, b) Zarzhitsky, S.; Rapaport, H., The interactions between doxorubicin and amphiphilic and acidic $\beta$-sheet peptides towards drug delivery hydrogels. J. Colloid Interface Sci. 2011, 360, 525-531.

94. Silva, G. A.; Czeisler, C.; Niece, K. L.; Beniash, E.; Harrington, D. A.; Kessler, J. A.; Stupp, S. I., Selective differentiation of neural progenitor cells by high-epitope density nanofibers. Science 2004, 303, 1352-1355.

95. Amabilino, D. B.; Puigmartí-Luis, J., Gels as a soft matter route to conducting nanostructured organic and composite materials. Soft Matter 2010, 6, 16051612.

96. Roy, G.; Miravet, J. F.; Escuder, B.; Sanchez, C.; Llusar, M., Morphology templating of nanofibrous silica through $\mathrm{pH}$-sensitive gels: "in situ" and "post-diffusion" strategies. J. Mater. Chem. 2006, 16, 1817-1824.

97. Ryu, J.; Kim, S.-W.; Kang, K.; Park, C. B., Mineralization of self-assembled peptide nanofibers for rechargeable lithium ion batteries. Adv. Mater. 2010, 22, 55375541.

98. a) Raynal, M.; Ballester, P.; Vidal-Ferran, A.; van Leeuwen, P. W. N. M., Supramolecular catalysis. Part 1: non-covalent interactions as a tool for building and modifying homogeneous catalysts. Chem. Soc. Rev. 2014, 43, 1660-1733, b) Raynal, M.; Ballester, P.; Vidal-Ferran, A.; van Leeuwen, P. W. N. M., Supramolecular catalysis. Part 2: artificial enzyme mimics. Chem. Soc. Rev. 2014, 43, 1734-1787, c) Lehn, J.-M., Supramolecular Reactivity and Catalysis, Wiley-VCH Verlag GmbH \& Co. 2006. 
99. a) Singh, N.; Tena-Solsona, M.; Miravet, J. F.; Escuder, B., Towards supramolecular catalysis with small self-assembled peptides. Isr. J. Chem. 2015, DOI: 10.1002/ijch.201400185 b) Gao, Y.; Zhao, F.; Wang, Q.; Zhang, Y.; Xu, B., Small peptide nanofibers as the matrices of molecular hydrogels for mimicking enzymes and enhancing the activity of enzymes. Chem. Soc. Rev. 2010, 39, 34253433

100. a) Davie, E. A. C.; Mennen, S. M.; Xu, Y.; Miller, S. J., Asymmetric catalysis mediated by synthetic peptides. Chem. Rev. 2007, 107, 5759-5812, b) Wennemers, H., Asymmetric catalysis with peptides. Chem. Commun. 2011, 47, 12036-12041, c) Lewandowski, B.; Wennemers, H., Asymmetric catalysis with short-chain peptides. Curr. Opin. Chem. Biol. 2014, 22, 40-46.

101. a) Escuder, B.; Rodriguez-Llansola, F.; Miravet, J. F., Supramolecular gels as active media for organic reactions and catalysis. New J. Chem. 2010, 34, 1044-1054, b) Diaz Diaz, D.; Kuhbeck, D.; Koopmans, R. J., Stimuli-responsive gels as reaction vessels and reusable catalysts. Chem. Soc. Rev. 2011, 40, 427-448.

102. Zhang, C.; Xue, X.; Luo, Q.; Li, Y.; Yang, K.; Zhuang, X.; Jiang, Y.; Zhang, J.; Liu, J.; Zou, G.; Liang, X.-J., Self-assembled peptide nanofibers designed as biological enzymes for catalyzing ester hydrolysis. ACS Nano 2014, 8, 11715-11723.

103. List, B.; Lerner, R. A.; Barbas, C. F., Proline-catalyzed direct asymmetric aldol reactions. J. Am. Chem. Soc. 2000, 122, 2395-2396.

104. a) List, B., Amine-catalyzed Aldol Reactions. In Modern Aldol Reactions, WileyVCH Verlag GmbH \& Co. 2008; b) Fessner, W.-D., Enzyme-catalyzed Aldol Additions. Wiley-VCH Verlag GmbH \& Co. 2013.

105. a) Rodriguez-Llansola, F.; Escuder, B.; Miravet, J. F., Switchable perfomance of an L-Proline-derived basic catalyst controlled by supramolecular gelation. J. Am. Chem. Soc. 2009, 131, 11478-11484, b) Rodríguez-Llansola, F.; Miravet, J. F.; Escuder, B., Supramolecular gel formation and self-correction induced by aggregation-driven conformational changes. Chem. Commun. 2009, 209-211, c) Rodríguez-Llansola, F.; Miravet, J. F.; Escuder, B., Supramolecular catalysis with extended aggregates and gels: Inversion of stereoselectivity caused by selfassembly. Chem. Eur. J. 2010, 16, 8480-8486.

106. Rodríguez-Llansola, F.; Miravet, J. F.; Escuder, B., A supramolecular hydrogel as a reusable heterogeneous catalyst for the direct aldol reaction. Chem. Commun. 2009, 7303-7305.

107. Berdugo, C.; Miravet, J. F.; Escuder, B., Substrate selective catalytic molecular hydrogels: the role of the hydrophobic effect. Chem. Commun. 2013, 49, 1060810610.

108. Jin, Q.; Zhang, L.; Cao, H.; Wang, T.; Zhu, X.; Jiang, J.; Liu, M., Self-assembly of copper(II) ion-mediated nanotube and its supramolecular chiral catalytic behavior. Langmuir, 2011, 27, 13847-13853. 
109. Yokoi, H.; Kinoshita, T.; Zhang, S., Dynamic reassembly of peptide RADA16 nanofiber scaffold. Proc. Nat. Acad. Sci. 2005, 102, 8414-8419. 


\section{CHAPTER 2}

OBJECTIVES OF THE THESIS 

CHAPTER 2

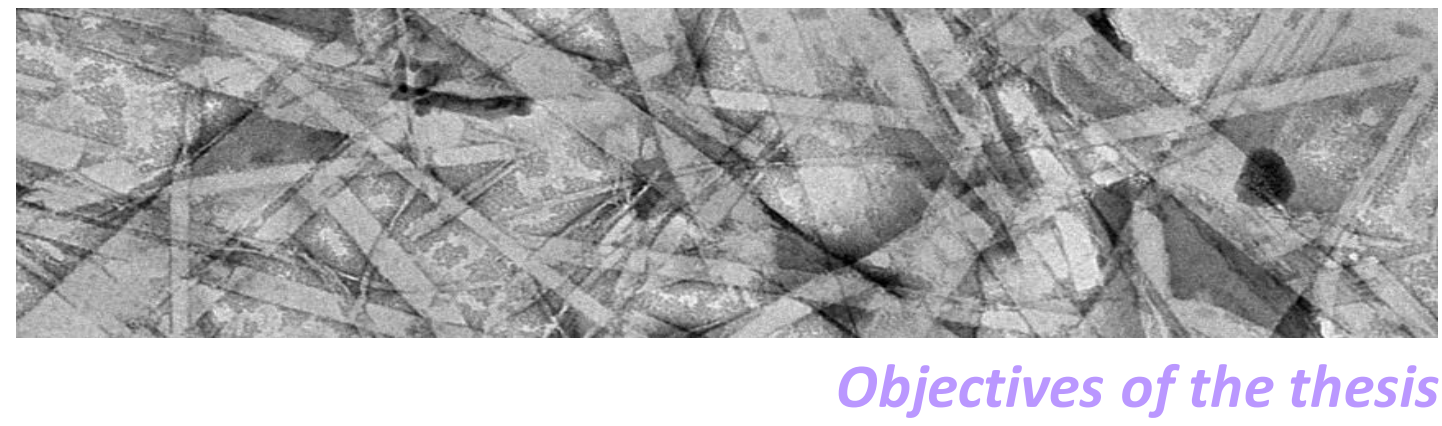





\section{OBJECTIVES OF THE THESIS}

\subsection{General objectives of the thesis}

Due to the close relationship between protein and peptide self-assembly with amyloid diseases, ${ }^{1}$ delving into the understanding of the principles governing this phenomenon is currently of great interest. The use of short peptides as models or inhibitors for the amyloid fibrillisation process is considered one of the best approaches ${ }^{2}$ because of their synthetic simplicity, versatility and biocompatibility among other advantages.

It is also well known that the hierarchical organization of peptidic fibrils into longer and physically cross-linked fibers often results in the formation of self-supported hydrogels. ${ }^{3}$ Such materials, hold on by non-covalent interactions, exhibit certain properties including reversibility, self-healing or responsiveness to different physicochemical stimuli which make them extremely useful in many diverse fields like biomedicine, catalysis or materials science.

Given these considerations, in the present work the main objective has been the development of new short amphipathic peptide derivatives with high tendency to undergo $\beta$-sheet formation in order to:

- Go deeply into the fundamentals of the self-assembly process providing then a better comprehension of the fibrillisation phenomenon.

- Study their features as supramolecular hydrogelators to use them as catalysts or stimuli responsive materials.

\subsection{Specific objetives}

\section{1) Design and synthesis (Chapter 3)}

A new family of isomeric tetrapeptides containing hydrophobic and hydrophilic amino acids will be designed in view of their tendency to form $\beta$-sheet assemblies. Design considerations include the incorporation of aromatic residues because of their important role in the self-assembly process and ionic amino acids to incorporate 
sensitiveness against external stimuli like $\mathrm{pH}$ or salts. Additional $\mathrm{N}$ - and C-terminal end capping groups will be also added to avoid further ionization at the main chain (Figure 2.1).

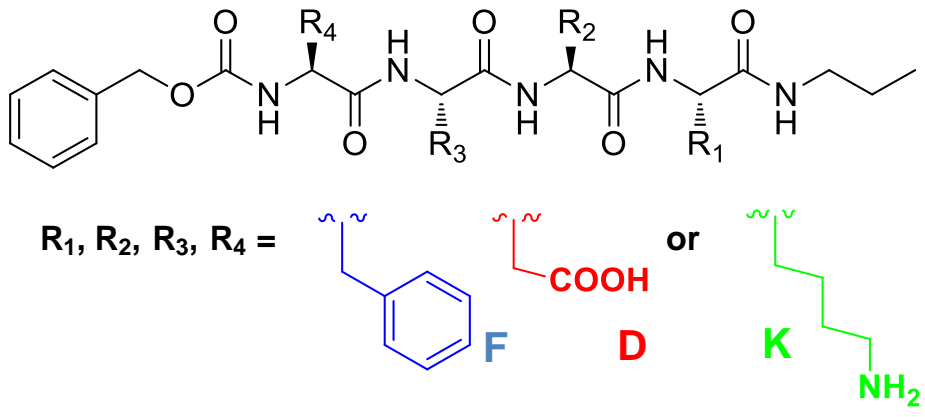

\section{$1 Z^{2} F D F D C_{3} \quad 4 Z^{2} D D F F C_{3} \quad 7 Z_{3 K F K C}$ \\ $2 \mathrm{ZDFDFC}_{3} \quad 5 \mathrm{ZFDDFC}_{3} \quad 8 \mathrm{ZKFKFC}_{3}$ \\ $3 Z_{F F D D C} \quad 6 Z_{3 D F F D C}$}

Figure 2.1 General structure of the amphipathic tetrapeptides containing F residues as non-polar amino acids and $\mathrm{D}$ or $\mathrm{K}$ as ionic moieties.

For catalytic purposes and aimed by previous results reported by our group ${ }^{4}$ a new family of peptide amphiphiles containing $\mathrm{P}$ as functional unit will be also designed and synthesised (Figure 2.2).
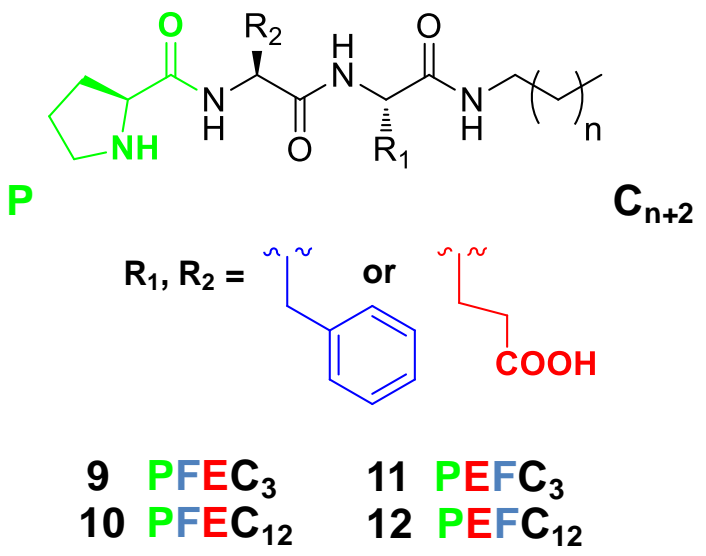

Figure 2.2 General structure for the amphiphilic peptides containing P as a functional group for catalytic purposes.

Although a general peptide synthesis procedure in solution is employed, the optimization of a solid phase methodology for one of them has been also planned in order to compare both approaches. 
The unusual lability of the benzyloxycarbonil $(Z)$ protecting group under mild basic conditions was detected unexpectedly. In order to provide a reasonable explanation to this phenomenon a systematic study with peptide derivatives containing the $Z$ group will be undertaken.

\section{2) Amphipathic tetrapeptides containing F and D (Chapter 4)}

The ability of these compounds as hydrogelators will be evaluated highlighting the role of the hydrophobic/hydrophilic balance and amino acid distribution. Therefore a full hydrogel characterization will be provided from microscopic to macroscopic level. Kinetics and thermodynamics of the fibrillisation process will be deeply analysed in order to provide some insights into the amyloid-like aggregation.

Finally their interaction with amyloid peptide $A \beta 40$ and shorter fragment ( $\beta A \beta A K L V F F)$ will be considered by screening positively charged Lysine $(K)$ residues and aromatic moieties which seem to play an important role in amyloid misfolding.

\section{3) Amphipathic tetrapeptides containing F and $K$ (Chapter 5)}

Basic tetrapeptides containing $\mathrm{F}$ and $\mathrm{K}$ will be designed as oppositely charged analogues of the acidic tetrapeptides. Firstly, the co-assembly between these two families at neutral $\mathrm{pH}$ will be studied and once attained this initial goal a more complex $\mathrm{pH}$ tuneable system will be developed.

\section{4) Amphiphilic peptides containing P (Chapter 6)}

The gelation properties of amphiphilic peptides containing proline (Figure 2.2) in aqueous media will be explored and the catalytic properties of this residue will be studied in aldol condensation reactions. The influence of self-assembly in catalytic efficiency will be carefully analysed. 


\subsection{References}

1. a) Knowles, T. P. J.; Vendruscolo, M.; Dobson, C. M., The amyloid state and its association with protein misfolding diseases. Nat. Rev. Mol. Cell Biol. 2014, 15, 384-396; b) Hamley, I. W., The amyloid beta peptide: A chemist's perspective. Role in Alzheimer's and fibrillization. Chem. Rev. 2012, 112, 5147-5192.

2. a) Lakshmanan, A.; Cheong, D. W.; Accardo, A.; Di Fabrizio, E.; Riekel, C.; Hauser, C. A. E., Aliphatic peptides show similar self-assembly to amyloid core sequences, challenging the importance of aromatic interactions in amyloidosis. Proc. Natl. Acad. Sci. 2013, 110, 519-524; b) Gazit, E., Self assembly of short aromatic peptides into amyloid fibrils and related nanostructures. Prion 2007, 1, 32-35; c) Hamley, I. W., Peptide fibrillization. Angew. Chem. Int. Ed. 2007, 46, 8128-8147; d) Gazit, E., Mechanisms of amyloid fibril self-assembly and inhibition. FEBS J. 2005, 272, 5971-5978.

3. a) Dasgupta, A.; Mondal, J. H.; Das, D., Peptide hydrogels. RSC Advances 2013, 3, 9117-9149; b) Jonker, A. M.; Löwik, D. W. P. M.; van Hest, J. C. M., Peptide- and protein-based hydrogels. Chem. Mater. 2012, 24, 759-773.

4. a) Berdugo, C.; Miravet, J. F.; Escuder, B., Substrate selective catalytic molecular hydrogels: the role of the hydrophobic effect. Chem. Commun. 2013, 49, 1060810610; b) Rodríguez-Llansola, F.; Miravet, J. F.; Escuder, B., A supramolecular hydrogel as a reusable heterogeneous catalyst for the direct aldol reaction. Chem. Commun. 2009, 7303-7305. 


\section{CHAPTER 3}

(1)

\section{DESIGN AND SYNTHESIS

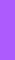 DES

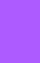

3

(

(n)

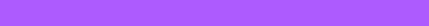

(n)

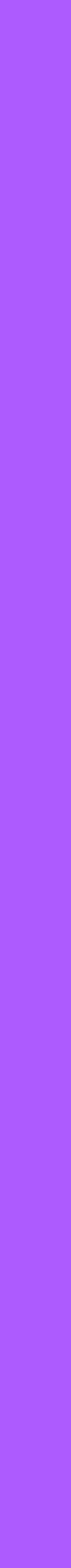





\section{CHAPTER 3}

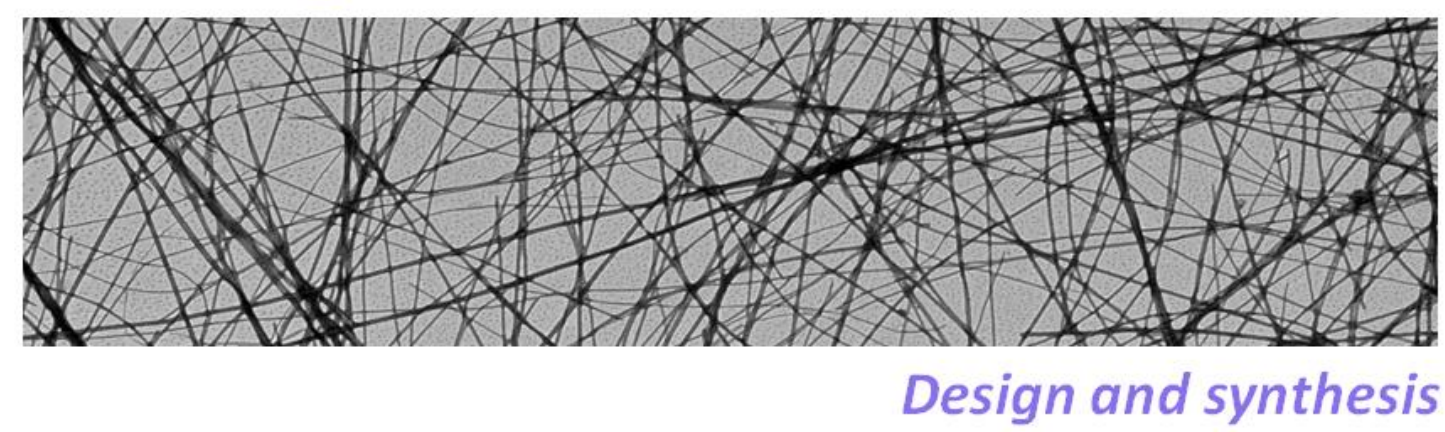

In this chapter a general approach for peptide synthesis in solution is detailed for tri- and tetrapeptides. A solid phase methodology is also provided for one of them in an attempt to establish the most efficient synthetic approach for our purposes. Finally unexpected removal of benzyloxycarbonil protecting group under mild basic conditions was studied and a set of experiments were designed in order to understand this striking behavior. 



\section{DESIGN AND SYNTHESIS}

\subsection{Design of amphipathic peptides}

For the present work three main families of amphipathic peptide derivatives have been designed and synthesised:

- $\quad$ Acidic tetrapeptides containing L-phenylalanine (F) and L-aspartic acid (D)

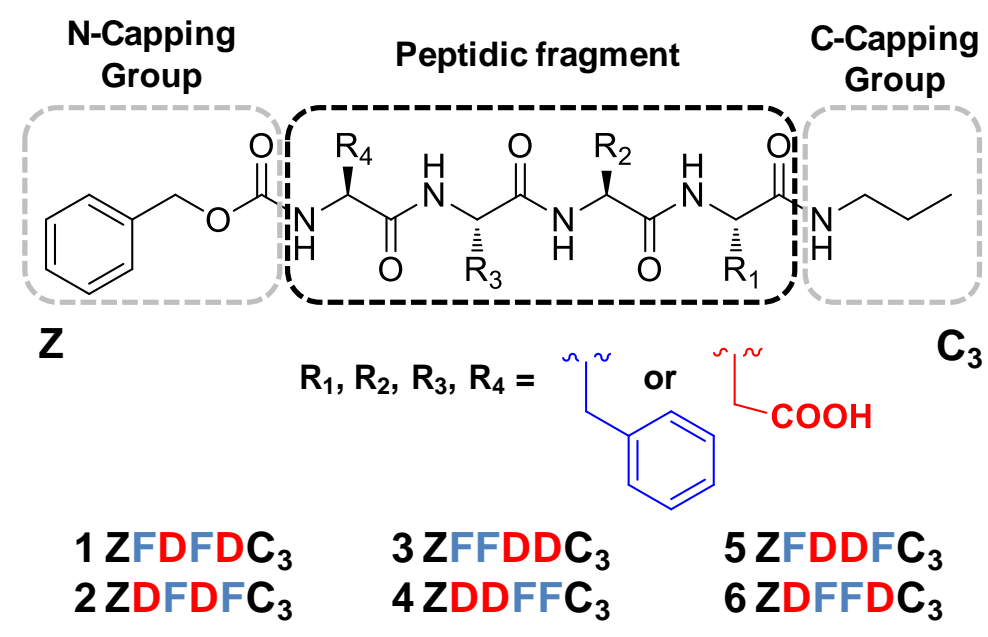

Figure 3.1 Chemical structure of the amphipathic acidic tetrapeptides.

The isomeric family of acidic tetrapeptides combines non-polar aromatic Lphenylalanine $(F)$ and $L$-aspartic acid residues $(D)$. The tendency to self-assemble into $\beta$ sheet nanostructure for this kind of amphipathic peptides alternating hydrophobic and hydrophilic amino acids have been described. ${ }^{1}$ In this work systematic variations on the amino acid sequence will allow us to study the role of hydrophobic/hydrophilic balance in the fibrillization process. Both chain termini were blocked by using propyl amide $\left(C_{3}\right)$ and benzyloxycarbonyl (Z) moieties at $\mathrm{N}$ - and $\mathrm{C}$ - ends respectively avoiding additional ionization and simplifying therefore the analysis of the aggregation process. The $Z$ protecting group besides may assist the aggregation through aromatic and hydrophobic interactions. ${ }^{2}$ Ionic residues (D) endow the molecules with sensitivity against $\mathrm{pH}$ changes and may play an important role for the interaction with amyloid $A \beta 1-40$ at the central core KLVFF by screening positively charged lysine (K) residues. 
- Basic tetrapeptides containing L-phenylalanine (F) and L-lysine (K)

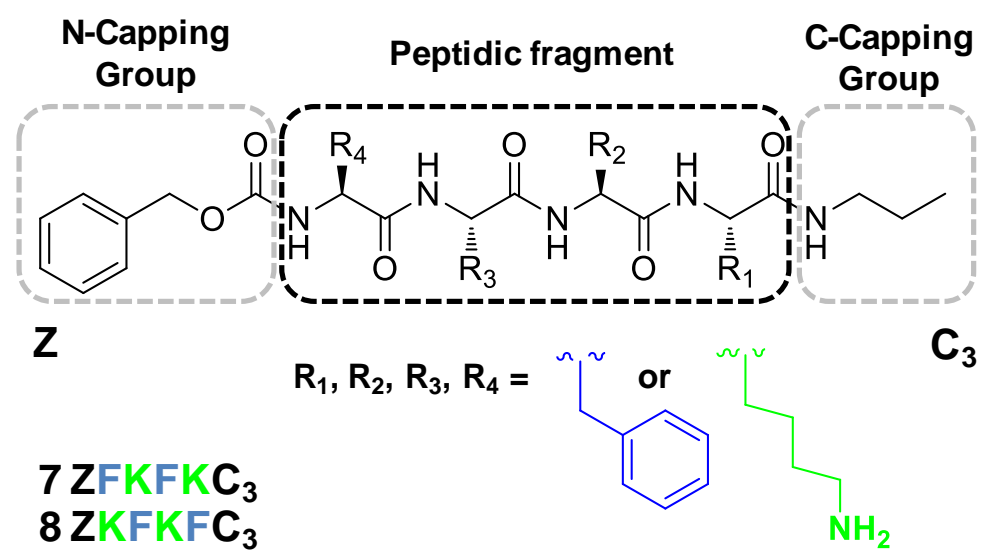

Figure 3.2 Chemical structure of the amphipathic basic tetrapeptides.

In a similar way two amphipathic basic tetrapeptides were designed in which the acidic residues (D) were replaced by L-lysine (K) with the main goal to obtain coassembled systems by electrostatic interactions among complementary charged amphipathic peptides. ${ }^{3}$

- $\quad$ Amphiphilic L-proline (P) peptides

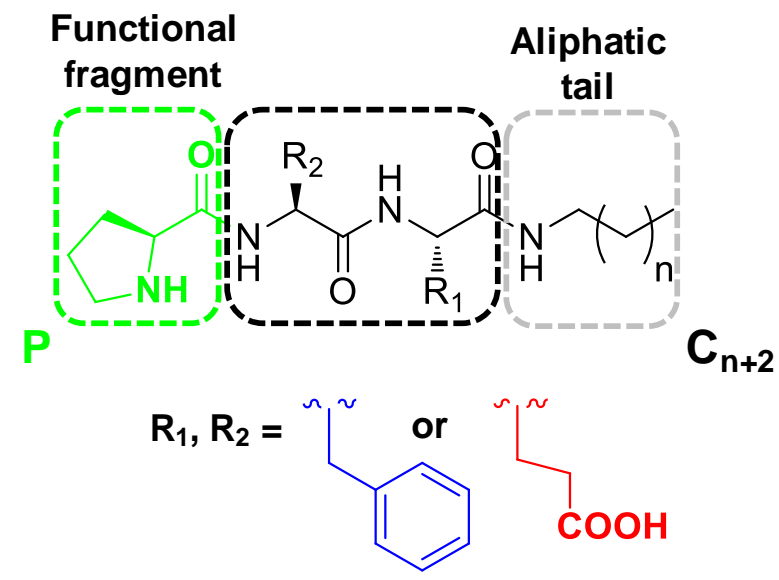

\section{$9 \mathrm{PFEC}_{3} 11 \quad \mathrm{PEFC}_{3}$ 10 PFEC $_{12} 12$ PEFC $_{12}$}

Figure 3.3 Chemical structure of the amphiphilic peptides containing $P$.

The amphiphilic peptides designed for catalytic purposes contain an aliphatic tail attached to a dipeptide fragment containing $L$-phenylalanine (F) and L-glutamic acid (E). The hydrophobic/hydrophilic balance between these two domains will be responsible for the self-assembly of these compounds in water. The ionic moiety will provide 
solubility to the molecule and $\mathrm{pH}$ sensitivity and finally the $L$-proline amino acid at the $\mathrm{N}$ terminus will be explored as functional fragment for the catalysis of aldol reactions. ${ }^{4}$

\subsection{Peptide synthesis in solution}

Most of the compounds reported in the present work were synthesized successfully in gram scale using a conventional step by step methodology in solution.

Peptide synthesis in the laboratory ${ }^{5}$ comprises the formation of peptide bonds generally by aminolysis of reactive carboxylic derivatives previously generated. The preparation of activated carboxylic acids is needed because at room temperature amide formation between ordinary carboxylic acids and amines is not achieved and an organic salt is generated instead.

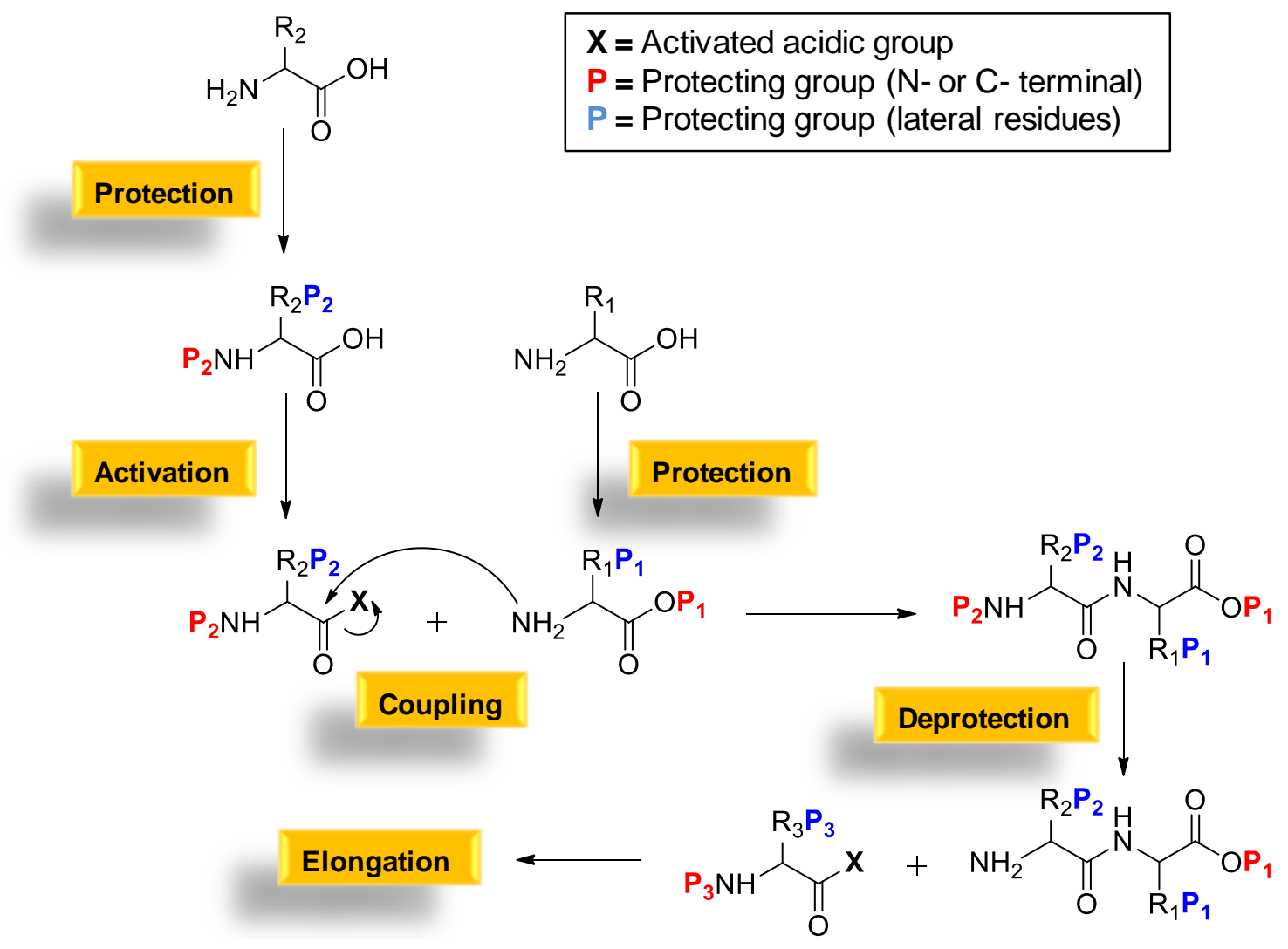

Figure 3.4 General scheme for peptide synthesis.

As it can be seen in Figure 3.4 the presence of other functional groups requires the use of protecting groups ${ }^{6}$ not only for the $\mathrm{N}$ - or C- terminus not involved in the coupling reaction $(P)$ but also for the side chain of the amino acids $(P)$. The orthogonality among them is an essential requirement to selectively remove one of them without 
modifying the others during the elongation process. Bearing in mind the previous considerations some decisions must be made before starting the peptide synthesis procedure:

Choose...

the C-terminal protecting group, the $\mathrm{N}$-terminal protecting group, the side chain protecting groups and the coupling reagent

Table 3.1 Orthogonal protecting groups chosen for the peptide synthesis in solution

\begin{tabular}{cccccc}
\hline $\begin{array}{c}\alpha \text { Carboxy } \\
\text { protection }\end{array}$ & $\begin{array}{c}\alpha \text { Carboxy } \\
\text { deprotection }\end{array}$ & $\begin{array}{c}\alpha \text { Amino } \\
\text { protection }\end{array}$ & $\begin{array}{c}\alpha \text { Amino } \\
\text { deprotection }\end{array}$ & $\begin{array}{c}\text { Side-chain } \\
\text { protection }\end{array}$ & $\begin{array}{c}\text { Side-chain } \\
\text { deprotection }\end{array}$ \\
\hline $\begin{array}{c}\text { Aliphatic } \\
\text { amide }\end{array}$ & Permanent & $\begin{array}{c}\text { Benzyloxycarbonyl } \\
(\mathrm{Z})\end{array}$ & $\begin{array}{c}\mathrm{H}_{2} / \mathrm{Pd} \text { or } \\
\mathrm{HBr} / \mathrm{AcOH}\end{array}$ & $t$-Bu/t-Boc & $\mathrm{TFA}$ \\
\hline
\end{tabular}

In the case at hand an aliphatic amide was used as permanent protecting group for the C-terminal (Figure 3.1 to Figure 3.3). The orthogonal strategy employed for the elongation was the use of benzyloxycarbonyl (Z) group for the $\mathrm{N}$-terminus and tertbutyloxycarbonyl ( $t$-Boc) or tert-butyl ester $(t-\mathrm{Bu})$ for the side chain protection. In this way $\mathrm{Z}$ group removal by using catalytic $\mathrm{Pd}$ and hydrogen would not affect the secondary protecting groups at the side chain which were displaced in acidic conditions using TFA at the end of the synthesis.

Benzyloxycarbonyl group (Z) is usually one of the first options to protect $\alpha$-amino position in peptide chemistry. Its introduction is conventionally achieved with the use of a chloroformate reagent under Schotten-Baumann conditions (Figure 3.5). Z group is stable to mildly basic or nucleophilic reagents (amines, dilute aqueous alkali) at room temperature as well as to mildly acidic conditions (TFA, low temperature and short time).<smiles>[R]N[C+](C)C(=O)OCc1ccccc1</smiles>

Figure 3.5 Amino group protection by reaction with benzyloxycarbonyl chloride.

Cleavage of the $Z$ protecting group is achieved mainly by two methods. Acidolysis of $\mathrm{Z}$ group is carried out usually by treatment with $\mathrm{HBr} / \mathrm{AcOH}(33 \%)$. An alternative 
method is catalytic hydrogenolysis which allows the cleavage of $Z$ group by treatment with palladium over activated carbon in $\mathrm{MeOH}$ under hydrogen atmosphere in the presence of other acid sensitive groups such as $t$-Boc.

\section{Acidolysis}<smiles>[R]NNC(=O)OCc1ccccc1</smiles>

Hydrogenolysis<smiles>[R]NC(=O)OC(c1ccccc1)C([R9])[R]([H])[H]</smiles>

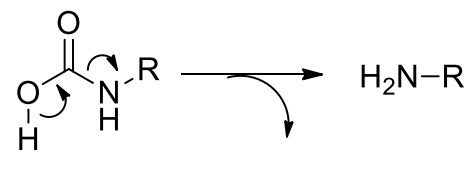

$\mathrm{CO}_{2}$

Figure 3.6 Deprotection mechanism for the $\mathrm{Z}$ group. Acidolysis $(\mathrm{HBr}$ in $\mathrm{AcOH} 33 \%)$ and hydrogenolysis $\left(\mathrm{H}_{2}\right.$, catalytic $\mathrm{Pd} / \mathrm{C}, \mathrm{MeOH}$ ).

For the side chain carbamate $(t-\mathrm{Boc})$ and ester $(t-\mathrm{Bu})$ were used as protecting groups for free amine $(K)$ and carboxylic acids ( $D$ and $E$ ) respectively.

a)<smiles>[R]NC[CH]C(=O)OC(C)(C)C</smiles>

b)

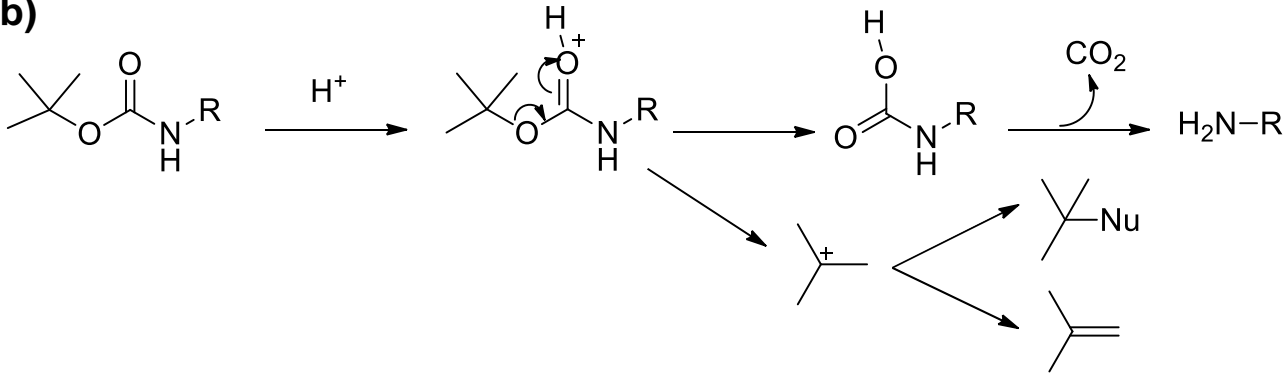

Figure 3.7 a) Introduction of $t$-Boc group using the $\mathrm{Boc}_{2} \mathrm{O}$ anhydride and b) mechanism of acidolytic cleavage of $t$-Boc group.

Conventionally the formation of $t$-Boc protected amines is achieved by reaction of the amine with the anhydride $\mathrm{Boc}_{2} \mathrm{O}$ (Figure 3.7). This protecting group can be 
removed by treatment with trifluoroacetic acid in dichloromethane. $t$-Boc group is resistant to nucleophilic or basic medium and is compatible (orthogonal) with $\mathrm{Z}$ group. On the other hand $t$-Bu group can be introduced by reaction of the corresponding carboxylic acid with isobutene in the presence of sulphuric acid and can be cleaved in a similar way as described for the $t$-Boc by using TFA (Figure 3.8).

a)

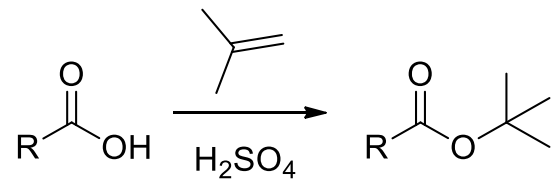

b)

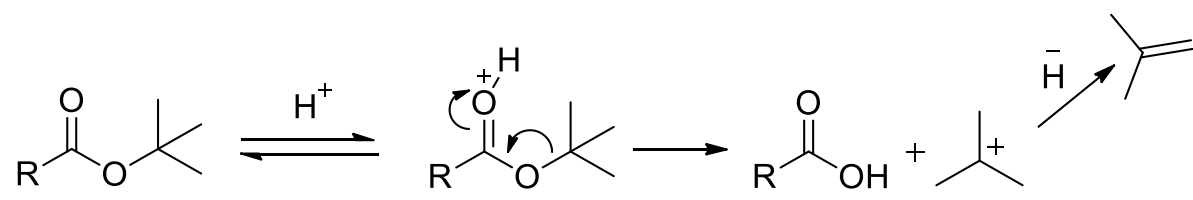

Figure 3.8 a) Introduction of $t$-Bu group using isobutene and sulphuric acid and b) mechanism of acidolytic cleavage of $t$-Bu group.

Dicyclohexylcarbodiimide (DCC) was used as coupling reagent for the peptide bond formation. The combination of DCC and stoichiometric amounts of N-protected amino acid and $\mathrm{N}$-hydroxysuccinimide in a proper solvent allows the formation of an active ester which can be isolated and easily separated from the accompanying dicyclohexylurea (DCU) by filtration. The possibility to isolate the activated amino acid and store it in crystalline form for long periods of time is one of the main advantages of this methodology. The mechanism for the activated ester formation is depicted in Figure 3.9:
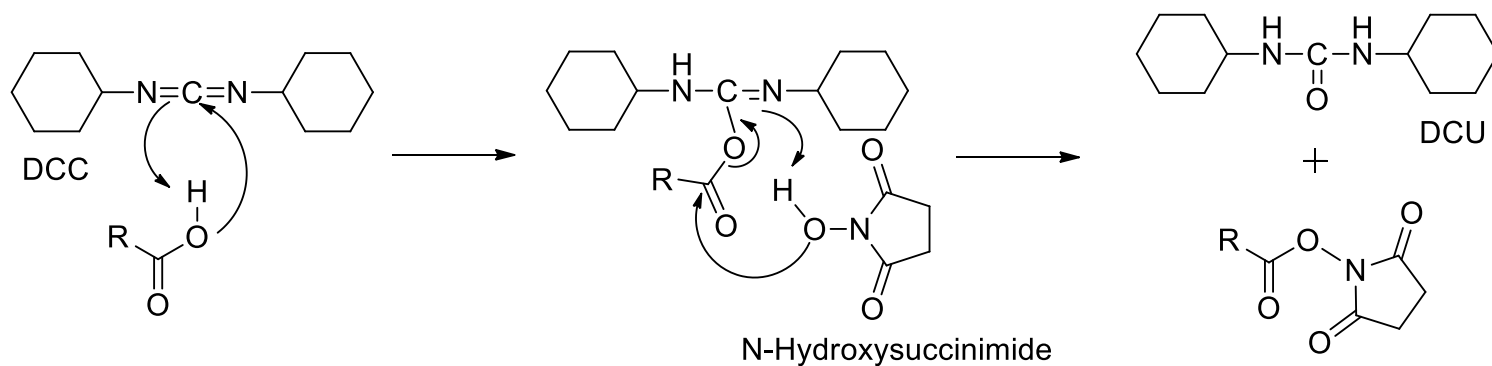

Active ester

Figure 3.9 Mechanism for the activated ester formation using DCC and N-hydroxysuccinimide.

In order to avoid misunderstandings with the nomenclature of compounds from now on final compounds will be appointed with a single number $(\mathbf{1}, \mathbf{2}, \mathbf{3} \ldots)$ and their corresponding intermediates will contain the main number and an additional letter (1a, 
1b...). In this way some compounds prepared at the beginning of the synthetic route may be numbered in two different ways depending on the particular route were they are prepared.

\subsubsection{Synthesis of compounds 1-12}

The preparation of compounds 1-8 (Figure 3.10) and 9-11 (Figure 3.11) was carried out by using a step-by-step procedure in solution. The chemical reactions involved are very robust and easy to carry out. Pure compounds were obtained by simply acidic or basic washing without need of column chromatography, however further HPLC purification of the final compounds were accomplished for particular applications

The general synthetic procedure can be described briefly as follows: starting with the $\mathrm{Z}-\mathrm{N}^{\alpha}$ protected L-amino acids, first the $\mathrm{N}$-hydroxysuccinimidyl esters (1-12a) were synthesized by reaction with $\mathrm{N}$-hydroxysuccinimide in the presence of DCC in THF. In this synthetic step DCU was formed as side product which precipitated and could be filtered off. The crude active ester was purified by recrystallization in isopropanol. In general, yields above $85 \%$ were obtained for $L$-phenylalanine derivatives (2a same as $4 a, 5 a, 8 a$, 11a, 12a) and activated L-lysine (7a). Activated $L$-aspartic acid (1a same as 3a, 6a) and Lglutamic acid (9a same as 10a) were obtained from commercial sources

The next step was the aliphatic amine coupling by simple reaction of the previously activated ester with propyl amine (1-8b, 9b and 11b) or dodecyl amine (10b and $\mathbf{1 2 b}$ ) in DME. Then, purification was achieved by thoroughly sequential washing with diluted $\mathrm{HCl}(0.1 \mathrm{M})$ and $\mathrm{Na}_{2} \mathrm{CO}_{3}(0.1 \mathrm{M})$. Yields between $85-95 \%$ were obtained for all the cases. After the coupling benzyloxycarbonyl deprotection was carried out by catalytic hydrogenolysis with palladium on activated carbon in $\mathrm{MeOH}$ and under hydrogen atmosphere to obtain the corresponding free $\mathrm{N}^{\alpha}$ amino acid derivates (1-12c) with excellent yields. 


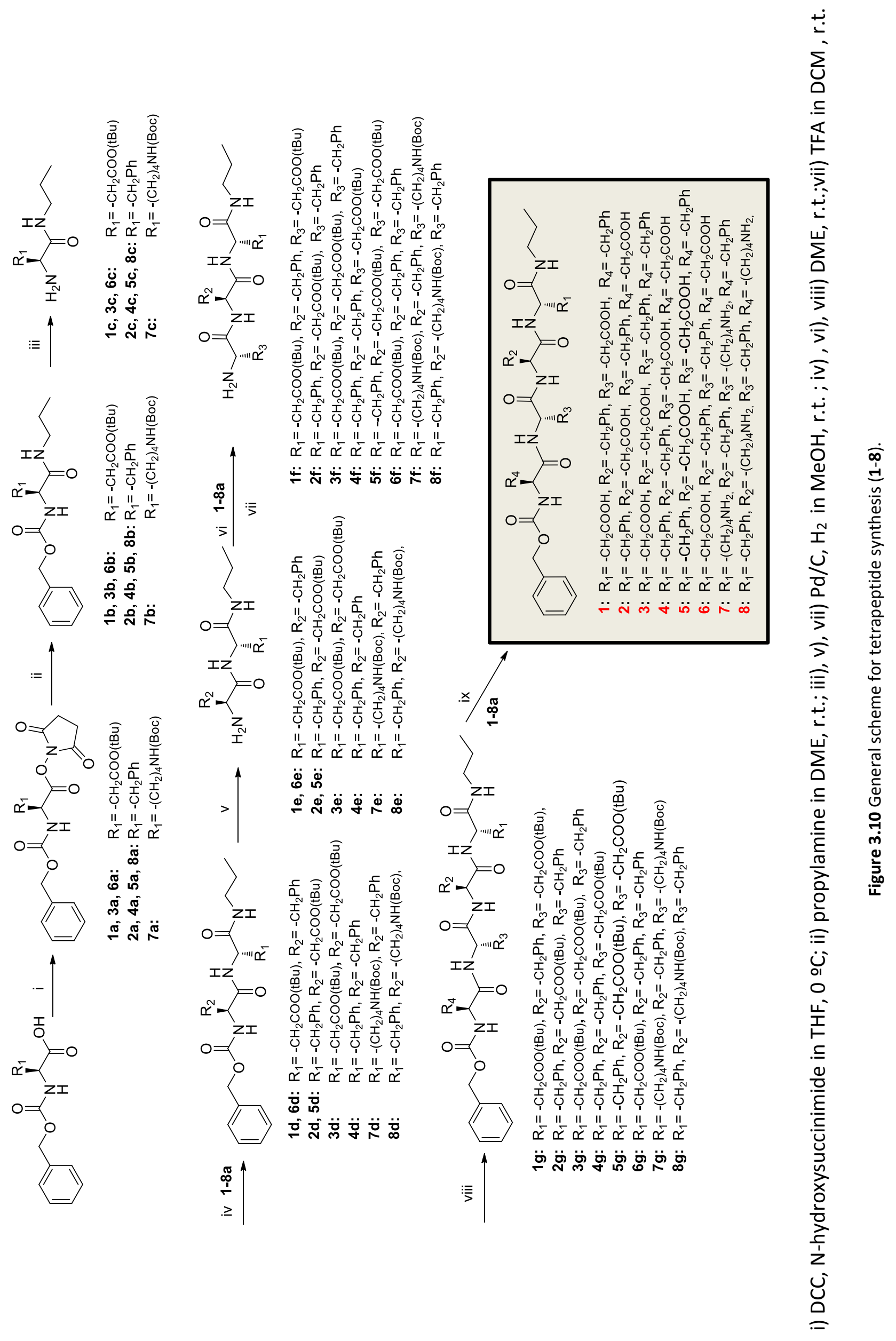




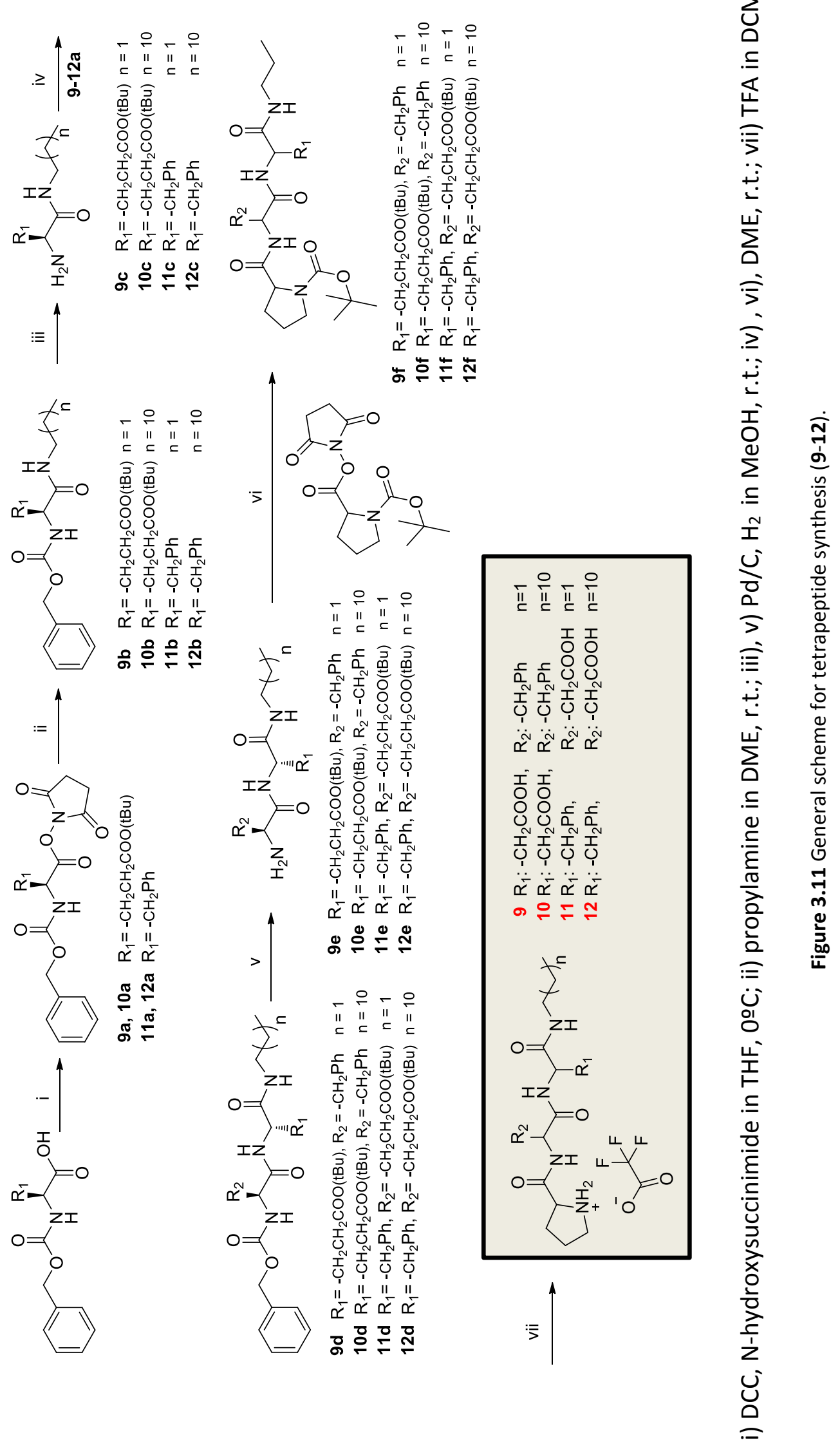


Hydrogenolysis reaction could be followed by TLC using ninhydrine as staining solution for the detection of the primary amines. The catalyst was removed by filtration through Celite, and the solvent was evaporated. The crude oils or white solids obtained were used without further purification. Then, the free $\mathrm{N}^{\alpha}$ amino acid capped at the $\mathrm{C}$ terminus by an aliphatic amide was coupled with the next Z- $\mathrm{N}^{\alpha}$ protected activated amino acid (1-12a) in DME leading to the corresponding $Z-\mathrm{N}^{\alpha}$ protected dipeptide (112d). Deprotection and coupling steps were repeated until the desired elongation was reached, tripeptides (9-12f) or tetrapeptides (1-8g). In order to obtain the final compounds the side chain protecting groups were cleaved by using TFA in DCM leading to compounds 1-12. TFA and DCM were removed under vacuum and the obtained light yellow solids were washed in aqueous mild basic or acidic solutions (depending on the ionic amino acid side chain) affording the final products as white solids. Yields for this last step were generally above $90 \%$ for compounds 1-6 and 9-12 and about $70 \%$ for compounds 7-8.

Table 3.2 collects the chemical structure, number of steps in synthesis and total yield for compounds 1-12.

Table 3.2 Chemical structures, short names, steps of synthesis and total yield for compounds 1-12.

\begin{tabular}{|c|c|c|c|c|}
\hline Ref & Chemical structure & Name & Steps & Total Yield (\%) \\
\hline 1 & & ZFDFDC $_{3}$ & 8 & 45 \\
\hline 2 & & ZDFDFC $_{3}$ & 9 & 46 \\
\hline 3 & & ZFFDDC $_{3}$ & 8 & 37 \\
\hline 4 & & ZDDFFC $_{3}$ & 9 & 36 \\
\hline
\end{tabular}




\begin{tabular}{|c|c|c|c|}
\hline 5 & ZFDDFC $_{3}$ & 9 & 46 \\
\hline 6 & ZDFFDC $_{3}$ & 8 & 40 \\
\hline 7 & ZFKFKC $_{3}$ & 9 & 40 \\
\hline 8 & ZKFKFC $_{3}$ & 9 & 30 \\
\hline 9 & PFEC $_{3}$ & 6 & 58 \\
\hline 10 & PFEC $_{12}$ & 6 & 59 \\
\hline 11 & PEFC $_{3}$ & 7 & 55 \\
\hline 12 & PEFC $_{12}$ & 7 & 56 \\
\hline
\end{tabular}

Solution peptide synthesis is being replaced in many laboratories by solid phase synthesis (SPPS), even for short peptides. The main advantage of synthesis in solution is that intermediates can be isolated and characterized at every step, if necessary, so then it is always possible to know which molecular species are present at any point. As a consequence problems that arise during elongation can be identified and dealt with at 
any moment. However in SPPS the presence of undesirable amount of side products in general can only be discovered at the end, after the peptide has been cleaved from the resin. On the other hand the numerous purification steps present in the solution phase procedure are an inconvenient because of many time consuming purification steps. Advantages and disadvantages of both methodologies (Table 3.3) placed SPPS as the most convenient strategy for long peptides while peptide synthesis in solution is more suitable for short peptides in large amounts.

Table 3.3 Advantages and disadvantages of solid and solution phase peptide synthesis.

\begin{tabular}{cc}
\hline Solid Phase & Solution Phase \\
\hline Suitable for long peptides & Suitable for short peptides \\
Makes a mixture of products & Makes only one product \\
Small amount of products formed & Large amount of product can be synthesized \\
Simple isolation of products by filtration & Work-up after each step \\
Two extra steps: linkage and cleavage & No extra steps needed \\
Automation available & Automation not as highly developed \\
Large excess of reagents should be used to & Do not use large excess of reagents \\
drive the reaction to completion & \\
\hline
\end{tabular}

The present tetrapeptides, considering that we usually work in gram scale, may be at the edge between both approaches and because of it a new SPPS approach will be described for compound $\mathbf{1}$ in order to clarify which is the most convenient methodology for future designs in our laboratory.

\subsection{Solid phase peptide synthesis (SPPS)}

The brilliantly simple idea of solid phase synthesis was first introduced by Merrifield in the early $1960 \mathrm{~s}^{7}$ who was awarded the Nobel prize in $1984^{8}$ because of his contribution to this field after the synthesis of the bovine pancreatic ribonuclease enzyme, a full protein with 124 amino acids. In this technique the amino acid that is to be at the C-terminus of the final peptide is $\mathrm{N}$-protected and then attached through its carboxyl group to an insoluble polymeric material, usually polystyrene (synthesis is carried out from the $\mathrm{C}$-terminus to the $\mathrm{N}$-terminus). The protecting group of the amino acid linked to the solid support is then removed and coupled with other N-protected and carboxyl-activated amino acid. The deprotection-coupling cycle is repeated as many 
times as is required. Finally the solid support or resin is cleaved from the peptide product.

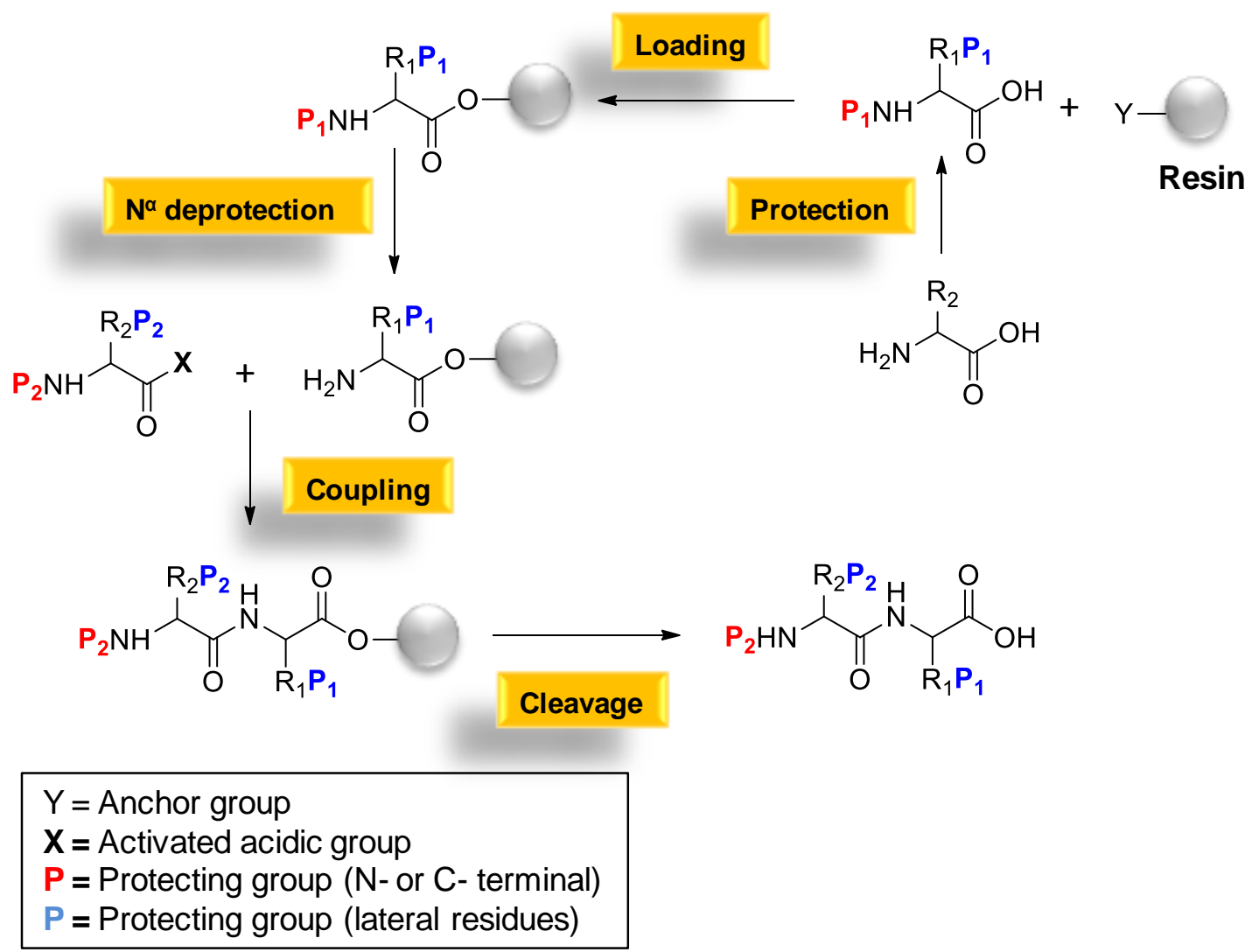

Figure 3.12 Schematic representation of a dipeptide synthesis by SPPS.

As can be seen in Figure 3.12 protecting groups ( $P$ and $P$ ) are also needed for SPPS and orthogonality among them is still a requirement for the elongation process. Carboxylic acid activation (X) for amide coupling is also necessary and besides two additional steps, the loading to the resin and the final cleavage, have to be considered. In the next section the SPPS procedure used for compound $\mathbf{1}$ is going to be detailed ${ }^{9}$ (Figure 3.13).

A modified Kenner sulfonamide ${ }^{10}$ linker supported on a styrene-1\% DVB resin was used, in particular the alkylsulfonamide linker depicted in Figure 3.15. This safetycatch linker reported by Backes and Ellman ${ }^{9 b}$ provides a support that is stable to both basic and strongly nucleophilic reaction conditions. At the end of a solid-phase synthesis sequence, treatment with iodoacetonitrile provides $\mathrm{N}$-cyanomethyl derivatives that can be cleaved by nucleophiles under mild reaction conditions to release the target compounds. In our case propylamine will play this nucleophilic role although many kinds 
of different amines could be used instead generating therefore a wide variety of products.

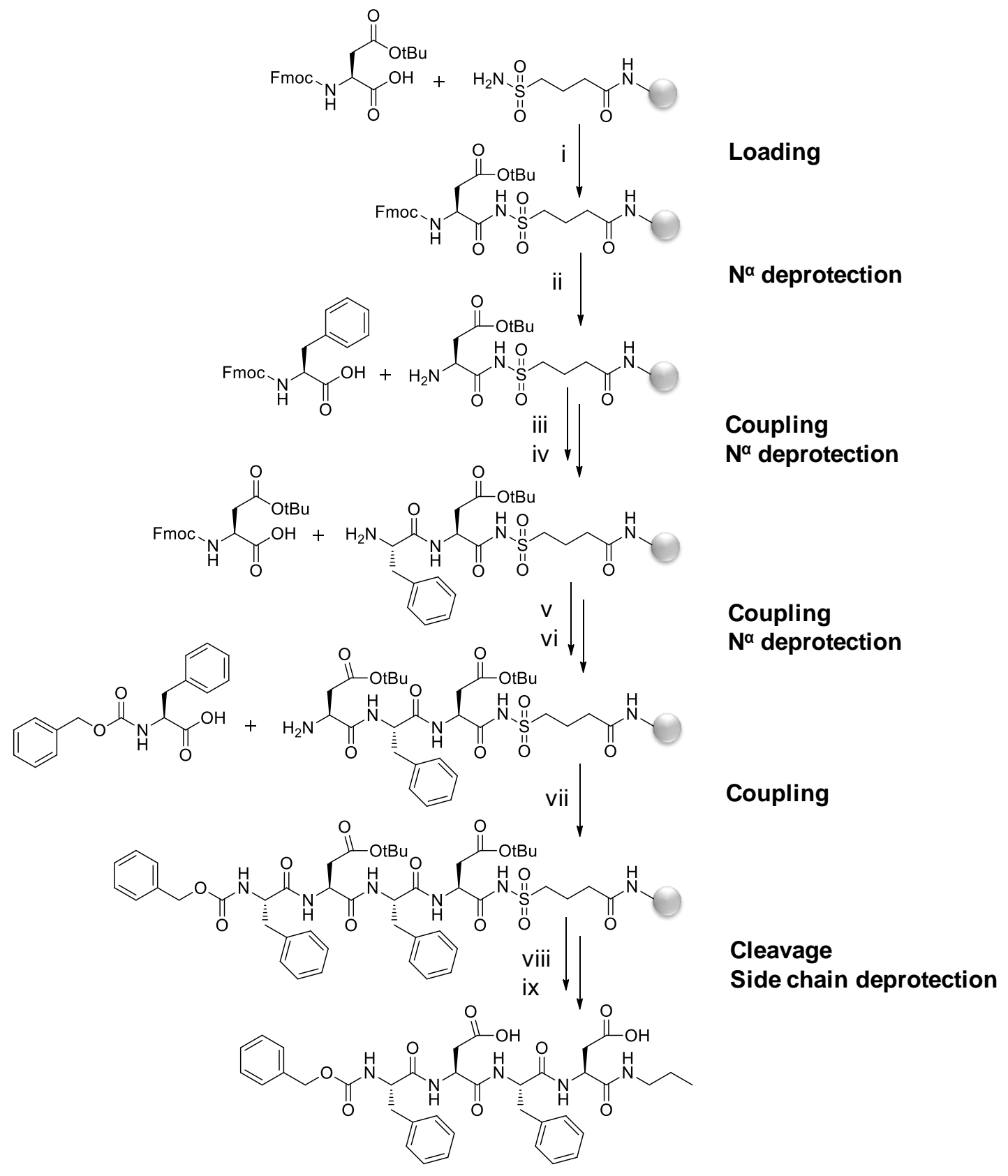

Figure 3.13 Synthesis scheme for compound 1 by SPPS i) DIPEA, PyBOP in $\mathrm{CH}_{2} \mathrm{Cl}_{2}, 16 \mathrm{~h}$ at 0 웅 ii), iv), vi) Piperidine (20 \%) in DMF, 20 min at r.t.; iii), v), vii) Ethyl(hydroxyimino)cyanoacetate, DIC in DMF, 2-3 h at r.t.; viii) iodoacetonitrile, DIPEA in NMP, $24 \mathrm{~h}$ at r.t. followed by propylamine in THF, $4 \mathrm{~h}$ at r.t.; ix) TFA in $\mathrm{CH}_{2} \mathrm{Cl}_{2}, 2$ h at r.t.

The activating agent employed to achieve the loading of the resin was the phosphonium salt PyBOP and a schematic representation of the mechanism involved in this process is depicted in Figure 3.14. 


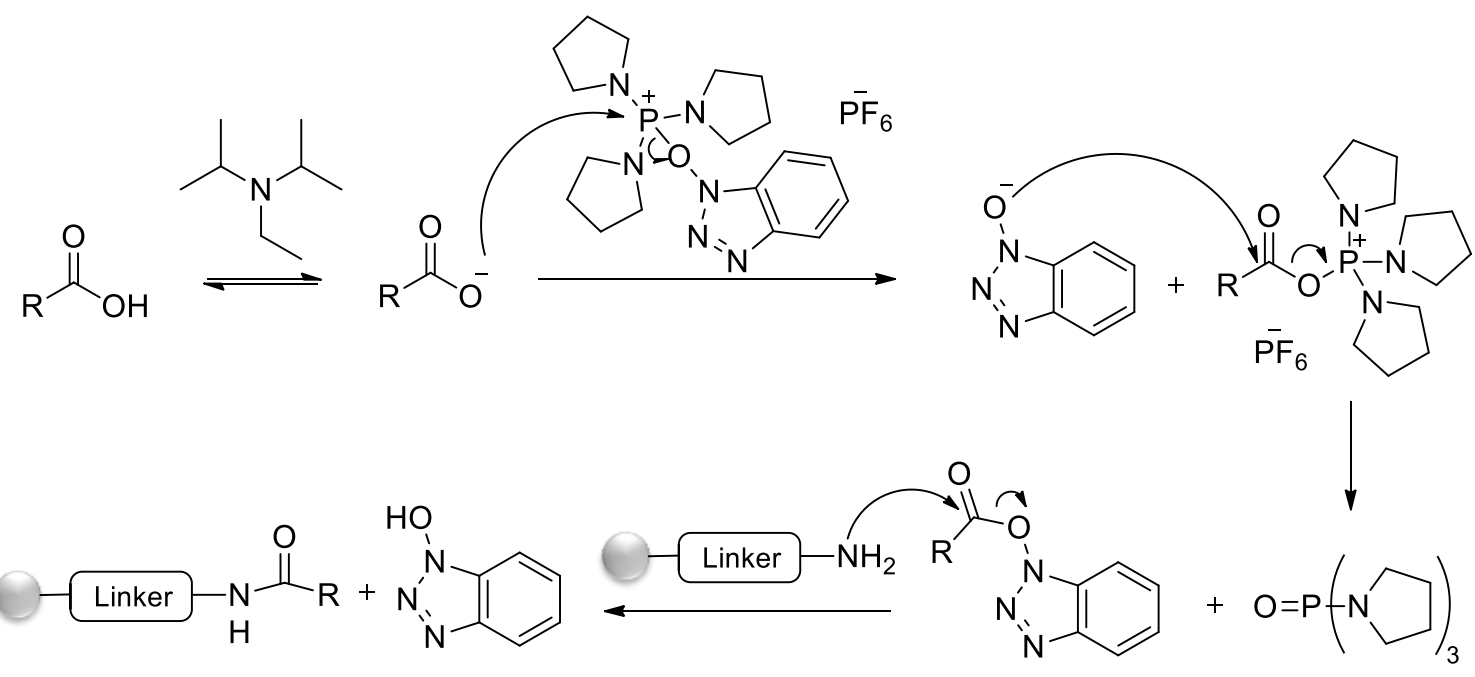

Figure 3.14 Schematic representation of the mechanism for peptidic bond formation using PyBOP as coupling agent.

The PyBOP reagent is used instead of the traditional BOP (Benzotriazol-1yloxy)tris(dimethylamino)phosphonium hexafluorophosphate) whose use is discouraged because it liberates HMPA (Hexamethylphosphoramide) which is carcinogenic.

The loading efficiency could be evaluated by a UV/Vis assay. ${ }^{11} \mathrm{~A}$ representative sample of the resin coupled to the first amino acid was treated with piperidine $(20 \%)$ in DMF causing Fmoc deprotection $\left(\mathrm{N}^{\alpha}\right)$ and the formation of an adduct of dibenzofulvene and piperidine (Figure 3.15) whose molar extinction coefficient is $\varepsilon_{301 \mathrm{~nm}}=7800 \mathrm{M}^{-1} \mathrm{~cm}^{-1}$. After two repetitions a total loading of $80 \%$ was achieved.

In this case, the strategy Fmoc/t-Bu was employed for the $\mathrm{N}^{\alpha}$ and side chain protection respectively. The Fmoc group is usually introduced by the Schotten-Baumman protocol, using the rather stable chloroformate. It is very stable to acidic reagents, but is usually cleaved easily under certain basic conditions. Piperidine (20\% in DMF) is the commonly used reagent and the mechanism is shown in Figure 3.15: 

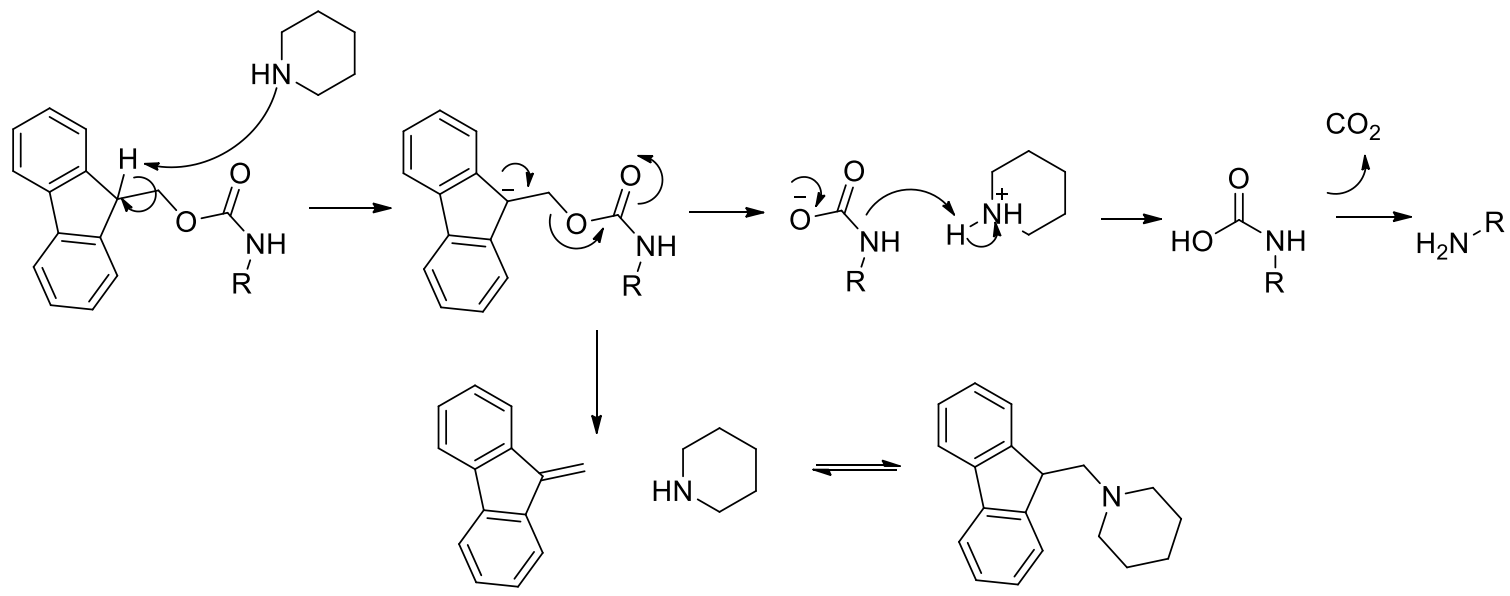

Figure 3.15 Deprotection mechanism of the Fmoc group using piperidine.

For the general coupling during the elongation process $N, N^{\prime}-$ diisopropylcarbodiimide (DIC) in combination with ethyl(hydroxyimino)cyanoacetate was employed. The later compound was used to avoid racemization during the coupling.

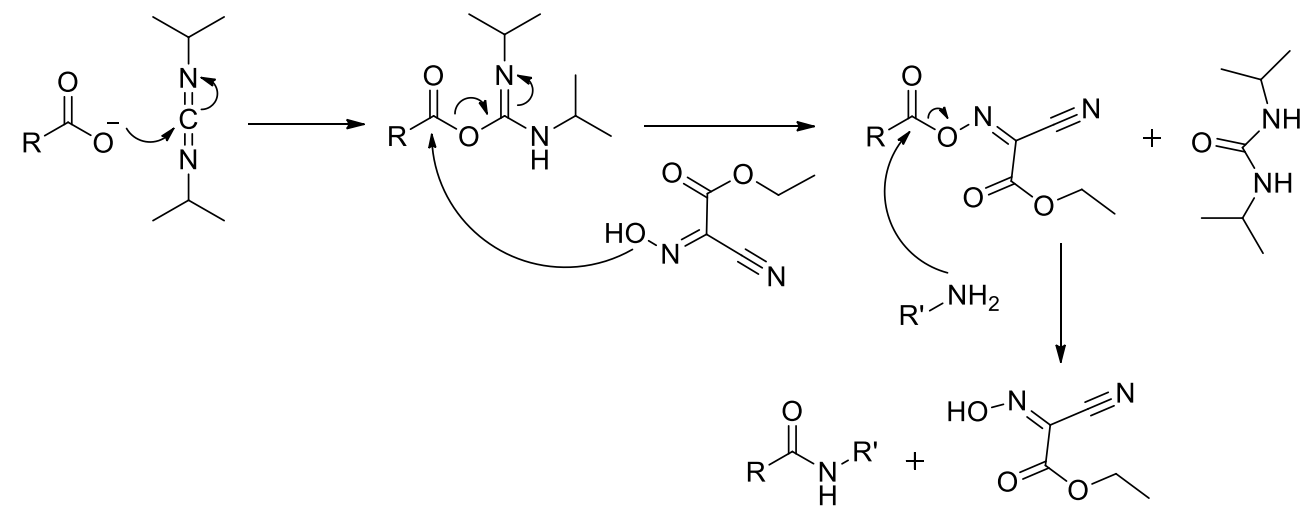

Figure 3.16 Coupling mechanism proposed by using DIC and ethyl (hydroxyimino)cyanoacetate.
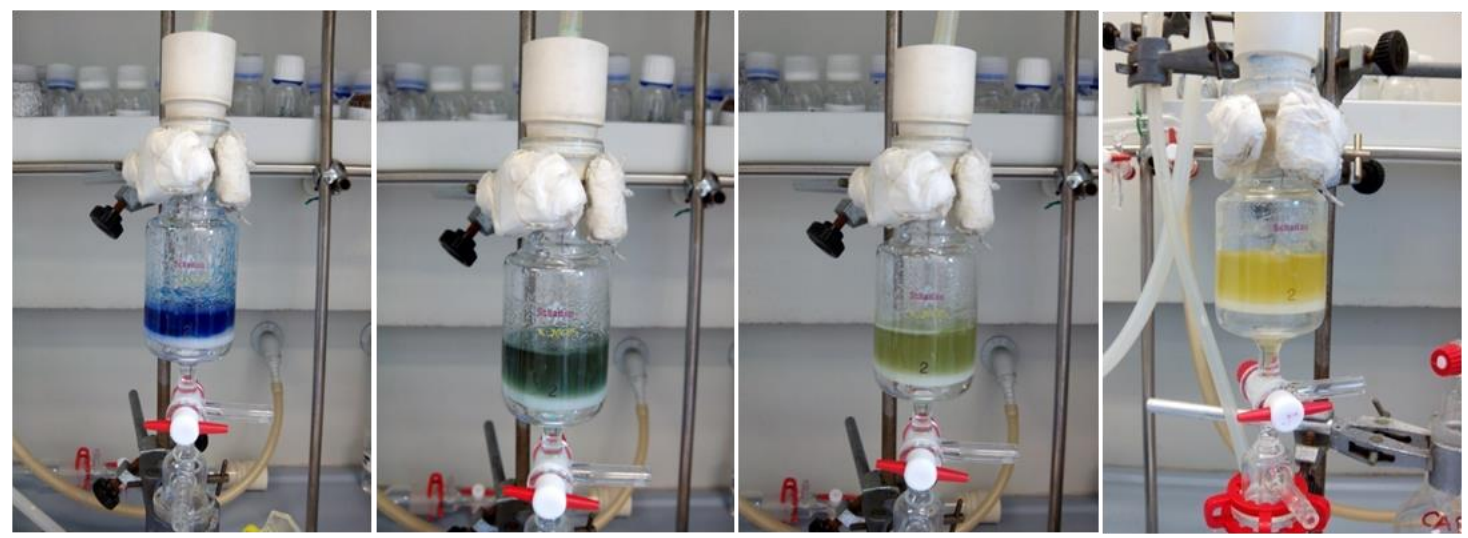

Figure 3.17 Coupling reaction using DIC and ethyl (hydroxyimino)cyanoacetate in the presence of Bromophenol Blue as $\mathrm{pH}$ indicator. 
The progress of the reaction can be monitored by eye using the non-invasive $\mathrm{pH}$ indicator Bromophenol Blue. ${ }^{12}$ When free amino acids are present the solution exhibits a deep blue color (Figure 3.17). During the progress of the reaction, while the amine groups are being consumed, the solution becomes blue-green to light green and finally turns into yellow when the resin lacks free amino acid groups.

After the corresponding number of deprotection-coupling cycles required, the last step corresponds to the resin cleavage which comprises first of all an $\mathrm{N}$-alkylation followed by nucleophilic displacement using propylamine. A general mechanism for this procedure is shown in Figure 3.18:

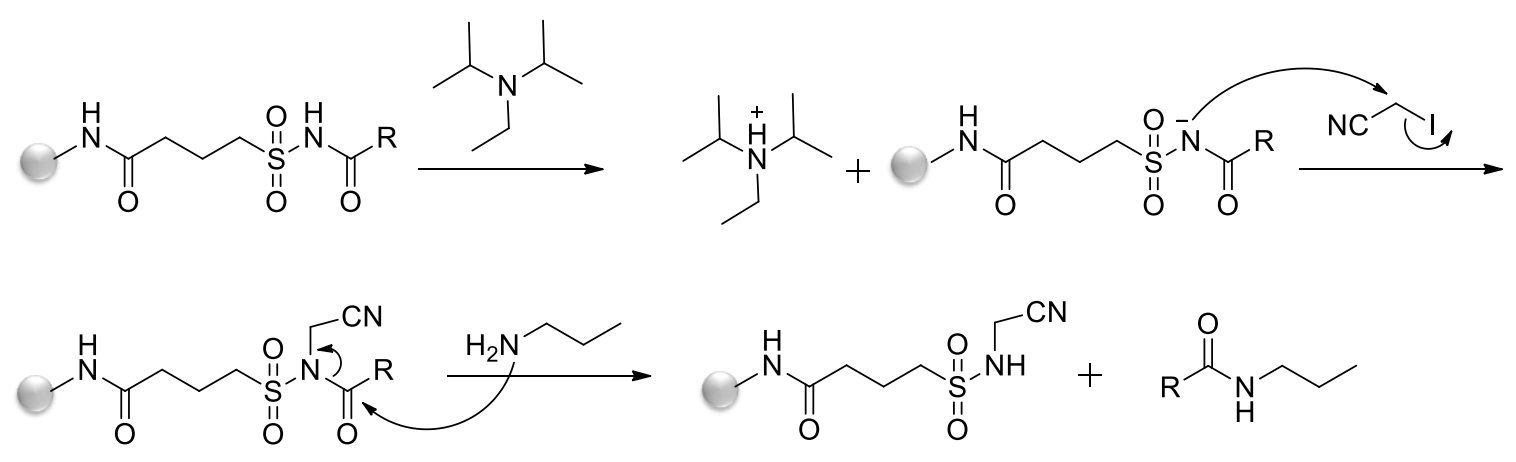

Figure 3.18 General mechanism for resin cleavage using iodoacetonitrile for $\mathrm{N}$-alkylation and propylamine as nucleophile.

After cleavage from the resin the tetrapeptide is released into the solution and, after filtration of the resin, a final deprotection of the side chains by using TFA (Figure $3.8 \mathrm{~b}$ ) was required leading to compound 1 as a white solid in a $48 \%$ (130 $\mathrm{mg}$ ) of yield.

As we have mentioned before the SPPS methodology skipped the necessity of intermediate characterisations reducing then the total time of synthesis, however the extra loading and cleavage steps required longer times reducing then the time difference between both procedures. This difference would be larger in favor of SPPS if longer peptides (penta-, hexa-, heptapeptides) were synthesized. SPPS was technically easier to develop because there was no need of transfer the product from one place to another and just simple filtrations were required after each step. Peptide synthesis in solution gave the tetrapeptide with high degree of purity (>95 \%) while HPLC purification was necessary after SPPS. The total yield was in principle pretty similar for both methodologies but nevertheless, further optimization of the loading process in the SPPS 
process may improve the total yield for future synthesis using this resin. The weak point for the use of SPPS in our case may be the fact that we use these compounds in gram scale. The resin price together with the excess of reagents employed raises the price of this methodology especially for big amounts. Considering advantages and disadvantages of each methodology SPPS could be considered as an alternative in our laboratory for the synthesis of small amounts of compounds which will be used for preliminary assays. Those compounds exhibiting the best properties for our purposes should be then synthesized in a bigger scale by using the traditional methodology in solution.

\subsection{Unexpected deprotection of benzyloxycarbonyl group (Z).}

The benzyloxycarbonyl group (Z) devised by Bergman and Zervas in $1932^{13}$ is considered a milestone in the development of modern synthetic chemistry. Due to its versatility it initiated a revolution in peptide chemistry and is still nowadays one of the more useful amino protecting groups not only in solution but also in solid phase synthesis because of its favorable stability and cleavage properties. ${ }^{14}$

It is well-known that the $\mathrm{Z}$ group can be cleaved by catalytic hydrogenolysis, acidolysis or, less commonly, by dissolving metal reduction. ${ }^{6,14 a}$ Fortunately the different conditions required for its removal are mild enough to tolerate a wide range of complementary protecting groups. Besides, Z group is reported to tolerate basic conditions $^{15}$ and only few hard conditions like refluxing with $\mathrm{Ba}(\mathrm{OH})_{2}$ in demethoxyethane $/ \mathrm{H}_{2} \mathrm{O}$ for long times or using $40 \% \mathrm{NaOH}$ in solvent mixtures $\mathrm{MeOH} / \mathrm{H}_{2} \mathrm{O}$ have been reported sometimes. ${ }^{16}$

Considering this background it was completely unexpected for us the cleavage of the benzyloxycarbonyl group under mild basic conditions. Upon dissolving acidic tetrapetides $(\mathbf{2}, \mathbf{5}$ and $\mathbf{6})$ in aqueous $\mathrm{NaOH} 0.1 \mathrm{M}$ at room temperature in less than $4 \mathrm{~h}$ complete removal of the proctecting group was noticed. The process was monitored by ${ }^{1} \mathrm{H}$ NMR and the signal corresponding to the benzyl proton of the $Z$ group ( $\delta=4.9-5.1$ ppm) progressively disappeared over the time and was replaced by a singlet signal at $\delta=$ $4.67 \mathrm{ppm}$ (Figure 3.19). This signal was unambiguously assigned to the benzylic protons of benzyl alcohol by comparison with commercial product (See S.I.3.7). 

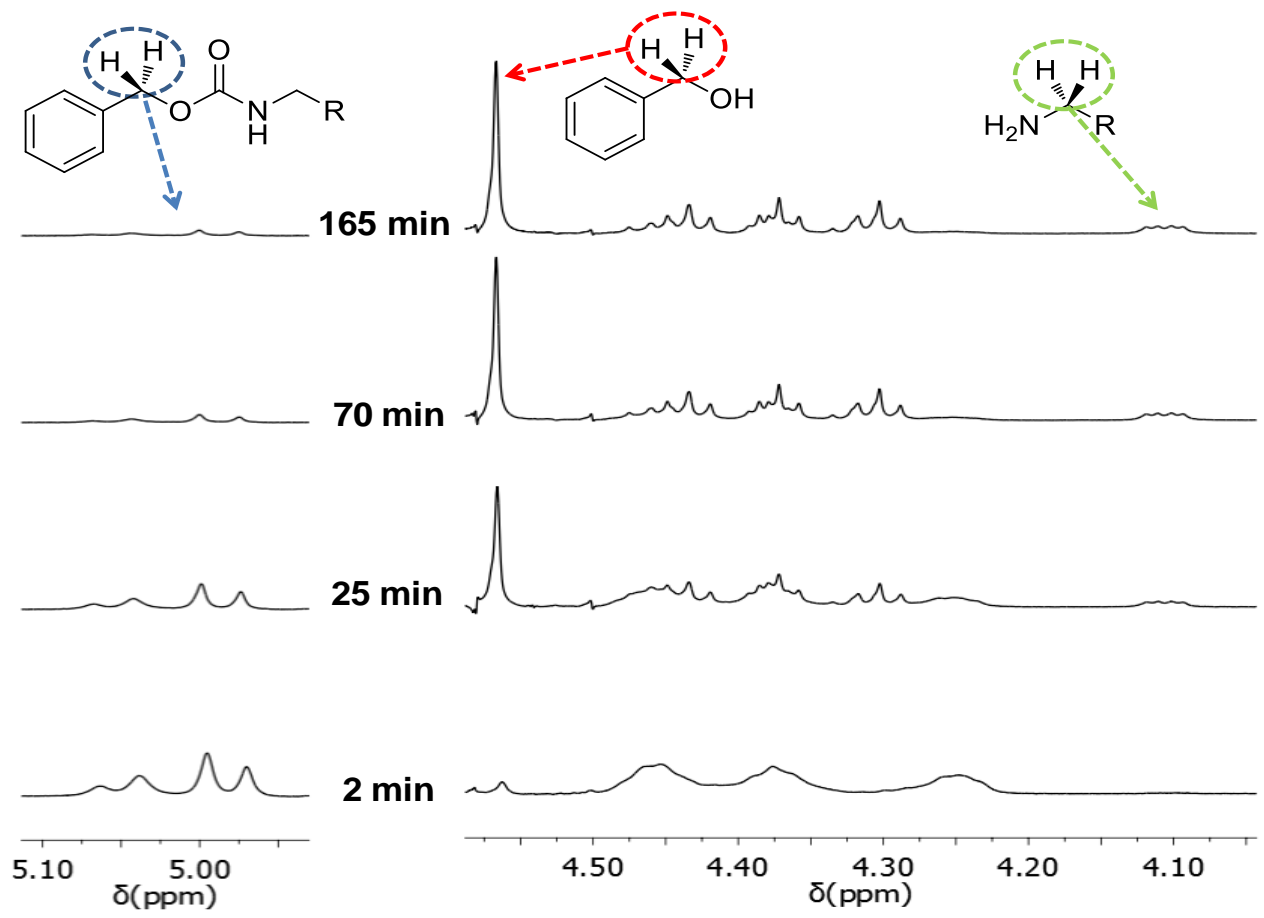

Figure 3.19 ${ }^{1} \mathrm{H}$ NMR spectra recorded over time for the hydrolysis of compound 6 at $15 \mathrm{mM}$ in basic $\mathrm{D}_{2} \mathrm{O}$ (0.1 $\mathrm{M}$ of $\mathrm{NaOH})$.

This unprecedented behavior of the $Z$ group was studied in more detail and for this purpose a set of experiments was designed to find out which structural factors may explain the observed reactivity and to propose a reasonable mechanism.

Kinetic studies by using ${ }^{1} \mathrm{H}$ NMR in basic $\mathrm{D}_{2} \mathrm{O}$ were firstly carried out for compounds 2, 5 and $\mathbf{6}$. The hydrolysis reaction could be fitted to a pseudo-first order reaction (due to the excess of hydroxide) (Figure 3.20). For all the peptides half-life times of 1-2 $\mathrm{h}$ were obtained confirming a fast cleavage of the $\mathrm{Z}$ group under such conditions (Table 3.4, Compounds 2, 5 and 6).

$$
\begin{gathered}
v=\frac{d\lfloor A\rfloor}{d t}=-k[A] \rightarrow \frac{d\lfloor A]}{[A]}=-k d t \quad \ln [A]=\ln [A]_{0}-k t \\
\int_{A_{0}}^{A} \frac{d[A]}{[A]}=-k \int_{0}^{t} d t \rightarrow \ln [A]-\ln [A]_{0}=-k t \quad \text { If } t=t_{1 / 2} \text { then }[A]=\frac{[A]_{0}}{2} \rightarrow t_{1 / 2}=\frac{\ln 2}{k}
\end{gathered}
$$

Figure 3.20 First order (pseudo-first) equations. 
Analysis of the results indicates that the lability of the Z-group may be due to an anchimeric assistance ${ }^{i}$ of the amide group of the vicinal amino acid (Figure 3.21a). As can be seen, upon the nucleophilic attack of the hydroxide anion a tetrahedral intermediate is formed that can be stabilized by an intramolecular $\mathrm{H}$-bonding if a vicinal amide is present within the molecule. Conversely if there is no vicinal amide, the Z-group cleavage will be very slow if happening at all.

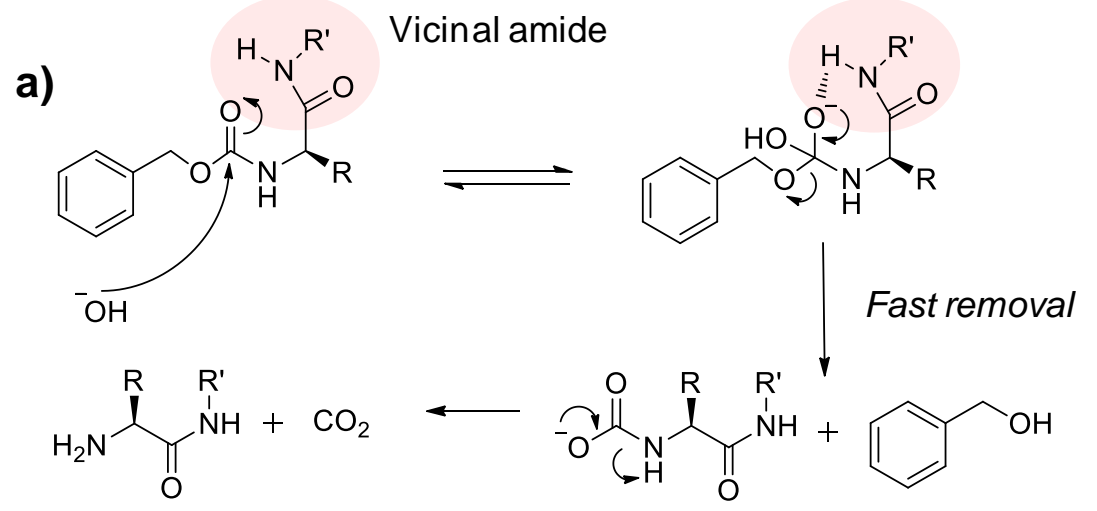

b)

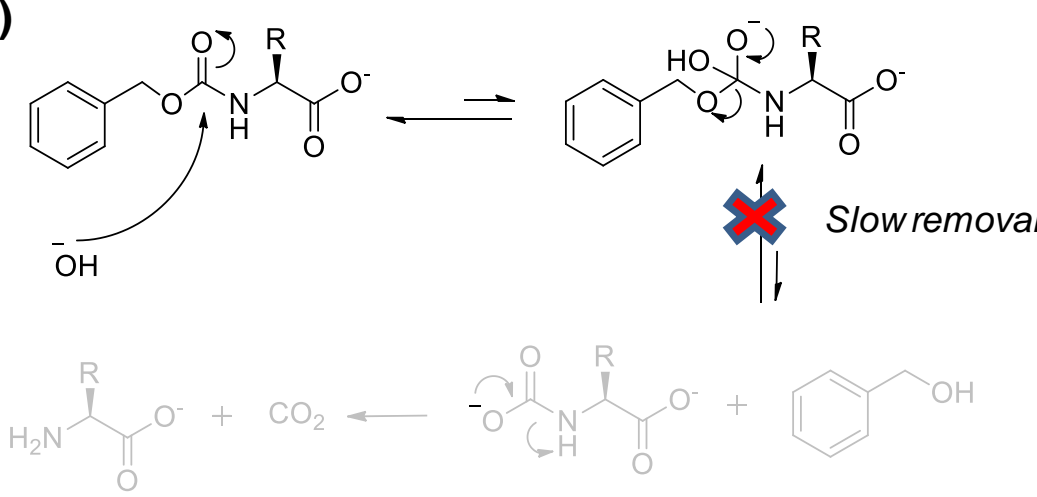

Figure 3.21 Proposed mechanism for the basic hydrolysis of the $Z$ group a) in the presence of vicinal amide and b) without vicinal amide.

In order to prove the feasibility of this mechanism a set of different Z-protected amino acids (Table 3.4, Compounds 13-17) were studied under the same conditions. No hydrolysis was observed for simple Z-N ${ }^{\alpha}$ protected amino acids ZVOH (13) and ZFOH (14) as expected due to the absence of vicinal amide. However, hydrolysis took place easily when the C-terminus was capped as an amide like in $\mathrm{ZDC}_{\mathbf{3}}(\mathbf{1 5})$. Due to the low solubility in water of some of the compounds the study was also carried out in MeOD. Once again no hydrolysis was observed for compounds 13 and 14 but Z-cleavage was rather efficient

i Anchimeric assistance (or neighbouring group participation) refers to the interaction of an electron pair with an adjacent reaction center during the course of the reaction mechanism. 
for compounds $\mathbf{1 5}$ to $\mathbf{1 7}$ in which terminal amides are present. This observation is supporting the hypothesized mechanism in Figure 3.21 which requires the anchimeric assistance by a vicinal amide to stabilise the tetrahedral intermediate.

To provide greater detail into the mechanism the two general paths for the basic hydrolysis of carbamates were considered. The reaction can take place through a $\mathrm{B}_{\mathrm{Ac}} 2$ mechanism as depicted in Figure 3.21 or through an E1CB mechanism based on the deprotonation of the amide and formation of an isocyanate intermediate. ${ }^{17}$ The use of the $\mathbf{Z S a r C}_{\mathbf{3}}(\mathbf{1 8})$ is an easy way to provide information on this regard. Sarcosine (Sar) is an amino acid derivative which contains a secondary carbamate and therefore cannot participate in an E1CB mechanism due to the lack of a deprotonable $\mathrm{NH}$ unit. As can be seen in Table 3.4, compound 18 reacted in MeOD even faster than previous compounds reinforcing therefore the $\mathrm{B}_{\mathrm{Ac}} 2$ mechanism. Furthermore, no reaction was observed for a $\mathrm{ZD}\left(\mathrm{CH}_{3}\right) \mathrm{C}_{3}$ and $\mathrm{ZF}\left(\mathrm{CH}_{3}\right) \mathrm{C}_{3}$ (Table 3.4, compounds 19 and 20 ), which are $\mathrm{N}$-methylated analogues of $\mathbf{Z D C}_{3}$ and $\mathbf{Z F C}_{3}$ respectively, confirming the key role of the primary amide $\mathrm{NH}$ unit in the hydrolysis.

Next, the hydrolysis of $Z$ carbamate in a homopeptidic family of glycine peptides containing mono-, di- and tripeptides was analyzed. Compounds 23-25 (Table 3.4) were designed to this purpose and considering our assumptions, fast $Z$ removal should be observed for dipeptide $\mathbf{2 4}$ (ZGGOH) and tripeptide $\mathbf{2 5}$ (ZGGGOH) in a similar way to the tetrapeptides reported due to the presence of a vicinal amide while no hydrolysis was expected to take place for Z-N $\mathrm{N}^{\alpha}$ protected glycine $\mathbf{2 3}$ (ZGOH).

Despite what we expected, carbamate hydrolysis took place for all $\mathrm{G}$ derivatives probably because the rather hydrophilic nature of this amino acid favours the reaction. However significant differences were observed among them. The tripeptide 25 underwent a really fast hydrolysis with a half-life time of $0.04 \mathrm{~h}$ while the reaction was much slower for amino acid 23 ( $t_{1 / 2}>72$ h). Surprisingly the dipeptide 24 reacted considerably slower that the corresponding tripeptide 25 , this effect being more pronounced in basic methanol with half-life times of $48 \mathrm{~h}$ and $2 \mathrm{~h}$ respectively. 
Table 3.4 Half-life times determined in basic media $\left(D_{2} \mathrm{O}\right.$ and $\left.\mathrm{MeOD}\right)$ for different Z-protected amino acids and peptides at $30 \stackrel{\circ}{ }$.

\begin{tabular}{|c|c|c|c|}
\hline Compound & Chemical structure and name & $t_{1 / 2}$ in $D_{2} O / h$ & $t_{1 / 2}$ in MeOD / h \\
\hline 2 & ZDFDFC $_{3}$ & 1.4 & 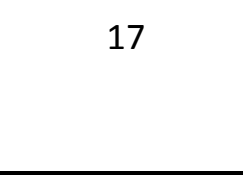 \\
\hline 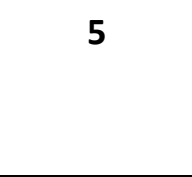 & ZFDDFC $_{3}$ & 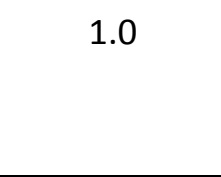 & n.d. \\
\hline 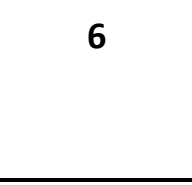 & ZDFFDC $_{3}$ & 2.0 & . \\
\hline 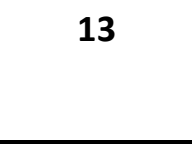 & ZVOH & n. r. & n. r. \\
\hline 14 & $\mathrm{ZFOH}$ & n. $r$. & n. r. \\
\hline 15 & $\mathrm{ZDC}_{3}$ & 1.8 & 36 \\
\hline 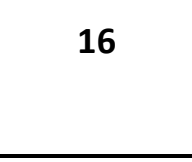 & $\mathrm{ZFC}_{3}$ & ins. & 26 \\
\hline 17 & $\mathrm{ZVC}_{3}$ & ins. & 8.3 \\
\hline 18 & $\mathrm{ZSarC}_{3}$ & ins. & 4.3 \\
\hline
\end{tabular}




\begin{tabular}{|c|c|c|c|}
\hline Compound & Estructure and name & $t_{1 / 2}$ in $D_{2} O / h$ & $t_{1 / 2}$ in MeOD / h \\
\hline 19 & $\mathrm{ZD}\left(\mathrm{CH}_{3}\right) \mathrm{C}_{3}$ & n. r. & n. r. \\
\hline 20 & $\mathrm{ZF}\left(\mathrm{CH}_{3}\right) \mathrm{C}_{3}$ & ins & n. r. \\
\hline 21 & ZFFOH & 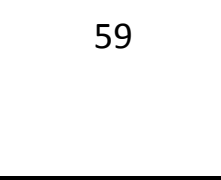 & n. r. \\
\hline 22 & $\mathrm{ZD}(\mathrm{tBu}) \mathrm{FOH}$ & $>72$ & n. r. \\
\hline 23 & ZGOH & $>72$ & $>72$ \\
\hline 24 & ZGGOH & 1.4 & 48 \\
\hline 25 & ZGGGOH & 0.04 & 2.0 \\
\hline 26 & $\mathrm{tBuFC}_{3}$ & Ins. & n.r \\
\hline
\end{tabular}

n.r. = no reaction; ins = insoluble; [Z-protected substrate] = $15 \mathrm{mM} ;[\mathrm{NaOH}]=0.1 \mathrm{M}$; Half-life times were calculated by considering pseudo-first-order kinetics. 
This unusual resistance showed by dipeptide $\mathbf{2 5}$ was confirmed by using other two dipeptides (21 and $\mathbf{2 2}$ ) available in the laboratory. For both compounds no reaction was observed in MeOD and only very slow hydrolysis was detected in water with half-life times larger than $59 \mathrm{~h}$ (Table 3.4, Compound 21 and 22).

Such big difference in reactivity of dipeptides compared to tripeptides or tetrapeptides may be explained by considering the intramolecular hydrogen bond that can be stablished between the terminal carboxylate unit and the $\mathrm{NH}$ of the vicinal amide as can be seen in Figure 3.22. The presence of this hydrogen bond has been previously reported ${ }^{18}$ and in dipeptides it blocks the anchimeric assistance of the amide $\mathrm{NH}$ in the stabilization of the tetrahedral intermediate required for carbamate hydrolysis.

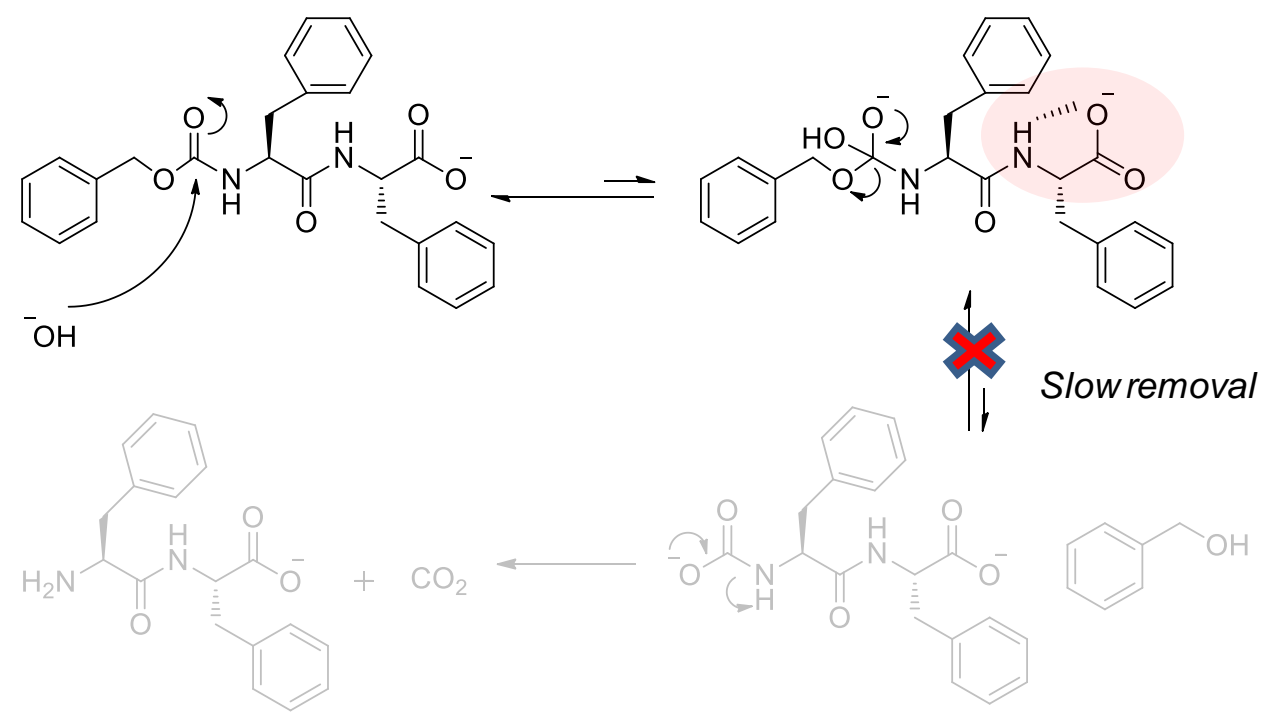

Figure 3.22 Hydrogen bond formation between terminal carboxylate and the $\mathrm{NH}$ of the vicinal amine avoiding the stabilization of the tetrahedral intermediate.

Interestingly, hydrolysis reaction was not blocked for compound $\operatorname{ZDC}_{\mathbf{3}}(\mathbf{1 5})$ despite a deprotonated carboxylic acid was present at the side chain. Most likely this is because the formation of a hydrogen bond involving this pendant carboxylic acid and the terminal amide would generate a seven-membered ring which is not as thermodynamically stable as the five-membered ring previously described for dipeptides.

Finally molecular models using computational chemistry (DFT-B3LYP/3-21G) also agreed with experimental data reported. Minimum energy models could be obtained with the negatively charged tetrahedral intermediate stabilized with intramolecular $\mathrm{H}$ - 
bonding from the adjacent amide bond (Figure 3.23A). Furthermore, computational models also point out to the formation of a stable intramolecular $\mathrm{H}$-bond between terminal carboxylate unit and vicinal peptide (Figure 3.23B) leading a five-membered ring.

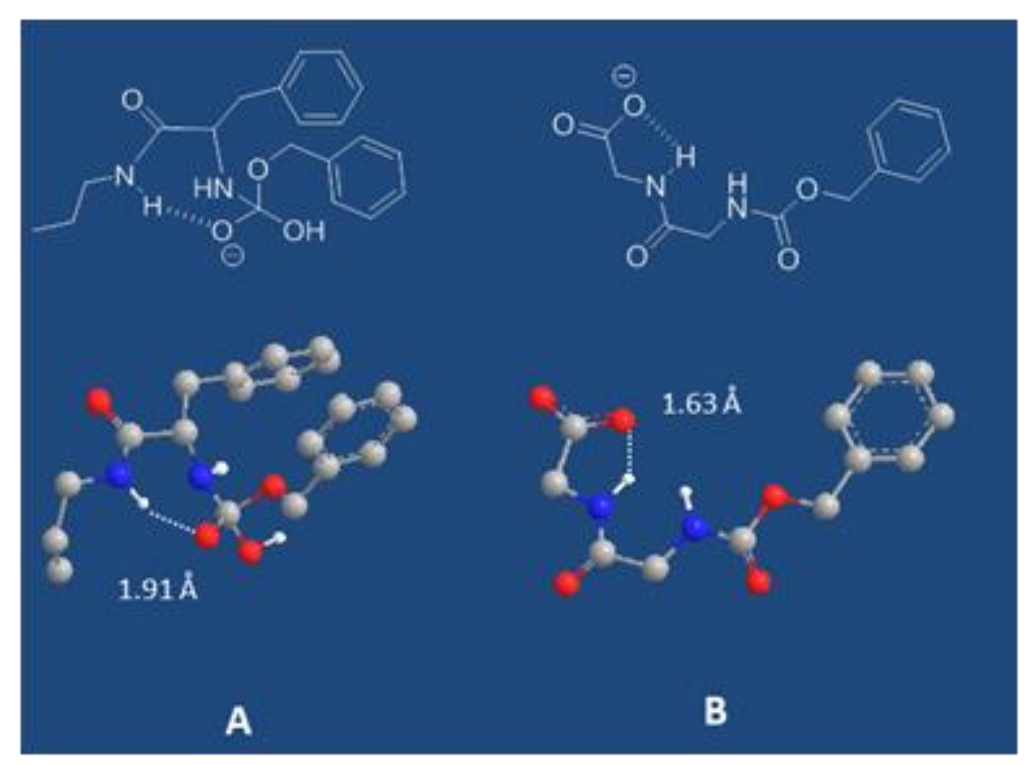

Figure 3.23 DFT-B3LYP/3-21G energy minimized conformations (solvent model: PCM, $\mathrm{H}_{2} \mathrm{O}$ ). The distances shown refer to the $\mathrm{H}$-bond distances. Tetrahedral intermediates for the addition of hydroxyde to $\mathrm{ZFC}_{3}(\mathrm{~A})$ and ZGlyGlyo- (B).

The stability of the carbamate generated after the $\mathrm{N}^{\alpha}$ protection with $t$-Boc was also assessed by studying peptide derivative $t$ - $\mathrm{BocFC}_{3}(26)$ in the presence of $0.1 \mathrm{M}$ $\mathrm{NaOH}$ in MeOD. No hydrolysis was observed after $24 \mathrm{~h}$. The lower reactivity of this compound in comparison with $\mathrm{ZFC}_{\mathbf{3}}(\mathbf{1 7})$ is consistent with the well-known resistance of $t$-butyl esters to basic hydrolysis as a consequence of steric hindrance provided by the $t$ butyl unit.

Unfortunately the advantages of this cleavage deprotection methodology cannot be applied for synthetic purposes because of the associated epimerisation. For example when $\mathrm{ZFC}_{3}$ was dissolved in methanol in the presence of $0.1 \mathrm{M} \mathrm{NaOH}$ quantitative Zremoval yielding $\mathrm{FC}_{3}$ was attained but, unfortunately, complete racemisation was detected for this product. NMR analysis of this reaction indicates that the racemisation process is associated to the H-D chemical exchange between the proton attached to the chiral carbon atom of the amino acid and deuterium of the solvent. Deprotection of the same compound using hydrogen with catalytic Pd over carbon was done in order to 
compare their optical purity. For this traditional methodology optical rotation was determined to be $[\alpha]_{D}=-86.0^{\circ}$ while this value was near $0^{\circ}$ for the product obtained under basic conditions.

Although this is not a synthetically useful methodology, the present study provides new and unreported incompatibilities for this widely used protecting group that should be considered to avoid unexpected deprotection of the $Z$ group. It is also important to highlight the importance of the anchimeric assistance by $\mathrm{H}$-bonding which affords the stabilization of the tetrahedral intermediate associated to carbamate hydrolysis. Anchimeric assistance and neighbouring group effects constitute one of the fundamental interactions in organic chemistry that can influence important factors like the reaction rate or the stereoselectivity among others. The present study increases the number of recently reported examples in which this effect plays an essential role in many different areas including synthesis of natural products, ${ }^{19}$ synthesis of saccharides, ${ }^{20}$ reactive intermediates ${ }^{21}$ or nucleotide chemistry. ${ }^{22}$

Oxyanion hole
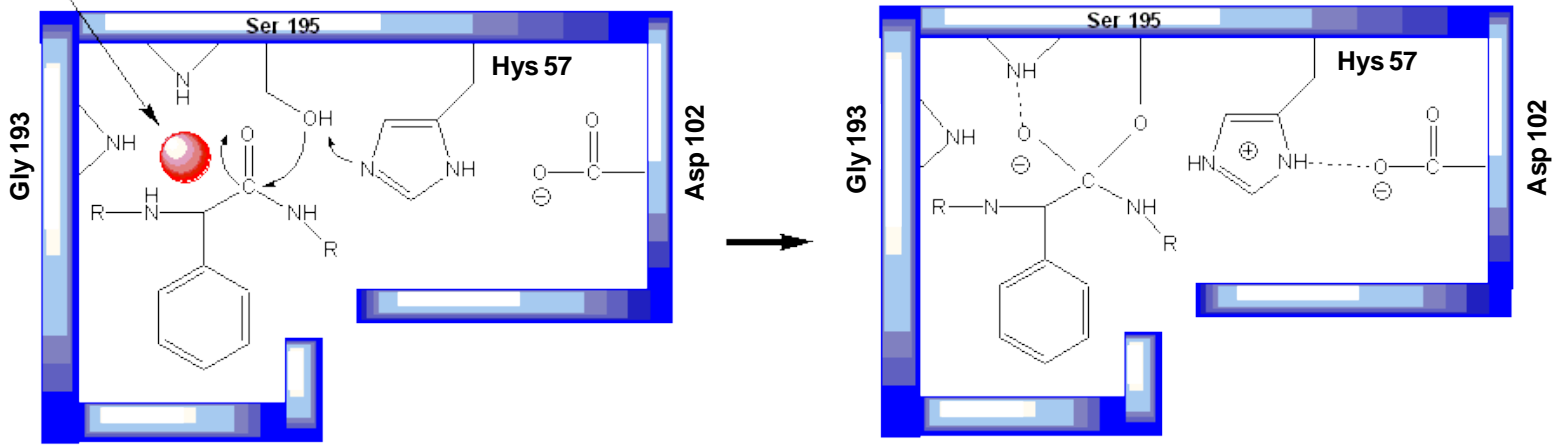

Figure 3.24 Schematic representation of the chymotrypsin oxyanion hole (Adapted from UCDavis BioWiki).

Particularly the anchimeric assistance described in our case resemble that observed in enzymatic catalysis, in particular, to the so called oxyanion holes where oxyanionic intermediates or transition states are stabilised through hydrogen bonding ${ }^{23}$ (Figure 3.24). A subtle interplay among different $\mathrm{H}$-bonds is key for the observed reactivity: intramolecular $\mathrm{H}$-bond between carboxylate terminal group and the adjacent amide explains the hydrolytic stability of Z-dipeptides but switching to larger Z-peptides results in the emergence of an intramolecular catalytic mechanism responsible for the observed hydrolysis. 


\subsection{Supplementary information}

S.I. 3.1 General considerations

S.I. 3.2 Synthesis of compounds $\mathbf{1 - 1 2}$ in solution

S.I. 3.3 Peptide purification by HPLC

S.I. 3.4 Characterisation of compounds 1-12

S.I. 3.5 Synthesis of compound 1 by SPPS

S.I. 3.6 Synthesis and characterization of compounds 15-26

S.I. 3.7 Kinetic studies

S.I. 3.8 Racemization studies

\section{S.I. 3.1 General considerations}

NMR spectra were recorded at $500 \mathrm{MHz}, 300 \mathrm{MHz}\left({ }^{1} \mathrm{H}\right.$ NMR) and $125 \mathrm{MHz}, 75$ $\mathrm{MHz}\left({ }^{13} \mathrm{C}\right.$ NMR $)$ in different solvents at $30 \stackrel{\circ}{ } \mathrm{C}$ with the solvent signals as internal reference. Mass spectra were run in the electrospray (ESMS) mode. Optical rotations were measured at $25 \stackrel{\circ}{\circ}$ ina Poartronic-E (Schmidt-Haensch). Reactions which required an inert atmosphere were carried out under dry $\mathrm{N}_{2}$. Commercial reagents were used as received. Solvents were evaporated on a Butchi Rotavap R-200 equipped with a Butchi heating bath B-490. All compounds synthesized were dried in a vacuum oven Pselecta or in a Memmert GmbH oven at $60 \cong$ to constant weight. HPLC purifications were performed in a Agilent instrument eqquiped with a solvent delivery module Varian 210/218, an autosampler Agilent ProStar 410 and a Fraction Collector Varian 440-LC (using degass water and HPLC quality acetonitrile).Compounds were weighted on a Mettler Toledo XA105 Dual Range (presicion > $0.01 \mathrm{mg}$ ) and a KERN PCB (precision > 1 $\mathrm{mg})$.

\section{S.I. 3.2 Synthesis of compounds 1-12 in solution}

General procedure for carboxylic acid activation: The corresponding Z-protected amino acid (70 mmol) and $\mathrm{N}$-hydroxysuccinimide $(8.8 \mathrm{~g}, 77 \mathrm{mmol})$ were dissolved in dry 
THF at $0^{\circ} \mathrm{C}$. Once a clear solution is obtained, dicylcohexylcarbodiimide (DCC) $(17.4 \mathrm{~g}, 85$ mmol) in anhydrous THF was added in several aliquots and the resulting solution was stirred at $0-5^{\circ} \mathrm{C}$ in ice-bath for $1 \mathrm{~h}$, and allowed to warm up to room temperature with vigorous stirring overnight. The dicyclohexylurea (DCU) formed was filtered off and the filtrate was concentrated to dryness. The crude product was recrystallized from 2propanol to furnish the pure product.

General procedure for coupling: The N-hydroxysuccinimide ester $(8.7 \mathrm{mmol})$ of the Z-protected amino acid was dissolved in DME $(50 \mathrm{~mL})$, then the corresponding peptide or amino acid with the C-terminal group as propyl or dodecylamide $(8.7 \mathrm{mmol})$ was dissolved in DME $(15 \mathrm{~mL})$ and added drop wise. The resulting solution was stirred at room temperature for 15 hours and then was warmed for 2 hours at $40-50$ ㅇ. The solvent was evaporated under vacuum. The resulting solid was washed with saturated sodium carbonated solution, $\mathrm{HCl} 0.1 \mathrm{M}$ aqueous solution and water. The final product was dried at $40 \circ \mathrm{C}$ under vacuum.

General procedure for N-benzyloxycarbonyl deprotection: The corresponding Nbenzyloxycarbonyl protected peptide derivative $(7.8 \mathrm{mmol})$ and catalytic amount of $\mathrm{Pd}$ over activated carbon ( $5-10 \% \mathrm{w} / \mathrm{w})$ were placed in a two necked round bottom flask and suspended in $\mathrm{MeOH}(50 \mathrm{~mL})$. The system was purged to remove the air with $\mathrm{N}_{2}$ and connected to $\mathrm{H}_{2}$ atmosphere. The pasty grey suspension was stirred for several hours until it turned completely black (also checked with TLC revealed with ninhydrin). The black suspension was filtered over Celite and the solvent was evaporated under reduced pressure. The resulting oil was dried further in vacuum pump for 12 hours.

General procedure t-butyl ester group deprotection: A solution of t-butyl ester (3.0 mmol) in a mixture of TFA $(12 \mathrm{~mL})$, dichloromethane $(12 \mathrm{~mL})$ and water $(0.9 \mathrm{~mL})$ was stirred for $40 \mathrm{~min}$ at room temperature. Dichloromethane and TFA were evaporated under reduced pressure and the residue was co-distilled three times with diethyl ether. The solid was washed with basic solution, acidic solution or just water depending on the final charge of the molecule. 


\section{S.I. 3.3 Peptide purification by HPLC}

HPLC purification of the tetrapeptides was conducted using a reverse phase C18 column (Agilent Prep-C18 5 mM, $21.2 \times 150 \mathrm{~mm}$ ). A mixture of water (50\%) and acetronitrile (50\%) with $0.5 \%$ TFA at $21 \mathrm{~mL} / \mathrm{min}$ was used to elute the compounds 1-6. Compounds 7 and 8 were eluted in a mixture of water (30\%) and methanol (70\%). The eluent was monitored by UV absorbance at $254 \mathrm{~nm}$. Fractions were collected and lyophilized. Purity was confirmed by NMR spectroscopy.

\begin{tabular}{|c|c|c|c|}
\hline Compound & Peptide Structure & Eluent & Rt (min) \\
\hline $\mathbf{1}$ & ZFDFDC $_{3}$ & Water (50\%):ACN (50\%) & 5.27 \\
\hline $\mathbf{2}$ & ZDFDFC $_{3}$ & Water (50\%):ACN (50\%) & 5.75 \\
\hline $\mathbf{3}$ & ZFFDDC $_{3}$ & Water (50\%):ACN (50\%) & 5.04 \\
\hline $\mathbf{4}$ & ZDDFFC $_{3}$ & Water (50\%):ACN (50\%) & 4.60 \\
\hline $\mathbf{5}$ & ZFDDFC $_{3}$ & Water (50\%):ACN (50\%) & 5.26 \\
\hline $\mathbf{6}$ & ZDFFDC $_{3}$ & Water (50\%):ACN (50\%) & 5.26 \\
\hline $\mathbf{7}$ & ZFKFKC $_{3}$ & Water (50\%): $\mathrm{MeOH} \mathrm{(50 \% )}$ & 9.89 \\
\hline $\mathbf{8}$ & ZKFKFC $_{3}$ & Water (50\%): $\mathrm{MeOH} \mathrm{(50 \% )}$ & 9.83 \\
\hline
\end{tabular}

\section{S.I. 3.3 Characterization of compounds 1-12}

- Compound 1, ZFDFDC 3 : Global yield: $1.1 \mathrm{~g}$ (1.50 mmol, 46\%); white solid. ${ }^{1} \mathrm{H}$ NMR (500 MHz, 30 으, $d_{6}-$ DMSO): $\delta=8.36(d, J=7.5 \mathrm{~Hz}, 1 \mathrm{H}), 8.11(\mathrm{~d}, J=8.0 \mathrm{~Hz}, 1 \mathrm{H}), 7.96$ (d, $J=12.0 \mathrm{~Hz}, 1 \mathrm{H}), 7.40-7.50(\mathrm{~m}, 2 \mathrm{H}), 7.37-7.03(\mathrm{~m}, 15 \mathrm{H}), 4.98-4.83(\mathrm{~m}, 2 \mathrm{H}), 4.61-$ $4.53(\mathrm{~m}, 1 \mathrm{H}), 4.52-4.45(\mathrm{~m}, 1 \mathrm{H}), 4.44-4.37(\mathrm{~m}, 1 \mathrm{H}), 4.30-4.19(\mathrm{~m}, 1 \mathrm{H}), 3.05-2.80$ (m, 5H), $2.77-2.57(\mathrm{~m}, 3 \mathrm{H}), 2.55-2.41(\mathrm{~m}, 2 \mathrm{H}), 1.44-1.33(\mathrm{~m}, 2 \mathrm{H}), 0.80(\mathrm{t}, J=7.4 \mathrm{~Hz}$, 3H) ppm. ${ }^{13} \mathrm{C}$ NMR $\left(126 \mathrm{MHz}, 30 \mathrm{C}, \mathrm{d}_{6}\right.$-DMSO): $\delta=172.3,172.2,172.1,171.2,170.9$, 170.3, 156.2, 138.5, 137.8, 137.4, 129.6, 129.6, 128.7, 128.5, 128.4, 128.1, 127.8, 126.71, 126.6, 65.6, 56.3, 54.8, 50.2, 50.0, 40.9, 37.9, 37.4, 36.6, 36.3, 22.6, 11.6 ppm.(ESI-TOF, positive mode): $\mathrm{m} / \mathrm{z}$ calcd. For $\mathrm{C}_{37} \mathrm{H}_{43} \mathrm{~N}_{5} \mathrm{O}_{10}{ }^{+}[\mathrm{M}+\mathrm{H}]^{+}$718.3088; found, $718.3093[\mathrm{M}+$ $H]^{+},(\Delta=0.7 \mathrm{ppm})$.

- Compound 2, ZDFDFC 3 : Global yield: $1.46 \mathrm{~g}$ (2.03 mmol, 47\%); white solid. ${ }^{1} \mathrm{H}$ $\operatorname{NMR}\left(300 \mathrm{MHz}, 30\right.$ 으, $\left.\mathrm{d}_{6}-\mathrm{DMSO}\right): \delta=8.28(\mathrm{~d}, J=7.2 \mathrm{~Hz}, 1 \mathrm{H}), 7.85$ (dd, $J=8.2 \mathrm{~Hz}, 2 \mathrm{H}$ ), $7.70(\mathrm{t}, J=5.8 \mathrm{~Hz}, 1 \mathrm{H}), 7.51(\mathrm{~d}, J=7.8 \mathrm{~Hz}, 1 \mathrm{H}), 7.42-7.03(\mathrm{~m}, 15 \mathrm{H}), 5.09-4.91(\mathrm{~m}, 2 \mathrm{H})$, $4.58-4.23(\mathrm{~m}, 4 \mathrm{H}), 2.48(\mathrm{~m}, 11 \mathrm{H}), 1.31(\mathrm{~m}, 2 \mathrm{H}), 0.75(\mathrm{t}, J=7.4 \mathrm{~Hz}, 3 \mathrm{H}) \mathrm{ppm} .{ }^{13} \mathrm{C}$ NMR $(75$ 
$\mathrm{MHz}, 30 \stackrel{\circ}{\circ}, \mathrm{d}_{6}$-DMSO): $\delta=172.2,172.1,171.3,171.2,170.5,170.4,156.2,138.0,137.8$, 137.27, 130.5, 129.6, 129.5, 128.7, 128.4, 128.4, 128.2, 128.1, 126.6, 66.0, 54.6, 54.2, 51.8, 50.0, 37.9, 37.8, 36.5, 36.3, 22.5, 11.7 ppm. (ESI-TOF, negative mode): $\mathrm{m} / \mathrm{z}$ calcd. For $\mathrm{C}_{37} \mathrm{H}_{42} \mathrm{~N}_{5} \mathrm{O}_{10^{-}}[\mathrm{M}-\mathrm{H}]^{-}$716.2932; found, $716.2930[\mathrm{M}-\mathrm{H}]^{-},(\Delta=0.3 \mathrm{ppm})$.

- Compound 3, ZFFDDC 3 : Global yield: $0.52 \mathrm{~g} \mathrm{(0.72} \mathrm{mmol,} \mathrm{37 \% );} \mathrm{white} \mathrm{solid}{ }^{1} \mathrm{H}$ $\operatorname{NMR}\left(300 \mathrm{MHz}, 30 \stackrel{\circ}{ } \mathrm{C}, \mathrm{d}_{6}-\mathrm{DMSO}\right): \delta=8.41(\mathrm{~d}, \mathrm{~J}=7.4 \mathrm{~Hz}, 1 \mathrm{H}), 8.08(\mathrm{~d}, \mathrm{~J}=8.0 \mathrm{~Hz}, 1 \mathrm{H}), 8.06$ $(\mathrm{d}, \mathrm{J}=8.5 \mathrm{~Hz}, 1 \mathrm{H}), 7.54(\mathrm{t}, \mathrm{J}=5.7 \mathrm{~Hz}, 1 \mathrm{H}), 7.37(\mathrm{~d}, \mathrm{~J}=8.6 \mathrm{~Hz}, 1 \mathrm{H}), 7.33-7.08(\mathrm{~m}, 15 \mathrm{H})$, $5.00-4.79(\mathrm{~m}, 2 \mathrm{H}), 4.61-4.38(\mathrm{~m}, 3 \mathrm{H}), 4.22(\mathrm{t}, \mathrm{J}=7.9 \mathrm{~Hz}, 1 \mathrm{H}), 3.10-2.52(\mathrm{~m}, 10 \mathrm{H})$, $1.49-1.28(\mathrm{~m}, 2 \mathrm{H}), 0.79(\mathrm{t}, \mathrm{J}=7.4 \mathrm{~Hz}, 3 \mathrm{H}) \mathrm{ppm} .{ }^{13} \mathrm{C}$ NMR $\left(75 \mathrm{MHz}, 30 \stackrel{\circ}{\circ}, \mathrm{d}_{6}-\mathrm{DMSO}\right): \delta=$ $172.4,172.3,171.8,171.6,170.6,170.3,156.1,138.4,137.9,137.4,129.7,129.5,128.71$, $128.4,128.0,127.8,126.6,126.6,65.6,56.4,54.2,50.1,37.9,37.8,36.5,22.6,11.6$ ppm. (ESI-TOF, negative mode): $\mathrm{m} / \mathrm{z}$ calcd. for $\mathrm{C}_{37} \mathrm{H}_{42} \mathrm{~N}_{5} \mathrm{O}_{10^{-}}[\mathrm{M}-\mathrm{H}]^{-}$716.2932; found, 716.2926 $[\mathrm{M}-\mathrm{H}]^{-},(\Delta=0.8 \mathrm{ppm})$.

- Compound 4, ZDDFFC 3 : Global yield: $2.3 \mathrm{~g}$ (3.2 mmol, 46\%); white solid. ${ }^{1} \mathrm{H}$ NMR

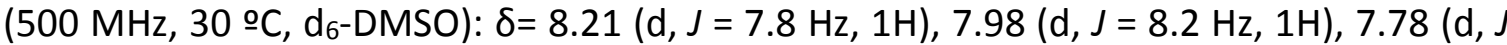
$=7.7 \mathrm{~Hz}, 1 \mathrm{H}), 7.65(\mathrm{t}, J=5.7 \mathrm{~Hz}, 1 \mathrm{H}), 7.56(\mathrm{~d}, J=8.0 \mathrm{~Hz}, 1 \mathrm{H}), 7.39-7.08(\mathrm{~m}, 15 \mathrm{H}), 5.02$ $(\mathrm{q}, J=12.5 \mathrm{~Hz}, 2 \mathrm{H}), 4.50(\mathrm{dd}, J=13.5,7.4 \mathrm{~Hz}, 1 \mathrm{H}), 4.46-4.30(\mathrm{~m}, 3 \mathrm{H}), 3.07-2.86(\mathrm{~m}$, $4 \mathrm{H}), 2.86-2.73(\mathrm{~m}, 2 \mathrm{H}), 2.57-2.65(\mathrm{~m}, 2 \mathrm{H}), 2.53-2.37(\mathrm{~m}, 2 \mathrm{H}), 1.39-1.25(\mathrm{~m}, 2 \mathrm{H})$, $0.76(\mathrm{t}, J=7.4 \mathrm{~Hz}, 3 \mathrm{H}) \mathrm{ppm} .{ }^{13} \mathrm{C}$ NMR $\left(75 \mathrm{MHz}, 30\right.$ ㅇ $\mathrm{C}, \mathrm{d}_{6}$-DMSO): $\delta=172.2,172.2,171.4$, 170.7, 170.7, 170.5, 156.3, 138.1, 137.8, 137.2, 129.5, 129.5, 128.7, 128.5, 128.4, 128.2, $128.1,126.7,126.6,66.0,54.6,51.8,50.0,38.2,37.5,36.7,36.2,22.5,11.7$ ppm. (ESITOF, negative mode): $\mathrm{m} / \mathrm{z}$ calcd. for $\mathrm{C}_{37} \mathrm{H}_{42} \mathrm{~N}_{5} \mathrm{O}_{10^{-}}[\mathrm{M}-\mathrm{H}]^{-}$716.2932; found, 716.2928 [M $\mathrm{H}^{-},(\Delta=0.8 \mathrm{ppm})$.

- Compound 5, ZFDDFC 3 : Global yield: $2.8 \mathrm{~g}$ (3.9 mmol, $46 \%$ ); white solid. ${ }^{1} \mathrm{H}$

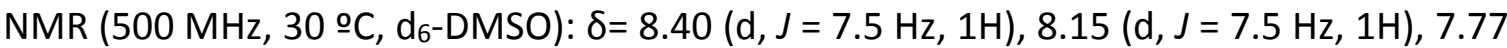
(d, J=8.2 Hz, 1H), $7.62(\mathrm{t}, J=5.5 \mathrm{~Hz}, 1 \mathrm{H}), 7.46(\mathrm{~d}, J=8.5 \mathrm{~Hz}, 1 \mathrm{H}), 7.39-6.96(\mathrm{~m}, 15 \mathrm{H})$, 4.97-4.87 (m, 2H), 4.58-4.54 (m, 1H), 4.50-4.56 (m, 1H), 4.38-4.34 (m, 1H), 4.32- 4.21 $(m, 1 H), 3.08-2.88(m, 4 H), 2.86-2.81(m, 1 H), 2.78-2.39(m, 6 H), 1.43-1.27(m, 2 H)$, $0.76(\mathrm{t}, J=7.4 \mathrm{~Hz}, 3 \mathrm{H}) \mathrm{ppm} .{ }^{13} \mathrm{C}$ NMR $\left(75 \mathrm{MHz}, 30 \stackrel{\circ}{ } \mathrm{C}, \mathrm{d}_{6}\right.$-DMSO): $\delta=172.3,172.2,172.2$, $171.1,170.56,170.3,156.3,138.5,138.1,137.3,129.6,129.5,128.7,128.5,128.4,128.1$, 
127.9, 126.6, 65.7, 56.4, 54.7, 50.2, 50.0, 37.8, 36.4, 36.1, 22.5, 11.7 ppm. (ESI-TOF, negative mode) $\mathrm{m} / \mathrm{z}$ calcd. for $\mathrm{C}_{37} \mathrm{H}_{42} \mathrm{~N}_{5} \mathrm{O}_{10}{ }^{-}[\mathrm{M}-\mathrm{H}]^{-} 716.2932$; found, $716.2924[\mathrm{M}-\mathrm{H}]^{-},(\Delta$ $=1.1 \mathrm{ppm})$.

- Compound 6, ZDFFDC 3 : Global yield: $1.5 \mathrm{~g}$ (2.09 mmol, 40\%); white solid. ${ }^{1} \mathrm{H}$ $\operatorname{NMR}\left(300 \mathrm{MHz}, 30 \stackrel{\circ}{\circ}, \mathrm{d}_{6}-\mathrm{DMSO}\right): \delta=8.16(\mathrm{dd}, J=7.4 \mathrm{~Hz}, 2 \mathrm{H}), 7.78(\mathrm{~d}, J=7.6 \mathrm{~Hz}, 1 \mathrm{H})$, $7.50(\mathrm{~m}, 2 \mathrm{H}), 7.36-7.10(\mathrm{~m}, 15 \mathrm{H}), 5.12-4.87(\mathrm{~m}, 2 \mathrm{H}), 4.62-4.16(\mathrm{~m}, 4 \mathrm{H}), 3.10-2.16$ $(\mathrm{m}, 11 \mathrm{H}), 1.51-1.27(\mathrm{~m}, 2 \mathrm{H}), 0.80(\mathrm{t}, J=7.4 \mathrm{~Hz}, 3 \mathrm{H}) \mathrm{ppm} .{ }^{13} \mathrm{C} \mathrm{NMR}\left(75 \mathrm{MHz}, 30 \stackrel{\circ}{ } \mathrm{e}_{6^{-}}\right.$ DMSO): $\delta=172.1,172.1,171.1,171.1,171.0,170.2,156.2,137.9,137.8,137.2,129.6$, 129.6, 128.7, 128.52, 128.3, 128.2, 128.0, 126.7, 126.6, 65.9, 54.5, 54.1, 51.7, 50.1, 40.9, 37.79, 36.6, 36.5, 22.6, 11.6 ppm. (ESI-TOF, negative mode): $\mathrm{m} / \mathrm{z}$ calcd. for $\mathrm{C}_{37} \mathrm{H}_{42} \mathrm{~N}_{5} \mathrm{O}_{10}{ }^{-}$ $[\mathrm{M}-\mathrm{H}]^{-}$716.2932; found, $716.2926[\mathrm{M}-\mathrm{H}]^{-},(\Delta=0.8 \mathrm{ppm})$.

- Compound 7, ZFKFKC 3 :Global yield: $0.96 \mathrm{~g} \mathrm{(0.99} \mathrm{mmol,} \mathrm{40 \% );} \mathrm{white} \mathrm{solid} \mathrm{(TFA}$ salt). ${ }^{1} \mathrm{H}$ NMR (300 MHz, $30 \stackrel{\circ}{\circ}, \mathrm{d}_{6}$-DMSO): $\delta=8.14(\mathrm{~d}, J=8.0 \mathrm{~Hz}, 1 \mathrm{H}), 8.03(\mathrm{~d}, J=8.0 \mathrm{~Hz}$, $1 \mathrm{H}), 7.95(\mathrm{~d}, J=7.9 \mathrm{~Hz}, 1 \mathrm{H}), 7.82(\mathrm{~s}, 6 \mathrm{H}), 7.76(\mathrm{t}, J=5.8 \mathrm{~Hz}, 1 \mathrm{H}), 7.45(\mathrm{~d}, J=8.5 \mathrm{~Hz}, 1 \mathrm{H})$, $7.41-7.10(\mathrm{~m}, 15 \mathrm{H}), 5.00-4.83(\mathrm{~s} 2 \mathrm{H}), 4.54(\mathrm{~m}, 1 \mathrm{H}), 4.32-4.09(\mathrm{~m}, 3 \mathrm{H}), 3.13-2.62(\mathrm{~m}$, $10 \mathrm{H}), 1.72-1.09(\mathrm{~m}, 14 \mathrm{H}), 0.81(\mathrm{t}, J=7.4 \mathrm{~Hz}, 3 \mathrm{H}) \mathrm{ppm} .{ }^{13} \mathrm{C} \mathrm{NMR}\left(75 \mathrm{MHz}, 30 \stackrel{\circ}{ } \mathrm{C} \mathrm{d}_{6}\right.$ DMSO): $\delta=172.0,171.7,171.4,171.0,158.2$, 156.3, 138.5, 137.9, 137.4, 129.6, 128.7, 128.4, 128.1, 127.9, 126.7, 65.7, 56.5, 54.1, 53.0, 52.9, 40.7, 37.8, 37.8, 32.1, 31.8, 27.1, 22.7, 22.6, $11.7 \mathrm{ppm}$. (ESI-TOF, positive mode): $\mathrm{m} / \mathrm{z}$ calcd. for $\mathrm{C}_{41} \mathrm{H}_{58} \mathrm{~N}_{7} \mathrm{O}_{6}{ }^{+}[\mathrm{M}+\mathrm{H}]^{+}$ 744.4449; found, $744.4452[\mathrm{M}+\mathrm{H}]^{+},(\Delta=0.4 \mathrm{ppm})$.

- Compound 8, ZKFKFC 3 : Global yield: $1.0 \mathrm{~g}$ (1.03 mmol, 30\%); white solid (TFA salt). ${ }^{1} \mathrm{H}$ NMR (500 MHz, 30 으, $\mathrm{d}_{6}$-DMSO): $\delta=8.14(\mathrm{~d}, J=7.6 \mathrm{~Hz}, 1 \mathrm{H}), 7.92(\mathrm{~m}, 2 \mathrm{H}), 7.84$ (d, $J=7.5 \mathrm{~Hz}, 1 \mathrm{H}), 7.68(\mathrm{~s}, 6 \mathrm{H}), 7.45-7.09(\mathrm{~m}, 16 \mathrm{H}), 5.00(\mathrm{~s}, 2 \mathrm{H}), 4.57(\mathrm{~m}, 1 \mathrm{H}), 4.49$ (dd, $J$ $=14.3,8.0 \mathrm{~Hz}, 1 \mathrm{H}), 4.22(\mathrm{dd}, J=13.7,7.9 \mathrm{~Hz}, 1 \mathrm{H}), 3.90(\mathrm{~d}, J=5.3 \mathrm{~Hz}, 1 \mathrm{H}), 3.09-2.68(\mathrm{~m}$, $10 \mathrm{H}), 1.67-1.15(\mathrm{~m}, 14 \mathrm{H}), 0.78(\mathrm{t}, J=7.4 \mathrm{~Hz}, 3 \mathrm{H}) \mathrm{ppm} .{ }^{13} \mathrm{C} N M R\left(126 \mathrm{MHz}, 30 \stackrel{\circ}{ } \mathrm{C} \mathrm{d}_{6}-\right.$ DMSO) $\delta 172.2,171.5,171.4,170.9,158.2,156.4,138.1,138.0,137.4,129.7,129.6$, $128.8,128.5,128.4,128.3,128.2$, 126.7, 126.7, 66.0, 55.3, 54.4, 53.9, 53.1, 40.8, 39.2, 39.1, 38.3, 37.8, 31.8, 27.1, 27.1, 22.8, 22.6, 22.6, 11.8 ppm. (ESI-TOF, positive mode): $\mathrm{m} / \mathrm{z}$ calcd. for $\mathrm{C}_{41} \mathrm{H}_{58} \mathrm{~N}_{7} \mathrm{O}_{6}{ }^{+}[\mathrm{M}+\mathrm{H}]^{+}$744.4449; found, $744.4453[\mathrm{M}+\mathrm{H}]^{+},(\Delta=0.5 \mathrm{ppm})$. 
- Compound 9, PFEC 3 : Global yield: $1.5 \mathrm{~g}$ (3.4 mmol, 58\%); white solid (TFA salt). ${ }^{1} \mathrm{H}$ NMR (300 MHz, 30 으, $\mathrm{d}_{6}$-DMSO): $\delta=8.71(\mathrm{~d}, J=8.2 \mathrm{~Hz}, 1 \mathrm{H}), 8.19$ (d, $J=7.9 \mathrm{~Hz}, 1 \mathrm{H}$ ), $7.78(\mathrm{t}, J=5.6 \mathrm{~Hz}, 1 \mathrm{H}), 7.35-7.09(\mathrm{~m}, 5 \mathrm{H}), 4.65-4.55(\mathrm{~m}, 1 \mathrm{H}), 4.21(\mathrm{dd}, J=13.5,8.0 \mathrm{~Hz}$, 1H), $4.13-3.93(\mathrm{~m}, 1 \mathrm{H}), 3.23-2.86(\mathrm{~m}, 5 \mathrm{H}), 2.77(\mathrm{dd}, J=14.0,9.8 \mathrm{~Hz}, 1 \mathrm{H}), 2.35-2.05$ $(\mathrm{m}, 3 \mathrm{H}), 2.00-1.58(\mathrm{~m}, 5 \mathrm{H}), 1.40-1.30(\mathrm{~m}, 2 \mathrm{H}), 0.81(\mathrm{t}, J=7.4 \mathrm{~Hz}, 3 \mathrm{H}) \mathrm{ppm} .{ }^{13} \mathrm{C}$ NMR $(75$ $\mathrm{MHz}, 30 \stackrel{\circ}{\circ} \mathrm{C}, \mathrm{d}_{6}$-DMSO): $\delta=173.7,170.7,170.4,167.8,137.2,129.0,128.0,126.3,58.6$, 54.3, 51.9, 45.6, 40.1, 37.0, 29.9, 29.4, 27.5, 23.2, 22.1, 11.1 ppm. (ESI-TOF, positive mode): $\mathrm{m} / \mathrm{z}$ calcd. for $\mathrm{C}_{22} \mathrm{H}_{33} \mathrm{~N}_{4} \mathrm{O}_{5}{ }^{+}[\mathrm{M}+\mathrm{H}]^{+} 433.2451$; found, $433.2451[\mathrm{M}+\mathrm{H}]^{+},(\Delta=0.0$ ppm).

- Compound 10, PFEC 12 : Global yield: $0.93 \mathrm{~g}$ (1.4 mmol, 59\%); white solid (TFA salt). ${ }^{1} \mathrm{H}$ NMR (500 MHz, $\left.30 \stackrel{\circ}{\circ}, \mathrm{d}_{6}-\mathrm{DMSO}\right): \delta=8.72(\mathrm{~d}, J=8.1 \mathrm{~Hz}, 1 \mathrm{H}), 8.22(\mathrm{~d}, J=8.0 \mathrm{~Hz}$, $1 \mathrm{H}), 7.78(\mathrm{t}, J=5.6 \mathrm{~Hz}, 1 \mathrm{H}), 7.35-7.12(\mathrm{~m}, 5 \mathrm{H}), 4.68-4.58(\mathrm{~m}, 1 \mathrm{H}), 4.31-4.16(\mathrm{~m}, 1 \mathrm{H})$, $4.11(\mathrm{dd}, J=8.1,6.1 \mathrm{~Hz}, 1 \mathrm{H}), 3.25-3.12(\mathrm{~m}, 2 \mathrm{H}), 3.08-2.90(\mathrm{~m}, 3 \mathrm{H}), 2.79$ (dd, $J=13.9,9.9$ $H z, 1 H), 2.33-2.23(m, 1 H), 2.23-2.14(m, 2 H), 1.93-1.65(m, 5 H), 1.46-1.31(m, 2 H)$, $1.28-1.14(\mathrm{~m}, 2 \mathrm{H}), 0.85(\mathrm{t}, J=6.9 \mathrm{~Hz}, 3 \mathrm{H}) \mathrm{ppm} .{ }^{13} \mathrm{C}$ NMR $\left(126 \mathrm{MHz}, 30 \stackrel{\circ}{\mathrm{C}}, \mathrm{d}_{6}-\mathrm{DMSO}\right) \delta$ 176.4, 173.0, 173.0, 170.7, 140.1, 131.7, 130.7, 129.0, 61.3, 57.0, 54.6, 48.3, 41.0, 39.8, 33.9, 32.6, 32.1, 31.6, 31.6, 31.6, 31.3, 31.3, 30.3, 28.9, 25.9, 24.7, 16.5ppm.ESI-TOF, positive mode): $\mathrm{m} / \mathrm{z}$ calcd. For $[\mathrm{M}+\mathrm{H}]^{+} \mathrm{C}_{31} \mathrm{H}_{51} \mathrm{~N}_{4} \mathrm{O}_{5}{ }^{+}$559.3860; found, $559.3860[\mathrm{M}+\mathrm{H}]^{+}$, $(\Delta=0.2 \mathrm{ppm})$.

- Compound 11, PEFC 3 : Global yield: $0.90 \mathrm{~g}$ (2.07 mmol, 54\%); White solid (TFA salt). ${ }^{1} \mathrm{H}$ NMR (500 MHz, $\left.30 \stackrel{\circ}{\circ}, \mathrm{d}_{6}-\mathrm{DMSO}\right): \delta=8.61(\mathrm{~d}, J=7.9 \mathrm{~Hz}, 1 \mathrm{H}), 8.09$ (d, $J=8.1 \mathrm{~Hz}$, 1H), $7.94(t, J=5.5 \mathrm{~Hz}, 1 \mathrm{H}), 7.35-7.07(\mathrm{~m}, 5 \mathrm{H}), 4.44$ (dd, $J=14.0,8.4 \mathrm{~Hz}, 1 \mathrm{H}), 4.30$ (dd, $J$ $=13.6,8.0 \mathrm{~Hz}, 1 \mathrm{H}), 4.24-4.09(\mathrm{~m}, 1 \mathrm{H}), 3.26-3.09(\mathrm{~m}, 2 \mathrm{H}), 3.07-2.87(\mathrm{~m}, 3 \mathrm{H}), 2.80-$ $2.70(\mathrm{~m}, 1 \mathrm{H}), 2.30-2.07(\mathrm{~m}, 3 \mathrm{H}), 1.99-1.64(\mathrm{~m}, 5 \mathrm{H}), 1.44-1.30(\mathrm{~m}, 2 \mathrm{H}), 0.78(\mathrm{t}, J=7.4$ $\mathrm{Hz}, 3 \mathrm{H}) \mathrm{ppm} .{ }^{13} \mathrm{C}$ NMR (126 MHz, 30 으, $\mathrm{d}_{6}$-DMSO): $\delta=179.0,175.6,175.3,173.2,142.8$, 134.3, 133.2, 131.4, 64.0, 59.2, 57.4, 50.9, 45.52, 35.22, 34.70, 32.7, 28.6, 27.4, 16.5 ppm. (ESI-TOF, positive mode): $\mathrm{m} / \mathrm{z}$ calcd. for $\mathrm{C}_{22} \mathrm{H}_{33} \mathrm{~N}_{4} \mathrm{O}_{5}{ }^{+}[\mathrm{M}+\mathrm{H}]^{+} 433.2451$; found, $433.2452[\mathrm{M}+\mathrm{H}]^{+},(\Delta=0.2 \mathrm{ppm})$.

- Compound 12, PEFC 12 : Global yield: 1.38 g (2.05 mmol, 56\%); White solid (TFA salt). ${ }^{1} \mathrm{H}$ NMR (500 MHz, $30 \stackrel{\circ}{\circ}, \mathrm{d}_{6}$-DMSO): $\delta=8.62(\mathrm{~d}, J=7.9 \mathrm{~Hz}, 1 \mathrm{H}), 8.08(\mathrm{~d}, J=8.0 \mathrm{~Hz}$, 
1H), $7.92(t, J=5.1 \mathrm{~Hz}, 1 \mathrm{H}), 7.31-7.06(\mathrm{~m}, 5 \mathrm{H}), 4.44(\mathrm{dd}, J=13.9,8.2 \mathrm{~Hz}, 1 \mathrm{H}), 4.30$ (dd, $J$ $=13.5,7.8 \mathrm{~Hz}, 1 \mathrm{H}), 4.25-4.14(\mathrm{~m}, 1 \mathrm{H}), 3.26-3.12(\mathrm{~m}, 2 \mathrm{H}), 3.09-3.00(\mathrm{~m}, 1 \mathrm{H}), 2.99-$ $2.87(\mathrm{~m}, 2 \mathrm{H}), 2.83-2.75(\mathrm{~m}, 1 \mathrm{H}), 2.32-2.10(\mathrm{~m}, 3 \mathrm{H}), 1.93-1.62(\mathrm{~m}, 5 \mathrm{H}), 1.43-1.02(\mathrm{~m}$, $20 \mathrm{H}), 0.84(\mathrm{t}, J=6.6 \mathrm{~Hz}, 3 \mathrm{H}) \mathrm{ppm} .{ }^{13} \mathrm{C}$ NMR (75 MHz, 30 으, $\mathrm{d}_{6}$-DMSO) $\delta 174.2,170.8$, 170.6, 168.5, 138.0, 129.6, 128.4, 126.6, 59.2, 54.4, 52.7, 46.2, 39.0, 38.4, 31.7, 30.5, 29.9, 29.5, 29.4, 29.1, 27.9, 26.7, 23.8, 22.5, 14.4 ppm. (ESI-TOF, positive mode): $\mathrm{m} / \mathrm{z}$ calcd. for $\mathrm{C}_{31} \mathrm{H}_{51} \mathrm{~N}_{4} \mathrm{O}_{5}{ }^{+}[\mathrm{M}+\mathrm{H}]^{+}$559.3860; found, $559.3860[\mathrm{M}+\mathrm{H}]^{+},(\Delta=0.2 \mathrm{ppm})$.

\section{S.I. 3.5 Synthesis of compound 1 by SPPS}

General considerations: Resin support is a copolymer of styrene/1\%-DVB attached to 4-sulfamoylbutyryl moiety provided by NovaBiochem. Mechanical stirring was used for reactions in $\mathrm{CH}_{2} \mathrm{Cl}_{2}$ and a stream of $\mathrm{N}_{2}$ for the rest of the solvents. Solvents were not distilled for resin washes and were removed from the resin by a filtration cannula for reactions performed in round bottom flasks or by suction when a cintered funnel provided with a filter was used. Individual resin washes endured 4-5 min. Synthetic procedures previously reported in the literature were used. ${ }^{9}$

Attachment of the first amino acid (Loading): In a typical experiment to a $25 \mathrm{~mL}$ round-bottom flask were added $1 \mathrm{~g}$ of 4-sulfamoylbutyryl-resin $(0.8 \mathrm{mmol} / \mathrm{g})$ and $14 \mathrm{~mL}$ of $\mathrm{CH}_{2} \mathrm{Cl}_{2}$ for the swelling step. After $1 \mathrm{~h}, 1.6 \mathrm{~g}$ (4 mmol) of FmocD(tBu)OH and $1.2 \mathrm{~mL}$ of DIPEA were incorporated and the solution was stirred for $15 \mathrm{~min}$, followed by cooling to 0 oC. Then benzotriazole-1-yl-oxy-trispyrrolidino-phosphonium hexafluorophosphate (PyBOP, $2.1 \mathrm{~g}, 4 \mathrm{mmol}$ ) was added as a solid, and the reaction mixture was stirred for $8 \mathrm{~h}$ at $0 \stackrel{\circ}{ } \mathrm{C}$ and $8 \mathrm{~h}$ at room temperature. Finally the solution was filtered and washed with $\mathrm{CH}_{2} \mathrm{Cl}_{2}$ and $\mathrm{MeOH}(3 \times 3 \mathrm{~mL}$ ). The extent of incorporation was quantified by the $\mathrm{Fmoc}$ release UV assay. ${ }^{11}$ Coupling was repeated when loading was $<70 \%$ (Figure 3.15 , dibenzofulvene adduct $\varepsilon_{301 \mathrm{~nm}}=7800 \mathrm{M}^{-1} \mathrm{~cm}^{-1}$ ).

General procedure for Fmoc deprotection: The resin $(1 \mathrm{~g})$ with the corresponding peptide attached placed in a funnel provided with a filter was swollen with $14 \mathrm{~mL}$ DMF for $1 \mathrm{~h}$. Then $2.8 \mathrm{~mL}$ of piperidine (20\%) was added and the reaction took place during $20 \mathrm{~min}$. The resin was washed with DMF $(3 \times 3 \mathrm{~mL})$ and dried. 
General procedure for coupling: To a separate $50 \mathrm{~mL}$ flask were added $\mathrm{N}^{\alpha}-$ protected amino acid $(6.4 \mathrm{mmol})$, ethyl(hydroxyimino)cyanoacetate $(0.9 \mathrm{mg}, 6.4 \mathrm{mmol})$, DIC (992 $\mu \mathrm{L}, 6.4 \mathrm{mmol})$, and DMF (20 mL). After a 15 min premix period, the solution was added into the cintered funnel were the resin was placed and previously swollen with 5 $\mathrm{mL}$ of DMF. After the slurry was stirred for $2-3 \mathrm{~h}$, the reaction was complete as determined by a Bromophenol Blue test ${ }^{24}$ ( $20 \mu \mathrm{L}$ of $0.04 \mathrm{M}$ of Bromophenol Blue were added into the solution mixture) The resin was washed with DMF $(3 \times 5 \mathrm{~mL}), \mathrm{CH}_{2} \mathrm{Cl}_{2}(3 \times$ $5 \mathrm{~mL})$, and $\mathrm{MeOH}(3 \times 5 \mathrm{~mL})$ and dried.

$\mathbf{N}^{\alpha}$-alkylation using iodoacetonitrile: The resin-bound $\mathrm{N}$-acylsulfonamide $(1 \mathrm{~g}$, $0.8 \mathrm{mmol} / \mathrm{g}$ ) was washed with several portions of NMP. To the swollen resin were added NMP (50 mL), DIPEA (2 mL, $12 \mathrm{mmol})$ and iodoacetonitrile $(4.4 \mathrm{~mL}, 61 \mathrm{mmol})$.The reaction flask was shielded from light. The resin was agitated for $24 \mathrm{~h}$ at room temperature, filtered, washed with NMP $(5 \times 5 \mathrm{~mL}$, ) and DMF $(3 \times 5 \mathrm{~mL})$ and dried.

Displacement with propylamine: The resin was swollen with $10 \mathrm{~mL}$ of THF during $1 \mathrm{~h}$ and then the nucleophile propylamine was added (200 $\mu \mathrm{L}, 2.4 \mathrm{mmol})$. The mixture was stirred for $4 \mathrm{~h}$ and the solution containing the tetrapeptide was filtered off from the resin. That solution was taken up in $\mathrm{CH}_{2} \mathrm{Cl}_{2}(100 \mathrm{~mL})$ and washed with $\mathrm{HCl} 0.1 \mathrm{M}, \mathrm{NaHCO}_{3}$ $0.1 \mathrm{M}$ and brine. The organic layer was dried with anhydrous magnesium sulfate and the solvent was removed under vacuum. The final side chain $t$-Bu ester deprotection and the purification by HPLC chromatography were performed as previously described in solution.

\section{S.I. 3.6 Synthesis and characterization of compounds 15-26}

Compounds 13, 14 and 23 are commercially available.

- Compound 16, ZFC 3 : The N-hydroxysuccinimide ester, ZFOSu, (3.2 g, $8.7 \mathrm{mmol})$ was dissolved in DME (50 mL). 1-aminopropane $(0.79 \mathrm{~mL}, 9.6 \mathrm{mmol})$ dissolved in DME $(15 \mathrm{~mL})$ was added drop wise and the resulting solution was stirred at room temperature for 18 hours and then was warmed for 2 hours at $40-50 \stackrel{\circ}{ }$. The solvent was evaporated under vacuum. The resulting solid was dissolved in dichloromethane $(25 \mathrm{~mL})$ and washed three times with $\mathrm{HCl} 0.1 \mathrm{M}(3 \times 25 \mathrm{~mL})$ and water $(3 \times 25 \mathrm{~mL})$. The organic phase 
was dried with anhydrous magnesium sulfate and the solvent was evaporated under vacuum. A white solid was obtained $(1.7 \mathrm{~g}, 4.99 \mathrm{mmol}, 93 \%) .{ }^{1} \mathrm{H} \mathrm{NMR}(500 \mathrm{MHz}, 30$ 으, $\mathrm{d}_{6}$-DMSO): $\delta=7.92(\mathrm{t}, \mathrm{J}=5.5 \mathrm{~Hz}, 1 \mathrm{H}), 7.45(\mathrm{~d}, \mathrm{~J}=15.6 \mathrm{~Hz}, 1 \mathrm{H}), 7.38-7.10(\mathrm{~m}, 10 \mathrm{H}), 4.99$ $-4.89(\mathrm{~s}, 2 \mathrm{H}), 4.21(\mathrm{~m}, 1 \mathrm{H}), 3.10-2.86(\mathrm{~m}, 3 \mathrm{H}), 2.77(\mathrm{dd}, J=13.6,10.1 \mathrm{~Hz}, 1 \mathrm{H}), 1.45-$ $1.30(\mathrm{~m}, 2 \mathrm{H}), 0.80(\mathrm{t}, J=7.4 \mathrm{~Hz}, 3 \mathrm{H}) \mathrm{ppm} .{ }^{13} \mathrm{C} \mathrm{NMR}\left(126 \mathrm{MHz}, 30 \stackrel{\circ}{\circ}, \mathrm{d}_{6}-\mathrm{DMSO}\right): \delta=$ 171.6, 156.2, 138.5, 137.5, 129.6, 128.7, 128.5, 128.1, 127.9, 126.7, 65.6, 56.7, 40.8, 38.3, 22.7, $11.8 \mathrm{ppm}$. (ESI-TOF, positive mode): $\mathrm{m} / \mathrm{z}$ calcd. for $\mathrm{C}_{20} \mathrm{H}_{25} \mathrm{~N}_{2} \mathrm{O}_{3}{ }^{+}[\mathrm{M}+\mathrm{H}]^{+}$ 341.1865; found, $341.1860[\mathrm{M}+\mathrm{H}]^{+},(\Delta=1.5 \mathrm{ppm})$.

- Compound 17, $\mathrm{ZVC}_{3}$ : A similar procedure to that described for $\mathrm{ZFC}_{\mathbf{3}}$ was used starting with ZVOSu (3.48 g, $10 \mathrm{mmol})$ and 1-aminopropane $(0.90 \mathrm{~mL}, 11 \mathrm{mmol})$. A white solid was obtained (2.23 g, $7.62 \mathrm{mmol}, 85 \%$ ). Compound $\mathbf{Z V C}_{3}$ was previously described in literature and both ${ }^{1} \mathrm{H}$ and ${ }^{13} \mathrm{C}$ NMR spectra were in good agreement with the literature spectra. ${ }^{25}$

- Compound 18, ZSarC 3 : A similar procedure to that described for $\mathrm{ZFC}_{3}$ was used starting with ZSarOSu (577 mg, $1.8 \mathrm{mmol}$ ) and 1-aminopropane (0.90 mL, $1.9 \mathrm{mmol})$. A white solid was obtained (0.36 g, $1.4 \mathrm{mmol}, 76 \%) .{ }^{1} \mathrm{H}$ NMR (500 MHz, $30 \stackrel{\circ}{\circ}, \mathrm{d}_{6}$-DMSO) $\delta$ $7.86(\mathrm{~s}, 1 \mathrm{H}), 7.43-7.24(\mathrm{~m}, 5 \mathrm{H}), 5.05$ (ds, 2H), 3.82 (ds, 2H), $3.01(\mathrm{~m}, 2 \mathrm{H}), 2.87$ (ds, 3H), $1.39(\mathrm{~m}, 2 \mathrm{H}), 0.92-0.72(\mathrm{dt}, J=7.4 \mathrm{~Hz}, 3 \mathrm{H}) \mathrm{ppm} .{ }^{13} \mathrm{C}$ NMR $\left(75 \mathrm{MHz}, 30 \stackrel{\circ}{ }, \mathrm{d}_{6}\right.$-DMSO) $\delta$ 168.9, 168.4, 156.4, 156.1, 137.4, 128.8, 128.7, 128.2, 128.4, 127.9, 127.5, 66.7, 66.5, 51.9, 51.6, 40.7, 36.4, 35.6, 22.8, 11.8 ppm. HRMS (ESI-TOF, positive mode) m/z exp [M + $\mathrm{H}]^{+}$calcd for $\mathrm{C}_{14} \mathrm{H}_{21} \mathrm{~N}_{2} \mathrm{O}_{3}{ }^{+} 265.1548$; found, $265.1552[\mathrm{M}+\mathrm{H}]^{+},(\Delta=1.5 \mathrm{ppm})$.

- Compound 15, ZDC 3 : The coupling between the N-hydroxysuccinimidyl ester, $\mathrm{ZD}(\mathrm{tBu}) \mathrm{OSu}(1.35 \mathrm{~g}, 3.2 \mathrm{mmol})$, and the corresponding amine $(3.5 \mathrm{mmol})$ was carried out in a similar way described above for $\mathbf{Z F C}_{3}$. Afterwards, an extra deprotection step was needed. A solution of t-butyl ester $\mathrm{ZD}(\mathrm{tBu}) \mathrm{C}_{3}(1.09 \mathrm{~g}, 3.0 \mathrm{mmol})$ in a mixture of TFA $(12 \mathrm{~mL})$ (trifluroacetic), dichloromethane $(12 \mathrm{~mL})$ and water $(0.9 \mathrm{~mL})$ was stirred for 40 min at room temperature. Dichloromethane and TFA were evaporated under reduced pressure and the residue was co-distilled three times with diethyl ether. The obtained product was dissolved in $20 \mathrm{~mL}$ of dichloromethane and washed with $\mathrm{HCl} 0.1 \mathrm{M}(3 \times 25$ $\mathrm{ml})$ and water $(3 \times 25 \mathrm{ml})$. The organic phase was dried with anhydrous magnesium 
sulfate and the solvent was evaporated under vacuum. A white solid was obtained $(0.83$ g, $2.69 \mathrm{mmol}$, Global Yield = 85 \%). ${ }^{1} \mathrm{H}$ NMR $\left(500 \mathrm{MHz}, 30 \stackrel{\circ}{ } \mathrm{C}, \mathrm{d}_{6}-\mathrm{DMSO}\right): \delta=7.81$ (t, J = $5.1 \mathrm{~Hz}, 1 \mathrm{H}), 7.46(\mathrm{~d}, \mathrm{~J}=8.2 \mathrm{~Hz}, 1 \mathrm{H}), 7.41-7.22(\mathrm{~m}, 5 \mathrm{H}), 5.10-4.97(\mathrm{~m}, 2 \mathrm{H}), 4.37-4.26$ $(\mathrm{m}, 1 \mathrm{H}), 3.08-2.90(\mathrm{~m}, 2 \mathrm{H}), 2.71-2.56(\mathrm{~m}, 1 \mathrm{H}), 2.56-2.42(\mathrm{~m}, 1 \mathrm{H}), 1.44-1.33(\mathrm{~m}, 2 \mathrm{H})$, $0.81(\mathrm{t}, \mathrm{J}=7.4 \mathrm{~Hz}, 3 \mathrm{H}) \mathrm{ppm} .{ }^{13} \mathrm{C}$ NMR (126 MHz, 30 으, $\left.\mathrm{d}_{6}-\mathrm{DMSO}\right): \delta=172.2,170.9$, 156.2, 137.4, 128.8, 128.2, 128.1, 65.9, 52.0, 40.9, 37.0, 22.7, 11.7 ppm. (ESI-TOF, negative mode): $\mathrm{m} / \mathrm{z}$ calcd. for $\mathrm{C}_{15} \mathrm{H}_{19} \mathrm{~N}_{2} \mathrm{O}_{5}{ }^{-}[\mathrm{M}-\mathrm{H}]^{-}$307.1294; found, 307.1295 [M -H] ${ }^{-},(\Delta$ $=0.3 \mathrm{ppm})$.

- Compound 19, $\mathrm{ZD}\left(\mathrm{CH}_{3}\right) \mathrm{C}_{3}$ : A similar procedure to that described for $\mathrm{ZDC}_{3}$ was used. In this case the coupling was between ZD(tBu)OSu $(1.35 \mathrm{~g}, 3.2 \mathrm{mmol})$ and $\mathrm{N}$ methylpropan-1-amine $(0.36 \mathrm{~mL}, 3.5 \mathrm{mmol})$. The deprotection with TFA and $\mathrm{CH}_{2} \mathrm{Cl}_{2}$ produced a transparent oil $(0.73 \mathrm{~g}, 2.26 \mathrm{mmol}$, Global Yield $=71 \%) .{ }^{1} \mathrm{H} \mathrm{NMR}(300 \mathrm{MHz}$, 30 ㅇ $\mathrm{C}, \mathrm{d}_{6}$-DMSO): $\delta=7.69$ (dd, J = 11.9, $\left.9.1 \mathrm{~Hz}, 1 \mathrm{H}\right), 7.43-7.17(\mathrm{~m}, 5 \mathrm{H}), 5.03(\mathrm{~s}, 2 \mathrm{H}), 4.72$ $(\mathrm{m}, 1 \mathrm{H}), 3.27(\mathrm{~m}, 2 \mathrm{H}), 3.00-2.77(\mathrm{ds}, 3 \mathrm{H}), 2.76-2.20(\mathrm{~m}, 2 \mathrm{H}), 1.47(\mathrm{dt}, J=29.1,14.1,7.1$ $\mathrm{Hz}, 13 \mathrm{H}), 0.78$ (dt, J $7.4 \mathrm{~Hz}, 3 \mathrm{H}$ ) ppm. ${ }^{13} \mathrm{C}$ NMR (75 MHz, 30 으, $\mathrm{d}_{6}$-DMSO) $\delta$ 172.2, 170.5, 170.2, 156.0, 156.0, 137.4, 137.3, 128.8, 128.2, 128.1, 128.1, 66.0, 66.0, 55.3, 50.7, 49.3, 49.0, 48.0, 37.3, 36.9, 35.0, 33.7, 21.5, 20.2, 11.4, 11.3 ppm. (ESI-TOF, negative mode): $\mathrm{m} / \mathrm{z}$ calcd. for $\mathrm{C}_{16} \mathrm{H}_{21} \mathrm{~N}_{2} \mathrm{O}_{5}^{-}[\mathrm{M}-\mathrm{H}]^{-} 321.1450$; found, $321.1451[\mathrm{M}-\mathrm{H}]^{-},(\Delta=0.3 \mathrm{ppm})$.

- Compound 20, $\mathrm{ZF}\left(\mathrm{CH}_{3}\right) \mathrm{C}_{3}$ : This compound was obtained by following the same synthesis described for the compound $\mathrm{ZFC}_{\mathbf{3}}$. The starting materials in this case were ZFOsu (369 mg, $1 \mathrm{mmol}$ ) and N-methylpropan-1-amine $(0.11 \mathrm{~mL}, 1.1 \mathrm{mmol})$. A transparent oil was obtained $(0.27 \mathrm{~g}, 0.76 \mathrm{mmol}, 76 \%) .{ }^{1} \mathrm{H} \mathrm{NMR}\left(300 \mathrm{MHz}, 30 \stackrel{\circ}{ } \mathrm{C} \mathrm{d}_{6^{-}}\right.$ DMSO): $\delta=7.63(\mathrm{dd}, J=8.3 \mathrm{~Hz}, 1 \mathrm{H}), 7.40-7.05(\mathrm{~m}, 10 \mathrm{H}), 5.05-4.78(\mathrm{~m}, 2 \mathrm{H}), 4.59(\mathrm{~m}$, $1 \mathrm{H}), 3.10-3.30(\mathrm{~m}, 4 \mathrm{H}), 2.95-2.62(\mathrm{~m}, 5 \mathrm{H}), 1.61-1.22(\mathrm{~m}, 2 \mathrm{H}), 0.74(\mathrm{dt}, J=7.6 \mathrm{~Hz}, 3 \mathrm{H})$ ppm. ${ }^{13} \mathrm{C}$ NMR (75 MHz, 30 으, $\mathrm{d}_{6}$-DMSO): $\delta=171.3,156.1,138.2,138.0,137.48,129.7$, 129.7, 128.7, 128.7, 128.5, 128.1, 127.9, 126.8, 65.7, 52.7, 52.6, 50.8, 49.3, 38.2, 37.7, 35.1, 33.8, 21.6, 20.2, 11.5, $11.3 \mathrm{ppm}$. (ESI-TOF, positive mode): $\mathrm{m} / \mathrm{z}$ calcd. for $\mathrm{C}_{21} \mathrm{H}_{27} \mathrm{~N}_{2} \mathrm{O}_{3}{ }^{+}[\mathrm{M}+\mathrm{H}]^{+}$355.2022; found, $355.2022[\mathrm{M}+\mathrm{H}]^{+},(\Delta=0.0 \mathrm{ppm})$.

- Compound 21, ZFFOH: In a first step the corresponding dipeptide methyl ester was obtained following a described procedure. ${ }^{26}$ L-Phenylalanine methyl ester 
hydrochloride (518 mg, $2.4 \mathrm{mmol}$ ) was dissolved in $30 \mathrm{~mL}$ of DME (dimethoxyethane). Then triethylamine were added $(0.36 \mathrm{~mL}, 2.6 \mathrm{mmol})$ and immediately a white precipitate appeared. A solution of ZFOSu (887 mg, $2.4 \mathrm{mmol})$ in DME (30 mL) was added drop wise and the reaction mixture was stirred at room temperature 2 hours, filtered and evaporated. The residue was dissolved in dichloromethane $(25 \mathrm{~mL})$ and washed four times with water $(25 \mathrm{~mL})$. The organic phase was dried with anhydrous magnesium sulfate and the solvent evaporated under vacuum.

Then, following a reported procedure ${ }^{27}$ the corresponding methyl ester ( $875 \mathrm{mg}$, $1.9 \mathrm{mmol})$ was dissolved in THF $(20 \mathrm{~mL})$ and cooled at $0 \stackrel{\circ}{\circ}$. A solution of lithium hydroxide $(62.4 \mathrm{mg}, 2.6 \mathrm{mmol})$ in water $(10 \mathrm{~mL})$ was added drop wise. The reaction mixture was stirred for 0.5 hour. Then this mixture was washed with diethyl ether (20 $\mathrm{mL}$ ). The aqueous layer was acidified with with $1 \mathrm{M} \mathrm{HCl}$ to adjust to $\mathrm{pH} 2$ and extracted with diethyl ether $(3 \times 30 \mathrm{~mL})$. The organic extracts were combined, dried with anhydrous magnesium sulfate and evaporated. A white solid was obtained (0.92 g, 2.06 mmol, global yield $82 \%) .{ }^{1} \mathrm{H}$ NMR (300 MHz, 30 ㅇ, $\mathrm{d}_{6}$-DMSO): $\delta=8.23$ (d, $J=7.8 \mathrm{~Hz}$, $1 \mathrm{H}), 7.42(\mathrm{~d}, J=8.8 \mathrm{~Hz}, 1 \mathrm{H}), 7.36-6.94(\mathrm{~m}, 15 \mathrm{H}), 5.03-4.81(\mathrm{~s}, 2 \mathrm{H}), 4.57-4.38(\mathrm{~m}, 1 \mathrm{H})$, $4.29(\mathrm{~m}, 1 \mathrm{H}), 3.43(\mathrm{dd}, J=41.4,34.4 \mathrm{~Hz}, 2 \mathrm{H}), 3.15-2.81(\mathrm{~m}, 3 \mathrm{H}), 2.70(\mathrm{dd}, J=13.7,10.9$ $\mathrm{Hz}, 1 \mathrm{H}) \mathrm{ppm} .{ }^{13} \mathrm{C}$ NMR $\left(75 \mathrm{MHz}, 30\right.$ o $\mathrm{C}, \mathrm{d}_{6}$-DMSO): $\delta=173.2,172.0,156.2,138.5,137.8$, 137.4, 129.6, 128.7, 128.6, 128.4, 128.1, 127.8, 127.2, 126.9, 126.7, 65.6, 56.4, 53.9, 37.9, $37.2 \mathrm{ppm}$. (ESI-TOF, positive mode) $\mathrm{m} / \mathrm{z}$ calcd. for $\mathrm{C}_{26} \mathrm{H}_{26} \mathrm{~N}_{2} \mathrm{NaO}_{5}{ }^{+}[\mathrm{M}+\mathrm{Na}]^{+}$ 469.1739; found, $369.1737[\mathrm{M}+\mathrm{Na}]^{+},(\Delta=0.4 \mathrm{ppm})$.

- Compound 22, ZD(tBu)FOH: A similar procedure to that described for ZFFOH was used. The starting materials in this case were L-Phenylalanine methyl ester hydrochloride $(518 \mathrm{mg}, 2.4 \mathrm{mmol})$, triethylamine $(0.36 \mathrm{~mL}, 2.6 \mathrm{mmol}$ ) and ZD(tBu)OSu $(1.00 \mathrm{~g}, 2.4 \mathrm{mmol})$. A white solid was obtained (0.89 g, $1.89 \mathrm{mmol}$, global yield $75 \%$ ). ${ }^{1} \mathrm{H}$ NMR (300 MHz, 30 으, $d_{6}-$ DMSO): $\delta=7.98$ (d, $\left.J=7.4 \mathrm{~Hz}, 1 \mathrm{H}\right), 7.51(\mathrm{~d}, J=8.4 \mathrm{~Hz}, 1 \mathrm{H}), 7.42$ - $7.12(\mathrm{~m}, 10 \mathrm{H}), 5.12-4.91(\mathrm{~m}, 2 \mathrm{H}), 4.49-4.25(\mathrm{~m}, 2 \mathrm{H}), 3.07-2.85(\mathrm{~m}, 2 \mathrm{H}), 2.71-2.30$ $(\mathrm{m}, 2 \mathrm{H}), 1.36(\mathrm{~s}, 9 \mathrm{H}) \mathrm{ppm} .{ }^{13} \mathrm{C}$ NMR $\left(75 \mathrm{MHz}, 30 \stackrel{\circ}{ } \mathrm{C}, \mathrm{d}_{6}-\mathrm{DMSO}\right): \delta=173.0,171.3,171.0$, 169.6, 156.1, 137.7, 137.3, 129.6, 128.8, 128.6, 128.2, 128.1, 126.9, 80.6, 65.9, 53.9, 51.8, 38.0, 37.0, 28.1 ppm. (ESI-TOF, positive mode): $\mathrm{m} / \mathrm{z}$ calcd. for $\mathrm{C}_{25} \mathrm{H}_{30} \mathrm{~N}_{2} \mathrm{NaO}_{7}^{+}[\mathrm{M}+$ $\mathrm{Na}]^{+}$493.1951; found, $493.1947[\mathrm{M}+\mathrm{Na}]^{+},(\Delta=0.8 \mathrm{ppm})$. 
- Compound 24, ZGGOH:GGOH (304 mg, $2.3 \mathrm{mmol}$ ) was dissolved in a $4 \mathrm{~N}$ aqueous solution of sodium hydroxide $(0.7 \mathrm{~mL})$. The solution was cooled at $0 \stackrel{\circ}{ } \mathrm{C}$ and a 4 $\mathrm{N}$ aqueous solution of sodium hydroxide $(1.4 \mathrm{~mL})$ and benzyloxycarbonylchloride $(0.40$ $\mathrm{mL}, 2.8 \mathrm{mmol}$ ) were added drop wise. Then the mixture was stirred overnight at 20 ㅇ. . The reaction mixture was washed with diethyl ether and the aqueous layer was cooled at $0 \stackrel{\circ}{ } \mathrm{C}$. To the aqueous layer was added $5 \mathrm{M} \mathrm{HCl}$ to adjust its $\mathrm{pH}$ to 3 which was left standing overnight at a cool place. Resulting crystalline precipitates were collected by filtration, washed with cool water and dried. White crystals were obtained $(0.43 \mathrm{~g}, 1.61$ mmol, yield $70 \%$ ). ${ }^{1} \mathrm{H}$ NMR (500 MHz, $30 \stackrel{\circ}{\circ}$, $\mathrm{d}_{6}$-DMSO): $\delta=8.12(\mathrm{t}, J=5.5 \mathrm{~Hz}, 1 \mathrm{H}), 7.51-$ $7.42(\mathrm{t}, J=6.2 \mathrm{~Hz} 1 \mathrm{H}), 7.41-7.25(\mathrm{~m}, 5 \mathrm{H}), 5.04(\mathrm{~s}, 2 \mathrm{H}), 3.76(\mathrm{t}, J=6.2 \mathrm{~Hz}, 2 \mathrm{H}), 3.68(\mathrm{~d}, J$ $=6.4 \mathrm{~Hz}, 2 \mathrm{H}) \mathrm{ppm} .{ }^{13} \mathrm{C}$ NMR $\left(126 \mathrm{MHz}, 30 \mathrm{C}, \mathrm{d}_{6}\right.$-DMSO): $\delta=171.1,169.5,156.5,137.0$, 128.4, 127.8, 127.7, 65.5, 43.4, $40.6 \mathrm{ppm}$. (ESI-TOF, negative mode): $\mathrm{m} / \mathrm{z}$ calcd. for $\mathrm{C}_{12} \mathrm{H}_{13} \mathrm{~N}_{2} \mathrm{O}_{5}^{-}[\mathrm{M}-\mathrm{H}]^{-}$265.0824; found, $265.0819[\mathrm{M}-\mathrm{H}]^{-},(\Delta=1.9 \mathrm{ppm})$.

- Compound 25, ZGGGOH: A similar procedure to that described for ZGGOH was used. The starting material in this case was GGGOH (435 mg, $2.3 \mathrm{mmol})$. White crystals were obtained (0.72 g, $2.23 \mathrm{mmol}$, yield $97 \%)^{1} \mathrm{H}$ NMR (500 MHz, $30 \stackrel{\circ}{\circ}, \mathrm{d}_{6}$-DMSO): $\delta=$ $8.12(\mathrm{~m}, 2 \mathrm{H}), 7.45(\mathrm{t}, J=5.4 \mathrm{~Hz}, 1 \mathrm{H}), 7.33(\mathrm{~m}, 4 \mathrm{H}), 5.03(\mathrm{~s}, 2 \mathrm{H}), 3.75(\mathrm{dd}, J=5.4 \mathrm{~Hz}, 3 \mathrm{H})$, $3.66(\mathrm{~d}, J=6.0 \mathrm{~Hz}, 2 \mathrm{H}) \mathrm{ppm} .{ }^{13} \mathrm{C}$ NMR $\left(75 \mathrm{MHz}, 30 \stackrel{\circ}{ } \mathrm{C}, \mathrm{d}_{6}\right.$-DMSO): $\delta=171.5,169.8,169.6$, 156.9, 137.4, 128.8, 128.2, 128.2, 66.0, 44.0, 42.2, 41.0 ppm. (ESI-TOF, negative mode): $\mathrm{m} / \mathrm{z}$ calcd for $\mathrm{C}_{14} \mathrm{H}_{16} \mathrm{~N}_{3} \mathrm{O}_{6}{ }^{-}[\mathrm{M}-\mathrm{H}]^{-} 322.1039 ;$ found, $322.1034[\mathrm{M}-\mathrm{H}]^{-},(\Delta=1.6 \mathrm{ppm})$.

\section{S.I. 3.7 Kinetic studies}

All the experiments were carried out at $30 \stackrel{\circ}{\circ}$. [Substrate] $=15 \mathrm{mM},[\mathrm{NaOH}]=0.1$ $\mathrm{M}$. The hydrolysis was followed by ${ }^{1} \mathrm{H}$ NMR $(500 \mathrm{MHz})$ monitoring the disappearance of the benzylic protons of the carbamate moiety. The data obtained by NMR at different times were adjusted to pseudo first order kinetics considering the concentration of hydroxide approximately constant in the studied time interval. Half-life times were calculated from the kinetic constant $\left(t_{1 / 2}=\ln 2 / k\right)$. The new singlet signal appeared upon deprotection was unambiguously assigned to the benzylic protons of benzyl alcohol by comparison with commercial product. DOSY experiments confirmed also that this new 
signal corresponded to species which diffuse much faster that the remaining peptidic moiety.

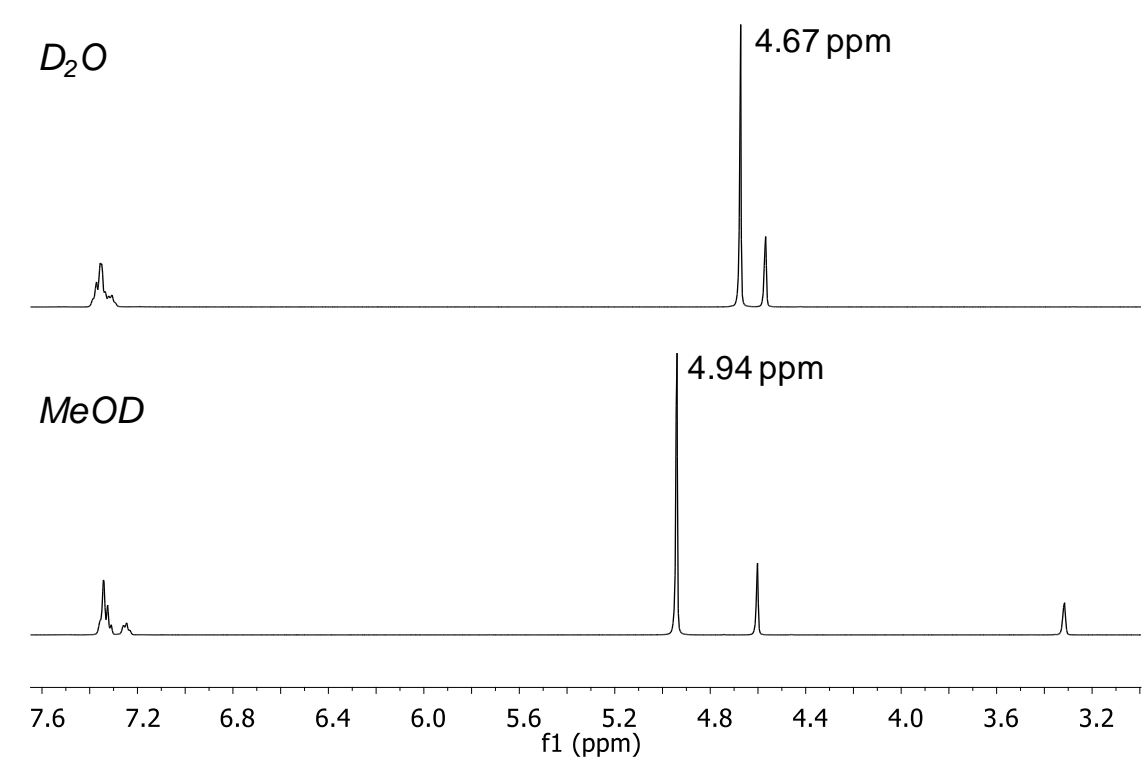

S.I. 3.7.1 ${ }^{1} \mathrm{H}$ NMR for benzyl alcohol in deuterated water and methanol

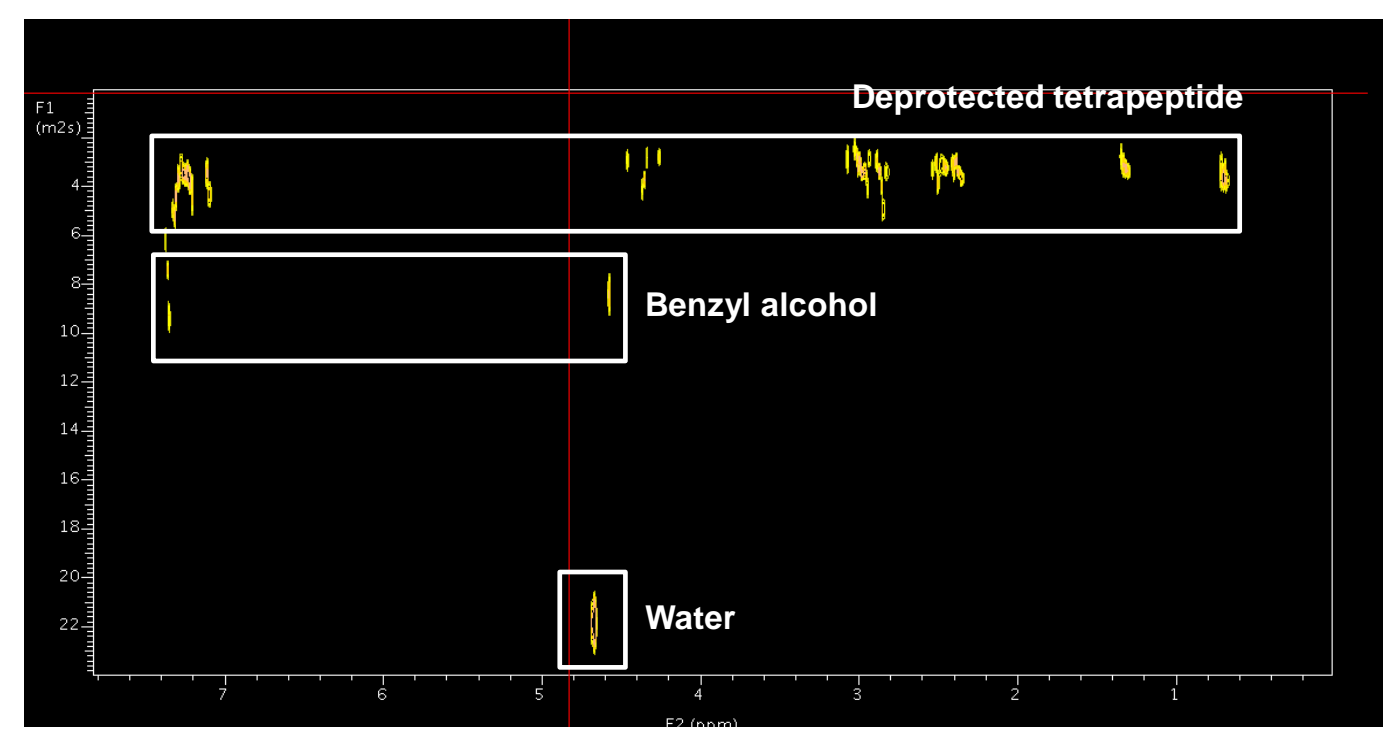

S.I. 3.7.2 DOSY experiment performed in water for compound 2 after deprotection with $\mathrm{NaOH} 0.1 \mathrm{M}$

\section{S.I. 3.8 Racemisation study}

$\mathrm{FC}_{\mathbf{3}}$ was prepared by Z-removal with hydrogenolysis and by treatment with $\mathrm{NaOH}$ in methanol and the optical rotation compared.

FC F $_{3}$ obtained by basic treatment: Compound ZFC $_{\mathbf{3}}(10.2 \mathrm{mg}, 0.03 \mathrm{mmol})$ was dissolved in $\mathrm{CD}_{3} \mathrm{OD} 0.1 \mathrm{M}$ of $\mathrm{NaOH}$. The reaction was monitorized by ${ }^{1} \mathrm{H}$ NMR. When the 
reaction was completed, the solvent was removed under reduced pressure. The crude was dissolved in $\mathrm{CH}_{2} \mathrm{Cl}_{2}(10 \mathrm{~mL})$ and washed with water $(2 \times 10 \mathrm{~mL})$ and brine $(10 \mathrm{~mL})$. The organic layer was dried withanhydrous $\mathrm{MgSO}_{4}$ and the solvent was removed under reduced pressure $\left(6 \mathrm{mg}, 0.029 \mathrm{mmol}, 95 \%,[\alpha]_{D}=0^{\circ}, c 0.1, \mathrm{CHCl}_{3}\right)$.

$\mathrm{FC}_{3}$ obtained by hydrogenolysis: Palladium catalyst ( $10 \% \mathrm{w} / \mathrm{w}, \mathrm{Pd} / \mathrm{C}, 30 \mathrm{mg}$ ) was suspended in $\mathrm{MeOH}(10 \mathrm{~mL})$ and stirred under $\mathrm{H}_{2}$ at room temperature for $10 \mathrm{~min}$. Subsequently, a solution of compound $\mathrm{ZFC}_{3},(300 \mathrm{mg}, 0.88 \mathrm{mmol})$ in $\mathrm{MeOH}(20 \mathrm{~mL})$ was added via syringe, followed by stirring under $\mathrm{H}_{2}$ at room temperature for $4 \mathrm{~h}$. The reaction mixture was then filtered through Celite, and the solvent was removed under reduced pressure $\left(172 \mathrm{mg}, 0.83 \mathrm{mmol}, 95 \%,[\alpha]_{D}=-86^{\circ}, c 0.3, \mathrm{CHCl}_{3}\right)$.

${ }^{1} \mathrm{H}$ NMR $\left(500 \mathrm{MHz}, 30 \stackrel{\circ}{\circ}, \mathrm{d}_{6}-\mathrm{DMSO}\right): \delta=7.71(\mathrm{t}, J=5.0 \mathrm{~Hz}, 2 \mathrm{H}), 7.27-7.21(\mathrm{~m}$, 2H), $7.20-7.14(\mathrm{~m}, 3 \mathrm{H}), 3.33(\mathrm{dd}, J=7.9,5.4 \mathrm{~Hz}, 1 \mathrm{H}), 3.06-2.91(\mathrm{~m}, 2 \mathrm{H}), 2.91-2.80$ $(\mathrm{m}, 2 \mathrm{H}), 2.65-2.52(\mathrm{~m}, 2 \mathrm{H}), 1.42-1.24(\mathrm{~m}, 2 \mathrm{H}), 0.76(\mathrm{t}, J=7.4 \mathrm{~Hz}, 3 \mathrm{H}) \mathrm{ppm} .{ }^{13} \mathrm{C} N M R$ (75 MHz, 30 으, $\mathrm{CDCl}_{3}$ ): $\delta$ 173.3, 137.2, 128.5, 127.8, 125.9, 55.7, 40.3, 40.0, 22.0, 10.6 ppm (ESI-TOF, positive mode) $\mathrm{m} / \mathrm{z}$ calcd for $\mathrm{C}_{12} \mathrm{H}_{19} \mathrm{~N}_{2} \mathrm{O}^{+}[\mathrm{M}+\mathrm{H}]^{+}$207.1497; found, $207.1497[\mathrm{M}+\mathrm{H}]^{+},(\Delta=0.0 \mathrm{ppm})$. 


\subsection{References}

1. Bowerman, C. J.; Nilsson, B. L., Review self-assembly of amphipathic beta-sheet peptides: Insights and applications. Biopolymers 2012, 98, 169-184.

2. a) Doran, T. M.; Kamens, A. J.; Byrnes, N. K.; Nilsson, B. L., Role of amino acid hydrophobicity, aromaticity, and molecular volume on IAPP(20-29) amyloid selfassembly. Proteins 2012, 80, 1053-1065; b) Gazit, E., A possible role for $\pi$-stacking in the self-assembly of amyloid fibrils. FASEB 2002, 16, 77-83.

3. Frisch, H.; Unsleber, J. P.; Lüdeker, D.; Peterlechner, M.; Brunklaus, G.; Waller, M.; Besenius, P., pH-switchable ampholytic supramolecular copolymers. Angew. Chem. Int. Ed. 2013, 52, 10097-10101.

4. a) Berdugo, C.; Miravet, J. F.; Escuder, B., Substrate selective catalytic molecular hydrogels: the role of the hydrophobic effect. Chem. Commun. 2013, 49, 1060810610; b) Rodriguez-Llansola, F.; Miravet, J. F.; Escuder, B., A supramolecular hydrogel as a reusable heterogeneous catalyst for the direct aldol reaction. Chem. Commun. 2009, 7303-7305.

5. a) Jones, J., Amino acid and peptide synthesis. Oxford Chemistry Primers 1992; b) Doonan, S., Peptides and proteins. RSC 2002.

6. Isidro-Llobet, A.; Álvarez, M.; F, A., Amino acid-protecting groups. Chem. Rev. 2009, 109, 2455-2504.

7. Merrifield, R. B., Solid phase peptide synthesis. The synthesis of a tetrapeptide. J. Am. Chem. Soc. 1963, 85, 2149-2154.

8. Merrifield, R. B., Solid phase synthesis (Nobel Lecture). Angew. Chem. Int. Ed. 1985, 24, 799-810.

9. a) Ingenito, R.; Bianchi, E.; Fattori, D.; Pessi, A., Solid phase synthesis of peptide C-terminal thioesters by Fmoc/t-Bu chemistry. J. Am. Chem. Soc. 1999, 121, 11369-11374; b) Backes, B. J.; Ellman, J. A., An alkanesulfonamide "safety-catch" linker for solid-phase synthesis. J. Org. Chem. 1999, 64, 2322-2330; c) Heidler, P.; Link, A., N-Acyl-N-alkyl-sulfonamide anchors derived from Kenner's safety-catch linker: powerful tools in bioorganic and medicinal chemistry. Bioorg. Med. Chem. 2005, 13, 585-599.

10. Kenner, G. W.; McDermott, J. R.; Sheppard, R. C., The safety catch principle in solid phase peptide synthesis. J. Chem. Soc.: Chem. Commun. 1971, 636-637.

11. Atherton, E. S., R.C, Solid Phase peptide synthesis: a practical approach. Oxford, England: IRL Press 1989.

12. Krchnak, V.; Vagner, J.; Lebl, M., Non-invasive continuous monitoring of solidphase synthesis by acid-base indicator. Int. J. Pept. Protein Res. 1988, 32, 415416. 
13. Bergmann, M.; Zervas, L., Über ein allgemeines verfahren der peptid-synthese. Ber. Dtsch. Chem. Ges. 1932, 65, 1192-1201.

14. a) Kociensk, P. J., Protecting Groups. Third Edition ed.; Thieme UK 2005; b) Geiger, R.; Konig, W., Amine Protecting Groups. In Protection of Functional Groups in Peptide Synthesis, Meienhofer, E. G., Ed. Academic Press 1981; Chapter 1, Vol. 3, pp 1-99.

15. Wuts, P. G. M.; Greene, T. W., Protection for the amino group. In Greene's protective groups in organic synthesis, John Wiley \& Sons, Inc.2006.

16. a) Overman, L. E.; Sharp, M. J., Enantioselective total synthesis of the pumiliotoxin $A$ alkaloids via reductive iminium ion-alkyne cyclizations. Total synthesis of (+)-pumiliotoxin A. Tetrahedron Lett. 1988, 29, 901-904; b) Angle, S. R.; Arnaiz, D. O., Stereoselective synthesis of substituted pipecolic acids. Tetrahedron Lett. 1989, 30, 515-518.

17. a) Nalbantova, D.; Cheshmedzhieva, D.; Hadjieva, B.; llieva, S.; Galabov, B., Reactivity of phenyl N-phenylcarbamates in the alkaline hydrolysis reaction. J. Phys. Org. Chem. 2011, 24, 1166-1171; b) Williams, A., Alkaline hydrolysis of substituted phenyl N-phenylcarbamates. Structure-reactivity relationships consistent with an E1cB mechanism. J. Chem. Soc., Perkin Trans. 2 1972, 808-812.

18. Castelletto, V.; Hamley, I. W.; Cenker, C.; Olsson, U.; Adamcik, J.; Mezzenga, R.; Miravet, J. F.; Escuder, B.; Rodríguez-Llansola, F., Influence of end-capping on the self-assembly of model amyloid peptide fragments. J. Phys. Chem. B 2011, 115, 2107-2116.

19. Fraga, B. M.; Gonzalez-Vallejo, V.; Bressa, C.; Guillermo, R.; Suarez, S., Gibberellin analogues by reaction of 7-oxo-diterpenes with diacetoxyiodobenzene. Tetrahedron 2013, 69, 3002-3012.

20. Titov, D. V.; Gening, M. L.; Gerbst, A. G.; Chizhov, A. O.; Tsvetkov, Y. E.; Nifantiev, N. E., Stereochemistry of intramolecular cyclization of tetra-beta-(1 $\rightarrow>6)-D-$ glucosamines and related tetrasaccharides: the role of the conformational stereocontrol and the neighboring group participation. Carbohydr. Res. 2013, 381, 161-178.

21. Ohwada, T.; Tani, N.; Sakamaki, Y.; Kabasawa, Y.; Otani, Y.; Kawahata, M.; Yamaguchi, K., Stereochemical evidence for stabilization of a nitrogen cation by neighboring chlorine or bromine. Proc. Nat. Acad. Sci. 2013, 110, 4206-4211.

22. Maiti, M.; Michielssens, S.; Dyubankova, N.; Maiti, M.; Lescrinier, E.; Ceulemans, A.; Herdewijn, P., Influence of the nucleobase and anchimeric assistance of the carboxyl acid groups in the hydrolysis of amino acid nucleoside phosphoramidates. Chem. Eur. J 2012, 18, 857-868.

23. Warshel, A.; Sharma, P. K.; Kato, M.; Xiang, Y.; Liu, H.; Olsson, M. H. M., Electrostatic basis for enzyme Catalysis. Chem. Rev. 2006, 106, 3210-3235. 
24. Krchnak, V.; Vagner, J.; Lebl, M., Noninvasive continuous monitoring of solidphase synthesis by acid-base indicator. Int. J. Pept. Protein Res. 1988, 32, 415416.

25. Escuder, B.; Martí, S.; Miravet, J. F., Organogel formation by coaggregation of adaptable amidocarbamates and their tetraamide analogues. Langmuir 2005, 21, 6776-6787.

26. Yde, B.; Thomsen, I.; Thorsen, M.; Clausen, K.; Lawesson, S. O., Studies on amino acids and peptides - VII1: Syntheses of aspartame and thioaspartame. Tetrahedron 1983, 39, 4121-4126.

27. Gibson, F. S.; Park, M. S.; Rapoport, H., Bis[[4-(2,2-dimethyl-1,3-dioxolyl)]methyl]carbodiimide (BDDC) and its application to residue-free esterifications, peptide couplings, and dehydrations. J. Org. Chem. 1994, 59, 7503-7507. 


\section{CHAPTER 4}

\section{ACIDIC TETRAPEPTIDES}

CONTAINING L-ASPARTIC (D) AND

L-PHENYLALANINE (F) 



\section{CHAPTER 4}

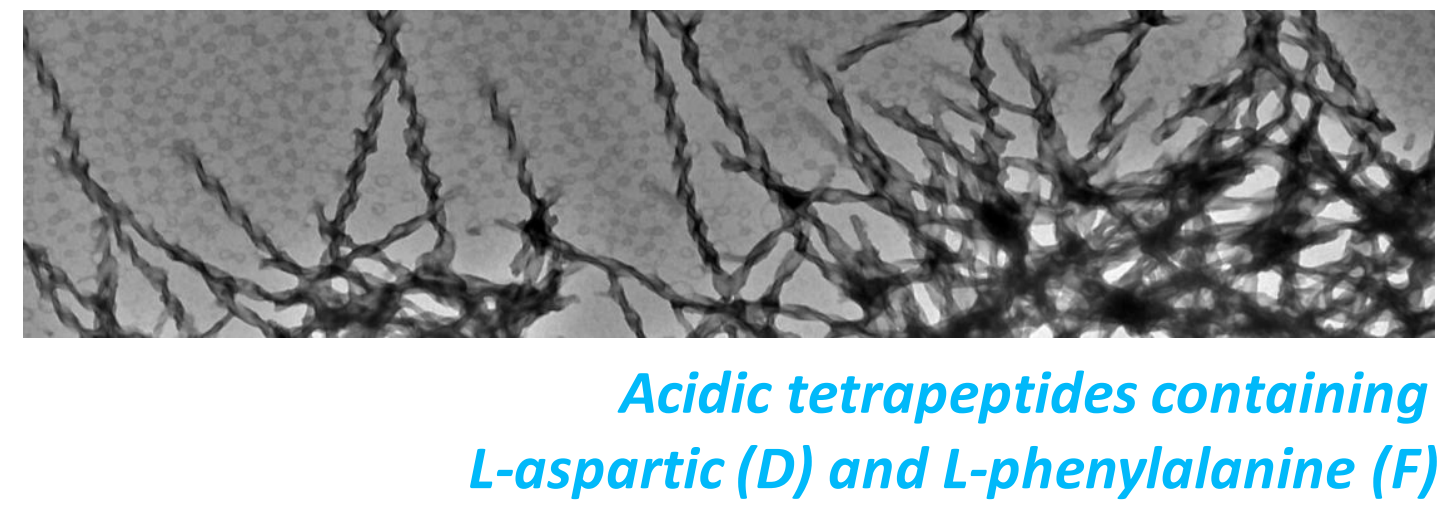

In this chapter the ability of isomeric tetrapeptides 1-6 to form gels by neutralisation of their basic solutions is tested. A general characterisation of their properties is provided including morphological, structural and mechanical studies. The thermodynamics and kinetics of the fibrillisation process are also described and a selfsorting system containing two different tetrapeptides is designed as a result. Finally the interaction between compounds 1-6 with the protein $A \beta 1-40$ is also evaluated. As a general trend, differences in sequence are shown to provide significant impact on the final properties of these systems.

SANS experiments were performed in collaboration with Prof. I. W. Hamley (University of Reading) at ISIS Neutron Source in Rutherford Appleton Laboratory on the Harwell Science and Innovation Campus in Oxfordshire. 



\section{ACIDIC TETRAPEPTIDES CONTAINING L-ASPARTIC (D) AND L- PHENYLALANINE (F)}

\subsection{Introduction}

Small peptides are excellent models to study the physicochemical determinants of self-assembly and the emergent properties of assembled materials. Amphipathic peptides containing alternated polar and non-polar amino acids have an increased propensity to undergo amyloid-like $\beta$-sheet assemblies. ${ }^{1}$ In this study six isomeric tetrapeptides that combine $F$ and $D$ residues will be used to study the effect of the hydrophobic/hydrophilic balance in the fibrillisation process (Figure 4.1).

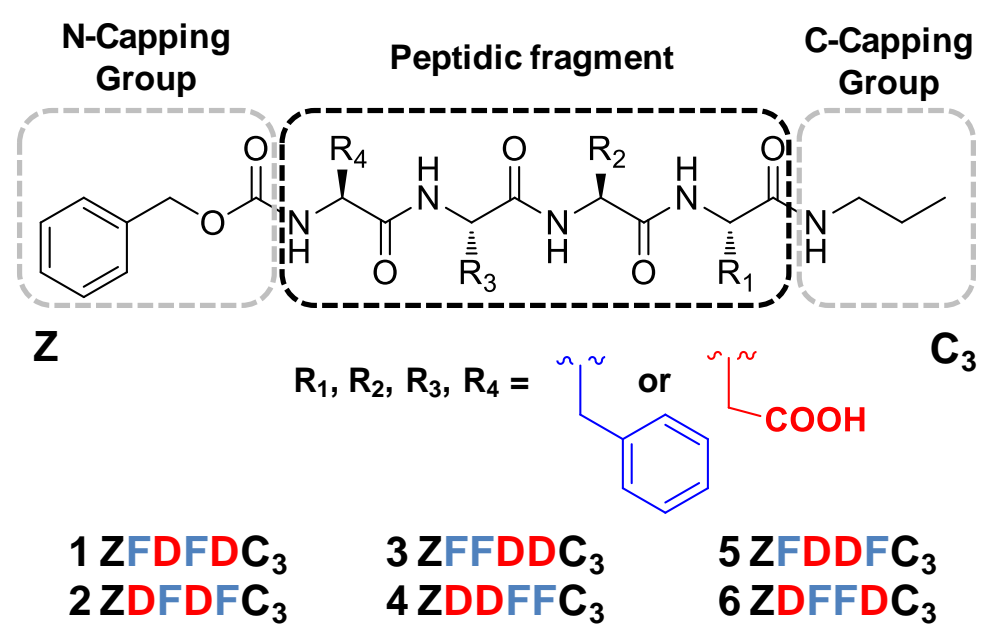

Figure 4.1 General structure for amphipatic tetrapeptides (1-6) containing F as non-polar residues and D as ionic residues.

\subsection{Hydrogelation with acidic tetrapeptides}

First of all the hydrogelation ability of compounds 1-6 as well as the properties of their hydrogels were evaluated and characterised going from macroscopic to microscopic level. This characterisation includes the determination of the minimum gel concentration (m.g.c.), the description of the morphological aspect of the fibrillar network (TEM and SEM), a wide range of structural studies including FTIR, CD, fluorescence, WAXD, modelling and finally the analysis of their rheological behaviour. 


\subsubsection{Determination of m.g.c. and morphological description}

The traditional heating-cooling methodology for gel formation was not the most convenient strategy for compounds 1-6 due to their poor solubility in water. Very high temperatures for a long period of time were required to dissolve them at concentrations in the millimolar range and they precipitated after cooling of the hot solutions. Exploting the presence of ionic groups in these molecules, the use of $\mathrm{pH}$ changes to induce gelation ${ }^{2}$ turned out to be a more useful approach. Thereby compounds 1-6 were easily dissolved in basic media by deprotonation of $D$ residues and subsequent acidification of these solutions by $\mathrm{HCl}$ (aqueous solution or vapours) lead to hydrogel formation. However, such hydrogels showed in general a non-homogeneous aspect and lacked reproducibility most likely because the presence of high local concentrations of $\mathrm{HCl}$ upon acidification.

These drawbacks could be finally circumvented using solutions of $\delta$-Dgluconolactone ( $\mathrm{GdL}$ ) as $\mathrm{pH}$-tuning media. This elegant approach, described by Adams and co-workers, ${ }^{3}$ allows a precisely controlled $\mathrm{pH}$ change during solution-to-hydrogel transition in the entire sample caused by progressive GdL hydrolysis into gluconic acid. In this way, initial basic solutions containing GdL were used to smoothly lower the $\mathrm{pH}$ and generate homogenous and reproducible gels as a consequence.

In a typical experiment compounds 1-6 were dissolved in basic solutions of $\mathrm{Na}_{2} \mathrm{CO}_{3}$ and the corresponding amount of $\mathrm{GdL}$ was added to this solution. Dissolution of GdL in basic water ${ }^{4}$ is very quick and its hydrolysis starts immediately with the resulting protonation of $D$ residues followed by the gel formation as a result (Figure 4.2).

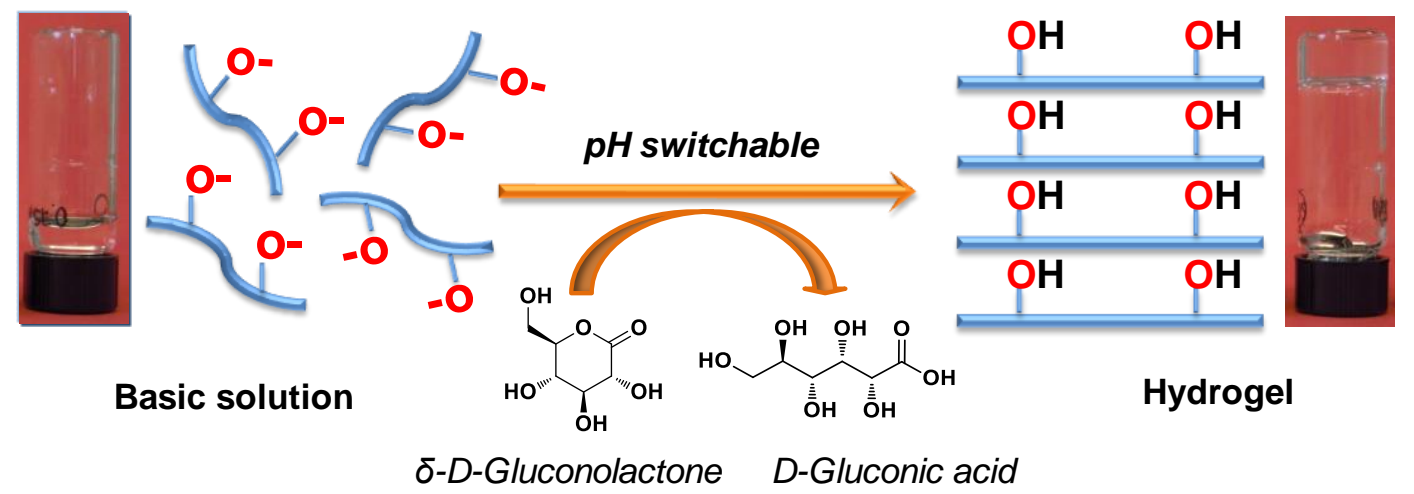

Figure 4.2 Schematic representation of gel formation by protonation of dianionic tetrapeptides 1-6 associated to $\mathrm{GdL}$ hydrolysis. 
To determine the m.g.c. the previous experiment was repeated for increasing amounts of each gelator in separated vials (See S.I. 4.1.1). $72 \mathrm{~h}$ after GdL addition (at 25 oC) the vial inversion test was used to establish this parameter. Basically a gel is present if, when placed inside a vial, the solvent does not flow upon turning the vial upside down (Figure 4.3).

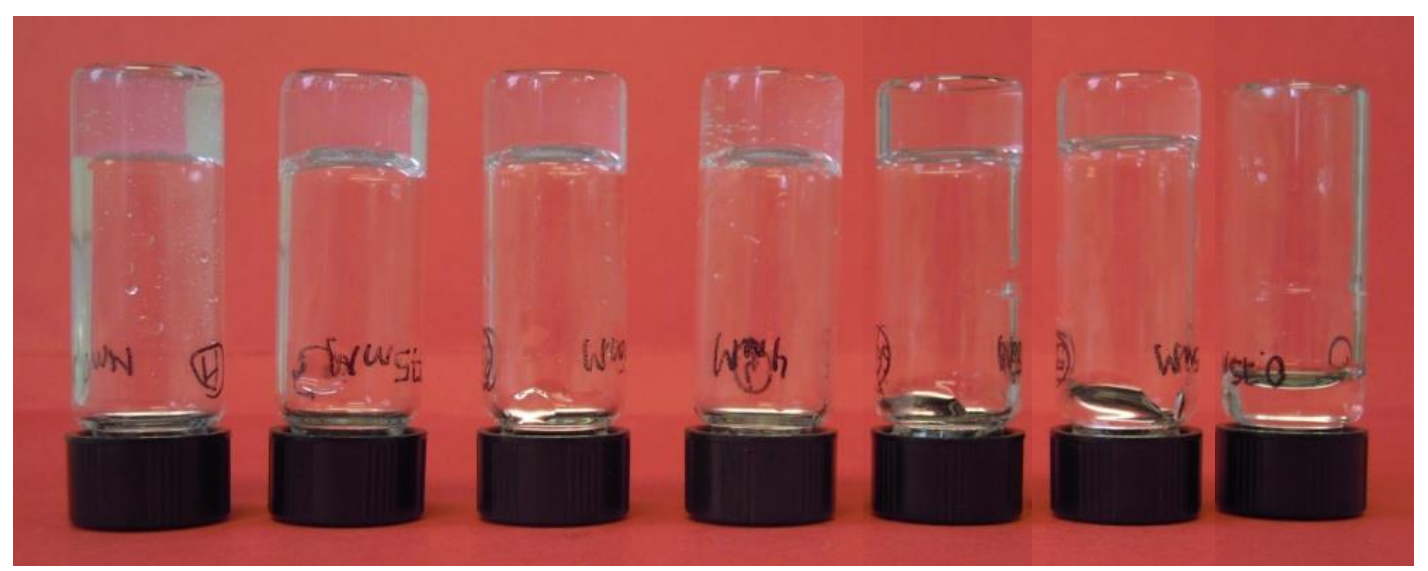

Figure 4.3 M.g.c. determination for compound 1. Concentrations from left to right: 10, 7.5, 5, 4, 2.5, 1.5 and $0.75 \mathrm{mM}$ respectively.

Following this methodology, hydrogels were obtained for all the compounds although significant differences were observed among them. The m.g.c. for compounds 1-6 are collected in Table 4.1.

Table 4.1 Hydrogelation behaviour and m.g.c. for compounds 1-6 at $25 \stackrel{\circ}{ } \mathrm{C}$.

\begin{tabular}{llcc}
\hline Compound & Macroscopic aspect & m.g.c. (mM) \\
\hline $\mathbf{1}$ & ZFDFDC $_{3}$ & Transparent gel & 1.5 \\
$\mathbf{2}$ & $Z_{\text {DDDFC }}$ & Translucent gel & 4.5 \\
$\mathbf{3}$ & ZFFDDC $_{3}$ & Transparent gel & 2.5 \\
$\mathbf{4}$ & ZDDFFC $_{3}$ & Translucent gel & 4.0 \\
$\mathbf{5}$ & ZFDDFC $_{3}$ & Opaque gel & 7.5 \\
$\mathbf{6}$ & ZDFFDC $_{3}$ & Transparent gel & 3.0 \\
\hline
\end{tabular}

Considering this parameter, the best hydrogelator found was compound 1 (1.5 $\mathrm{mM}$ ) followed by compound $3(2.5 \mathrm{mM})$ and compound $6(3 \mathrm{mM})$. Those three formed transparent gels as can be seen in Figure 4.4. 


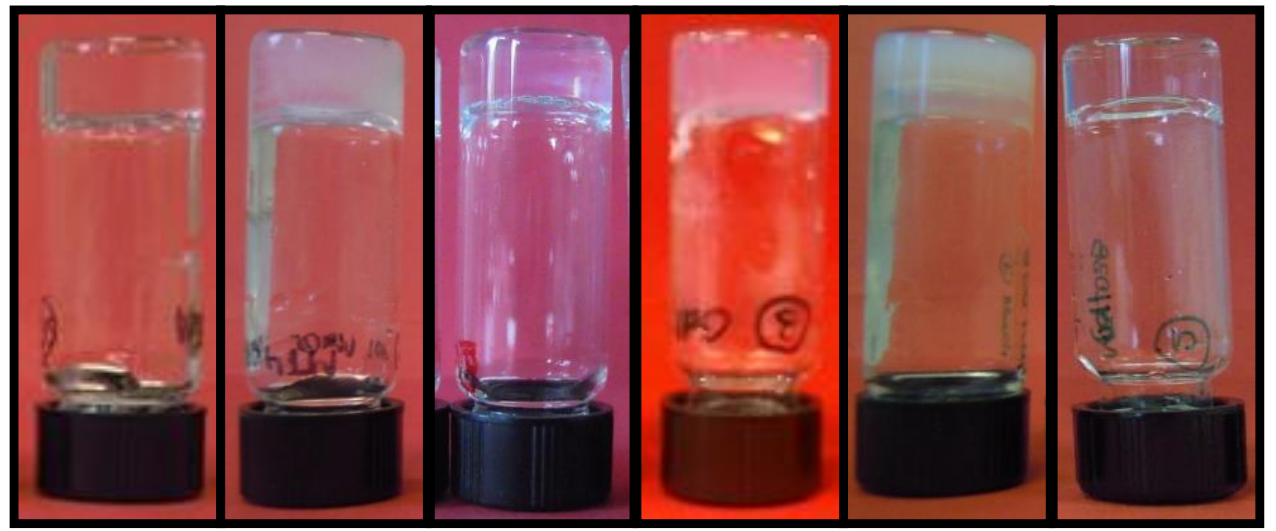

Figure 4.4 Macroscopic aspect of the hydrogels at their m.g.c. for compounds 1-6 (from left to right).

TEM images of the materials formed by compounds 1 (Figure 4.5) and $\mathbf{3}$ (Figure 4.7) revealed highly uniform and cross-linked fibrillar networks with few defects and branching for both of them. Such networks showed regular and thin fibres with widths about 6-8 $\mathrm{nm}$ and microns in length. SEM agreed with TEM showing a regular mesh size for the two compounds.
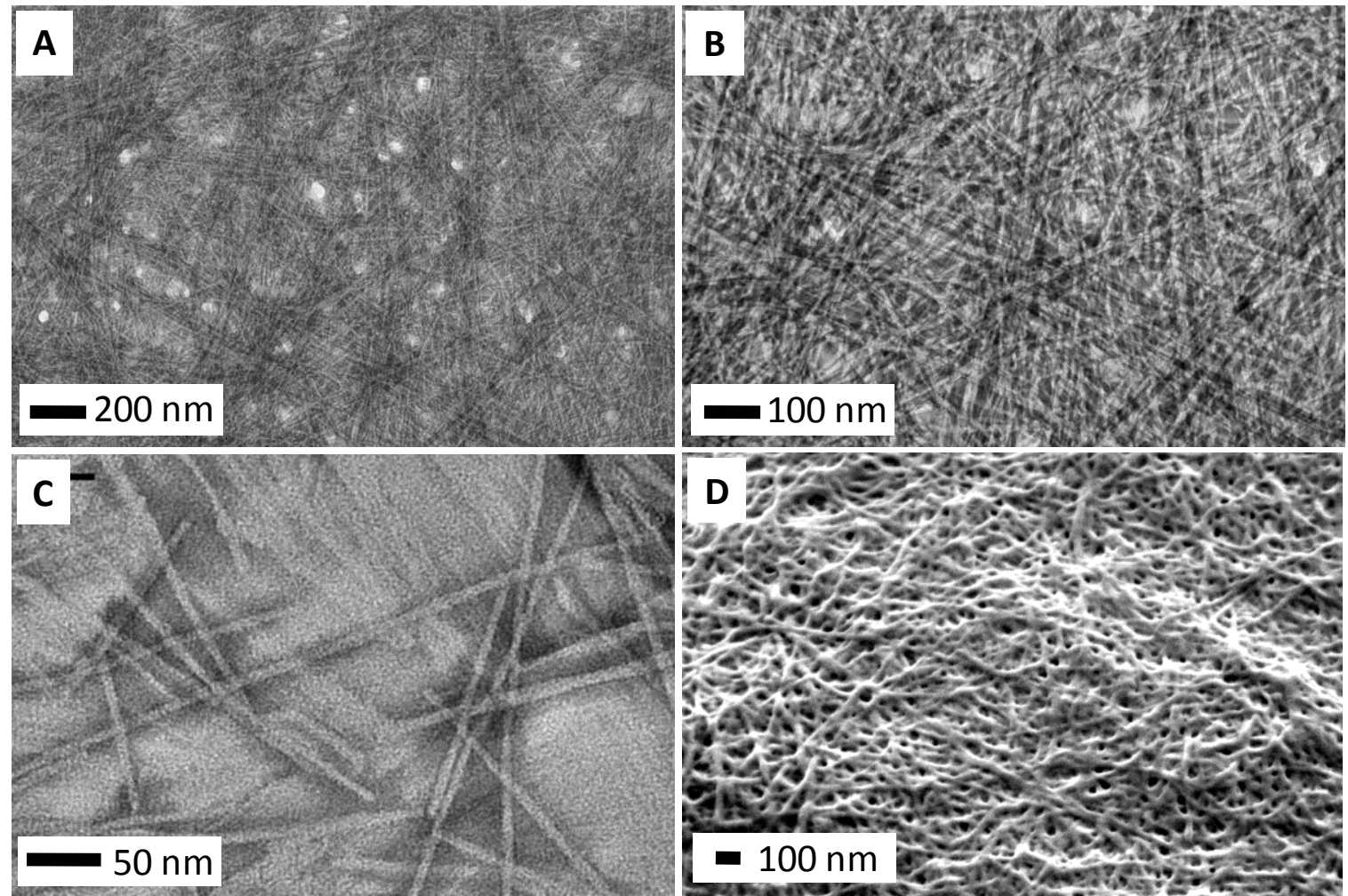

Figure 4.5 Images for hydrogel of compound 1 (ZFDFDC 3 ) at its m.g.c (TEM: A,B and C; SEM: D). 

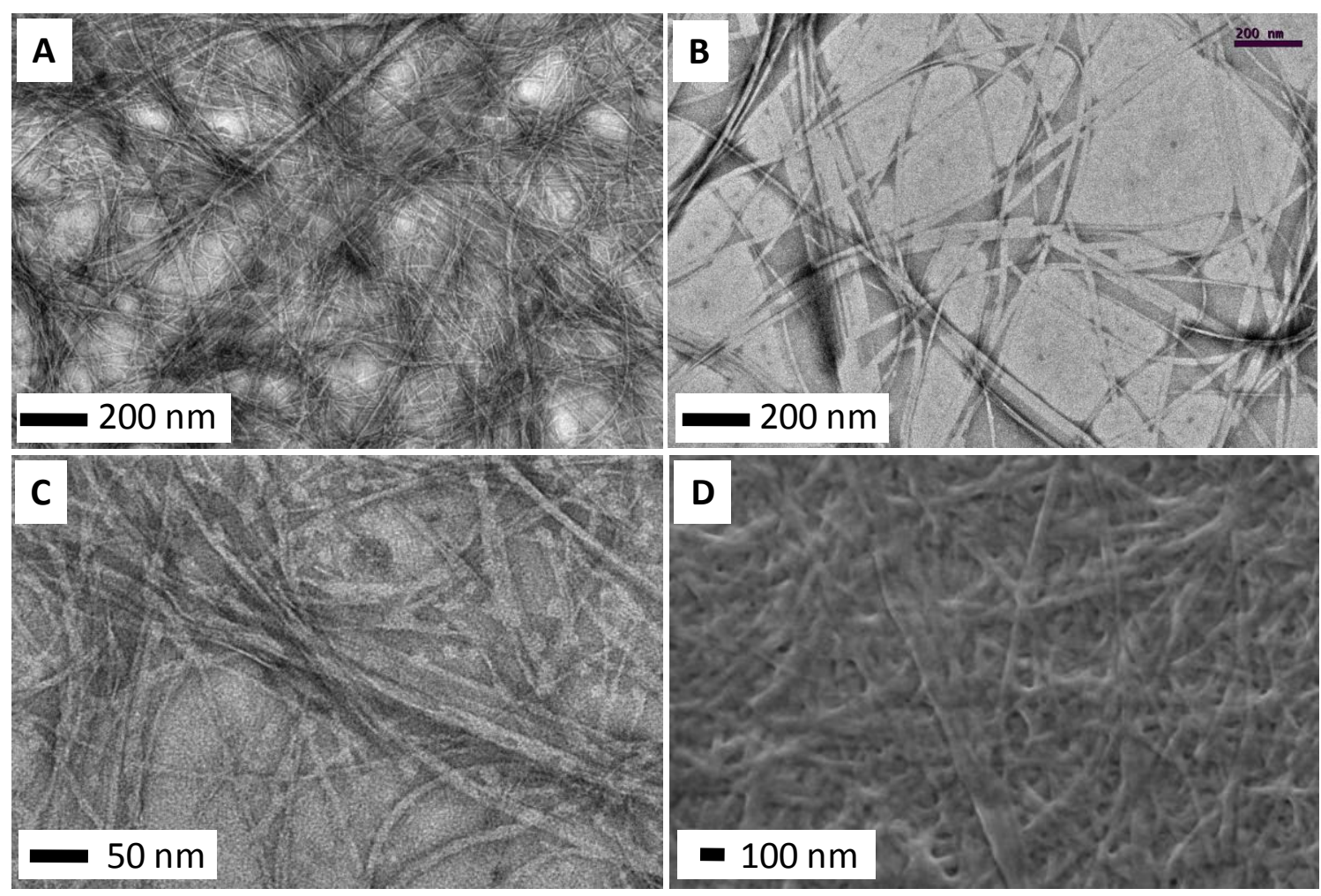

Figure 4.6 TEM images for hydrogel of compound 2 (ZDFDFC 3 ) at its m.g.c (TEM: A,B and C; SEM: D).
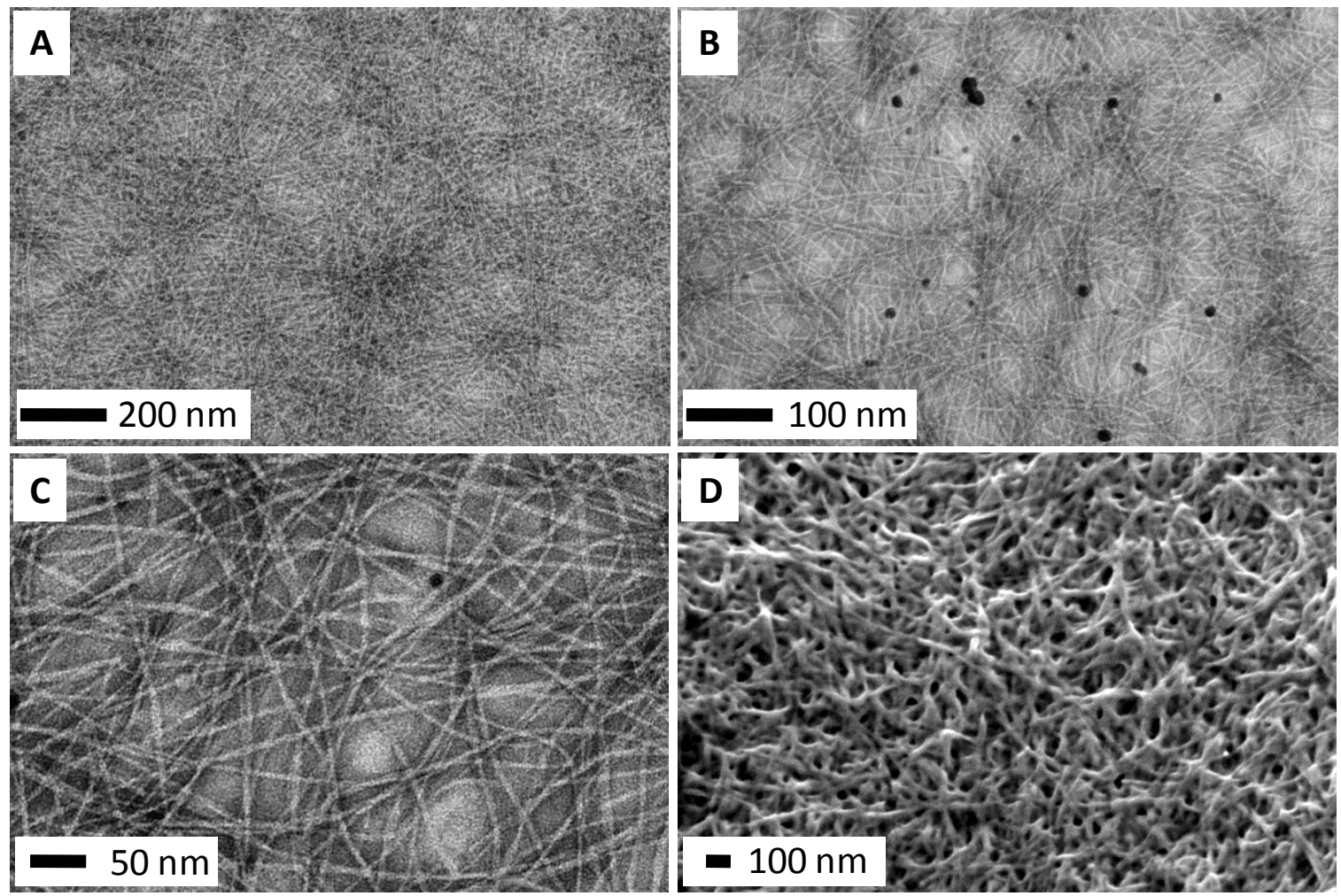

Figure 4.7 TEM images for hydrogel of compound 3 (ZFFDDC 3 ) at its m.g.c (TEM: A,B and C; SEM: D)

In the case of compound 6, the general aspect of the microscopic network was less crowded than in previous compounds and fibres were about $10 \mathrm{~nm}$ in width and 
several micrometres in length (Figure 4.10). In this case some chiral fibres could also be observed in at least two different shapes (Figure 4.10C), some as loosely curled righthanded helices (around 200 and $600 \mathrm{~nm}$ in pitch) and other left-handed helices with a shorter pitch (around $50 \mathrm{~nm}$ ). Most likely these latter are formed by the assembly of two fibrils of the former type. SEM was not able to distinguish the chirality of the fibres and just a uniform mesh was observed once again.
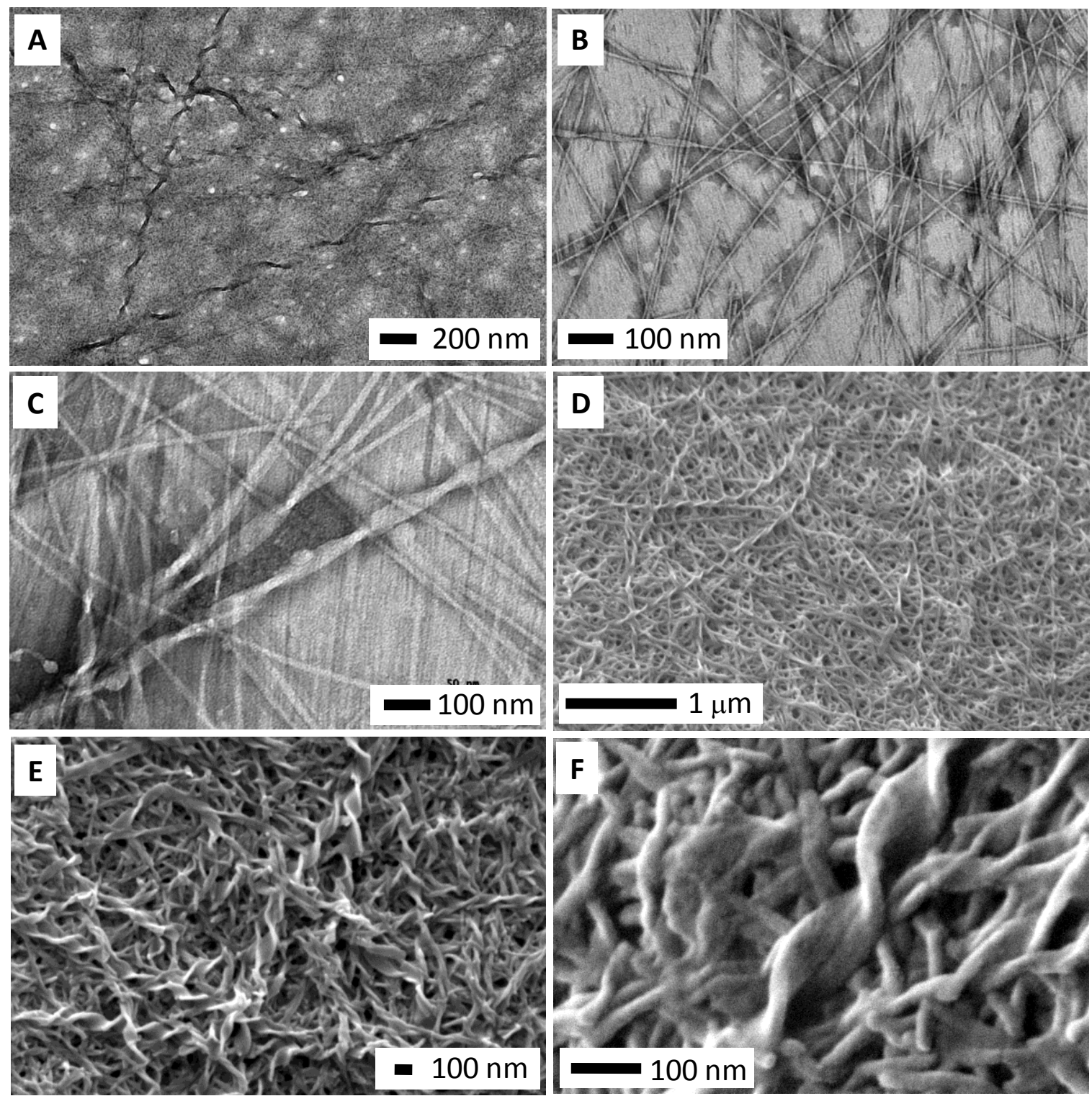

Figure 4.8 Images for hydrogel of compound 4 (ZDDFFC 3 ) at its m.g.c (TEM: A, B and C; SEM: D, E and F).

Compounds 2 and 4 presented slightly higher values of m.g.c. ( 4 and $4.5 \mathrm{mM}$ respectively) and formed translucent hydrogels (Figure 4.4). Such difference in macroscopic aspect in comparison with previous transparent gels may be ascribed to the 
larger objects observed. TEM micrographs of compound $\mathbf{2}$ revealed a mixture of fibres around 5-10 nm in width together with tapes around 40-50 nm. SEM showed even longer and wider tapes of more than $100 \mathrm{~nm}$. The presence of these big objects provokes the scattering of light and a translucent macroscopic aspect.

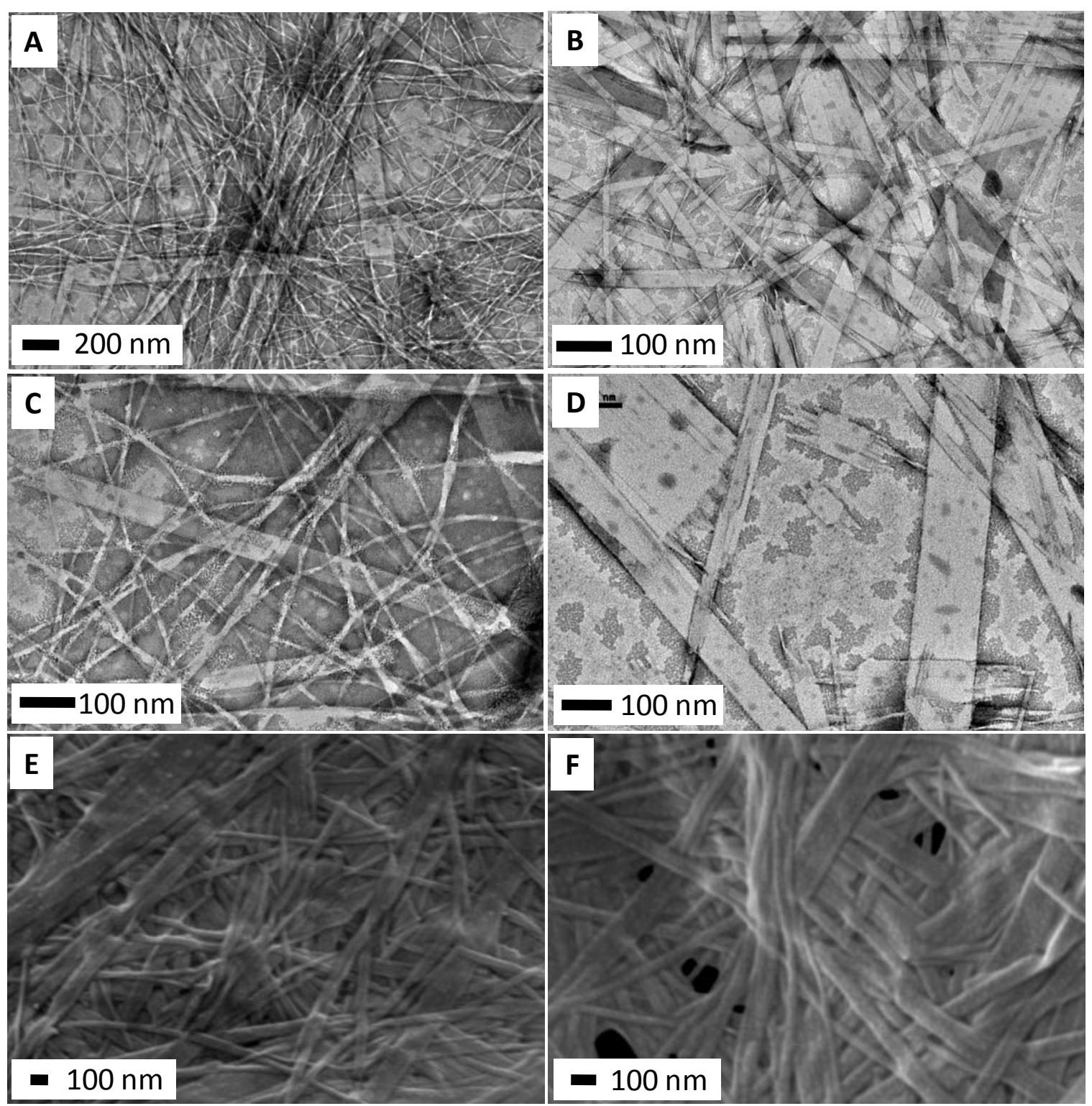

Figure 4.9 Images for hydrogel of compound 5 (ZFDDFC 3 ) at its m.g.c (TEM: A, B, C and D; SEM:E and F).

On the other hand hydrogel of compound 4 (Figure 4.8) is formed by a combination of thin fibres around $8 \mathrm{~nm}$ in width with larger left handed helical fibres which appear upon the assembly of several fibrils (Figure 4.8C). These helical fibres showed different pitches and widths but a constant value of pitch-to-width ratio and equal to 5 . Compound 5 finally formed an opaque gel with the highest m.g.c. observed. In this case thin fibres of $10 \mathrm{~nm}$ in with co-existed with larger tapes of a few hundreds of 
$\mathrm{nm}$ in width (Figure 4.9). The rigidity of these tapes hinders the possibility of their crosslinking justifying as a consequence, the larger amount of compound needed for gel formation. Closer inspection revealed that these tapes are formed by the merging of tens of fibrils aligned following the direction of the tape.
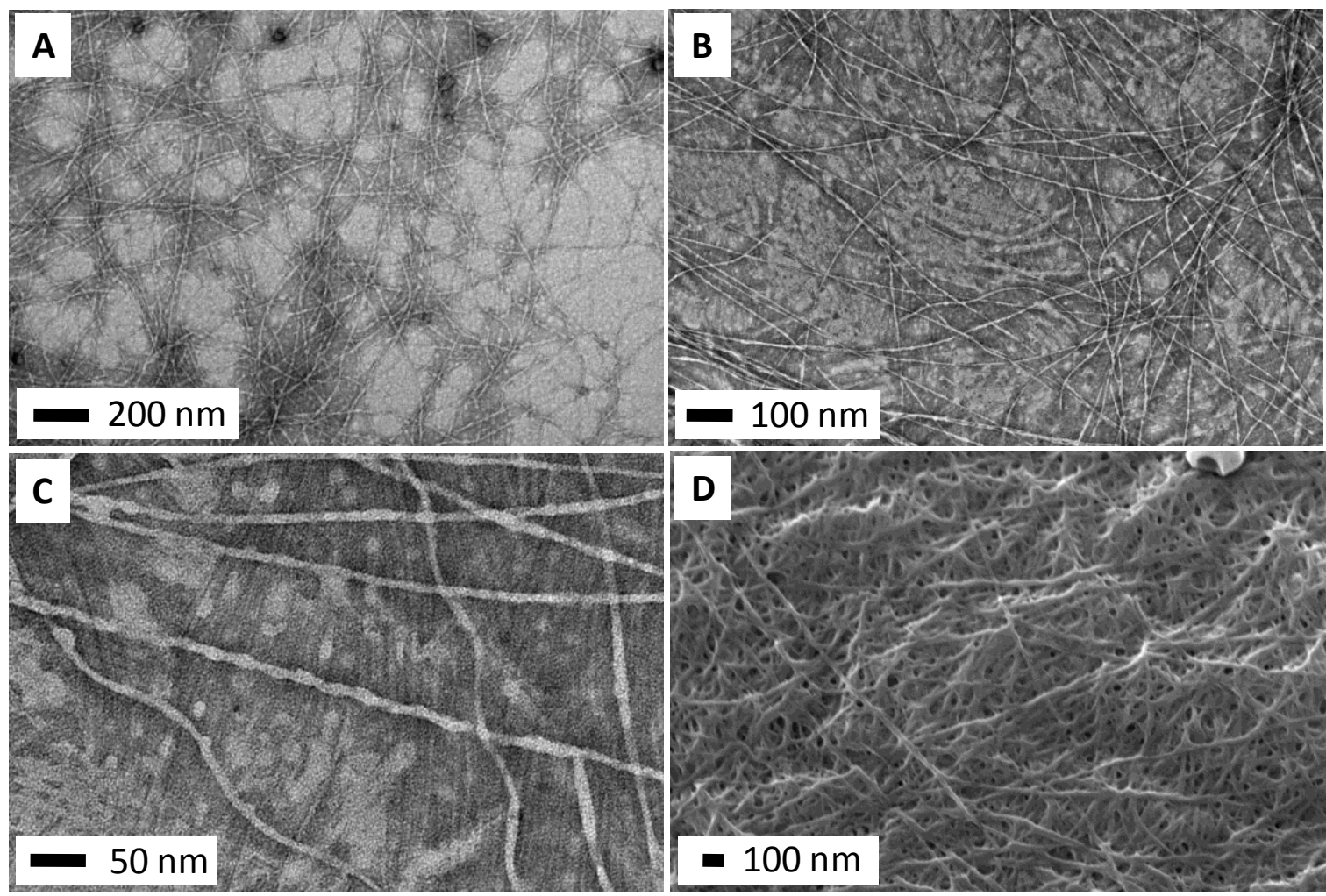

Figure 4.10 Images for hydrogel of compound 6 (ZDFFDC 3 ) at its m.g.c (TEM: A,B and C; SEM: D).

\subsubsection{Structural studies}

Spectroscopic techniques such as FTIR, CD and fluorescence were used for the study of the supramolecular structures of the aggregates. ${ }^{5}$ Particularly FTIR spectroscopy is a very useful technique for confirming hydrogen bond interactions between the molecular building blocks. For example $\mathrm{O}-\mathrm{H}, \mathrm{N}-\mathrm{H}$ and $\mathrm{C}=\mathrm{O}$ stretching bands show a characteristic response to hydrogen bonding resulting in a shift to lower wavenumber due to the change in the strength of the bond. Especially useful for the analysis of peptide and protein secondary structures is the intense carbonyl stretching band amide I. ${ }^{6}$ Besides, the presence of two carboxylic acids at the side chains may be also helpful in the current case because the position of their vibration bands is also sensitive to the 
strength of the hydrogen bond involving this functional group, as previously described by Rogers and co-workers. ${ }^{7}$

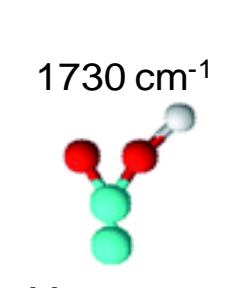

Monomer

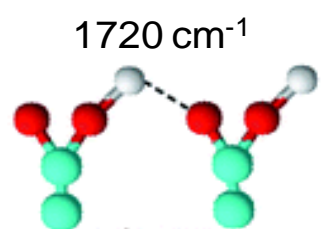

Acyclic Dimer

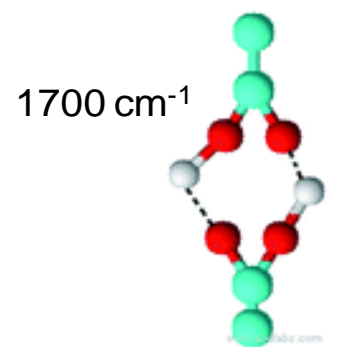

Cyclic Dimer

Figure 4.11 Diagram of the free carboxylic acid monomer, acyclic carboxylic acid dimer and cyclic carboxylic acid dimer with their typical wavenumbers. ${ }^{7 a}$

For FTIR measurements, hydrogels were prepared as previously described and then filtered, washed several times with water to remove non-aggregated compounds (GdL and salts) and finally dried in order to avoid water interference (See S.I. 4.1.4). The spectra recorded for all the compounds clearly showed an intense signal corresponding to the amide Istretching in the range $1634-1641 \mathrm{~cm}^{-1}$ (Table 4.2). This band is generally ascribed to a $\beta$-sheet structure as the main feature of these aggregates. ${ }^{6 a}$ However, because it is at the upper limit for this kind of secondary structures, we suggest that the sheets may be twisted or distorted from the ideal planar arrangement. A weaker band between 1684-1693 $\mathrm{cm}^{-1}$ was also identified for compounds 1-6 which is usually indicative of an antiparallel $\beta$-sheet secondary structure. ${ }^{8}$ In addition to these bands, other less intense broad shoulders could be detected at higher frequencies corresponding mainly to the carboxylic acids vibrations and other minor secondary structure components of the amide I. The position of such bands was difficult to analyze directly and a curve-fitting analysis (JASCO FTIR Curve Fitting software, see S.I. 4.1.4) was employed to deconvolute the spectra into several peaks. The bands found are shown in Table 4.2.

In this way compound $\mathbf{1}$ with the alternating sequence ZFDFDC $_{3}$ showed a single broad band centred at $1701 \mathrm{~cm}^{-1}$ suggesting that both $\mathrm{D}$ residues are in a strongly $\mathrm{H}$ bonding environment. On the contrary, compound $\mathbf{2}$ with the reverse alternating sequence ZDFDFC 3 showed two bands of similar strength centered at $1733 \mathrm{~cm}^{-1}$ and $1709 \mathrm{~cm}^{-1}$ that suggest two different carboxylic acid components, one in a non $\mathrm{H}$-bonded 
environment leading to the higher wavenumbers and the other in a medium strength $\mathrm{H}$ bonding region. Compound 3, with a block sequence ZFFDDC $_{3}$, showed a single broad band centered at $1724 \mathrm{~cm}^{-1}$ denoting that both $\mathrm{D}$ residues are involved in weak $\mathrm{H}$-bonds. The strength in $\mathrm{H}$-bonding is increased for compound $\mathbf{4}$ with the reverse block sequence ZDDFFC $_{3}$ and in this case two different bands could be assigned, a strong one at 1722 $\mathrm{cm}^{-1}$ and a weaker one at $1704 \mathrm{~cm}^{-1}$. For compound 5, with the sequence ZFDDFC 3 the combination of two bands was observed (1712 and $\left.1703 \mathrm{~cm}^{-1}\right)$ suggesting again a strongly $\mathrm{H}$-bonded environment for both $\mathrm{D}$ residues. Finally, for compound $\mathbf{6}$ with the sequence $Z_{\text {ZFFDC }}$ the major band appeared at $1722 \mathrm{~cm}^{-1}$ suggesting a poor $\mathrm{H}$-bonding environment.

Table 4.2 FTIR peaks of xerogels 1-6 after deconvolution analysis $\left(\mathrm{cm}^{-1}\right) .^{\text {a }}$

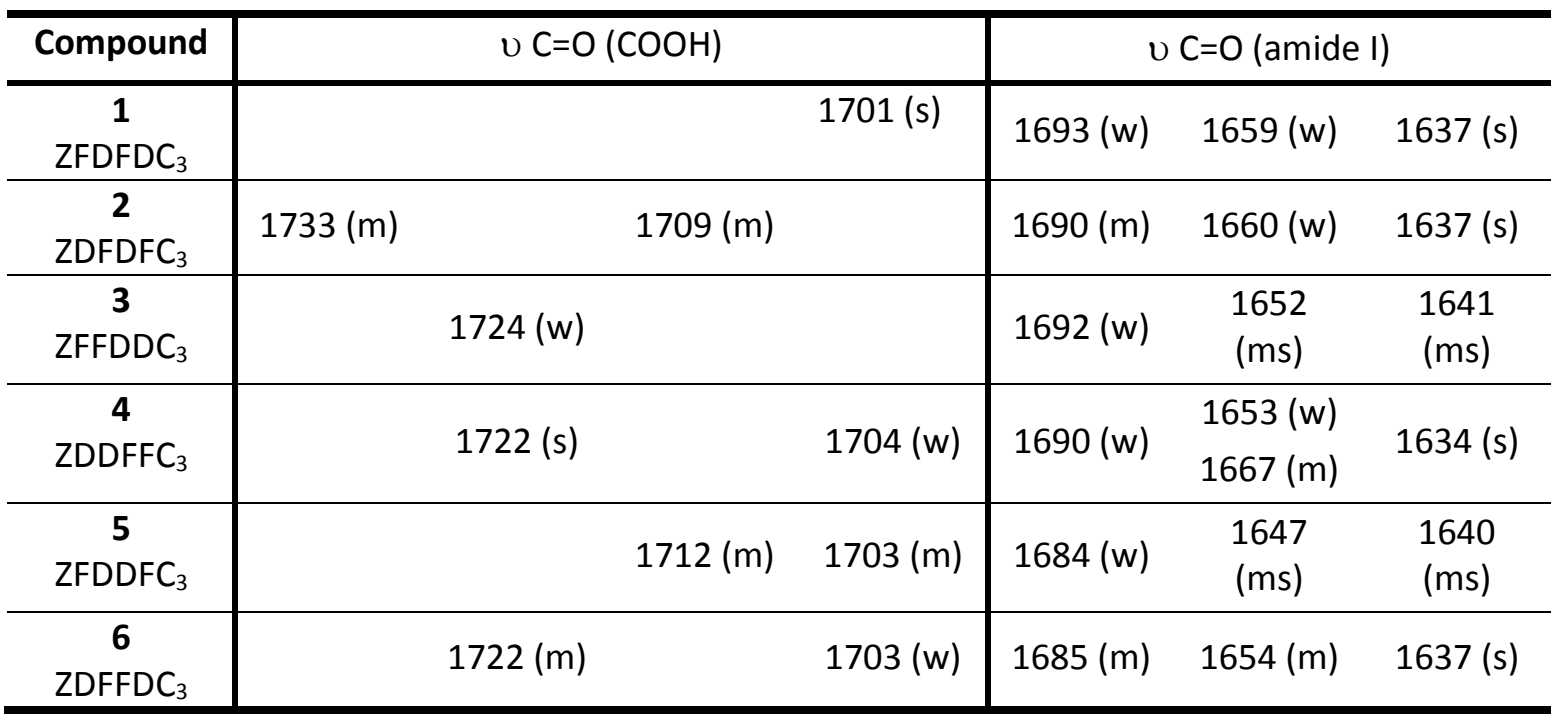

${ }^{a}$ Band intensity: (s) strong, (m) medium, (w) weak.

Circular dichroism (CD) has also been extensively used to give useful information about protein and peptide structure. ${ }^{9}$ This technique relies on the differential absorption of left and right circularly polarized radiation by chromophores that possess intrinsic chirality or are placed in chiral environments. Peptides in general have different chromophores which can produce CD signals. In the far UV region (240-180 $\mathrm{nm}$ ) the absorbing group is mainly the peptide bond and such signals can be used to determine the content of regular secondary structural features such as $\alpha$-helix or $\beta$-sheet. The near UV region (320-260 $\mathrm{nm}$ ) reflects the environment of the aromatic groups of phenylalanine, tyrosine or tryptophan and provides useful information of the tertiary structure of the proteins. 
For the present work $C D$ spectra of compounds 1-6 were recorded in solution $(0.75 \mathrm{mM})$ as well as at their respective m.g.c. (See S.I. 4.1.5). For all the compounds in solution a random structure was suggested because CD spectra did not show any pattern ascribable to a secondary structure (Figure 4.12). Besides, the presence of several aromatic groups in the molecules could lead to a mixing of excitons and alteration of the spectral shape.

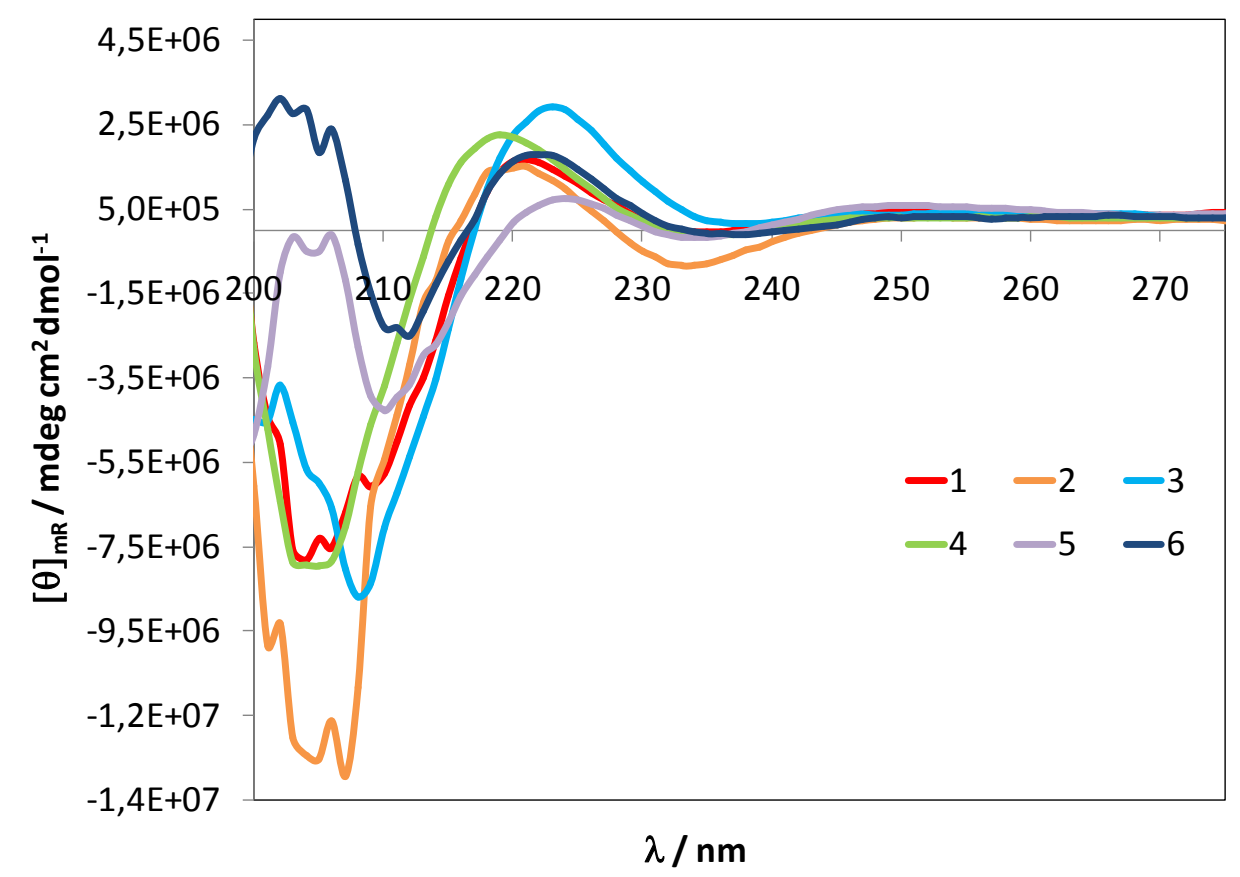

Figure 4.12 Mean-residue molar ellipticity of compounds 1-6 in solution (0.75 mM).

However, after hydrogelation CD signals were significantly more intense for all the compounds but especially for sequences ZFDFDC 3 (1) and ZDDFFC 3 (4) (Figure 4.13). Although there are not clear similarities in their primary sequences both of them showed an intense negative band at $228 \mathrm{~nm}$ confirming an important conformational change on going from solution to gel phase. The rest of the hydrogels are in general less CD active. Compound $\mathbf{3}$ for example presented a typical $\beta$-sheet structure with a negative bands at $222 \mathrm{~nm}$ and a positive lobe at $211 \mathrm{~nm}$. ${ }^{9 a} A$ broad band at far UV was observed for compound $5(230-250 \mathrm{~nm})$ revealing the importance of the aromatic side chain reorganization on going from solution to hydrogel. Finally compounds $\mathbf{2}$ and $\mathbf{6}$ are much less active, probably due to the cancellation of excitons, and showed small negative bands at 235 and $230 \mathrm{~nm}$ respectively. 


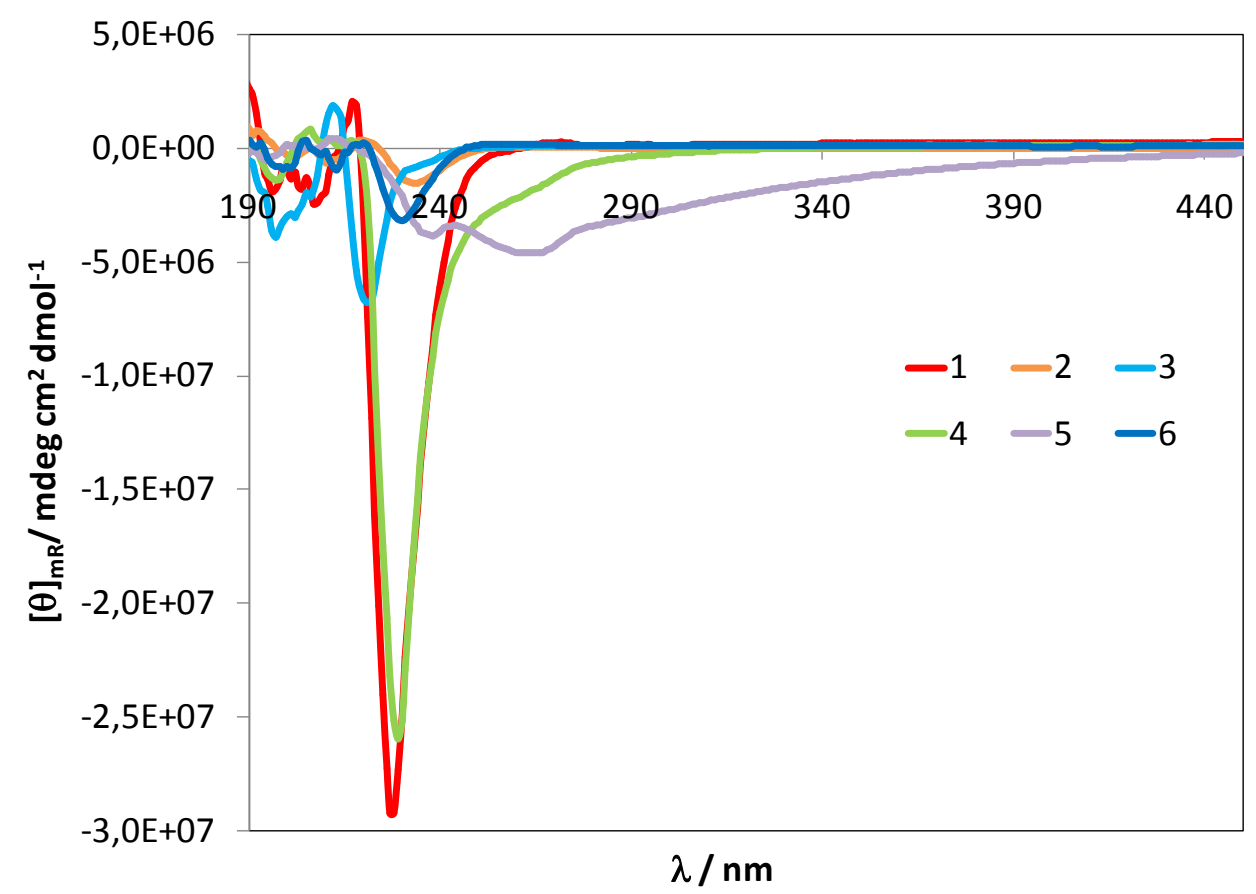

Figure 4.13 Mean-residue molar ellipticity of compounds 1-6 at their m.g.c.

Fluorescence spectroscopy is an especially useful technique to identify hydrophobic pockets inside hydrogels or to detect changes in the hydrophobicity at the surroundings of a reporter group. In our case, it was used to investigate the environment of the F residues. Such residues show a characteristic emission peak at 284 $\mathrm{nm}$ under excitation at $260 \mathrm{~nm}$ and the shift of this peak has been reported as a useful way to monitor the participation of the aromatic fragment in $\pi$-stacking interactions ${ }^{10}$ In a similar way to $C D$, fluorescence spectra were recorded for samples in solution and after the hydrogels formation at their respective m.g.c. (Table 4.3) (See S.I. 4.1.6). A common peak at 284-285 $\mathrm{nm}$ was observed for all of them, except compound 5, indicating the presence of isolated aromatic fragments. The red-shift observed for compound $\mathbf{5}$ (around $4 \mathrm{~nm}$ ) can be ascribed to an intramolecular interaction between aromatic fragments which requires the folding of the molecule, and may be caused by the presence of the central DD block.

The energy minimized structure of this compound in solution (AMBER* force field, GB/SA solvent simulation for water), reveals an amphipathic structure that packed the aromatic groups on one side of the molecule hiding them from water in agreement with the red-shifted fluorescence band found in solution at $288 \mathrm{~nm}$ and also the additional shoulder at $400 \mathrm{~nm}$ (See S.I. 4.1.6.1). 


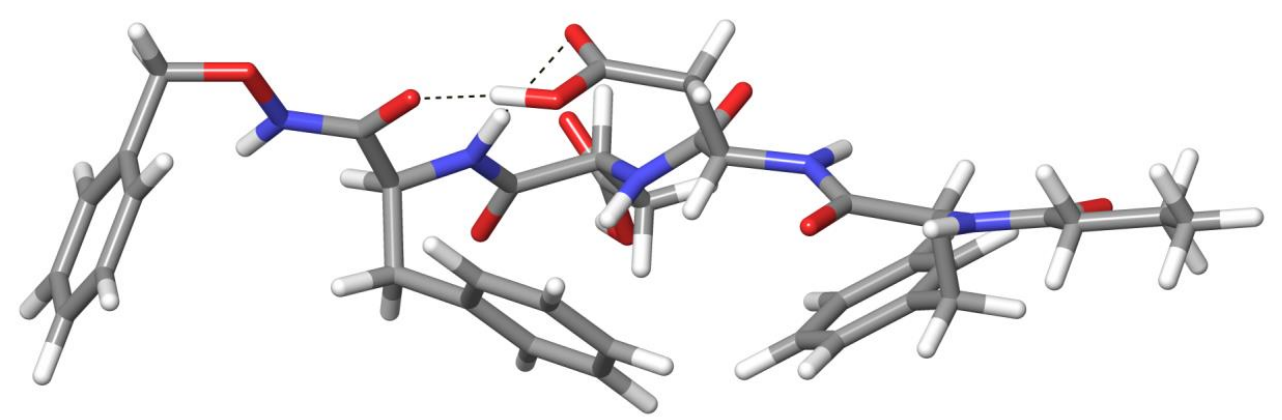

Figure 4.14 A) Minimum energy structure for compound 5 found by molecular mechanics conformational search (Macromodel 9.3. AMBER* force field, water GB/SA solvent simulation).

Fluorescence studies for the hydrogels revealed in general a common red-shift of 8 to $14 \mathrm{~nm}$ suggesting the presence of strong $\pi$-stacking interactions upon the aggregation. ${ }^{10-11}$ Particularly the largest red-shift reported corresponds to compound $\mathbf{5}$ revealing the strong involvement of aromatic residues in the structural rearrangement from solution to gel state. Other significant broad bands at around $460 \mathrm{~nm}$ were observed for compounds $\mathbf{2 ,} \mathbf{4}$ and $\mathbf{5}$.

Table 4.3 Fluorescence studies of solutions $(0.75 \mathrm{mM})$ and hydrogels (m.g.c.) of compounds 1-6 $\left(\lambda_{\mathrm{ex}}=260\right.$ $\mathrm{nm})$.

\begin{tabular}{|c|c|c|c|c|c|}
\hline \multicolumn{2}{|c|}{ Compound } & \multirow{2}{*}{$\frac{\lambda_{\text {em }} \text { at } \mathbf{( \mathbf { n m } )}}{0.75 \mathrm{mM}}$} & \multirow{2}{*}{$\frac{\lambda_{\text {(nm) }}^{\lambda \text { at mgc }}}{293}$} & \multirow{2}{*}{$\begin{array}{c}\begin{array}{c}\text { Aggregation } \\
\text { induced red shift } \\
\text { (nm) }\end{array} \\
8\end{array}$} & \multirow{2}{*}{$\begin{array}{c}\begin{array}{c}\text { Additional } \\
\text { peak at } 460 \\
\mathrm{~nm}\end{array} \\
\text { No }\end{array}$} \\
\hline 1 & $\mathrm{ZFDFDC}_{3}$ & & & & \\
\hline 2 & ZDFDFC $_{3}$ & 284 & 296 & 12 & Yes \\
\hline 3 & $\mathrm{ZFFDDC}_{3}$ & 284 & 295 & 11 & Weak \\
\hline 4 & $\mathrm{ZDDFFC}_{3}$ & 285 & 297 & 12 & Yes \\
\hline 5 & $\mathrm{ZFDDFC}_{3}$ & 288 & 302 & 14 & Yes \\
\hline 6 & ZDFFDC $_{3}$ & 284 & 295 & 11 & No \\
\hline
\end{tabular}

The appearance of this band has been previously attributed by many authors to the disposition of the aromatic residues forming J-aggregates. ${ }^{11-12}$ Interestingly this band was not present for compounds 1, 3 and $\mathbf{6}$ which are the best gelators showing the lowest m.g.c. values and the more transparent aspect. 


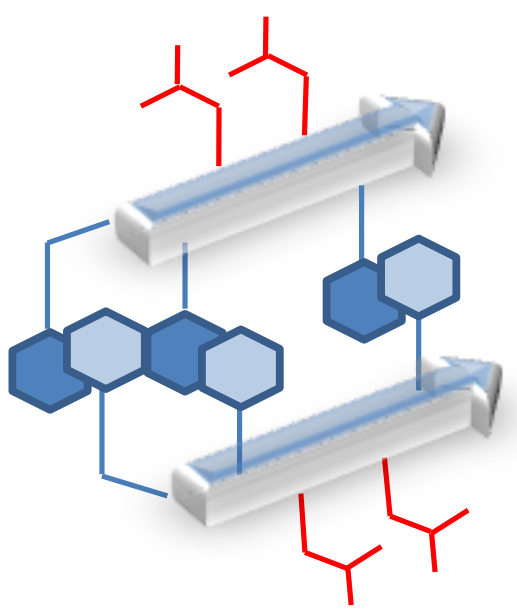

Figure 4.15 Schematic representation of J-aggregates proposed for compound $\mathbf{5}$.

Diffraction techniques can also be useful to elucidate the packing mode of the gelators. In particular wide-angle X-ray diffraction (WAXD) patterns of the freeze-dried hydrogels obtained for compounds 1-6 at their m.g.c. were investigated. Unfortunately the main part of these results lack of useful information (regarding the packing mode) since xerogels diffraction patterns showed a highly amorphous aspect. However, compounds $\mathbf{2}$ and $\mathbf{5}$ seemed to have a more crystalline aspect. These compounds, which are formed by tapes of different widths, showed characteristic peaks of a lamellar packing (See S.I. 4.1.7.1). Remarkably the least effective hydrogelator (Compound 5) forms the most crystalline xerogel.

The aggregation of the peptide was also assessed by a thioflavin T (ThT) binding assay. ThT is a benzothiazole dye considered as a small molecular rotor ${ }^{13}$ that exhibits enhanced fluorescence as a consequence of binding to amyloid-like fibrils and has been extensively used for the detection of amyloid fibrils for over half a century. ThT specifically binds to amyloid fibrils, giving an enhanced fluorescence emission at $482 \mathrm{~nm}$, and the corresponding fluorescence intensity reflects the degree of fibrillar aggregation. ${ }^{14}$ 
<smiles>Cc1ccc2c(c1)sc(-c1ccc(N(C)C)cc1)[n+]2C</smiles>

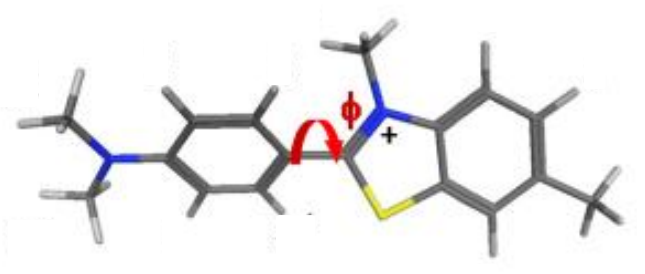

Figure 4.16 Chemical structure of Thioflavin T (ThT) and torsion angle between the benzothiazole and aniline rings.

The increase in ThT fluorescence on binding amyloid fibrils is due to changes in the rotational freedom of the $\mathrm{C}-\mathrm{C}$ bond between the benzothiazole and aniline rings. In the unbound state, the ultrafast twisting dynamics around this bond causes rapid selfquenching of the excited state, resulting in low emission. However, upon binding to fibrils, the excited state is readily populated because the rotational freedom is restricted. ${ }^{11,13}$

In our case ThT assay was employed in order to have an estimation of the presence of accessible extensive aromatic surfaces caused by aggregation. The optimal ThT final concentration was estimated to be $5 \mu \mathrm{M}$ (See S.I. 4.1.8.1) after a preliminary experiment in which increasing amounts of ThT were added into the hydrogel of compound 1 at its m.g.c. The fluorescence at $482 \mathrm{~nm}$ increased with ThT concentration up to $24 \mu \mathrm{M}$ and then a progressive decrease was observed. As a consequence, a lower ThT concentration was used to avoid uncontrolled effects previously described by some authors at higher concentrations which produce a decrease in fluorescence intensity. ${ }^{11}$ 15 The measurements reported were acquired after $20 \mathrm{~min}$ of ThT addition into the hydrogels at their m.g.c. After this time fluorescence intensities remained constant (See S.I. 4.1.8.1). As can be seen in Figure 4.17, hydrogels 6,1 and 3 show higher affinity for ThT, followed by $\mathbf{5}$, with hydrogels 2 and $\mathbf{4}$ being the least effective binders of ThT. Compounds 6, 3 and 1, which are the best gelators, share a common feature in their structure, the aspartic acid at C-terminal position, however we could not elucidate how it can contribute to the ThT affinity. Apparently no other sequence similarities could give an explanation to these data so therefore they will be reviewed after modeling the packing of aggregates. 


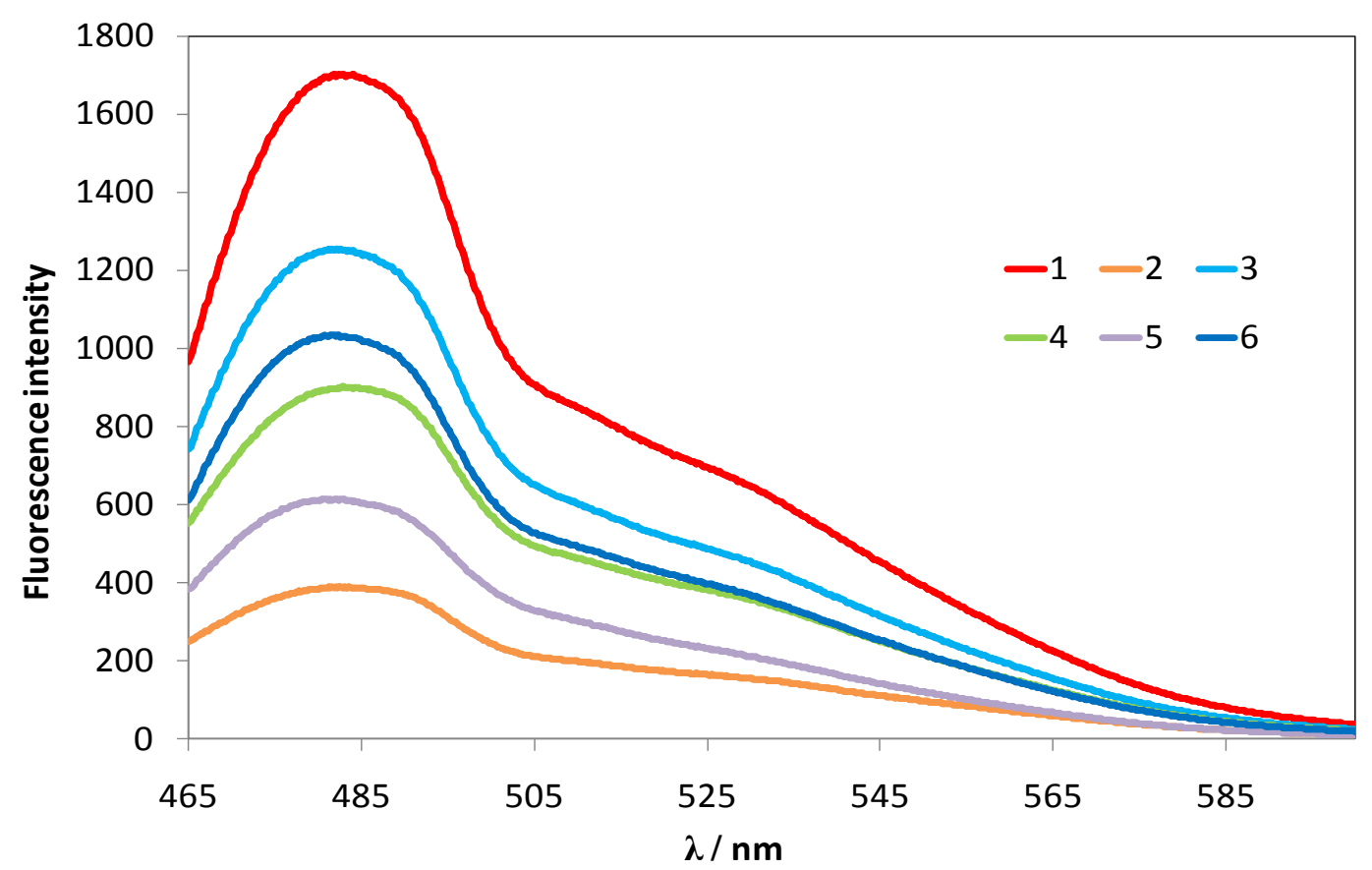

Figure 4.17 Fluorescence emission spectra $\left(\lambda_{\mathrm{ex}}=450 \mathrm{~nm}\right)$ of the hydrogels 1-6 at their m.g.c. after the addition of ThT (5 $\mu \mathrm{M}, 20 \mathrm{~min})$.

Considering all the structural data obtained so far, tentative packing models for the assemblies were constructed using Macromodel 9.9 software ${ }^{16}$ (AMBER* force field and a generalized Born surface area (GB/SA) solvent simulation for water). First of all a conformational search of a single molecule was carried out to generate low-energy molecular structures. These structures were used with slight modifications to generate the assemblies by using an antiparallel arrangement (according to IR data) of the molecules and the energy of those assemblies was finally minimized. Taking into consideration the important role of the $\pi-\pi$ and hydrophobic interactions for the final arrangement, the aromatic amino acid disposition will be deeply analyzed. Such aromatic distribution will also lead $D$ residues more or less accessible for intra or interlayer $\mathrm{H}$-bonding.

The alternated sequences of compounds $\mathbf{1}$ and $\mathbf{2}$ self-assemble in an antiparallel arrangement exposing polar residues on one face of the sheet and non-polar residues on the other one (Figure 4.18). Compound 2 shows a more regular aromatic distribution because the $\mathrm{Z}$ group is not close to an $\mathrm{F}$ residue as in compound 1 . This subtle difference among them would have an impact on their aggregation into fibrils. As it was suggested by electron microscopy and WAXD, the packing models also point to a more compact 
packing of compound $\mathbf{2}$ into lamellar aggregates. The presence of a broad fluorescence band around $460 \mathrm{~nm}$ supports this idea as well.

Compounds $\mathbf{3}$ and $\mathbf{4}$ are made by blocks of FF and DD. The proposed aggregated models show a mixture of polar/non-polar residues in both faces of the sheet leading $D$ residues buried by the aromatic residues and less accessible to $\mathrm{H}$-bonding as suggested previously by IR data (Figure 4.19). In the case of compound $\mathbf{3}$ the presence of the aromatic block ZFF may also have an influence on the inter-sheet assembly, whereas compound $\mathbf{4}$ shows slightly higher cristallinity of the aggregates as well as the additional fluorescence band at $460 \mathrm{~nm}$.

A

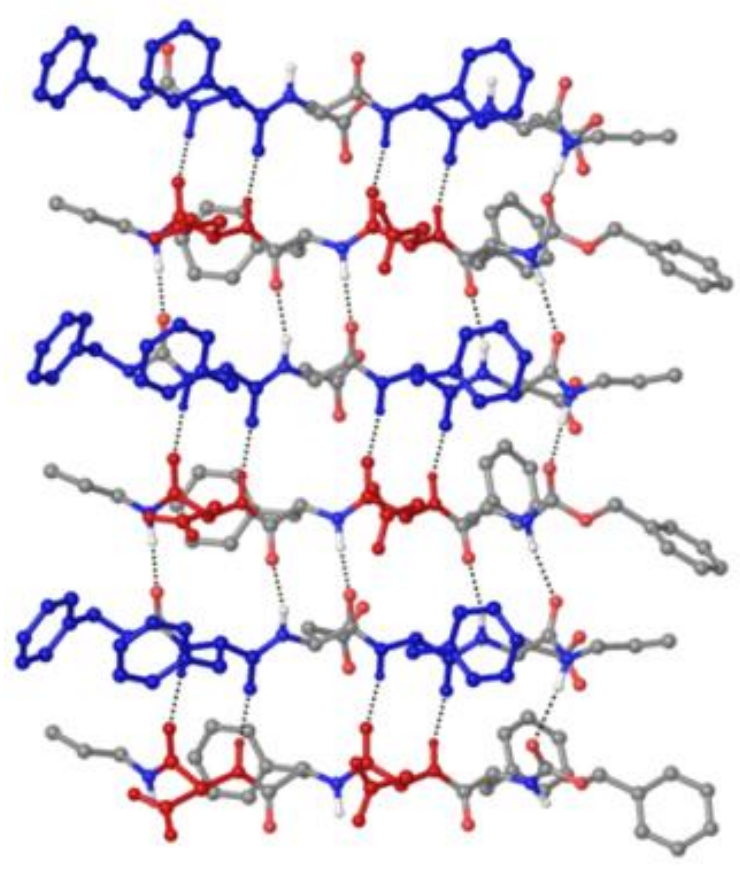

B

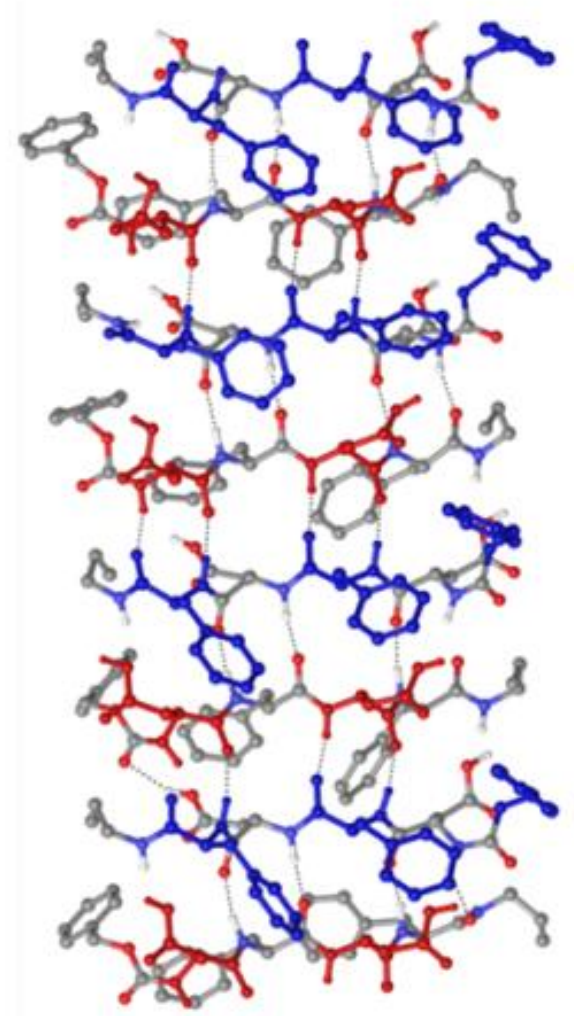

Figure 4.18 Minimised assembly models for compounds 1 (A) and $\mathbf{2}(\mathrm{B})$ in water. Top side aromatic (Z, F) and $D$ residues highlighted in blue and red respectively. Non-polar hydrogens have been omitted for clarity. 
A
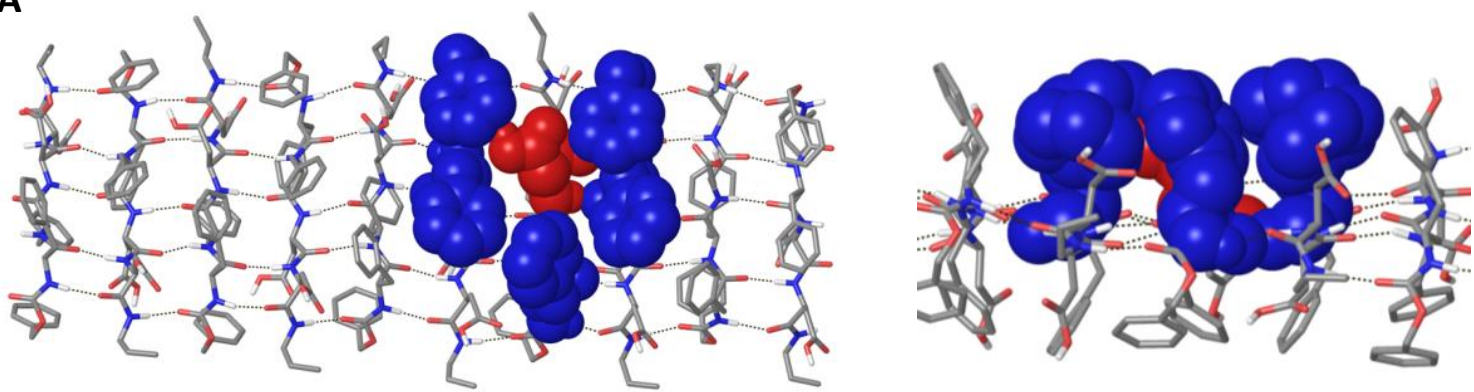

B
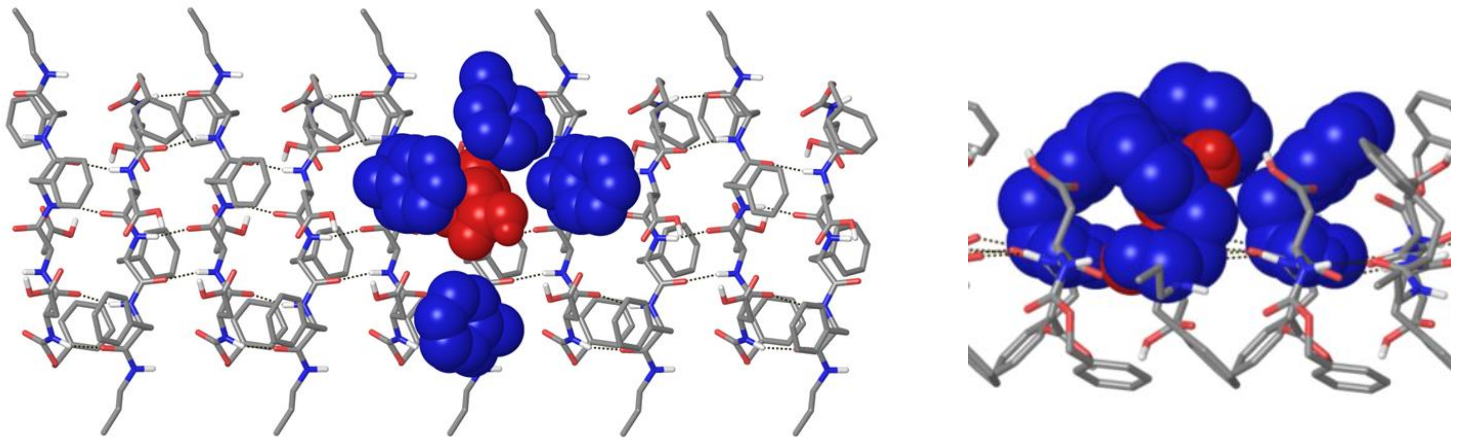

Figure 4.19 Minimised assembly models for compounds 3 (A) and 4 (B). Top side aromatic (Z, F) and D residues highlighted in blue and red respectively. Non-polar hydrogens have been omitted for clarity
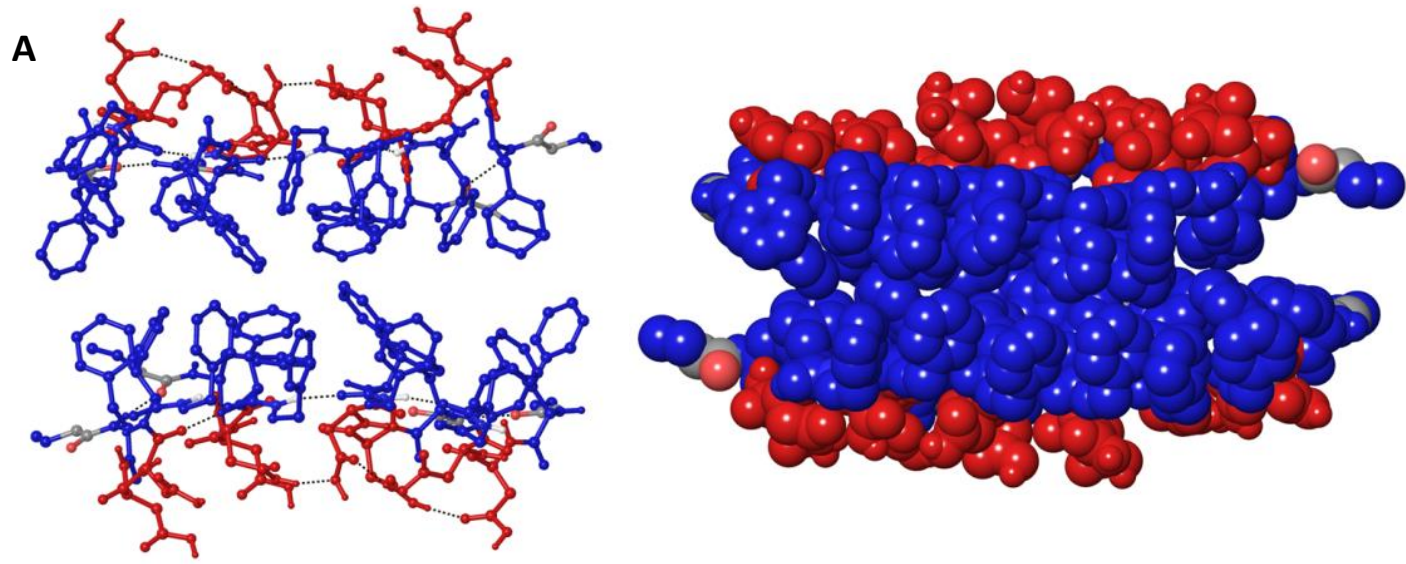

\section{B}
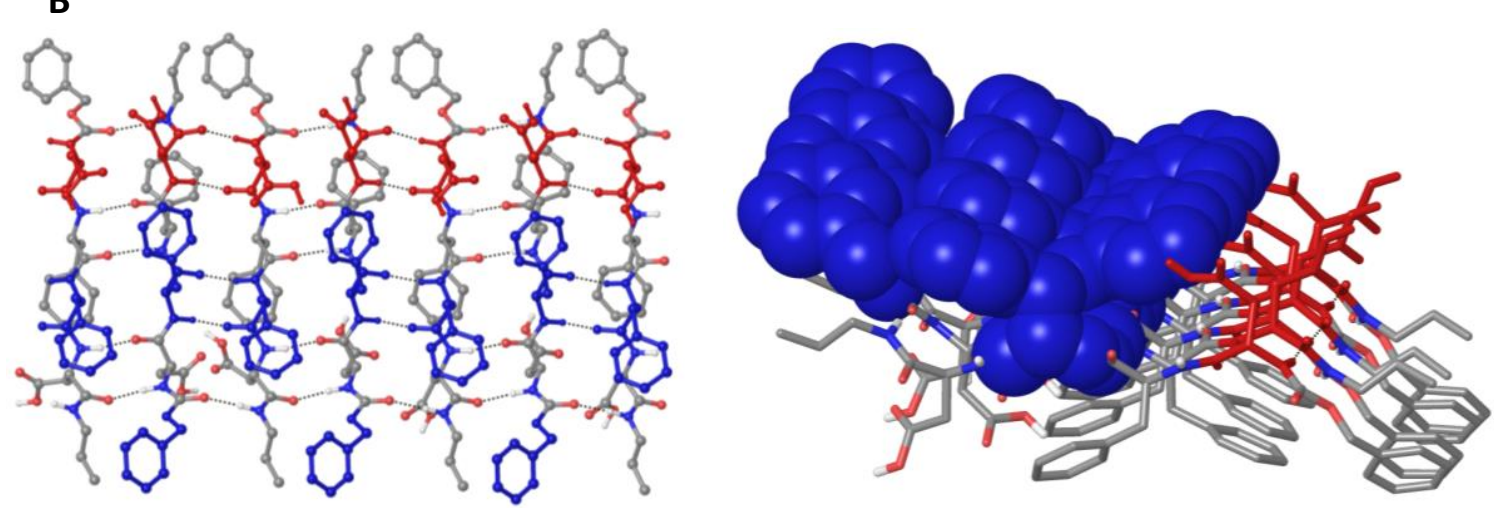

Figure 4.20 Minimised assembly model for compound 5 (B) and compound 6 (C). Aromatic (Z, F) and D residues are highlighted in blue and red, respectively. Non polar hydrogens atoms have been omitted for clarity. 
Considering the lamellar structure suggested specially by WAXD data, a packing mode containing two sheets assembled into a bilayer was proposed for compound $\mathbf{5}$. In this model the aromatic groups are closely packed in a hydrophobic region and the aspartic side chains on the outer face available for $\mathrm{H}$-bonding (Figure 4.20A). This final arrangement agrees with the largest shift in the main fluorescence band of aromatic groups $(14 \mathrm{~nm})$, the presence of an additional band at $460 \mathrm{~nm}$ and the low wavenumbers of carboxylic group IR vibrations for this compound. Finally, compound 6 behaves similarly to compounds $\mathbf{1}$ and $\mathbf{3}$, showing segregated blocks of aromatic and acidic groups in both sides of the sheet leading to low crystallinity (Figure 4.20B).

Compiling now ThT fluorescence data, it can be observed by looking at the models, that compounds 1, 3 and 6, which are the strongest binders, present extended aromatic surfaces in their aggregates. Compounds $\mathbf{2}$ and $\mathbf{4}$, which are the poorest binders, contain a more dispersed distribution of aromatic moieties with no significant hydrophobic blocks. Surprisingly compound $\mathbf{5}$ showed an unusual low ThT affinity considering the large aromatic surfaces that can be seen in the lamellar packing proposed. We suggest that the aromatic groups are so closely packed within the aggregates that the access of ThT to the hydrophobic layer could be quite difficult. So then, ThT data provide us useful information not only about the presence of aromatic surfaces but also about their accessibility.

\subsubsection{Mechanical properties of the hydrogels}

Gels are considered viscoelastic materials, namely, they behave like a hybrid material with properties between those of a solid or a liquid. To determine both the elastic component G' (storage modulus) and the viscous component G" (loss modulus) of a specific material, oscillatory rheological experiments are usually employed. It is important to work in a linear viscoelastic regime (LVR) in which both moduli behave independently of the frequency and oscillatory stress otherwise unreliable results will be obtained. 
A

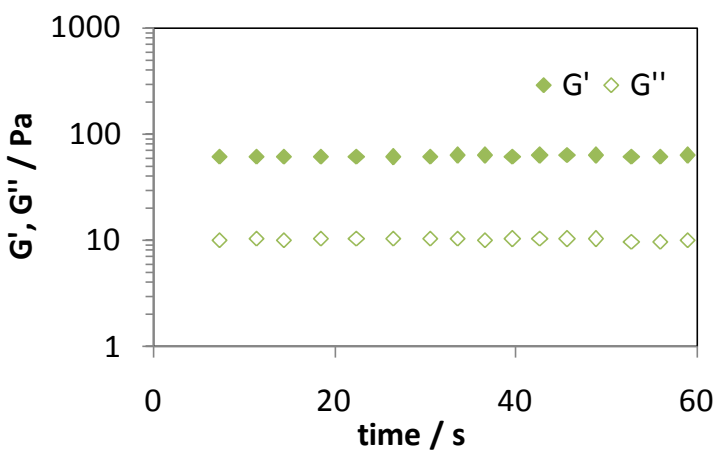

B

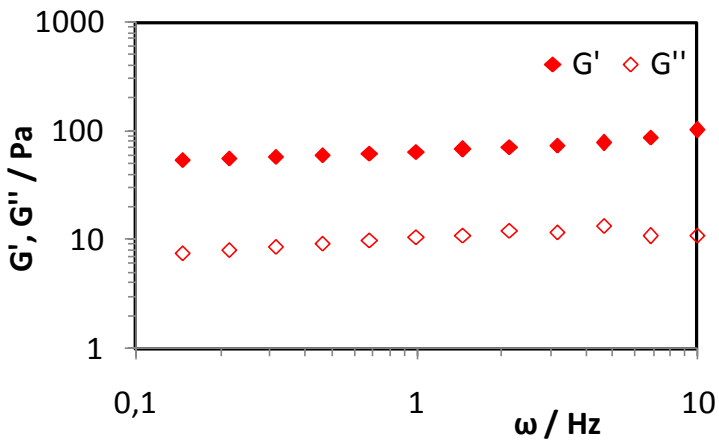

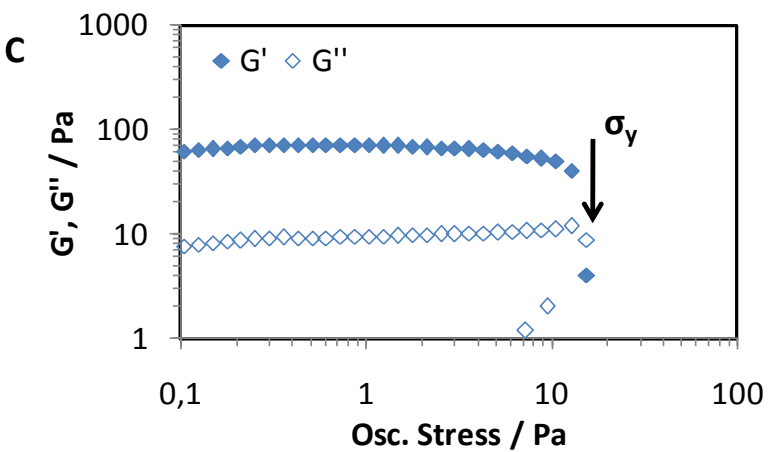

Figure 4.21 Rheological characterization for a hydrogel of compound $\mathbf{3}$ at its m.g.c. A) Storage ( $G^{\prime}$ ) and loss moduli $\left(\mathrm{G}^{\prime \prime}\right)$ monitored over time at constant frequency $(1 \mathrm{~Hz})$ and oscillatory stress $(0.2 \mathrm{~Pa})$; $\left.\mathrm{B}\right)$ Frequency sweep step at a constant oscillatory stress (0.2 Pa); C) Stress sweep step at a constant frequency $(1 \mathrm{~Hz})$.

In a typical experiment (See S.I. 4.1.10) a stabilisation step of 1 minute was required allowing the gel to recover after the partial destruction due to the transfer from the vial to the rheometer. One minute was considered enough time since both modulus reached stable values at this time (Figure 4.21A). After this, the determination of the LVR was carried out by running a frequency sweep at a constant oscillatory stress of $0.2 \mathrm{~Pa}$ (Figure 4.21B) and a stress sweep at a constant frequency of $1 \mathrm{~Hz}$ (Figure 4.21C). On the one hand the LVR as a function of the frequency could be establish from 0.1 to $10 \mathrm{~Hz}$. On the other hand the LVR as a function of the oscillatory stress could be establish from 0.1 to 10 Pa supporting then that measurements were carried out within the LVR.

Interesting information can be extracted specially from the stress sweep shown in Figure 4.21C. The value of the elastic modulus $\left(G^{\prime}\right)$ is higher than that for loss modulus $\left(G^{\prime \prime}\right)$ and remain constant up to the gel breaking point (yield stress, $\left.\sigma_{y}\right)$. This behavior is characteristic of a 3D entangled fibrillar network able to recover from the stress applied and the value of $\mathrm{G}^{\prime}$ can be then considered as a measure of gel strength. 
The data reported for compounds 1-6 are collected in Figure 4.22:

A
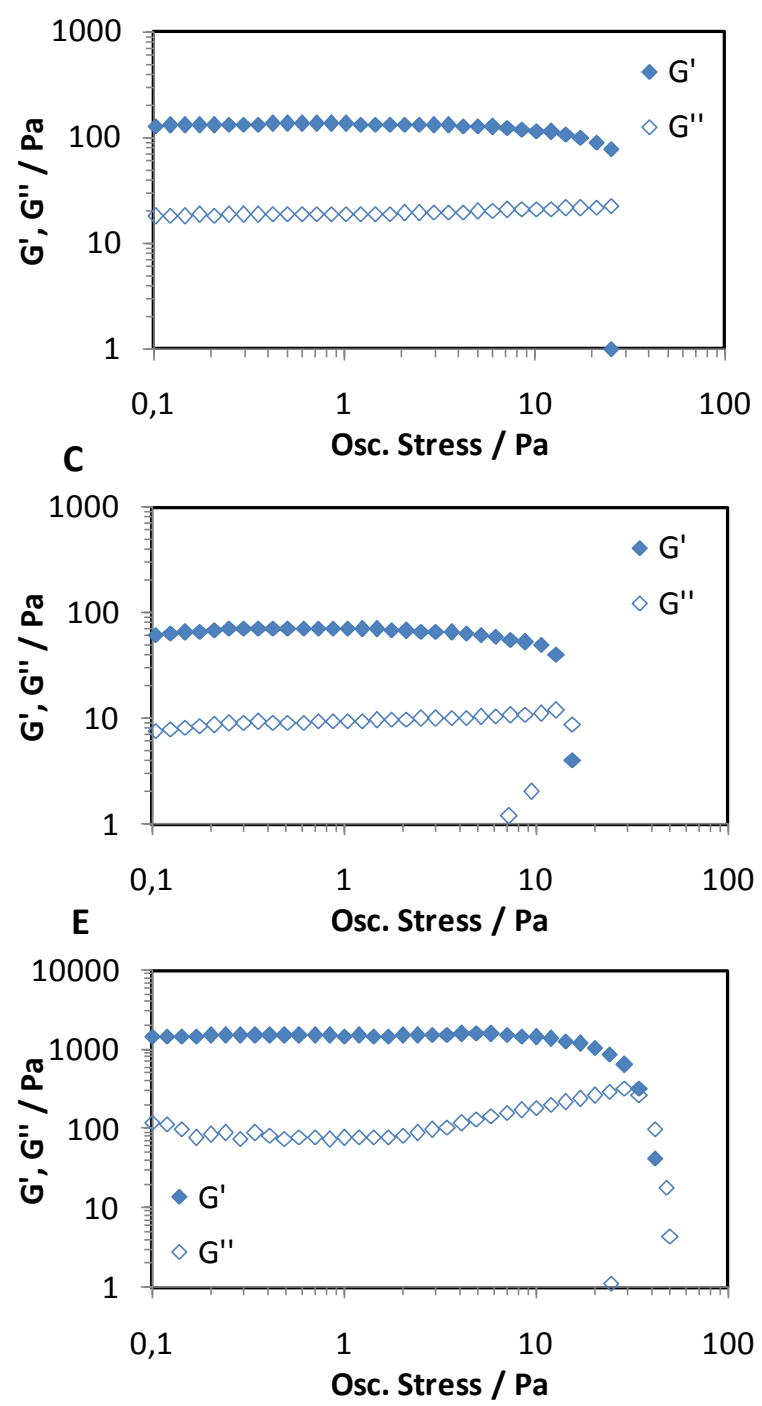

B

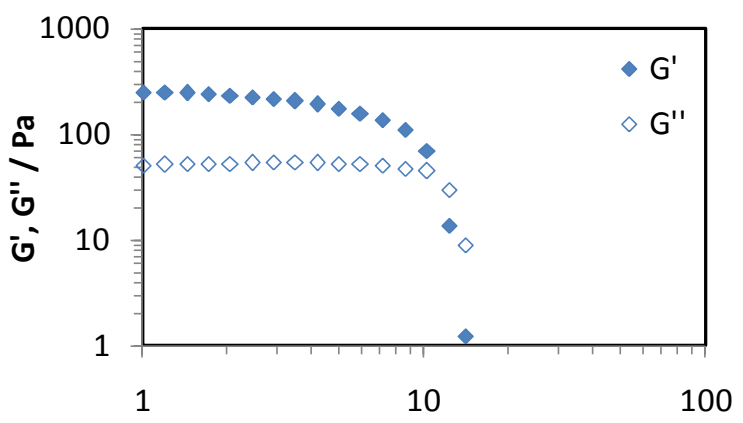

Osc. Stress / Pa
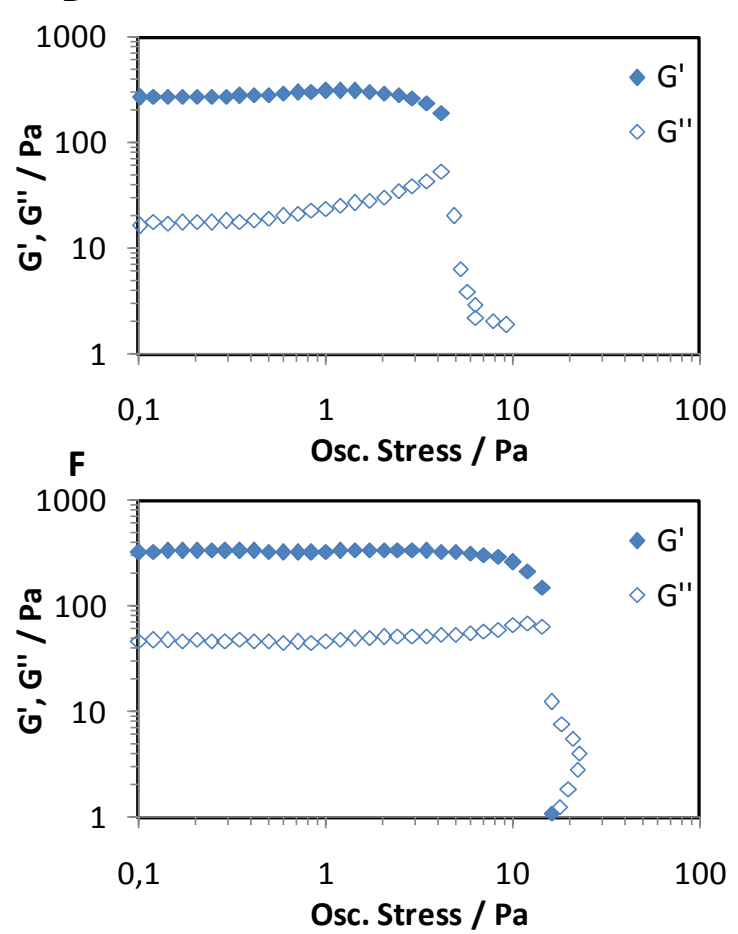

Figure 4.22 Rheological characterisation of hydrogels 1-6 at their m.g.c. Stress sweep step at a constant frequency (1 Hz) for compound A) 1, B) 2, C) 3, D) 4, E) 5 and F) 6.

In general a viscoelastic behavior can be ascribed to the gels formed by compounds 1-6 since $G^{\prime}$ value is bigger than $G^{\prime \prime}$ until the breaking point $\left(\sigma_{y}\right)$ is reached. However, all the hydrogels at their m.g.c. are relatively weak with $G^{\prime}$ values around 100 Pa. Significant differences are shown for compound 5 which reveals a $G^{\prime}$ value of one order of magnitude bigger and a yield stress around $50 \mathrm{~Pa}$. 


\subsection{Thermodynamic and kinetic studies of the fibrillisation process}

During last decades researchers have succeeded in elucidating the structural features of amyloid fibrils revealing a common $\beta$-cross structure. ${ }^{17}$ It is possible now to distinguish between amyloid fibrils and oligomers from other amorphous aggregates due to the development of cryo-electron microscopy, solid-state NMR spectroscopy or $\mathrm{X}$-ray diffraction techniques. ${ }^{18}$ The increasing knowledge on this topic has meant great advances in material sciences among others fields. However despite the efforts involved in the discovery of new drugs for amyloid diseases in recent years, commonly available therapies have mainly palliative effects and are not able to reverse the progression of the disease. The search for effective drugs becomes complicated in part by the lack of knowledge about kinetics and specially thermodynamics of fibrillisation mechanisms that lead to the formation of the different structures involved in such diseases.

It is increasingly accepted and demonstrated that the amyloid state might be thermodynamically more stable than the functional native states of many proteins even under physiological conditions. ${ }^{19}$ The conversion from the soluble to amyloid state involves intermolecular interactions and as a consequence the thermodynamic stability of the amyloid state will be favored at higher concentrations. These observations raise the possibility that at the concentrations present in living systems, the native states may not always represent the absolute free energy minima of the corresponding polypeptide chains, that is, the native form of a protein could in some cases simply be a metastable monomeric state which is separated from its polymeric amyloid form by high kinetic barriers. Nature has tried to minimize the risk of amyloid formation by evolving proteins with 300-500 residues on average because the topological constraints associated with packing such long polypeptides avoids the transition from soluble to aggregate state. In fact, the amyloid fibrils associated with disease are all composed of relatively short peptides, proteins or proteolytic fragments of larger precursor proteins. ${ }^{20}$

The determination of thermodynamic parameters associated to amyloid formation remains largely unknown. Recently isothermal titration calorimetry has been described by Ikenoue and co-workers ${ }^{21}$ or direct measurements of fluctuations in fibril mass reported by Dobson and co-workers. ${ }^{22}$ 
The kinetics of fibrillisation generally follows a sigmoidal trend which is characteristic of nucleation-dependent polymerization. An initial lag phase in which a steady-state distribution of oligomeric species is established is followed by a growth phase in which oligomers larger than a critical nucleus size are extended to form much larger aggregates or fibrils. Due to the existence of a preliminary fibril template, the growth step is thermodynamically favoured over nucleation. This aggregation mechanism can be described with an Avrami type analysis using two parameters related respectively to nucleation and growth rates. ${ }^{23}$ Kinetics in the growth phase has been found to be first order, namely, the rate of fibril formation is proportional to the concentration of monomers. ${ }^{24}$ Interestingly shear flow or agitation accelerates fibres growth and this behaviour is ascribed to the fragmentation of fibrils which would produce an increase in the number of growing fibril ends in a similar way to the addition of pre-formed fibrils (seeding). ${ }^{25}$

A range of different techniques has been developed to study the kinetic aspects of this aggregation process. ${ }^{26}$ Some of the more useful methodologies include monitoring the increase in light scattering (turbidimetry) of a growing amyloid suspension or the change in fluorescence or absorption of dyes that bind to amyloid. However amyloid quantification using such techniques is not always an easy task because for instance, light scattering measurements are highly sensitive to other processes than fibril growth or dyes can bind non-specifically to non-amyloid structures such as amorphous aggregates. Other techniques have been therefore developed like atomic force microscopy ${ }^{27}$ and dynamic light scattering ${ }^{26 b}$ which allows monitoring directly the growth of individual or assembled fibrils respectively. In addition other methods like mass spectrometry have also emerged and focusing on changes in concentration of the precursor protein as a measure of its incorporation into growing fibrils.

The relationship between thermodynamic and kinetic processes in peptide fibrillisation is not clearly established but it has been pointed out that at least in the case of $A \beta 40$ the determinants of both processes have a similar physicochemical basis. ${ }^{28}$ However more studies are needed to extend this statement for other peptides and proteins. 
Small peptides have been used to model the aggregation of larger native peptides or to gain general insight into the mechanism of fibre formation because they are often easier to handle and have higher reproducibility in terms of aggregation behaviour. ${ }^{29}$ Considering the differences previously reported for the family of isomeric tetrepeptides 1-6 in terms of hydrogelation capability, fibrillar morphology and structural arrangements we decided to go a step further with these compounds and delve into the kinetics and thermodynamics of their fibrillisation process. One of the main goals here would be to elucidate the complex relationship between thermodynamics and kinetics in peptide fibrillisation as well as the high impact of $\mathrm{pH}$ on the process as a result of the ionisable character of these compounds. Additionally, kinetic self-sorting of two isomeric hydrogelators is also reported as an application of the present study.

\subsubsection{Thermodynamics}

The use of water as solvent for gelators 1-6 and the presence of ionisable groups in such compounds force us to determine their $\mathrm{pKa/ionisation} \mathrm{behaviour} \mathrm{for} \mathrm{a} \mathrm{full}$ description of the systems. Potentiometric titration will allow evaluating acid-base thermodynamic constants in a first place and further thermodynamic data regarding the fibrillisation will be extracted from the pKa shifts associated to the aggregation process. The slow formation (on the titration time scale) of insoluble species during these titrations may hinder the process and some technical considerations should be taken to overcome it. Some authors for instance, reported a standing time between each addition of the titrant ${ }^{30}$ or even heating and vigorous agitation of the samples to ensure the absence of artefacts related to gel formation and clogging the membrane of the electrode. ${ }^{31}$ Other authors however, preferred starting the titrations at a $\mathrm{pH}$ where the molecules are already in their aggregated state to avoid kinetic effects. ${ }^{32}$ Particularly in our case the hydrogelators were dissolved in water as their dianionic form $\left(\mathrm{P}^{-2}\right)$ by addition of an excess of triethylamine and then titrated with aqueous $\mathrm{HCl}$ (See S.I. 4.2.1). A typical titration curve and a schematic representation of species formed during the process are shown in Figure 4.23: 

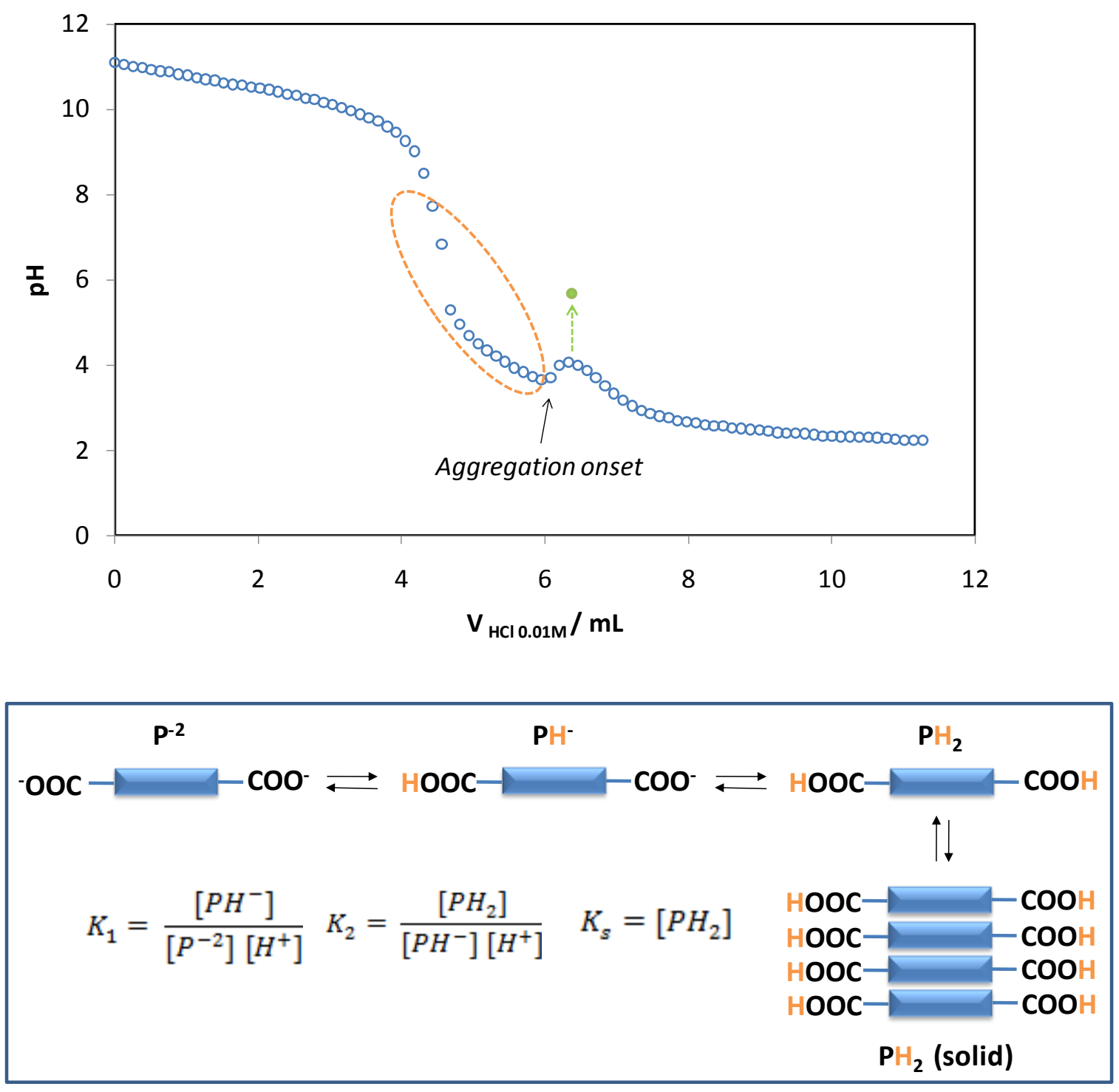

Figure 4.23 Representative example of a full titration curve. The points inside the dashed oval are used for the calculation of acidity constants of soluble species. Green point represents the $\mathrm{pH}$ value $24 \mathrm{~h}$ after the addition of the corresponding $\mathrm{V}$ of $\mathrm{HCl}$ (top). Schematic representation of the different species present during the titration experiment (bottom).

Thermodynamic acidity constants for the species in solution $\left(K_{1}\right.$ and $\left.K_{2}\right)$ were determined for all compounds using titration data acquired before the onset of aggregation (points inside the dashed oval). On the other hand, to assess the solubility product $\left(\mathrm{K}_{\mathrm{s}}\right)$, titration was stopped when a solid precipitate was observed and $\mathrm{pH}$ was measured after $24 \mathrm{~h}$ when thermodynamic equilibrium was reached $(\mathrm{pH}$ values were constant after this time).

For the calculations an important assumption was considered: the fibrillar network is composed exclusively by the neutral species $\left(\mathrm{PH}_{2}\right)$. Although no experimental evidences are provided to support it, we consider that this is a good approach due to the 
high solubility of ionic species in water. In addition other authors have previously reported results for $\mathrm{pH}$ sensitive gelators assuming this same hypothesis. ${ }^{33}$

Table 4.4 Thermodynamic acid-base and solubility constants of tetrapeptides 1-6 at 25 으 in water. ${ }^{a}$

\begin{tabular}{cccccccc}
\hline \multicolumn{2}{c}{ Compound } & $\log \mathrm{K}_{\mathbf{1}}$ & $\log \mathrm{K}_{\mathbf{2}}$ & $\log \mathrm{K}_{\mathbf{2 a p p}}$ & $\log \mathrm{K}_{\mathbf{2 a p p}}-\log \mathrm{K}_{\mathbf{2}}$ & $\mathbf{p K _ { \mathbf { s } }}$ & $\Delta \mathbf{G}_{\text {fib }} / \mathbf{~ k J ~} \mathbf{~ m o l}^{-\mathbf{1}}$ \\
\hline $\mathbf{1}$ & $\mathrm{ZFDFDC}_{3}$ & 4.27 & 4.14 & 6.0 & 1.9 & 5.4 & -31 \\
$\mathbf{2}$ & ZDFDFC $_{3}$ & 4.12 & 3.37 & 7.0 & 3.6 & 6.8 & -39 \\
$\mathbf{3}$ & ZFFDDC $_{3}$ & 4.31 & 4.17 & 6.1 & 1.9 & 5.2 & -30 \\
$\mathbf{4}$ & ZDDFFC $_{3}$ & 4.40 & 3.26 & 6.6 & 3.3 & 6.6 & -38 \\
$\mathbf{5}$ & ZFDDFC $_{3}$ & 4.47 & 4.25 & 7.5 & 3.3 & 6.7 & -38 \\
$\mathbf{6}$ & ZDFFDC $_{3}$ & 4.34 & 2.77 & 6.0 & 3.2 & 6.6 & -38 \\
\hline
\end{tabular}

a) Errors affect the last digit, being \pm 0.05 or lower for $\log K_{1}$ and $\log K_{2}, \pm 0.1$ or lower for $\log K_{2 a p p}-\log K_{2}$ and $p K_{s}$ and \pm 1 for $\Delta G_{\text {fib. }}$.

Values for $\mathrm{K}_{1}$ and $\mathrm{K}_{2}$ were determined by using the software Hyperquad-2008 and the results appear collected in Table 4.4. As can be observed, similar values were obtained for the first protonation constant of dianionic species in a range between 4.1 and 4.4. However significant differences arose for second protonation constants. Looking at the sequence of the tetrapeptides those with aspartic acid close to the benzyloxycarbonyl group $(\mathbf{2}, \mathbf{4}, \mathbf{6})$ exhibited lower values of $\mathrm{pK}_{2}(\mathrm{ca} .3)$ than the other compounds ( $\mathrm{pK}_{2}$ ca. 4). This means that compounds $\mathbf{2 ,} 4$ and 6 have higher acidity most likely due to the stabilization of the carboxylate unit at the $\mathrm{N}$-terminus via intramolecular $\mathrm{H}$-bonding with the carbamate $\mathrm{NH}$ to yield a 6-membered ring (Figure 4.24). For the rest of compounds both protonation constants are virtually indistinguishable and it is not possible to assign each value to a specific aspartic acid of the sequence.<smiles>[R]C(=O)C1CC(=O)O[C@@H]1NC(=O)OCc1ccccc1</smiles><smiles>[BH2-]1[C+]=C1</smiles><smiles>[R]C(=O)C(CC(=O)O)NC(=O)OCc1ccccc1</smiles>

$\ominus$

Figure 4.24 Schematic representation of the acid-base equilibrium involving aspartic acid at the $\mathrm{N}$ terminus.

To proceed with the discussion it is necessary to define an apparent protonation constant, $\mathrm{K}_{2 a p p}$ which describes the conversion of $\mathrm{PH}^{-}$into solid fibres $\mathrm{PH}_{2}$ (solid). This apparent constant encompasses the free energy contributions of the protonation 
process and the aggregation into solid fibres. Such value was obtained by fitting the titration data to a theoretical system without solid formation using the software Hyss2009. As can be seen in Table 4.4 all the values for $p K_{2 a p p}$ are above 6.0 indicating an aggregation-induced shift for $\mathrm{pK}_{2}$ of the carboxylic acids which is expected to have $\mathrm{pK}_{\mathrm{a}}$ values around 4.5 in solution. Similar $\mathrm{pK}_{\mathrm{a}}$ shifts have been previously reported by Ulijn ${ }^{31 a}$ and Adams $^{34}$ for Fmoc- and naphthalene-dipeptides respectively. It is also known that pKa can shift dramatically in proteins, especially in hydrophobic environments as it has been proved many times by Urry and co-workers. ${ }^{35}$ The present shift in the second protonation constant for our systems allows hydrogel formation around neutrality becoming therefore useful for potential biological applications.

Shifts between $\mathrm{pK}_{2 \mathrm{app}}$ and $\mathrm{pK}_{2}$ are shown in Table 4.4 and their magnitude is directly related to the solubility of the tetrapeptides, that is, to the free energy change associated with fibrillisation. For example the highest shift of $\mathrm{pK}_{2}$ is observed for compound 2 which presents the lowest solubility product (pKs $=6.8$ ). Conversely compounds $\mathbf{1}$ and $\mathbf{3}$ which are the more soluble hydrogelators undergo the lowest shift in the second protonation constant. Also noticeable is the significant differences found among the different isomeric tetrapeptides. For example alternated compounds $\mathbf{1}$ and $\mathbf{2}$ show quite different fibrillisation tendencies, with markedly different solubility and protonation constants. These results support once again how important is the relative positioning of the amino acids along the peptide sequence.

In Figure 4.25 an experimental titration curve of compound 4 is compared with both the calculated theoretical curve obtained using the constants in Table 4.4 and the curve that would be obtained with no fibrillisation. The curves are overlaid until the calculated fibrillisation onset (c.a. $3.2 \mathrm{~mL}$ ). From that point the experimental titration curve (circle line) diverges dramatically from the thermodynamically predicted one (dashed line). This behaviour should be ascribed to very important kinetic effects, the system being in a metastable state. On the other hand the experimental titration curve shows a sudden increase of $\mathrm{pH}$, for an added volume of ca. $4 \mathrm{~mL}$, which corresponds to the onset of fibrillisation of the metastable solutions. However, the fibrillisation is not fast enough, in the titration time scale, to reach the thermodynamic equilibrium and does not match therefore the calculated curve. It is also important to highlight that the 
differences between calculated curves with (dashed line) and without fibrillisation (cross line) come out for $\mathrm{pH}<6$ when fibre formation should start thermodynamically, resulting in an apparent basicity increase linked to the aggregation process.

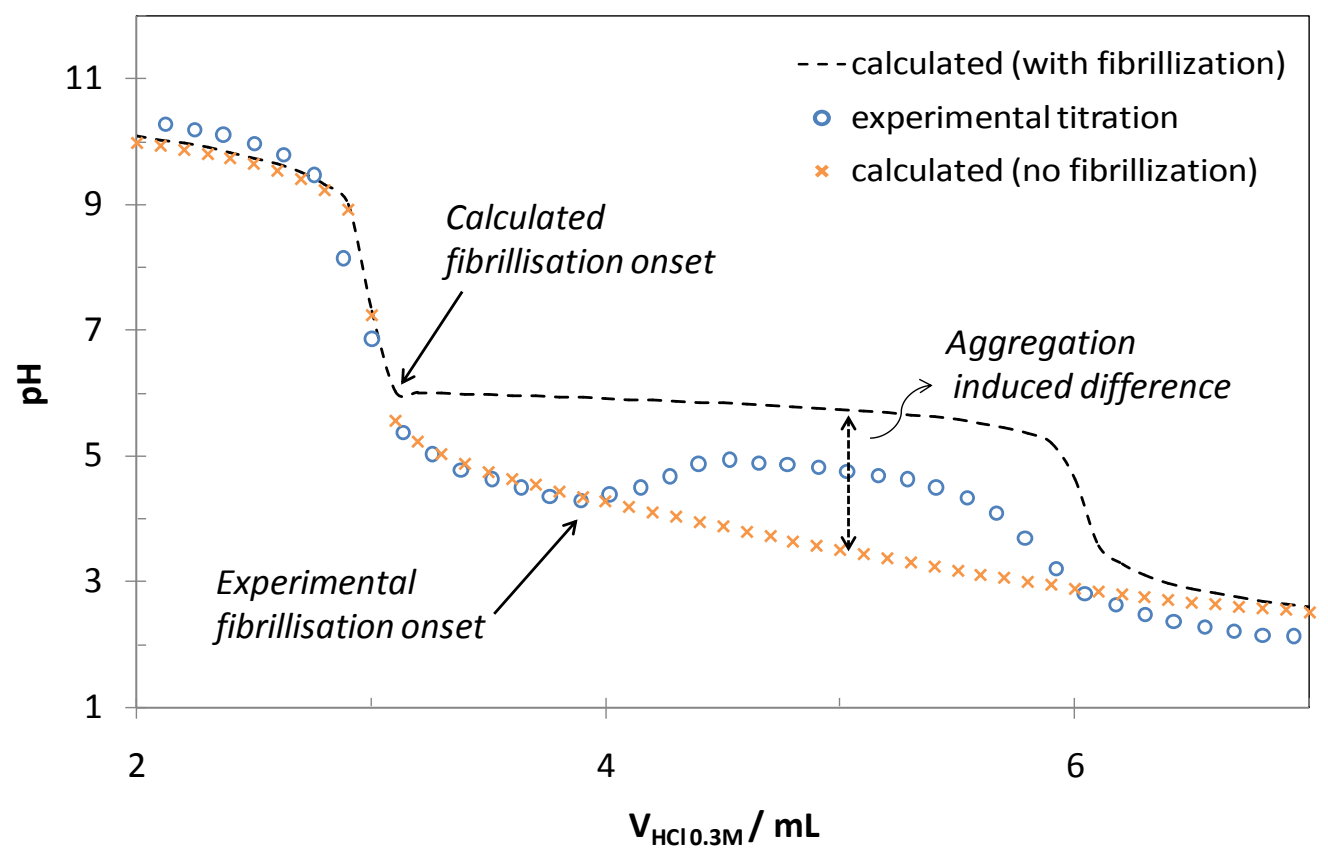

Figure 4.25 Experimental and calculated tiration curves for compound $\mathbf{4}$ at 25 으. The initial solution was composed of $9 \mathrm{mM}$ peptide and $36 \mathrm{mM}$ of triethylamine.

\subsubsection{Kinetics}

Once we know some thermodynamic aspects of our systems it is time to gain further insight into the aggregation kinetics in order to assess a possible correlation among both aspects. To monitor the kinetics of the process ${ }^{1} \mathrm{H}$ NMR and fluorescence spectroscopy were employed. The gelation was induced by hydrolysis of $\mathrm{GdL}$ as previously described in this chapter. ${ }^{1} \mathrm{H}$ NMR is a highly convenient tool since aggregates present a reduced transversal relaxation time $\left(T_{2}\right)$ resulting in long correlation times and therefore a broadening of the signals that often are hidden under the baseline (NMRsilent). Thereby a decrease in intensity (over time) in the NMR signals will be associated to fibril formation (Figure 4.26). According to that, the kinetics of fibrillisation was monitored for compounds 1-6 and the corresponding data are collected in Figure 4.27. As can be seen in this graph, the onset of fibrillisation is preceded in all the cases by an induction time which significantly differs for each compound. Compounds $\mathbf{1}$ and $\mathbf{3}$ for instance show an induction time around $2.5 \mathrm{~h}$ while other tetrapeptides like 4 and 6 
present values larger than $4 \mathrm{~h}$. As a general behaviour once the aggregation is started, the fibrillisation process is rather slow taking several hours to reach equilibrium.

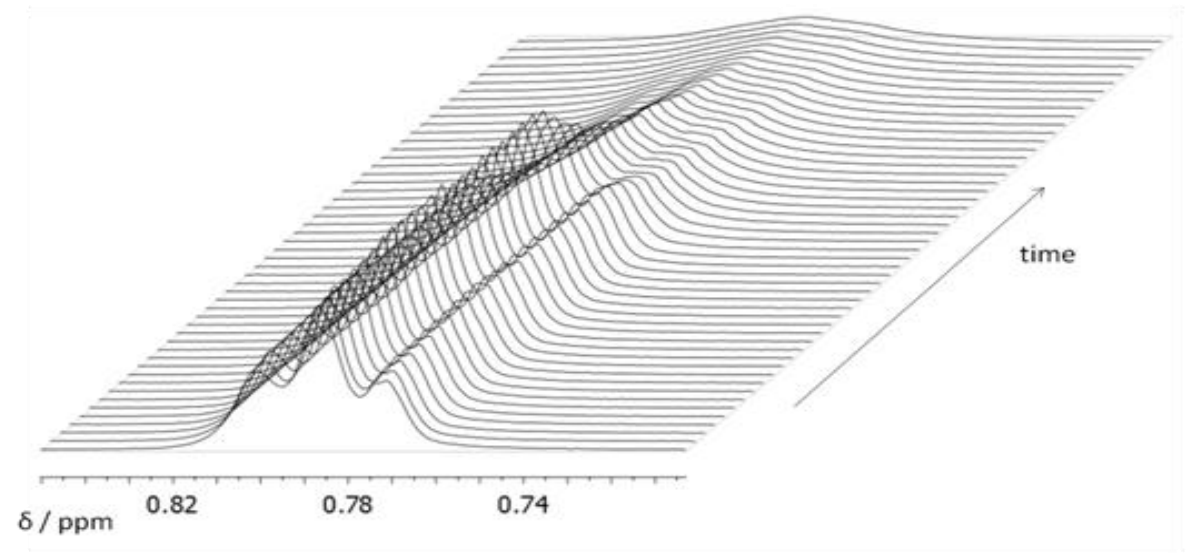

Figure 4.26 ${ }^{1} \mathrm{H}$ NMR signal monitored over time during gel form at ion by means of GdL (the signal corresponds to terminal $\mathrm{CH}_{3}$ of compound 5 ).

In a first instance it was thought that such differences in induction times were just a coincidence and maybe not reproducible from one experiment to another. However the experiments were repeated leading reproducible induction times in all the cases. Such reproducibility cannot be explained by stochastic nucleation events similar to a crystallization process ${ }^{36}$ and other plausible explanation should be provided.

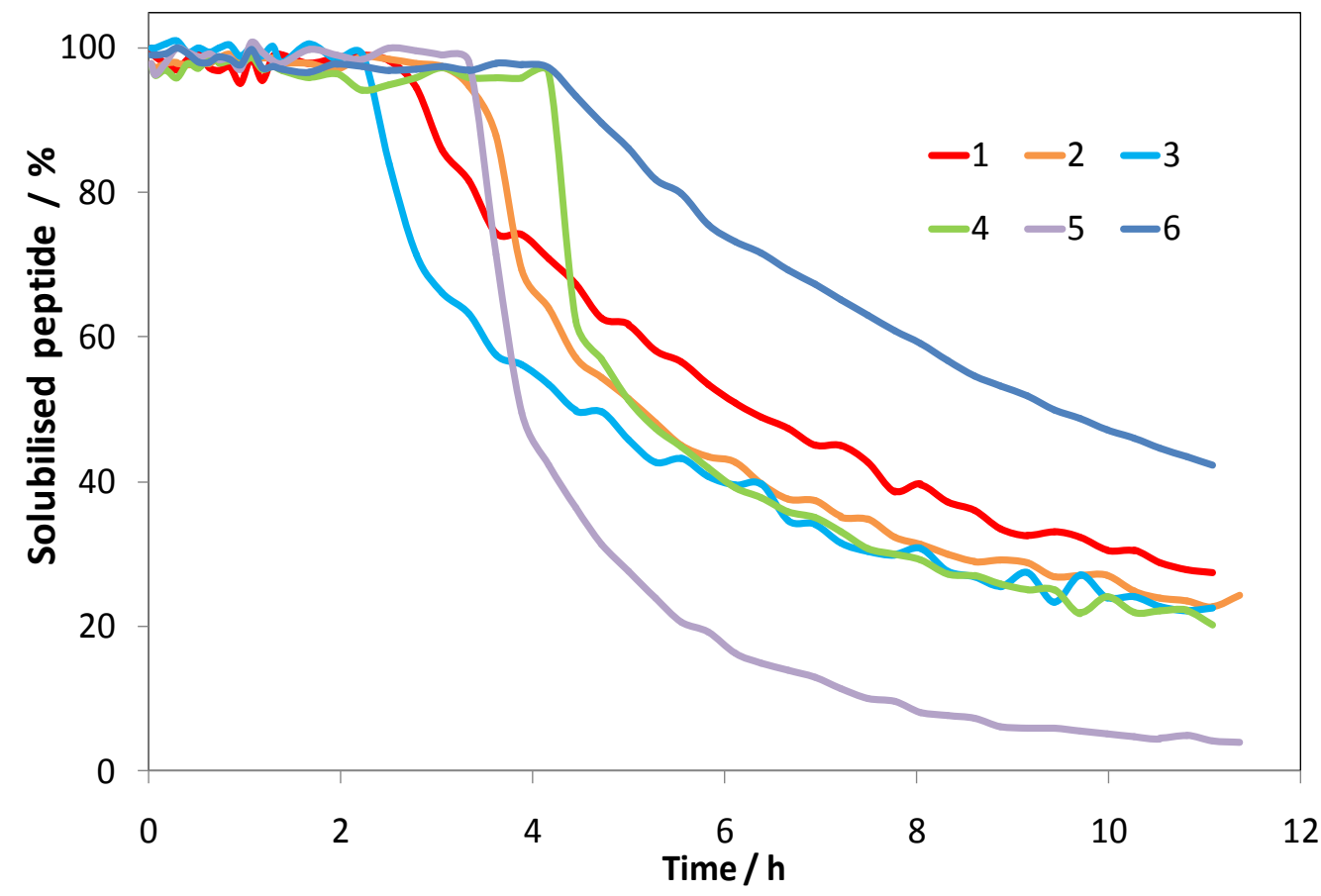

Figure 4.27 Variation of NMR signal $\left(-\mathrm{CH}_{3}\right)$ intensity with time upon smooth acidification of a solution containing the tetrapeptides in their dianionic form. [Tetrapeptide] $=10 \mathrm{mM},\left[\mathrm{Na}_{2} \mathrm{CO}_{3}\right]=25 \mathrm{mM},[\mathrm{GdL}]=$ $38 \mathrm{mM}, 25 \stackrel{\circ}{ } \mathrm{C}$. 
Going deeply into this behaviour the $\mathrm{pH}$ values during the gelation process were also monitored and then compared with previous ${ }^{1} \mathrm{H}$ NMR kinetics. As a representative example, the variations of NMR signal intensity and of $\mathrm{pH}$ values for compound $\mathbf{2}$ are represented in Figure 4.28. As we expected the total induction time, around $2.7 \mathrm{~h}$ in this case, includes the time required the $\mathrm{pH}$ to reach the thermodynamic aggregation onset (1.5 h) and besides, an extra period where thermodynamically metastable solutions are present $(1.2 \mathrm{~h})$. Therefore, as mentioned before, in these systems metastable, supersaturated, solutions are formed which are kinetically trapped (green area). The very low concentration of $\mathrm{PH}_{2}$ species in the metastable region due to the free activation energy required for aggregation (associated to conformational changes most likely) may explain this behaviour.

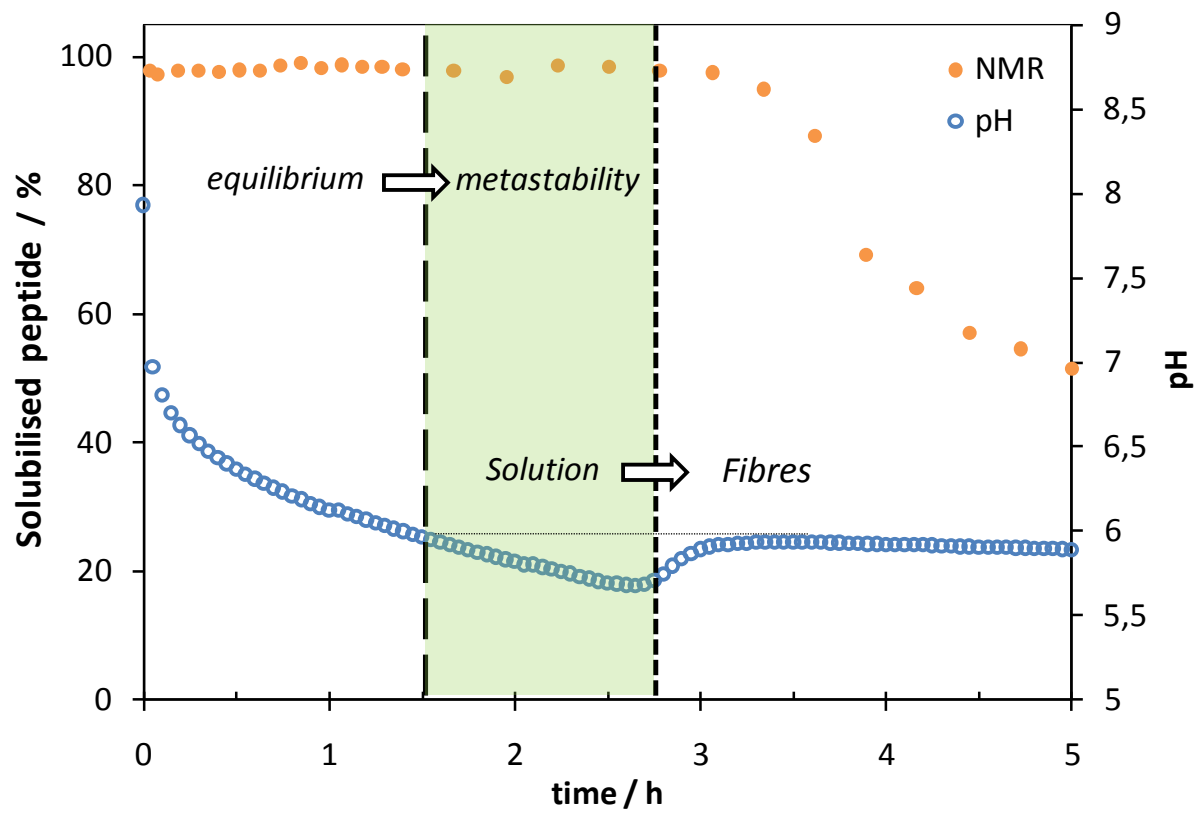

Figure 4.28 Variation of $\mathrm{pH}$ and ${ }^{1} \mathrm{H}$ NMR signal intensity with time upon smooth acidification of a solution of dianionic compound $\mathbf{2}$ in water by means of $\mathrm{GdL}$ hydrolysis. [Tetrapeptide] $=10 \mathrm{mM},\left[\mathrm{Na}_{2} \mathrm{CO}_{3}\right]=40 \mathrm{mM}$, $[\delta-\mathrm{GdL}]=38 \mathrm{mM} ; 25 \stackrel{\circ}{\circ}$.

Once we know the presence of this period of metastability for all the compounds, one may wonder which is the rate determining step responsible for the fibrillisation process to take several hours. To go further into this aspect, the kinetics of fibrillisation was monitored by fluorescence using phenylalanine aromatic groups as chromophores. The fluorescence emission of phenylalanine units was recorded from $270 \mathrm{~nm}$ to $600 \mathrm{~nm}$ with excitation at $260 \mathrm{~nm}$ and afterwards a representative wavelength was plotted over 
time as can be observed in Figure 4.29 (orange circles) for the case of compound 2. As a general trend the onset of fibrillisation is accompanied by a dramatic increase of fluorescence intensity followed by a continued decline during fibre formation. These results can be ascribed to the formation of transient intermediate species which most likely correspond to dimers $\left(\mathrm{PH}_{2}-\mathrm{PH}_{2}\right)$ whose fluorescence is much more intense than in the case of free peptides.

The initial burst of dimer concentration would take place when the accumulated concentration of $\mathrm{PH}_{2}$ species in the metastable solutions is large enough for the dimerisation to take place fast enough on the time scale of the measurements. Then, a progressive reduction in fluorescence intensity along with the advance of fibrillisation is observed. This behaviour can be explained if one considers that the fibres are poorly fluorescent and the observed emission corresponds almost exclusively of the transient dimer species whose concentration decreases with time until the equilibrium is reached.

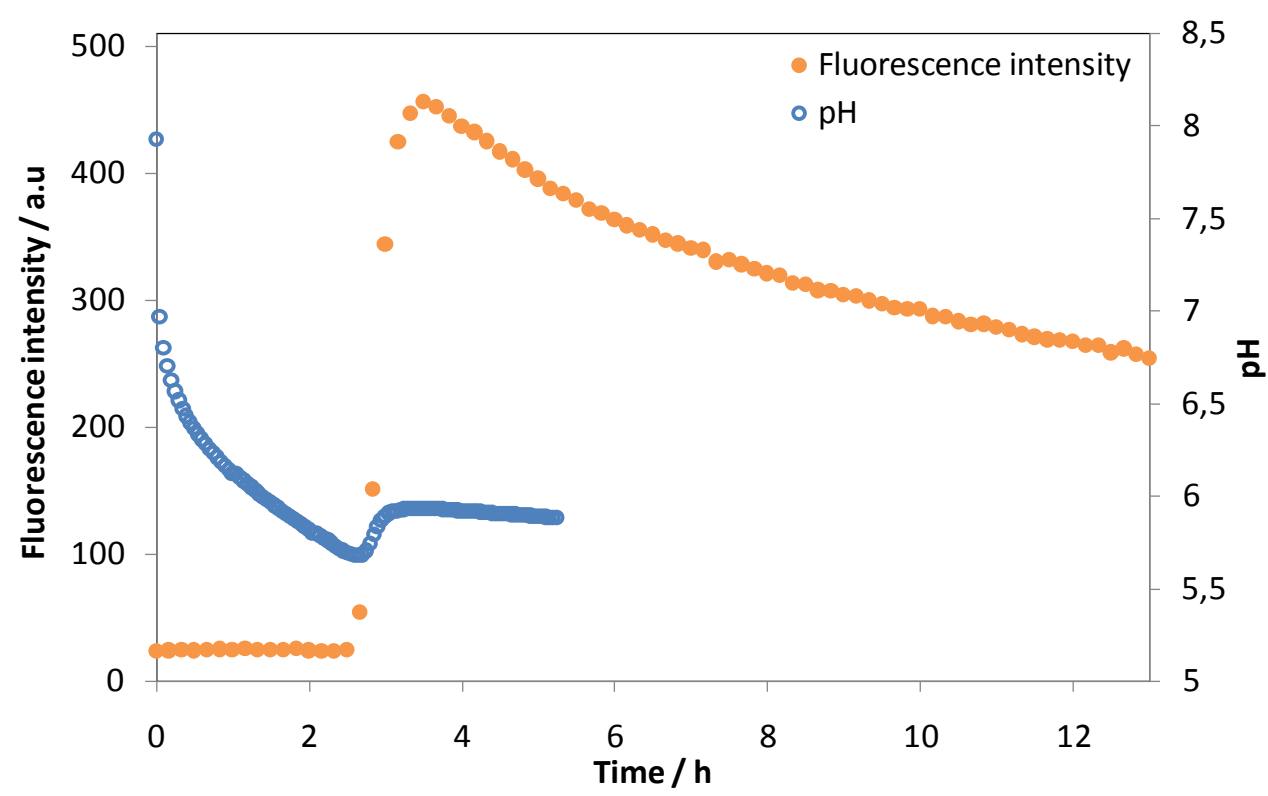

Figure 4.29 Variation of $\mathrm{pH}$ and fluorescence intensity $\left(\lambda_{\mathrm{ex}}=260 \mathrm{~nm}, \lambda_{\mathrm{em}}=295 \mathrm{~nm}\right)$ with time for a solution compound 2 at $10 \mathrm{mM},\left[\mathrm{Na}_{2} \mathrm{CO}_{3}\right]=25 \mathrm{mM},[\mathrm{GdL}]=38 \mathrm{mM}, 25 \stackrel{\circ}{\circ}$.

A simple system was mathematically modeled, consisting of two different steps which are dimerisation of monomers and self-assembly of dimers to provide tetramer. A similar profile to the one provided in Figure 4.29 was obtained if the formation of dimers is considered to be the rate determining step ( $\left.K_{\text {dim }}<<K_{\text {tet }}\right)$. However, if the rate determining step would take place after dimerisation $\left(K_{\text {dim }}>>K_{t e t}\right)$, then the model 
predicts a continuous increase of dimer concentration and fluorescence until equilibrium is finally reached (Figure 4.30).

The parallelism with the theoretical model together withthe fluorescence data reported so far, suggest that fibrillisation is rather fast compared to dimer formation, therefore the formation of transient dimeric species would be the rate determining step (Figure 4.31). Obviously this fits with a cooperative self-assembly process whose first step is significantly slower that the successive ones.

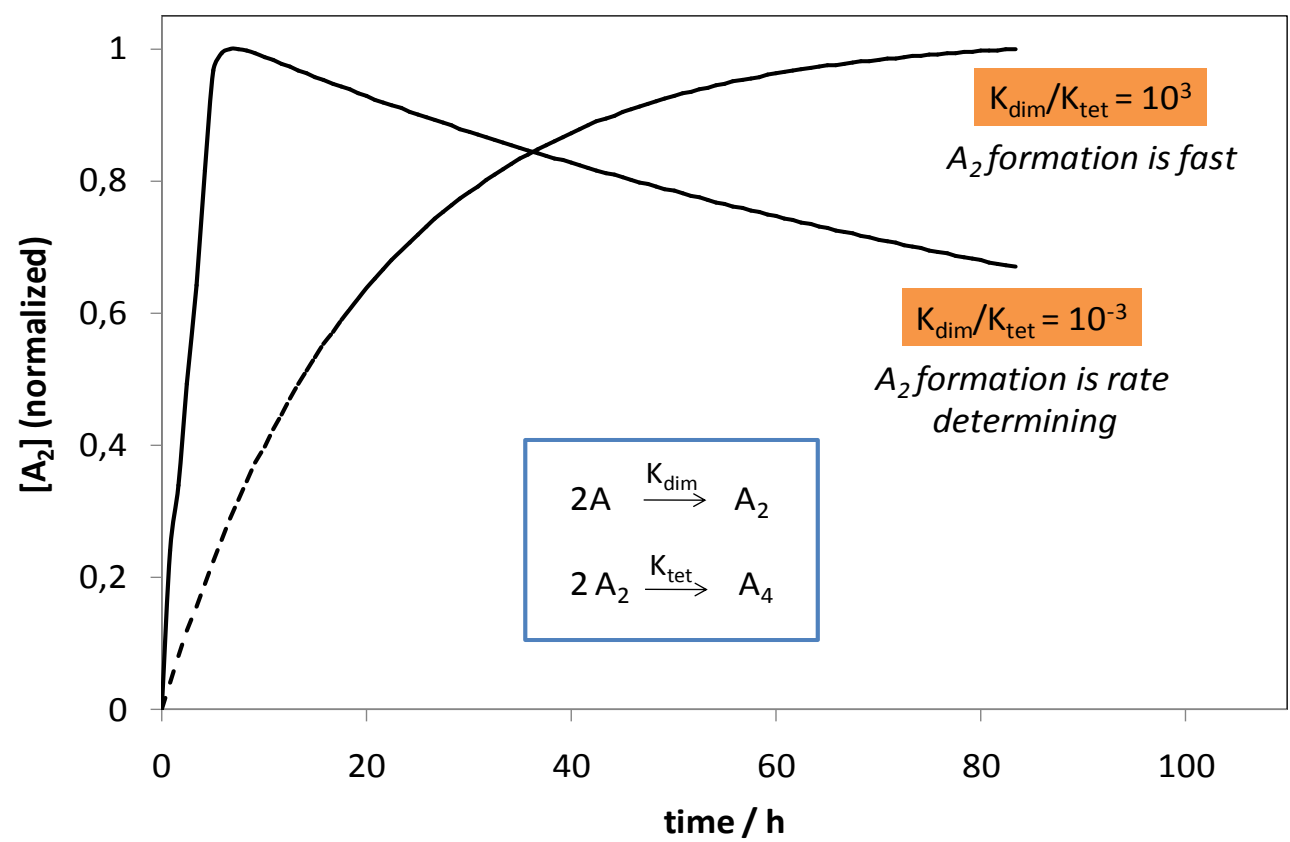

Figure 4.30 Simulated change of species concentration with time for systems having dimer formation as rate determining and as fast step respectively.

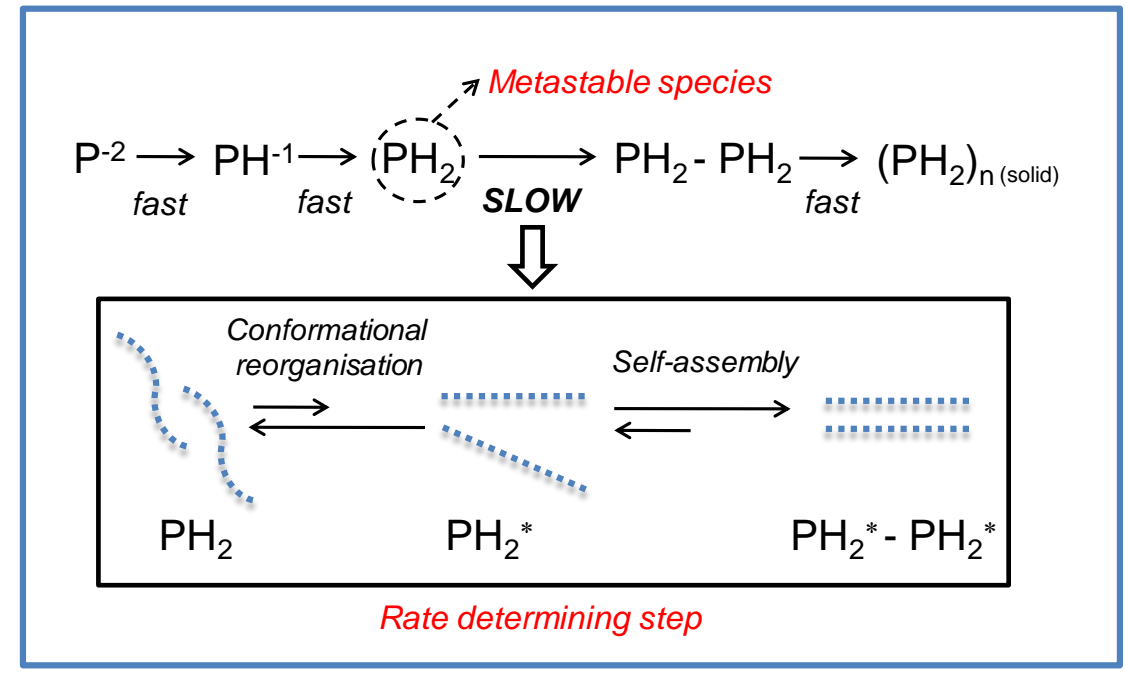

Figure 4.31 Schematic representation of the fibrillisation process highlighting the rate determining step. 
Considering dimerisation as the rate determining step, the experimental kinetic data could be fitted in all cases to a second order process. By plotting $1 /\left[\mathrm{PH}_{2}\right]_{\mathrm{t}}$ against time is it possible to determine the kinetic aggregation constants and the half-life times ${ }^{\mathrm{i}}$ according the equations shown below (Figure 4.32):

$$
\begin{aligned}
& v(t)=\frac{-d\left[\mathrm{PH}_{2}\right]}{d t}=k\left[\mathrm{PH}_{2}\right]^{2} \quad \frac{1}{\left[P \mathrm{PH}_{2}\right]_{t}}=\frac{1}{\left[P \mathrm{PH}_{2}\right]_{0}}+k t \\
& {\left[\mathrm{PH}_{2}\right]_{t}=\frac{1}{2}\left[\mathrm{PH}_{2}\right]_{0} \rightarrow t=t_{\frac{1}{2}} \rightarrow \frac{1}{\frac{1}{2}}=\frac{1}{k\left[\mathrm{PH}_{2}\right]_{0}}}
\end{aligned}
$$

Figure 4.32 Second order kinetic equations

As can be seen in Table 4.5, half-life times values around 2-3 h were obtained for compounds 1-4. Compound 5 however showed faster aggregation behavior with a halflife time lower than $1 \mathrm{~h}$ and conversely compound $\mathbf{6}$ exhibited the slowest fibrillisation with a value larger than $5 \mathrm{~h}$. Considering these data and the previous ${ }^{1} \mathrm{H}$ NMR kinetics assays there is no clear correlation between the experimental induction time and the kinetics of fibrillisation (both of them reported in Table 4.5). It is important to mention here that the experimental induction time includes not only the dimerisation but also the time required to reach the fibrillisation $\mathrm{pH}$ which is related to the pKa values of the different peptides. In a similar way the free energy of aggregation and the activation energy of the rate determining step (dimerisation) are neither related. Most likely the free energy of activation is mainly related to conformational changes required for aggregation.

ii $\mathrm{A}$ constant $\mathrm{pH}$ value is required to assume:

$\frac{d\left[P^{*}\right]}{d t}=K\left[P^{*}\right]^{2}=K^{\prime}\left[P H_{2}\right]^{2}$,

Being $\left[P^{*}\right]=\left[P H_{2}\right]+\left[P H^{-}\right]+\left[P^{-2}\right]=\left[P H_{2}\right]\left(1+\frac{\beta_{2}}{\beta_{1}\left[H^{+}\right]}+\frac{\mathrm{K}_{1} \mathrm{~K}_{2}}{\left[H^{+}\right]^{2}}\right)$;

$K_{1}=\frac{\left[P^{-2}\right]\left[H^{+}\right]}{\left[\mathrm{PH}^{-}\right]} ; K_{2}=\frac{\left[\mathrm{PH}^{-}\right]\left[\mathrm{H}^{+}\right]}{\left[\mathrm{PH}_{2}\right]} ; \beta_{1}=\frac{\left[\mathrm{P}^{-2}\right]\left[\mathrm{H}^{+}\right]}{\left[\mathrm{PH}^{-}\right]} ; \beta_{2}=\frac{\left[\mathrm{P}^{-2}\right]\left[\mathrm{H}^{+}\right]\left[\mathrm{H}^{+}\right]^{2}}{\left[\mathrm{PH}_{2}\right]}$ 
Table 4.5 Second order kinetic constants for fibrillisation of the tetrapeptides 1-6. ${ }^{a}$

\begin{tabular}{cccccc}
\hline Compound & $\mathbf{k} / \mathbf{M}^{-\mathbf{1}} \mathbf{h}^{\mathbf{- 1}}$ & $\mathbf{t}_{\mathbf{1} / 2} / \mathbf{h}$ & $\begin{array}{c}\text { Induction time / } \\
\mathbf{h}\end{array}$ & $\begin{array}{c}\text { fibrillisation } \\
\text { onset } \mathbf{~} \mathbf{H}\end{array}$ \\
\hline $\mathbf{1}$ & ZFDFDC $_{3}$ & 31 & 3.2 & 2.5 & 5.68 \\
$\mathbf{2}$ & ZDFDFC $_{3}$ & 40 & 2.5 & 3.0 & 5.68 \\
$\mathbf{3}$ & ZFFDDC $_{3}$ & 37 & 2.7 & 2.2 & 5.59 \\
$\mathbf{4}$ & ZZDDFFC $_{3}$ & 47 & 2.2 & 4.2 & 5.53 \\
$\mathbf{5}$ & ZFDDFC $_{3}$ & 184 & 0.6 & 3.3 & 5.59 \\
$\mathbf{6}$ & ZDFFDC $_{3}$ & 19 & 5.3 & 4.2 & 5.35 \\
\hline
\end{tabular}

Initial concentrations: $[$ peptide $]=10 \mathrm{mM},,\left[\mathrm{Na}_{2} \mathrm{CO}_{3}\right]=28 \mathrm{mM},[\mathrm{GdL}]=38 \mathrm{mM}$. Errors affect the last digit.

The kinetics of aggregation was finally also monitored by small angle neutron scattering (SANS). This technique uses elastic neutron scattering at small scattering angles to investigate the structure at a mesoscopic scale ranging from 1 to $1000 \mathrm{~nm} .{ }^{36}$ Both SANS and SAXS operate at small angles however during a SANS experiment, a beam of neutrons is directed at a sample and the neutrons are elastically scattered by nuclear interaction with the nuclei while in X-ray scattering, photons interact with electron clouds. Such differences endow SANS technique with interesting advantages like high sensitivity to light elements, the possibility of isotope labelling and the strong scattering by magnetic moments.

As previously reported by other techniques (NMR and fluorescence) an induction time was followed by an increase of scattering corresponding to the fibrillisation onset. Such scattering pattern could be fitted to the formation of elongated cylindrical objects with a large length/radius ratio in agreement with TEM and SEM images. Values after 16 $\mathrm{h}$ of fibrillisation for $10 \mathrm{mM}$ samples are collected in Table 4.6:

Table 4.6 Calculated radius of the cylindrical fibres obtained from SANS data after $16 \mathrm{~h}$ of fibrillisation.

\begin{tabular}{ccc}
\hline \multicolumn{2}{c}{ Compound } & Radius / A \\
\hline $\mathbf{1}$ & ZFDFDC $_{3}$ & 42 \\
$\mathbf{2}$ & ZDFDFC $_{3}$ & 37 \\
$\mathbf{3}$ & ZFFDDC $_{3}$ & 30 \\
$\mathbf{4}$ & ZDDFFC $_{3}$ & 60 \\
$\mathbf{5}$ & ZFDDFC $_{3}$ & 74 \\
$\mathbf{6}$ & ZDFFDC $_{3}$ & 41 \\
\hline
\end{tabular}




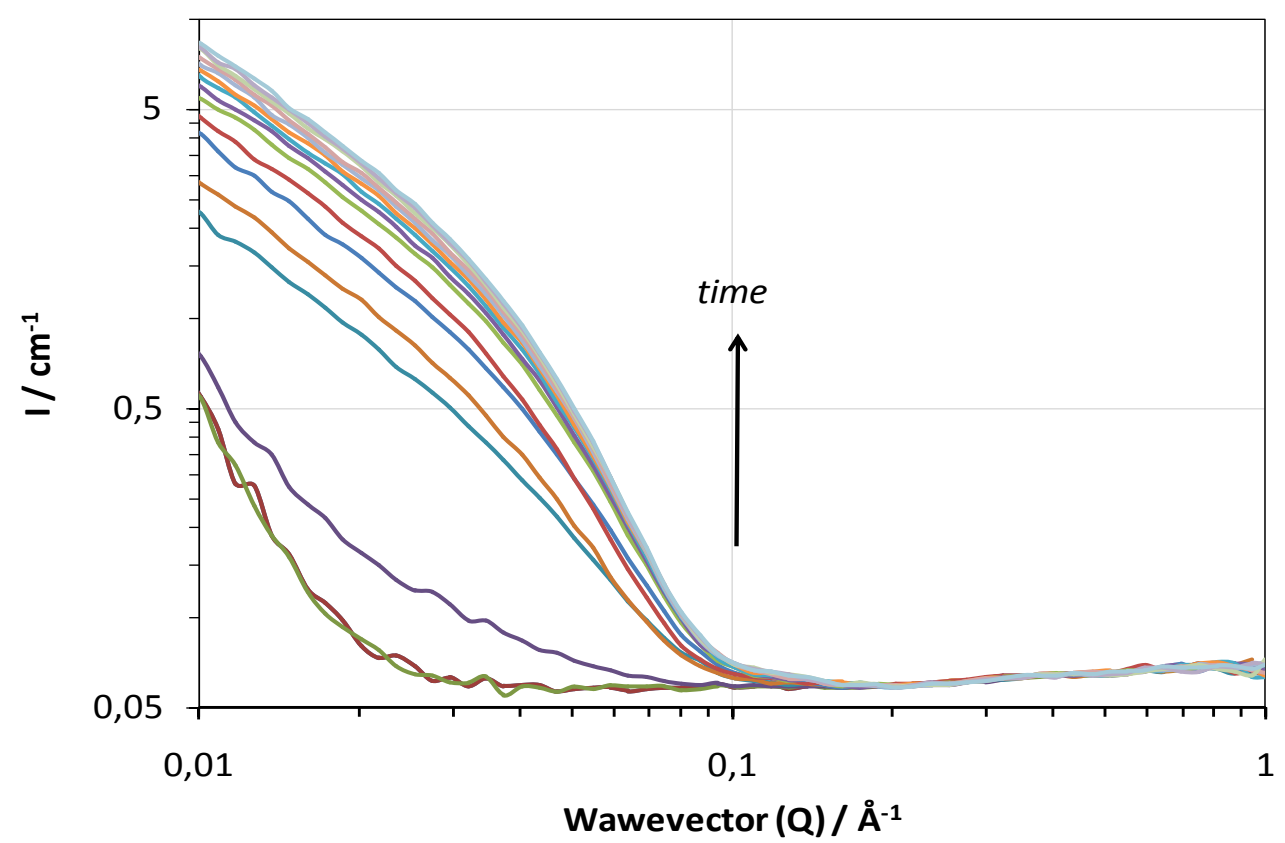

Figure 4.33 Variation of scattering intensity with time for the fibrillisation of compound 1 at $10 \mathrm{mM}$. Initial: $\left.\left[\mathrm{Na}_{2} \mathrm{CO}_{3}\right]=25 \mathrm{mM}, \mathrm{GdL}\right]=38 \mathrm{mM}$

Plotting the scattering intensity at a given $Q$ value $\left(0.02 \AA^{-1}\right)$ against time leads to an exponential curve (Figure 4.34) which can be fitted to second order kinetics as reported for NMR data.

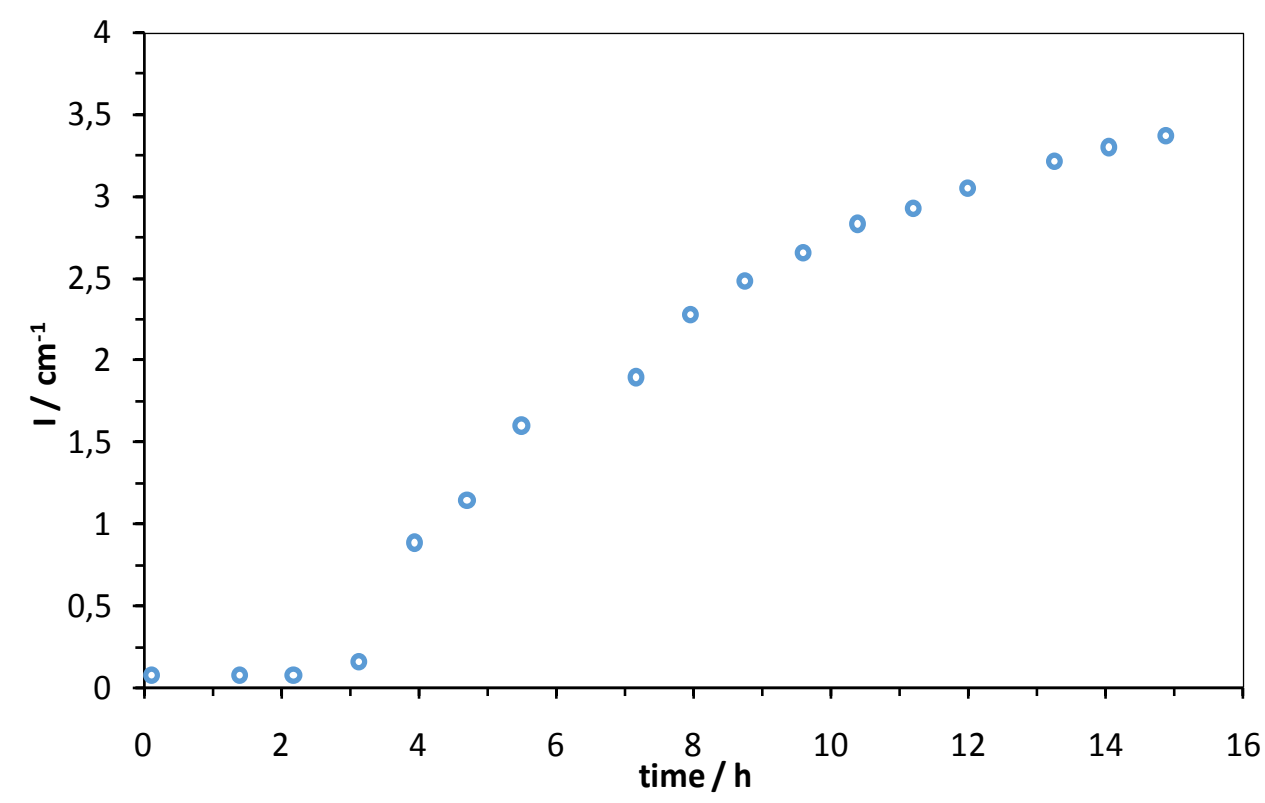

Figure 4.34 Time variation of intensity of SANS at $Q=0.02 \AA^{-1}$ upon progressive acidification by means of in situ GdL hydrolysis. $[\mathbf{1}]=10 \mathrm{mM},\left[\mathrm{Na}_{2} \mathrm{CO}_{3}\right]=25 \mathrm{mM},[\mathrm{GdL}]=38 \mathrm{mM}$ 


\subsubsection{Self-sorting of a two-component hydrogel}

When self-assembly takes place in a solution of two different molecules, which can also aggregate by themselves, different options can come about. One the one hand the molecules can co-assemble either randomly or specifically leading to fibres made of both compounds (Figure $4.35 \mathrm{~b}, \mathrm{c}$ ) Conversely both molecules may assemble independently leading to self-sorted networks where pure assemblies of one molecule coexist with pure assemblies of the other (Figure $4.35 a) .{ }^{37}$

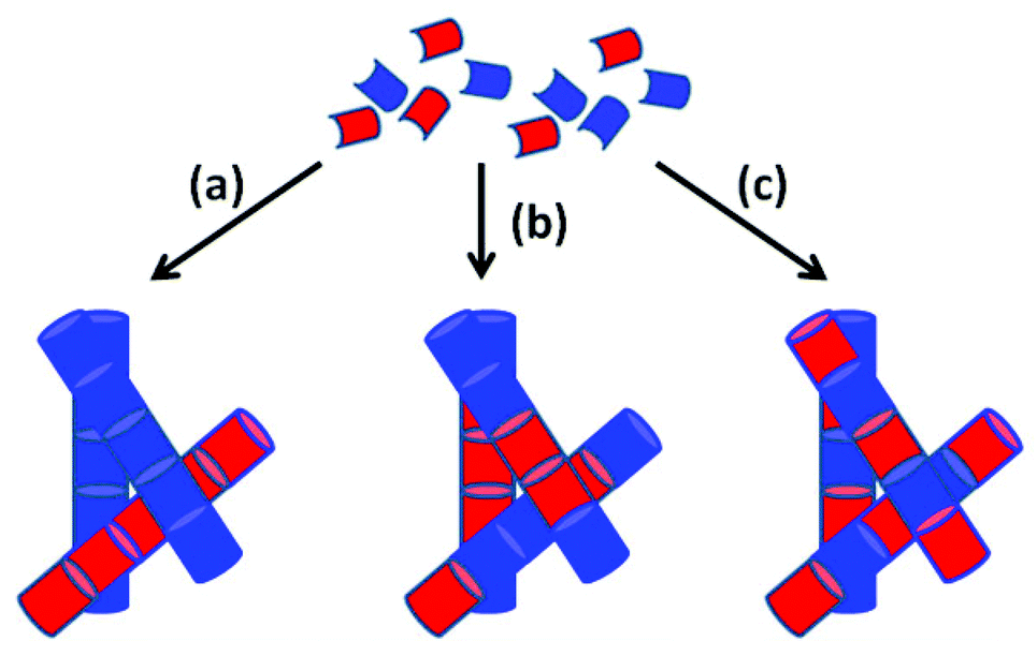

Figure 4.35 Schematic representation of self-assembly possibilities for a mixture of two compounds: (a) self-sorting; (b) random co-assembly; (c) specific co-assembly. ${ }^{37 a}$

The control over these multiple possibilities is not always easy to reach because requires an in-depth knowledge of the molecules as well as the potential interactions involved in the self-assembly process. In particular the self-sorting approach in supramolecular gels is a rare phenomenon although is considered a good strategy to generate complex systems with interesting new applications in catalysis or optoelectronic materials among others. ${ }^{38}$

In general self-sorting can proceed under either thermodynamic or kinetic control. ${ }^{39}$ In thermodynamic self-sorting the system is at its most stable state when sorted while in kinetic self-sorting the metastable species can be present. Most of the examples reported in the literature operate under thermodynamic conditions however, new promising kinetic examples have been recently described. ${ }^{39 a}$ Particularly interesting due to the resemblance with our systems, is the example of thermodynamic control approach described by Adams and co-workers. ${ }^{40}$ Two naphthalene dipeptides (Figure 4.36a) with different pKa values were initially dissolved into basic solution and GdL was 
added to slowly acidify the medium. As can be seen in Figure $4.36 \mathrm{~b}$ the self-assembly of dipeptides started when the $\mathrm{pH}$ value matched their $\mathrm{pKa}$ leading to self-sorted hydrogels made of pure rather than mixed fibres.

a<smiles>CC(NC(=O)COc1ccc2cc(Br)ccc2c1)C(=O)NC(C(=O)O)C(C)C</smiles><smiles>[R16]=[R15]=[W]</smiles>

b

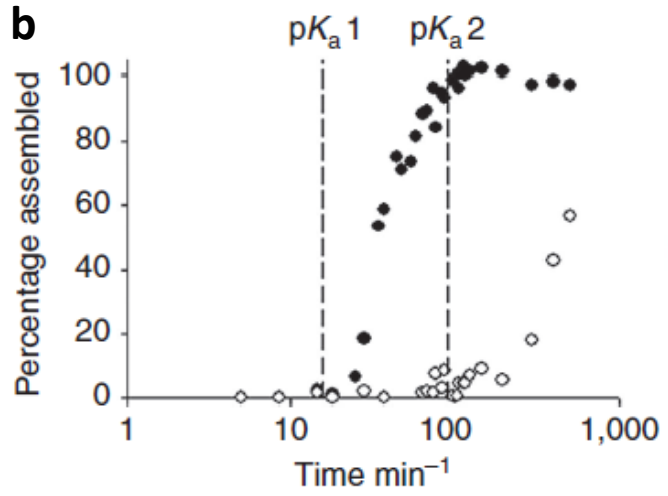

C

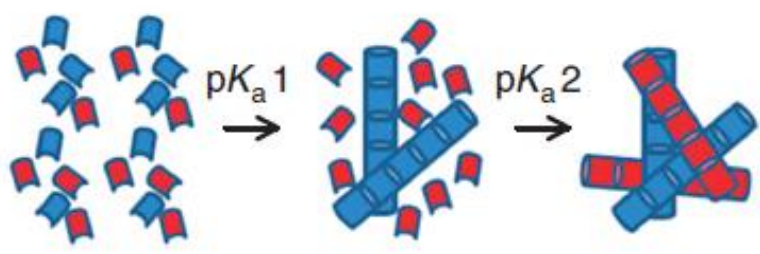

Figure 4.36 a) Molecular structure and $\mathrm{pK}_{\mathrm{a}}$ of the dipeptides reported by Adams. b) Aggregation process monitored by ${ }^{1} \mathrm{H}$ NMR. c) Schematic representation of the self-sorting between dipeptides. ${ }^{40}$

This $\mathrm{pH}$-programming method offers several advantages in comparison with the traditional thermal induced self-sorting. ${ }^{41}$ This last approach is difficult to predict and to design because there is little correlation between the molecular structure and the assembly temperatures. However, the $\mathrm{pH}$ at which the assembly of each component occurs is determined by the apparent pKa of the gelator. This value generally correlates with the overall hydrophobicity of the gelator providing therefore a 'molecular gelation trigger' that can be controlled by careful design of the gelator molecule.

Considering the thermodynamic and kinetic data reported above for tetrapeptides 1-6 an experiment was designed to achieve selective self-assembly from a mixture of two isomeric peptides. In practice a mixture of compounds $\mathbf{1}$ and $\mathbf{5}$ was dissolved in the presence of triethylamine and then progressively acidified using GdL. The use of triethylamine accelerates significantly the GdL hydrolysis reducing the induction time as a consequence (in comparison with those reported in Table 4.5). As previously described, fibrillisation kinetics was followed by ${ }^{1} \mathrm{H}$ NMR taking advantage of differences on shifts of methyl protons for compounds 1 and 5 (Figure 4.37). 


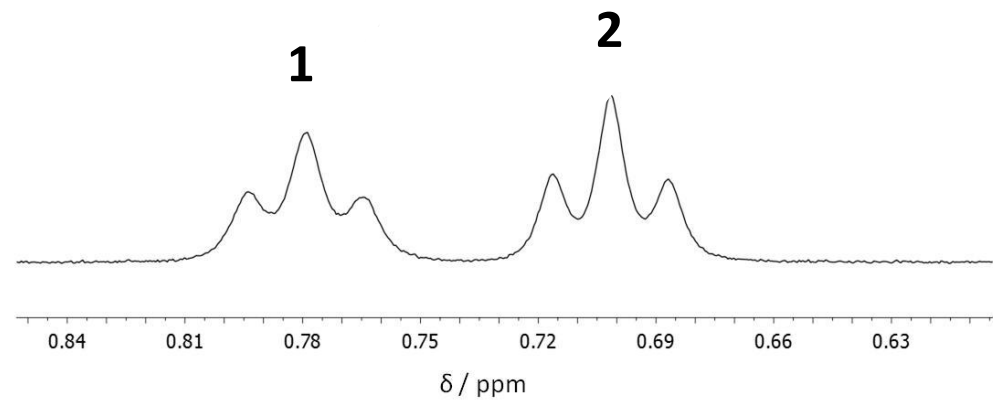

Figure 4.37 Methyl protons shift for compounds 1 and 2 in basic $\mathrm{D}_{2} \mathrm{O}$.

Remarkably, ${ }^{1} \mathrm{H}$ NMR indicated selective fibrillisation of compound 1 which is the less basic compound according to the determined $\mathrm{pK}_{\mathrm{app}}=6.0$ (Figure 4.38). After $1.4 \mathrm{~h}$ the intensity of NMR signals of this compound decreased to a $60 \%$ of their initial value. During the same time tetrapeptide $\mathbf{5}$, which is more basic than $1\left(\mathrm{pK}_{\mathrm{app}}=7.5\right)$ and should be neutralized first under thermodynamic control, remained fully in solution.
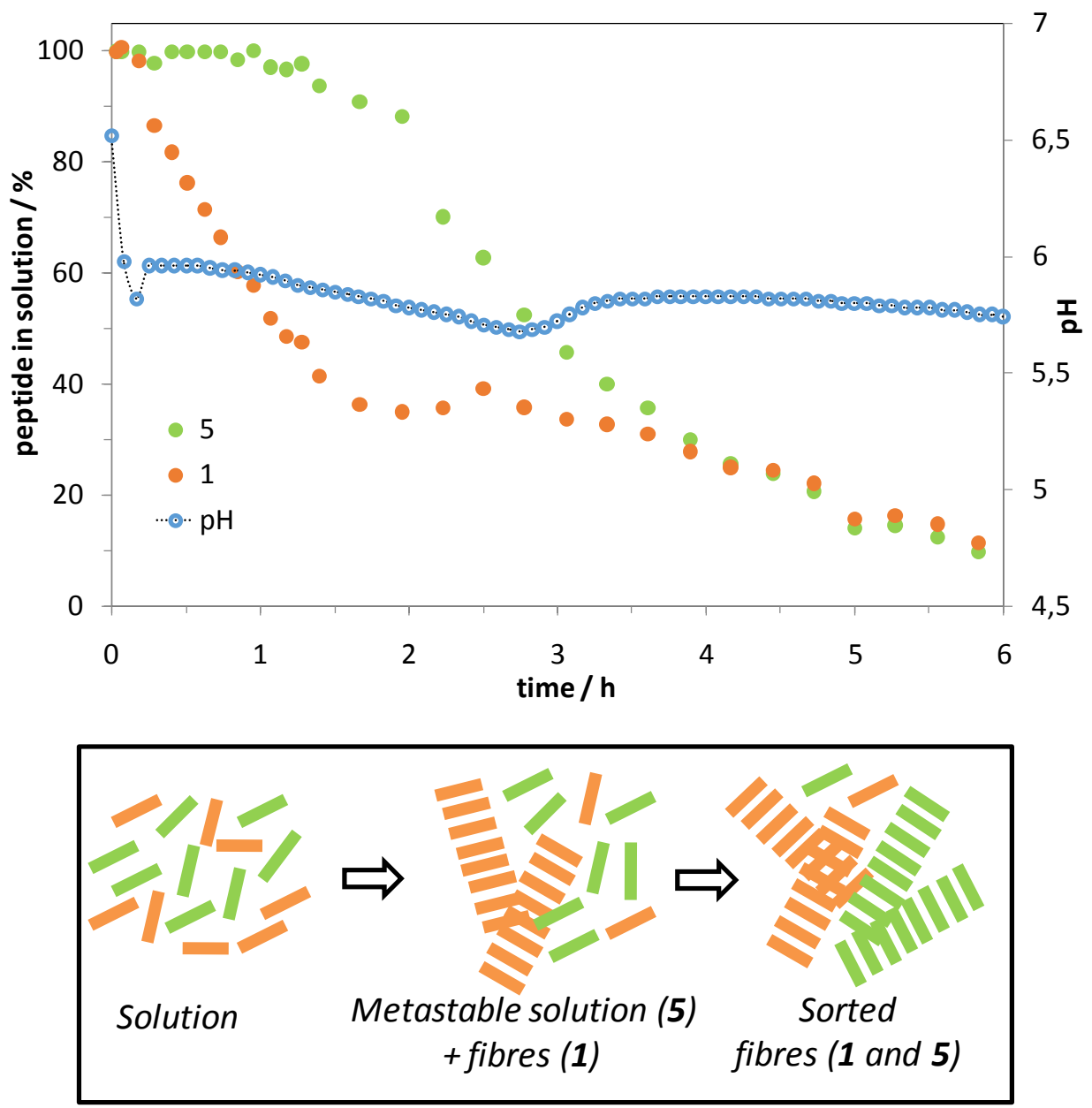

Figure 4.38 NMR intensity variation of a mixture of compounds 1 and $\mathbf{5}$ upon smooth acidification by means of GdL hydrolysis. Initial concentrations:[1] $=[5]=5 \mathrm{mM},\left[\mathrm{Et}_{3} \mathrm{~N}\right]=25 \mathrm{mM},[\mathrm{GdL}]=38 \mathrm{mM}$ (top). Schematic representation of kinetic self-sorfing of compounds $\mathbf{1}$ and $\mathbf{5}$ (bottom). 
It is important to mention here that the present self-sorting system is kinetically controlled, distinct to the previous example described by Adams and coworkers ${ }^{40}$ where the more basic compound forms fibres in first place upon progressive acidification, namely, under thermodynamic control. In our case the fibrillisation order is opposite to the basicity order and the more basic compound (5) remains in a kinetically trapped metastable state during the initial period of time. After $1.4 \mathrm{~h}$ compound $\mathbf{5}$ starts to form the solid-like fibrillar network and after $6 \mathrm{~h}$ ca $90 \%$ of both peptides have evolved into fibres.

\subsection{Interaction of tetrapeptides 1-6 with amyloid peptide $A \beta 1-40$}

As it has been mentioned previously small peptides are considered relevant not only as models for the aggregation of native proteins ${ }^{29 c, 42}$ but also as inhibitors to prevent the amyloidogenic process. ${ }^{43}$ Their biocompatibility, biomimetic nature, versatility and easy synthesis are some advantages over other strategies employed so far to interfere with this process.

During the design step of the current work, two important features regarding amyloid misfolding and aggregation were included: aromatic residues and aspartate side-chains. On the one hand the presence of aromatic residues has been shown to promote self-assembly although their role into this fibrillisation process remains still under debate. The possibility of $\pi-\pi$ interactions ${ }^{1 b}, 29 b$ has to be considered but also the hydrophobicity and planar geometry of phenylalanine (F) residues. ${ }^{29 a}$ On the other hand the carboxylate side-chains may participate in salt bridges with lysine residues (K) present along amyloid protein as previously described by Meredith and co-workers ${ }^{44}$ (Figure 4.39).

In the current case, not only the presence of such residues but also their distribution in the primary sequence has a clear influence in their aggregation properties as it has been described in previous section. These differences made us envisage a potential sequence-dependent effect on the interaction of these compounds with amyloid peptides as for instance $A \beta 1-40$. Considering this possibility a qualitative study using TEM and CD was carried out. 


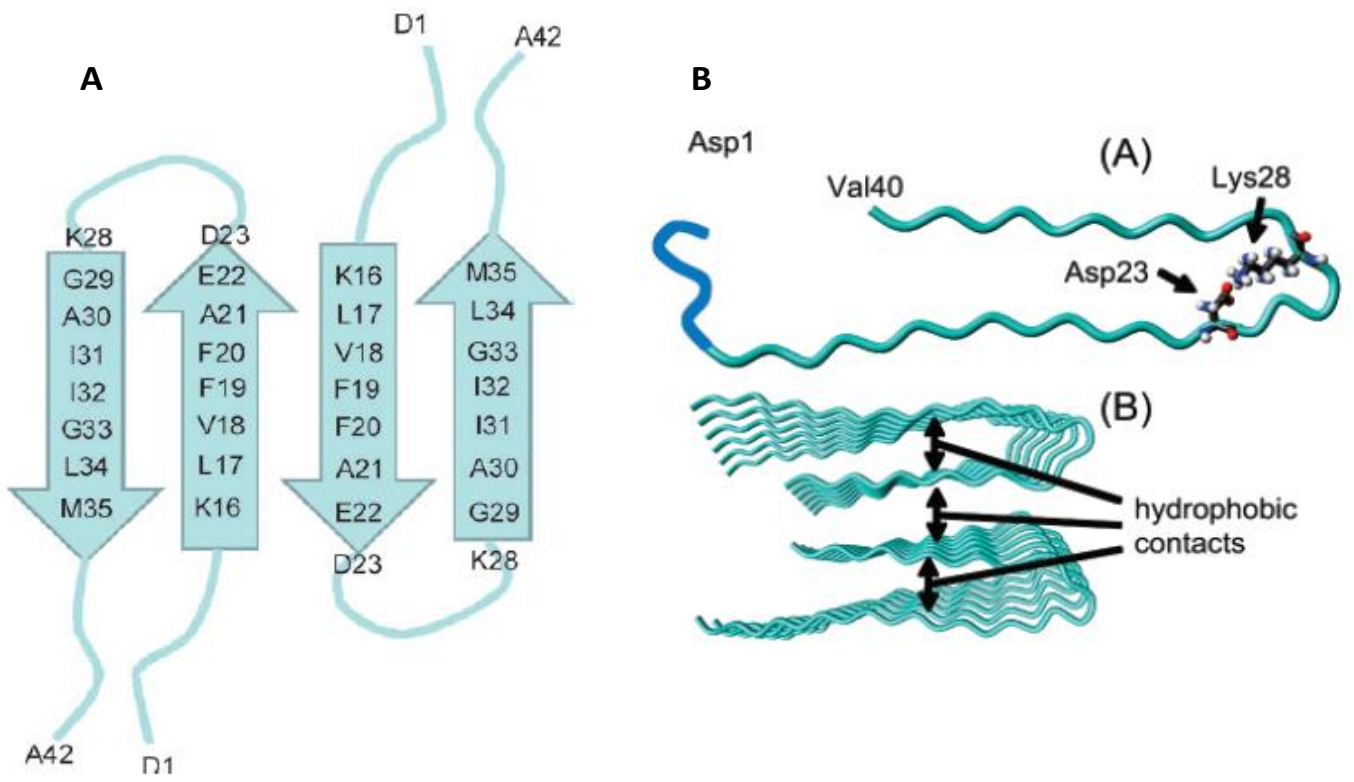

Figure 4.39 Amino-acid sequence of $A \beta$ 1-40 dimer $(A) .{ }^{45}$ Salt bridge described by Meredith and coworkers between K28 and E23 and three dimensional structural arrangement of A $\beta$ 1-40 dimer (B). ${ }^{44}$

Equimolar mixtures of $\mathrm{A} \beta 1-40(50 \mu \mathrm{M})$ and compounds 1-6 $(50 \mu \mathrm{M})$ were incubated in phosphate-buffered saline (PBS) one week at 37 ㅇ․ TEM samples were taken at 6 h, 30 h, 3 days and 7 days to determine the kinetics of aggregation. CD measurements were also performed for all of them after 1 week of stabilization and blank solutions of $A \beta 1-40(50 \mu \mathrm{M})$ and 1-6 $(50 \mu \mathrm{M})$ were also prepared under strictly the same conditions (S.I. 4.3.1). As it can be observed in Figure 4.40, blank samples of A $\beta 1$ $40(50 \mu \mathrm{M})$ showed a tendency to fibril formation. After $30 \mathrm{~h}$ unstructured objects observed at the beginning undergo short fibril formation having a width of around 20 $\mathrm{nm}$. After 3 days long fibres with a dendritic aspect were observed and single fibres were no longer detected. These fibres formed an entangled network after 7 days that could be observed at naked eye as a foamy, white precipitate. 


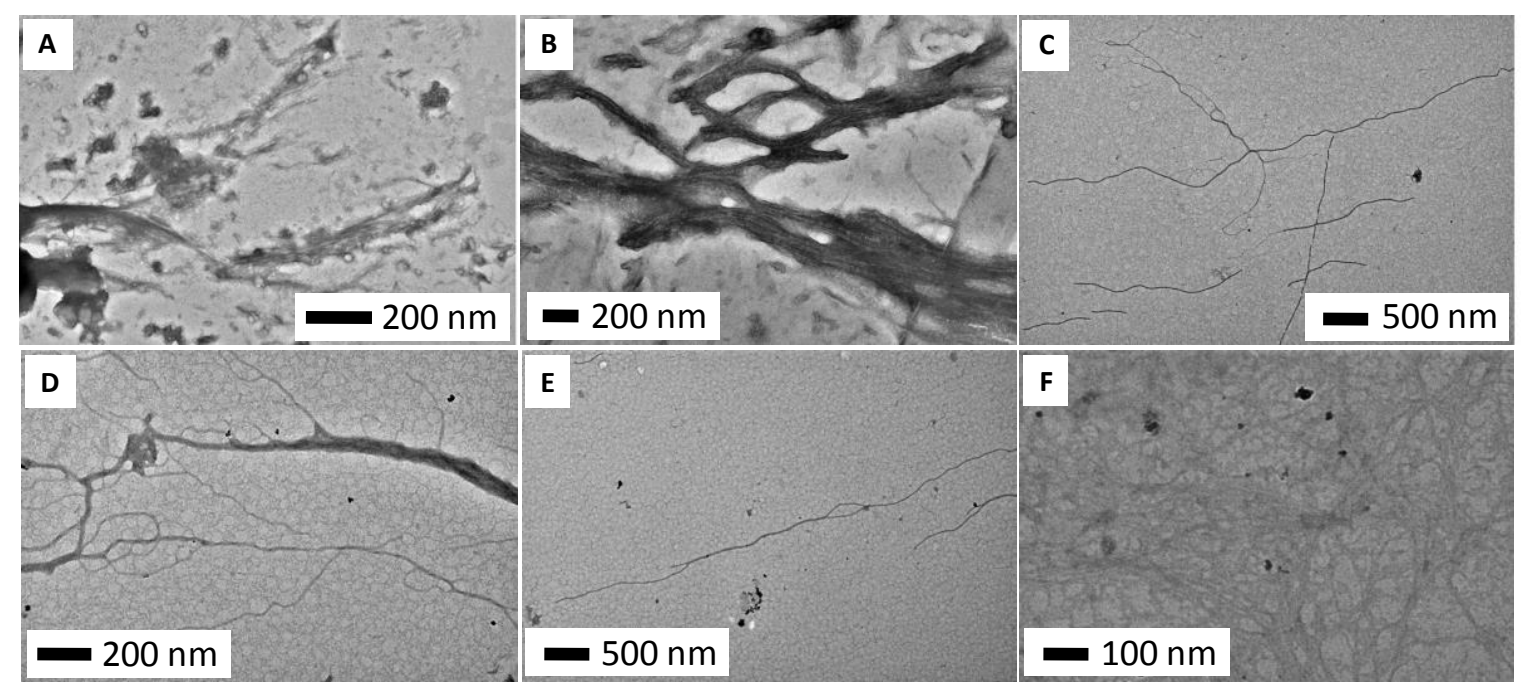

Figure 4.40 TEM micrographs of $A \beta 1-40(50 \mathrm{mM})$ in PBS at 37 ㅇ $\mathrm{C}$ after $(\mathrm{A}) 6 \mathrm{~h},(\mathrm{~B}) 30 \mathrm{~h},(\mathrm{C}-\mathrm{D}) 3$ days and (EF) 7 days.

Samples of compounds 1-6 at the same concentration were also analysed and, even at such low concentration, aggregation was observed for some of them. For example, TEM images of compound 1 (Figure 4.41A) showed thin fibrils of $6 \mathrm{~nm}$ in width even at short times $(6 \mathrm{~h})$. Compound 3 formed a mesh of thin fibres as well after $30 \mathrm{~h}$ of incubation (Figure 4.43A) and compound 5 exhibited 2D aggregates at the same time. Compounds 2, 4 and 6 showed however, a minor tendency to aggregate and just isolated objects were observed in general for all of them even after 1 week of incubation (Figure $4.42 \mathrm{~A}$, Figure $4.44 \mathrm{~A}$ and Figure $4.46 \mathrm{~A}$ respectively). After the study of blank samples, equimolar mixtures of $A \beta 1-40$ and compounds 1-6 were also analyzed. Compounds 2 (Figure 4.42) and 6 (Figure 4.46), which are poorly aggregating by themselves, did not show any appreciable effect on the aspect of the amyloid nanostructure even after 1 week of incubation. For the rest of the compounds an increase of the aggregation rate was observed in general but especially relevant were the micrographs obtained for compounds $\mathbf{1}$ and $\mathbf{5}$. In both cases, the equimolar mixture with the amyloid $A \beta 1-40$ looked like the pure tetrapeptidic compound, that is thin fibrils in the case of compound $\mathbf{1}$ (Figure 4.41) and 2D sheets in the case of compound 5 (Figure 4.45). These results suggest the co-assembly of both compounds with $A \beta 1-40$ governed by the template effect of the tetrapeptides. In the case of mixtures of compounds 3 (Figure 4.43) or 4 (Figure 4.44) with A $\beta 1-40$, none seems to dominate and no significant information could be obtained in this respect. 
After 7 days of incubation at 37 ㅇ, $C D$ spectra of blank samples and equimolar mixtures were recorded. $A \beta 1-40$ spectrum showed a typical $\beta$-sheet secondary structure with a positive lobe at $194 \mathrm{~nm}$ and a negative band centered at around $225 \mathrm{~nm}$. The incubation with the tetrapeptides leaded to important changes in this band in some cases. Once again compounds $\mathbf{1}$ and $\mathbf{5}$ deserve an especial mention. Particularly in the case of compound 1 (Figure 4.41) the equimolar mixture adopted a similar structure to the pure tetrapeptide in solution with two negative bands centered at 225 and $231 \mathrm{~nm}$. In the case of compound 5 (Figure 4.45) although it was not very active in solution, the intensity of the $C D$ signal of $A \beta 1-40$ decreased considerably in the presence of this tetrapeptide. These data suggests that the secondary structure of $A \beta 1-40$ has been modified in the co-assembly with $\mathbf{5}$ and $\mathbf{1}$. A similar effect was observed for the mixture of compound 4 .

For the rest of the compounds $(2,3$ and 6$)$ the $C D$ spectra of the $A \beta 1-40$ were almost unaffected for the equimolar mixtures suggesting a poor interaction between them and the amyloid protein in agreement with TEM observations.
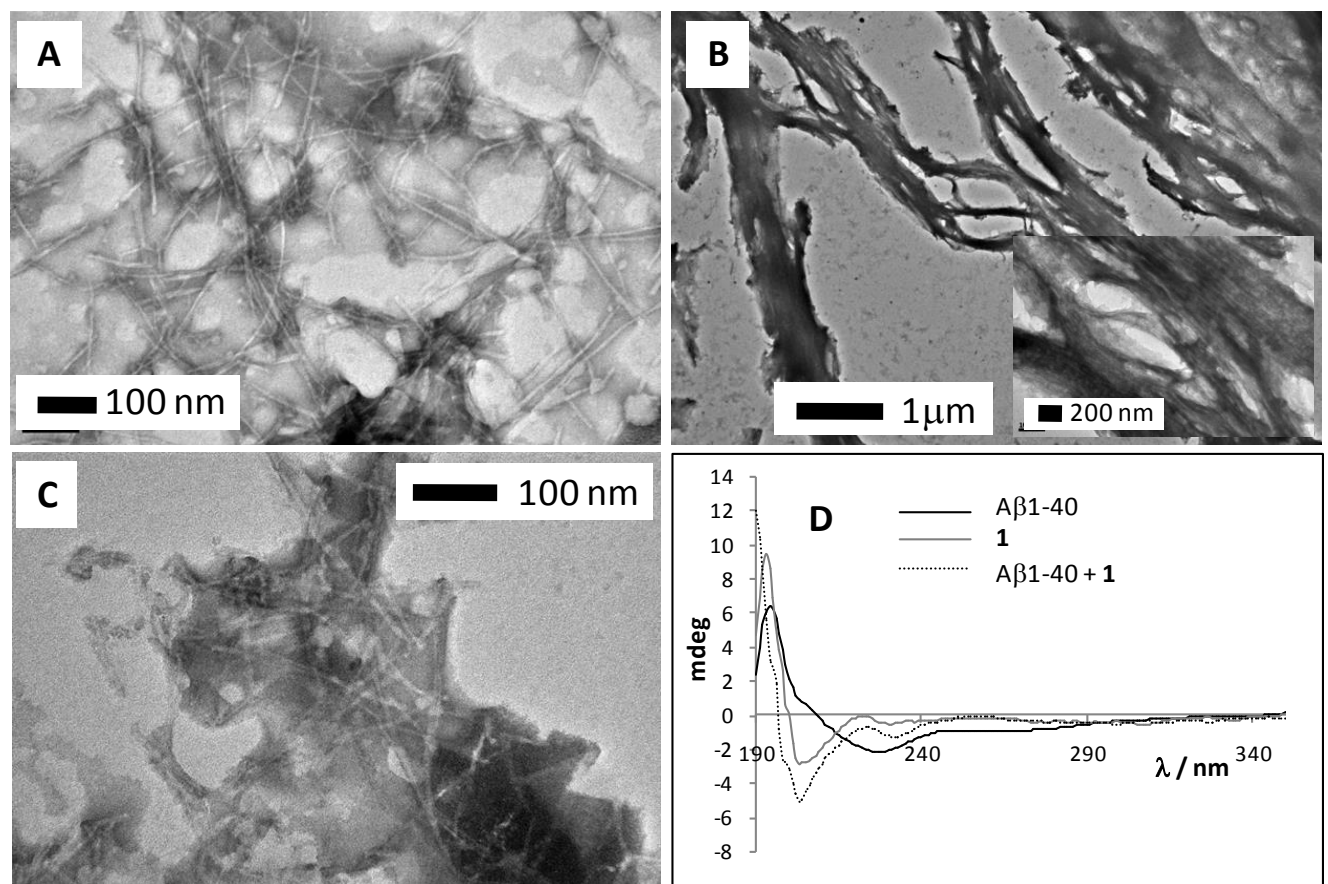

Figure 4.41 TEM micrographs of compound 1 after $6 \mathrm{~h}(\mathrm{~A})$ and equimolar mixture of $A \beta 1-40$ and compound 1 after (B) $6 \mathrm{~h}$ and (C) 7 days; (D) CD spectra of A $1-40$, compound 1 and their equimolar mixture after 7 days. 

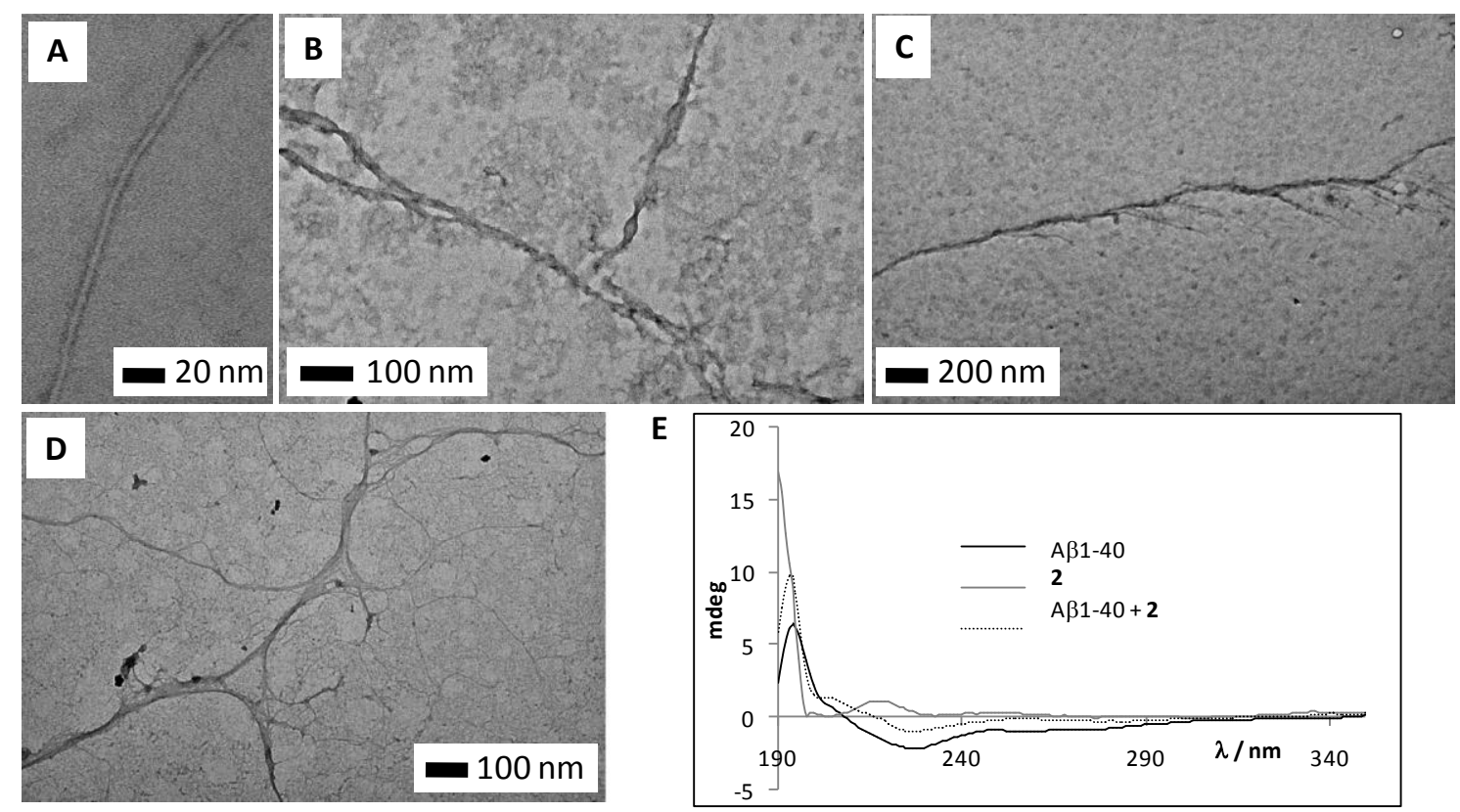

Figure 4.42 TEM micrographs of compound 2 after $6 \mathrm{~h}$ (A) and equimolar mixture of $A \beta 1-40$ and compound 2 after (B) $6 \mathrm{~h}$, (C) $30 \mathrm{~h}$ and (D) 3 days; (E) CD spectra of $A \beta 1-40$, compound 2 and their equimolar mixture after 7 days.
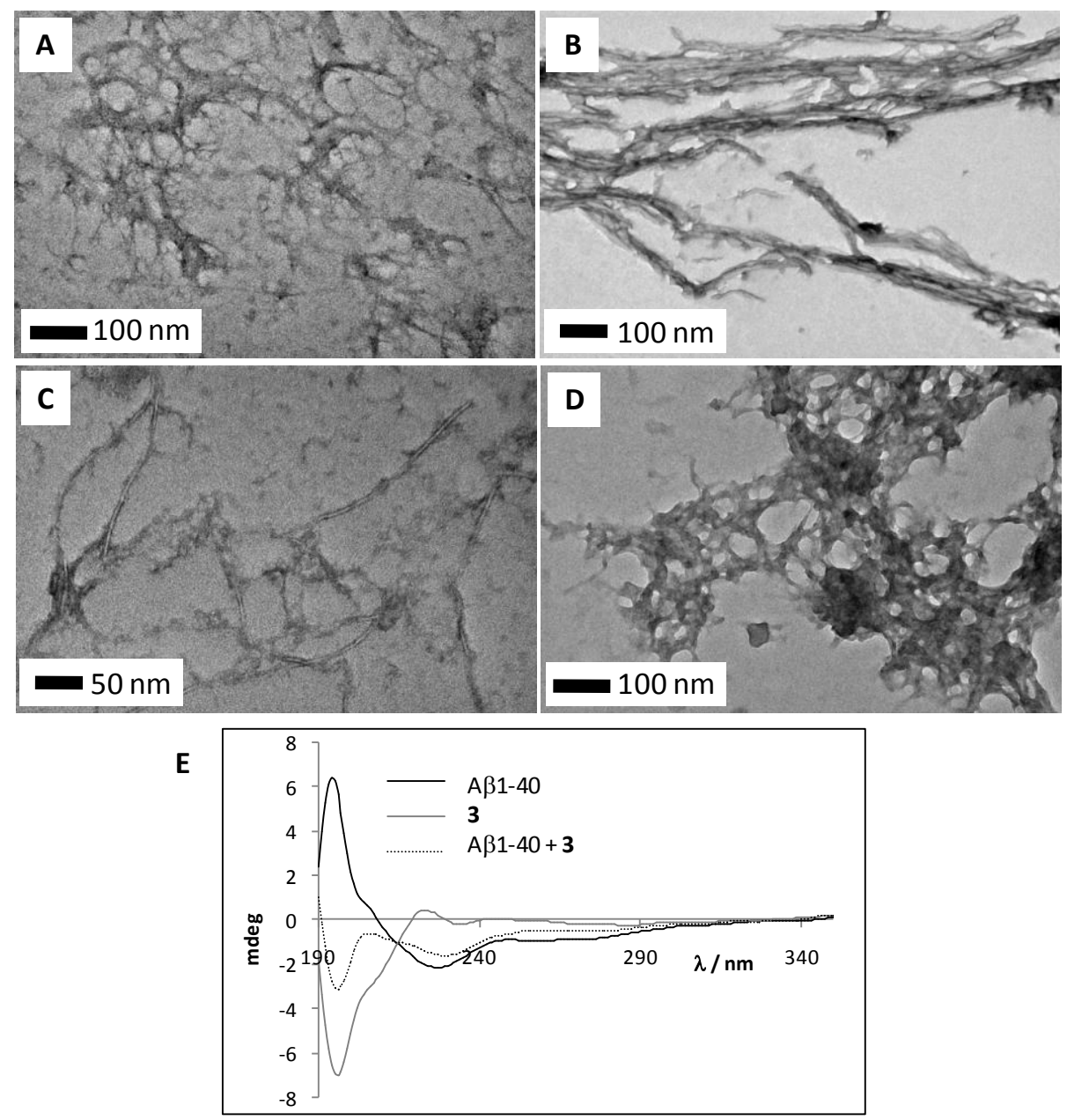

Figure 4.43 TEM micrographs of compound 3 after $30 \mathrm{~h}(\mathrm{~A})$ and 7 days $(\mathrm{C})$ and equimolar mixture of $\mathrm{A} \beta 1$ 40 and compound 3 after (B) $30 \mathrm{~h}$, and (D) 7 days; (E) CD spectra of $A \beta 1-40$, compound 3 and their equimolar mixture after 7 days. 

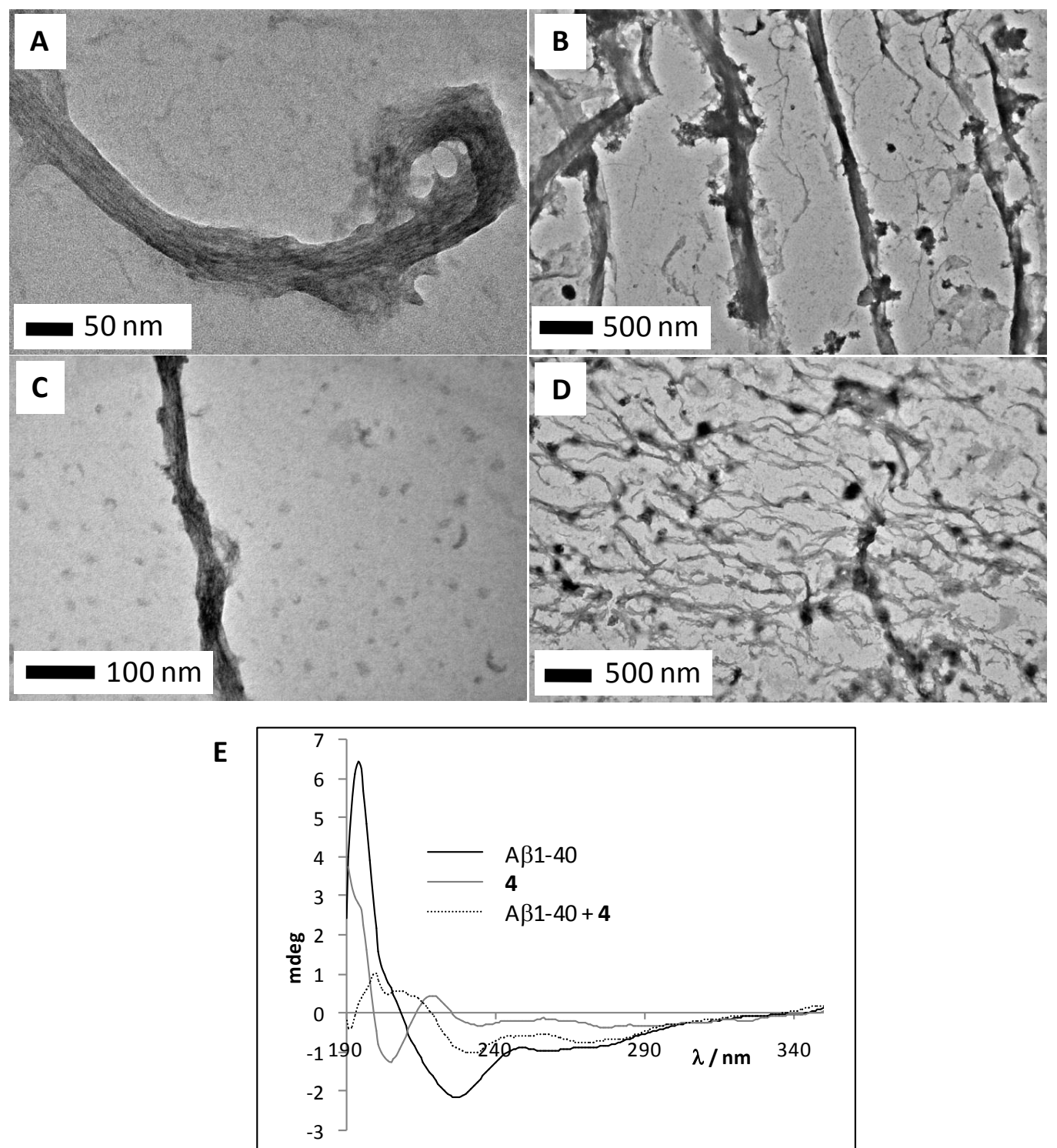

Figure 4.44 TEM micrographs of compound 4 after $6 \mathrm{~h}(\mathrm{~A})$ and 7 days $(\mathrm{C})$ and equimolar mixture of A $\beta 1-40$ and compound 4 after (B) 6 h, and (D) 7 days; (E) CD spectra of A $31-40$, compound 4 and their equimolar mixture after 7 days. 

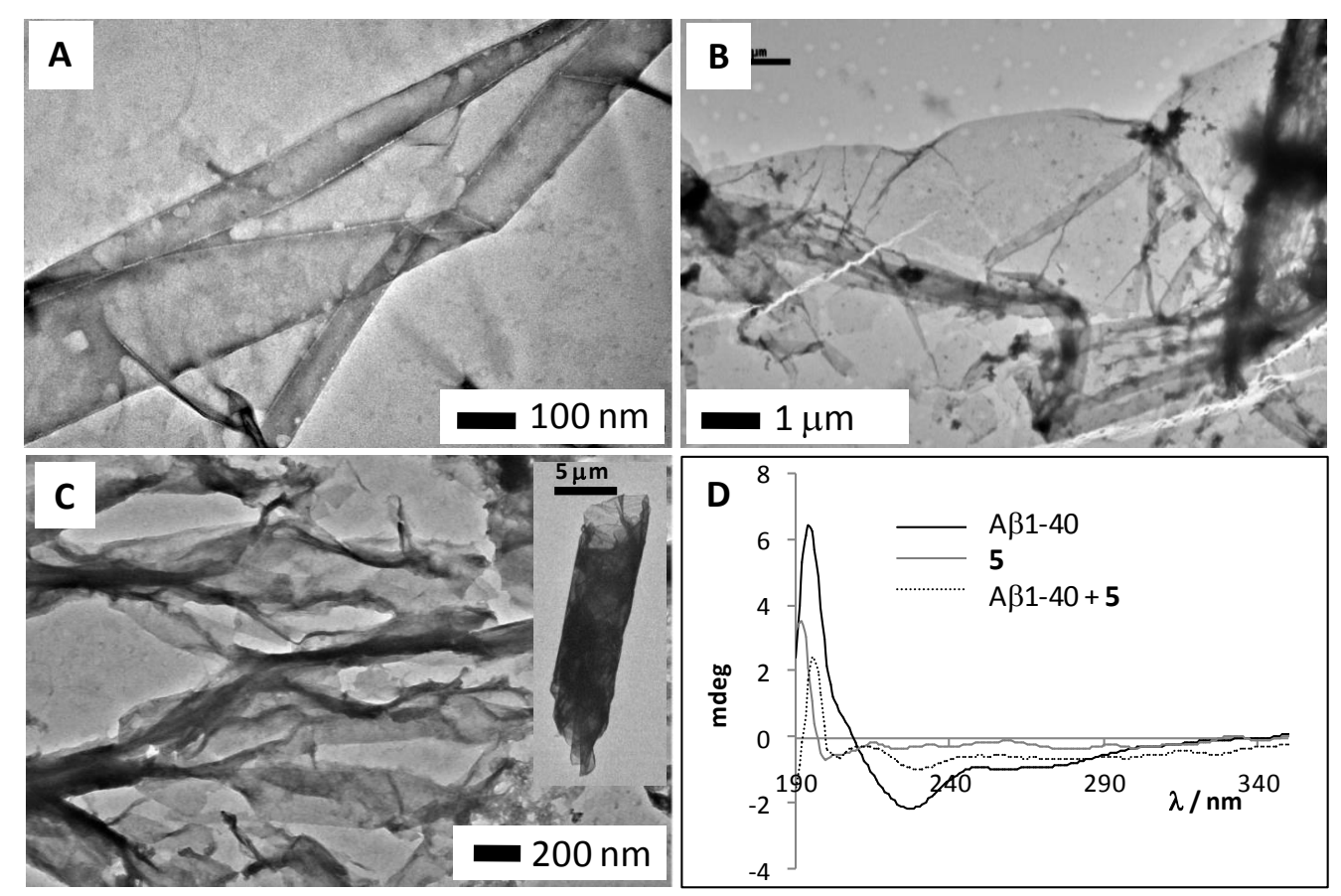

Figure 4.45 TEM micrographs of compound 5 after $30 \mathrm{~h}(\mathrm{~A})$ and equimolar mixture of $A \beta 1-40$ and compound 5 after (B) 30 h and (C) 3 days (inset: 7 days); (D) CD spectra of A 1 1-40, compound 5 and their equimolar mixture after 7 days.
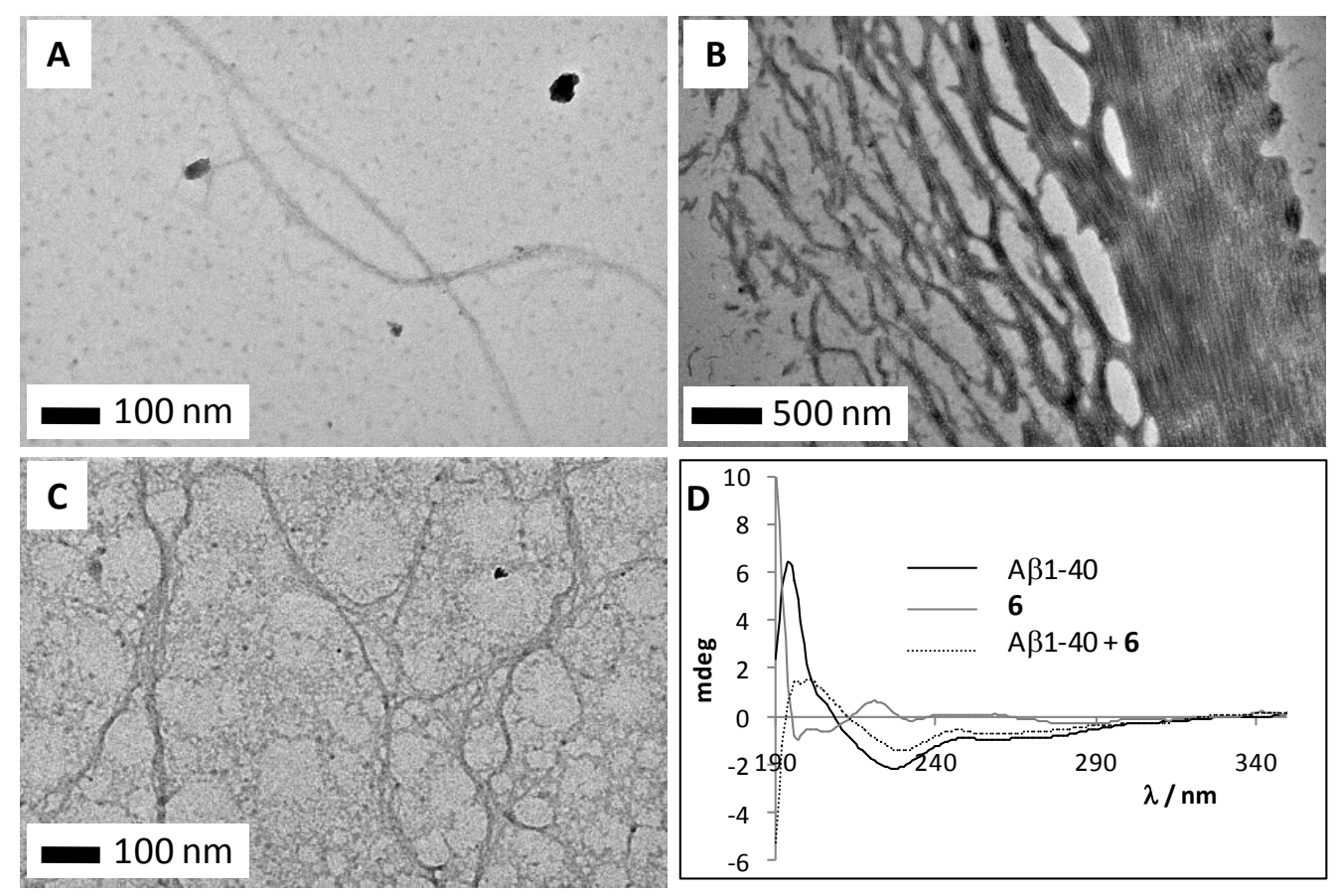

Figure 4.46 TEM micrographs of compound 6 after $30 \mathrm{~h}$ (A) and equimolar mixture of AB1-40 and compound 6 after (B) $30 \mathrm{~h}$ and (C) 7 days; (D) CD spectra of A $31-40$, compound 6 and their equimolar mixture after 7 days.

Aiming to go deeper into this topic, a solubility experiment by using ${ }^{1} \mathrm{H}$ NMR was performed. In order to simplify the experiment, $A \beta 1-40$ peptide was replaced by the 
heptapeptide sequence $A c \beta A \beta A K L V F F N H_{2}$ which contains the core fragment KLVFF considered as the key sequence involved in $\beta$-sheet-fibril formation. ${ }^{46}$ Particularly this sequence has been recently studied by Hamley and co-workers in collaboration with our group ${ }^{47}$ and its aggregation behaviour in water, methanol or in the presence of salts is well known. The main idea was to study how the addition of equimolecular amounts of tetrapeptides could affect the solubility of $A c \beta A \beta A K L V F F H_{2}$.

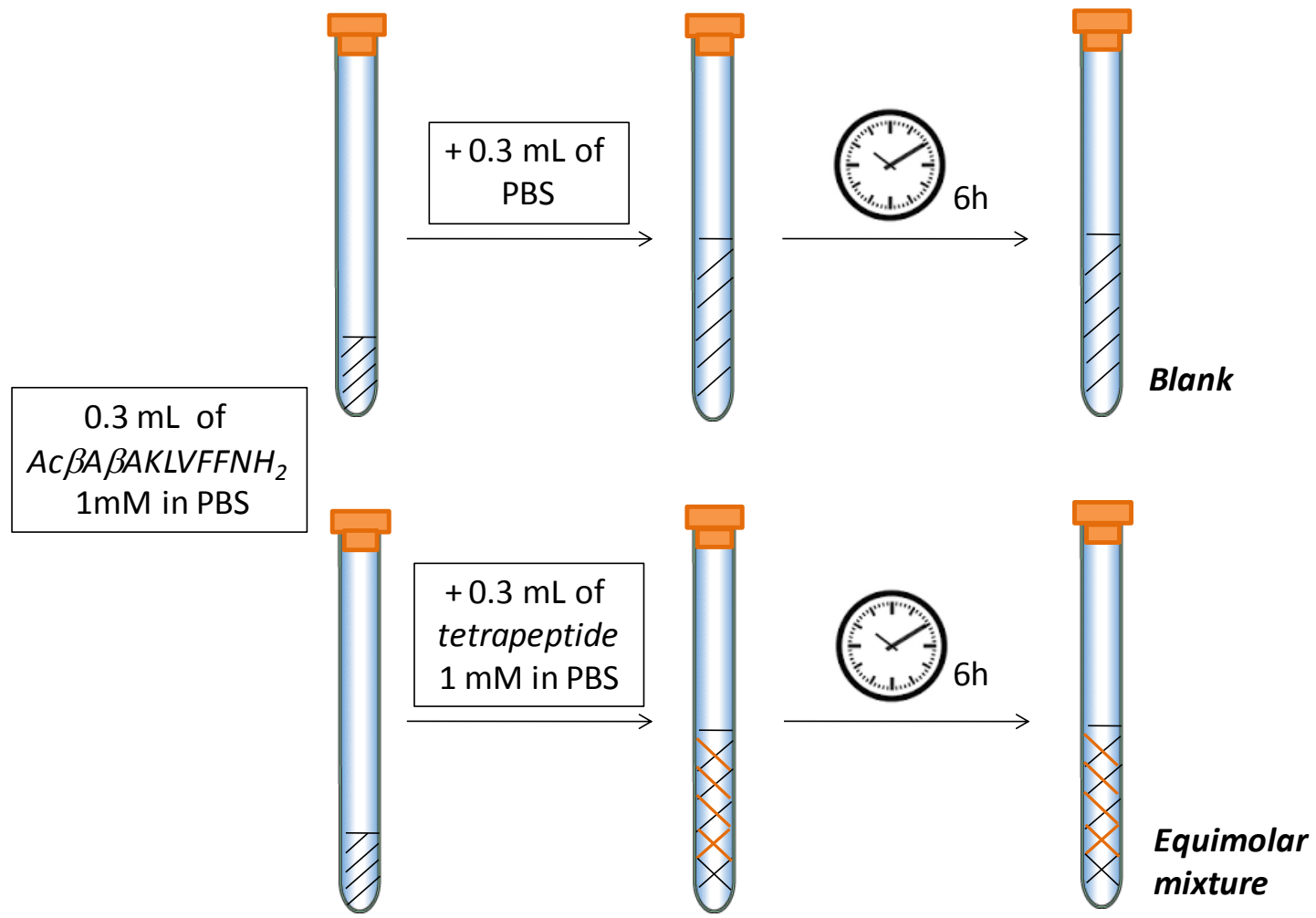

Figure 4.47 Schematic representation for the ${ }^{1} \mathrm{H}$ NMR solubility experiment to determine the solubility of $\mathrm{Ac} \beta \mathrm{A} \beta \mathrm{AKLVFFNH} \mathrm{H}_{2}$ in the presence of equimolar amounts of tetrapeptides.

In practice $0.3 \mathrm{~mL}$ of heptapeptide (provided by Prof. Hamley) solution $1 \mathrm{mM}$ in PBS were placed inside two different NMR tubes. An equivalent volume of PBS was added in one of them to generate the blank sample after $6 \mathrm{~h}$ of incubation at 37 ㅇ. In the same way $0.3 \mathrm{~mL}$ of an equimolar amount of one tetrapeptide were placed in the other tube and this sample was incubated also at the same temperature during $6 \mathrm{~h}$ (Figure 4.47). ${ }^{1} \mathrm{H}$ NMR spectra were recorded for both of them at $37 \stackrel{\circ}{\mathrm{C}}$ and integral values were compared to determine the solubility of the amyloid derivative in the presence of different tetrapeptides (Figure 4.48). A concentric capillary tube with hydroquinone $5 \mathrm{mM}$ in $\mathrm{D}_{2} \mathrm{O}$ was used as standard pattern. 


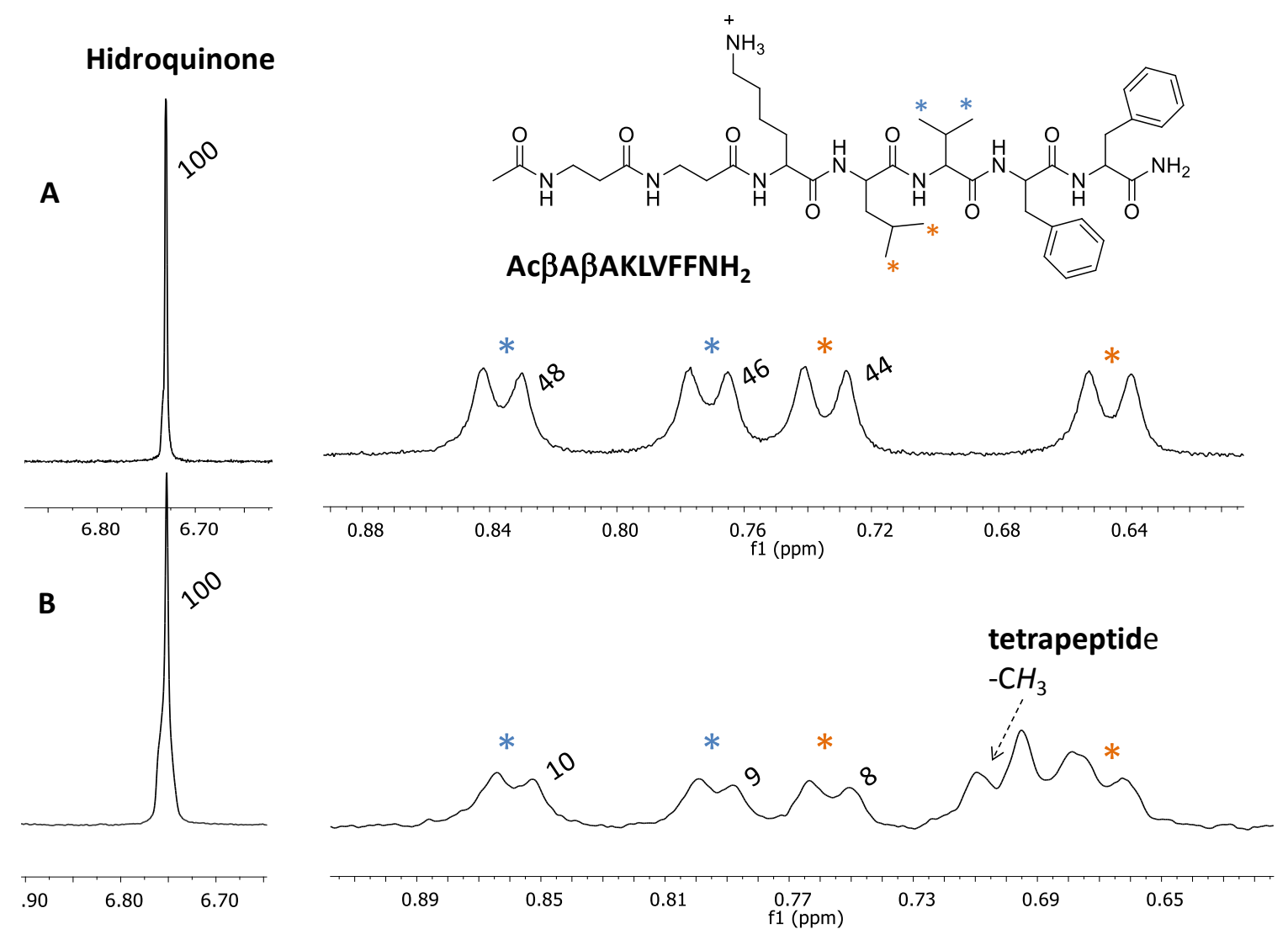

Figure 4.48 ${ }^{1} \mathrm{H}$ NMR spectra of $\mathrm{A}$ ) blank solution of $\mathrm{Ac} \beta \mathrm{A} \beta \mathrm{AKLVVFFNH_{2 }}$ in PBS at $37{ }^{\circ} \mathrm{C}$ and $\mathrm{B}$ ) equimolar mixture of compound $\mathbf{5}$ and $A c \beta A \beta A K L V F F N H_{2}$. Numbers above the signals refers to their corresponding integral values.

Following this procedure it was easy to determine the amount of Ac $\beta A \beta A K L V F F N_{2}$ in solution. For mixtures with compounds $\mathbf{2 , 4}$ and $\mathbf{6}$, which are poorly aggregating according to TEM data, $75 \%$ of the heptapeptide $(0.4 \mathrm{mM})$, remained in solution. Such value was slightly lower for compound 3 with $65 \%$ of the heptapeptide in solution and was significantly reduced for compounds $\mathbf{1}$ and $\mathbf{5}$. For instance, mixture with compound 1 revealed a solubility of $0.2 \mathrm{mM}$ for $A c \beta A \beta A K L V F F N H_{2}$ (40\% in solution) and this value was even lower for compound $\mathbf{5}$ with just $20 \%$ of the heptapeptide in solution, which means a value for solubility of $0.1 \mathrm{mM}$. As can be seen in this experiment the presence of equimolar amounts of compounds 1-6 modified in a different way the solubility of $A c \beta A \beta A K L V F F N H_{2}$. The presence of compounds $\mathbf{1}$ and $\mathbf{5}$ altered significantly this value in agreement with previous TEM and CD results. In summary, the use of this short sequence can be considered as a good approach considering the parallelism with the $A \beta 1-40$ reported data. Furthermore there is clear influence of the amino acid sequence on the interaction of compounds 1-6 with 
Ac $\beta A \beta A K L V F F N H_{2}$ and $A \beta 1-40$ and in particular the presence of the Z-FD moiety at the $\mathrm{N}$-terminus in the most effective compounds $\mathbf{1}$ and $\mathbf{5}$ (in terms of amyloid peptide interaction).

\subsection{Conclusions}

In summary, in this section six new isomeric Z-tetrapeptides containing $F$ and $D$ have been tested as low-molecular-weight hydrogelators and successful results have been obtained for all of them. The use of GdL hydrolysis to smoothly decrease the $\mathrm{pH}$ has let to homogeneous and reproducible gels in all the cases. After that, these hydrogels have been studied by microscopic and spectroscopic techniques revealing a clear influence of the primary sequence on the supramolecular behaviour of these compounds. In addition the key role of hydrophobicity and $\pi$-stacking interactions has been also confirmed by spectroscopic studies. Tentative packing models have been proposed considering the data reported so far and the importance of segregated blocks of aromatic and polar fragments has been pointed out for the best hydrogelators. ThT binding experiments have also confirmed the presence of extended and accessible aromatic surfaces.

In addition a detailed study of the thermodynamics and kinetics of the fibrillisation process has been performed. An important pKa shift of the ionic moieties has been observed for all the tetrapeptides. This behavior is linked to the fibrillisation allowing the gels to be formed around the neutrality. Interestingly the magnitude of this pKa shift can be correlated well with the thermodynamics of the aggregation. ${ }^{1} \mathrm{H} N M R$ has been employed to monitor the kinetics of the aggregation process revealing the presence of an induction time where metastable species are present. Furthermore fluorescence experiments have allowed setting the dimer formation as the rate determining step. This behavior has been ascribed to a kinetically cooperative process related to the entropic cost associated with peptide reorganization to form dimers. As a remarkable result a kinetic self-sorting system has been designed yielding in the first place the formation of the least thermodynamically stable type of fibre. Most likely this kinetic effect will be much more intense in longer peptides 
Finally the binding of these compounds to amyloid peptide $A \beta 1-40$ and to $a$ shorter heptapeptide sequence was also studied. The results revealed a remarkable preference for the interaction of $A \beta 1-40$ and $A c \beta A \beta A K L V F F N_{2}$ with compounds 1 and 5. They seems to act as seeds for the aggregation of $A \beta 1-40$ and have therefore a significant influence on the secondary structure domains of this peptide as can be appreciated in TEM images and CD measurements. Such results are of great interest if one considers the capture of amyloids to form large aggregates through interaction with other molecules as a good strategy to reduce the toxic oligomeric species in solution as previously reported by Mihara and co-workers. ${ }^{48}$ Interesting differences among previously described peptides are the small size of our compounds bearing just four amino acids and the absence of any $\beta$-amyloid natural fragment.

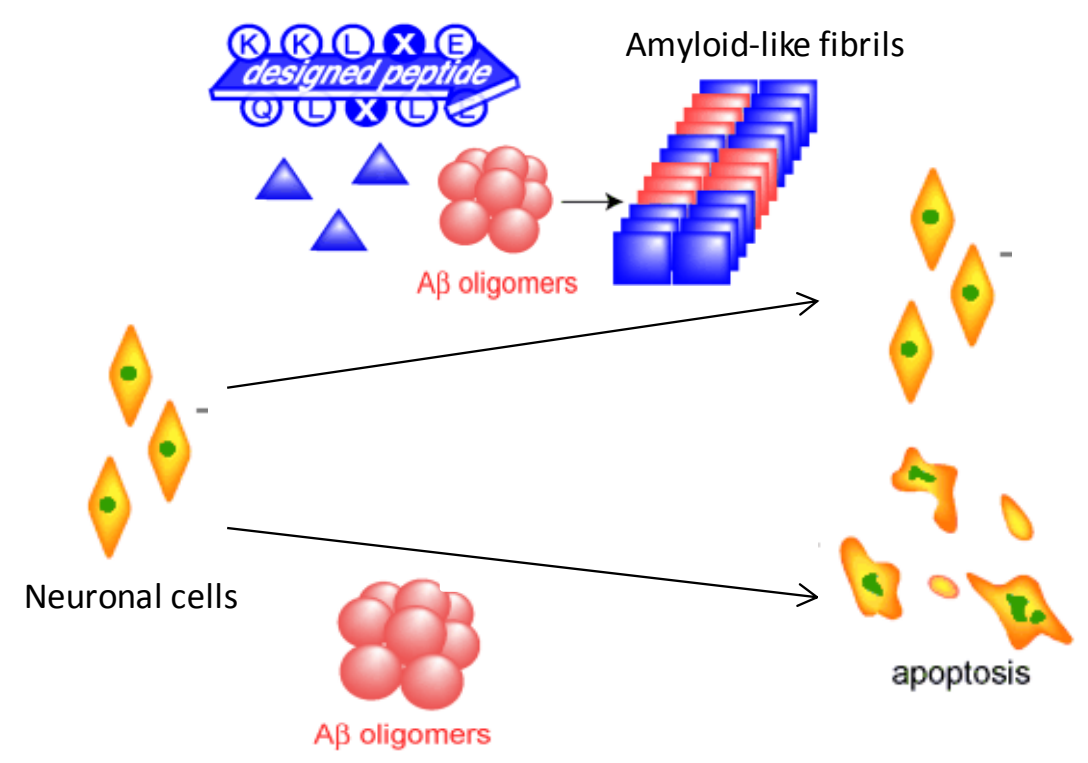

Figure 4.49 Schematic representation of suppression of $A \beta$ toxicity through the action of the designed peptides capable of forming amyloid-like fibrils in co-assembly with $A \beta$ oligomers. ${ }^{48 c}$

Considering the ability of our compounds as hydrogelators and the dynamic nature of these systems in which free molecules are constantly exchanging from solution to the aggregate phase, hydrogels of compounds $\mathbf{1}$ and $\mathbf{5}$ may allow a smooth release of the active free tetrapeptide into, for example, the blood stream where it could capture misfolded amyloids. 


\subsection{Supplementary information}

\section{S.I.4.1 Hydrogelation of acidic tetrapeptides}

S.I. 4.1.1 Gelation experimental procedure using $\mathrm{GdL}$

S.I. 4.1.2 Transmission electron microscopy (TEM)

S.I. 4.1.3 Scanning electron microscopy (SEM)

S.I. 4.1.4 Fourier Transform Infrared Spectroscopy (FTIR)

S.I. 4.1.5 Circular dichroism (CD)

S.I. 4.1.6 Fluorescence

S.I. 4.1.7 Wide angle X-ray diffraction (WAXD)

S.I. 4.1.8 Thioflavine T (ThT) binding assay

S.I. 4.1.9 Molecular Modeling

S.I. 4.1.10 Rheology

S.I.4.2 Thermodynamic and kinetic study of fibrillisation

S.I. 4.2.1 Potentiometric titrations with $\mathrm{HCl}$

S.I. 4.2.2 Potentiometric titrations with $\mathrm{GdL}$

S.I. 4.2.3 ${ }^{1} \mathrm{H}$ NMR kinetic experiments

S.I. 4.2.4 Fluorescence kinetic experiments

S.I. 4.2.5 Small angle neutron scattering (SANS)

S.I.4.3 Interaction with amyloid peptide $A \beta 1-40$ and $A c \beta A \beta A K L V F F N_{2}$

S.I. 4.3.1 $\beta$-amyloid fibril formation 


\section{S.I.4.1 Hydrogelation of acidic tetrapeptides}

S.I. 4.1.1 Gelation experimental procedure using GdL

In all cases, the desired amounts of compounds 1-6 were dissolved in $\mathrm{Na}_{2} \mathrm{CO}_{3}$ solution ( 5 equiv.).These solutions were then sonicated until clear. After that, these solutions were added over a known amount of $\mathrm{GdL}$, typically 1.5 equiv. relative to $\mathrm{Na}_{2} \mathrm{CO}_{3}$ and sonicated for 10 seconds. Finally, samples were allowed to stand at room temperature, with gelation taking place over 3 days. The minimum gel concentration (mgc) was determined using the tube inversion method. This method was tested in cylindrical screw capped vials with internal diameter of $1.2 \mathrm{~cm}$ and $4.5 \mathrm{~cm}$ in length. The ultrasound bath employed was an Elma Elmasonic ultrasound bath.

\section{S.I. 4.1.2 Transmission electron microscopy (TEM)}

Samples of gels at their mgc were applied directly onto Formvar carbon film on 200 mesh coppe rgrids. Excess gel was carefully removed by capillarity. After that one drop of distillated water was added in order to remove salts and excess solvent was removed again in the same manner. The grids were immediately stained with one drop of phosphotungstic acid $1 \%$ for 5 min. Excess stain was removed by capillary action. TEM images were recorded in a Transmission Electron Microscope JEOL 2100.

\section{S.I. 4.1.3 Scanning electron microscopy (SEM)}

Gels at their mgc were lyophilized to produce a fluffy white solid. The corresponding freeze-dried gels were placed on top of an aluminum specimen mount stub and sputtered with Pt. SEM images were taken on a JEOL $7001 \mathrm{G}$ microscope equipped with a digital camera.

\section{S.I. 4.1.4 Fourier Transform Infrared Spectroscopy (FTIR)}

Gels at their m.g.c. were filtered and quickly washed with water to remove nonaggregated material (gluconic acid or salts). $\mathrm{KBr}$ discs were prepared mixing the resulting dry solid with $200-300 \mathrm{mg}$ of $\mathrm{KBr}$ in an agate mortar and pressing the mixture at 10 ton for ca. 2-3 min. Then, FT-IR spectra were collected in a JASCO FTIR-6200 spectrometer. Curve-fitting procedure was done using JASCO FTIR Curve Fitting software (Japanese 
Journal of Spectroscopy (Bunko Kenkyu) 35, 142, 1986). An example of curve fitting analysis is shown in the next figure:
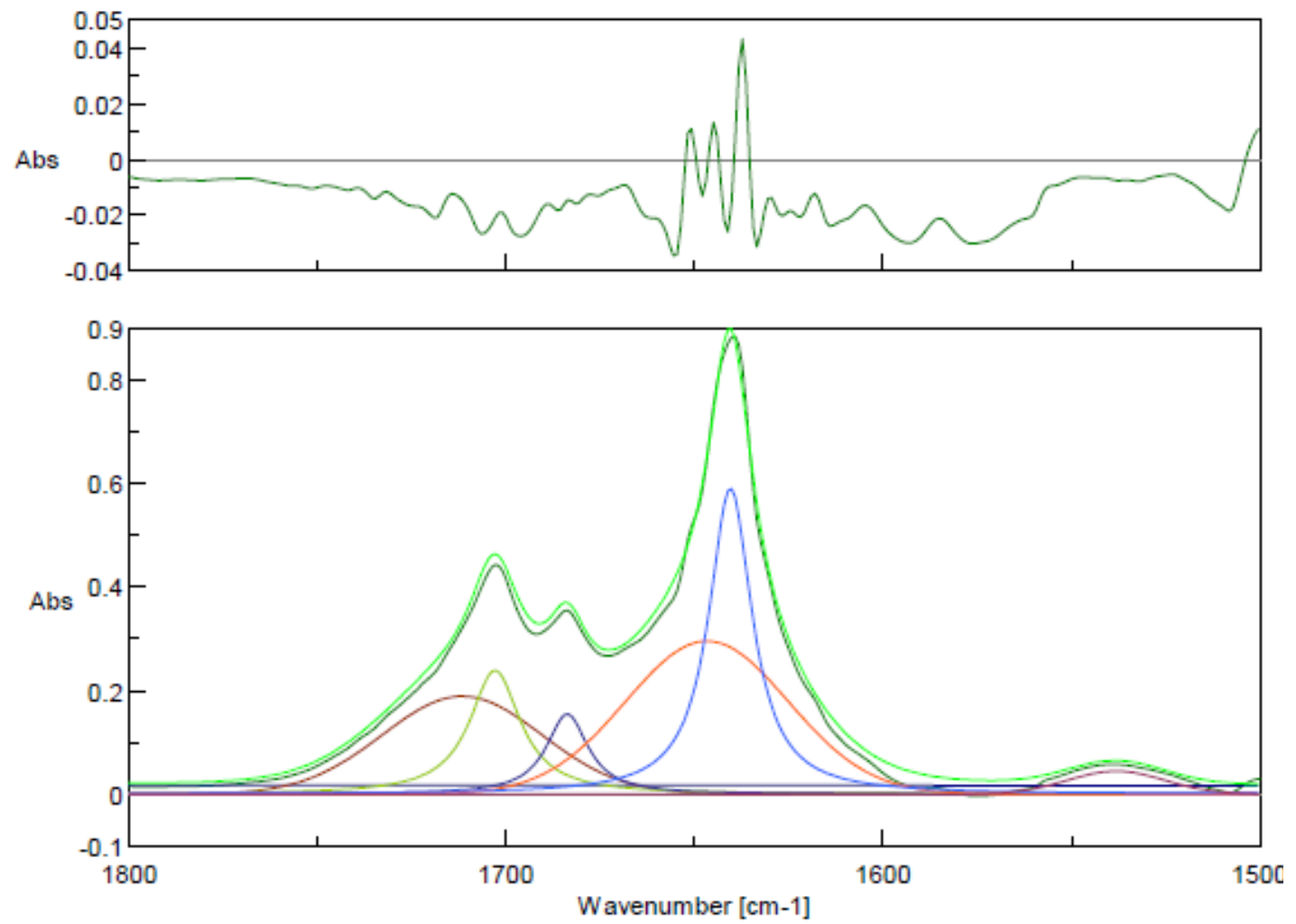

S.I. 4.1.4.1 Curve fitting analysis for compound 5. Black line corresponds to experimental data. Light green line corresponds to theoretical IR spectra. The error is shown at the upper part.

\section{S.I. 4.1.5 Circular dichroism}

Gels at their mgc and solutions $(0.75 \mathrm{mM})$ were prepared directly into $1 \mathrm{~mm}$ quartz cell using the methodology mentioned above. Measurements were performed in a JASCO J-810 instrument, at room temperature and the spectra were recorded from 180 to $450 \mathrm{~nm}$ with $1.0 \mathrm{~nm}$ step, $1 \mathrm{~nm}$ bandwidth and10 accumulations. Final spectra were the average of three measurements.

\section{S.I. 4.1.6 Fluorescence}

Gels at their mgc were prepared directly into a $1 \mathrm{~cm}$ path length PMMA fluorescence cell (Final volume: $2 \mathrm{~mL}$ ). The fluorescence emission was recorded from $270 \mathrm{~nm}$ to $600 \mathrm{~nm}$ with excitation at $260 \mathrm{~nm}$ in a Jasco FP-8300 Spectrofluorimeter. 

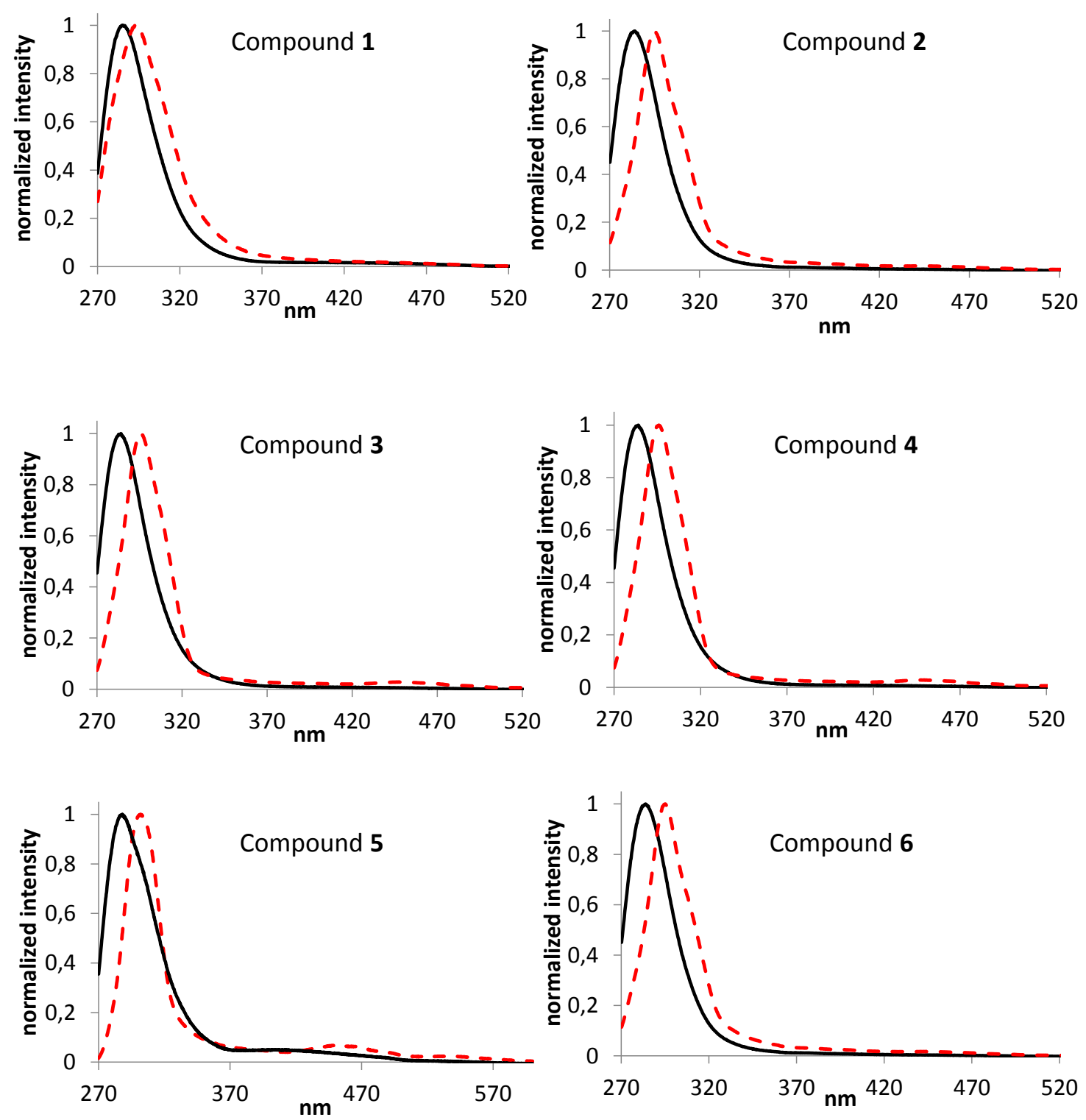

S.I. 4.1.6.1 Fluorescence emission spectra $\left(\lambda_{\mathrm{em}}=260 \mathrm{~nm}\right.$ ) of compounds $1-6$ in solution (black line) and at their m.g.c (red line).

\section{S.I. 4.1.7 Wide angle X-ray diffraction}

Gels at their mgc were filtered and quickly washed with water to remove nonaggregated material (gluconic acid or salts). The resulting dry solid was placed on a sample holder and data were collected for $2 \theta$ values between 2 and $40^{\circ}$ with a step size of $0.03^{\circ}$ and a time step of $10 \mathrm{~s}$. Data collection was performed at room temperature with a Bruker D4 Endeavor X-ray powder diffractometer by using $\mathrm{Cu}-\mathrm{K}_{\alpha}$ radiation. 

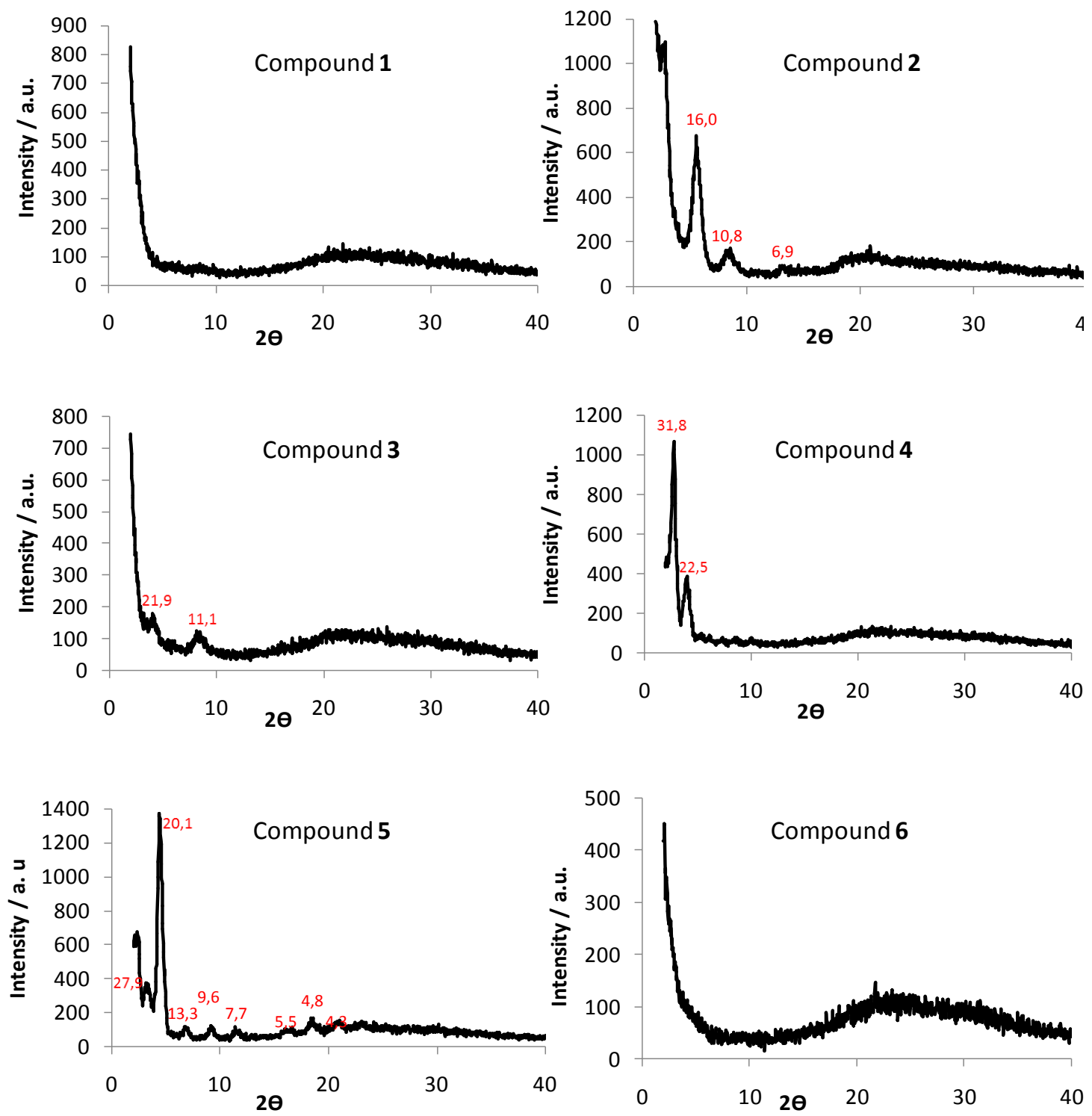

S.I. 4.1.7.1 WAXS for xerogels of compounds 1-6 (distance in $\AA$ ).

\section{S.I. 4.1.8 ThT binding assay}

Gels at their minimum gelation concentration were prepared directly into a PMMA fluorescence cell of $1 \mathrm{~cm}$ path length as mentioned before. When the gelation process was completed (typically after 3 days), $20 \mu \mathrm{L}$ of a stock solution $0.5 \mathrm{mM}$ of ThT in PBS were added and their fluorescence emission spectra were recorded at different times from 465 to $600 \mathrm{~nm}$ with excitation at $450 \mathrm{~nm}$. The final ThT concentration was set to $5 \mu \mathrm{M}$ to avoid concentration-dependent artifacts. 

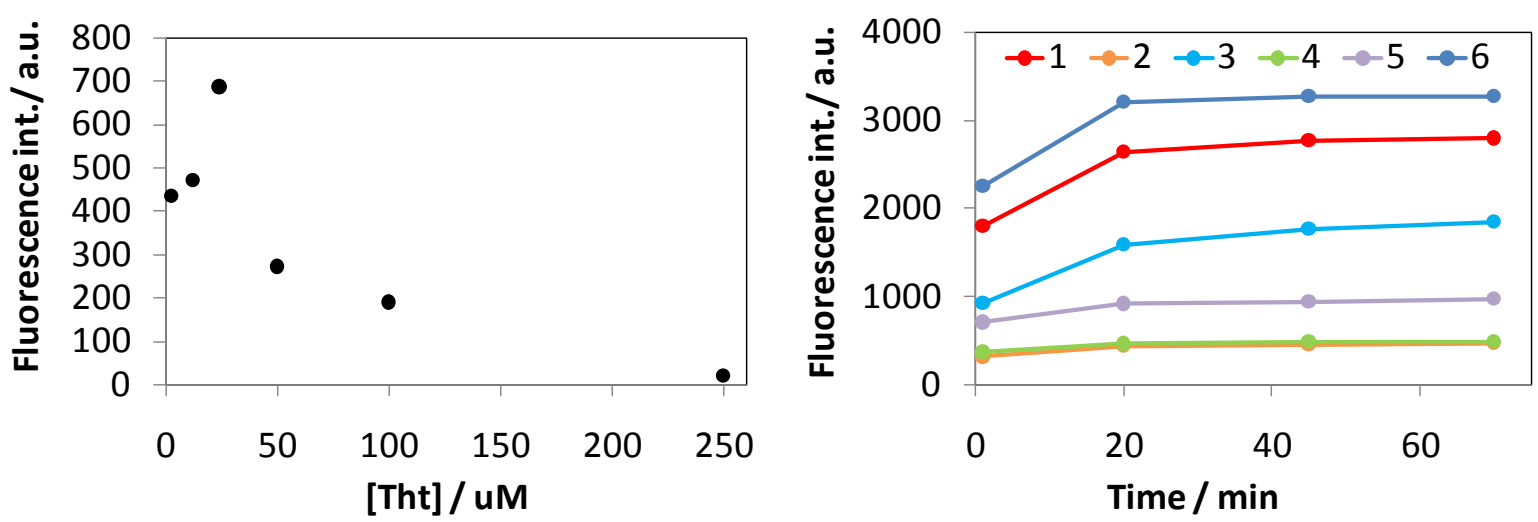

S.I. 4.1.8.1 ThT fluorescence vs concentration of ThT in the presence of compounds 1 (left) and ThT fluorescence vstime in the presence of compounds 1-6 (right)

\section{S.I. 4.1.9 Rheology}

Rheologycal measurements were carried out on a MARS III (HAAKE MARS III) rheometer equipped with a MARS temperature control accessory, using steel parallel plate-plate geometry (35 mm diameter). The gap distance was fixed at $1000 \mathrm{~nm}$. A homogeneous layer of the gel was placed between the two plates. Frequency and stress sweep steps were performed at $20 \stackrel{\circ}{ } \mathrm{C}$. To ensure the LVR regime during all the measurements a general protocol was established. An initial stabilization step of 1 minute was followed by a frequency sweep step at a constant oscillatory stress of $0.2 \mathrm{~Pa}$ and finally a stress sweep step at a constant frequency of $1 \mathrm{~Hz}$.

\section{S.I. 4.2 Thermodynamic and kinetic study of fibrillisation}

\section{S.I. 4.2.1 Potentiometric titrations with $\mathrm{HCl}$}

Potentiometric titrations to determine acid-base constants were carried out at 25 ㅇ. In a typical experiment $10 \mathrm{~mL}$ of an aqueous solution of the corresponding tetrapeptide $(15 \mathrm{mM})$ and triethylamine $(60 \mathrm{mM})$ were titrated with a $0.01 \mathrm{M}$ normalized solution of aqueous hydrogen chloride with vigorous stirring. Addition rate was $0.38 \mathrm{~mL} \mathrm{~min}^{-1}$ and $\mathrm{pH}$ was monitored every 10 seconds (in a S220 Seven Compact pH-meter Mettler Toledo). Thermodynamic constants for the species in solution could be calculated with Hyperquad 2008 using titration data previous to the experimental aggregation onset. To assess solubility product of the peptides, titration was stopped when a solid precipitate was observed and $\mathrm{pH}$ measured after $24 \mathrm{~h}$ once equilibrium was 
reached. Then the solubility product was calculated iteratively with Hyss2009, adjusting its value to fit the calculated and experimental $\mathrm{pH}$. Data fitting for the different compounds are shown in next figure:
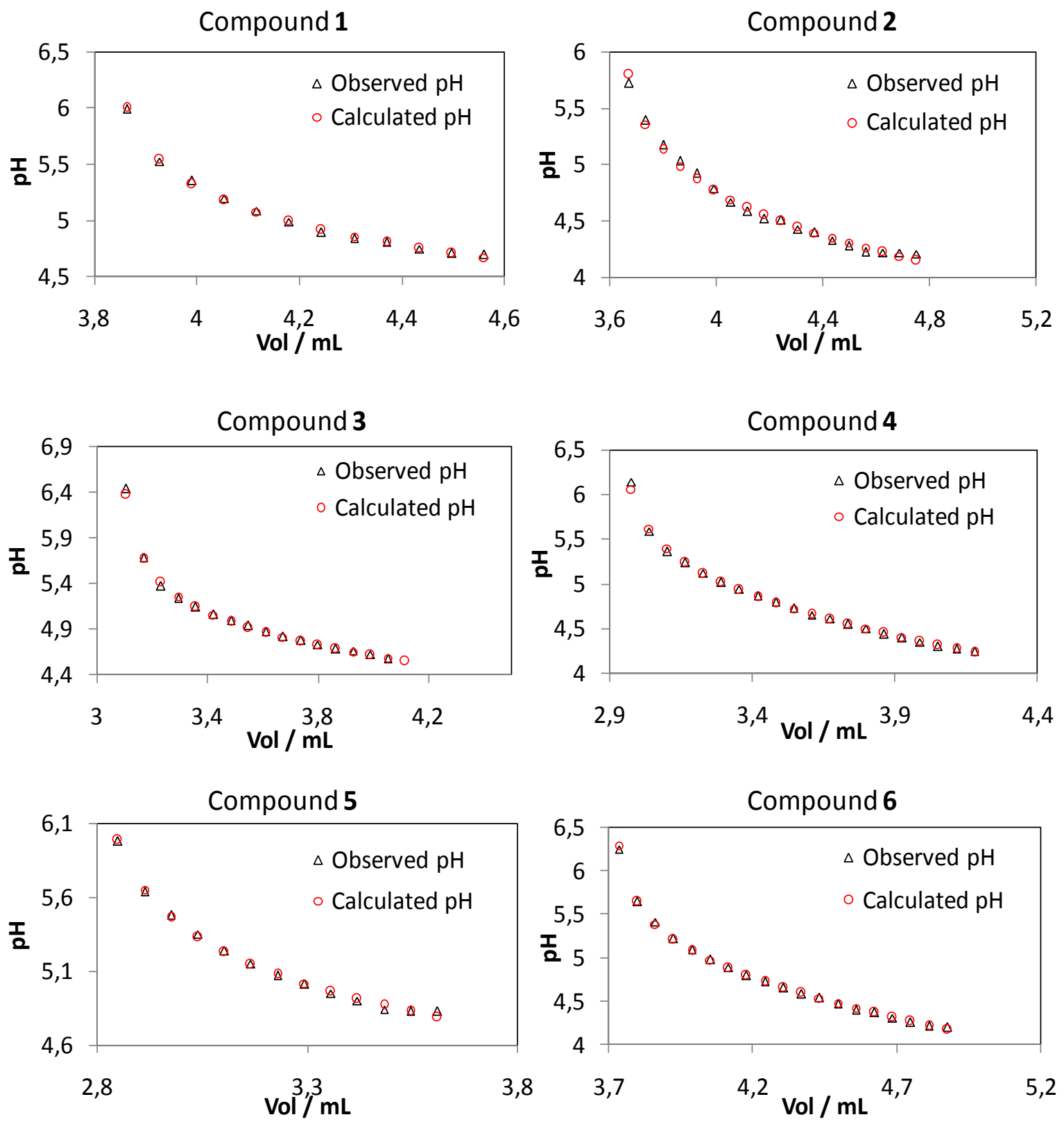

S.I. 4.2.1 Experimental and calculated titration points used for the calculation of acidity constants 

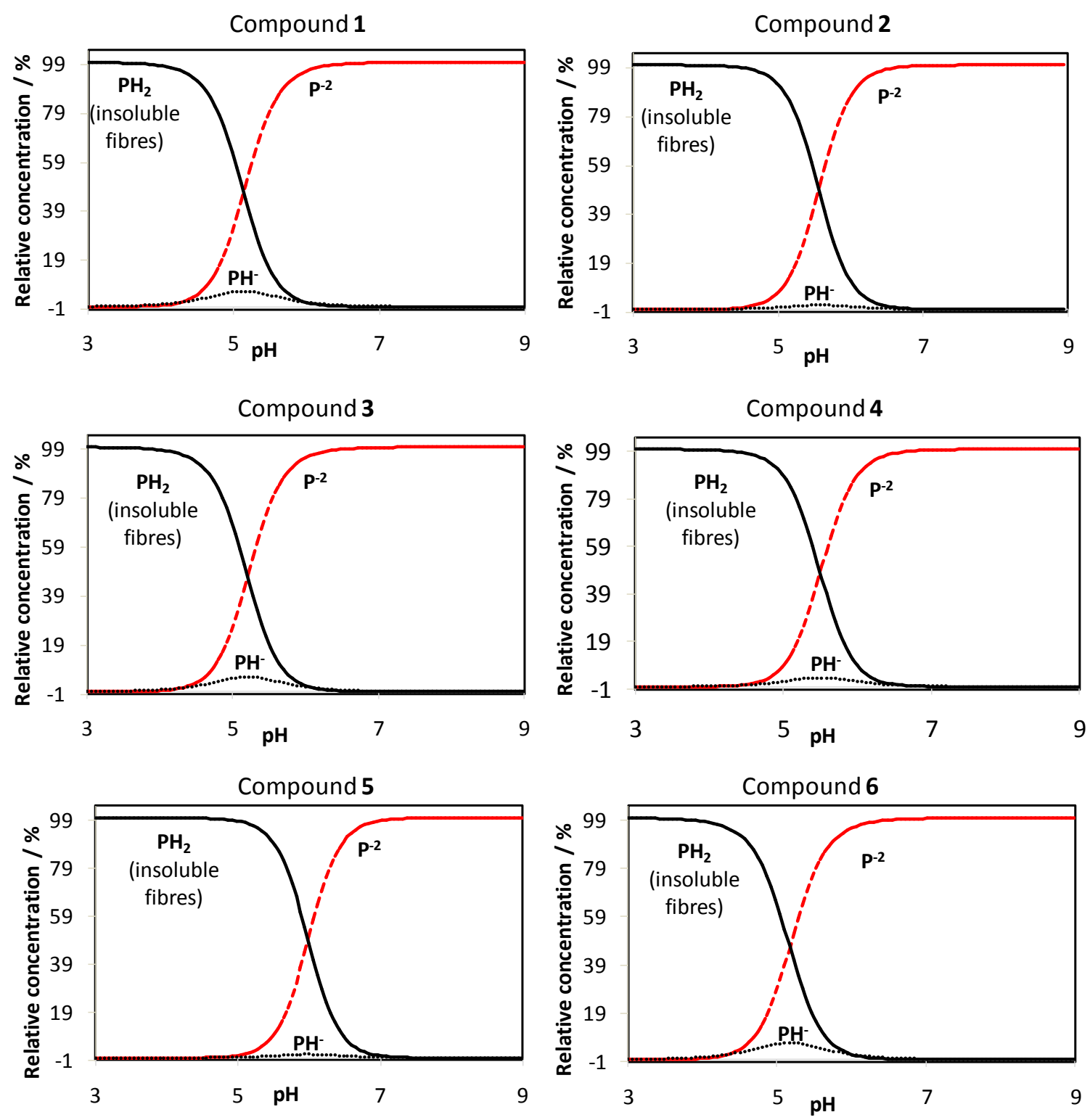

S.I. 4.2.2 Species distribution diagram calculated for the different tetrapeptides

\section{S.I. 4.2.2 Potentiometric titrations with $\mathrm{GdL}$}

The $\mathrm{pH}$ change during the gel formation using GdL was also monitored. In a typical experiment an aqueous solution $(2 \mathrm{~mL}$ ) of the corresponding tetrapeptide (10 $\mathrm{mM}), \mathrm{Na}_{2} \mathrm{CO}_{3}(25 \mathrm{mM})$ and $\mathrm{GdL}(38 \mathrm{mM})$ were placed in a test tube and the $\mathrm{pH}$ was monitored every 3 seconds during 4-5 h. Data were recorded in a S220 Seven Compact pH-meter Mettler Toledo. 


\section{S.I. 4.2.3 ${ }^{1} \mathrm{H}$ NMR kinetic experiments}

Fibrillisation was monitored by measuring the intensity of the ${ }^{1} \mathrm{HNMR}(500 \mathrm{MHz})$ signals which were progressively reduced upon aggregation. In a typical experiment an aqueous solution $(0.5 \mathrm{~mL})$ of the corresponding tetrapeptide $(10 \mathrm{mM})$, tryethylamine $(25$ $\mathrm{mM}$ ) or $\mathrm{Na}_{2} \mathrm{CO}_{3}(25 \mathrm{mM})$ and $\mathrm{GdL}(38 \mathrm{mM})$ were placed in an NMR tube. Spectra were recorded every 15 minutes for 14 hours. An external standard (hydroquinone $5 \mathrm{mM}$ ) was used for integration. The monitored signal was the methyl group of the compounds.
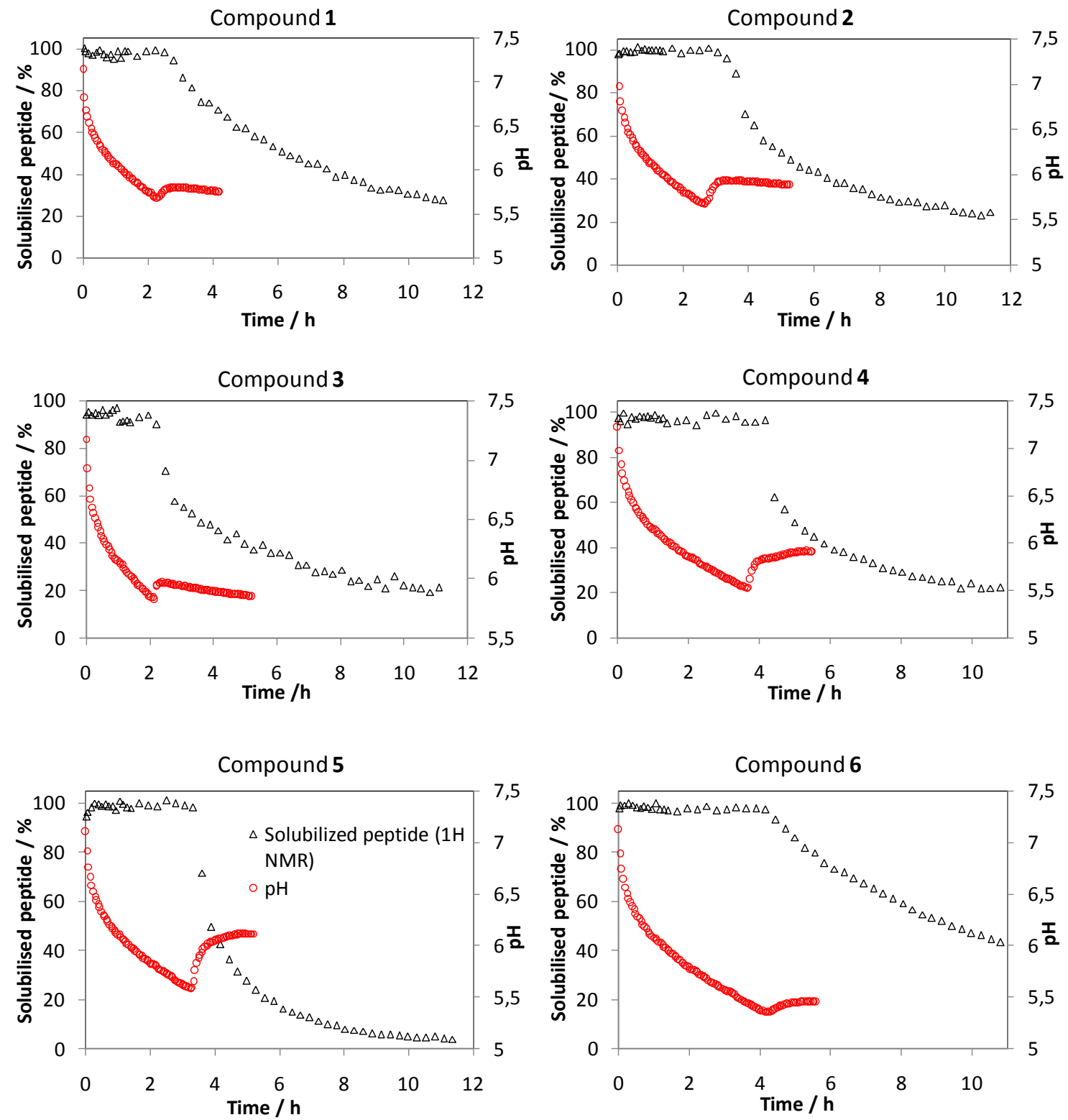

S.I.4.2.3.1 Variation of fluorescence intensity and $\mathrm{pH}$ with time upon progressive acidification by means of GdL hydrolysis 
The experimental conditions for the mixture of compounds $\mathbf{1}$ and $\mathbf{5}$ were the same but $5 \mathrm{mM}$ concentrations of each peptide were used. Different chemical shifts for both methyl groups allowed monitoring the relative concentration of both compounds. Experiments were carried out in a Varian VNMR System $500 \mathrm{MHz}$.

S.I. 4.2.4 Fluorescence kinetic experiments
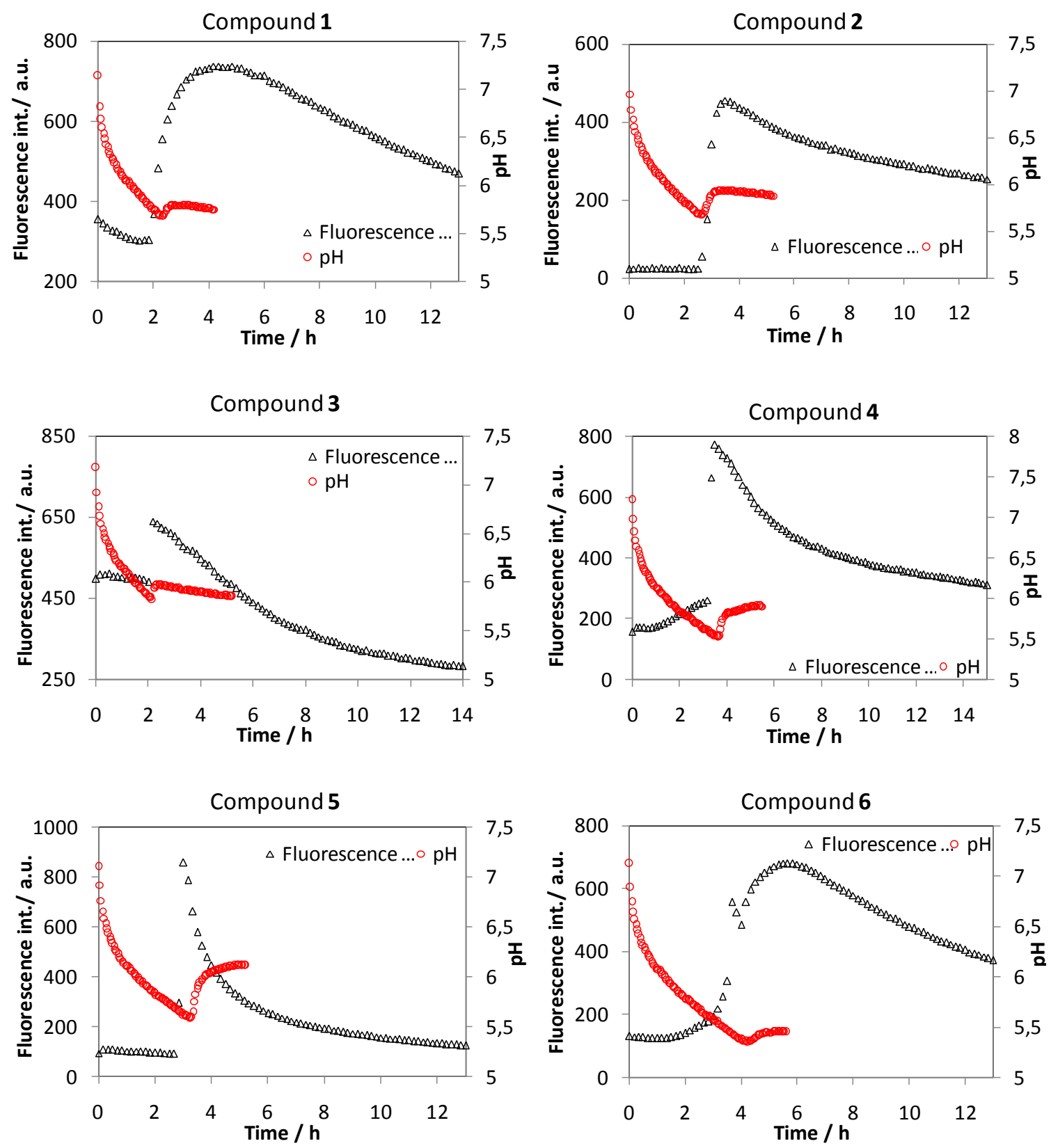

S.I.4.2.4.1 Variation of fluorescence intensity and $\mathrm{pH}$ with time upon progressive acidification by means of GdL hydrolysis

An aqueous solution $(1 \mathrm{~mL})$ of the corresponding tetrapeptide $(10 \mathrm{mM}), \mathrm{Na}_{2} \mathrm{CO}_{3}$ $(25 \mathrm{mM})$ and $\mathrm{GdL}(38 \mathrm{mM})$ were placed into a $1 \mathrm{~cm}$ path length PMMA fluorescence 
cuvette. Excitation was performed at $260 \mathrm{~nm}$ and the emission intensity at 294-296 nm monitored every 15 minutes for 13 hours in a Jasco FP-8300 spectrofluorimeter.

\section{S.I. 4.2.5 Small angle neutron scattering (SANS)}

SANS experiments were carried out on the Sans2d small-angle diffractometer at the ISIS Pulsed Neutron Source (STFC Rutherford Appleton Laboratory, Didcot, U.K.). A simultaneous range of wavenumber $Q=4 \pi \sin \theta / \lambda$ (scattering angle $2 q$, wavelength $\lambda$ ) from $0.01-1 \AA^{-1}$ was achieved utilizing an incident wavelength range of 1.75-16.5. Samples were prepared in deuterated solvents, providing the necessary contrast and were contained in $2 \mathrm{~mm}$ path length Hellma quartz cells. Each raw scattering data set was corrected for the detector efficiencies, sample transmission and background

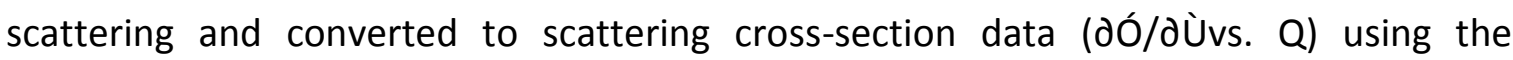
instrument-specific software MANTID. These data were placed on an absolute scale $\left(\mathrm{cm}^{-}\right.$ ${ }^{1}$ ) using the scattering from a standard sample (a solid blend of hydrogenous and perdeuterated polystyrene) in accordance with established procedures.

\section{S.I. 4.3 Interaction with amyloid peptide $A \beta 40$}

\section{S.I. 4.3.1 $\beta$-amyloid fibril formation ${ }^{49}$}

$1 \mathrm{mg} 5$ of $\beta$-amyloid (1-40) (GenScript HK Ltd.) was mixed with $9.26 \mathrm{~mL} \mathrm{HFPI}$ to yield a 25 $\mu \mathrm{M}$ solution. The solution was sonicated for 2 hours to produce uniform $\beta$-amyloid monomers. Aliquoted samples of $1 \mathrm{~mL}(108 \mu \mathrm{g})$ were frozen at $-78 \stackrel{\text { oc }}{\mathrm{C}}$ for later use. Immediately before use, frozen $\beta$-amyloid samples were lyophilized for30 minutes to produce a fluffy solid. The samples were then dissolved in $250 \mu \mathrm{l}$ of phosphate buffer saline (PBS). Immediately after that, a freshly prepared equimolar solution of each peptide in PBS was added (50 $\mu \mathrm{M}$ amyloid: $50 \mu \mathrm{M}$ compounds 1-6). $50 \mu \mathrm{M}$ blank solutions of $\beta$-amyloid and compounds 1-6 were also prepared. All the solutions were incubated in a thermostatic bath at $37^{\circ} \mathrm{C}$ for a period of 7 days. Samples for TEM analysis (Transmission Electron Microscope JEOL 2100.) were taken at $6 \mathrm{~h}, 30 \mathrm{~h}, 3 \mathrm{~d}$ and $7 \mathrm{~d}$ and applied directly onto a 200 mesh carbon coated Formvar copper grid. Excess of solvent was carefully removed by capillary action using filter paper. One drop of water was then added to remove salts and the excess of solvent was removed in same manner. 
The grids were immediately stained with one drop of phosphotungstic acid $1 \%$ for 1 min. and excess of stain was removed by capillarity. After 1 week of incubation at 37 oc , the samples were placed into $1 \mathrm{~mm}$ quartz cell and spectra were recorded at the same temperature from $190 \mathrm{~nm}$ to $400 \mathrm{~nm}$ with $1.0 \mathrm{~nm}$ step, $1 \mathrm{~nm}$ bandwidth and 10 accumulations. The final spectra are the average of three measurements (JASCO J-810 instrument). 


\subsection{References}

1. a) Bowerman, C. J.; Nilsson, B. L., Self-assembly of amphipathic beta-sheet peptides: Insights and applications. Biopolymers 2012, 98, 169-184; b) Marshall, K. E.; Morris, K. L.; Charlton, D.; O’Reilly, N.; Lewis, L.; Walden, H.; Serpell, L. C., Hydrophobic, aromatic, and electrostatic interactions play a central role in amyloid fibril formation and stability. Biochemistry 2011, 50, 2061-2071; c) Davies, R. P. W.; Aggeli, A., self-assembly of amphiphilic $\beta$-sheet peptide tapes based on aliphatic side chains. J. Pept. Sci. 2011, 17, 107-114.

2. a) Segarra-Maset, M. D.; Nebot, V. J.; Miravet, J. F.; Escuder, B., Control of molecular gelation by chemical stimuli. Chem. Soc. Rev. 2013, 42, 7086-7098; b) Miravet, J. F.; Escuder, B., Pyridine-functionalised ambidextrous gelators: towards catalytic gels. Chem. Commun. 2005, 5796-5798; c) Terech, P.; Weiss, R. G., Low molecular mass gelators of organic liquids and the properties of their gels. Chem. Rev. 1997, 97, 3133-3160.

3. Adams, D. J.; Butler, M. F.; Frith, W. J.; Kirkland, M.; Mullen, L.; Sanderson, P., A new method for maintaining homogeneity during liquid-hydrogel transitions using low molecular weight hydrogelators. Soft Matter 2009, 5, 1856-1862.

4. Pocker, Y.; Green, E., Hydrolysis of D-Glucono- $\delta$-Lactone: General acid-base catalysis, solvent deuterium-isotope effects and transition-state characterization J. Am. Chem. Soc. 1973, 95, 113-119.

5. Nebot, V. J.; Smith, D. K., Chapter 2: Techniques for the characterisation of molecular gels. Functional Molecular Gels, RSC 2014.

6. a) Barth, A., Infrared spectroscopy of proteins. Biochim Biophys Acta 2007, 1767, 1073-1101; b) Kong, J.; Yu, S., Fourier transform infrared spectroscopic analysis of protein secondary structures. Acta Bioch. Bioph. Sin. 2007, 39, 549-559.

7. a) Grahame, D. A. S.; Olauson, C.; Lam, R. S. H.; Pedersen, T.; Borondics, F.; Abraham, S.; Weiss, R. G.; Rogers, M. A., Influence of chirality on the modes of self-assembly of 12-hydroxystearic acid in molecular gels of mineral oil. Soft Matter 2011, 7, 7359-7365; b) Abraham, S.; Lan, Y.; Lam, R. S. H.; Grahame, D. A. S.; Kim, J. J. H.; Weiss, R. G.; Rogers, M. A., Influence of positional isomers on the macroscale and nanoscale architectures of aggregates of racemic hydroxyoctadecanoic acids in their molecular gel, dispersion, and solid states. Langmuir 2012, 28, 4955-4964.

8. Barth, A.; Zscherp, C., What vibrations tell about proteins. Q. Rev. Biophys. 2002, 35, 369-430.

9. a) Kelly, S. M.; Price, N. C., The use of circular dichroism in the investigation of protein structure and function. Curr. Protein Pept. Sci. 2000, 1, 349-384; b) Berova, N.; Nakanishi, K.; Woody, R., Circular dichroism: principles and applications. John Wiley \& Sons 2000. 
10. Amdursky, N.; Molotskii, M.; Aronov, D.; Adler-Abramovich, L.; Gazit, E.; Rosenman, G., Blue luminescence based on quantum confinement at peptide nanotubes. Nano Lett. 2009, 9, 3111-3115.

11. Anand, U.; Mukherjee, M., Exploring the self-assembly of a short aromatic $A \beta(16-$ 24) Peptide. Langmuir 2013, 29, 2713-2721.

12. Smith, A. M.; Williams, R. J.; Tang, C.; Coppo, P.; Collins, R. F.; Turner, M. L.; Saiani, A.; Ulijn, R. V., Fmoc-Diphenylalanine self assembles to a hydrogel via a novel architecture based on $\pi-\pi$ interlocked $\beta$-sheets. Adv. Mater. 2008, 20, 3741.

13. Robbins, K. J.; Liu, G.; Selmani, V.; Lazo, N. D., Conformational analysis of thioflavin $T$ bound to the surface of amyloid fibrils. Langmuir 2012, 28, 1649016495.

14. LeVine III, H., Quantification of $\beta$-sheet amyloid fibril structures with thioflavin T. In Methods Enzymol., Ronald, W., Ed. Academic Press 1999; Vol. Volume 309, pp 274-284.

15. Sabate, R.; Rodríguez-Santiago, L.; Sodupe, M.; Saupe, S. J.; Ventura, S., Thioflavin-T excimer formation upon interaction with amyloid fibers. Chem. Commun. 2013, 49, 5745-5747.

16. Mohamadi, F.; Richards, N. G. J.; Guida, W. C.; Liskamp, R.; Lipton, M.; Caufield, C.; Chang, G.; Hendrickson, T.; Still, W. C., Macromodel-an integrated software system for modeling organic and bioorganic molecules using molecular mechanics. J. Comput. Chem. 1990, 11, 440-467.

17. Fitzpatrick, A. W. P.; Debelouchina, G. T.; Bayro, M. J.; Clare, D. K.; Caporini, M. A.; Bajaj, V. S.; Jaroniec, C. P.; Wang, L.; Ladizhansky, V.; Müller, S. A.; MacPhee, C. E.; Waudby, C. A.; Mott, H. R.; De Simone, A.; Knowles, T. P. J.; Saibil, H. R.; Vendruscolo, M.; Orlova, E. V.; Griffin, R. G.; Dobson, C. M., Atomic structure and hierarchical assembly of a cross- $\beta$ amyloid fibril. Proc. Natl. Acad. Sci. 2013, 110, 5468-5473.

18. Knowles, T. P. J.; Vendruscolo, M.; Dobson, C. M., The amyloid state and its association with protein misfolding diseases. Nat. Rev. Mol. Cell Biol. 2014, 15, 384-396.

19. a) Thirumalai, D.; Reddy, G., Protein thermodynamics: Are native proteins metastable? Nature Chem. 2011, 3, 910-911; b) Baldwin, A. J.; Knowles, T. P. J.; Tartaglia, G. G.; Fitzpatrick, A. W.; Devlin, G. L.; Shammas, S. L.; Waudby, C. A.; Mossuto, M. F.; Meehan, S.; Gras, S. L.; Christodoulou, J.; Anthony-Cahill, S. J.; Barker, P. D.; Vendruscolo, M.; Dobson, C. M., Metastability of native proteins and the phenomenon of amyloid formation. J. Am. Chem. Soc. 2011, 133, 1416014163 ; c) Gazit, E., The "Correctly Folded" state of proteins: Is it a metastable state? Angew. Chem. Int. Ed. 2002, 41, 257-259. 
20. Baldwin, A. J.; Knowles, T. P. J.; Tartaglia, G. G.; Fitzpatrick, A. W.; Devlin, G. L.; Shammas, S. L.; Waudby, C. A.; Mossuto, M. F.; Meehan, S.; Gras, S. L.; Christodoulou, J.; Anthony-Cahill, S. J.; Barker, P. D.; Vendruscolo, M.; Dobson, C. M., Metastability of native proteins and the phenomenon of amyloid formation. J. Am. Chem. Soc. 2011, 133, 14160-14163.

21. Ikenoue, T.; Lee, Y.-H.; Kardos, J.; Yagi, H.; Ikegami, T.; Naiki, H.; Goto, Y., Heat of supersaturation-limited amyloid burst directly monitored by isothermal titration calorimetry. Proc. Natl. Acad. Sci. 2014, 111, 6654-6659.

22. Knowles, T. P. J.; Shu, W.; Devlin, G. L.; Meehan, S.; Auer, S.; Dobson, C. M.; Welland, M. E., Kinetics and thermodynamics of amyloid formation from direct measurements of fluctuations in fibril mass. Proc. Natl. Acad. Sci. 2007, 104, 10016-10021.

23. a) Crespo, R.; Damas, A. R.; Martins P.M., General model for amyloid fibril formation: A generic crystallization-like model that describes the kinetics of amyloid fibril formation. J. Biol. Chem. 2012, 287, 30595; b) Jarrett, J. T.; Lansbury, P. T., Amyloid fibril formation requires a chemically discriminating nucleation event: studies of an amyloidogenic sequence from the bacterial protein OsmB. Biochemistry 1992, 31, 12345-12352.

24. Esler, W. P.; Stimson, E. R.; Ghilardi, J. R.; Lu, Y.-A.; Felix, A. M.; Vinters, H. V.; Mantyh, P. W.; Lee, J. P.; Maggio, J. E., Point substitution in the central hydrophobic cluster of a human $\beta$-amyloid congener disrupts peptide folding and abolishes plaque competence. Biochemistry 1996, 35, 13914-13921.

25. a) Tiiman, A.; Noormägi, A.; Friedemann, M.; Krishtal, J.; Palumaa, P.; Tõugu, V., Effect of agitation on the peptide fibrillization: Alzheimer's amyloid- $\beta$ peptide 142 but not amylin and insulin fibrils can grow under quiescent conditions. J. Pept. Sci. 2013, 19, 386-391;b) Hill, E. K.; Krebs, B.; Goodall, D. G.; Howlett, G. J.; Dunstan, D. E., Shear flow induces amyloid fibril formation. Biomacromolecules 2006, 7, 10-13.

26. a) Nilsson, M. R., Techniques to study amyloid fibril formation in vitro. Methods 2004, 34, 151-160; b) Yong, W.; Lomakin, A.; Kirkitadze, M. D.; Teplow, D. B.; Chen, S.-H.; Benedek, G. B., Structure determination of micelle-like intermediates in amyloid $\beta$-protein fibril assembly by using small angle neutron scattering. Proc. Natl. Acad. Sci. 2002, 99, 150-154; c) Demaimay, R.; Harper, J.; Gordon, H.; Weaver, D.; Chesebro, B.; Caughey, B., Structural aspects of congo red as an Inhibitor of protease-resistant prion protein formation. J. Neurochem. 1998, 71, 2534-2541; d) LeVine iii, H., Quantification of $\beta$-sheet amyloid fibril structures with thioflavin T. In Methods Enzymol., Ronald, W., Ed. Academic Press 1999; Vol. Volume 309, pp 274-284.

27. a) Goldsbury, C.; Frey, P.; Olivieri, V.; Aebi, U.; Müller, S. A., Multiple assembly pathways underlie amyloid- $\beta$ fibril polymorphisms. J. Mol. Biol. 2005, 352, 282298; b) Smith, J. F.; Knowles, T. P. J.; Dobson, C. M.; MacPhee, C. E.; Welland, M. 
E., Characterization of the nanoscale properties of individual amyloid fibrils. Proc. Natl. Acad. Sci. 2006, 103, 15806-15811.

28. Meinhardt, J.; Tartaglia, G. G.; Pawar, A.; Christopeit, T.; Hortschansky, P.; Schroeckh, V.; Dobson, C. M.; Vendruscolo, M.; Fändrich, M., Similarities in the thermodynamics and kinetics of aggregation of disease-related $A \beta(1-40)$ peptides. Protein Sci. 2007, 16, 1214-1222.

29. a) Doran, T. M.; Kamens, A. J.; Byrnes, N. K.; Nilsson, B. L., Role of amino acid hydrophobicity, aromaticity, and molecular volume on IAPP(20-29) amyloid selfassembly. Proteins: Struct., Funct., Bioinf. 2012, 80, 1053-1065; b) Profit, A. A.; Felsen, V.; Chinwong, J.; Mojica, E.-R. E.; Desamero, R. Z. B., Evidence of $\pi-$ stacking interactions in the self-assembly of hIAPP22-29. Proteins: Struct., Funct., Bioinf. 2013, 81, 690-703; c) Lakshmanan, A.; Cheong, D. W.; Accardo, A.; Di Fabrizio, E.; Riekel, C.; Hauser, C. A. E., Aliphatic peptides show similar selfassembly to amyloid core sequences, challenging the importance of aromatic interactions in amyloidosis. Proc. Natl. Acad. Sci. 2013, 110, 519-524.

30. Fowler, M.; Siddique, B.; Duhamel, J., Effect of sequence on the ionization behavior of a series of amphiphilic polypeptides. Langmuir 2013, 29, 4451-4459.

31. a) Tang, C.; Ulijn, R. V.; Saiani, A., Effect of glycine substitution on Fmocdiphenylalanine self-assembly and gelation properties. Langmuir 2011, 27, 14438-14449; b) Tang, C.; Smith, A. M.; Collins, R. F.; Ulijn, R. V.; Saiani, A., Fmocdiphenylalanine self-assembly mechanism induces apparent $\mathrm{pK}(\mathrm{a})$ shifts. Langmuir 2009, 25, 9447-9453.

32. Xu, X.-D.; Chen, C.-S.; Lu, B.; Cheng, S.-X.; Zhang, X.-Z.; Zhuo, R.-X., Coassembly of oppositely charged short peptides into well-defined supramolecular hydrogels. J. Phys. Chem. B 2010, 114, 2365-2372.

33. a) Rodríguez-Llansola, F.; Hermida-Merino, D.; Nieto-Ortega, B.; Ramírez, F. J.; Navarrete, J. T. L.; Casado, J.; Hamley, I. W.; Escuder, B.; Hayes, W.; Miravet, J. F., Self-assembly studies of a chiral bisurea-based superhydrogelator. Chem. Eur. J. 2012, 18, 14725-14731; b) Jayawarna, V.; Ali, M.; Jowitt, T. A.; Miller, A. F.; Saiani, A.; Gough, J. E.; Ulijn, R. V., Nanostructured hydrogels for three-dimensional cell culture through self-assembly of fluorenylmethoxycarbonyl-dipeptides. Adv. Mater. 2006, 18, 611-614.

34. Chen, L.; Morris, K.; Laybourn, A.; Elias, D.; Hicks, M. R.; Rodger, A.; Serpell, L.; Adams, D. J., Self-assembly mechanism for a naphthalene-dipeptide leading to hydrogelation. Langmuir 2010, 26, 5232-5242.

35. a) Urry, D. W.; Gowda, D. C.; Peng, S.; Parker, T. M.; Jing, N.; Harris, R. D., Nanometric design of extraordinary hydrophobic-induced pKa shifts for aspartic acid: Relevance to protein mechanisms. Biopolymers 1994, 34, 889-896; b) Urry, D. W.; Peng, S. Q.; Parker, T. M.; Gowda, D. C.; Harris, R. D., Relative significance of electrostatic- and hydrophobic-induced pKa shifts in a model protein: The aspartic acid residue. Angew. Chem. Int. Ed. 1993, 32, 1440-1442. 
36. Yu, G.; Yan, X.; Han, C.; Huang, F., Characterization of supramolecular gels. Chem. Soc. Rev. 2013, 42, 6697-6722.

37. a) Colquhoun, C.; Draper, E. R.; Eden, E. G. B.; Cattoz, B. N.; Morris, K. L.; Chen, L.; McDonald, T. O.; Terry, A. E.; Griffiths, P. C.; Serpell, L. C.; Adams, D. J., The effect of self-sorting and co-assembly on the mechanical properties of low molecular weight hydrogels. Nanoscale 2014, 6, 13719-13725; b) Buerkle, L. E.; Rowan, S. J., Supramolecular gels formed from multi-component low molecular weight species. Chem. Soc. Rev. 2012, 41, 6089-6102.

38. Sugiyasu, K.; Kawano, S.-i.; Fujita, N.; Shinkai, S., Self-sorting organogels with p-n heterojunction points. Chem. Mater. 2008, 20, 2863-2865.

39. a) Osowska, K.; Miljanić, O. Š., Kinetic and thermodynamic self-sorting in synthetic systems. Synlett 2011, 1643-1648; b) Safont-Sempere, M. M.; Fernández, G.; Würthner, F., Self-sorting phenomena in complex supramolecular systems. Chem. Rev. 2011, 111, 5784-5814.

40. Morris, K. L.; Chen, L.; Raeburn, J.; Sellick, O. R.; Cotanda, P.; Paul, A.; Griffiths, P. C.; King, S. M.; O'Reilly, R. K.; Serpell, L. C.; Adams, D. J., Chemically programmed self-sorting of gelator networks. Nat. Commun. 2013, 4, 1480-1480.

41. a) Smith, M. M.; Smith, D. K., Self-sorting multi-gelator gels-mixing and ageing effects in thermally addressable supramolecular soft nanomaterials. Soft Matter 2011, 7, 4856-4860; b) Hirst, A. R.; Huang, B.; Castelletto, V.; Hamley, I. W.; Smith, D. K., Self-organisation in the assembly of gels from mixtures of different dendritic peptide building blocks. Chem. Eur. J.2007, 13, 2180-2188.

42. a) Gazit, E., Self assembly of short aromatic peptides into amyloid fibrils and related nanostructures. Prion 2007, 1, 32-35 ;b) Hamley, I. W., Peptide fibrillization. Angew. Chem. Int. Ed. 2007, 46, 8128-8147; c) López de la Paz, M.; Goldie, K.; Zurdo, J.; Lacroix, E.; Dobson, C. M.; Hoenger, A.; Serrano, L., De novo designed peptide-based amyloid fibrils. Proc. Natl. Acad. Sci. 2002, 99, 1605216057.

43. a) Cheng, P.-N.; Liu, C.; Zhao, M.; Eisenberg, D.; Nowick, J. S., Amyloid beta-sheet mimics that antagonize protein aggregation and reduce amyloid toxicity. Nature Chem. 2012, 4, 927-933; b) Liu, R.; Su, R.; Liang, M.; Huang, R.; Wang, M.; Qi, W.; He, Z., Physicochemical strategies for inhibition of amyloid fibril formation: An overview of recent advances. Curr. Med. Chem. 2012, 19, 4157-4174.

44. Sciarretta, K. L.; Gordon, D. J.; Petkova, A. T.; Tycko, R.; Meredith, S. C., A $340-$ lactam(D23/K28) models a conformation highly favorable for nucleation of amyloid. Biochemistry 2005, 44, 6003-6014.

45. Rauk, A., The chemistry of Alzheimer's disease. Chem. Soc. Rev. 2009, 38, 26982715.

46. a) Krysmann, M. J.; Castelletto, V.; Kelarakis, A.; Hamley, I. W.; Hule, R. A.; Pochan, D. J., Self-assembly and hydrogelation of an amyloid peptide fragment. 
Biochemistry 2008, 47, 4597-4605; b) Gordon, D. J.; Tappe, R.; Meredith, S. C., Design and characterization of a membrane permeable $\mathrm{N}$-methyl amino acidcontaining peptide that inhibits A $\beta 1-40$ fibrillogenesis. J. Pept. Res. 2002, 60, 3755 .

47. a) Castelletto, V.; Hamley, I. W.; Cenker, C.; Olsson, U.; Adamcik, J.; Mezzenga, R.; Miravet, J. F.; Escuder, B.; Rodríguez-Llansola, F., Influence of end-capping on the self-assembly of model amyloid peptide fragments. J. Phys. Chem. B 2011, 115, 2107-2116; b) Castelletto V.; Hamley I.W.; Hule R. A.; Pochan D., Helical-ribbon formation by a beta-amino acid modified amyloid beta-peptide fragment. Ang. Chem. Int. Ed. 2009, 48, 2317-2320; c) Castelletto, V.; Hamley, I. W.; Cenker, C.; Olsson, U., Influence of salt on the self-assembly of two model amyloid heptapeptides. J. Phys. Chem. B 2010, 114, 8002-8008.

48. a) Takahashi, T.; Mihara, H., Peptide and protein mimetics inhibiting amyloid $\beta$ peptide aggregation. Acc. Chem. Res. 2008, 41, 1309-1318; b) Sato, J.; Takahashi, T.; Oshima, H.; Matsumura, S.; Mihara, H., Design of peptides that form amyloidlike fibrils capturing amyloid $\beta 1-42$ peptides. Chem. Eur. J. 2007, 13, 7745-7752; c) Suzuki, M.; Takahashi, T.; Sato, J.; Mie, M.; Kobatake, E.; Mihara, H., Designed short peptides that form amyloid-like fibrils in co-assembly with amyloid $\beta$ peptide $(A \beta)$ decrease the toxicity of $A \beta$ to neuronal PC12 cells. Chem. Bio. Chem. 2010, 11, 1525-1530.

49. Smith, T. J.; Stains, C. I.; Meyer, S. C.; Ghosh, I., Inhibition of $\beta$-amyloid fibrillisation by directed evolution of a beta-sheet presenting miniature protein. $J$. Am. Chem. Soc. 2006, 128, 14456-14457. 
CHAPTER 5

\title{
BASIC TETRAPEPTIDES CONTAINING
}

\author{
L-LYSINE (K) AND
}

L-PHENYLALANINE (F) 



\section{CHAPTER 5}

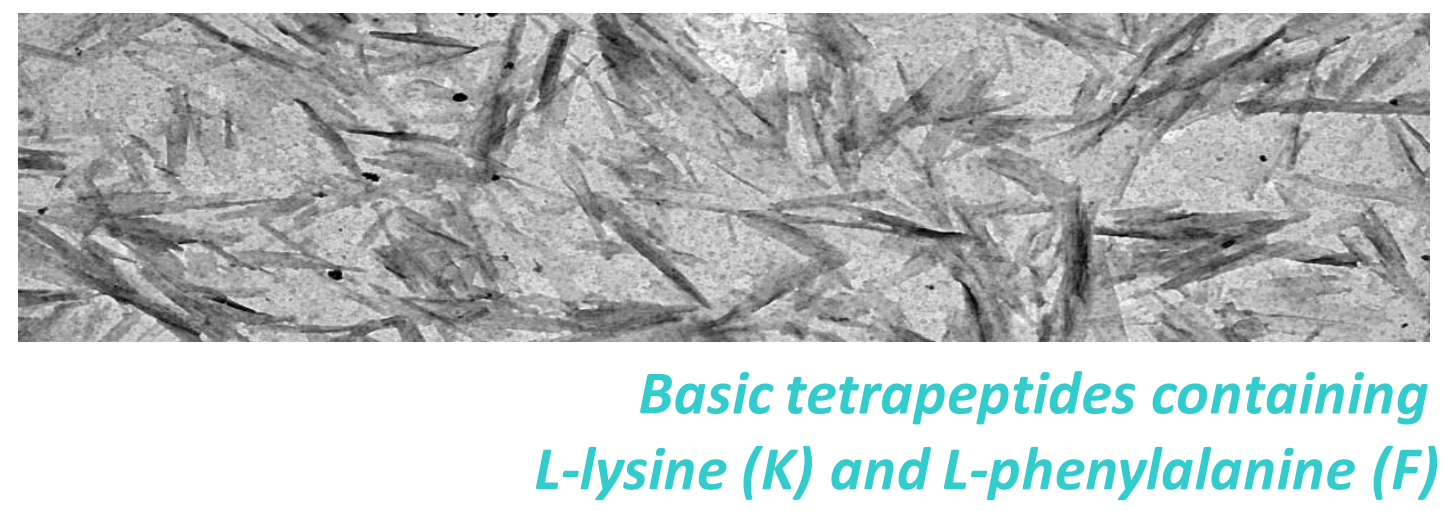

In this chapter two isomeric tetrapeptides containing $K$ and $F$ will be tested as hydrogelators in basic media. Right after the co-assembly between them and the acidic tetrapeptides formed by $D$ and $F$ will be studied at neutral $p H$ exploring electrostatic and hydrophobic interactions. Finally the properties of these basic and acidic tetrapeptides will be combined to generate a complex two-component system which will be able to maintain gel stability through all pH due to exchange among different networks. 



\section{BASIC TETRAPEPTIDES CONTAINING L-LYSINE (K) AND L- PHENYLALANINE (F)}

\subsection{Introduction}

The tetrapeptides reported in previous chapter form hydrogels by the presence of an external stimulus, namely, a $\mathrm{pH}$ change. In the present section a different approach is going to be considered in order to obtain gels without any external stimulus. Thus, the co-assembly among two oppositely charged peptides will be carried out as previously described by Stupp or Hamley among others. ${ }^{1}$ Usually these compounds fail to self-aggregate at neutral $\mathrm{pH}$ due to charge repulsion however, they effectively coassemble. At the same time with this new convenient strategy peptides can be easily dissolved and administrated at a neutral $\mathrm{pH}$ providing therefore advantages in terms of potential biological applications.

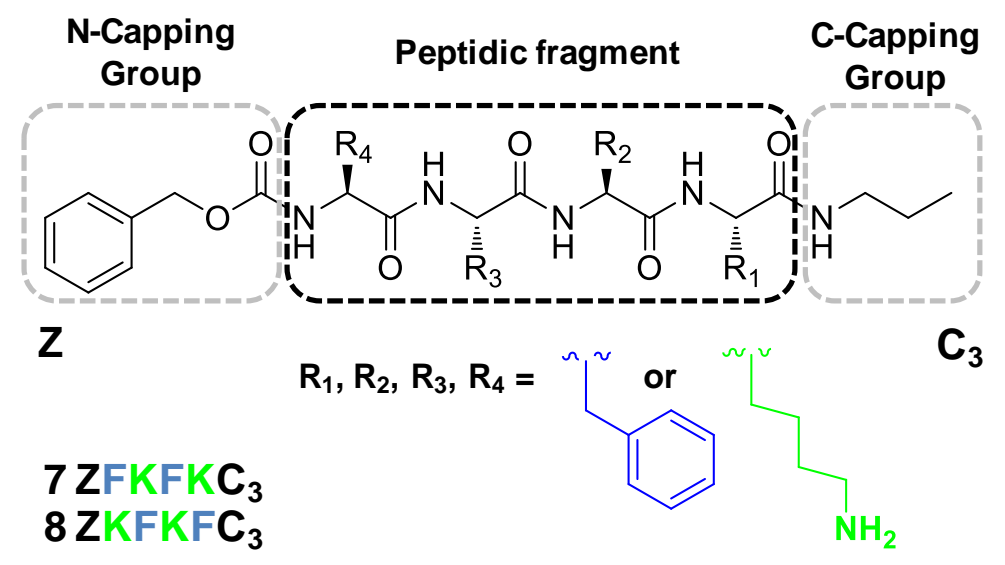

Figure 5.1 General structure of amphipathic tetrapeptides (7 and 8) containing F residues as non-polar amino acids and $\mathrm{K}$ as ionic residue.

For the current purpose, two new Z-protected tetrapeptides were designed. In this case aspartic acid residues of compounds 1 and $\mathbf{2}$ were replaced by lysine residues leading to compounds $\mathbf{7}$ and $\mathbf{8}$. First of all the hydrogelation ability of these new molecules will be tested by a $\mathrm{pH}$ change methodology and later on the co-assembly among them and their acidic analogues $\mathbf{1}$ and $\mathbf{2}$, will be explored. 


\subsection{Hydrogelation of basic tetrapeptides 7 and 8}

The traditional heating-cooling methodology was discarded once again mainly because Z-deprotection evidences were observed in some cases. The best methodology was the use of ammonia vapours trying to avoid inhomogeneities during gel formation. ${ }^{2}$ In a typical experiment the required amount of compounds $\mathbf{7}$ or $\mathbf{8}$ was firstly dissolved in $\mathrm{HCl} 0.1 \mathrm{M}$ and then introduced into a closed container containing an ammonia solution (Figure 5.2). The vapours generated inside gave place to lysine deprotonation and subsequent hydrogel formation.

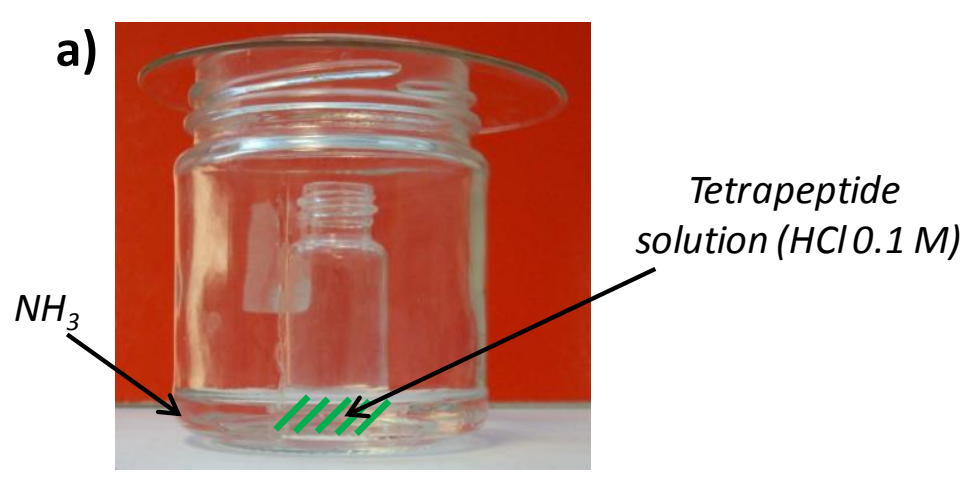

b)

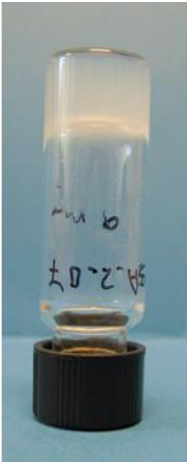

c)

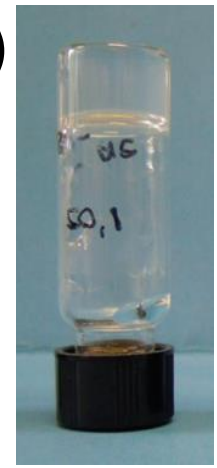

Figure 5.2 a) Setup for the hydrogelation under ammonia vapours. Hydrogels at their m.g.c. for compounds b) 7 (4 mM) and c) 8 (1 mM).

The m.g.c. was established by the tube inversion methodology leading values of 4 $\mathrm{mM}$ for compound $\mathbf{7}$ and $1 \mathrm{mM}$ for compound $\mathbf{8}$. In this case the most effective sequence was ZKFKFC $_{3}$ (8) and not ZFKFKC $_{3}$ (7) as would be expected considering previous results for acidic tetrapeptides (1-6). Hydrogel of compound 7 showed a translucent aspect whereas compound $\mathbf{8}$ presented a completely transparent appearance. TEM images revealed that hydrogel 7 is formed by a network of thin tapes around $15 \mathrm{~nm}$ in width, not overly cross-linked among them. Some chiral fibres with pitch around $100 \mathrm{~nm}$ can be also observed although it is not the general trend in the overall sample. Compound 8 showed a regular mesh of thin fibres around $8 \mathrm{~nm}$ in width. The network in general showed a more cross-linked aspect and this may explain the lower m.g.c. value for this compound.

Spectroscopic techniques such as IR or CD were used in an attempt to elucidate their structural arrangements. ${ }^{3}$ IR spectra showed a common band around $1633 \mathrm{~cm}^{-1}$ which corresponds to the stretching amide I revealing again a $\beta$-sheet structure. ${ }^{4}$ An 
additional small band at $1685 \mathrm{~cm}^{-1}$ suggests an antiparallel arrangement of the hydrogen bonds along the peptide sequence.
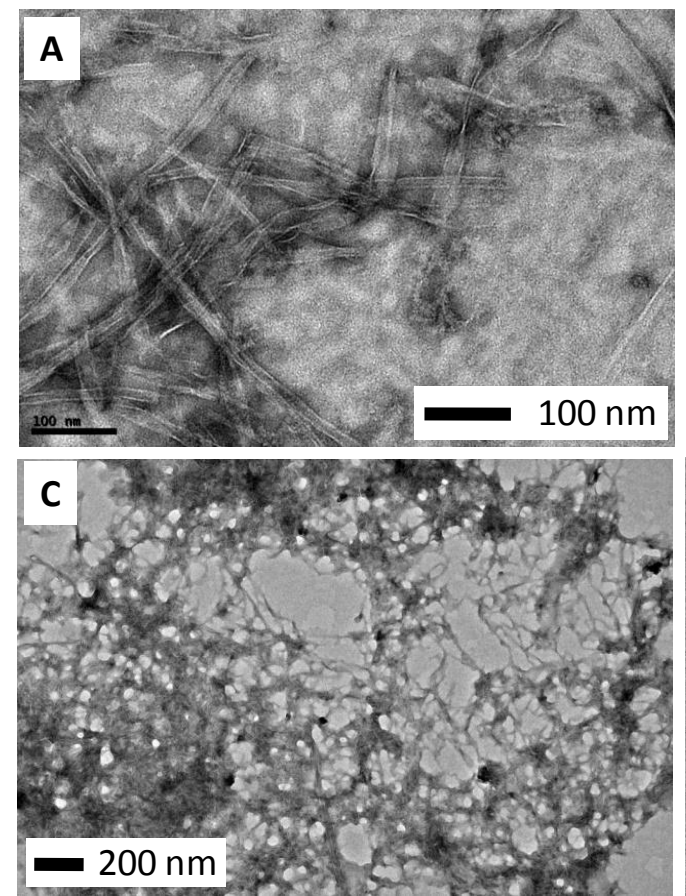
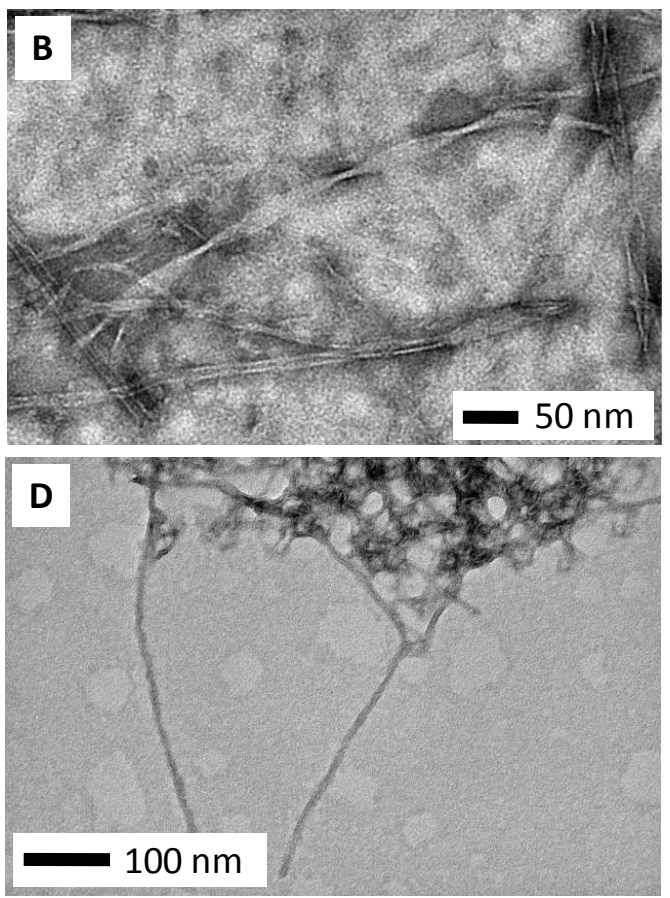

Figure 5.3 TEM images for hydrogel of compound $7(A, B)$ and compound $8(C, D)$ at their m.g.c.

The $C D$ spectra of both compounds revealed a negative band at $230 \mathrm{~nm}$ significantly more intense for compound $\mathbf{8}$. These bands which are red-shifted in comparison with the traditional $\beta$-sheet strand suggest the presence of twisted $\beta$-sheets as previously described. ${ }^{5}$ A positive band between $250-270 \mathrm{~nm}$ in the aromatic region highlights the importance of phenyl rings arrangement in the self-assembly process.

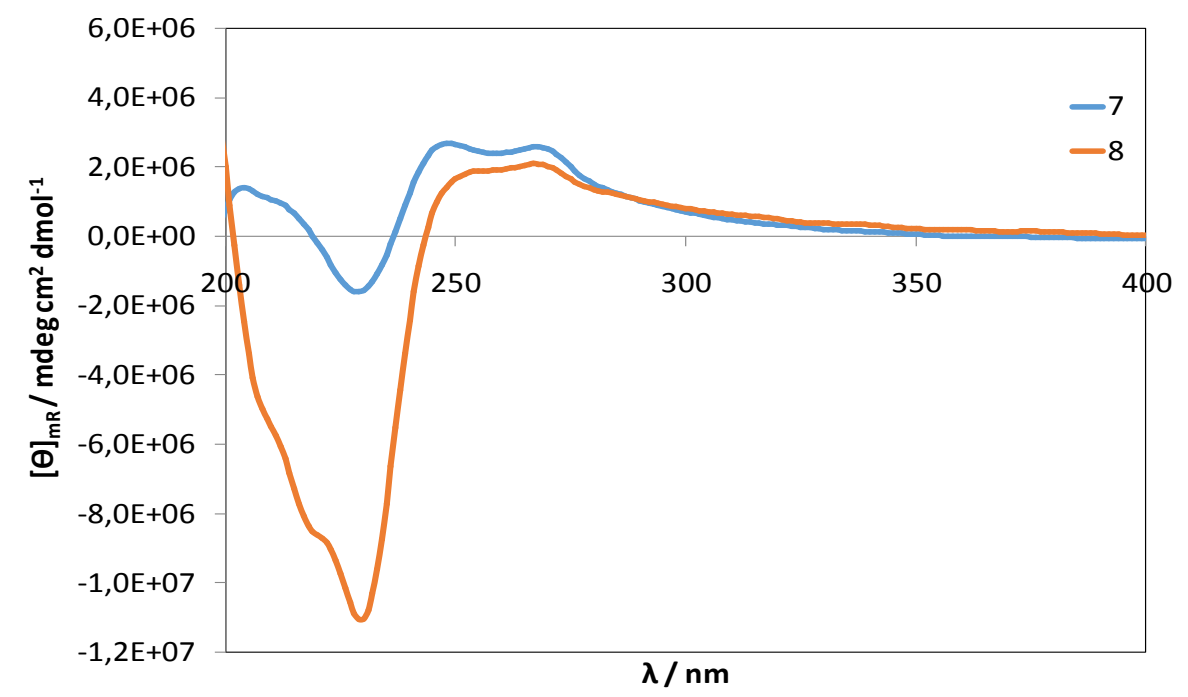

Figure 5.4 CD spectra for compounds $\mathbf{7}$ and 8 at their m.g.c. 
Potentiometric titrations were also carried out for these two new peptides but in this case the tetrapeptide was initially dissolved in aqueous $\mathrm{HCl}$ and subsequently titrated with normalized $\mathrm{NaOH} 0.01 \mathrm{M}$ (S.I. 5.1.5). Values for acidity and solubility constants were obtained by using the software Hyperquad 2008 as previously described in chapter 4 for compounds 1-6. Values found are collected in Table 5.1. Both compounds showed similar values the first protonation constant being slightly bigger than the second one as it could be expected.

Table 5.1 Thermodynamic acid-base and solubility constants of the tetrapeptides 7-8 at 25 ㅇ $\mathrm{C}$ in water. ${ }^{\mathrm{a}}$

\begin{tabular}{|c|c|c|c|}
\hline Compound & $\log K_{1}$ & $\log K_{2}$ & pKs \\
\hline 7 ZFKFK & 10.5 & 19.9 & 4.8 \\
\hline 8 ZKFKF & 11.2 & 20.8 & 5.0 \\
\hline
\end{tabular}

a) Errors affect the last digit, being \pm 0.1 or lower for $\log K_{1}, \log K_{2}$ and $p K_{s}$

The main goal of these titration experiments was to build a species distribution diagram in order to confirm the solubility of both acidic and basic tetrapeptides at $\mathrm{pH}$ values around neutrality. In this way considering the values reported in Table 5.1 the diagram of species distribution showed that compounds 1, 2, 7 and 8 would remain in solution at $\mathrm{pH}=7$ and the only way to obtain aggregates at this $\mathrm{pH}$ goes through the formation of co-aggregates via electrostatic interactions among aspartic and lysine ionic residues.

\section{CO-AGGREGATION}

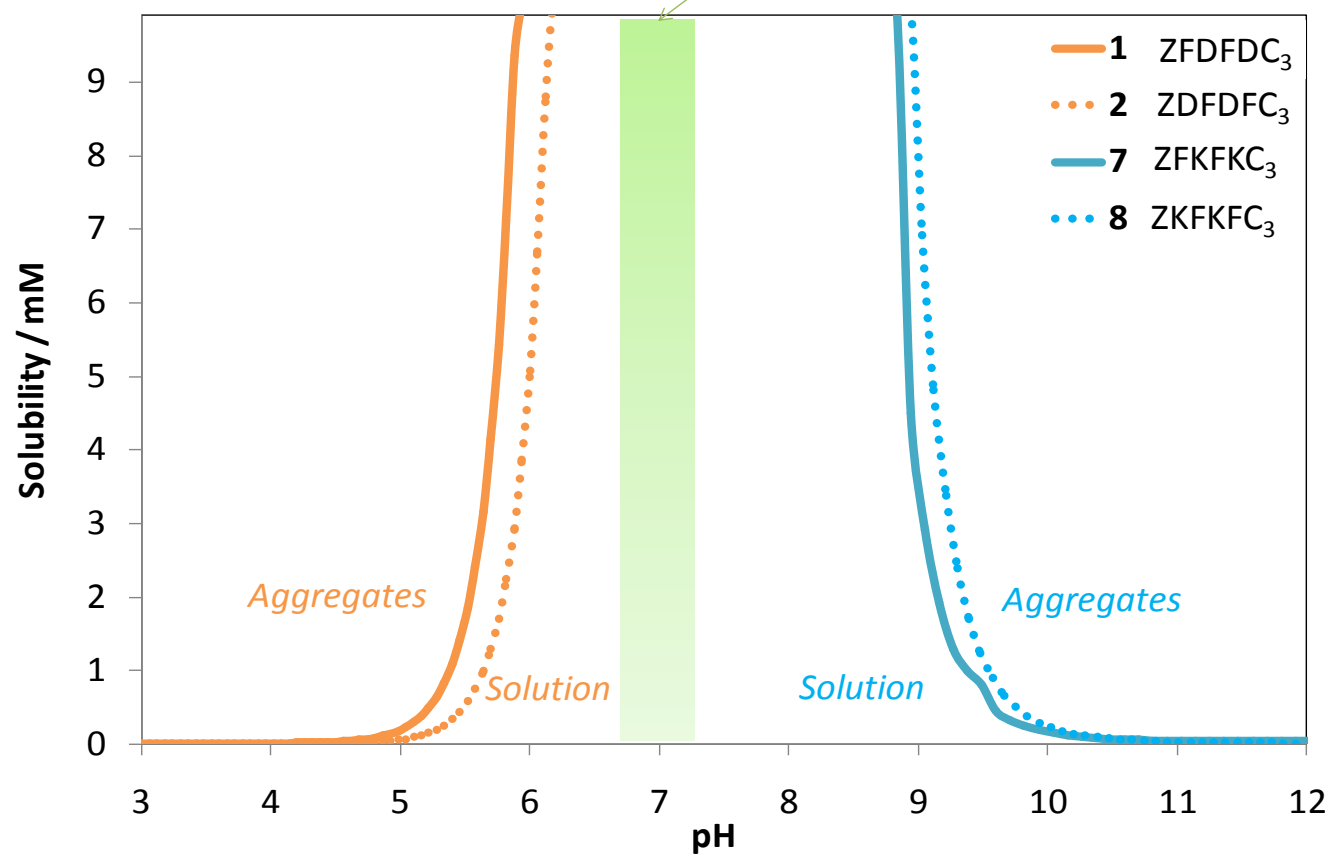

Figure 5.5 Species distribution diagram for compounds 1, 2, 7 and 8. 
In the next section the optimal conditions for the co-aggregation between acidic and basic tetrapeptides at neutral $\mathrm{pH}$ values will be discussed and a complete characterization of the new systems will be also provided including stoichiometric studies and macroscopic/microscopic characterisation.

\subsection{Co-assembly between acidic $(1,2)$ and basic $(7,8)$ tetrapeptides at neutral $\mathrm{pH}$}

In a first attempt to reach the optimal conditions for the co-aggregation process, PB (phosphate buffer) at $\mathrm{pH}=7.4$ was suggested as solvent medium because of its biocompatibility. However basic tetrapeptides were completely insoluble even at lower concentrations of PB (10 mM) and acidic tetrapeptides showed solubility problems as PB concentration was increased. Phosphate ions have therefore a significant effect on the solubility of the tetrapeptides considering the theoretical species distribution diagram previously described in Figure 5.5. Considering Hofmeister's series, ${ }^{6}$ phosphate anions are considered as kosmotropic ions since they reinforce the hydrogen bond network of the solvent reducing then the solubility of peptides and proteins. These kinds of ions are also called "structure making" ions and act conversely to "structure breaking" ions also known as chaotropes which reduce the order in water causing an increase of solubility as a consequence.

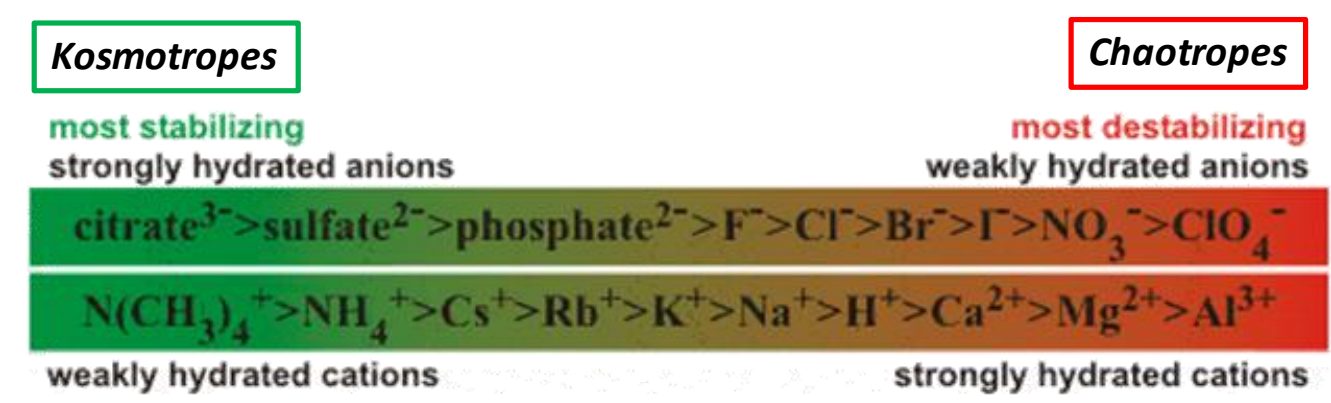

Figure 5.6 Hofmeister series for anions and cations.

In order to diminish this effect, a different buffer solution containing TRIS-HCl was employed. As can be observed in Figure 5.6 chloride ion is located on the left of phosphate ion and therefore is considered a more destabilizing salt. The solubility of different tetrapeptides for increasing concentration of buffer (See S.I. 5.2.1) was determined by ${ }^{1} \mathrm{H}$ NMR leading to the next graph as a result: 


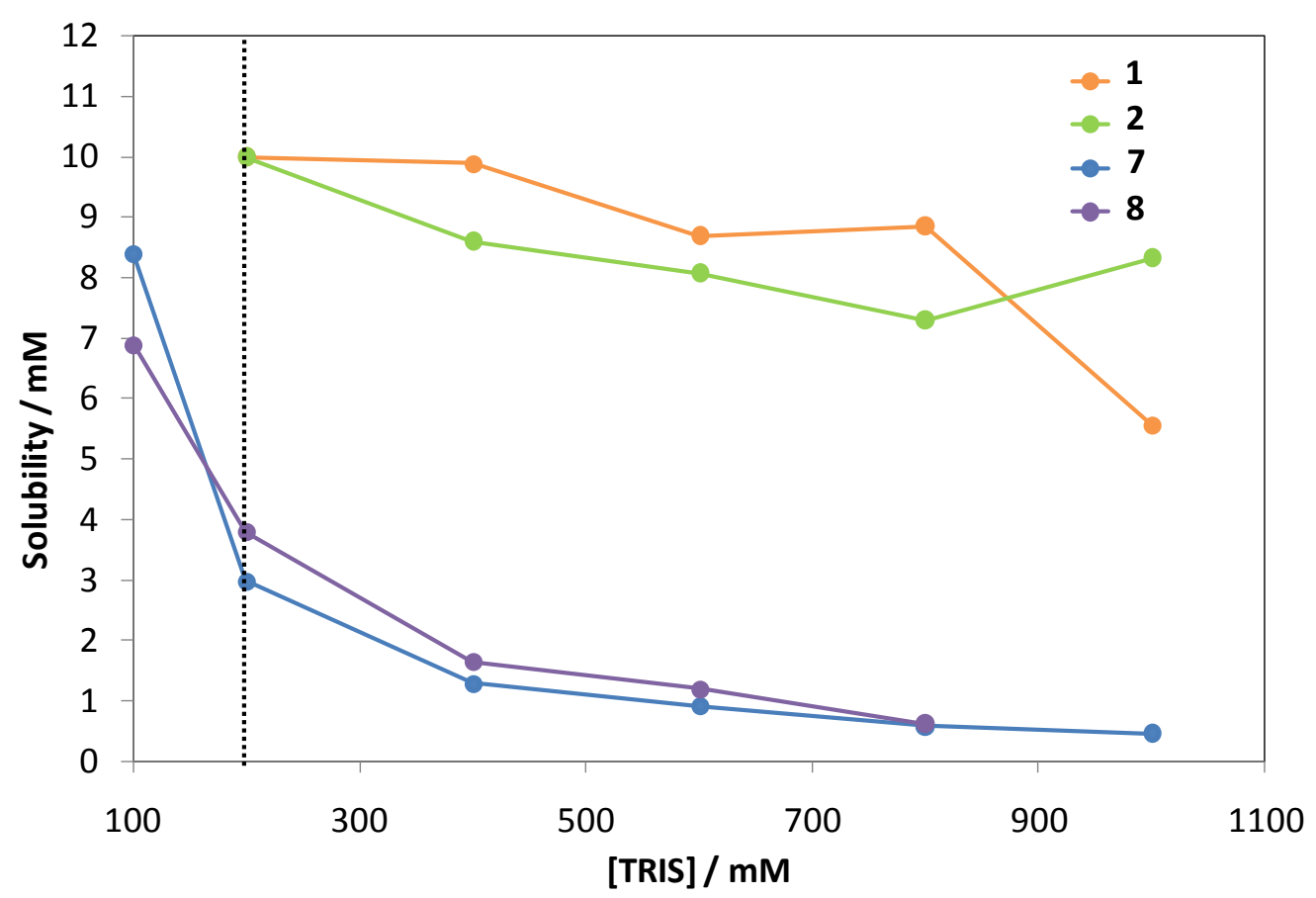

Figure 5.7 Solubility of compounds 1, 2, 7 and 8 for increasing concentration of TRIS-HCl. The solubility was determined by ${ }^{1} \mathrm{H}$ NMR.

As can be observed in Figure 5.7, the solubility of the compounds decreased upon increasing buffer concentration as a general trend. However this effect was more pronounced for basic tetrapeptides containing lysine (7 and $\mathbf{8}$ ) than for acidic tetrapeptides ( $\mathbf{1}$ and $\mathbf{2}$ ). This behaviour most likely could be ascribed to the higher Hofmeister effect the anions show against cations. Basically the data reported in Figure 5.7 allow us to determine the working conditions for the co-aggregation experiment which were set to be $200 \mathrm{mM}$ of TRIS-HCl. The initial concentrations for separated solutions of tetrapeptides should be lower than $3 \mathrm{mM}$, especially for basic tetrapeptides, if we want to ensure a complete dissolution thereof.

\subsubsection{Stoichiometry of the co-assembled mixtures}

In a first attempt the co-aggregation among basic and acidic tetrapeptides was assessed to the naked eye by mixing solutions of compounds 1 or $\mathbf{2}$ in TRIS-HCl (200 $\mathrm{mM}$ ) with different amounts of $\mathbf{7}$ and $\mathbf{8}$. The good results obtained in this regard encouraged us to go a step further and determine the stoichiometry of the different mixtures by ${ }^{1} \mathrm{H}$ NMR. In practice, for each mixture of basic and acidic tetrapeptides a series of NMR tubes were prepared. In all of them a constant volume of basic peptide (7 or 8) solution was added followed by the injection of an equivalent volume of increasing 
amounts of acidic tetrapetide (1 or 2 ) in a range between $0.5 \mathrm{mM}$ and $4 \mathrm{mM}$. The amount of basic tetrapeptide in solution was determined comparing the integral values of the mixture with the corresponding blank at the same concentration (fully in solution) using hydroquinone as standard (See S.I.5.2.2). Plotting the percentage of basic peptide in solution against the molar ratio of both compounds it is easy to recognise the stoichiometry of the mixture by looking at the intersection point between the two different tendencies (Figure 5.8). In this point the relative acidic tetrapeptide concentration is enough to reach the total aggregation of the basic tetrapeptide.

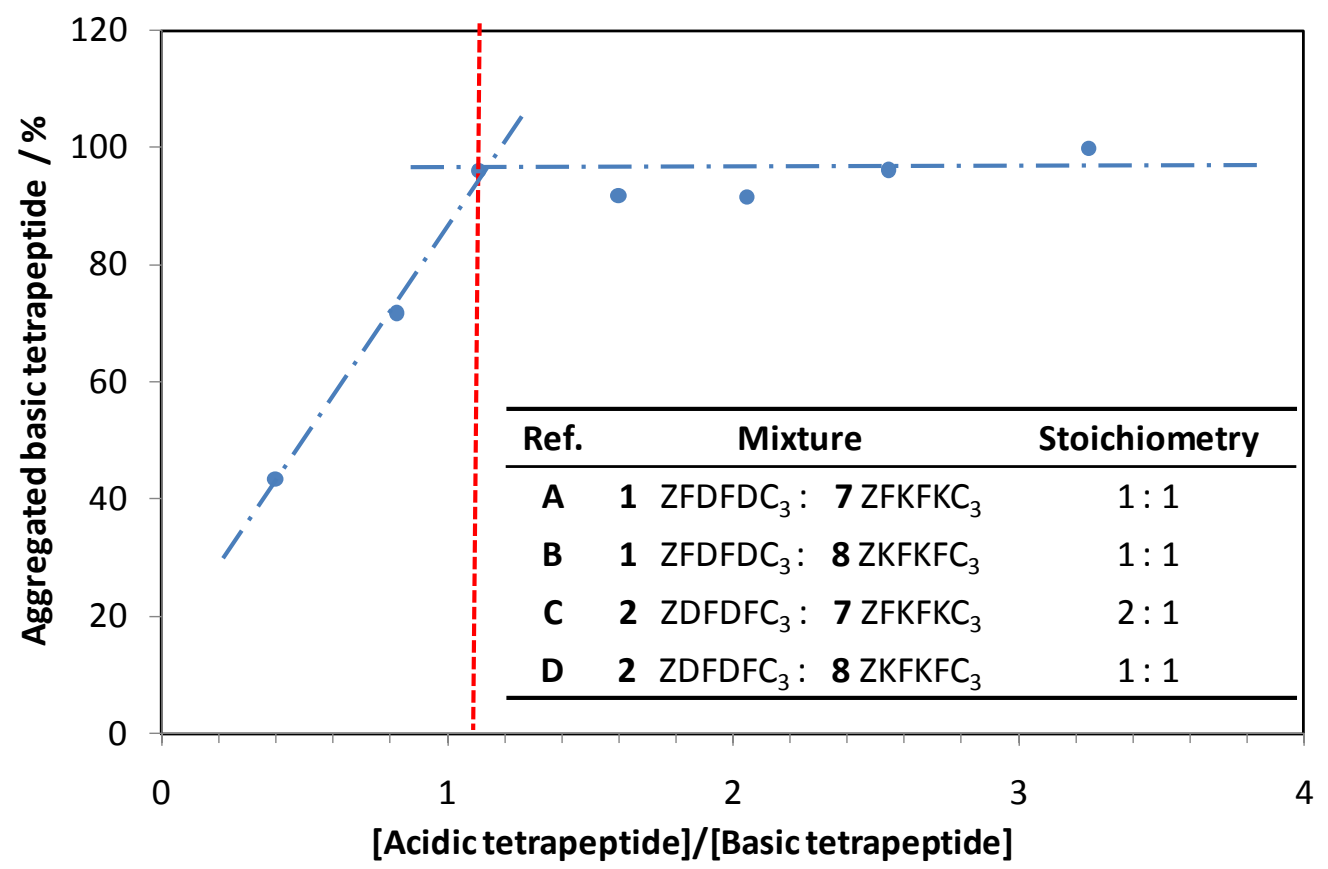

Figure 5.8 Representative example of stoichiometry determination for co-assembled mixture $\boldsymbol{B}$. Inset: table containing the stoichiometries obtained for the different mixtures.

In a similar way for all possible mixtures we obtained a general 1:1 stoichiometry except for the co-assembly between compounds $\mathbf{2}$ and $\mathbf{7}$ in which a preferred 2:1 $\left(\text { ZDFDFC }_{3} \text { : ZFKFKC }\right)_{3}$ ) ratio was obtained. Assuming the formation of neutral solid species after the co-assembly we hypothesized that the aggregates formed by compounds $\mathbf{2}$ and 7 in a 2:1 molar ratio are stabilised by TRIS cations in order to compensate the two extra negative charges provided by the acidic tetrapeptide. However we do not have experimental evidences to prove it.

According to these results hydrogels at total concentration of $2.5 \mathrm{mM}$ were obtained by injection methodology, that is, acidic peptides in TRIS-HCl at pH 7.4 were 
added over basic peptides under the same conditions. It is important to highlight that the gel formation is extremely fast and the obtained gels are completely transparent and homogeneous (Figure 5.9).

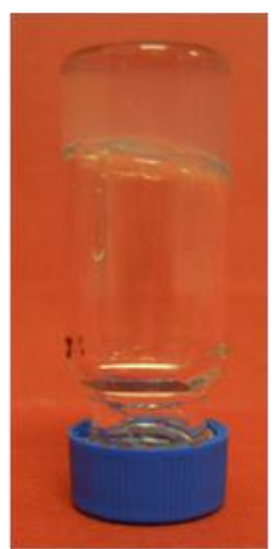

Mixture A

1:1

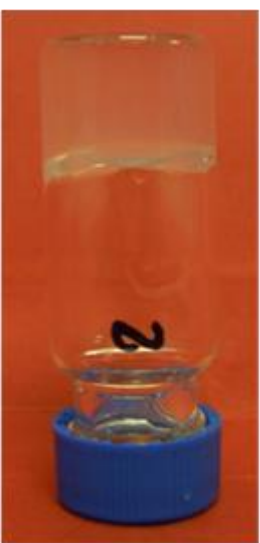

Mixture B 1:1

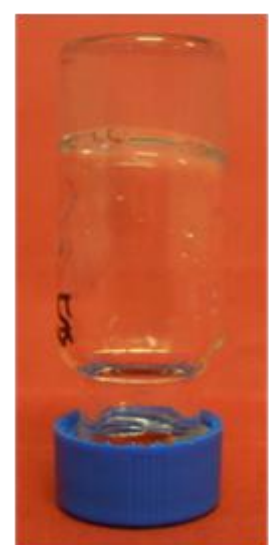

Mixture C 2:1

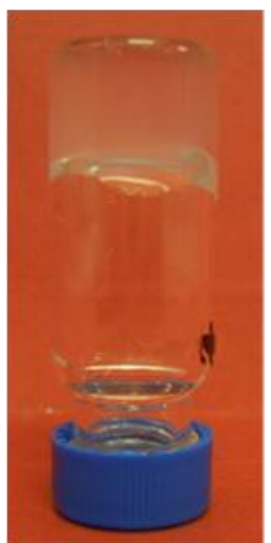

Mixture D 1:1

Figure 5.9 Macroscopic aspect of the co-assembled hydrogels at the stoichiometry previously determined by ${ }^{1} \mathrm{H}$ NMR. Total concentration of the mixtures: $2.5 \mathrm{mM}$. Mixture $\boldsymbol{A}(\mathbf{1}-\mathbf{7})$, mixture $\boldsymbol{B}(\mathbf{1}-\mathbf{8})$, mixture $\boldsymbol{C}(\mathbf{2}-\mathbf{7})$ and mixture $\boldsymbol{D}(\mathbf{2}-\mathbf{8})$.

Hydrogel formation was reached even at total concentrations of $1.5 \mathrm{mM}$. Such values of m.g.c. are significantly better than previously reported systems considering the small size of our molecules in comparison, for instance, with the large amphiphilic compounds reported by Stupp ${ }^{1 c, 7}$ and co-workers or the decapeptides described by Ramachandran ${ }^{8}$ and co-workers.

\subsubsection{Microscopic and structural studies}

Samples of the co-assembled hydrogels at $2.5 \mathrm{mM}$ were analyzed by TEM (S.I. 5.2.3) in order to study the microscopic morphology of the networks. The mixture $A$ (Figure 5.10) formed by equimolar amounts of 1 and 7 showed thin and short belts of around $15 \mathrm{~nm}$ in width which seem to be clustered around a common nucleation point. Such network revealed in general a low degree of cross-linking. Conversely mixtures $B$ (Figure 5.11) and $D$ (Figure 5.13) formed by compounds 1-8 or 2-8 respectively, showed more connected fibres with defects on branching. The fibres are around 15-20 nm in width and self-assemble between them to form larger objects. Chiral fibres could be also observed in both cases, especially for mixture $D$, although this is not the general trend of these networks. Finally mixture $C$ (2-7 in a 2:1 ratio) revealed also a cross-linked network but made of very long and thin fibers about $7 \mathrm{~nm}$ in width (Figure 5.12). The general 
appearance of this mixture is very homogenous with no defects on branching and no clustered objects.
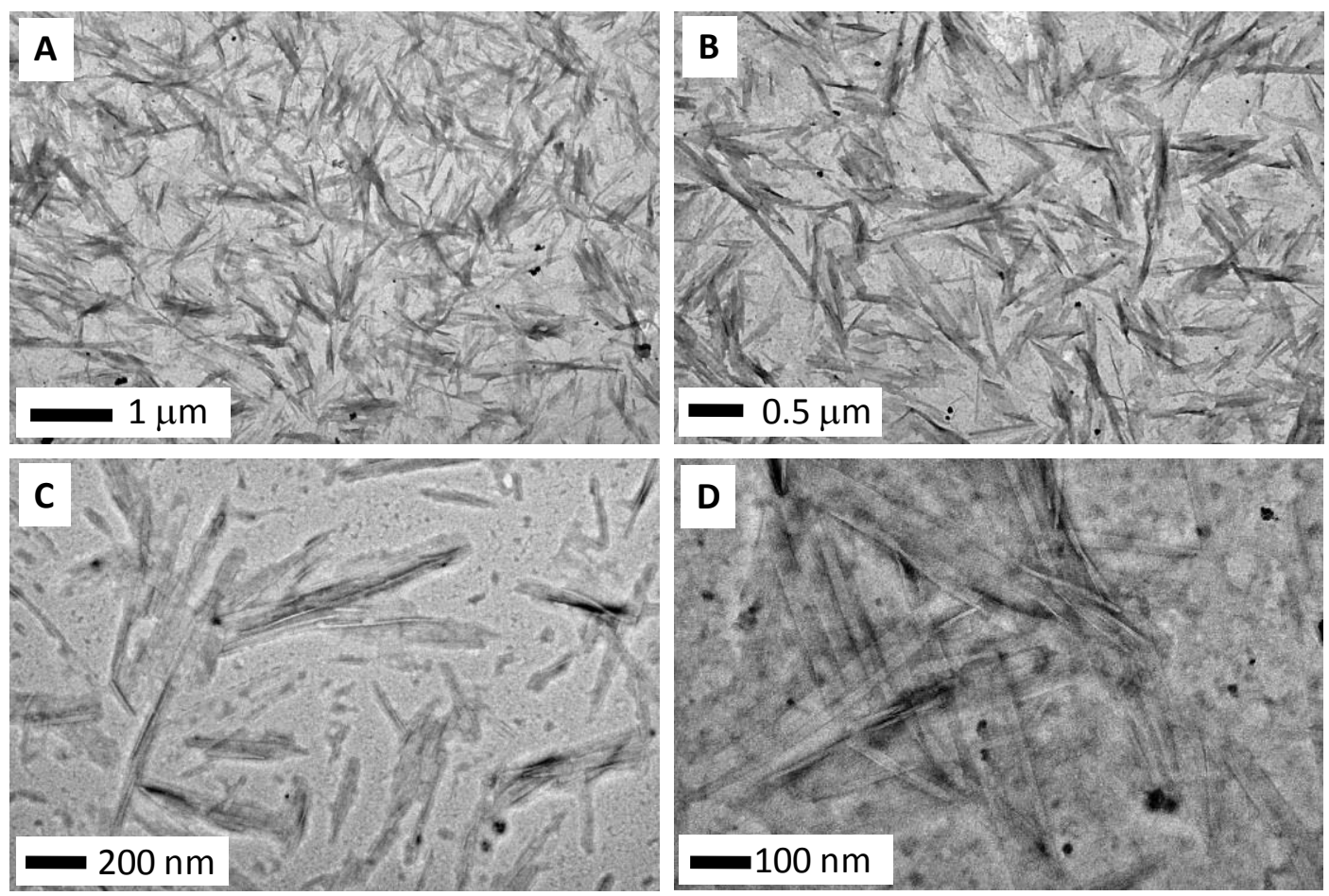

Figure 5.10 TEM images of the co-assembled hydrogel of compounds 1 (ZFDFDC 3 ) and 7 (ZFKFKC 3 ). Total concentration of mixture $\mathbf{A}=2.5 \mathrm{mM}$.
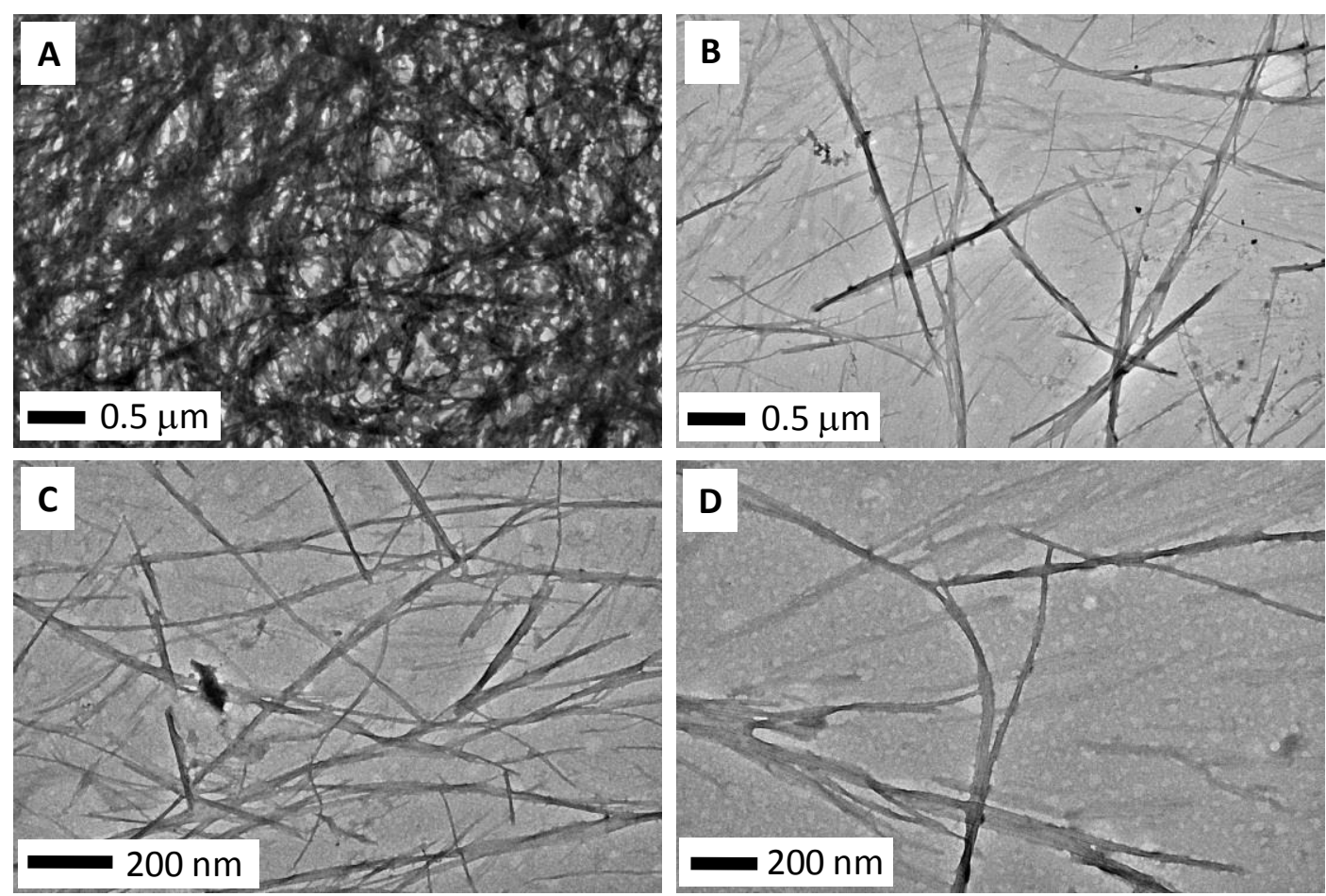

Figure 5.11 TEM images of the co-assembled hydrogel of compounds 1 (ZFDFDC 3 ) and 8 (ZKFKFC 3 ). Total concentration of mixture $\mathbf{B}=2.5 \mathrm{mM}$. 

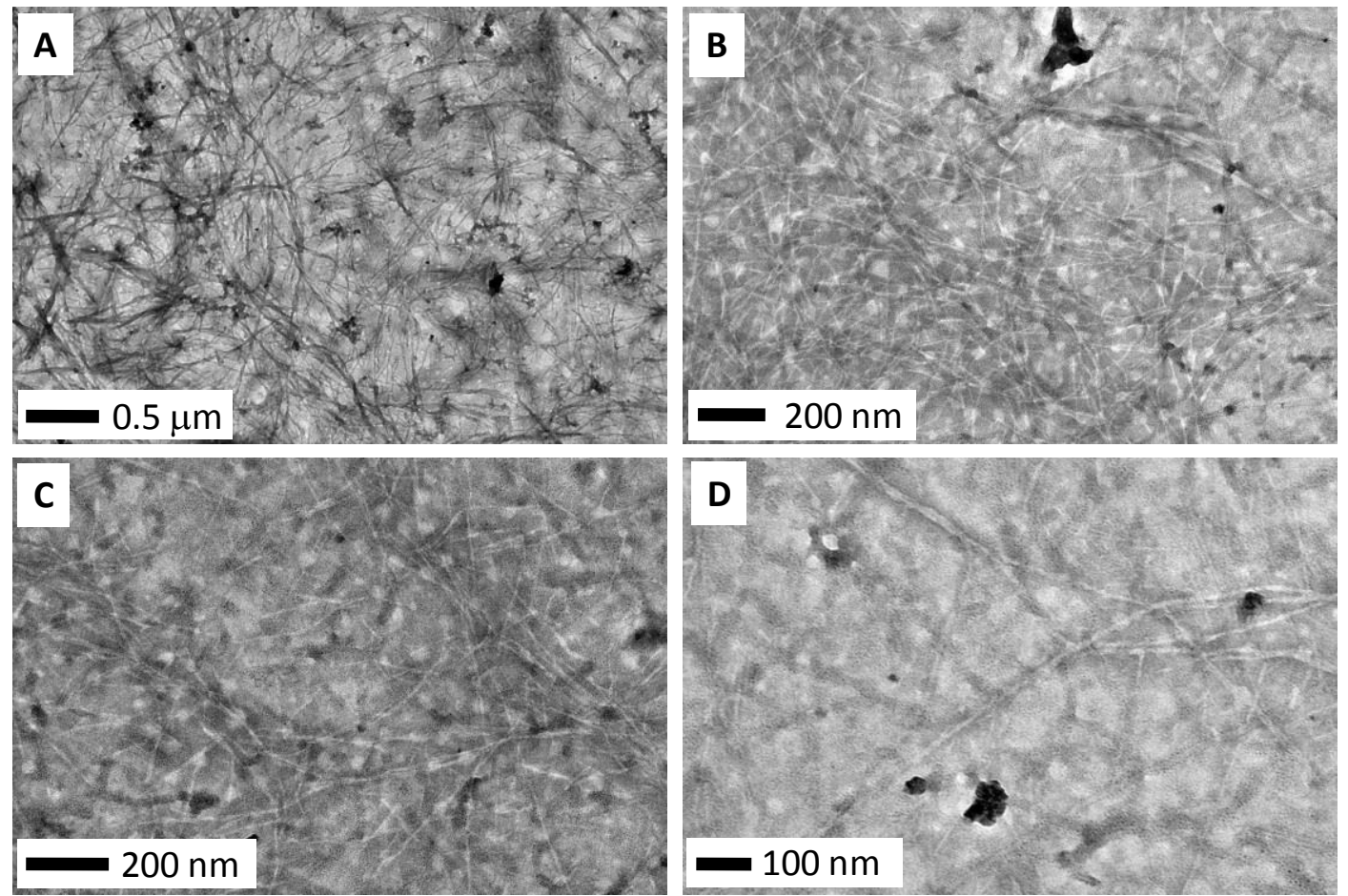

Figure 5.12 TEM images of the co-assembled hydrogel of compounds $\mathbf{2}$ (ZFDFDC 3 ) and $\mathbf{7}\left(\mathrm{ZFKFKC}_{3}\right)$. Total concentration of mixture $\mathbf{C}=2.5 \mathrm{mM}$.
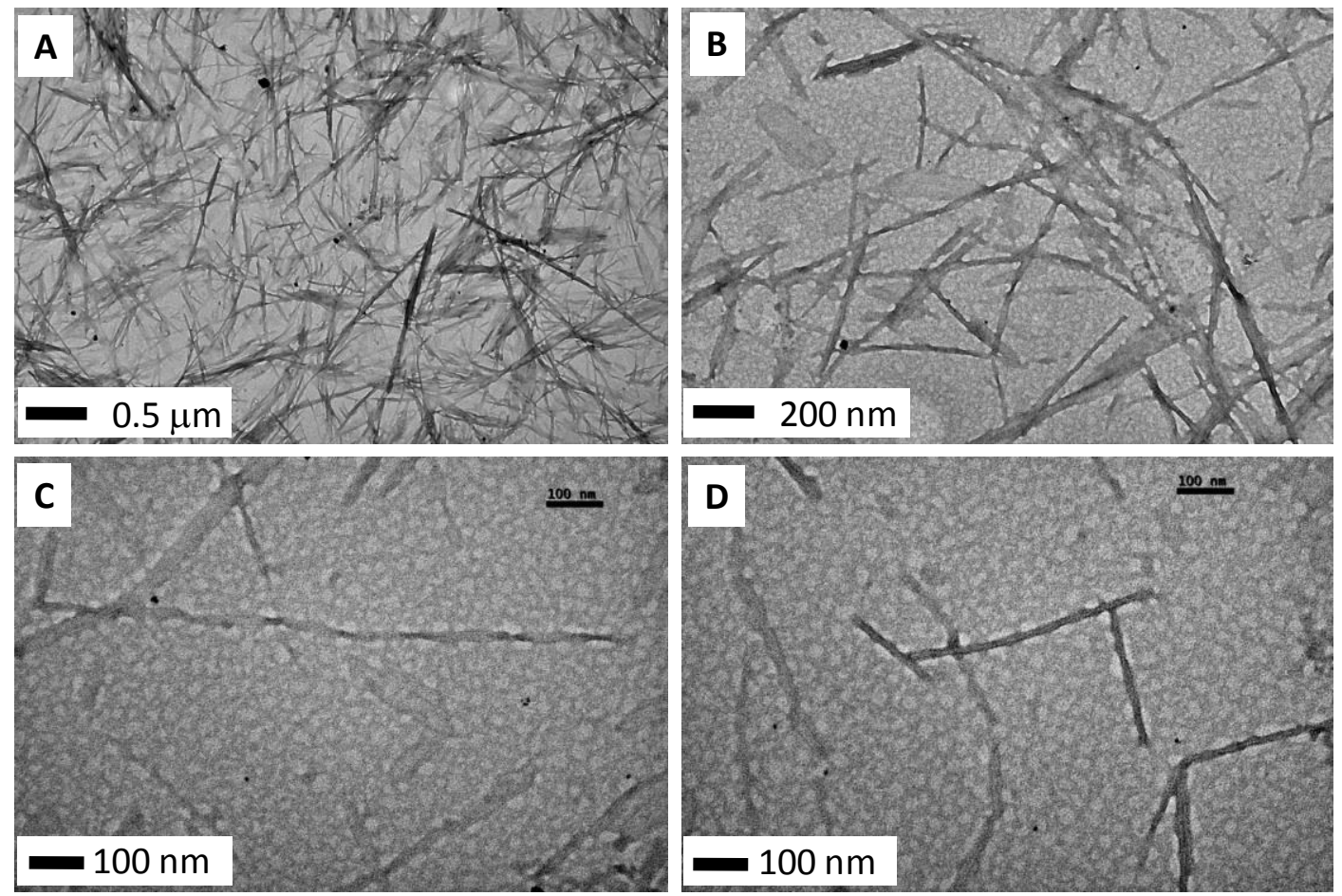

Figure 5.13 TEM images of the co-assembled hydrogel of compounds $\mathbf{2}$ (ZFDFDC 3 ) and $\mathbf{8}\left(\right.$ ZKFKFC $\left._{3}\right)$. Total concentration of mixture $\mathbf{D}=2.5 \mathrm{mM}$.

$\mathrm{CD}$ spectra of these mixtures at a total concentration of $2.5 \mathrm{mM}$ were also performed in order to get into structural details of the different co-aggregates. As can be 
observed in Figure 5.14 mixture $\mathbf{A}$ showed an intense negative band at $217 \mathrm{~nm}$ which can be attributed to a $n-\pi$ transition suggesting the presence of a $\beta$-sheet conformation. $^{9}$ A similar red-shifted band was observed for the other mixtures suggesting as previously mentioned a twisted $\beta$-sheet conformation. ${ }^{5 a}, 7$ Other authors have attributed this red-shift to the existence of strong aromatic interactions. ${ }^{10} \mathrm{~A}$ positive broad band, especially important for mixtures $\mathbf{C}$ and $\mathbf{D}$ revealed the importance of the arrangement of aromatic groups for the self-assembly process.

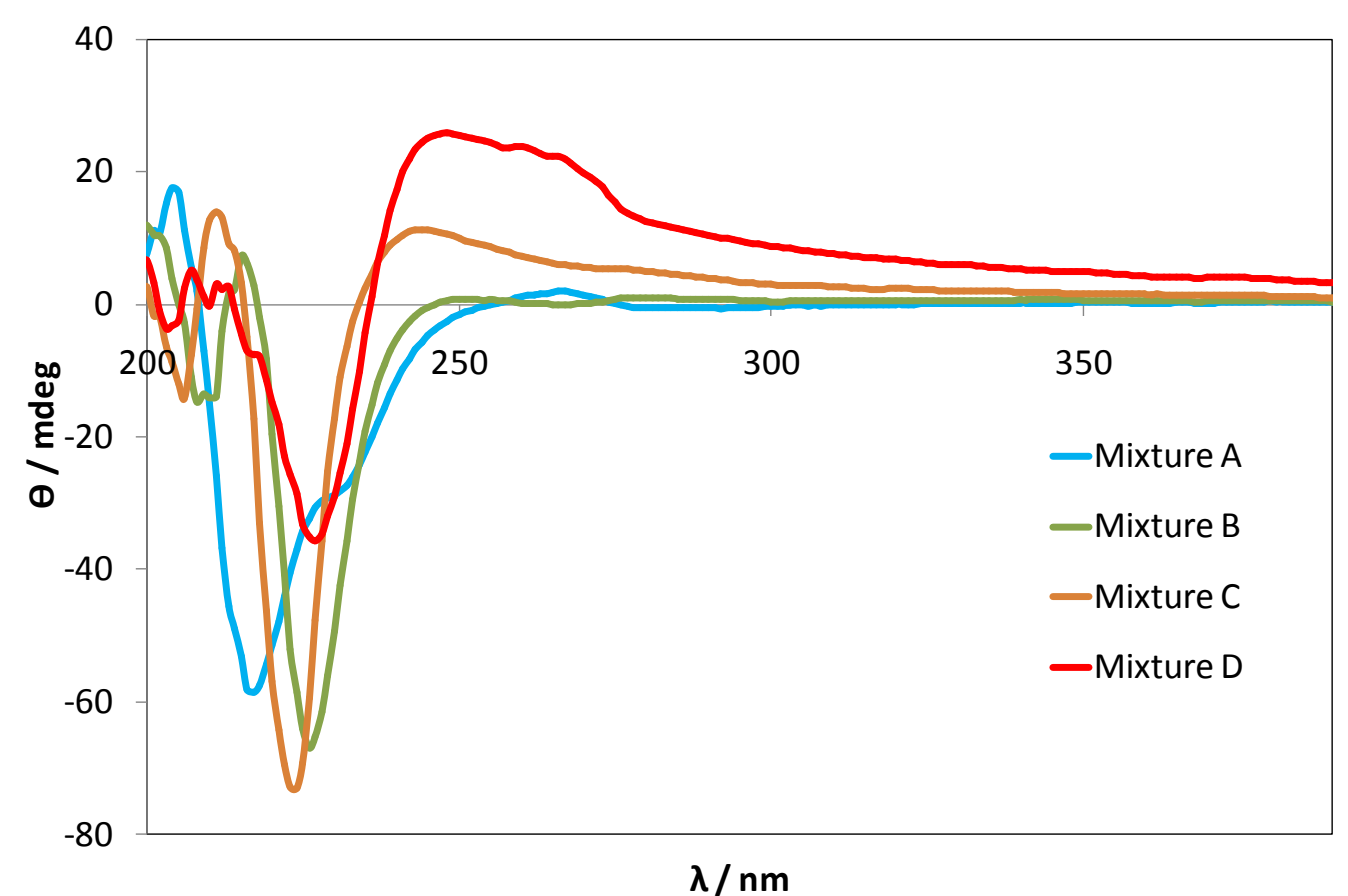

Figure 5.14 CD spectra for co-assembled mixtures A-D at a total concentration of $2.5 \mathrm{mM}$. Mixture $\boldsymbol{A}(\mathbf{1 - 7})$, mixture $\boldsymbol{B}(\mathbf{1 - 8})$, mixture $\boldsymbol{C}(\mathbf{2 - 7})$ and mixture $\boldsymbol{D}(\mathbf{2}-\mathbf{8})$.

ThT assay ${ }^{10-11}$ was employed once again to explore the presence of accessible hydrophobic surfaces after self-assembly. As can be observed in Figure 5.15 there are significant differences between all the mixtures. Mixtures $\mathbf{C}$ and $\mathbf{D}$ showed almost no ThT fluorescence enhancement in comparison with the pure precursors in solution (not shown for clarity). However mixtures B and A showed a general enhancement of ThT emission upon the interaction between their precursors although ThT enhancement of mixture $\mathbf{A}$ is massive in comparison with mixture $\mathbf{B}$. An explanation to this fact can be found looking at the amino acid sequences of the co-assembled $\mathbf{A}$ (compounds $\mathbf{1}$ and 7). Reviewing ThT data reported for acidic compounds 1-6 in chapter 4, the presence of a Z- 
group close to F, as in the case of compound 1 and 7 , creates extended aromatic binding sites for flat substrates such as ThT.

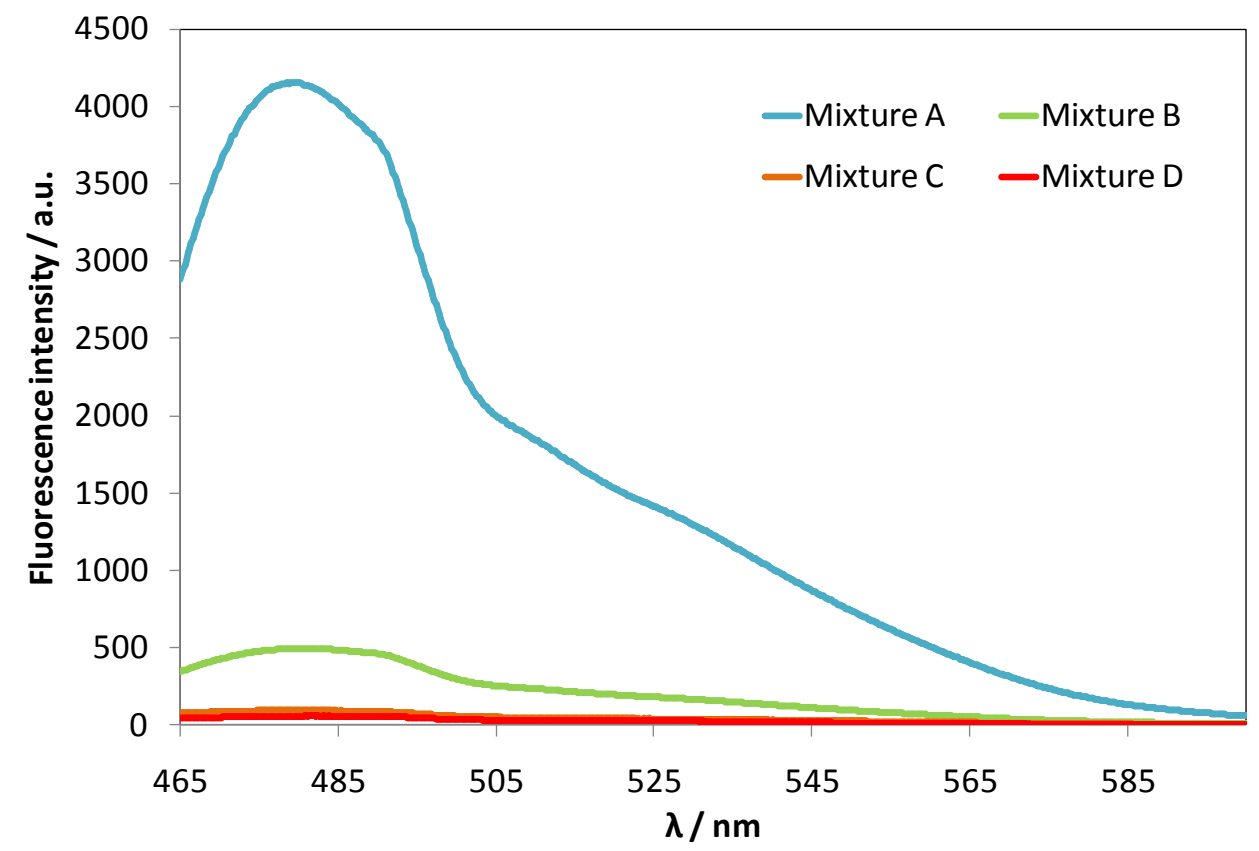

Figure 5.15 ThT fluorescence emission for mixtures $A-D$ at $2.5 \mathrm{mM}$ total concentration $\left(\lambda_{\mathrm{ex}}=450 \mathrm{~nm}\right.$; [ThT] $=5 \mu \mathrm{M})$. Mixture $\boldsymbol{A}(\mathbf{1}-7)$, mixture $\boldsymbol{B}(\mathbf{1}-\mathbf{8})$, mixture $\boldsymbol{C}(\mathbf{2}-\mathbf{7})$ and mixture $\boldsymbol{D}(\mathbf{2}-\mathbf{8})$.

In summary the combination of two complementary charged tetrapeptides has allowed the formation of co-assembled hydrogels at neutral $\mathrm{pH}$ values. The possibility of modifying the original precursors has resulted in four different mixtures with clear differences in morphology and structural organization. All of them are able to develop gel formation at really low concentration by using a simple injection methodology. CD and ThT binding data have shown that aromatic and hydrophobic interactions play an important role driving the self-assembly in conjunction with electrostatic interactions among charged residues. The significant differences found in the presence of accessible hydrophobic surfaces (by ThT binding assay) may be useful in terms of drug release since an specific molecule could be entrapped in a different way depending on the mixture employed showing then differences in release pattern.

\section{$5.4 \mathrm{pH}$ responsive co-assembled systems}

During the course of this work we have performed gels in acidic (1-6), basic (7-8) or neutral conditions (co-assembled mixtures A-D) in a simple way. At this point, one step further was envisaged by combining the different properties reported so far to 
create a more complex system that allows to adapt the gel state through all the $\mathrm{pH}$ range. Different aspects concerning kinetics of the assembly-disassembly process and mutual interference should be considered in order to obtain a versatile system. In this way we would achieve a suitable exchangeable system to test its behaviour in interesting applications such as selective load release. ${ }^{12}$

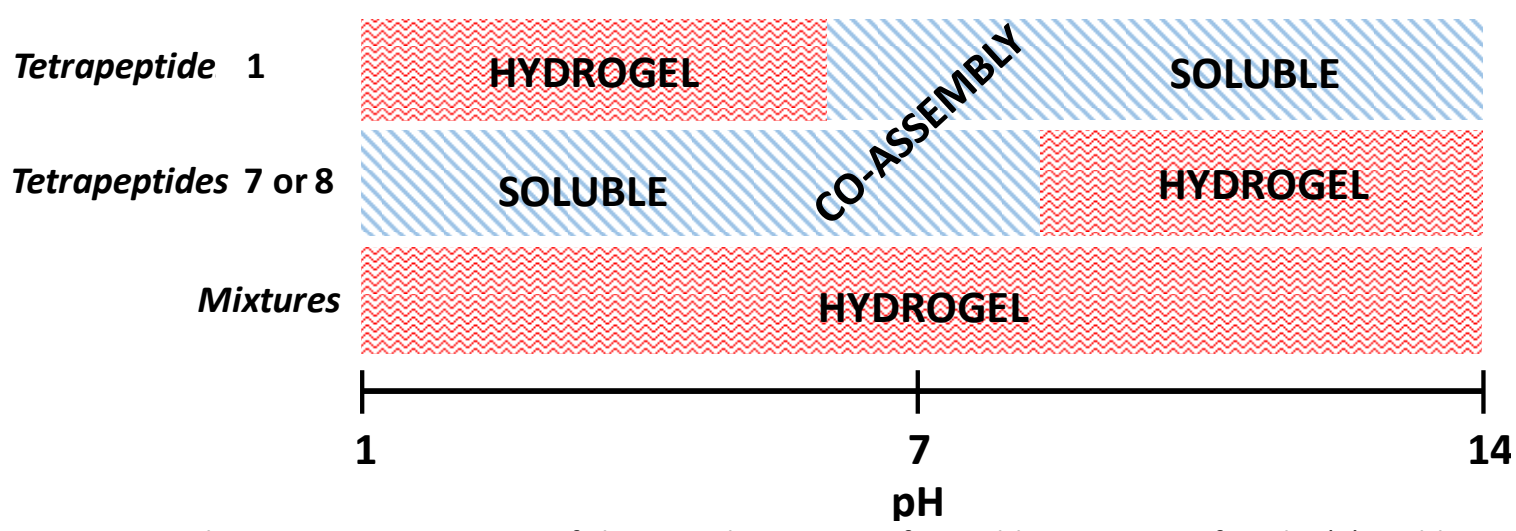

Figure 5.16 Schematic representation of the complex systems formed by mixtures of acidic (1) and basic tetrapeptides ( $\mathbf{7}$ and $\mathbf{8}$ ) over all $\mathrm{pH}$ range.

\subsubsection{Hydrogel formation and characterization}

Conversely to the co-assembled gels reported in last section, in this case the use of buffer it is definitely not recommended since our main objective is now to modulate the properties of the new complex system by $\mathrm{pH}$ changes in all over the range. In this way in order to achieve the co-assembled hydrogel at neutral $\mathrm{pH}$, the corresponding solutions of acidic and basic tetrapeptides were prepared by using $\mathrm{Na}_{2} \mathrm{CO}_{3}$ and $\mathrm{HCl}$ respectively. In a practical example for instance a $5 \mathrm{mM}$ solution of compound 1 in $\mathrm{Na}_{2} \mathrm{CO}_{3} 10 \mathrm{mM}$ was added over an equimolar acidic solution of compound 7 or 8 in $\mathrm{HCl}$ $10 \mathrm{mM}$ leading immediately to a slightly translucent hydrogel. Aggregates were also formed at lower concentrations ( $1 \mathrm{mM})$ although in this case they were not effective on percolating the solvent. As can be seen in Figure 5.17, ${ }^{1} \mathrm{H}$ NMR of these aggregates was silent, namely, no signals from any of the single components could be detected. This means that the solubility of the co-aggregates is very low, almost negligible regarding NMR sensitivity. 
Compound 7 ZFKFKC $_{3}$

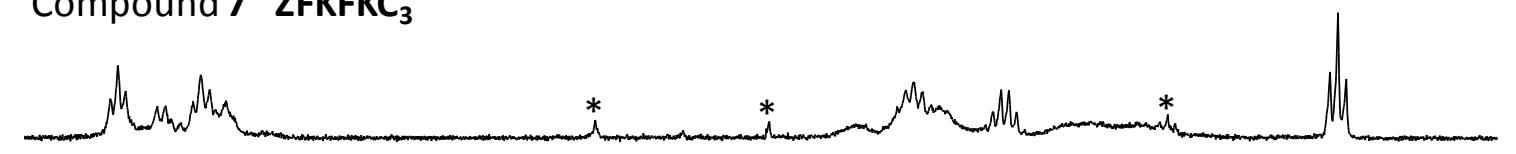

\section{Compound 1 ZFDFD $_{3}$}

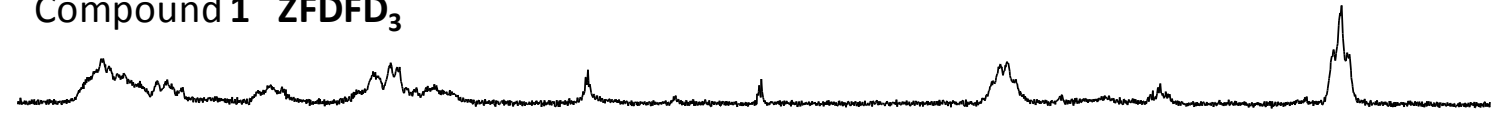

Equimolar mixture (1+7)

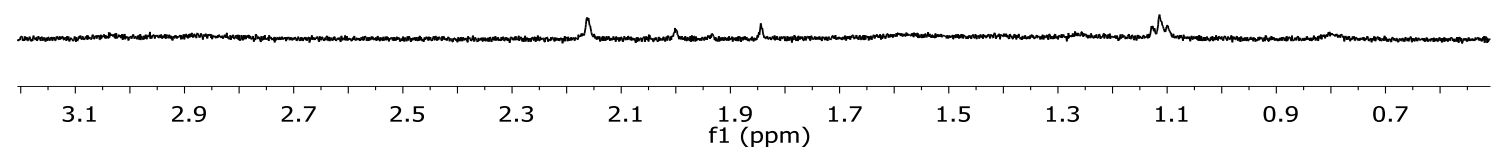

Figure $5.17{ }^{1} \mathrm{H}$ NMR $\left(\mathrm{D}_{2} \mathrm{O}\right)$ spectra of ionised compounds 1 and 7 at basic and acidic $\mathrm{pH}$ respectively. The bottom spectrum corresponds to their equimolar mixture at neutral $\mathrm{pH}$. (*solvent impurities). [Tetrapeptides] $=2.5 \mathrm{mM}$, total concentration of the mixture $=5 \mathrm{mM}$.

Data obtained from ThT binding assay ${ }^{10-11}$ were in agreement with previous results obtained for mixtures A-B in TRIS-HCl buffer. As in that case co-aggregate 1-7 showed a massive enhancement in comparison with co-aggregate 1-8 which may be explained by the position of the amino acid in tetrapeptide sequence.
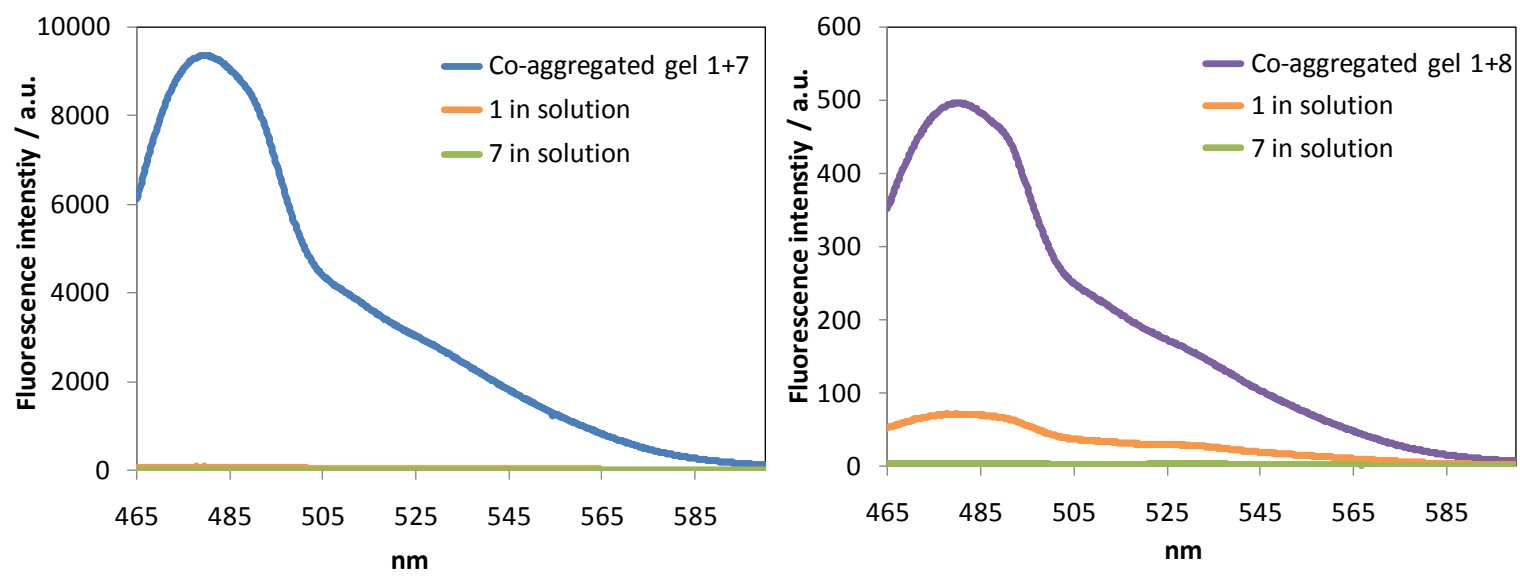

Figure 5.18 ThT binding assays for compounds 1, 7 and 8 in solution and for the co-aggregated mixtures of 1-7 and 1-8. $[1]=[2]=[7]=[8]=2.5 \mathrm{mM}$, total concentration $=5 \mathrm{mM},[\mathrm{ThT}]=5 \mu \mathrm{M}$.

Having managed the co-assembly between acidic and basic tetrapeptides using slightly different conditions than before, it is time to explore the presence of ionisable groups to make our aggregates pH-responsive. It is supposed that the addition of acid over the neutral co-aggregate (see species distribution diagram in Figure 5.5) should protonate compound $\mathbf{1}$ leading to its neutral form, which is poorly soluble in aqueous 
solution, and should therefore aggregate by itself. Meanwhile compounds $\mathbf{7}$ or $\mathbf{8}$ should remain positively charged but without the possibility to charge screening and most likely they should become soluble. Conversely the addition of a basic solution over the neutral co-aggregate should result in the solubilisation of compound $\mathbf{1}$ whereas compounds 7 and $\mathbf{8}$ should remain as neutral (an insoluble) species which should aggregate. If such initial hypotheses are accomplished the macroscopic hydrogel aspect would be maintained through all $\mathrm{pH}$ range even though the composition of the networks would be different for each case. As an experimental probe of that, co-aggregated gels of $\mathbf{1}$ and $\mathbf{7}$ at $5 \mathrm{mM}$ were prepared as previously described in the presence of Bromocresol Green (blue gel) as a $\mathrm{pH}$ indicator (Figure 5.19). The addition of $\mathrm{HCl}$ solution over this hydrogel showed a progressive diffusion of an acidic band (yellow) but nevertheless the hydrogel disassembly was not macroscopically observed during the whole process (final $\mathrm{pH}=1.5$ ). A similar process was observed for the addition of $\mathrm{Na}_{2} \mathrm{CO}_{3}$ solution over a hydrogel formed in the presence of Bromothymol Blue (final $\mathrm{pH}=10.5$ ).
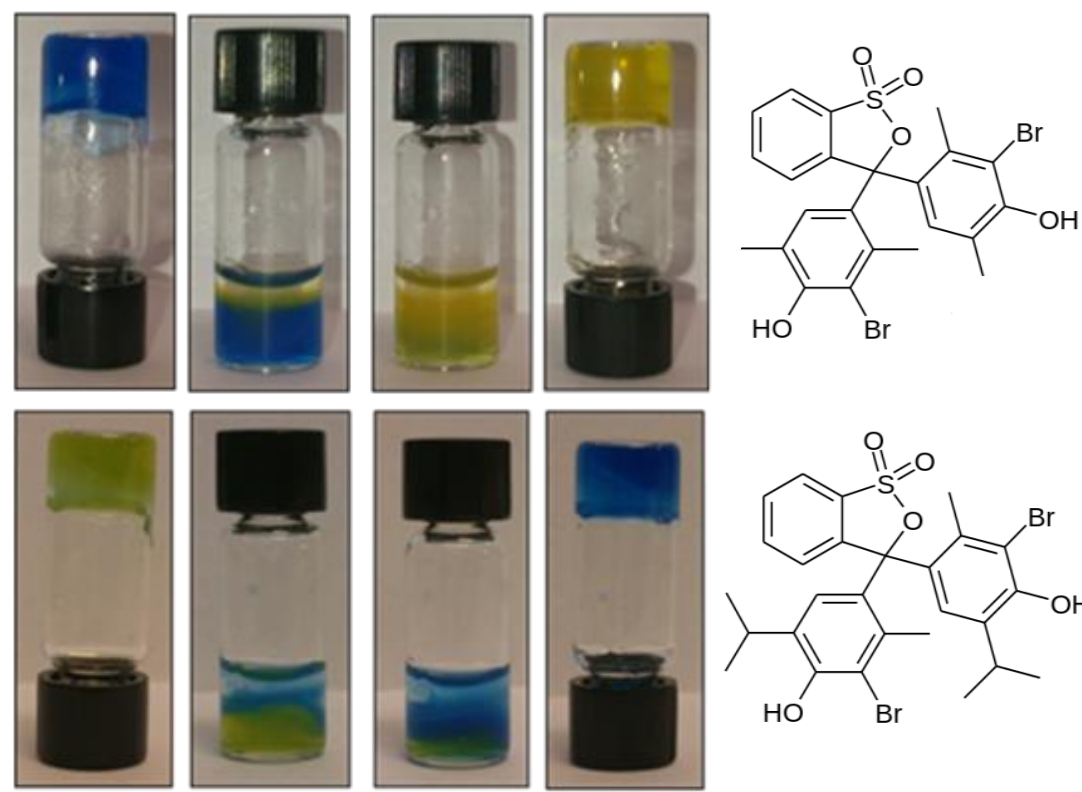

A

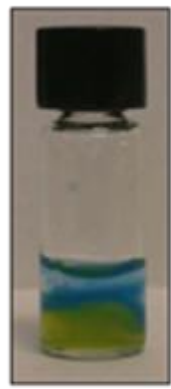

B

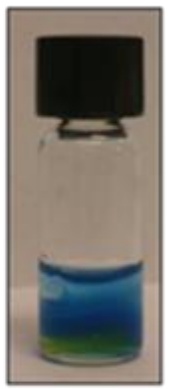

C

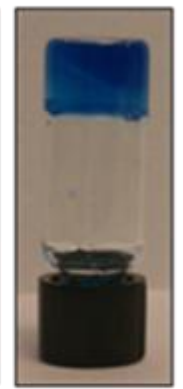

D $p K a=4.8$

Below pH 3.8 Above pH 5.4 3.8 5.4

Bromocresol Green

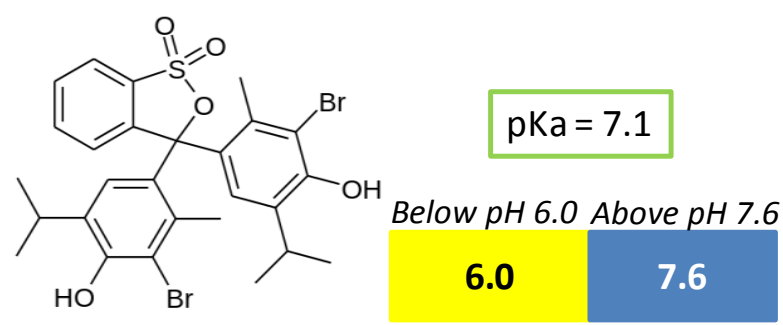

Bromothymol Blue

Figure 5.19 Hydrogels of co-aggregated 1 and 7 (Total concentration $5 \mathrm{mM}$ ) in the presence of Bromocresol Green (top) or Bromothymol Blue (bottom) before (A) and after the addition of $100 \mu \mathrm{L} \mathrm{of} \mathrm{HCl}$ $0.1 \mathrm{M}$ and $100 \mu \mathrm{L}$ of $\mathrm{Na}_{2} \mathrm{CO}_{3} 0.1 \mathrm{M}$ respectively ( $\mathrm{B}$ at $5 \mathrm{~min}, \mathrm{C}$ at $25 \mathrm{~min}$ and $\mathrm{D}$ at $50 \mathrm{~min}$ ).

The composition of these hydrogels at different $\mathrm{pH}$ values was assessed by ${ }^{1} \mathrm{H}$ NMR since soluble ionised components should appear in the spectrum while networked components should stay silent. In this way, it can be seen if the primary co-aggregated 
network persists after the protonation or deprotonation of one of the components or conversely evolves in situ into a new one-component network.

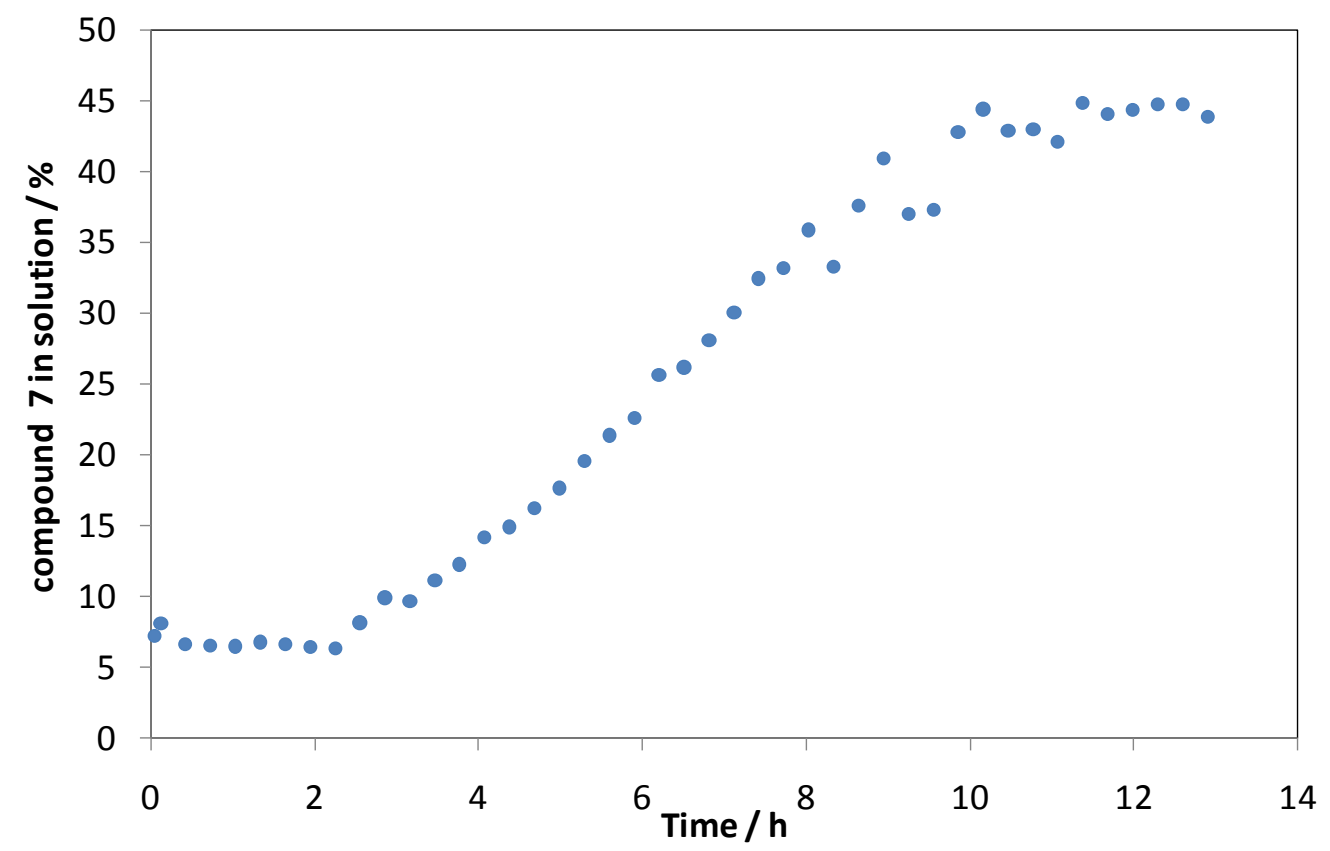

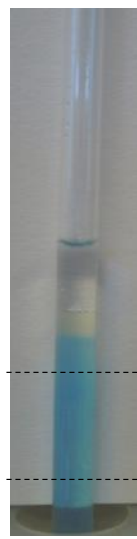

$30 \min$

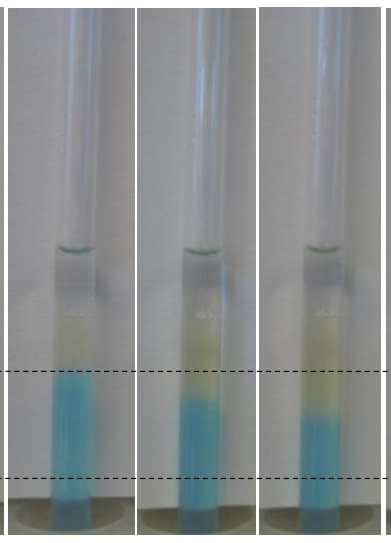

$1 \mathrm{~h} \quad 1 \mathrm{~h} 30 \min 2 \mathrm{~h}$

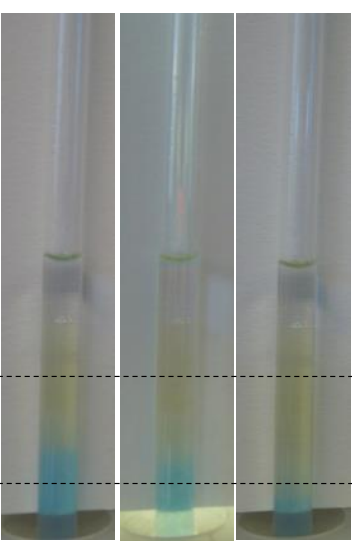

$3 \boldsymbol{h}$

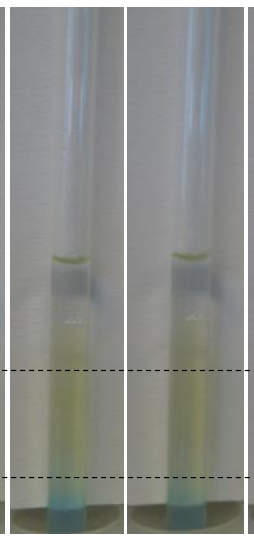

$6 h$
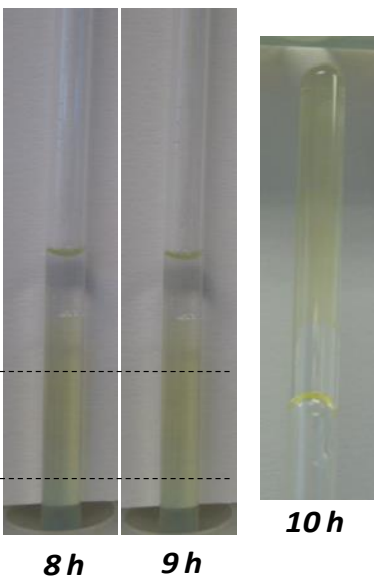

Figure 5.20 Kinetics of release of protonated compound 7 monitored by ${ }^{1} \mathrm{H}$ NMR after addition of $\mathrm{HCl} 0.1$ $\mathrm{M}$ to a neutral two-component hydrogel 1-7 (top). Change in Bromocresol Green colour associated to this diffusion process (bottom). [Tetrapeptides] $=5 \mathrm{mM}$.

As can be observed in Figure 5.20 the addition of $\mathrm{HCl}$ to a neutral co-assembled mixture of compounds $\mathbf{1}$ and $\mathbf{7}$ went along with the progressive solubilisation of compound $\mathbf{7}$ (increase in ${ }^{1} \mathrm{H}$ NMR integrals of compound $\mathbf{7}$ while signals of compound $\mathbf{1}$ remained silent). The presence of Bromocresol Green in a parallel experiment using exactly the same conditions allowed the naked eye observation of the local $\mathrm{pH}$ change during diffusion process. These qualitative results indicate that in principle the release of compound 7 from the co-assembled network is happening at the same time scale of 
hours than the diffusion of the acidic additive. A similar profile was obtained for the addition of $\mathrm{Na}_{2} \mathrm{CO}_{3}$ to the co-assembled mixture of $\mathbf{1}$ and $\mathbf{7}$ although a larger gap between diffusion and solubilisation of compound 1 was detected in this case (S.I. 5.3.2). Circular dichroism was performed on samples of both co-aggregates at different $\mathrm{pH}$ and, as can be seen in Figure 5.21, significant differences could be observed between them. CD spectra for co-assembled mixtures 1-7 and 1-8 at neutral $\mathrm{pH}$ were in agreement with previous CD spectra reported for co-assembled hydrogels in TRIS-HCl buffer.
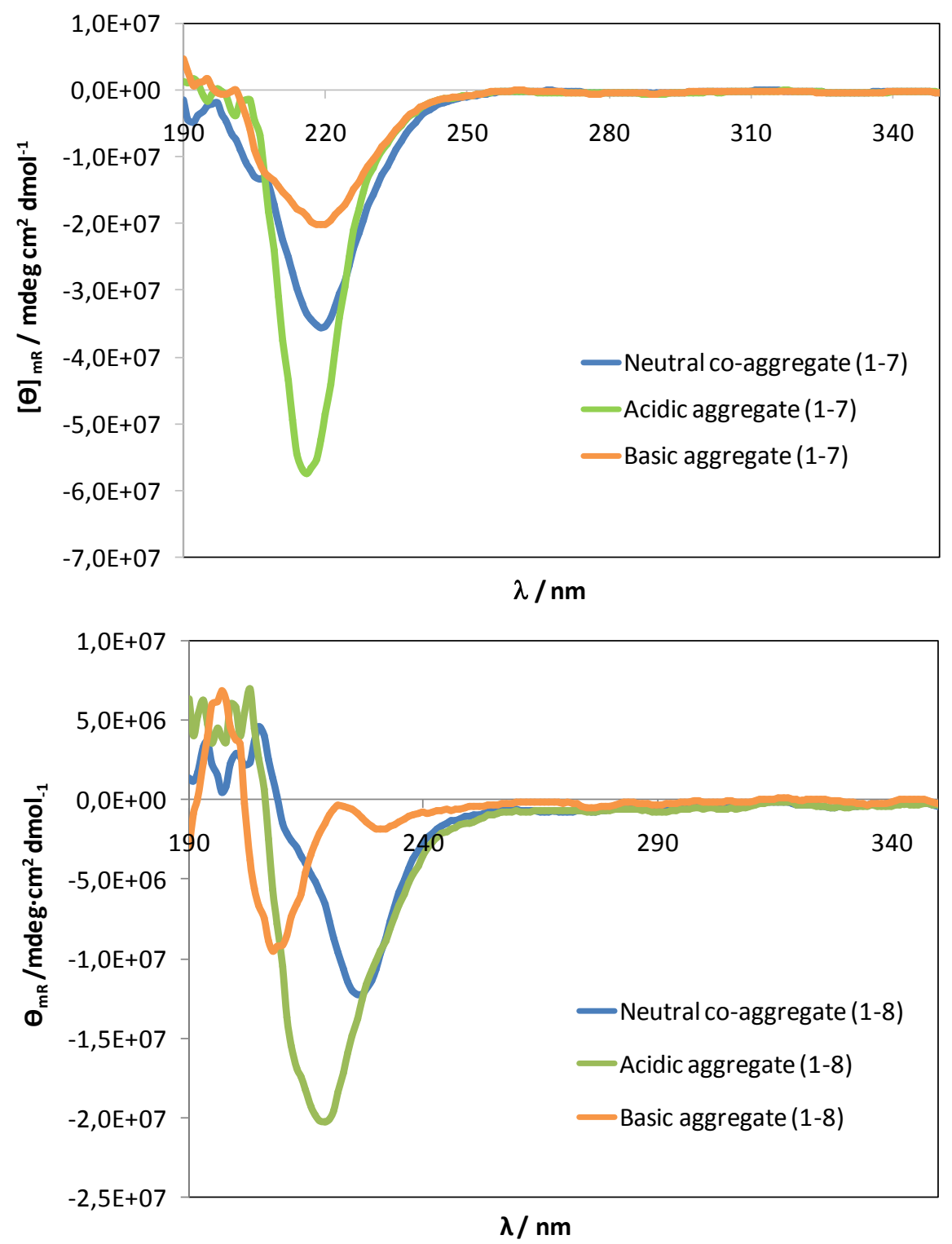

Figure 5.21. CD spectra of co-assembly 1-7 (top) and co- assembly 1-8 (bottom) at different pH. Total concentration of the mixtures $1 \mathrm{mM}$. 
The mixture 1-7 showed a negative band centred at $218 \mathrm{~nm}$ that could be assigned to a $\beta$-sheet conformation and that is only slightly shifted upon changing the $\mathrm{pH}$. However, in the case of co-assembly 1-8 relevant differences on the band position were observed from $227 \mathrm{~nm}$ for the neutral aggregates to $219 \mathrm{~nm}$ at acidic $\mathrm{pH}$ and 208 $\mathrm{nm}$ under basic conditions. In both cases acidic co-aggregates presented higher CD signals than neutral and finally basics mixtures. Acidic CD bands in both cases are centered at $217 \mathrm{~nm}$ and showed a similar pattern since the network in this case is mainly formed by compound 1. Bands for basic mixtures correspond with two different compounds ( $\mathbf{7}$ and $\mathbf{8}$ ) and revealed significant differences among them.

Trying to understand slightly better the mechanical properties of these two networks at different $\mathrm{pH}$ values, rheological measurements were carried out on hydrogel samples equilibrated at the required $\mathrm{pH}$ for $24 \mathrm{~h}$ at room temperature. In general all of them showed the common viscolastic behaviour that could be expected for a gel material. The storage modulus $G^{\prime}$ had larger values that the loss modulus $G^{\prime \prime}$ for the different samples at different pH (S.I. 5.3.5.1). The differences in moduli were of about one order of magnitude and together with low values of yield stress suggest that these gels are only moderately strong. In particular both co-assembled gels at neutral pH showed quite similar values of $\mathrm{G}^{\prime}$. The addition of acidic and basic solutions over the neutral co-aggregates lead significant differences among both mixtures. In the case of mixture 1-8, basic and acidic conditions revealed lower values of $\mathrm{G}^{\prime}$ as it could be expected considering that the network in this case is mainly formed by just one component. However in the case of mixture 1-7 this effect was not so clear specially under basic conditions because $G^{\prime}$ value in this case is even slightly higher than for the co-assembled mixture at neutral $\mathrm{pH}$.

From these results it seems apparent that several factors could be affecting the mechanical properties of the gels, not only the composition of the network at a given $\mathrm{pH}$ but also the supramolecular structure of the starting co-assembled network. In this sense, the kinetics of network exchange could play a relevant role and deserve a deeper study that should be undertaken in the near future. 


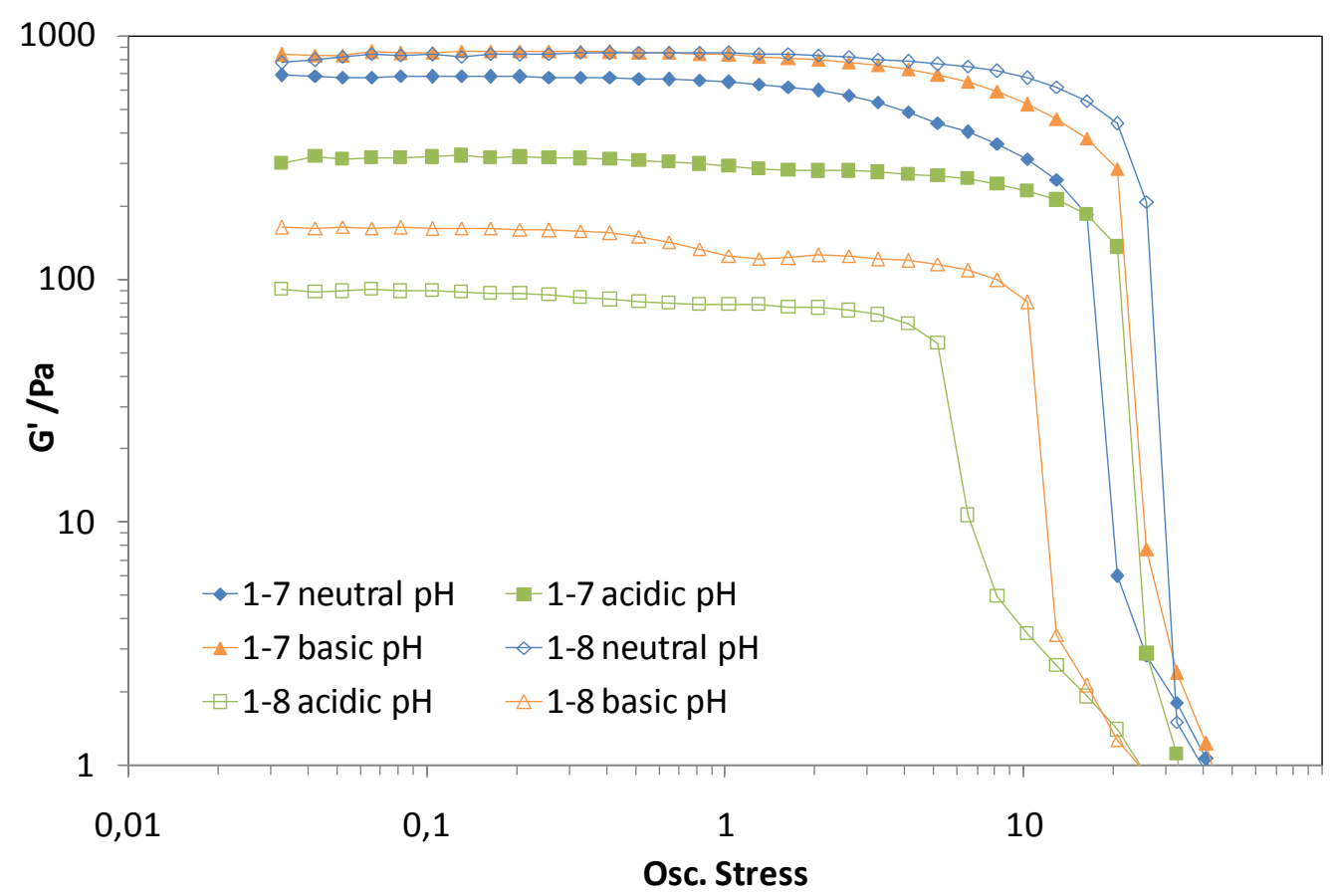

Figure 5.22 Storage modulus $\left(\mathrm{G}^{\prime}\right)$ data under an oscillatory stress experiment at a frequency of $1 \mathrm{~Hz}$.

\subsubsection{Exchange of fibrillar networks by pH tunning}

In order to avoid possible diffusion artefacts, the amount of free compounds in solution as well as the exchange between all different networks (Figure 5.23) with $\mathrm{pH}$ was finally studied using samples at total concentration of $1 \mathrm{mM}$ where it is known the presence of aggregates even though they are not able to percolate the solvent.

Co-aggregates of compounds 1-7 and 1-8 were prepared as previously described by mixing equimolar mixtures at neutral $\mathrm{pH}$ and the solubility of such co-aggregates was determined to be less than $5 \%$ for both mixtures. TEM images (Figure 5.24) revealed similar structures to those observed for co-aggregated samples using TRIS-HCl buffer as a solvent (Figure 5.10 and 5.11). 


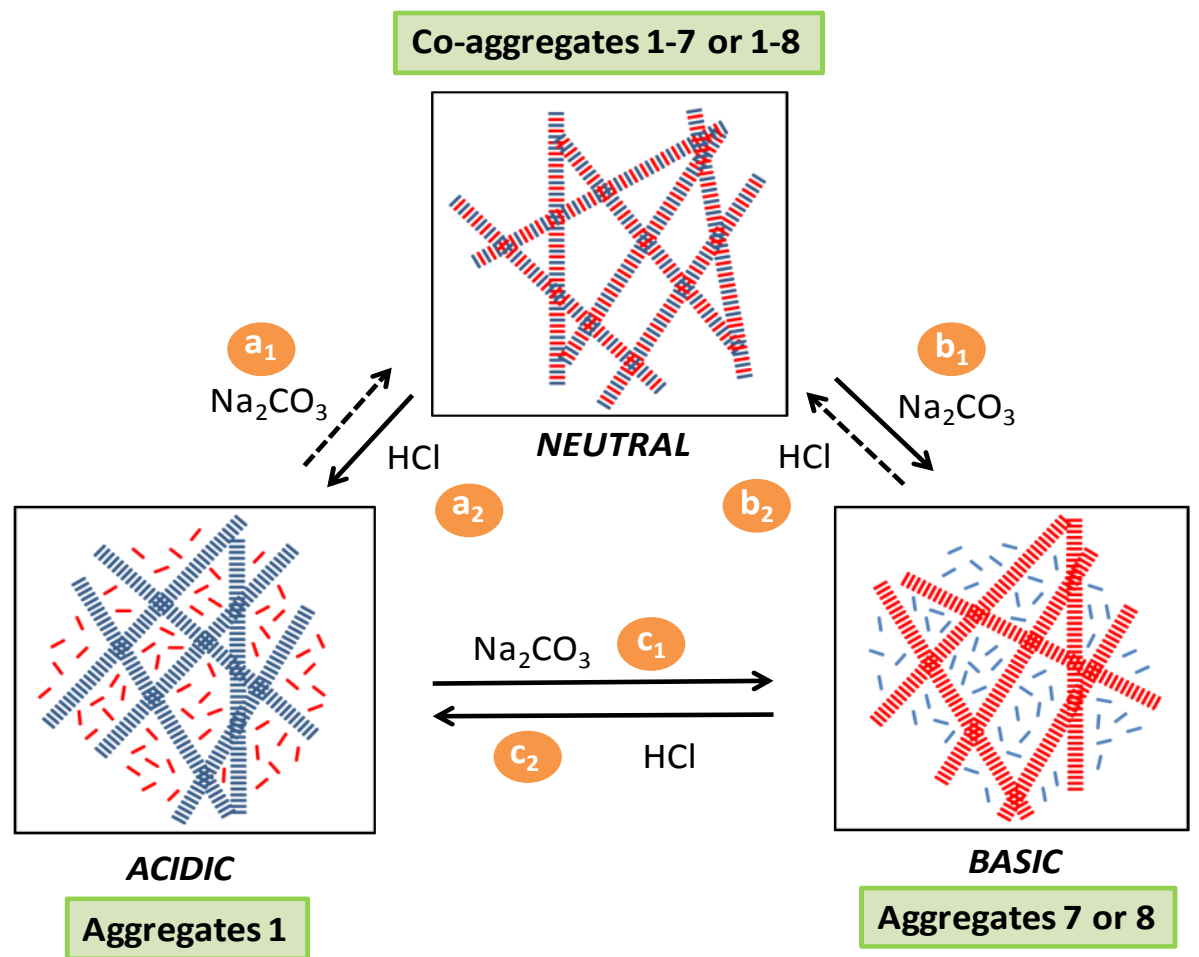

Figure 5.23 Schematic representation of the $\mathrm{pH}$-responsive system.
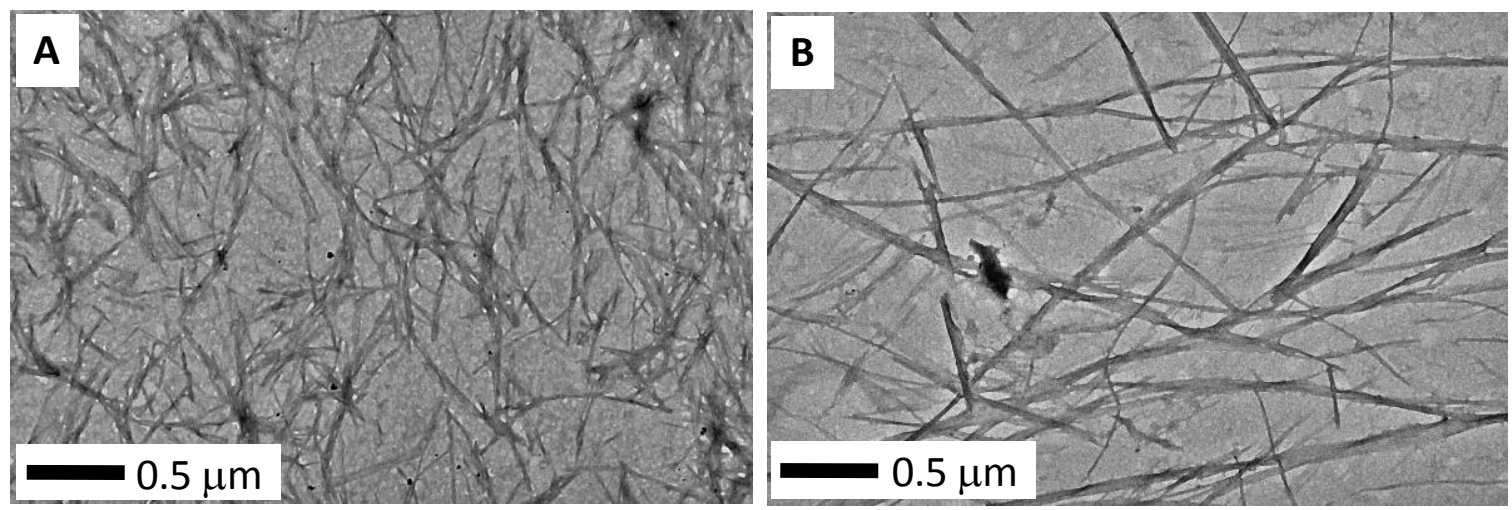

Figure 5.24 TEM images of co-aggregates at neutral $\mathrm{pH}$ for compounds 1-7 $(\mathrm{A})$ and 1-8 (B). $[\mathbf{1}]=[\mathbf{7}]=[\mathbf{8}]=$ $0.5 \mathrm{mM}$. Total concentrations of the mixtures $1 \mathrm{mM}$.

The acidification of these neutral mixtures by using $\mathrm{HCl}$ allowed in both cases the formation of aggregates of compound $\mathbf{1}$ (step $\mathbf{a}_{\mathbf{2}}$ ). Aggregates of compound $\mathbf{1}$ can also be obtained from basic aggregates upon acidification with $\mathrm{HCl}$ (step $\mathbf{c}_{2}$ ). In all the cases TEM images showed thin and regular fibres of around 10-15 nm in width, similarly to the blank of the compound that remained within the network, in this case compound $\mathbf{1}$ (Figure 5.25A). The percentage of ionised compound detected in solution (compound 7 or 8) was similar (65-75\%) independently of the path. 


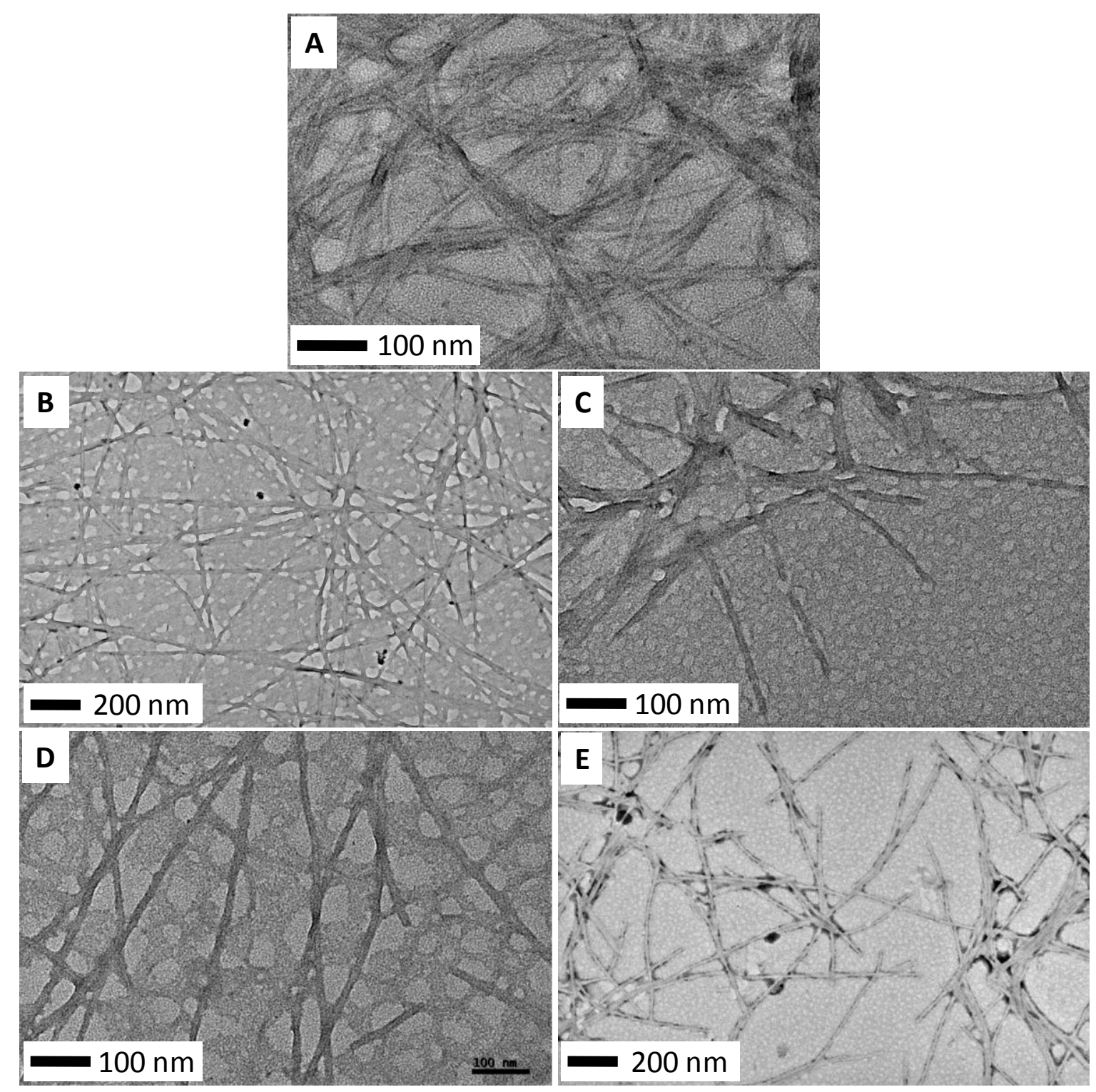

Figure 5.25 TEM images for aggregates of compound 1 in $\mathrm{HCl}(\mathrm{A})$, aggregates of mixtures 1-7 (B) and 1-8 (C) at acidic $\mathrm{pH}$ after acidification of neutral co-aggregates with $\mathrm{HCl}$, step $\mathrm{a}_{2}$ and aggregates of mixtures 1-7 (D) and 1-8 (E) at acidic $\mathrm{pH}$ after acidification of basic aggregates with $\mathrm{HCl}$, step $\mathbf{c}_{2}$. [1] = [7] = [8] = $0.5 \mathrm{mM}$. Total concentrations of the mixtures: $1 \mathrm{mM}$.

In a similar way, the addition of $\mathrm{Na}_{2} \mathrm{CO}_{3}$ over neutral co-aggregates of compounds 1-7 and 1-8 (step $b_{1}$ ) released compound 1 to the solution while compounds 7 and 8 remained respectively in the aggregated form. The percentage of compound 1 detected in solution was around $65-75 \%$. The addition of $\mathrm{Na}_{2} \mathrm{CO}_{3}$ to acidic aggregates of compounds 1-7 and 1-8 (step $c_{1}$ ) allowed also the formation of such basic aggregates. The percentage of compound 1 detected in solution was also around 65-75\%. TEM images (Figure 5.26) of the samples at basic $\mathrm{pH}$ revealed the presence of twisted fibres for both mixtures 1-7 and 1-8 in accordance with blank samples of pure $\mathbf{7}$ and $\mathbf{8}$. 


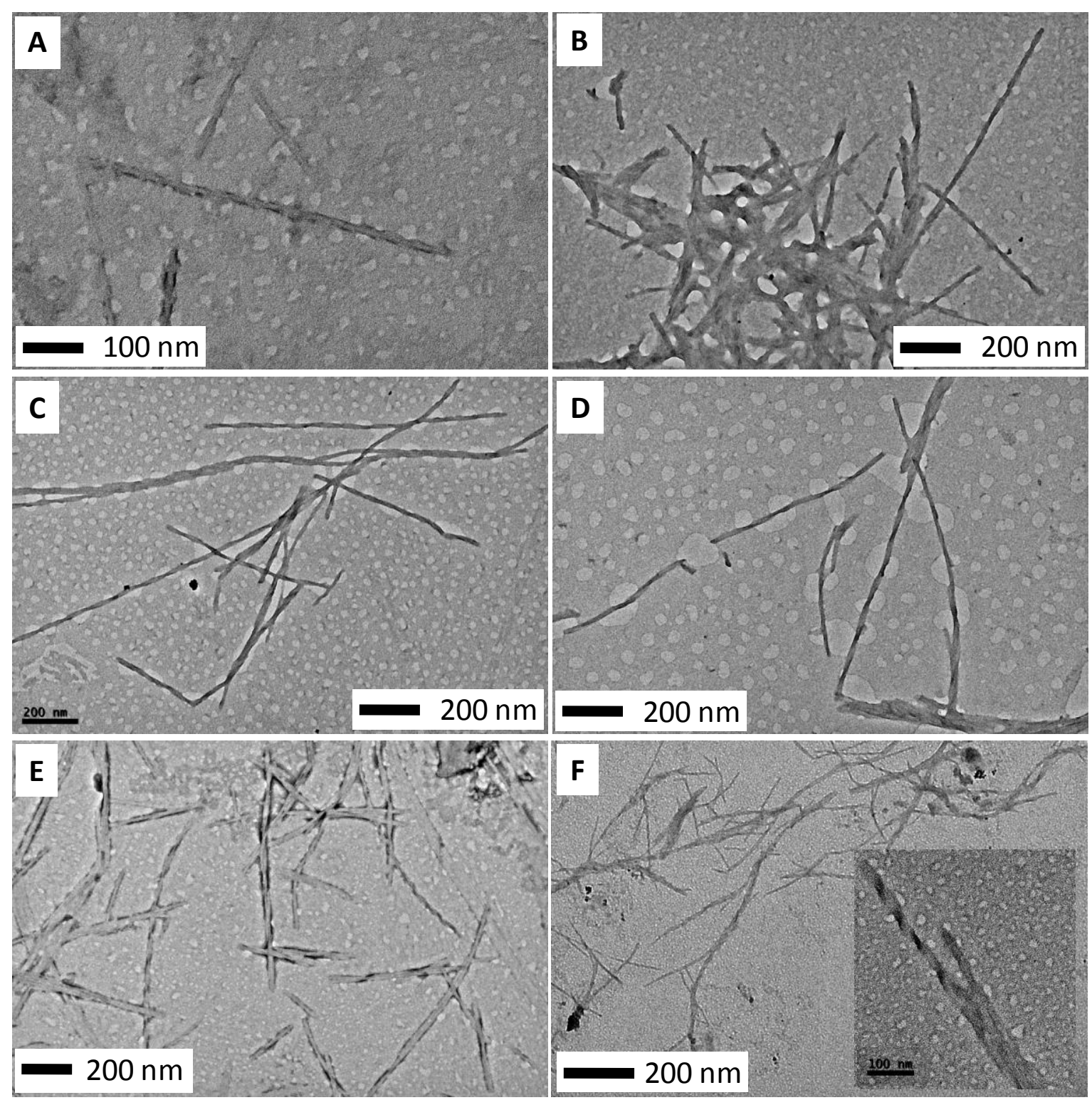

Figure 5.26 TEM images for aggregates of compound $7(A)$ and $8(B)$ in $\mathrm{Na}_{2} \mathrm{CO}_{3}$, aggregates of mixtures 1-7 (C) and 1-8 (D) at basic $\mathrm{pH}$ after basification of neutral co-aggregates with $\mathrm{Na}_{2} \mathrm{CO}_{3}$, step $\mathbf{b}_{1}$ and aggregates of mixtures 1-7 (E) and 1-8 (F) at basic $\mathrm{pH}$ after acidification of acidic aggregates with $\mathrm{Na}_{2} \mathrm{CO}_{3}$, step $\mathrm{c}_{1}$. [1] = $[7]=[8]=0.5 \mathrm{mM}$. Total concentrations of the mixtures: $1 \mathrm{mM}$.

The neutralization of basic and acidic aggregates (steps $\mathbf{a}_{\mathbf{1}}$ and $\mathbf{b}_{\mathbf{1}}$ ) was also achieved leading to co-aggregates of compounds 1-7 and 1-8. The amount of compounds detected in solution was around $10-20 \%$, values slightly bigger than for direct formation of co-aggregates at neutral $\mathrm{pH}$ by mixing both compounds in solution. In general the process of reversible $\mathrm{pH}$ switching between three different aggregated states as schematised in Figure 5.23 could be performed. A residual amount of ionised compound remains adsorbed on the aggregates after the corresponding $\mathrm{pH}$ change most likely due to non-specific interactions. 


\subsubsection{Tunable release of loads by $\mathrm{pH}$ changes}

The particular features displayed by these two-component hydrogels can be of great interest in the field of drug delivery as a co-assembled hydrogel loaded with drugs can be prepared easily by injecting two solutions at near physiological $\mathrm{pH}$ and moreover different drugs could be released at will by tuning the $\mathrm{pH}$. In order to evaluate their potential use in this field two $\mathrm{pH}$ sensitive dyes were studied as models of hydrophobic drugs: Methylene Blue (MB) and Bromothymol Blue (BTB). $M B$ is a flat aromatic compound with a permanent positive charge and a tertiary amine that is protonated in acidic medium (ammonium pKa $=3.8$ ). BTB (as previously described in Figure 5.19 ) is a $\mathrm{pH}$ dye indicator that turns from yellow below pH 6 (non-polar cyclic form) into blue above $\mathrm{pH} 7.6$ (anionic form).

In a typical experiment co-assembled hydrogels (neutral $\mathrm{pH}$ ) containing MB (25 $\mu \mathrm{M})$ were prepared by addition of an acidic solution of compound 7 and MB to a basic solution of compound $\mathbf{1}$ and stabilisation for $24 \mathrm{~h}$ (final gel concentration $5 \mathrm{mM}$, final pH of the hydrogel $6.8-7.4$, total volume $1 \mathrm{~mL}$ ). After this period of time $1 \mathrm{~mL}$ of a solution of the required $\mathrm{pH}$ was added on top of the gel and the release of $\mathrm{MB}$ from the gel was monitored in situ following the absorbance at $\lambda=624 \mathrm{~nm}$ of the supernatant solution (S.I. 5.4.1.2A). On the other hand hydrogels loaded with BTB $(32 \mu \mathrm{M})$ were prepared by mixing a basic solution of compound 1 and BTB, and an acidic solution of compound 7 (final gel concentration $5 \mathrm{mM}$, final $\mathrm{pH}$ of the hydrogel $6.8-7.4$, total volume $1 \mathrm{~mL}$ ). After $24 \mathrm{~h}$ of stabilisation of the hydrogels and addition of supernatant solutions, released BTB was monitored at $\lambda=435 \mathrm{~nm}$ for acidic $\mathrm{pH}$ and water and at $\lambda=616 \mathrm{~nm}$ for basic $\mathrm{pH}$ (S.I. 5.4.1.1). Three different solutions were added on top of the hydrogels: a) $0.1 \mathrm{M} \mathrm{HCl}, \mathrm{b}$ ) water and c) $0.1 \mathrm{M} \mathrm{Na}_{2} \mathrm{CO}_{3}$. As it can be seen in Figure 5.27 in the case of $\mathrm{MB}$, after $12 \mathrm{~h}$ the release was more efficient at acidic $\mathrm{pH}$. Under this conditions protonated $\mathrm{MB}$ is excluded from the hydrogel network together with protonated compound 7 . The release of $\mathrm{MB}$ is in general much slower upon addition of neutral water and almost negligible at basic $\mathrm{pH}$. It has to be noted that the absorption band of released MB appear blue-shifted compared to the expected absorption ( $\lambda_{\max }=665 \mathrm{~nm}$ for free monomer, S.I. 5.4.1.2B-C) in all the samples despite of the different $\mathrm{pH}$. This observation points to a remarkable interaction between $\mathrm{MB}$ and the neutral co-aggregate and its release as a complex with 
compound 7. On the other hand, BTB is preferentially released under basic conditions, in parallel with the expulsion of deprotonated compound 1 (Figure 5.28). In this case no shifts were observed suggesting that the interactions with the aromatic fragments are not as intense and specific as in the case of MB.
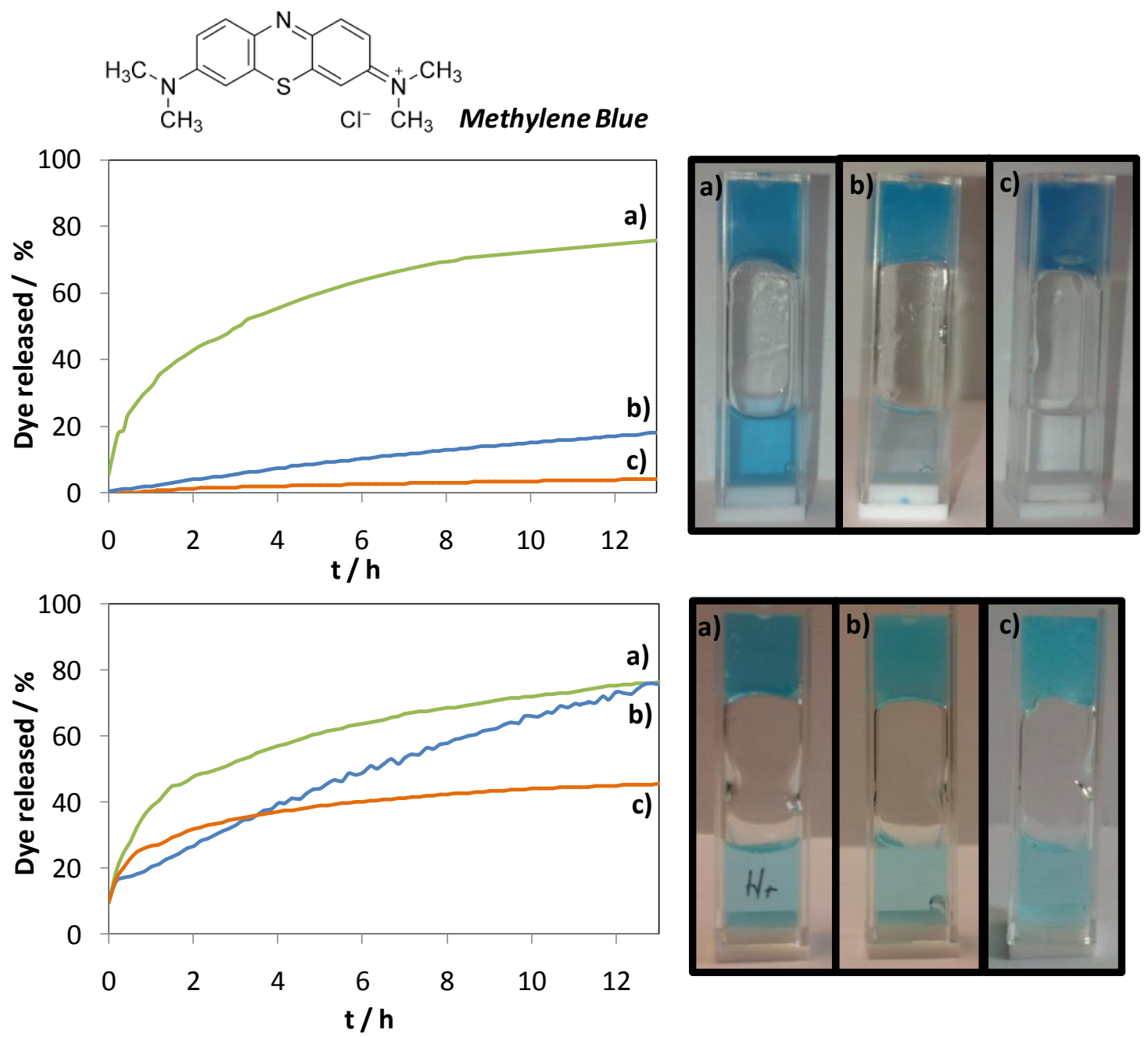

Figure 5.27 Release profile of Methylene Blue from co-assembled hydrogels 1-7 (top) and 1-8 (bottom) after addition of $1 \mathrm{~mL}$ of solutions: a) $0.1 \mathrm{M} \mathrm{HCl}$, b) water and c) $0.1 \mathrm{M} \mathrm{Na}_{2} \mathrm{CO}_{3}$. Macroscopic aspect of the gels and their supernatants $24 \mathrm{~h}$ after the addition (right).

Similar experiments were performed for co-aggregates 1-8. In this case, the maximum of absorption of released MB was coincident with the free monomer $(\lambda=665$ $\mathrm{nm}$ ) discarding any interaction of the dye with compound $\mathbf{8}$. Besides, although the release under acidic conditions was slightly better, the addition of water or basic solution also released a considerable amount of dye (Figure 5.27). These observations suggest a relevant difference between both networks, not only because of the 
interaction of $\mathrm{MB}$ with the gelator molecules but also caused by a different network response to $\mathrm{pH}$ changes.
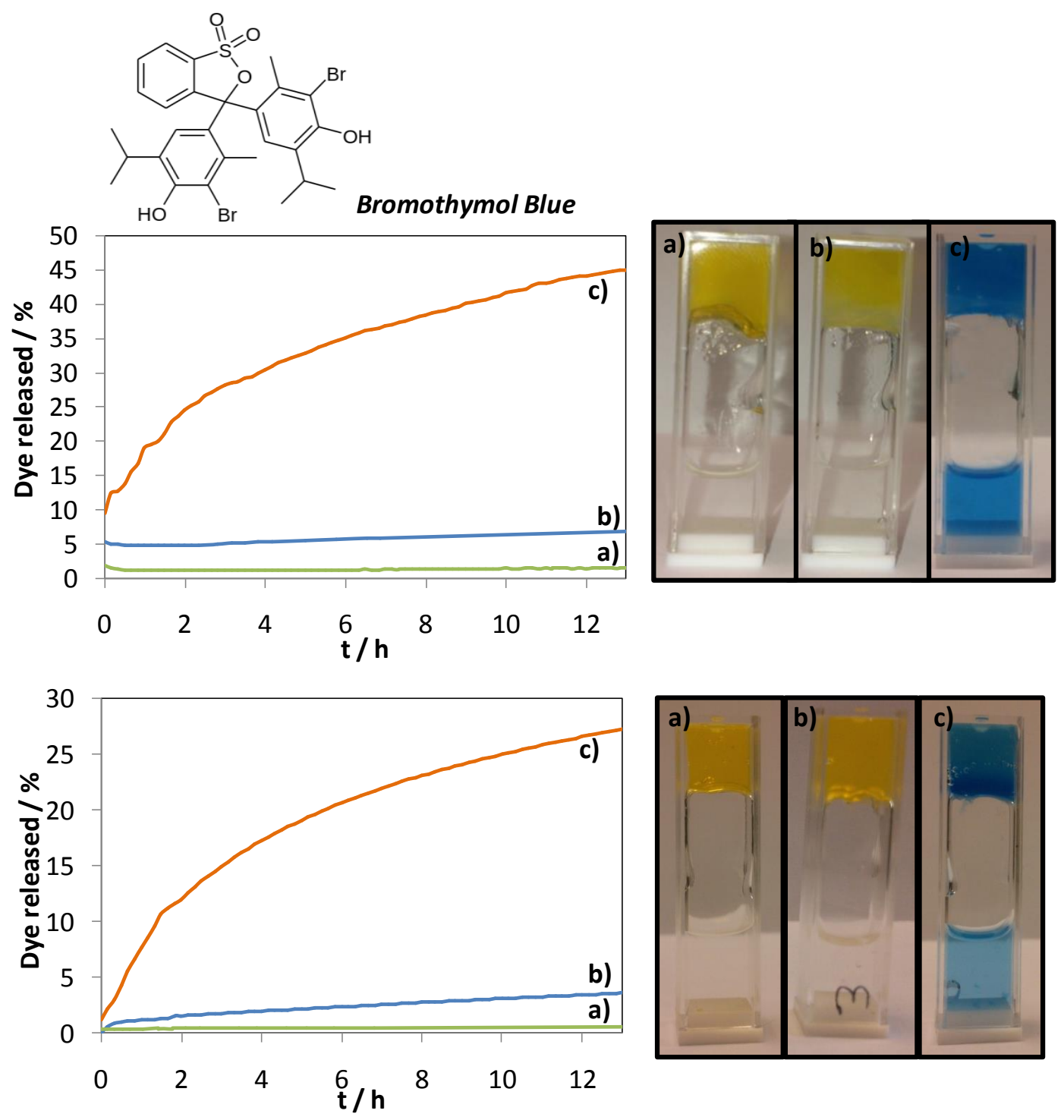

Figure 5.28 Release profile of Bromothymol Blue from co-assembled hydrogels 1-7 (top) and 1-8 (bottom) after addition of $1 \mathrm{~mL}$ of solutions: a) $0.1 \mathrm{M} \mathrm{HCl}$, b) water and c) $0.1 \mathrm{M} \mathrm{Na}_{2} \mathrm{CO}_{3}$. Macroscopic aspect of the gels and their supernatants $24 \mathrm{~h}$ after the addition (right).

As pointed before by the ThT fluorescence experiments (Figure 5.18), aggregates of mixture 1-8 would not have extensive aromatic regions able to strongly bind $\mathrm{MB}$ and then the mechanism of release may be also different. The absence of these large hydrophobic regions could be also crucial for the strength of the network and it would explain why in neutral and basic media MB is released in a larger extend than for the coaggregated 1-7. In the case of BTB, the release from co-aggregated 1-8 was only efficient at basic $\mathrm{pH}$ and no release was observed either at neutral or acidic $\mathrm{pH}$ (Figure 5.28). In 
summary, these experiments reveal that several factors are playing a role; in one hand the intrinsic differences between networks of 1-7 and 1-8 and the $\mathrm{pH}$ tuned interconversion from two- to one-component hydrogels, and on the other hand the intermolecular interactions between network components and released compounds and the change of polarity of the dyes. A fine tuning of all these factors may allow the loading of multiple drugs for a convenient $\mathrm{pH}$ controlled distribution.

\subsection{Kinetically entrapped networks}

Basic and acidic co-aggregates of compounds $1: 7$ could be also formed by direct acidification or basification, that is, compound 1 (1 mM) was dissolved in $\mathrm{Na}_{2} \mathrm{CO}_{3} 10 \mathrm{mM}$ and mixed with a solution of compound $7(1 \mathrm{mM})$ in $\mathrm{HCl} 50 \mathrm{mM}$. The final $\mathrm{pH}$ of this mixture would be therefore around 1.5. Conversely to form the basic co-aggregate compound 1 ( $1 \mathrm{mM}$ ) was dissolved in $\mathrm{Na}_{2} \mathrm{CO}_{3} 50 \mathrm{mM}$ and mixed with a solution of compound $7(1 \mathrm{mM})$ in $\mathrm{HCl} 10 \mathrm{mM}$ leading to a final $\mathrm{pH}$ around 10.5 . Acidic mixtures of 1-7 in this case revealed similar structures as those described in Figure 5.25 and the amount of compound 7 in solution was also around 65-75 \%. However unexpected results were obtained for the direct basification of mixtures 1-7 because in this case the amount of compound $\mathbf{1}$ detected in solution was lower than $30 \%$ and as a consequence important changes in TEM images could be detected. As it can be seen in Figure 5.29 A-B instead of the typical chiral fibres observed previously in basic conditions (Figure 5.26) some straight tubes are also present most likely due to the increased amount of acidic compound 1 that remained attached to the basic network. As an evidence of that, we increased the amount of compound $\mathbf{1}$ in the mixtures and once again TEM images revealed the presence of even more rigid tubes (Figure 5.29C-F). A similar effect was observed when we prepared a $5 \mathrm{mM}$ gel in a 1:1 ratio by using this methodology of direct basification (Figure 5.29G). It seems that the fast $\mathrm{pH}$ change during gel formation drives the system into a different aggregation pathway than the previously described and kinetically trapped metastable aggregates containing both compounds $\mathbf{1}$ and $\mathbf{7}$ appear in the form of tubes. Most likely compound $\mathbf{1}$ acts as a template for compound $\mathbf{7}$ since bigger amount of compound 1 leads to the formation of nanotubes as the main morphology. 

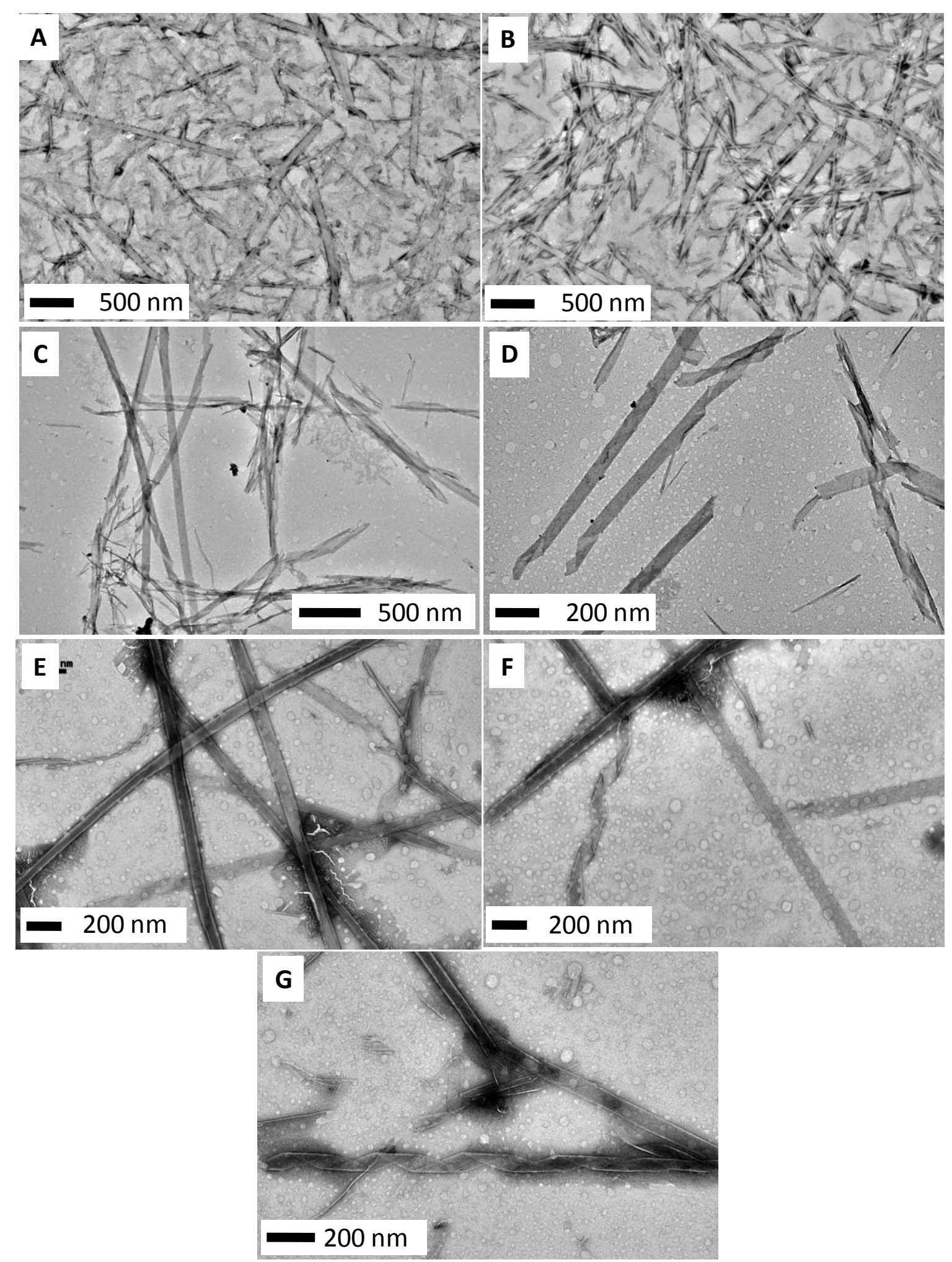

Figure 5.29 TEM images for co-assembled mixture 1-7 at basic $\mathrm{pH}, \mathrm{A}, \mathrm{B}) 1 \mathrm{mM}$ total concentration, 1:1 ratio; C, D) 1.5:1 ratio; E, F) 2:1 ratio. G) $5 \mathrm{mM}$ total concentration, 1:1 ratio. 


\subsection{Conclusions}

In this chapter the ability of two new tetrapeptides $(\mathbf{7}, \mathbf{8})$ containing $\mathrm{K}$ and $\mathrm{F}$ as hydrogelators has been demonstrated by using $\mathrm{pH}$ change methodology. Besides, the co-aggregation with acidic analogues $\mathbf{1}$ and $\mathbf{2}$ at neutral $\mathrm{pH}$ using TRIS-HCl buffer has been also successfully achieved. The combination of acidic compounds $\mathbf{1 ,} \mathbf{2}$ and basic compounds 7, 8 has allowed the formation of four co-assembled hydrogels at very low concentration which showed differences in morphology and structural arrangements. Charge screening among lysine and aspartate residues as well as aromatic and hydrophobic interactions have been shown to be responsible of driving the selfassembly in a particular way. These co-assembled hydrogels can be prepared easily by a simple injection methodology using solutions of the precursors at neutral $\mathrm{pH}$ which represents a convenient strategy for biomedical applications since no external stimulus such as $\mathrm{pH}$, temperature or salt addition are required to form the gel. Besides, this approach may endow the possibility to combine different bioactive epitopes within a single nanofibre.

Moreover, the well-known behaviour of all our systems has allowed us to create a new more complex system combining two oppositely charged self-assembling peptides which is able to maintain gel stability through all pH range (Figure 5.16). We have shown then that it is possible to switch between two-component networks at neutral $\mathrm{pH}$ to one-component networks at either basic or acidic $\mathrm{pH}$ with a concomitant change in the features of the material. In the same way, changes in the internal structure of the networks upon $\mathrm{pH}$ variation do not affect the macroscopic appearance of the gels. Overall this case highlights how introducing complexity by means of incorporating an additional hydrogelator provides outstanding new properties not present in their precursors when they are separated.

Dye-release studies using these systems indicate that they can be used for tuneable release of loads based not only on their molecular structures but also on the particular features of the network involved. The composition of these hydrogels could be modified by using other isomeric analogues reported in chapter 4. Moreover, compound 1 and analogues have been shown to interact with amyloid fragment $A \beta 40$ 
which combined with the particular release properties could be of great interest from a biomedical point of view.

\subsection{Supplementary information}

\section{S.I.5.1 Hydrogelation of basic tetrapeptides}

S.I. 5.1.1 Hydrogel formation using ammonia fumes

S.I. 5.1.2 Transmission electron microscopy (TEM)

S.I. 5.1.3 Fourier Transform Infrared Spectroscopy (FTIR)

S.I. 5.1.4 Circular dichroism (CD)

S.I. 5.1.5 Potentiometric titrations of basic tetrapeptides

S.I.5.2 Co-assembly among acidic $(1,2)$ and basic $(7,8)$ tetrapeptides at neutral pH

S.I. 5.2.1 Solubility of compounds $1,2,7$ and 8 in TRIS-HCl buffer ( ${ }^{1} \mathrm{H}$ NMR)

S.I. 5.2.2 Determination of stoichiometry $\left({ }^{1} \mathrm{H} N M R\right)$

S.I. 5.2.3 Transmission electron microscopy (TEM)

S.I. 5.2.4 Circular dichroism (CD)

S.I. 5.2.5 Thioflavine T (ThT) binding assay

\section{S.I.5.3 pH responsive co-assembled system}

S.I. 5.3.1 Hydrogel formation at neutral $\mathrm{pH}$

S.I. 5.3.2 Kinetics release by ${ }^{1} \mathrm{H} N M R$

S.I. 5.3.3 Transmission electron microscopy (TEM)

S.I. 5.3.4 Cirular dichroism (CD)

S.I. 5.3.5 Rheological measurements

\section{S.I.5.4 Tunable release of loads by $\mathrm{pH}$ change}


S.I. 5.4.1 Methylene Blue (MB) and Bromothymol Blue (BTB) release

\section{S.I.5.1 Hydrogelation of basic tetrapeptides}

S.I. 5.1.1 Hydrogel formation using ammonia fumes

Different amounts of compound 7 and 8 were dissolved in $1 \mathrm{~mL}$ of $\mathrm{HCl} 0.1 \mathrm{M}$ inside cylindrical vials with internal diameter of $1.2 \mathrm{~cm}$ and $4.5 \mathrm{~cm}$ in length. Such opened vials were introduced into a closed glass container with ammonia solution on the bottom. The ammonia fumes were responsible to protonate the lysine residues and generate the gel as a result. The gel formation took around 2-4 $\mathrm{h}$ at room temperature. The tube inversion methodology was employed to determine the m.g.c.

\section{S.I. 5.1.2 Transmission electron microscopy (TEM)}

Gels of compounds $\mathbf{7}$ and $\mathbf{8}$ at their m.g.c. were prepared as previously described and directly placed onto Formvar carbon film on 200 mesh copper grids. TEM samples were prepared as previously described in S.I. 4.1.2.

\section{S.I. 5.1.3 Fourier Transform Infrared Spectroscopy (FTIR)}

Gels at their m.g.c. were lyophilised ( $24 \mathrm{~h}$ ) and the white fluffy solid obtained was mixed with $\mathrm{KBr}$ (200-300 mg). To generate the corresponding discs, the mixture was pressed at 10 ton for ca. 2-3 min. Then, FT-IR spectra were collected in a JASCO FTIR6200 spectrometer.

\section{S.I. 5.1.4 Circular dichroism (CD)}

Gels (m.g.c.) formed into glass vials as previously described in S.I. 5.1.1 were carefully transferred into $0.5 \mathrm{~mm}$ detachable quartz cell. Measurements were performed in a JASCO J-810 instrument, at room temperature and the spectra were recorded from 190 to $450 \mathrm{~nm}$ with $1.0 \mathrm{~nm}$ step, $1 \mathrm{~nm}$ bandwidth and 10 accumulations. Final spectra were the average of three measurements.

S.I. 5.1.5 Potentiometric titrations of basic tetrapeptides 
Potentiometric titrations to determine acidity constants were carried out using the same conditions described in Chapter 4 (S.I. 4.2.1). In this case aqueous solutions of tetrapeptides (7 and 8$)$ and $\mathrm{HCl}(60 \mathrm{mM})$ were titrated with $0.01 \mathrm{M}$ normalised solution of sodium hydroxide. Shorter stabilisation times (upon fibrillisation) were used in order to avoid benzyloxycarbonil deprotection.

\section{S.I.5.2 Co-assembly between acidic $(1,2)$ and basic $(7,8)$ tetrapeptides at} neutral pH

S.I. 5.2.1 Solubility of compounds $1,2,7$ and 8 in TRIS-HCl buffer ( ${ }^{1} \mathrm{H}$ NMR)

For each compound $10 \mathrm{mM}$ samples were prepared by using increasing concentrations of TRIS-HCl buffer (ranging from $100 \mathrm{mM}$ to $1 \mathrm{M}$ ). Solubility of the compounds in different TRIS- $\mathrm{HCl}$ concentration was determined by ${ }^{1} \mathrm{H} \mathrm{NMR}$ comparing the integral values of these samples with their corresponding blanks. Blanks at $10 \mathrm{mM}$ were prepared in $\mathrm{Na}_{2} \mathrm{CO}_{3} 0.1 \mathrm{M}$ and $\mathrm{HCl} 0.1 \mathrm{M}$ respectively for compounds $\mathbf{1 , 2}$ and 7, 8 . An internal standard of hydroquinone $5 \mathrm{mM}$ was used in order to normalise the integral values in both cases.

\section{S.I. 5.2.2 Determination of stoichiometry $\left({ }^{1} \mathrm{H} N M R\right)$}

For each possible mixture different NMR tubes were prepared containing a constant amount of basic tetrapeptides 7 or $8(250 \mu \mathrm{L} 2.5 \mathrm{mM})$ in TRIS-HCl $200 \mathrm{mM}$. Increasing concentrations of acidic tetrapeptides 1 or $2(0.5-4 \mathrm{mM})$ in an equivalent volume of TRIS- $\mathrm{HCl} 200 \mathrm{mM}(250 \mu \mathrm{L})$ were then injected in these tubes leading to aggregates or gels as a result. The amount of basic tetrapeptide in solution or aggregated form was determined by comparing the integral values of these samples with the corresponding blank. Blanks of compounds 7 and 8 at $1.25 \mathrm{mM}$ were prepared in TRIS-HCl $200 \mathrm{mM}$. Hydroquinone $5 \mathrm{mM}$ as internal standard was used to normalise the integral values. 


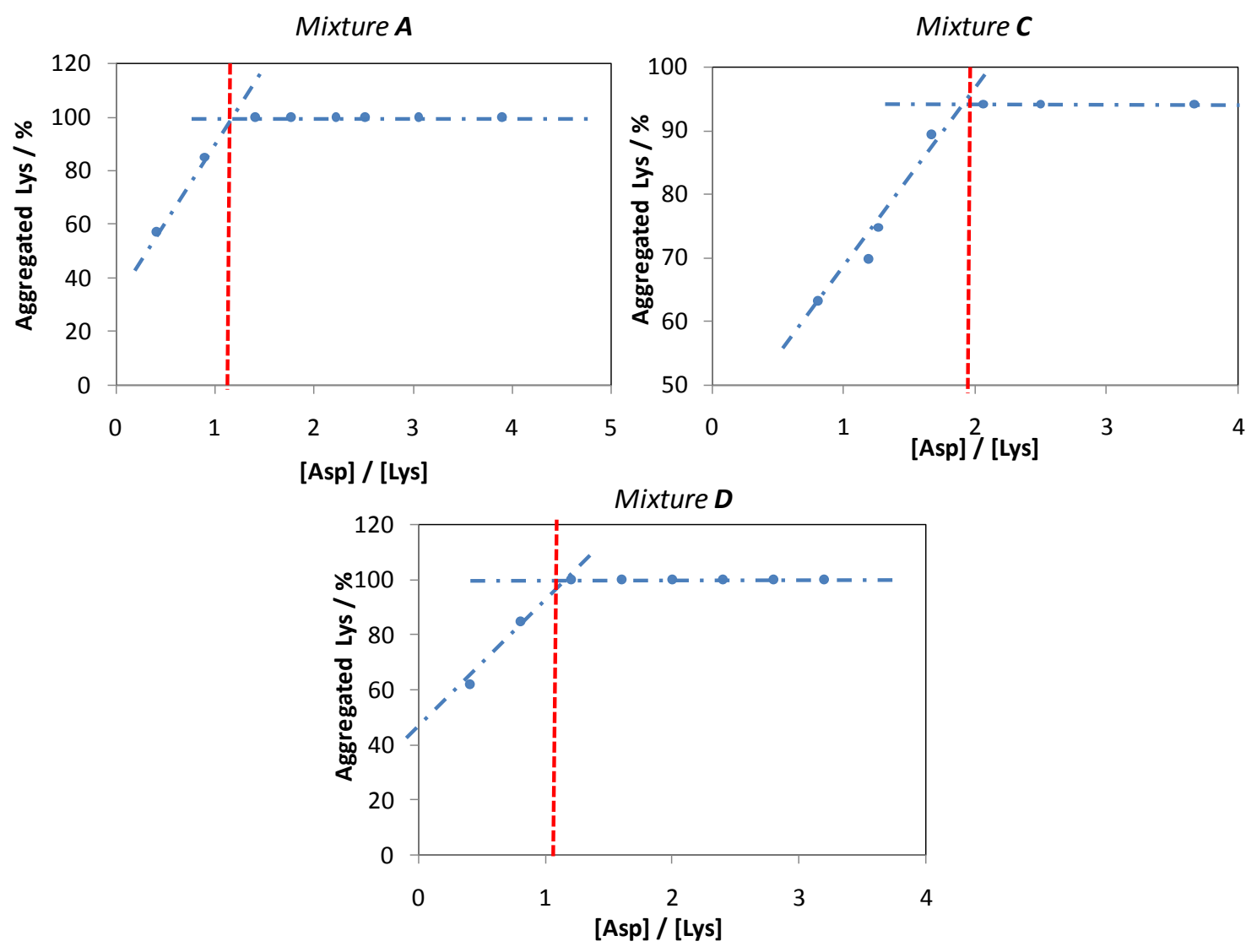

S.I. 5.2.2.1 Stoichiometry determination for co-assembled mixtures $\mathbf{A}, \mathbf{C}$ and $\mathbf{D}$ by ${ }^{1} \mathrm{H}$ NMR.

S.I. 5.2.3 Transmission electron microscopy (TEM)

Samples of the mixtures A-D at total concentrations of $2.5 \mathrm{mM}$ were prepared by injection methodology in TRIS-HCl buffer $200 \mathrm{mM}$. After $24 \mathrm{~h}$ of stabilization at room temperature gels were placed directly onto Formvar-carbon film on 200 mesh copper grids. TEM samples were prepared as previously described in S.I. 4.1.2. It is extremely important to remove the buffer salts by repeated washes with distillated water.

\section{S.I. 5.2.4 Circular dichroism (CD)}

Gels of mixtures A-D at $2.5 \mathrm{mM}$ (total concentration) were prepared directly into $1 \mathrm{~mm}$ quartz cell using the injection methodology mentioned above. After $24 \mathrm{~h}$ of stabilization at room temperature measurements were performed in a JASCO J-810 instrument and the spectra were recorded from 190 to $450 \mathrm{~nm}$ with $1.0 \mathrm{~nm}$ step, $1 \mathrm{~nm}$ band width and 3 accumulations. Final spectra were the average of three measurements. 
S.I. 5.2.5 Thioflavine T (ThT) binding assay

Gels of co-assembled mixtures A-D at total concentration of $2.5 \mathrm{mM}$ were prepared directly into $1 \mathrm{~cm}$ path length PMMA fluorescence cell (total volume $2 \mathrm{~mL}$ ). After $24 \mathrm{~h}$ at room temperature $20 \mu \mathrm{L}$ of a stock solution $0.5 \mathrm{mM}$ of ThT in TRIS-HCl were added and their fluorescence emission spectra were recorded at different times from 465 to $600 \mathrm{~nm}$ with excitation at $450 \mathrm{~nm}$. The final ThT concentration was set to $5 \mu \mathrm{M}$. Data reported correspond to $20 \mathrm{~min}$ after ThT addition.

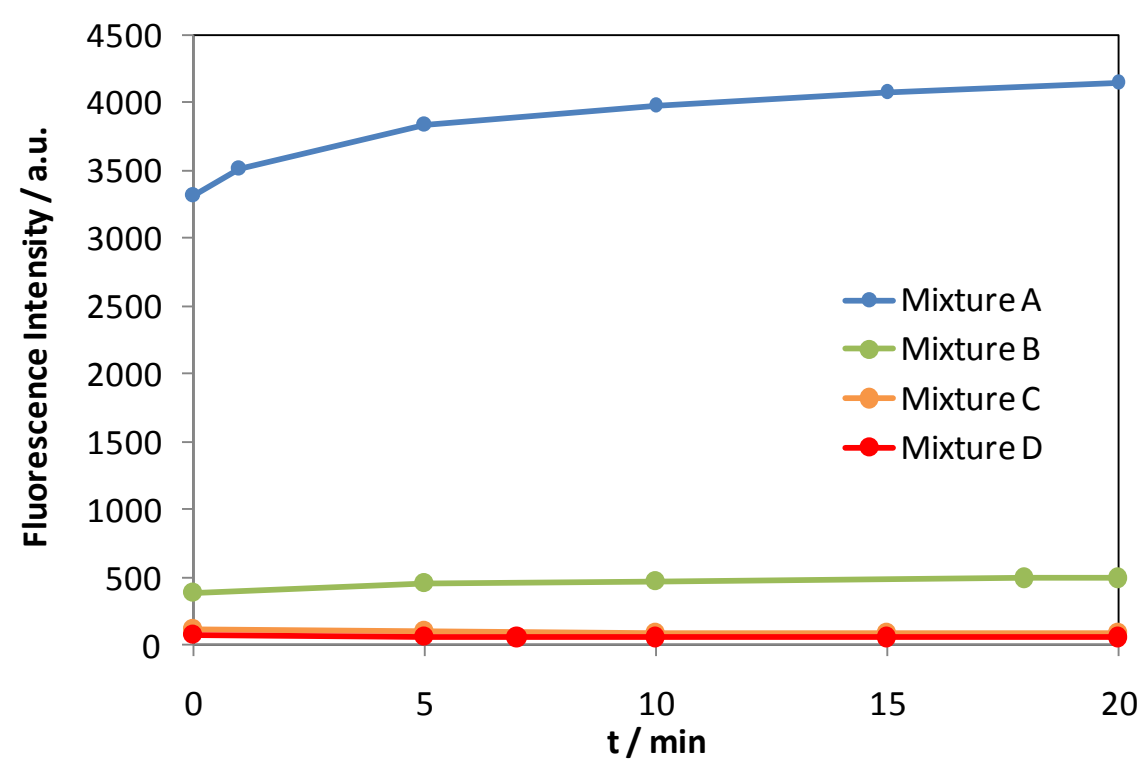

S.I. 5.2.5.1 ThT fluorescence emission over time for mixtures A-D. Total concentration of the mixture: 2.5 $\mathrm{mM}$. ThT concentration $5 \mu \mathrm{M}$.

\section{S.I. 5.3 pH responsive co-assembled system}

S.I. 5.3.1 Hydrogel formation at neutral $\mathrm{pH}$

Typically $0.5 \mathrm{~mL}$ of compound 1 at $5 \mathrm{mM}$ in $\mathrm{Na}_{2} \mathrm{CO}_{3}(10 \mathrm{mM})$ was added over 0.5 $\mathrm{mL}$ of compound 7 or compound 8 at $5 \mathrm{mM}$ in $\mathrm{HCl}(10 \mathrm{mM})$. The gel was formed immediately with a final $\mathrm{pH}$ value between 6.5 and 7. The addition of aqueous solution of $\mathrm{HCl}$ and $\mathrm{Na}_{2} \mathrm{CO}_{3}$ leaded to new hydrogels with $\mathrm{pH}$ values of 1.5 and 10.5 respectively. Gel formation was tested by the tube inversion methodology at room temperature using cylindrical screw capped vials with internal diameter of $1.2 \mathrm{~cm}$ and $4.5 \mathrm{~cm}$ in length. 
S.I. 5.3.2 Kinetics of release by ${ }^{1} \mathrm{H} N M R$

Two-component gel (1-7) was formed directly into the NMR tube as previously described in S.I.5.3.1 (total gel concentration $5 \mathrm{mM}$ ). After $24 \mathrm{~h}$ of stabilisation $50 \mu \mathrm{L}$ of $\mathrm{HCl} 0.1 \mathrm{M}$ or $50 \mu \mathrm{L}$ of $\mathrm{Na}_{2} \mathrm{CO}_{3}$ were added and allowed to diffuse. Solubilisation of compound 1 or 7 was monitored by ${ }^{1} \mathrm{H}$ NMR. Hydroquinone $5 \mathrm{mM}$ was used as standard to compare integral values with the blank samples. Blank samples of compounds $\mathbf{1}$ and $\mathbf{7}$ at $2.5 \mathrm{mM}$ were prepared using $\mathrm{Na}_{2} \mathrm{CO}_{3} 0.1 \mathrm{M}$ and $\mathrm{HCl} 0.1 \mathrm{M}$ respectively.

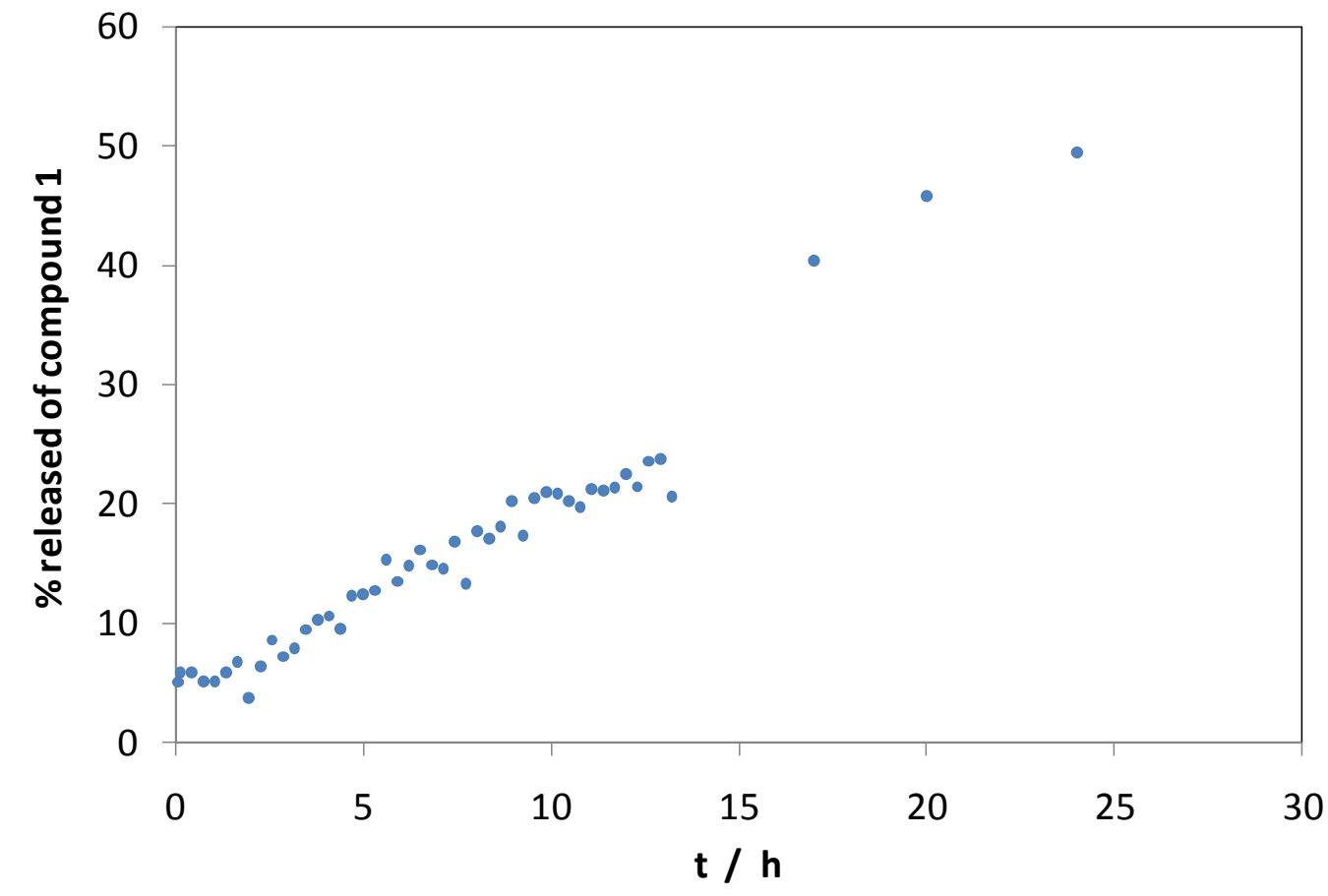

S.I. 5.3.2.1 Kinetics of release of deprotonated compound 1 after the addition of $\mathrm{Na}_{2} \mathrm{CO}_{3}$ to a twocomponent hydrogel 1-7 (5 mM each one) monitored by ${ }^{1} \mathrm{H}$ NMR. The gel was formed inside the NMR tube at a total concentration of $5 \mathrm{mM}$. After $24 \mathrm{~h}$ of stabilisation, $50 \mu \mathrm{L}$ of $\mathrm{Na}_{2} \mathrm{CO}_{3}$ were added.

S.I. 5.3.3 Transmission electron microscopy (TEM)

Two-component samples of 1-7 and 1-8 were prepared at $1 \mathrm{mM}$. The addition of $\mathrm{HCl}$ or $\mathrm{Na}_{2} \mathrm{CO}_{3}$ leads to the formation of acidic and basic aggregates of $\mathbf{1}$ and $\mathbf{7}$ or $\mathbf{8}$, respectively. After $4 \mathrm{~h}$ of stabilisation one drop of each sample was added onto Formvar carbon film on 200 mesh copper grids. TEM samples were prepared as previously described in S.I. 4.1.2.

\section{S.I. 5.3.4 Circular dichroism (CD)}

Co-assembled gels at $1 \mathrm{mM}$ of compounds 1-7 and 1-8 were prepared directly into a $1 \mathrm{~mm}$ quartz cell using the injection methodology (Final volume of co-aggregates 
$300 \mu \mathrm{L}$ ). To generate the acidic and basic aggregates of these mixtures $50 \mathrm{~mL}$ of $\mathrm{HCl}$ and $50 \mathrm{~mL}$ of $\mathrm{Na}_{2} \mathrm{CO}_{3}$ were added respectively and allowed to diffuse during $24 \mathrm{~h}$. After this time CD spectra were recorded as previously described in S.I. 5.2.4.

\section{S.I. 5.3.5 Rheological measurements}

Gels at a total concentration of $5 \mathrm{mM}$ were prepared using the injection methology previously described (total volume of the co-assembled gels $1.6 \mathrm{~mL}$ ). After 24 $\mathrm{h}$ of stabilisation the corresponding amount of supernatant was added $(800 \mu \mathrm{L}$ of $\mathrm{HCl} 0.1$ $\mathrm{M}$ or $800 \mu \mathrm{L}$ of $\mathrm{Na}_{2} \mathrm{CO}_{3} 0.1 \mathrm{M}$ ) and let to diffuse during $24 \mathrm{~h}$. The aqueous supernatant was removed before rheological measurements.

Rheological measurements were carried out on a TA AR-1000-N rheometer using an aluminium parallel plate-to-plate geometry ( $25 \mathrm{~mm}$ diameter). The gap distance was fixed at $1000 \mu \mathrm{m}$. The gels were prepared under the desired conditions and aged for $24 \mathrm{~h}$. A homogeneous layer of gel was placed between the two plates.

Frequency and stress sweep steps were performed at $23^{\circ} \mathrm{C}$. Viscoelastic properties were studied under oscillatory experiments. All the measurements were carried out within the linear viscoelastic regime. For this purpose the experimental conditions to achieve a linear viscoelastic regime (LVR) were determined by running a stress sweep step (oscillatory stress $0.1-500 \mathrm{~Pa}$ at $1 \mathrm{~Hz}$ ) and a frequency sweep step (0.1$100 \mathrm{~Hz}$ at $1 \mathrm{~Pa}$ ). The storage and loss modulus independence with frequency and oscillatory stress applied defined the LVR. For the stress sweep step the G' and G" values were constant up to the yield stress point (gel break). 

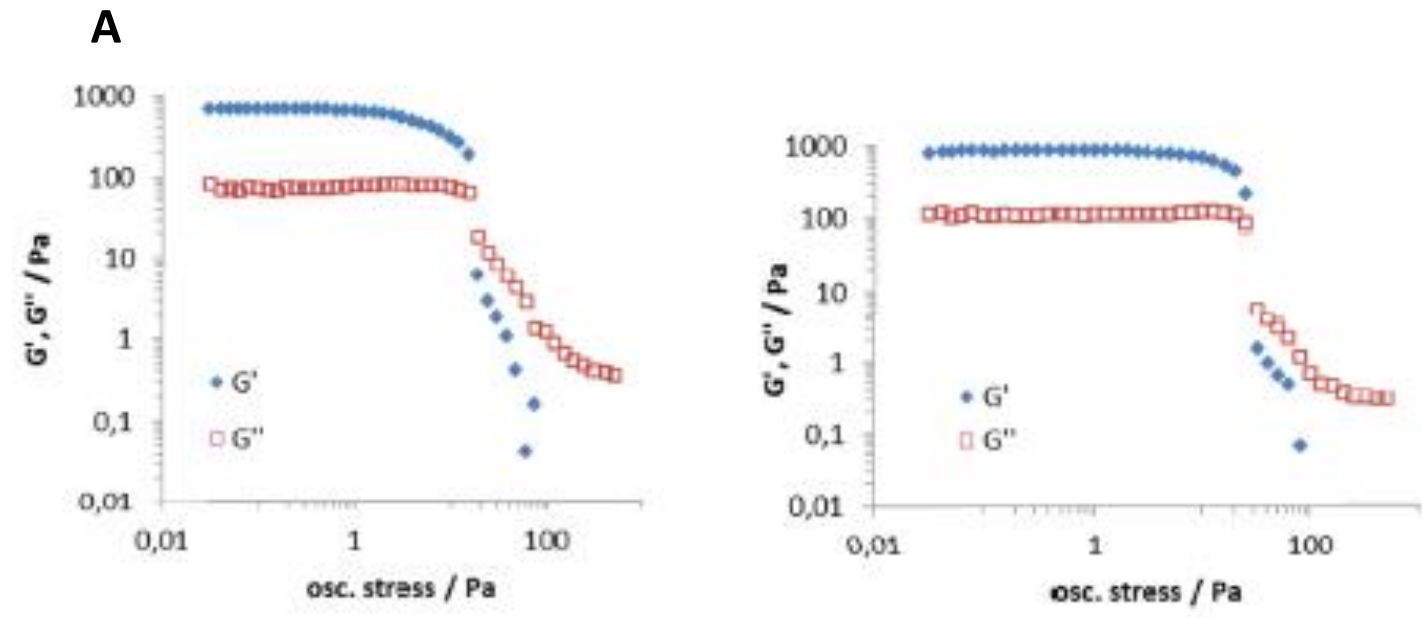

\section{B}
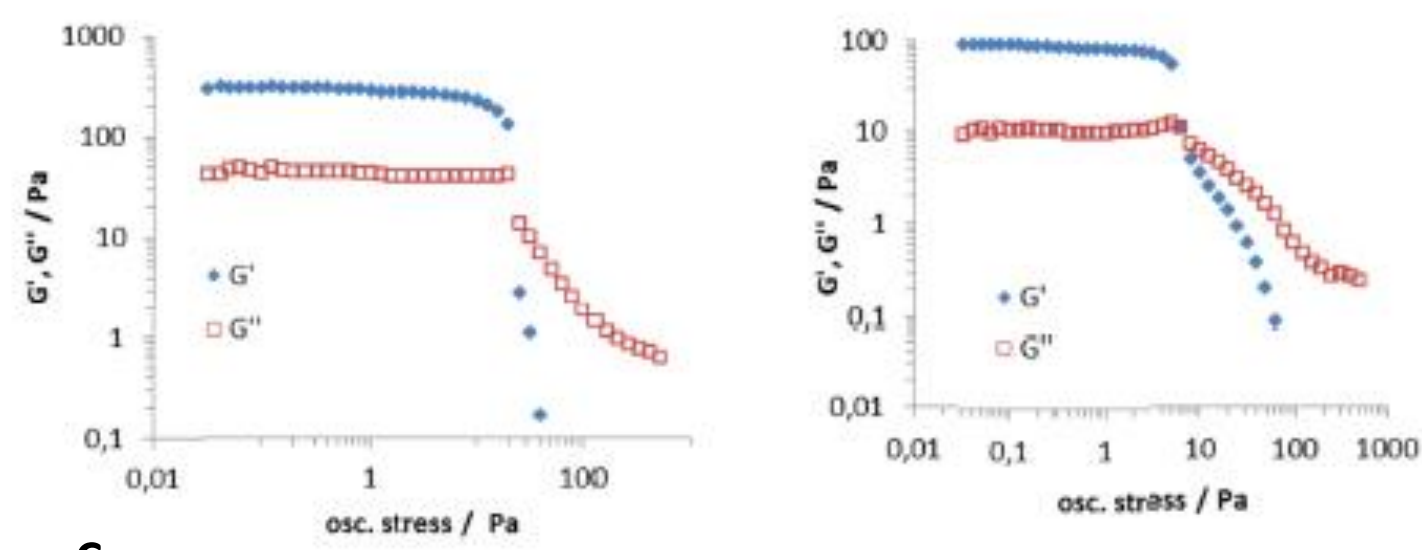

\section{C}
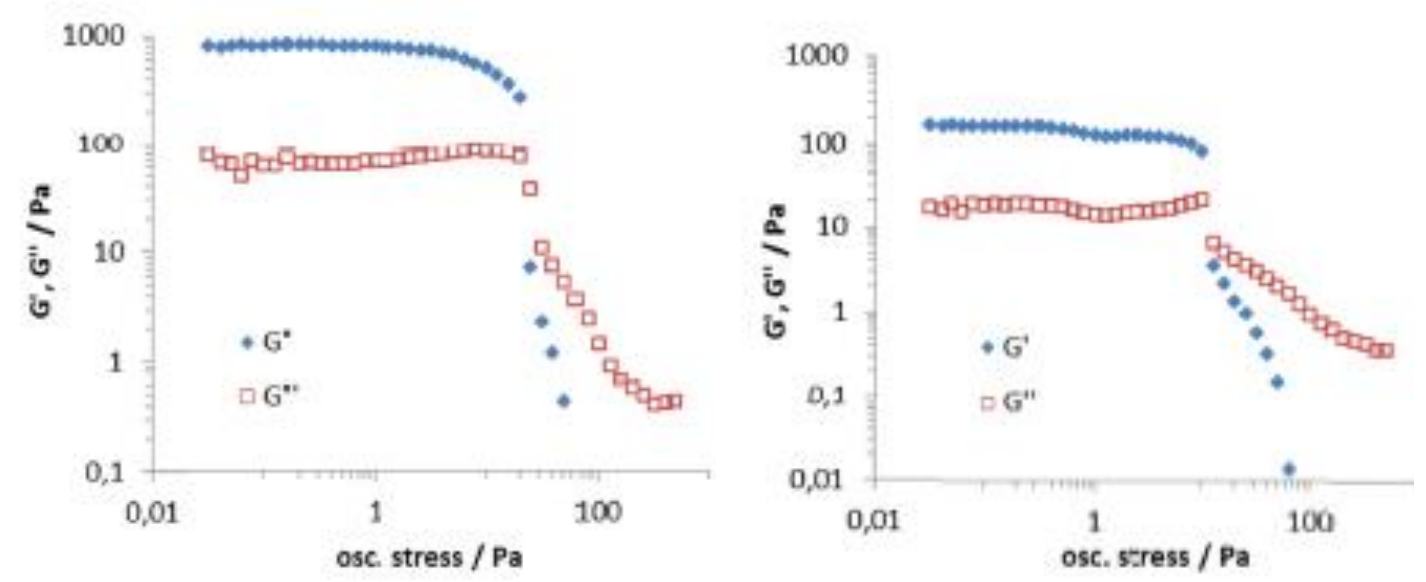

S.I. 5.3.5.1 Stress sweep at $1 \mathrm{~Hz}$ for samples of co-aggregates 1-7 (left) and 1-8 (right) at A) neutral, B) acidic and $\mathrm{C}$ ) basic $\mathrm{pH}$. 


\section{S.I.5.4 Tunable release of loads by $\mathrm{pH}$ change}

S.I. 5.4.1 Bromothymol Blue (BTB) and Methylene Blue (MB) release Co-assembled gels containing $\mathrm{MB}(25 \mu \mathrm{M})$ or BTB $(32 \mu \mathrm{M})$ at neutral $\mathrm{pH}$ were prepared at a total concentration of $5 \mathrm{mM}$. After $24 \mathrm{~h}$ of stabilisation a solution of the required $\mathrm{pH}$ was added on top of the gel, namely $1 \mathrm{~mL}$ of water, $1 \mathrm{~mL}$ of $\mathrm{HCl} 0.1 \mathrm{M}$ or 1 $\mathrm{mL}$ of $\mathrm{Na}_{2} \mathrm{CO}_{3}$. The release of dye was monitored in situ following the absorbance of the supernatant at $\lambda=624$ for the MB and $\lambda=435 \mathrm{~nm}$ for acidic $\mathrm{pH}$ and water and at $\lambda=$ $616 \mathrm{~nm}$ for basic $\mathrm{pH}$ in the case of BTB. Blanks in water, basic and acidic $\mathrm{pH}$ containing $\mathrm{MB}$ or $\mathrm{BTB}$ at the same concentrations were prepared in order to normalize the percentage of release.

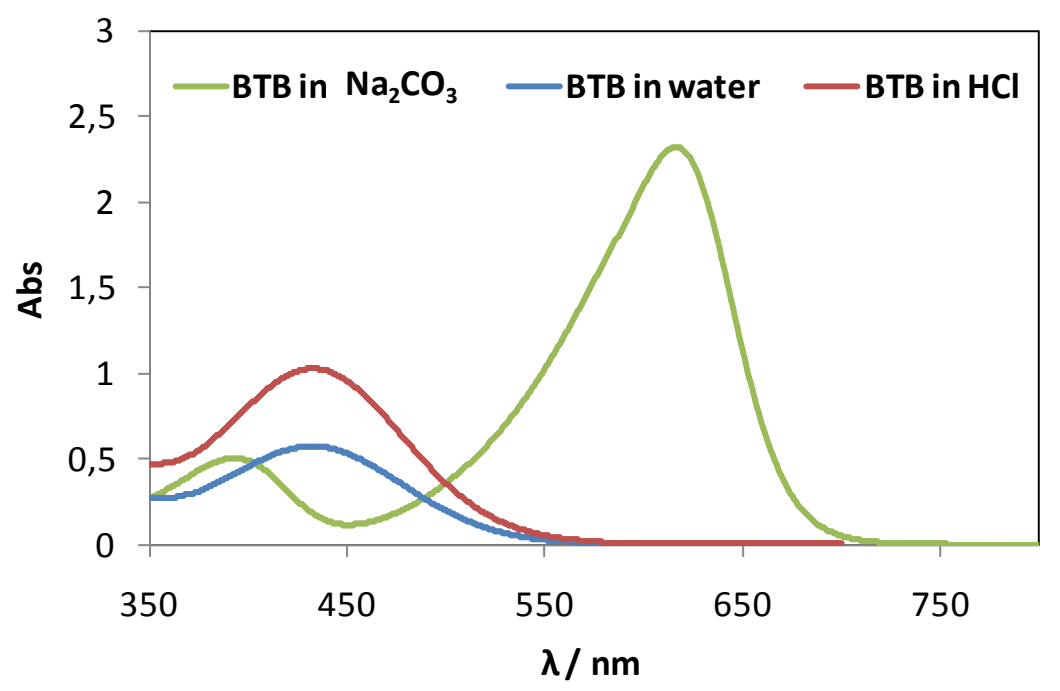

S.I. 5.4.1.1 Absorbance spectra of blank solutions of Bromothymol Blue $(32 \mu \mathrm{m})$ at different pH. $32 \mu \mathrm{M}$ of BTB in water, $0.1 \mathrm{M} \mathrm{HCl}$ and $0.1 \mathrm{M}$ of $\mathrm{Na}_{2} \mathrm{CO}_{3}$. 

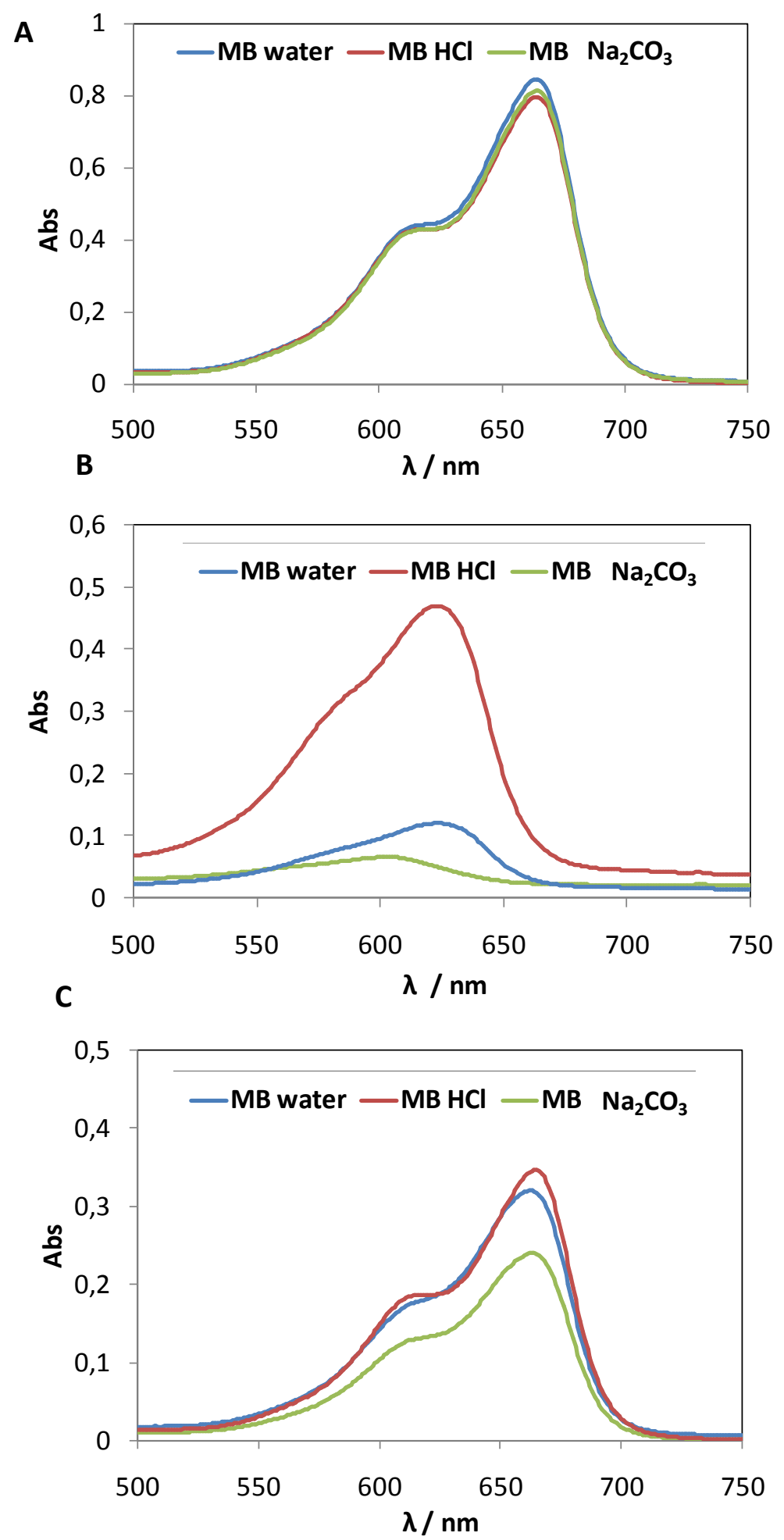

S.I. 5.4.1.2 A) Absorbance spectra of blank solutions of methylene blue $(25 \mu \mathrm{m})$ at different $\mathrm{pH}$. B) Absorbance spectra of supernatants of hydrogels 1-7 at different $\mathrm{pH}$. C) Absorbance spectra of supernatants of hydrogels 1-8 at different $\mathrm{pH}$ (water, $0.1 \mathrm{M} \mathrm{HCl}$ and $0.1 \mathrm{M} \mathrm{of} \mathrm{Na}_{2} \mathrm{CO}_{3}$ ). 


\subsection{References}

1. a) Hamley, I. W.; Dehsorkhi, A.; Castelletto, V., Co-assembly in binary mixtures of peptide amphiphiles containing oppositely charged residues. Langmuir 2013, 29, 5050-5059; b) Xu, X.-D.; Chen, C.-S.; Lu, B.; Cheng, S.-X.; Zhang, X.-Z.; Zhuo, R.-X., Co-assembly of oppositely charged short peptides into well-defined supramolecular hydrogels. J. Phys. Chem. B 2010, 114, 2365-2372; c) Behanna, H. A.; Donners, J.; Gordon, A. C.; Stupp, S. I., Co-assembly of amphiphiles with opposite peptide polarities into nanofibers. J. Am. Chem. Soc. 2005, 127, 11931200; d) Ramachandran, S.; Taraban, M. B.; Trewhella, J.; Gryczynski, I.; Gryczynski, Z.; Yu, Y. B., Effect of Temperature during assembly on the structure and mechanical properties of peptide-based materials. Biomacromolecules 2010, $11,1502-1506$.

2. Miravet, J. F.; Escuder, B., Pyridine-functionalised ambidextrous gelators: towards catalytic gels. Chem. Commun. 2005, 5796-5798.

3. Nebot, V. J.; Smith, D. K., Chapter 2: Techniques for the characterisation of molecular gels. Functional Molecular Gels, RSC 2014.

4. Barth, A., Infrared spectroscopy of proteins. BBA-Bionergetics 2007, 1767, 10731101.

5. a) Cinar, G.; Ceylan, H.; Urel, M.; Erkal, T. S.; Deniz Tekin, E.; Tekinay, A. B.; Dâna, A.; Guler, M. O., Amyloid inspired self-assembled peptide nanofibers. Biomacromolecules 2012, 13, 3377-3387; b) Pashuck, E. T.; Cui, H.; Stupp, S. I., Tuning supramolecular rigidity of peptide fibers through molecular structure. $J$. Am. Chem. Soc. 2010, 132, 6041-6046.

6. a) Lo Nostro, P.; Ninham, B. W., Hofmeister Phenomena: An Update on Ion Specificity in Biology. Chem. Rev. 2012, 112, 2286-2322; b) Nostro, P. L.; Nostro, A. L.; Ninham, B. W.; Pesavento, G.; Fratoni, L.; Baglioni, P., Hofmeister specific ion effects in two biological systems. Curr. Opin. Colloid Interface Sci. 2004, 9, 97101; c) Kunz, W.; Lo Nostro, P.; Ninham, B. W., The present state of affairs with Hofmeister effects. Curr. Opin. Colloid Interface Sci. 2004, 9, 1-18.

7. Niece, K. L.; Hartgerink, J. D.; Donners, J.; Stupp, S. I., Self-assembly combining two bioactive peptide-amphiphile molecules into nanofibers by electrostatic attraction. J. Am. Chem. Soc. 2003, 125, 7146-7147.

8. a) Ramachandran, S.; Tseng, Y.; Yu, Y. B., Repeated rapid shear-responsiveness of peptide hydrogels with tunable shear modulus. Biomacromolecules 2005, 6, 1316-1321; b) Ramachandran, S.; Flynn, P.; Tseng, Y.; Yu, Y. B., Electrostatically controlled hydrogelation of oligopeptides and protein entrapment. Chem. Mater. 2005, 17, 6583-6588.

9. Berova, N.; Nakanishi, K.; Woody, R., Circular dichroism: principles and applications, John Wiley \& Sons 2000. 
10. Anand, U.; Mukherjee, M., Exploring the self-assembly of a short aromatic $A$ $\beta(16-24)$ peptide. Langmuir 2013, 29, 2713-2721.

11. Robbins, K. J.; Liu, G.; Selmani, V.; Lazo, N. D., Conformational analysis of Thioflavin T bound to the surface of amyloid fibrils. Langmuir 2012, 28, 1649016495.

12. a) Howe, E. J.; Okesola, B. O.; Smith, D. K., Self-assembled sorbitol-derived supramolecular hydrogels for the controlled encapsulation and release of active pharmaceutical ingredients. Chem. Commun. 2015, 51, 7451-7454; b) Friggeri, A.; Feringa, B. L.; van Esch, J., Entrapment and release of quinoline derivatives using a hydrogel of a low molecular weight gelator. J. Control. Release 2004, 97, 241248; c) Baral, A.; Roy, S.; Dehsorkhi, A.; Hamley, I. W.; Mohapatra, S.; Ghosh, S.; Banerjee, A., Assembly of an Injectable noncytotoxic peptide-based hydrogelator for sustained release of drugs. Langmuir 2014, 30, 929-936. 


\section{AMPHIPHILIC PEPTIDES CONTAINING L-PROLINE (P) \\ CHAPTER 6 \\ \begin{tabular}{l} 
L-PROLINE (P) \\
\hline
\end{tabular}

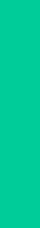 \\ L-PROLINE (P)
AMPHIPHILIC PEPTIDES CONTAINING \\ AINING \\ \begin{tabular}{l} 
L-PROLINE (P) \\
\hline
\end{tabular}

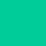 )

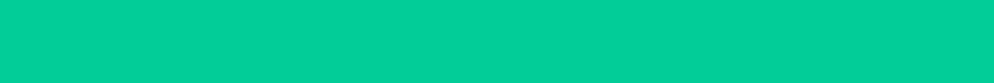 \\ $x^{-2}$

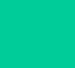

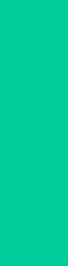

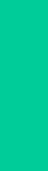

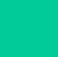





\section{CHAPTER 6}

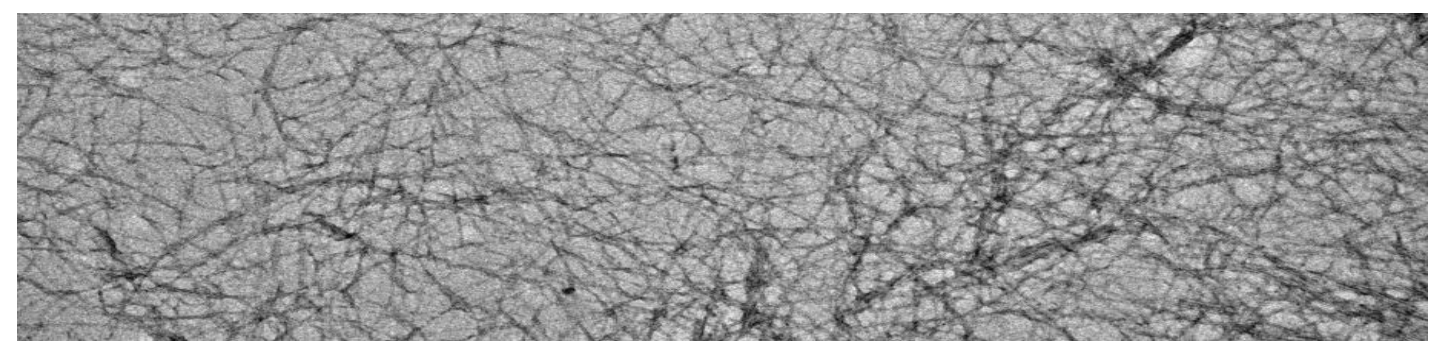

\section{Amphiphilic peptides containing L-proline (P)}

In this chapter the aggregation ability of amphiphilic tripeptides containg $P$ will be studied in buffered water and the catalytic behaviour of the assemblies will be tested in direct aldol reactions. A set of experiments will be additionally designed in order to rationalise the catalytic activity with the structural arrangements of the corresponding aggregates. Finally carbohydrate derivatives will be also synthesized using this same approach as an example of biomimetic systems.

The work presented in this chapter have been developed in collaboration with Prof. G. Ashkenasy group of the Ben Gurion University in Israel 



\section{AMPHIPHILIC PEPTIDES CONTAINING L-PROLINE (P)}

\subsection{Introduction}

Catalysis is probably one of the main goals of Supramolecular Chemistry and has attracted the attention of many researchers giving rise to a growing number of publications in last decade. ${ }^{1}$ The emergence of new functional properties after noncovalent self-assembly is the key point that scientists explore to create new complex supramolecular systems. ${ }^{2}$ In this sense, after self-assembly of building blocks containing catalytic functional fragments, different supramolecular structures (such as nanotubes, vesicles, micelles or fibres) with built-in catalytic sites can be obtained (Figure 6.1). This precise organisation of such multiple catalytic fragments could result in synergistic features including multivalent interactions, neighbouring effects or cooperativity among others.
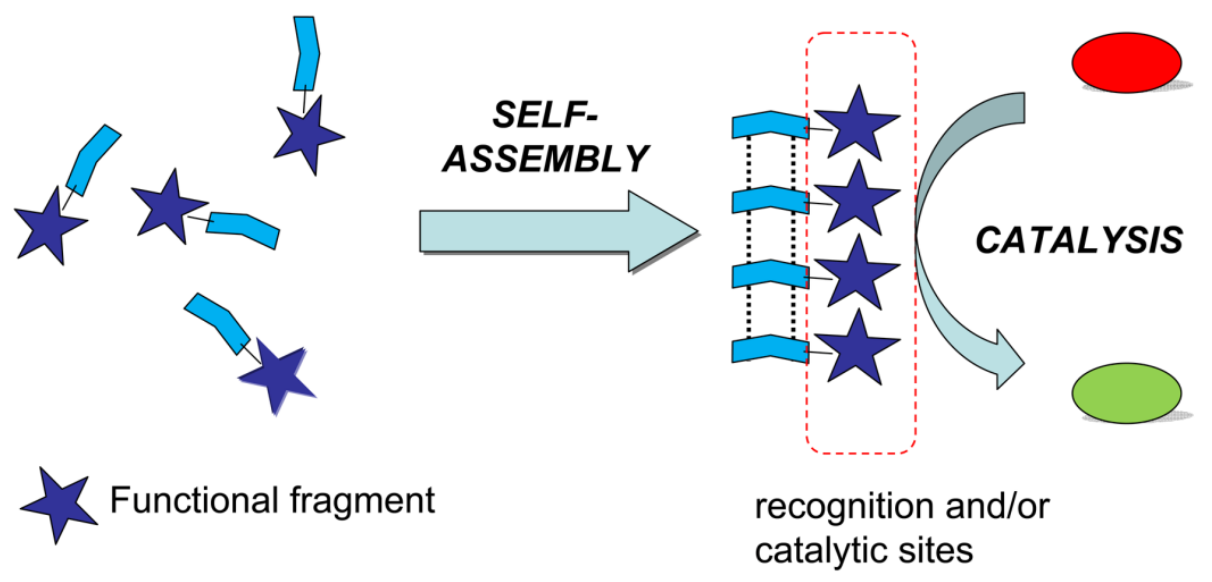

Figure 6.1 Schematic representation of building blocks self-assembly containing catalytic fragments.

The non-covalent nature of the interactions responsible of the self-assembly process endows these systems with appealing features including reversibility and stimuli responsive behaviour. ${ }^{3}$ This means that catalytic properties can be easily switched on and off going from solution to aggregate state and vice-versa by simple stimuli when a convenient trigger has been included in the molecular design. Besides, the complexity of self-assembled catalytic systems can be increased by combining molecules with different functionalities and playing with different non-covalent interactions. 
The main part of the work developed so far in supramolecular catalytic systems has been inspired by nature trying to mimic the efficiency and selectivity of the most powerful catalysts, the enzymes. ${ }^{1 b, 4}$ Although most synthetic models are smaller and structurally simpler than enzymes they can be used to estimate the relative importance of different factors that contribute to the catalysis. Small peptides for instance, are widely employed in asymmetric catalysis ${ }^{5}$ since they consist of the same building blocks as natural enzymes but have low molecular weight and are then easy to synthesise and modify. Moreover, peptide self-assembly is a process that emulates protein hierarchical structural organization (Figure 6.2).

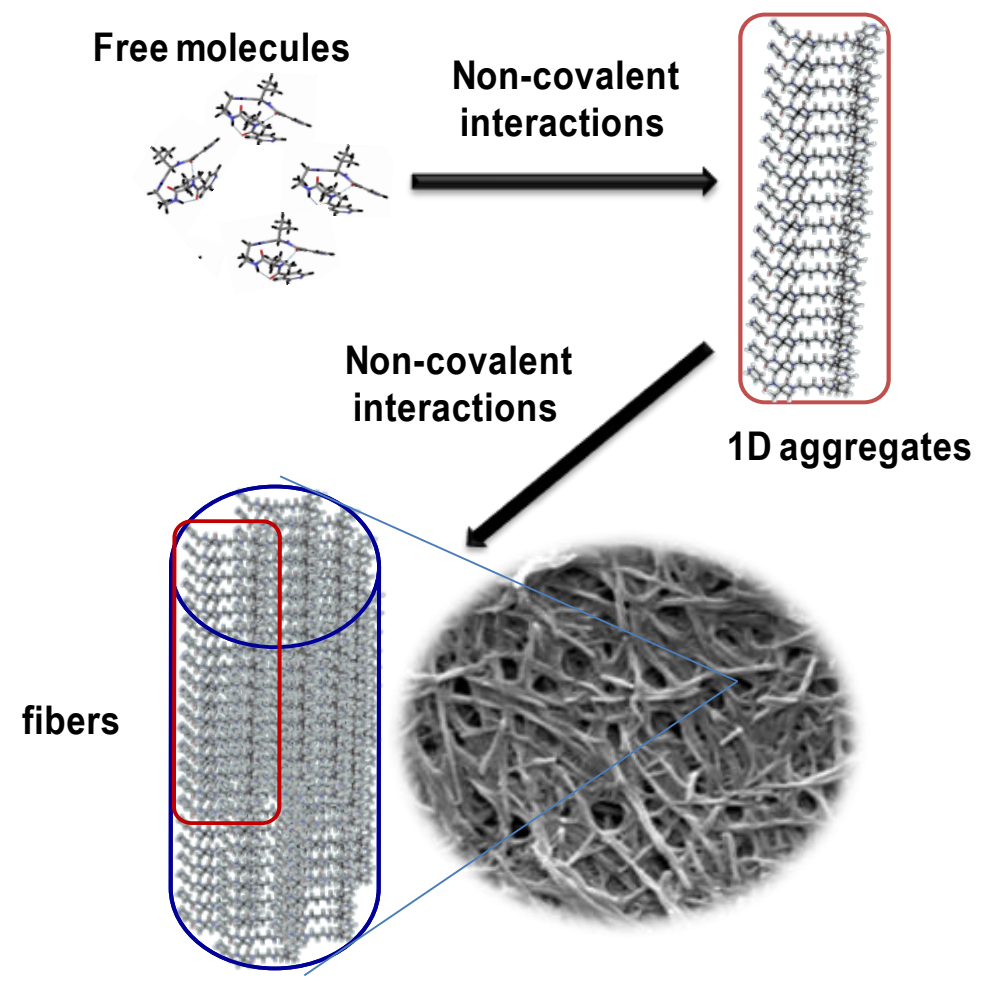

Figure 6.2 Hierarchical supramolecular organization of peptide-based self-assembled hydrogels. Free peptide molecules are self-assembled into 1D-aggregates which then form fibrils that finally cross-link to form a gel.

Amino acid side chains of peptides contain many different functional fragments that can get involved into the catalytic process either directly or as ligands for catalytically active metal ions. Among all of them, proline has been proved to be an excellent selective catalyst for direct aldol reactions as reported in seminal works of Barbas, List, MacMillan or Córdova. ${ }^{6}$ The combination of proline properties with selfassembled fragments has allowed our group to design efficient catalytic gels in which an 
enhancement of basicity was observed upon the self-assembly due to the cooperation of neighbouring proline moieties. ${ }^{7}$

However, unlike enzymes, the vast majority of the developed peptidic catalysts perform best in organic solvents. The replacement of organic solvents by water is a highly convenient strategy for environmental, safety and economic reasons but also because water is the biological solvent and as a consequence the hydrophobic effect plays a relevant role in biocatalysis. ${ }^{8}$ For instance, in the case of aldolase type I enzyme the reaction occurs in a hydrophobic site which means that diminishing contacts between bulk water and reactants may be critical for high enantioselectivities. Having in mind this consideration and trying to mimic natural enzymes, pioneering works by Barbas $^{9}$ and Hayashi ${ }^{10}$ demonstrated that providing a small organic catalyst, such as proline, with appropriate hydrophobic groups it is possible to create hydrophobic pockets that shield the organic substrates and the catalyst from the aqueous media creating a hydrophobic microenvironment in a similar way to enzymes.

The addition of such hydrophobic residues to proline moiety usually results in heterogeneous catalytic systems such as emulsions ${ }^{11}$ or gels. Our group has been especially interested in this last topic reporting interesting results in this regard previously discussed in Chapter $1 .{ }^{12}$ The use of a supramolecular gel as reaction media endow the catalytic system with additional remarkable features since the gels can behave as self-supported catalyst and can be regenerated and recycled allowing for the complete recovery of catalytic performance.

The catalytic activity of such self-assembled peptides is usually tested in benchmark aldol reactions however, taking nature as inspiration aldol reaction can be also used to generate biologically relevant products such as carbohydrate derivatives. ${ }^{6 c}$ In particular aldolases type I function via enamine mechanism in which a lysine residue of the enzyme reacts with dihydroxyacetone phosphate, DAHP (the donor component) to generate an enamine intermediate which reacts with $C_{2}$ or $C_{3}$ aldehydes, leading to either tetroses or pentoses, respectively. In this context, the relevance of organocatalysis in water, and in particular proline catalysis, for the pre-biotic origin of carbohydrates has been highlighted by several authors. ${ }^{13}$ 
Following previous work in catalytic supramolecular hydrogels ${ }^{12}$ a new family of amphipathic peptides containing proline $(P)$ as a functional fragment will be tested in the direct aldol reaction. Their solubility in water as well the formation of gels and aggregates will be pointed out as an important feature for an efficient catalytic process. Finally the emergence of catalytic activity after the self-assembly will be used for the formation of biologically relevant metabolites.

The new family of amphiphilic peptides studied here (Figure 6.3) consists of a set of tripeptides equipped with proline $(P)$ and an alternated sequence of phenylalanine $(F)$ and glutamic acid (E). It is expected that the presence of this alternated sequence would promote the assembly of the peptides into $\beta$-sheet structures ${ }^{14}$ and would create extended non-polar aromatic regions able to bind hydrophobic guests as previously described in Chapters 4 and $5 .{ }^{15}$ As can be seen, two different alternated sequences have been chosen in which either $\mathrm{F}$ or $\mathrm{E}$ is located near proline in order to test possible differences on the catalytic activity. Finally an additional aliphatic chain at the Cterminus will modulate their solubility in water and will finally contribute to selfassembly.

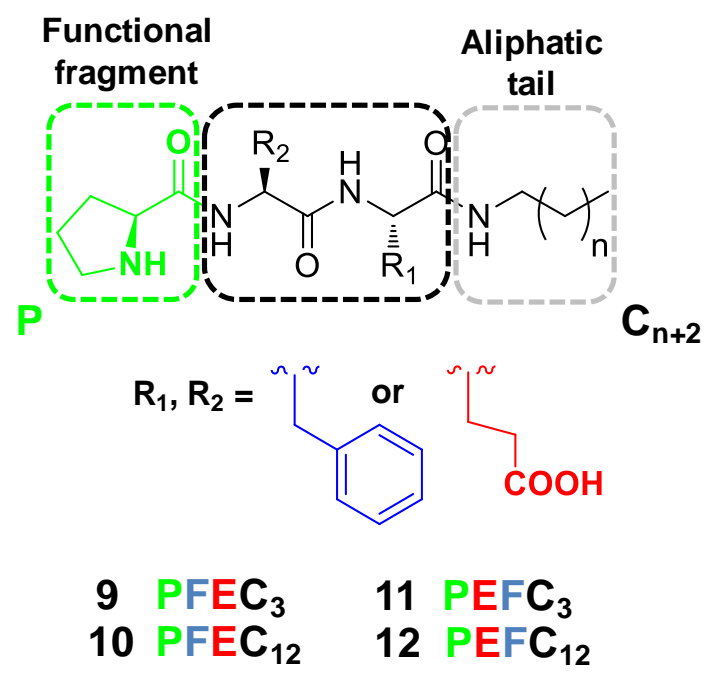

Figure 6.3 General structure for amphiphilic tripeptides (9-12) containing F, E and P.

Additionally two decapeptides provided by Prof. Ashkenasy and co-workers (Ben Gurion University, IL) (Figure 6.4) which contain the same alternating sequences will also be included in the present study in order to check the effect of the extension of the peptide chain. 


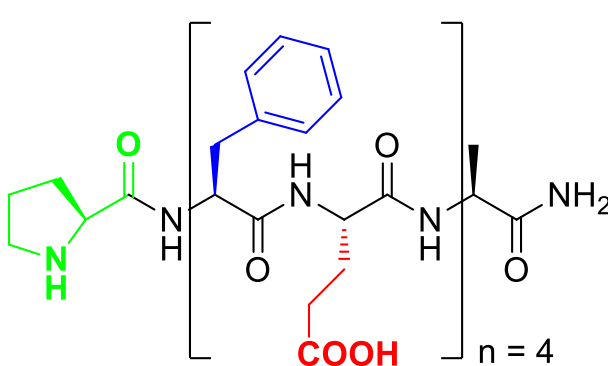

$27 \mathrm{P}(\mathrm{FE})_{4} \mathrm{ANH}_{2}$

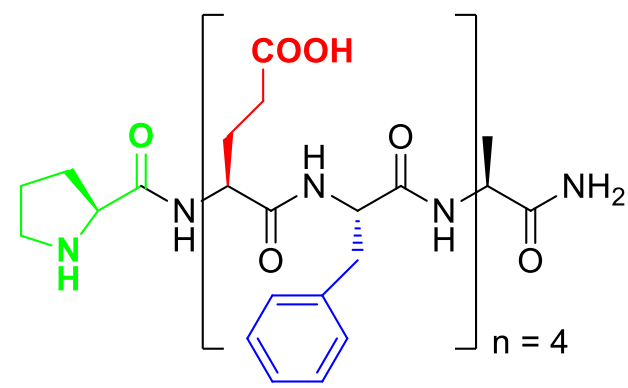

$28 \mathrm{P}(\mathrm{EF})_{4} \mathrm{ANH}_{2}$

Figure 6.4 Chemical structure for amphiphathic decapeptides ( 27 and $\mathbf{2 8}$ ) containing F, E and P.

\subsection{Self-assembly of proline derivatives in phosphate buffer}

As described in chapter 3, compounds $\mathbf{9 - 1 2}$ were synthesized as TFA salts and as a consequence they are highly soluble in water leading to a final acidic $\mathrm{pH}$ not convenient at all for proline catalysis since the catalytic residue would be protonated. In order to skip this problem and trying to avoid acidic or basic general catalysis a neutral $\mathrm{pH}$ media was finally set as the best option as previously reported by Janda ${ }^{16}$ and Clarke. ${ }^{17}$ Besides, the use of buffered media at neutral $\mathrm{pH}$ should be a prerequisite for biomimetic conditions. Having in mind these considerations catalytic reactions and aggregation studies were performed in phosphate buffer (PB) at neutral pH. Additionally phosphate is considered a kosmotropic ion and it will reduce the solubility of the compounds promoting therefore the self-assembly.
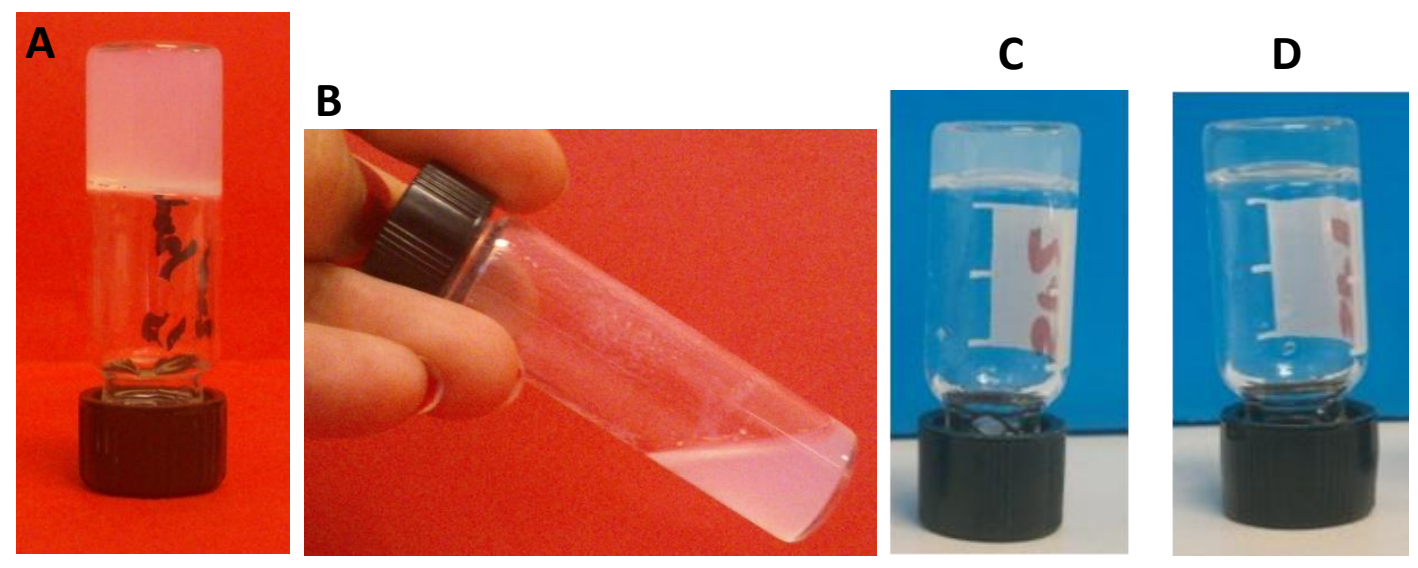

Figure 6.5 Macroscopic aspect of aggregates of compound 10 (A, $1.5 \mathrm{mM}), 12(B, 1.5 \mathrm{mM}), 27(\mathrm{C}, 7.5 \mathrm{mM})$ and $28(D, 7.5 \mathrm{mM})$.

Compounds 9 and $\mathbf{1 1}$, which have the shortest aliphatic chain, were soluble under catalytic conditions ( $\mathrm{PB} 0.1 \mathrm{M}, \mathrm{pH}=7$ ) at least in a concentration range from 1 to 
$25 \mathrm{mg} / \mathrm{mL}$. Conversely compounds $\mathbf{1 0}$ and $\mathbf{1 2}$ were highly insoluble in such conditions (not detectable by ${ }^{1} \mathrm{H}$ NMR) and formed aggregates at very low concentrations $(<0.1$ $\mathrm{mg} / \mathrm{mL}$ ). Compound $\mathbf{1 0}$ is able to percolate the solvent at $1.5 \mathrm{mM}$ after the traditional heating-cooling methodology for gel formation (Figure 6.5) whereas compound 12 lead to a milky suspension unable to form gels (at least for concentration $<20 \mathrm{mM}$ ). On the other hand the self-assembly of compounds $\mathbf{2 7}$ and $\mathbf{2 8}$ was also studied in similar conditions $(0.5 \mathrm{M} \mathrm{PB}, \mathrm{pH}=7)$ and both of them were shown to form hydrogels at concentration of $7.5 \mathrm{mM}$. These results indicate that the replacement of the alkyl fragment by an amide at the C-terminus has a noteworthy influence on the solubility and the m.g.c. as it is evidenced by comparing compounds $\mathbf{1 0}$ and $\mathbf{1 2}$ vs $\mathbf{2 7}$ and 28 .
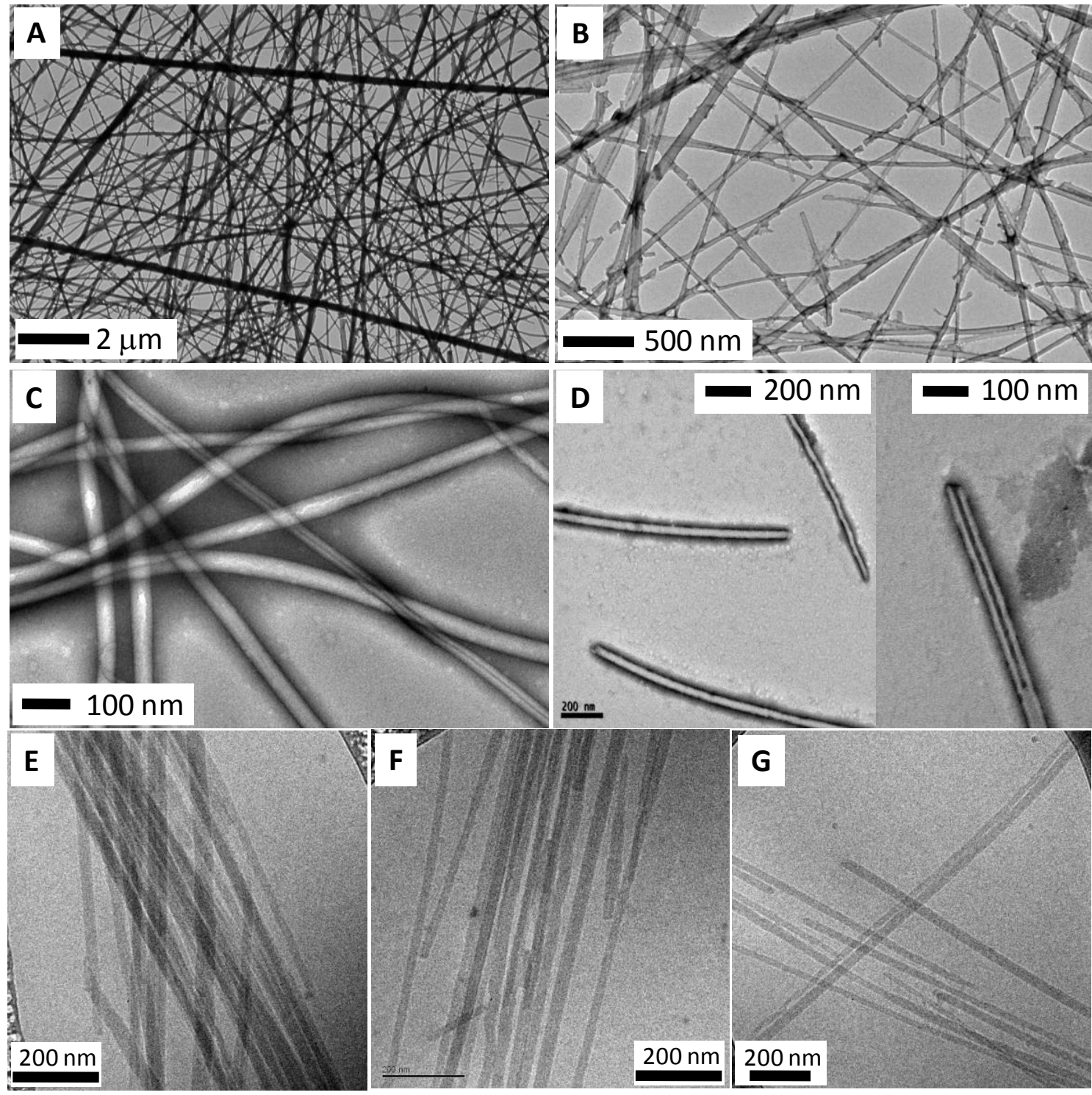

Figure 6.6 TEM (A-D, $1.5 \mathrm{mM})$ and cryo-TEM (E-G, 0.6 mM) images of aggregates formed by compound 10. 
The morphology of the networks was studied by electron microscopy using TEM and cryo-TEM (S.I. 6.1.1). Both techniques were in agreement and revealed that hydrogel of compound $\mathbf{1 0}$ was formed by long rigid tubes of ca. $30 \mathrm{~nm}$ in diameter (Figure 6.6). Aggregates of compound 12 showed a mesh of left-handed helical fibers of 50-70 nm in width with a pitch of ca. $80 \mathrm{~nm}$. Looking at the images it is remarkable the influence of the peptide sequence in the microscopic aspect of the aggregates of these two isomeric compounds.

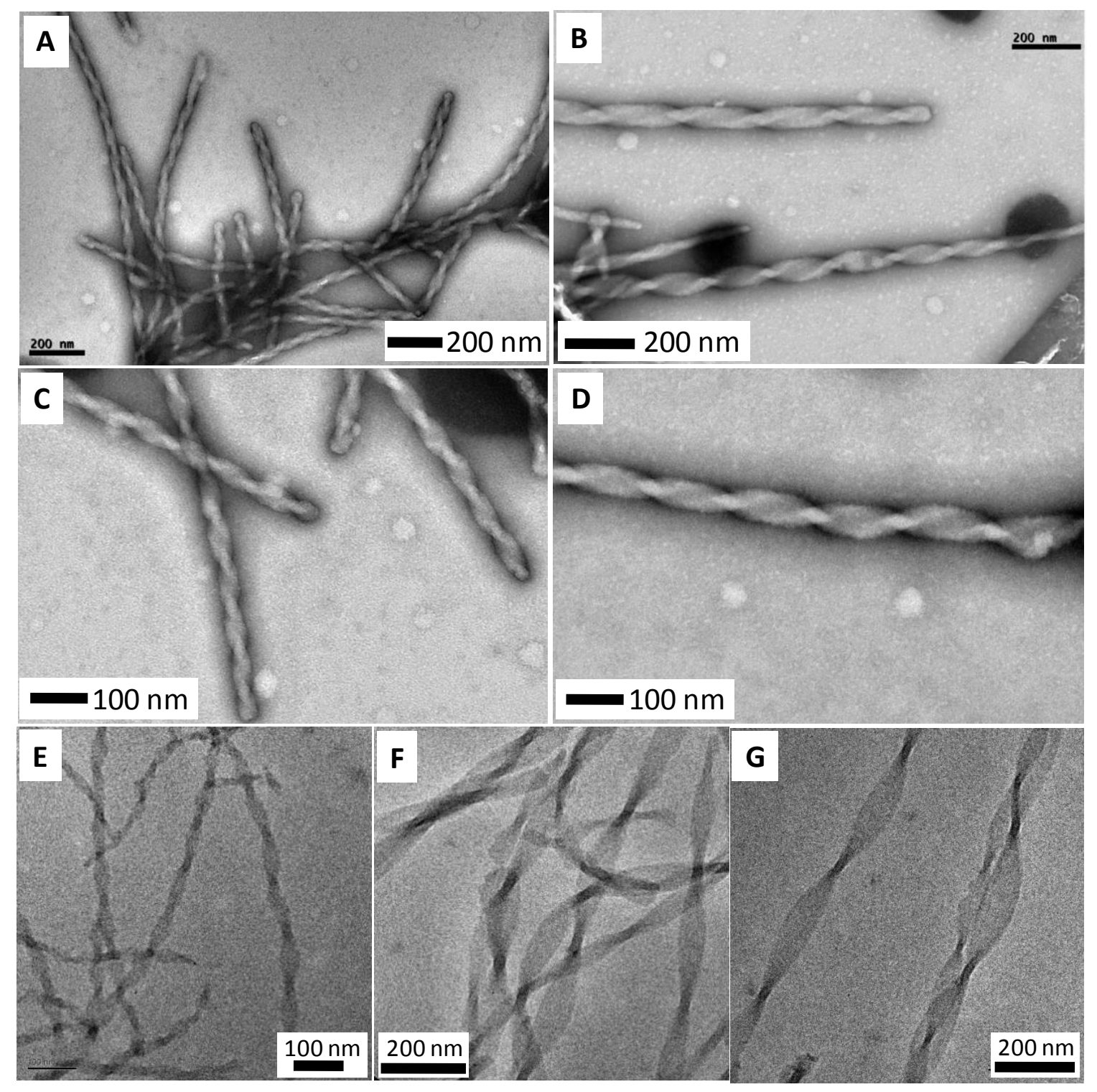

Figure 6.7 TEM (A-D, 1.5 mM) and cryo-TEM (E-G, 0.6 mM) images of aggregates formed by compound 12.

On the other hand, cryo-TEM images of compound $\mathbf{2 7}$ showed straight and long fibers of ca. $30 \mathrm{~nm}$ in diameter (Figure 6.7A-B) but unfortunately the resolution achieved was not enough to distinguish the presence of tubes as in the case of compound $\mathbf{1 0 .}$ 
Compound $\mathbf{2 8}$ revealed longer and more flexible fibers of ca $20 \mathrm{~nm}$ of width. At high magnification, some of the fibers displayed helical structures although less defined than for compound 12 confirming the tendency of PEF sequences to adopt chiral supramolecular arrangements.
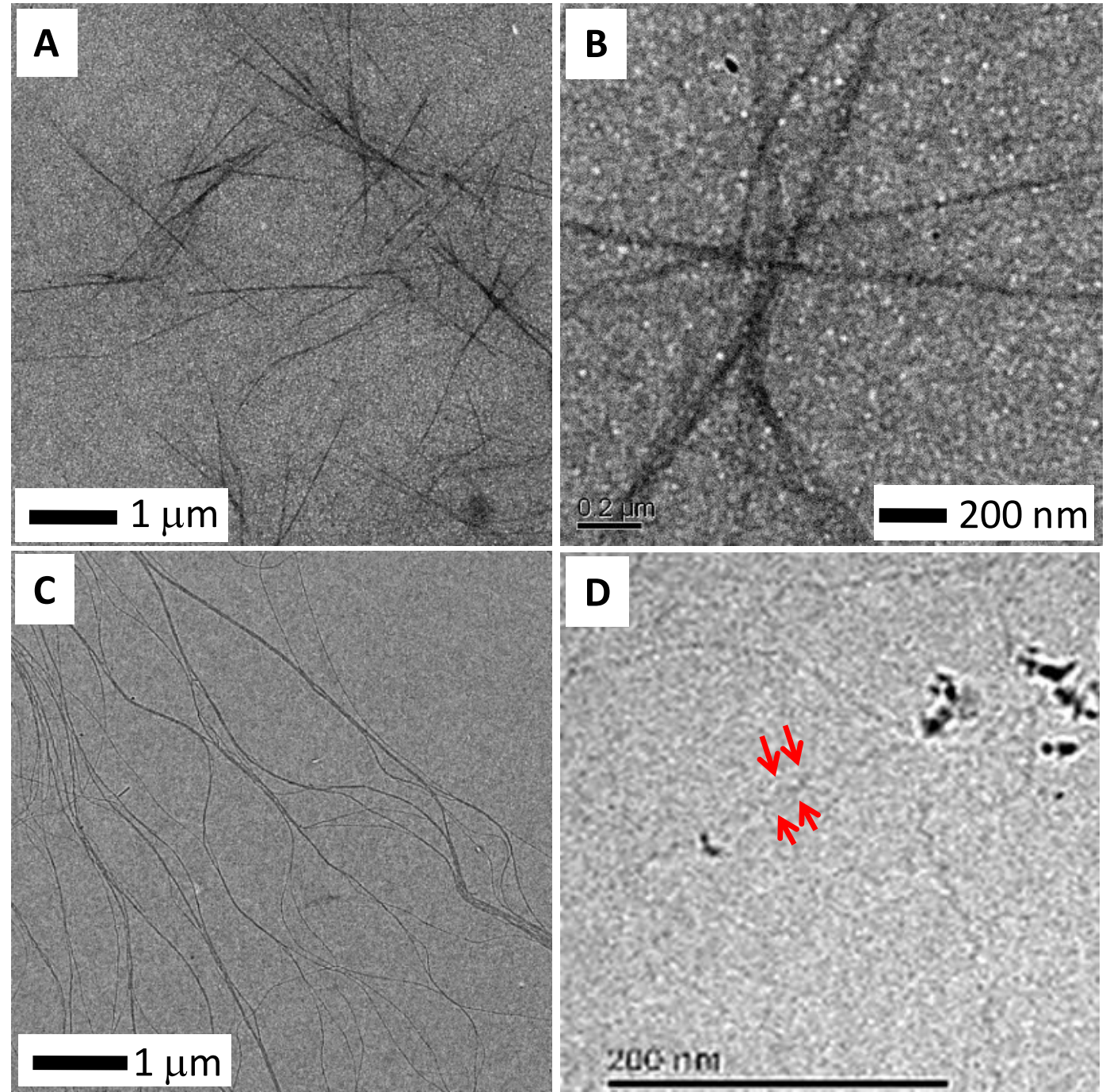

Figure 6.8 Cryo-TEM images of fibrils formed by compounds $27(\mathrm{~A}, \mathrm{~B})$ and $28(\mathrm{C}, \mathrm{D})$ at $0.45 \mathrm{mM}$.

The molecular arrangement within the different nanostructures was also studied by CD (Figure 6.9). Compounds that remain in solution, namely compound $\mathbf{9}$ and $\mathbf{1 1}$ showed non-structured arrangements with low CD signal intensities (S.I. 6.1.2.1). Conversely compounds $\mathbf{1 0}$ and $\mathbf{1 2}$ revealed more intense CD signals with significant differences among them (Figure 6.9, top). Compound 10 revealed a bisignate band with the shape typical to the $\beta$-sheet secondary structure with a positive lobe at $208 \mathrm{~nm}$, zero-crossing at $217 \mathrm{~nm}$ and a negative lobe at $227 \mathrm{~nm}$. These values appear slightly red- 
shifted from a typical amide absorption in a $\beta$-sheet structure probably due to the contribution of aromatic $\mathrm{F}$ residues. ${ }^{18}$ On the other hand, aggregates of compound 4 showed a completely different CD spectrum with two less intense negative peaks at 213 $\mathrm{nm}$ and $230 \mathrm{~nm}$. Regarding decapeptides 27 and 28, CD of aggregated samples at 7.5 $\mathrm{mM}$ showed an intense negative band at $235 \mathrm{~nm}$ for both of them (Figure 6.9 bottom). However CD spectra of more diluted samples (S.I. 6.1.2.2) displayed also positive bands at $222 \mathrm{~nm}$ suggesting a twisted $\beta$-sheet structure. ${ }^{19}$
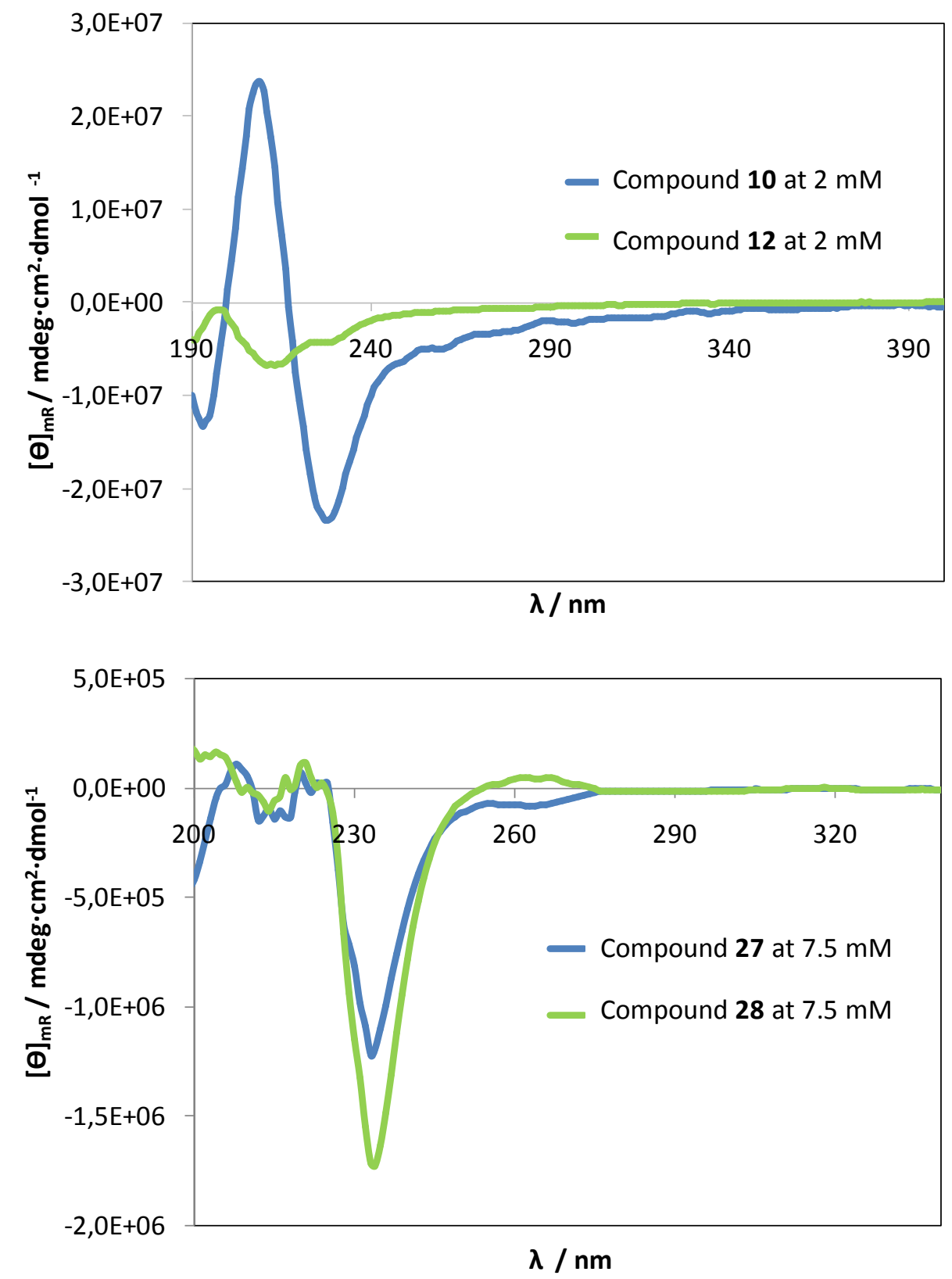

Figure 6.9 CD spectra of aggregated compounds 10, 12 (top), 27 and 28 (bottom). 


\subsection{Catalytic activity of $\mathrm{P}$ peptide amphiphiles in the aldol reaction}

The catalytic activity of compounds 9-12 and 27-28 was tested in a benchmark aldol reaction between cyclohexanone and p-nitro-benzaldehyde (Figure 6.10).<smiles>O=C1CCCCC1</smiles><smiles>O=Cc1ccc([N+](=O)[O-])cc1</smiles>

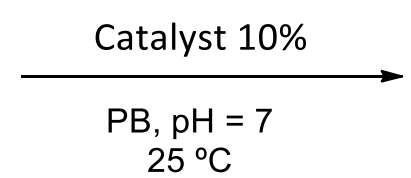<smiles>O=C1CCCC[C@H]1[C@H](O)c1ccc([N+](=O)[O-])cc1</smiles>

Figure 6.10 Aldol reaction between the cyclohexanone and $p$-nitro-benzaldehyde.

In a typical experiment a $10 \%$ loading of catalyst and 10 equiv. of cyclohexanone per equiv. of aldehyde were employed and the reaction was run at $25 \stackrel{\circ}{ } \mathrm{C}$ in buffered conditions at $\mathrm{pH}=7$. The corresponding gels or aggregates were prepared by heating up the solutions and letting them cool down to room temperature during 4 hours. The catalytic results obtained are collected in Table 6.1.

Table 6.1 Catalytic results ${ }^{a}$

\begin{tabular}{cccccc}
\hline Entry & Catalyst & $\mathbf{t} / \mathbf{h}$ & Yield $^{\mathbf{b}} / \mathbf{\%}$ & d.r. $^{\mathbf{b}}$ (syn:anti) & e.r. $^{\mathbf{c}}$ anti \\
\hline 1 & - & 72 & 14 & - & - \\
2 & $\mathbf{9}$ & 72 & 32 & $15: 85$ & - \\
3 & 10 & 72 & $>99$ & $14: 86$ & $12: 88$ \\
4 & 11 & 72 & 17 & $18: 82$ & - \\
5 & 12 & 72 & $>99$ & $20: 80$ & $12: 88$ \\
6 & $\mathbf{9}$ & 15 & 9 & $15: 85$ & - \\
7 & 10 & 15 & $>99$ & $15: 85$ & - \\
8 & $\mathbf{1 1}$ & 15 & 6 & $20: 80$ & - \\
9 & $\mathbf{1 2}$ & 15 & $>99$ & $9: 91$ & - \\
10 & $\mathbf{1 0}$ & 2 & 93 & $8: 92$ & - \\
11 & $\mathbf{1 2}$ & 2 & 51 & $15: 85$ & - \\
12 & $\mathbf{1 0}$ & 1 & 83 & $10: 90$ & - \\
13 & $\mathbf{1 2}$ & 1 & 32 & $14: 86$ & - \\
14 & $\mathbf{2 7}$ & 72 & 85 & $15: 85$ & $12: 88$ \\
15 & $\mathbf{2 8}$ & 72 & 50 & $16: 84$ & $20: 80$ \\
\hline
\end{tabular}

a Catalytic conditions for compounds 9-12: $6.5 \times 10^{-3} \mathrm{mmol}$ of catalyst (10\%) and 10 equiv. of cyclohexanone in $2 \mathrm{~mL}$ of phosphate buffer $0.1 \mathrm{M}$ at pH = 7 and $25 \stackrel{\circ}{\circ}$. For compounds 27 and 28: $6.5 \times 10^{-}$ ${ }^{3} \mathrm{mmol}$ of catalyst (10\%) and 10 equiv. of cyclohexanone in $0.5 \mathrm{~mL}$ of phosphate buffer $0.5 \mathrm{M}$ at $\mathrm{pH}=7$ and 25 o $\mathrm{C}$. bYields and diastereoisomeric ratios were determined by ${ }^{1} \mathrm{H}$ NMR. ${ }^{\mathrm{C}}$ Enantiomeric ratios were determined by chiral HPLC (See S.I. 6.2.1). 
As can be seen in the Table 6.1, compounds 9 and 11, which are completely soluble under these conditions, did not lead to significant yields of aldol even after $72 \mathrm{~h}$ of reaction (entries 2 and 4). These results are pretty similar to those obtained when no catalyst is present (Blank, entry 1). Fortunately quantitative conversions of the aldehyde at the same time were obtained when the self-assembled catalysts $\mathbf{1 0}$ and $\mathbf{1 2}$ were employed (entries 3 and 5). These results confirmed the emergence of catalytic activity after the self-assembly. In addition a reduction in reaction time revealed interesting differences in reaction rate among these two compounds. After $2 \mathrm{~h}$ of reaction, yield of aldol was up above $90 \%$ for catalyst 10 (entry 10) while for catalyst 12 it was only $51 \%$ (entry 11). As can be observed in Figure 6.11 the reaction in the presence of selfassembled catalyst $\mathbf{1 0}$ is faster than with catalyst $\mathbf{1 2 .}$

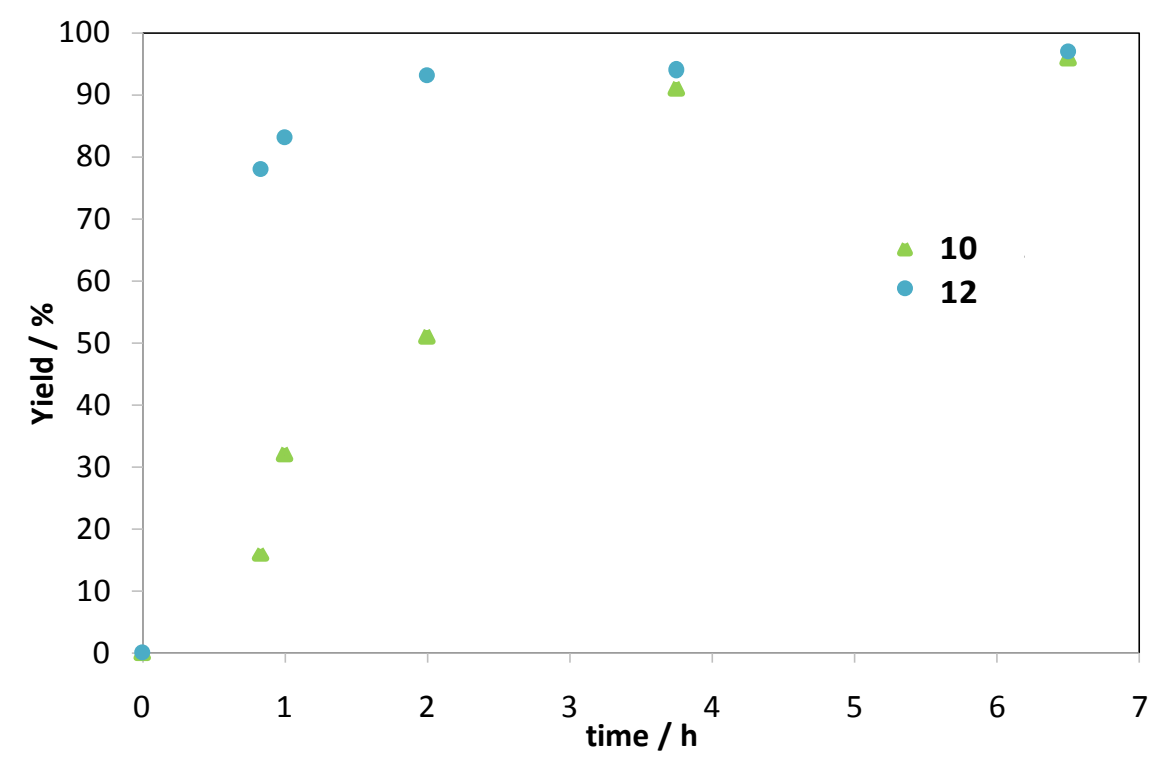

Figure 6.11 Yield of the aldol reactions over time in the presence of self-assembled catalysts 10 (PFEC 12 ) and $12\left(\right.$ PEFC $\left._{12}\right)$.

The major diastereoisomer obtained in both cases was the aldol anti with similar syn:anti ratio. Moderate to high enantioselectivities (e.r. anti 12:88) could also be observed for the two compounds being the $S, R$-anti the major enantiomer. Both diastero- and enantioselectivity were improved to a 5:95 syn:anti and 5: 95 (S,R-anti) respectively by performing the reactions at 0 으.

Reviewing the literature several examples have been reported in which simple amino acids and peptides are studied as organocatalysts for 'in water' and 'on water' 
direct aldol reactions. ${ }^{5,20}$ However, in most of the cases although excellent yields or stereoselectivities were achieved the relationship between supramolecular structure of the assemblies and catalytic activity was not further studied..$^{9,11,17}$ To delve into this topic different experiments were performed trying to explain the observed differences in reaction rate.

In the first instance we tried to identify the active catalytic species at neutral $\mathrm{pH}$ by carrying out potentiometric titrations. For that purpose compounds 9-12 were dissolved in basic solution of $\mathrm{NaOH}$ which did not show any precipitation or gelation and such solutions were titrated with $\mathrm{HCl} 0.01 \mathrm{M}$ until an acidic final $\mathrm{pH}$ was reached (See S.I. 6.2.2). A general pH-dependent speciation diagram can be observed in Figure 6.12 and the pKa values obtained for the protonation of compounds $\mathbf{9 - 1 2}$ are collected in Table 6.2 .<smiles>CC(C)(C)CNC(=O)[C@H](CCC(=O)O)NC(=O)C(Cc1ccccc1)NC(=O)C1CCCN1</smiles><smiles>CC(NC(=O)[C@H](CCC(=O)[O-])NC(=O)C(Cc1ccccc1)NC(=O)C1CCCN1)C(C)(C)C</smiles>

AH

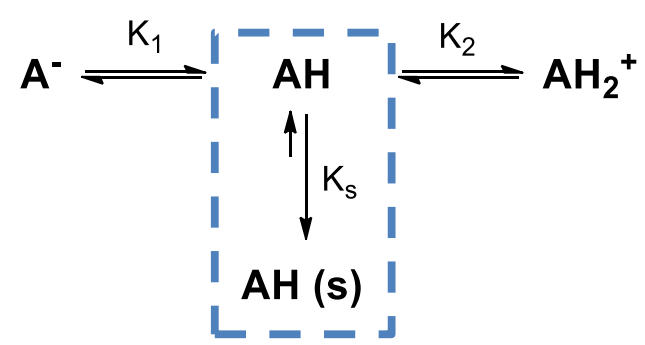

for 10 and 12<smiles>CC(C)(C)CNC(=O)[C@H](CCC(=O)O)NC(=O)[C@H](Cc1ccccc1)NC(=O)[C@@H]1CCC[NH2+]1</smiles>

Figure 6.12 Left: General scheme for $\mathrm{pH}$ dependent speciation exemplified for compounds $\mathbf{9}(\mathrm{n}=1)$ and $\mathbf{1 0}$ $(n=10)$. Right: Equilibria diagram valid for compounds 9-12. 
Table 6.2 pKa values for compounds $\mathbf{9 - 1 2}$ determined by potentiometric titrations.

\begin{tabular}{cccc}
\hline \multicolumn{2}{c}{ Catalyst } & $\mathrm{pK}_{\mathbf{1}}$ & $\mathrm{pK}_{\mathbf{2}}$ \\
\hline $\mathbf{9}$ & $\mathrm{PFEC}_{3}$ & $8.22 \pm 0.02$ & $4.34 \pm 0.02$ \\
$\mathbf{1 0}$ & $\mathrm{PFEC}_{12}$ & $9.72 \pm 0.03$ & $6.85 \pm 0.04$ \\
$\mathbf{1 1}$ & $\mathrm{PEFC}_{3}$ & $8.27 \pm 0.02$ & $4.21 \pm 0.04$ \\
$\mathbf{1 2}$ & $\mathrm{PEFC}_{12}$ & $7.60 \pm 0.01$ & $6.92 \pm 0.01$ \\
\hline
\end{tabular}

Starting with compounds $\mathbf{9}$ and $\mathbf{1 1}$, which are soluble for the whole $\mathrm{pH}$ range, they showed $\mathrm{pK}_{1}$ values around 8.2 in both cases. This means that at neutral $\mathrm{pH}$ the major species would be a zwitterion and as a consequence the proline residue would be protonated and not available for enamine-based catalysis in solution. However pKa values around 8 are abnormally low values for a proline residue in solution if one considers that this amino acid shows values around 10.6. Most likely the nitrogen of proline in tripeptides $\mathbf{9}$ and $\mathbf{1 1}$ is involved in a hydrogen bond and the energy involved in the protonation includes also the energy required for breaking this hydrogen bond.
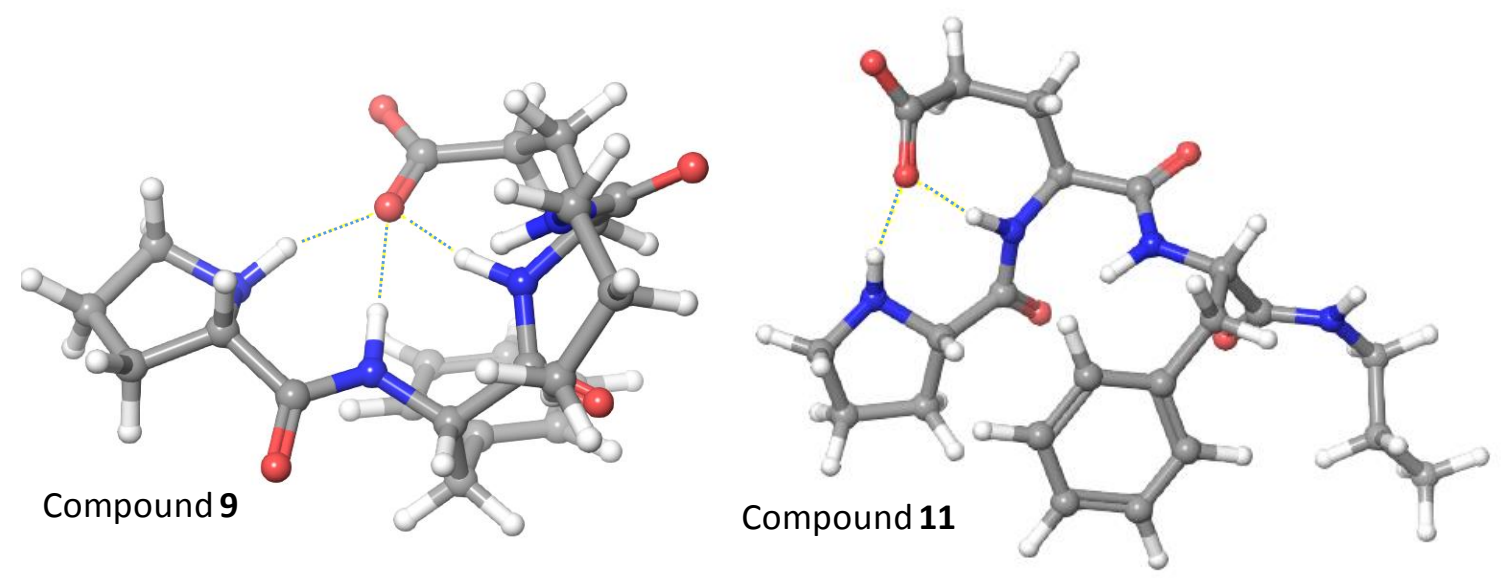

Figure 6.13 Minimum energy structures for compound 9 and 10 found by molecular mechanics conformational search (Macromodel 9.3, AMBER* force field, water GB/SA solvent simulation).

On the other hand, compounds $\mathbf{1 0}$ and $\mathbf{1 2}$ having a $\mathrm{C}_{12}$ alkyl tail are much more hydrophobic and therefore insoluble and their neutral species $(\mathrm{AH})$ tend to aggregate into a hydrogel and a sticky suspension respectively. In these cases we proposed, as it is reasonable, that these aggregates are formed by neutral non-charged molecules in which proline residues would be available to react with the substrate. Interestingly the formation of these aggregates has a different effect on the $\mathrm{pK}_{1}$ values depending on how 
stable these aggregates are. In this way $\mathrm{pK}_{1}$ values of 9.72 and 7.60 were obtained for compounds 10 and 12 respectively and as a consequence significant differences on the amount of active catalytic species will be observed at a given $\mathrm{pH}$. Looking at $\mathrm{pH}=7$ in the speciation diagram (S.I. 6.2.2.1) the amount of active species (AH) for compound 10 (60\%) is higher than for compound 12 (40\%). In principle this significant difference could justify the better activity of compound $\mathbf{1 0}$ against compound $\mathbf{1 2}$. However it has to be mentioned that titrations were performed in pure water whereas catalytic experiments were done in phosphate buffer. As previously mentioned, the presence of salts has an impact on the solubility due to the so-called Hofmeister effect. ${ }^{21}$ Phosphate ions act as a kosmotropic salt lowering the solubility of hydrophobic solutes in water. Indeed ${ }^{1} \mathrm{H}$ NMR spectra of compounds 10 and 12 under catalytic conditions (PB $0.1 \mathrm{M}$ and $\mathrm{pH}=7$ ) did not show any signal corresponding to free compounds revealing that the solubility of both of them falls below the detection limit of this technique. Considering these results it seems that the differences in $\mathrm{pK}_{\mathrm{a}}$ values are not enough to justify the differences in catalytic activity and other contributions have to be considered like for example, the formation of a pre-organised catalyst-substrate complex. Kinetic studies were therefore performed keeping constant the concentration of catalyst and the ratio cyclohexanone:aldehyde and varying the total concentration of substrate. However the results did not follow the Michaelis-Menten velocity profile typical of enzymatic catalysis (S.I. 6.2.3) and the formation of such intermediate for these substrates was discarded. The presence of hydrophobic pockets where substrates (especially $p$-nitrobenzaldehyde) can be located was then studied by using 1-anilinonaphthalene-8-sulphonate (ANS), a fluorescence probe widely used for this purpose in protein science. ${ }^{22}$ Binding of ANS within hydrophobic pockets is accompanied by a blue-shift of the emission signal and an increase in the fluorescence intensity (S.I. 6.2.4).

As can be observed in Figure 6.14 a fluorescence band at ca. $460 \mathrm{~nm}$ is observed for both compounds (10 and 12) which is blue-shifted from the blank emission (ca. 490 $\mathrm{nm}$ ). However this band is more intense in the case of compound $\mathbf{1 2}$ indicating that those aggregates present larger hydrophobic pockets. These results seem reasonable since compound 12, with a sequence PEFC12, locates $F$ residue closed to the $C_{12}$ tail creating then larger hydrophobic surfaces than compound $\mathbf{1 0}$ (PFEC12). Then, it is 
proposed that hydrophobic substrates could be bound into these pockets but not necessarily close to the catalytic site and the difference between the rates of two catalysts could be finally related to their relative accessibility for the substrates and not to the hydrophobicity of the assemblies.

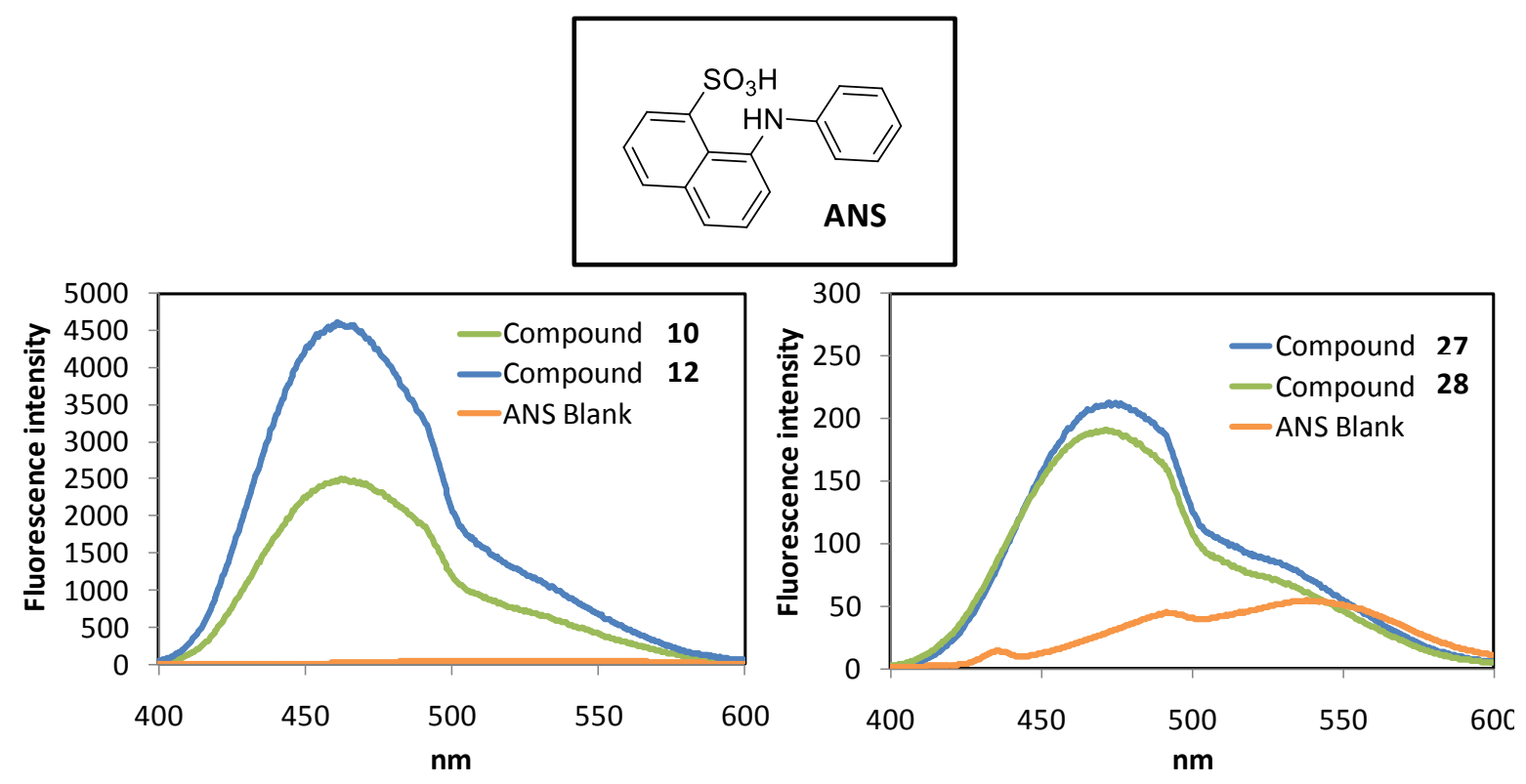

Figure 6.14 Fluorescence emission of ANS in aggregates of compounds 10-12 (left), 27-28 (right) and blank solution (right). Chemical structure of ANS (top).

This idea was confirmed by ${ }^{1} \mathrm{H}$ NMR. Aggregated samples of compounds $\mathbf{1 0}$ and 12 were prepared and a known amount of cyclohexanone $(2.5 \mathrm{eq})$ was added on the top. After $4 \mathrm{~h}$ of stabilisation the amount of cyclohexanone that remained in solution was determined by ${ }^{1} \mathrm{H}$ NMR (S.I. 6.2.5). It is supposed that the cyclohexanone incorporated into the aggregated phase is due to enamine formation because this substrate is significantly soluble in water ( $90 \mathrm{~g} / \mathrm{L}$ at $20 \mathrm{oC})$. Once the enamine is formed it becomes part of the aggregate and in consequence undetectable by ${ }^{1} \mathrm{H}$ NMR. Interestingly compound $\mathbf{1 2}$ was able to incorporate one equivalent of cyclohexanone into the gel whereas compound 10 only entrapped 0.5 eq. These results, which are in agreement with catalytic reported data, confirm that catalytic sites of $\mathbf{1 2}$ are more accessible to substrates than those of catalyst 10.

Additionally, freeze-dried hydrogels of compound $\mathbf{1 0}$ were suitable for WAXS powder diffraction analysis (S.I. 6.2.6) and therefore a model of packing for its aggregates could be proposed (Figure 6.15). A lamellar organization was suggested that 
generates segregated hydrophobic regions, formed by alkyl tails and aromatic residues, and arrays of accessible proline residues.
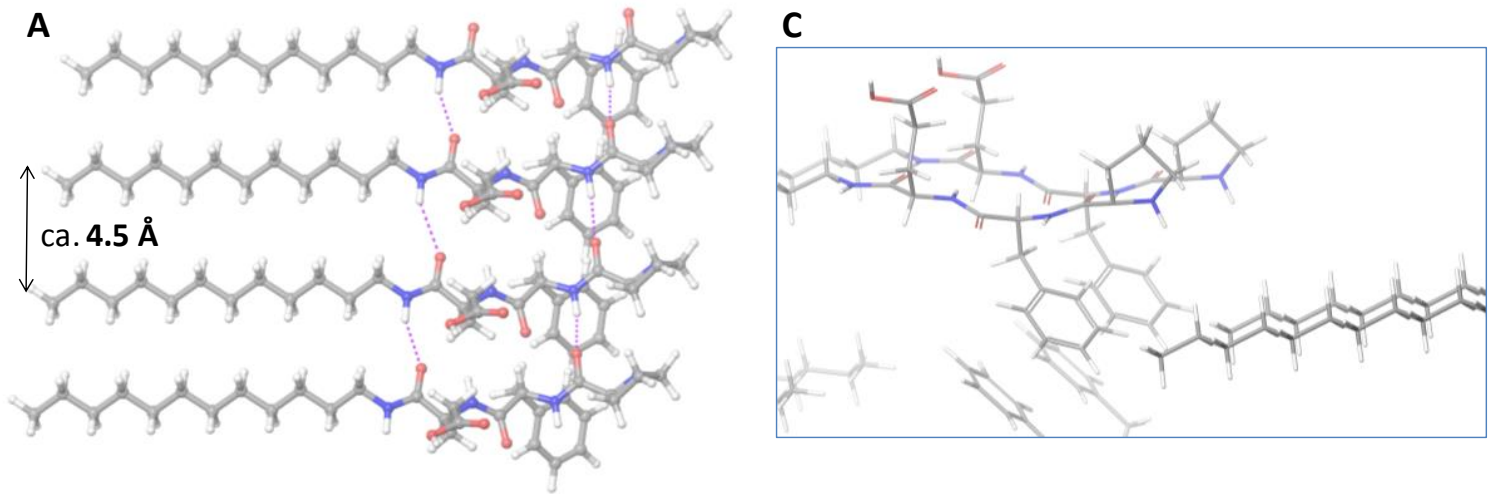

B

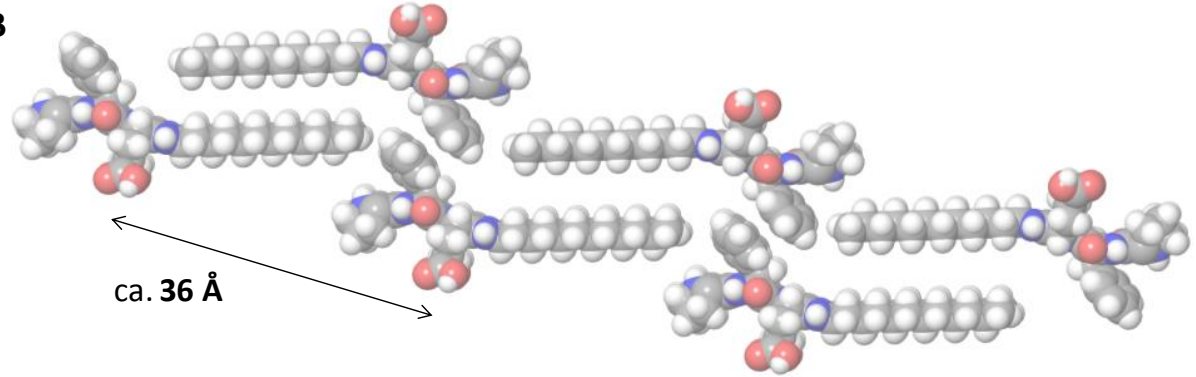

Figure 6.15 Proposed supramolecular packing of compound 10. A, B) models based on diffraction data, and C) partial zoom into the proline catalytic regions.

The catalytic activity of compounds $\mathbf{2 7}$ and $\mathbf{2 8}$ was also analyzed for the aldol reaction between the cyclohexanone and $p$-nitro-benzaldehyde. As can be observed in Table 6.1 the reaction in the presence of these two aggregated catalysts is generally slower than for amphiphilic catalyst $\mathbf{1 0}$ and $\mathbf{1 2}$, full conversions being not achieved even after $72 \mathrm{~h}$ (entries 14 and 15). These two compounds possess the same amino acid sequences at the catalytic sites although the long aliphatic chain has been eliminated from the C-terminus. This change has an important effect on the hydrophobicity of the final assemblies revealed by ANS experiments (Figure 6.14, right). The fluorescence emission for compounds $\mathbf{2 7}$ and $\mathbf{2 8}$ were significantly lower than for compounds $\mathbf{1 0}$ and 12 which means that decapeptides present poorer hydrophobic pockets than amphiphilic compounds. The incorporation of cyclohexanone within the aggregates of compounds 27 and 28 was also quantified by ${ }^{1} \mathrm{H}$ NMR showing than less than 0.1 eq. was entrapped. Taking together these experiments correlate well with the slower catalytic rate of these compounds in comparison with tripeptides 10 and $\mathbf{1 2}$. Interestingly a significant difference was observed related to the peptide sequence. Once again when 
an $\mathrm{F}$ residue is located next to the $\mathrm{P}$ (compound 27 ) faster conversion is achieved (Table 6.1 entries 14 and 15$)$. This general trend suggests that $F$ plays a role in catalysis most likely via secondary interactions at the transition state of the reaction.

It has to be remembered that the sequence did not affect significantly the stereoselectivity of the reaction and this fact also supports our hypothesis that there is no specific binding of substrates close to the catalytic site.

\subsection{Biomimetic catalysis}

As mentioned before, the aldol reaction can be used to obtained carbohydrate derivatives in a similar way as aldolase type I performs in Nature. ${ }^{6 c, 6 d, 8}$ In this way we decided to study the hydrogels and aggregates of compounds $\mathbf{1 0}$ and $\mathbf{1 2}$ as catalysts for the self-condensation of several $\alpha$-oxy-aldehydes and phenylalkyl aldehydes (Figure 6.16).
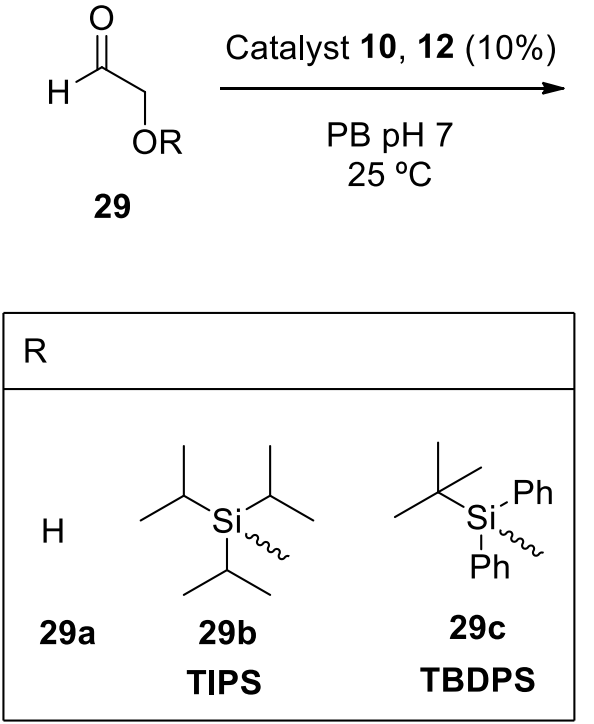<smiles>[R]OC[C@H](O)[C@H]([R])C=O</smiles>

(D)-2-anti-erythrose<smiles>[R]OCC(O)C([R])C=O</smiles>

(L)-2-anti-erythrose

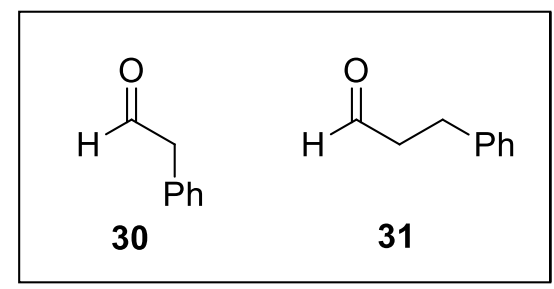

Figure 6.16 General scheme for the self-condensation of aldehydes (29-31).

First of all 2-hydroxyacetaldehyde derivatives (29a-c) were studied as substrates leading to tetrose-based products and the results are shown in Table 6.3. 
Table 6.3 Catalytic results for the self-condensation of aldehydes 29-31 using catalysts 10 and $12 .^{a}$

\begin{tabular}{ccccc}
\hline Entry & Catalyst & Aldehyde & Time/h & Aldol yield/\%b \\
\hline 1 & 10 & 29a & 48 & $<5$ \\
2 & 12 & 29a & 48 & $<5$ \\
3 & 10 & 29b & 15 & $>95^{\mathrm{c}}$ \\
$a$ & 12 & 29b & 15 & $>95^{\mathrm{c}}$ \\
5 & 10 & 29c & 2 & $84^{\mathrm{d}}$ \\
6 & 12 & $\mathbf{2 9 c}$ & 2 & $50^{\mathrm{d}}$ \\
7 & 10 & $\mathbf{2 9 c}$ & 15 & 92 \\
8 & 12 & $\mathbf{2 9 c}$ & 15 & 76 \\
9 & 10 & $\mathbf{3 1}$ & 2 & 17 \\
10 & 12 & 31 & 2 & 2 \\
11 & 10 & 31 & 15 & 57 \\
12 & 12 & 31 & 15 & 24 \\
\hline
\end{tabular}

${ }^{a}$ Catalytic conditions: $6.5 \times 10^{-3} \mathrm{mmols}$ of catalyst $(4.37 \mathrm{mg}, 10 \%)$ and $6.5 \times \cdot 10^{-2} \mathrm{mmol}$ of the corresponding aldehyde in $2 \mathrm{~mL}$ of phosphate buffer $0.1 \mathrm{M}$ at pH = 7 and $25{ }^{\circ} \mathrm{C}$. byields and diasteroisomeric ratio are determined by ${ }^{1} \mathrm{H}$ NMR (see SI). ${ }^{c}$ mixture of compounds, see text. ${ }^{d}$ d.r. (syn:anti), 10:90, e.r. anti product 91:9, determined as previously reported ${ }^{6 c}$, see S.I. 6.3.1.

For unprotected glycolaldehyde (29a) no reaction was observed even after long time of reaction (entries 1 and 2). Such lack of reactivity for polar substrates has been previously described in our group for related systems. ${ }^{12 a}$ However once we protected the 2-hydroxyl group as silyl ether $(29 b-c)$ the self-condensation reaction took place significantly faster.

TIPS-protected glycolaldehyde (29b) reacted as previously described by Clarke at al. and a mixture of aldols together with a trimeric acetal was obtained (S.I. 6.3.1.1). ${ }^{17}$ However, different results were obtained for TBDPS-protected analogue $29 c$. In this case high conversions were achieved for both catalysts (10 and 12) at significantly shorter times and interestingly differences depending on the amino acid sequence were also observed. For instance catalyst 10 showed a yield of $80 \%$ after $2 \mathrm{~h}$ of reaction in comparison with $50 \%$ obtained for catalyst $\mathbf{1 2}$. According to that we suggest that the presence of aromatic fragments in substrate as well as F residues in the catalyst play a role which favors the aldol product. The major product was determined to be the L-2anti-erythrose derivative revealing a remarkable stereoselectivity (d.r. 90:10, e.r. 91:9). ${ }^{6 c}$ 
Self-condensation of aldehydes $\mathbf{3 0}$ and $\mathbf{3 1}$ was also studied trying to explore the role of the oxygen group at the $\alpha$-position of substrate. Substrate $\mathbf{3 0}$ led to a complex mixture of products when the crude of the reaction was analysed by ${ }^{1} \mathrm{H}$ NMR (S.I. 6.3.1.3). ESI-MS of this complex mixture revealed the presence of different peaks corresponding to polycondensation products. Finally the self-condensation of compound 31 led to the dehydrated aldol as the main product (S.I. 6.3.1.4). In general for both aldehydes, using either $\mathbf{1 0}$ or $\mathbf{1 2}$ as catalyst, the rates of reaction were slower than for the $\alpha$-oxy-analogues. Nevertheless, from a prebiotic chemistry point of view, these condensation reactions interestingly resulted in the formation of polyaldols, potential precursors of larger carbohydrates and polyketide natural products. ${ }^{23}$

\subsection{Conclusions}

In this chapter we described a new family of peptide amphiphiles (9-12) containing $\mathrm{P}, \mathrm{F}$ and $\mathrm{E}$ whose solubility in buffered water is modulated by the length of the aliphatic chain attached to the C-terminus. Hydrogels or aggregates formed by amphiphiles $\mathbf{1 0}$ or $\mathbf{1 2}$ have been characterised and tested as catalysts in aldol condensation reactions.

The data reported provide an example of the emergence of catalytic activity via the self-assembly of short peptides in water. Although the use of peptides in asymmetric catalysis is widely reported, in particular the so-called on-water reactions, here we go a step further trying to rationalise the catalytic activity in terms of the supramolecular structure of the assemblies, which is not generally considered in the field of organocatalysis. We have considered the possibility of shifts in pKa values of the catalytic group, the relative stability of the aggregates, and the hydrophobicity of both the assembled catalyst and the substrate and finally the accessibility to the catalytic site. Interesting differences have been observed depending on the amino acid sequence which can be extended to related decapeptide sequences ( 27 and $\mathbf{2 8}$ ).

Although these systems may be considered as conventional heterogeneous catalysts, it is important to remind that they are formed by simple molecules with preprogrammed information, which is translated into complex catalytic systems solely via 
non-covalent interactions. These non-covalent interactions endow the current systems with reversibility that can be used to easily switch on/off their catalytic properties by external stimuli such as such as temperature or $\mathrm{pH}$ changes.

The formation of $\mathrm{C}-\mathrm{C}$ bonds through aldol reaction is of great value since it increases molecular complexity and structural diversity in just one simple step. The results presented here are in particular especially relevant in the context of prebiotic chemistry. These systems combined the importance of the self-assembly for the formation of compartments and the emergence of catalysis, both undoubtedly important for the appearance of chemical complexity. ${ }^{24}$ In this way, catalytic selfassembled peptides could be seen intermediate evolutionary systems between simple soluble molecular catalysts and complex protein entities, namely the enzymes. 


\subsection{Supplementary information}

S.I. 6.1 Self-assembly study in phosphate buffer

S.I. 6.1.1 Transmission and Cryo-Transmission and electron microscopy

S.I. 6.1.2 Circular dichroism (CD)

S.I. 6.2 Catalytic activity of proline peptide amphiphiles in the aldol reaction between cyclohexanone and $p$-nitro-benzaldehyde.

S.I. 6.2.1 Catalytic conditions

S.I. 6.2.2 Potentiometric titration experiments

S.I. 6.2.3 Kinetic studies with $p$-nitro-benzaldehyde and cyclohexanone

S.I. 6.2.4 ANS (1-anilinonaphthalene-8-sulphonate) fluorescence assay

S.I. 6.2.5 Cyclohexanone incorporation experiment ( ${ }^{1} \mathrm{H}$ NMR)

S.I. 6.2.6 Wide angle X-ray powder diffraction

\section{S.I. 6.3 Biomimetic catalysis}

S.I. 6.3.1 Catalytic conditions for self-condensation of aldehydes

S.I. 6.3.2 Chemical correlation of aldol product from 29c

\section{S.I. 6.4 Synthesis and characterisation data}

S.I. 6.4.1 Synthesis and characterisation data of decapeptides 27-28

S.I. 6.4.1 Synthesis and characterisation data of aldehydes 29-31 


\section{S.I. 6.1 Self-assembly study in phosphate buffer}

\section{S.I. 6.1.1 Transmission and Cryo-Transmission and electron microscopy}

TEM: Samples of compounds 10 and $\mathbf{1 2}$ at $1.5 \mathrm{mM}$ in phosphate buffer $0.1 \mathrm{M}(\mathrm{pH}$ 7) were applied directly onto a 200 mesh carbon coated copper grids (after $4 \mathrm{~h}$ of incubation at room temperature). Excess solvent was carefully removed by capillary action using filter paper. After that one drop of distilled water was added in order to remove some salts and excess solvent was removed again in like manner. The grids were immediately stained with one drop of phosphotungstic acid $1 \%$ for $1 \mathrm{~min}$. Excess stain was removed by capillarity. Images were recorded in a Transmission Electron Microscopy JEOL 2100.

Samples of compounds $\mathbf{2 7}$ and $\mathbf{2 8}$ were prepared from stock solutions that have been prepared at $9 \mathrm{mM}$ concentration in $\mathrm{pH} 7$ phosphate buffer $50 \mathrm{mM}$. Before the measurements, the samples were incubated at room temperature for $4 \mathrm{~h}$ and then diluted to $0.45 \mathrm{mM}$. $5 \mu \mathrm{L}$ of solution (for each $\mathbf{5}$ and 6 ) was dropped onto a 200 mesh carbon coated copper grids and allowed for 1 minute and excess solvent was removed carefully by capillary action using filter paper. Finally TEM grids are air-dried for one day before the experiment.

Cryo-TEM: Samples of compounds 10 and $\mathbf{1 2}$ were prepared from stock solutions of peptides that have been prepared at $12.4 \mathrm{mM}$ concentration in $\mathrm{pH} 7$ phosphate buffer $0.5 \mathrm{M}$. Before the measurements the samples were incubated at room temperature for $4 \mathrm{~h}$ and then diluted 20 times to $0.62 \mathrm{mM}$. Samples for direct imaging of the aqueous dispersions using cryo-TEM were prepared as follows: in the controlled environment box of a vitrification robot (Vitrobot), a drop of the solution was deposited on a glow-discharged TEM grid (300-mesh Cu Lacey substrate; Ted Pella, Ltd.). The excess liquid was automatically blotted with a filter paper, and the specimen was rapidly plunged into liquid ethane and transferred to liquid nitrogen where it was kept until used. The samples were examined below -175 으 using an FEI Tecnai 12 G2 TWIN TEM operated at $120 \mathrm{kV}$ in low-dose mode and with a few micrometers under focus to increase 3 phase contrast. The images were recorded with a Gatan charge-coupled device camera (model 794) and analyzed by Digital Micrograph software, Version 3.1. 


\section{S.I. 6.1.2 Circular dichroism (CD)}

Gels or solutions (after $4 \mathrm{~h}$ of stabilisation) at the corresponding concentrations were transferred into the $1 \mathrm{~mm}$ or $0.5 \mathrm{~mm}$ quartz cell. Measurements were performed at room temperature and the spectra were recorded from 190 to $450 \mathrm{~nm}$ with $1.0 \mathrm{~nm}$ step and $1 \mathrm{~nm}$ bandwidth. The final spectra are the average of three measurements (with three accumulations each one). The CD spectra were recorded at 25 o $\mathrm{C}$ in a JASCO J-810 instrument. CD spectra for compounds $\mathbf{9}$ and $\mathbf{1 1}$ and for diluted samples of decapeptides $\mathbf{2 7}$ and $\mathbf{2 8}(0.25 \mathrm{mM})$ are shown below:

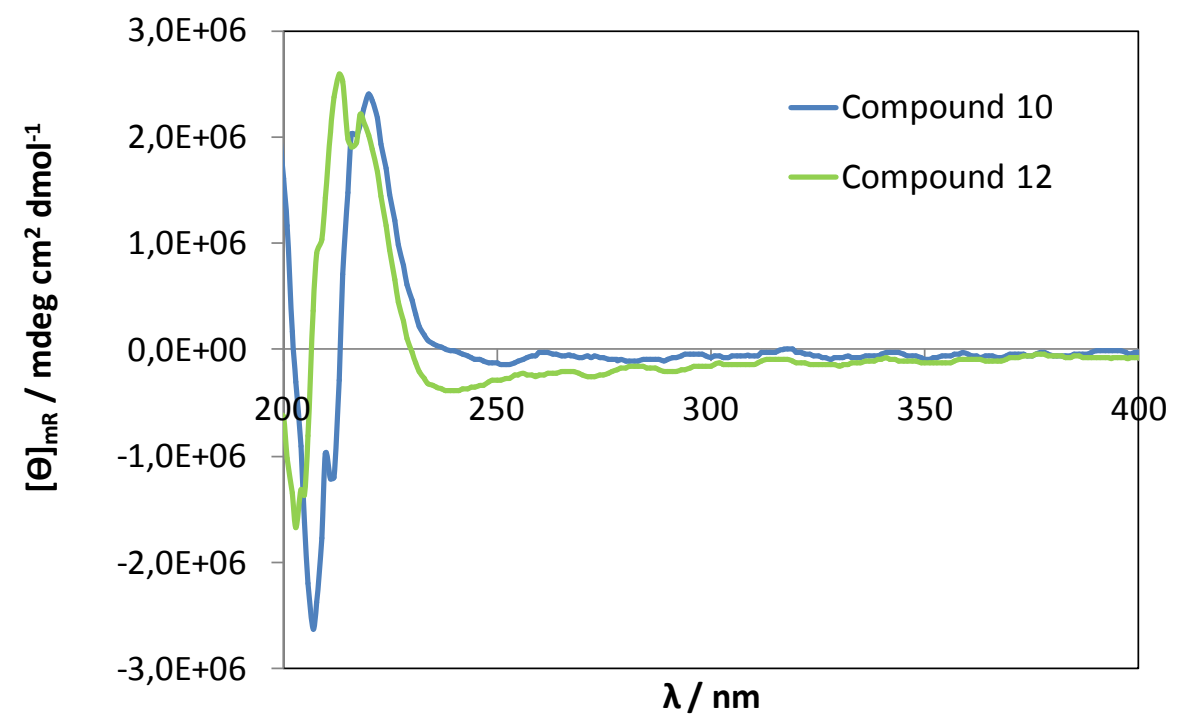

S.I. 6.1.2.1 CD spectra for compounds 9 and 11 at $2 \mathrm{mM}$.

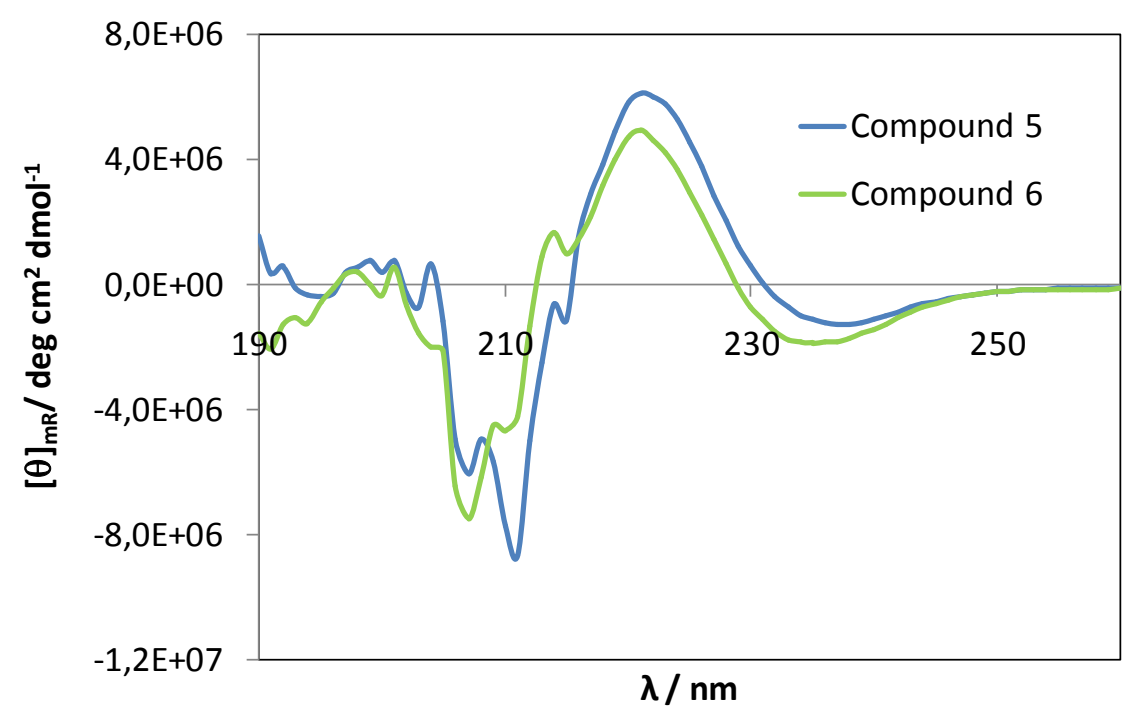

S.I. 6.1.2.2 CD spectra for compounds 27 and 28 at $0.25 \mathrm{mM}$. 
S.I. 6.2 Catalytic activity of proline peptide amphiphiles in the aldol reaction between cyclohexanone and $p$-nitro-benzaldehyde.

S.I. 6.2.1 Catalytic conditions

Gels, aggregates or solutions of compounds $9-12\left(6.5 \cdot 10^{-3} \mathrm{mmol}\right.$ in $2 \mathrm{~mL}$ of phosphate buffer $0.1 \mathrm{M}$ at $\mathrm{pH}$ 7) were prepared using a heating-cooling methodology. Samples were incubated at room temperature during $4 \mathrm{~h}$ and after that $65 \cdot 10^{-3} \mathrm{mmol}$ of $p$-nitro-benzaldehyde solubilized in 10 eq. of cyclohexanone were added on the top of the gel, aggregates or solution. Catalytic reaction took place at room temperature without stirring. To determine the reaction yield by ${ }^{1} \mathrm{H}$ NMR a direct extraction with 1 $\mathrm{mL}$ of $\mathrm{CDCl}_{3}$ was performed (S.I. 6.2.1.1). For further analysis a complete extraction with $\mathrm{CH}_{2} \mathrm{Cl}_{2}(3 \times 2 \mathrm{~mL})$ was carried out. Solvent was dried with anhydrous $\mathrm{MgSO}_{4}$ and removed under vacuum.

Catalytic conditions for compounds $\mathbf{2 7}$ and $\mathbf{2 8}$ were exactly the same but in this case the phosphate buffer used was $0.5 \mathrm{M}$ and more concentrated gels were used $\left(6.5 \cdot 10^{-3} \mathrm{mmol}\right.$ in $0.5 \mathrm{~mL}$ of phosphate buffer $0.5 \mathrm{M}, 65 \cdot 10^{-3} \mathrm{mmol}$ of $p$-nitrobenzaldehyde and 10 eq. of cyclohexanone). To determine the enantioselectivity a Chiralpack IA chromatographic column was used. The different enantiomers were separated using hexane/THF (v/v: 75/25) as mobile phase with a flow rate of $1 \mathrm{~mL} / \mathrm{min}$. Compounds were detected at $\lambda=256$ and $220 \mathrm{~nm}$ (S.I. 6.2.1.2). 


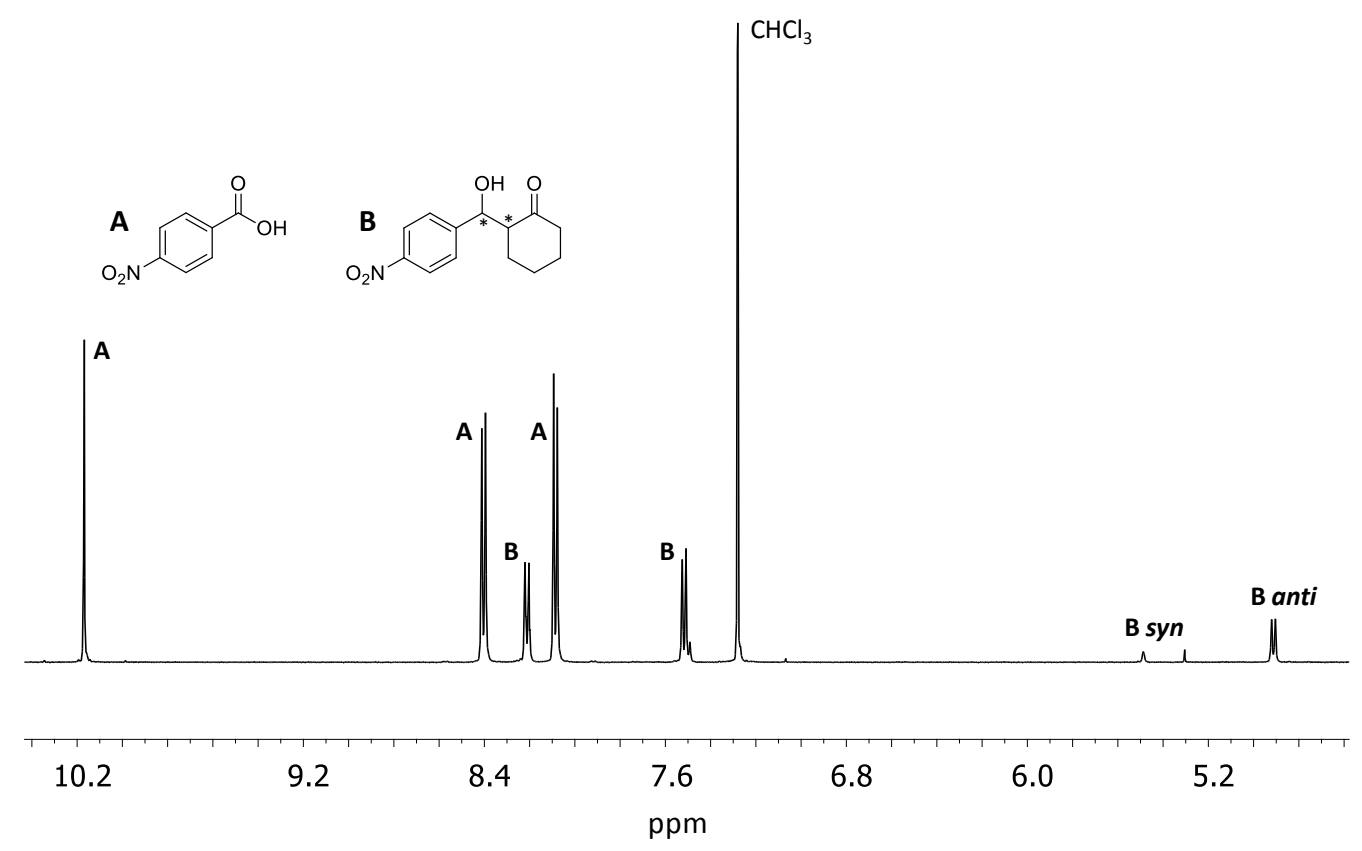

S.I. 6.2.1.1 Typical ${ }^{1} \mathrm{H}$ NMR spectra of the reaction between cyclohexanone and $p$-nitro-benzaldehyde catalysed by compounds 9-12 and 27-28. Integral ratio was used to determine the yield. B syn and B anti signals were used to determine the diasteromeric ratio.

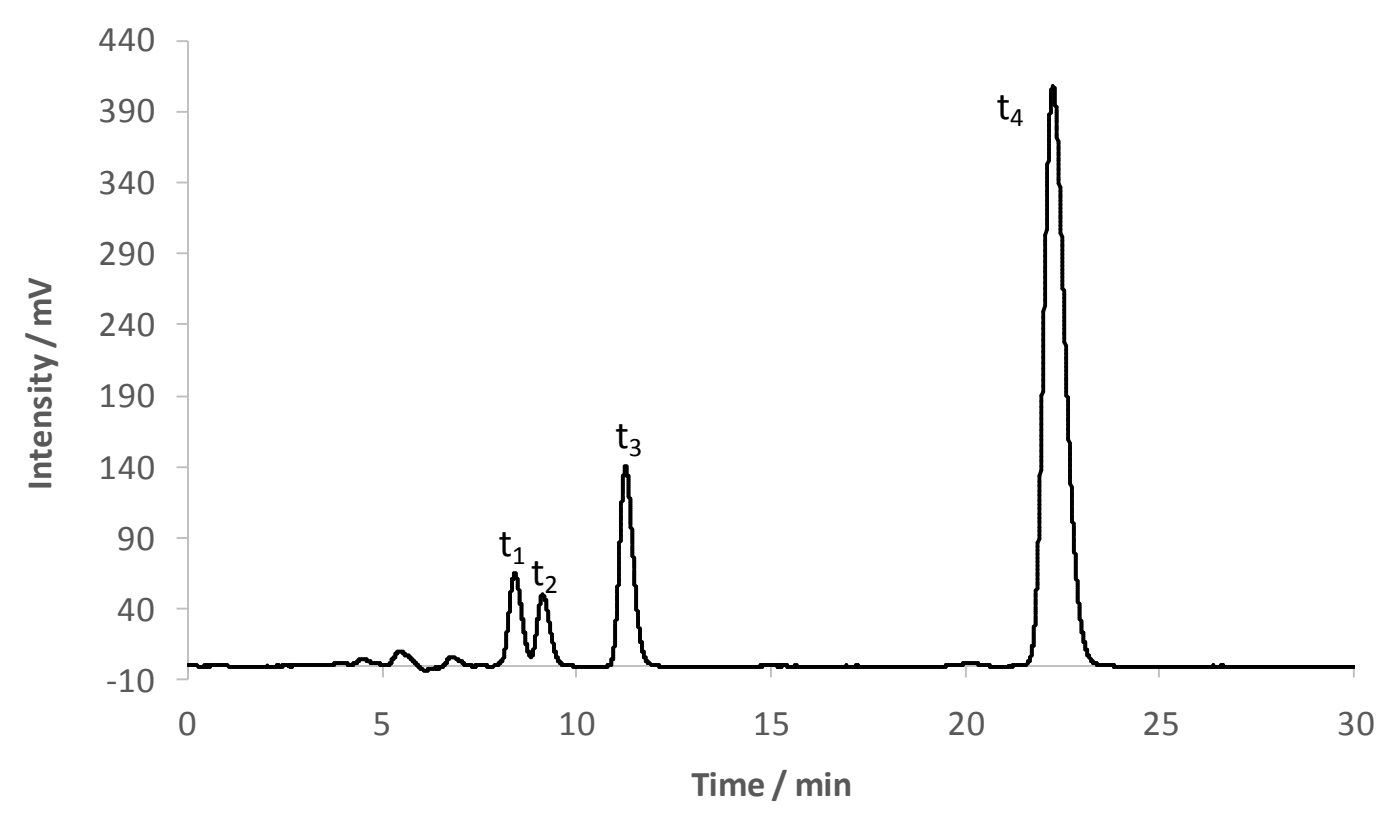

S.I. 6.2.1.2 Typical chromatogram for the aldol products. $t_{1}$ and $t_{2}$ correspond to syn aldol and $t_{3}$ and $t_{4}$ to anti aldol. Integral ratio between the minor and the major enantiomer was used to determine the enantiomeric ratio.

\section{S.I. 6.2.2 Potentiometric titration experiments}

Potentiometric titrations to determine acid-base constants were carried out at 298 K. In a typical experiment $5 \mathrm{~mL}$ of an aqueous solution of the corresponding 
compound $(3 \mathrm{mM})$ and sodium hydroxide $(12 \mathrm{mM})$ were titrated with a $0.01 \mathrm{M}$ normalized solution of aqueous hydrogen chloride with vigorous stirring. The addition rate was $0.01 \mathrm{~mL} \mathrm{~min}{ }^{1}$ and $\mathrm{pH}$ was monitored every 30 seconds. Thermodynamic constants for the different species could be determined analysing the data with HYPERQUAD-2008 software. Titrations were performed at a very slow flow rate in order to avoid metastable entrapment of $\mathrm{AH}(\mathrm{s})$. Thermodynamic equilibrium conditions were therefore supposed and solubility of $\mathrm{pH}$ was assumed negligible.

The speciation diagrams of compounds $\mathbf{9 - 1 2}$ are shown below:
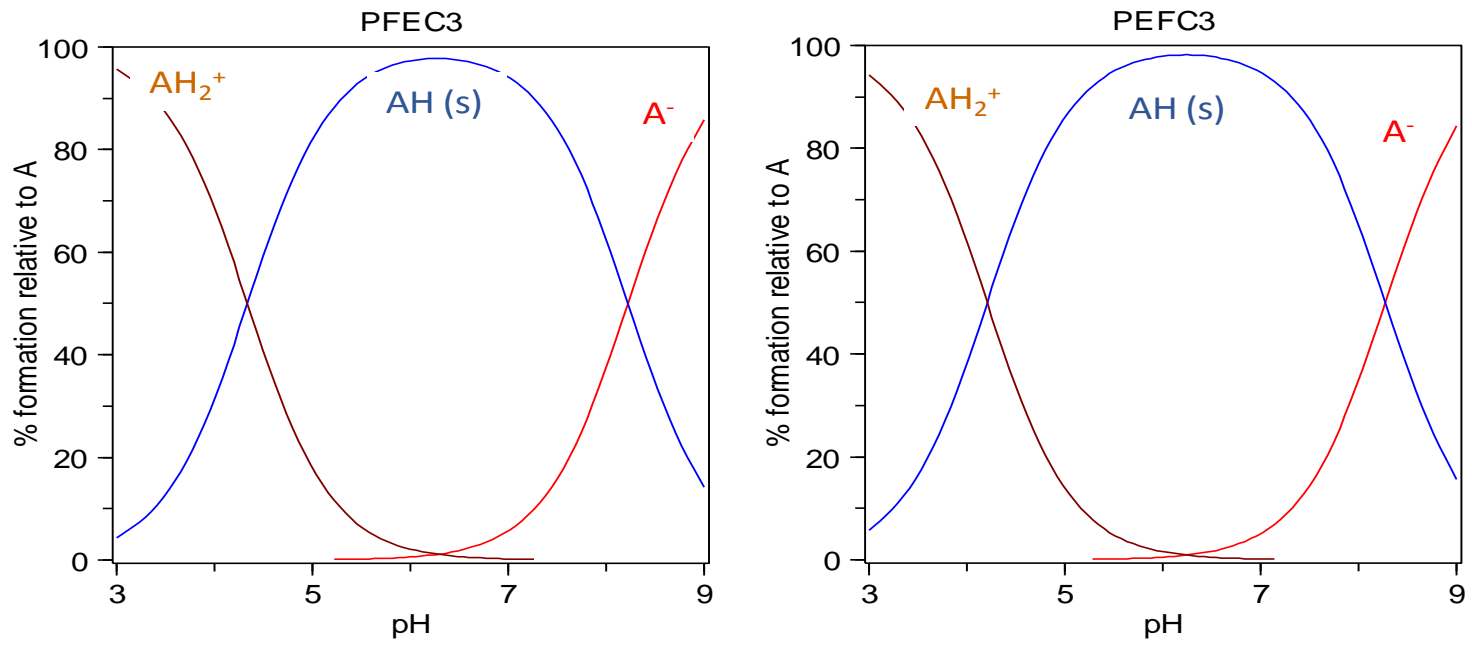

S.I. 6.2.2.1 Speciation diagrams for compounds $\mathbf{9}$ (left) and $\mathbf{1 1}$ (right).
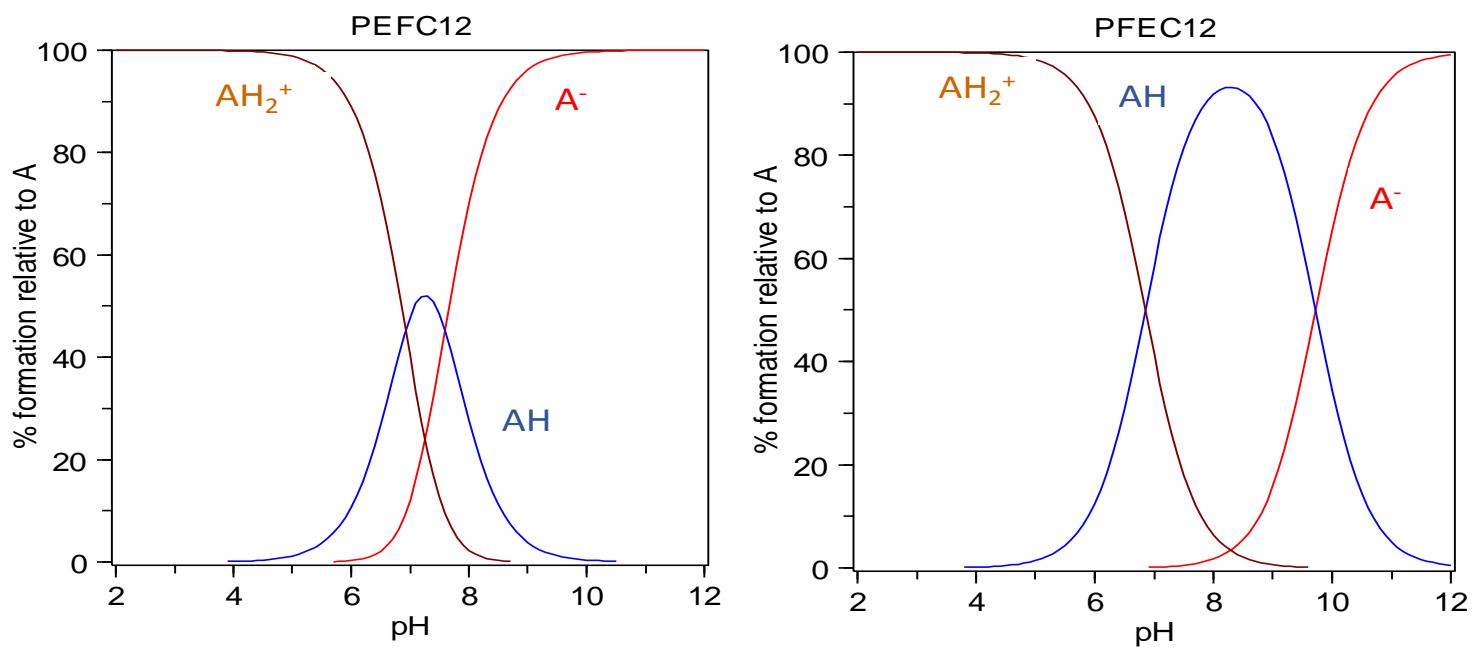

S.I. 6.2.2.2 Speciation diagrams for compounds $\mathbf{1 0}$ (left) and $\mathbf{1 2}$ (right).

S.I. 6.2.3 Kinetic studies with $p$-nitro-benzaldehyde and cyclohexanone

A set of gels/aggregates of compounds $\mathbf{1 0}$ and $\mathbf{1 2}$ at the same concentration $\left(6.5 \cdot 10^{-3} \mathrm{mmol}\right.$ in $2 \mathrm{~mL}$ of phosphate buffer $0.1 \mathrm{M}$ at $\left.\mathrm{pH}=7\right)$ were prepared as previously 
described. After $4 \mathrm{~h}$ of incubation at room temperature increasing amounts of $p$-nitrobenzaldehyde (substrate) and cyclohexanone were added keeping constant cyclohexanone:aldehyde ratio (10:1). The catalytic reaction took place for $60 \mathrm{~min}$ at room temperature. To determine the yield by ${ }^{1} \mathrm{H} N M R$ a direct extraction with $1 \mathrm{~mL}$ of $\mathrm{CDCl}_{3}$ was performed.
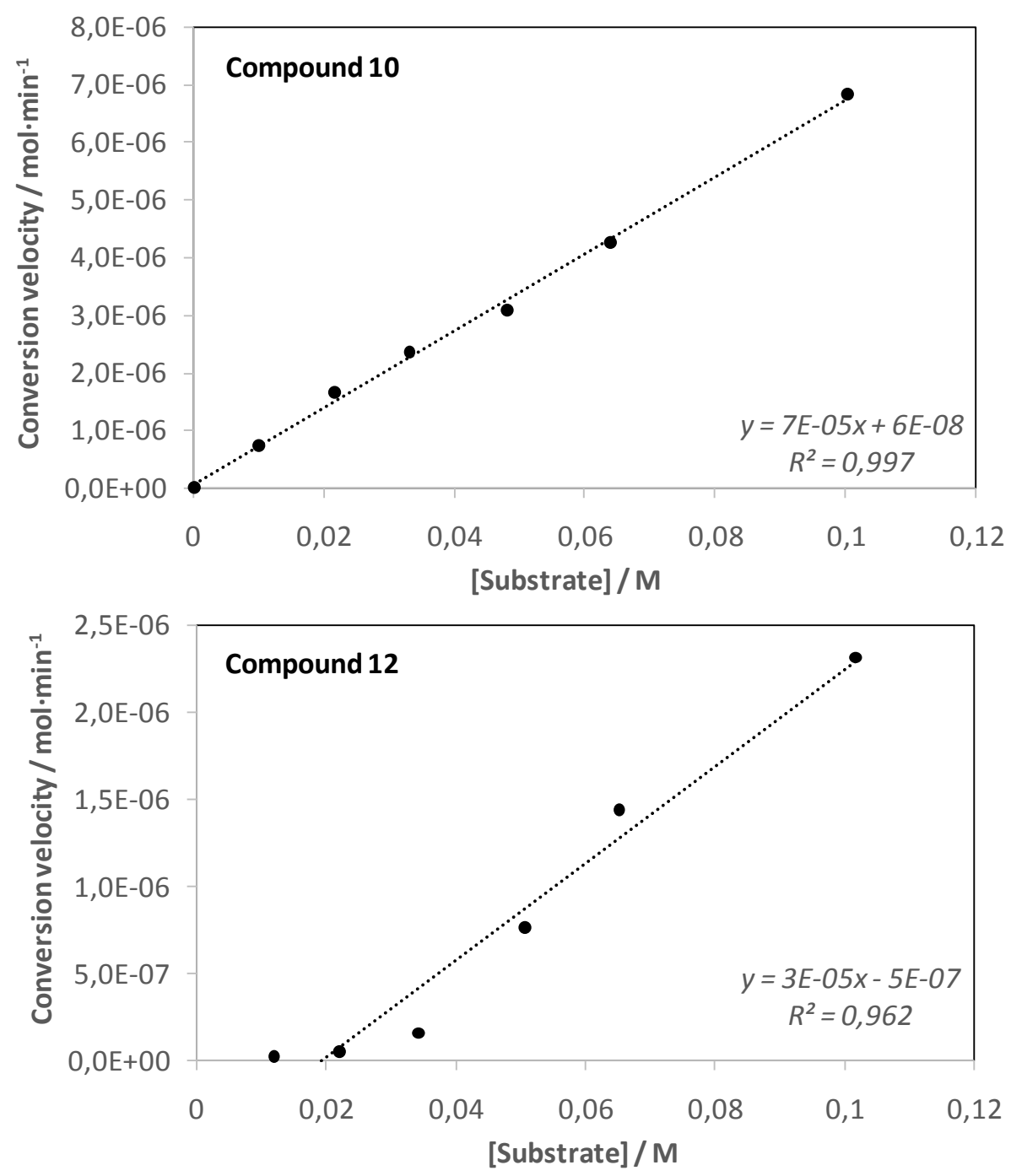

S.I. 6.2.3.1 Reaction kinetics profile for compounds 10 and $\mathbf{1 2}$.

S.I. 6.2.4 ANS (1-anilinonaphthalene-8-sulphonate) fluorescence assay

Gels/aggregates of compound 10 and 12 were prepared at $3 \mathrm{mM}$ in $1 \mathrm{~mL}$ of phosphate buffer $0.1 \mathrm{M}$ at $\mathrm{pH}=7$. For compounds $\mathbf{2 7}$ and $\mathbf{2 8}$ the gels were prepared at $7.5 \mathrm{mM}$ in $1 \mathrm{~mL}$ of phosphate buffer $0.5 \mathrm{M}$. After the incubation of the samples during 4 $\mathrm{h}$ at room temperature, $20 \mu \mathrm{L}$ of a stock solution of ANS (20 mg of ANS in $25 \mathrm{~mL}$ of 
distilled water) were added on the top. Samples were broken and stirred to ensure ANS distribution and fluorescence was recorded at $\lambda_{\mathrm{ex}}=380 \mathrm{~nm}$ from 390 to $600 \mathrm{~nm}$.

S.I. 6.2.5 Cyclohexanone incorporation experiment ( $\left.{ }^{1} \mathrm{H} N M R\right)$

Samples of compounds 10, 12, 27 and 28 at $6 \mathrm{mM}$ in phosphate buffer $0.1 \mathrm{M}$ in $\mathrm{D}_{2} \mathrm{O}(\mathrm{pH}=7)$ were prepared by the heating-cooling methodology. After leaving the samples to cool down until room temperature, $2 \mu \mathrm{L}$ of cyclohexanone were added in each one. The samples were stirred in order to ensure cyclohexanone distribution around the sample and transferred into an NMR tube. A blank with the same amount of cyclohexanone in phosphate buffer (without any compound) and an internal standard (hydroquinone $5 \mathrm{mM}$ ) was used to determine the internalisation ratio.

\section{S.I. 6.2.6 Wide angle X-ray powder diffraction}

Hydrogel of compound $10(2 \mathrm{mM})$ was lyophilised and the fluffy white solid obtained was placed onto a sample holder. Data were collected as previously described in S.I. 4.1.7.

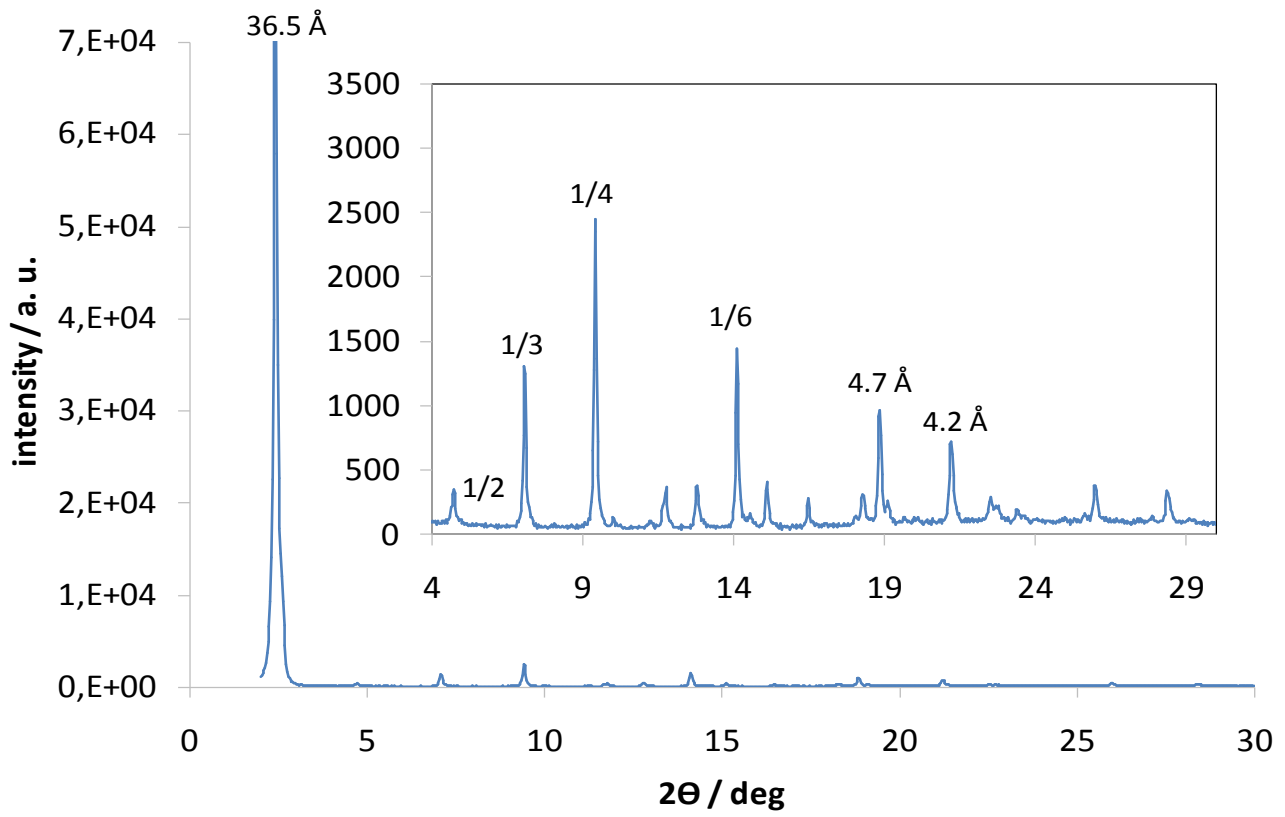

S.I. 6.2.6.1 Wide-angle X-ray powder diffraction of a freeze-dried hydrogel of compound 10 at $2 \mathrm{mM}$. 


\section{S.I. 6.3 Biomimetic catalysis}

S.I. 6.3.1 Catalytic conditions for self-condensation of aldehydes

Gels, aggregates or solutions of compounds $9-12\left(6.5 \cdot 10^{-3} \mathrm{mmol}\right.$ in $2 \mathrm{~mL}$ of phosphate buffer $0.1 \mathrm{M}$ at $\mathrm{pH}=7$ ) were prepared using the heating-cooling methodology previously described. Samples were incubated at room temperature during $4 \mathrm{~h}$ and after that $65 \cdot 10^{-3} \mathrm{mmol}$ of the different aldehydes solubilized in $50 \mu \mathrm{L}$ of DMSO were added on the top of the gel/aggregates. Catalytic reaction took place at room temperature without stirring. To determine the reaction yield by ${ }^{1} \mathrm{H} N M R$ a direct extraction with $1 \mathrm{~mL}$ of $\mathrm{CDCl}_{3}$ was performed for compounds 29a, 30 and 31. For other aldehydes (29b, 29c) extraction with $\mathrm{CH}_{2} \mathrm{Cl}_{2}(3 \times 2 \mathrm{~mL})$ was carried out, solvent was dried with anhydrous $\mathrm{MgSO}_{4}$ and removed under vacuum. The crude product was dissolved in $1 \mathrm{~mL}$ of $\mathrm{CDCl}_{3}$ with an internal standard (mesitylene chloride) to determine the yield by ${ }^{1} \mathrm{H}$ NMR.
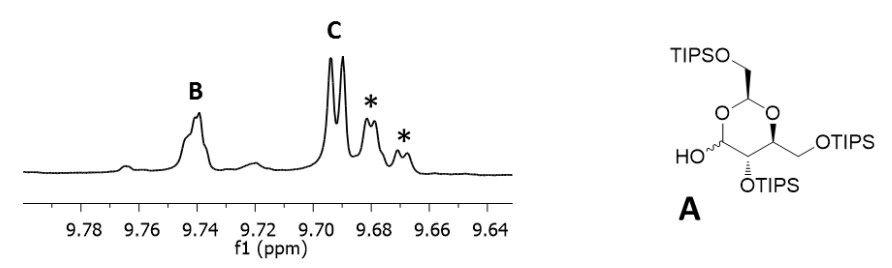

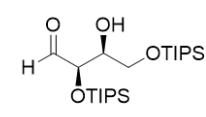

B

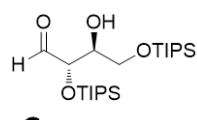

A

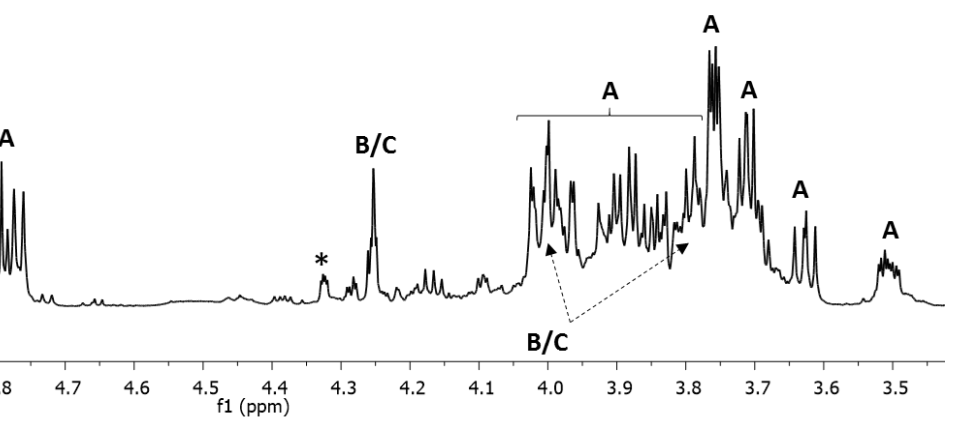

S.I. 6.3.1.1: ${ }^{1} \mathrm{H}$ NMR spectra of reaction crude product after $15 \mathrm{~h}$ using aldehyde $29 \mathrm{~b}$ and catalyst 10 . The formation of $\mathrm{A}-\mathrm{C}$ was detected by ${ }^{1} \mathrm{H}$ NMR and also by mass spectrometry. $[\mathrm{A}+\mathrm{Na}]^{+}=671.5 .[\mathrm{A}+\mathrm{K}]^{+}=687.4$, $[\mathrm{C} / \mathrm{B}+\mathrm{Na}]^{+}=455.3 .{ }^{17}$ 


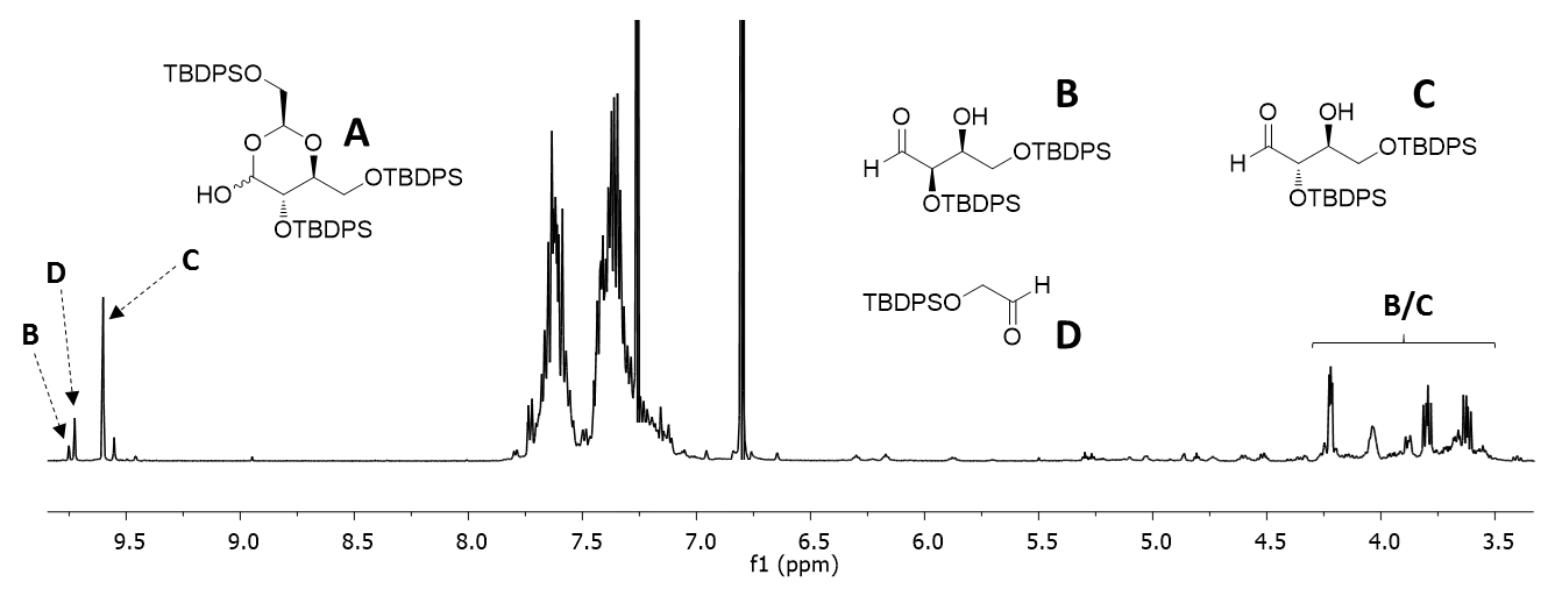

S.I. 6.3.1.2: ${ }^{1} \mathrm{H}$ NMR spectra of reaction crude product after $15 \mathrm{~h}$ using aldehyde $29 \mathrm{c}$ and catalyst 10 . The formation of B-D was detected by ${ }^{1} \mathrm{H}$ NMR and also by mass spectrometry. $[\mathrm{C} / \mathrm{B}+\mathrm{Na}]^{+}=619.2,[\mathrm{C} / \mathrm{B}-\mathrm{H}]^{-}=$ 595.4. ${ }^{6 \mathrm{~d}}$

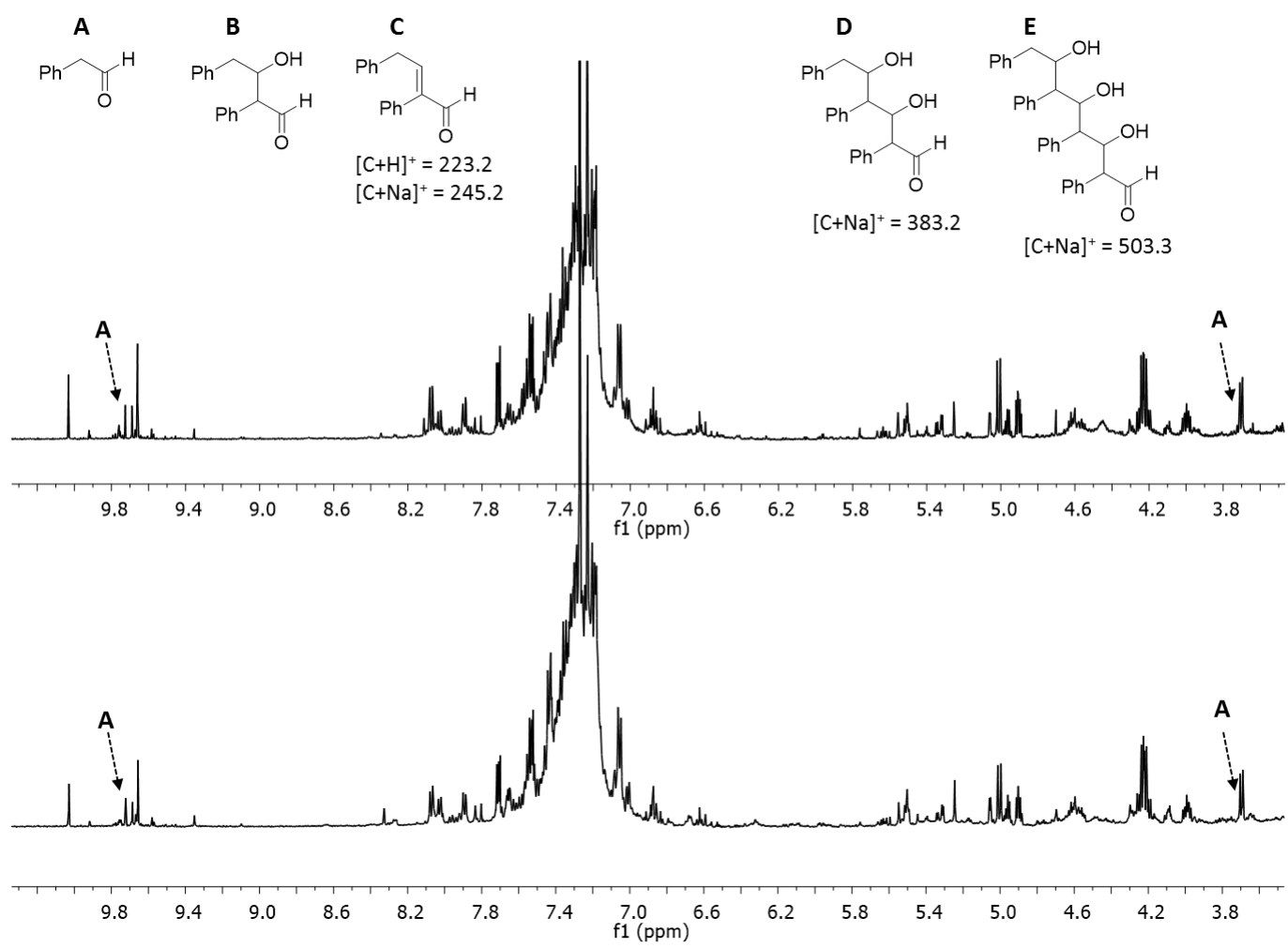

S.I. 6.3.1.3 ${ }^{1} \mathrm{H}$ NMR of the mixture of compounds obtained using catalyst $\mathbf{1 0}$ (top) and $\mathbf{1 2}$ (bottom) and aldehyde 30. The formation polycondensation products was detected by ${ }^{1} \mathrm{H}$ NMR and also by mass spectrometry. 


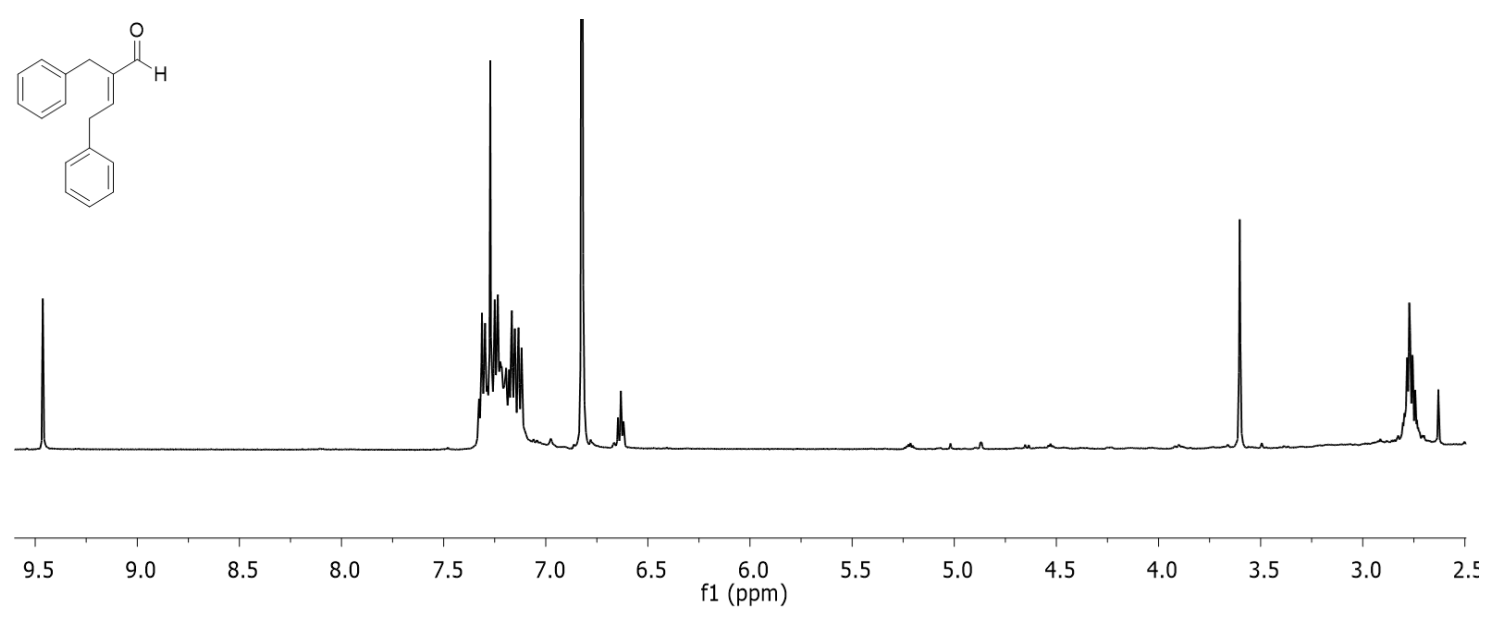

S.I. 6.3.1.4 ${ }^{1} \mathrm{H}$ NMR spectra of the dehydrated compound obtained using catalyst $\mathbf{1 0}$ and $\mathbf{1 2}$ and aldehyde 31. $[\mathrm{M}+\mathrm{Na}]^{+}=273.2,[\mathrm{M}+\mathrm{K}]^{+}=289.2$

S.I. 6.3.2 Chemical correlation of aldol product from 29c

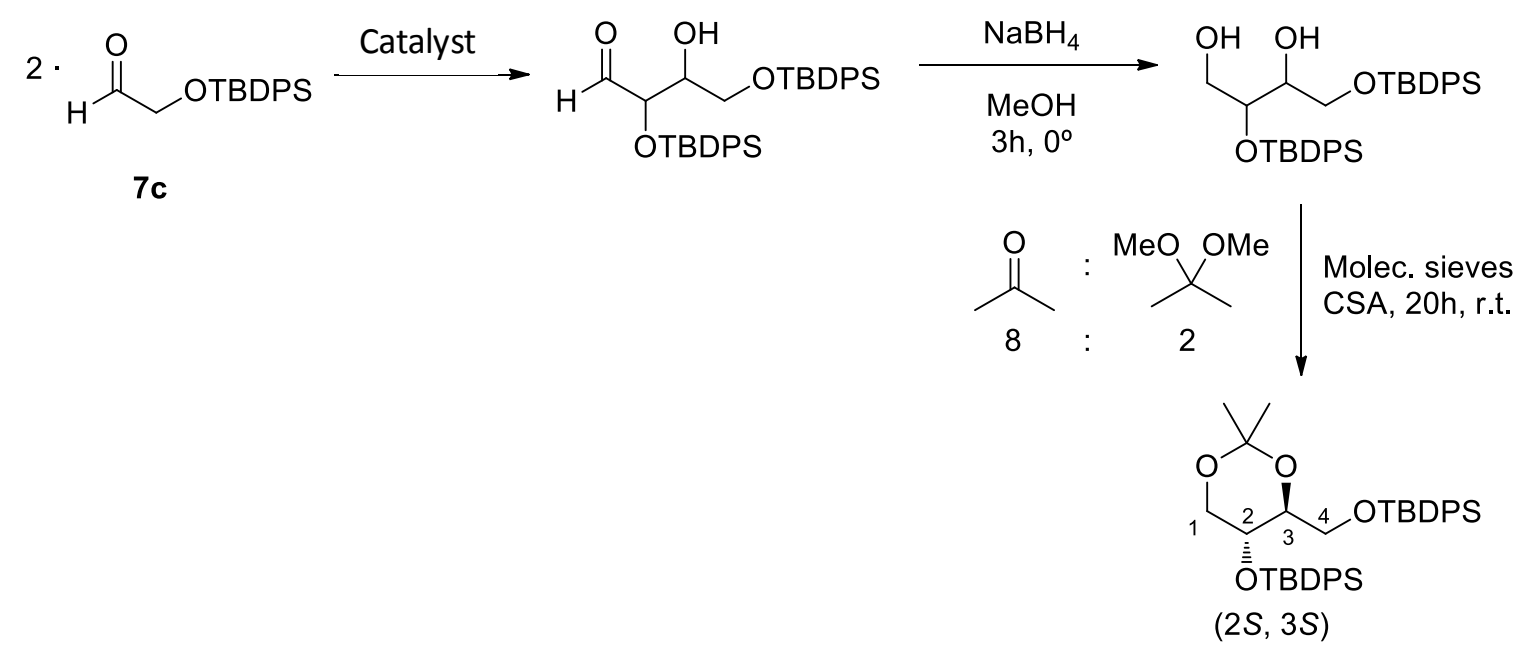

The enantiomeric purity of the anti-aldol obtained by self-condensation of aldehyde $\mathbf{2 9 c}$ with catalyst $\mathbf{1 0}$ or $\mathbf{1 2}$ was determined by chemical correlation to the corresponding acetonide, as follows: reduction of the crude aldol mixture with $\mathrm{NaBH}_{4}$ and silica gel chromatography of the mixture of diols (9:1 hexane:ethyl acetate). Then, acetonide formation with 2, 2-dimethoxy propane and camphorsulfonic acid as catalyst. The anti-isomer of the acetonide was isolated by silica gel chromatography (99:1 hexane:ethyl acetate) as a clear, colorless oil. ${ }^{1} \mathrm{H} N M R\left(500 \mathrm{MHz}, \mathrm{CDCl}_{3}\right): \delta$ 7.72-7.66 (m, $\left.4 \mathrm{H}, \mathrm{CH}_{\mathrm{ar}}\right), 7.62-7.58\left(\mathrm{~m}, 4 \mathrm{H}, \mathrm{CH}_{\mathrm{ar}}\right), 7.44-7.37\left(\mathrm{~m}, 4 \mathrm{H}, \mathrm{CH}_{\mathrm{ar}}\right), 7.37-7.28\left(\mathrm{~m}, 8 \mathrm{H}, \mathrm{CH}_{\mathrm{ar}}\right), 3.89$ (dd, $1 \mathrm{H}, J=11,1.7 \mathrm{~Hz}, \mathrm{H}_{4}$ ), 3.87 (ddd, $\left.1 \mathrm{H}, J=9,5.6,1.7 \mathrm{~Hz}, \mathrm{H}_{3}\right), 3.77(\mathrm{dt}, 1 \mathrm{H}, J=9,5.7 \mathrm{~Hz}$, $\left.\mathrm{H}_{2}\right), 3.70\left(\mathrm{dd}, 1 \mathrm{H}, J=11,5.6 \mathrm{~Hz}, \mathrm{H}_{4^{\prime}}\right), 3.58\left(\mathrm{dd}, 1 \mathrm{H}, J=11.3,9 \mathrm{~Hz}, \mathrm{H}_{1}\right), 3.53(\mathrm{dd}, 1 \mathrm{H}, J=$ 
11.3, $5.7 \mathrm{~Hz}, \mathrm{H}_{1^{\prime}}$ ), 1.47 (s, 3H, Meacet), 1.34 (s, 3H, Meacet), 1.02 (s, 9H, tBu), 1.01 (s, 9H, tBu); ${ }^{13} \mathrm{C}$ NMR (125 MHz, $\left.\mathrm{CDCl}_{3}\right): \delta 135.9,135.8,135.7,135.6\left(2 \times \mathrm{CH}_{\mathrm{ar}}\right), 134.0,133.9$, 133.8, 133.2 ( $\left(\mathrm{Cq}_{\mathrm{ar}}\right), 129.8\left(2 \times \mathrm{CH}_{\mathrm{ar}}\right), 129.4,129.3\left(\mathrm{CH}_{\mathrm{ar}}\right), 127.7,127.6,127.5,127.4(2 \times$ $\left.\mathrm{CH}_{\mathrm{ar}}\right), 98.3\left(\mathrm{Cq}_{\text {acet }}\right), 75.6\left(\mathrm{C}_{3}\right), 65.0\left(\mathrm{C}_{2}\right), 64.8\left(\mathrm{C}_{1}\right), 64.0\left(\mathrm{C}_{4}\right), 28.4\left(\mathrm{CH}_{3}\right.$, acet $), 26.9\left(3 \times \mathrm{CH}_{3}\right.$, $t \mathrm{Bu}), 26.8$ (3 $\left.\mathrm{x} \mathrm{CH}_{3}, t \mathrm{Bu}\right), 19.4\left(\mathrm{CH}_{3}\right.$, acet), 19.3 ( $\left.\mathrm{Cq}, t \mathrm{Bu}\right), 19.2$ (Cq, $\left.t \mathrm{Bu}\right)$; HRMS (ESI) exact mass calcd. for $[\mathrm{M}+\mathrm{Na}]^{+}\left(\mathrm{C}_{39} \mathrm{H}_{50} \mathrm{NaO}_{4} \mathrm{Si}_{2}\right)$ requires $\mathrm{m} / \mathrm{z} 661.3145$, found $\mathrm{m} / \mathrm{z} 661.3130$. The absolute configuration of the major enantiomer $(2 S, 3 S)$ was assigned by comparison of the optical rotation of the acetonide with the published data: found $[\alpha]_{D}$ $=-3.3 \pm 0.6\left(c=0.85, \mathrm{CHCl}_{3}\right)$, lit. $[\alpha]_{D}=-6.1\left(c=2.2, \mathrm{CHCl}_{3}\right) \cdot{ }^{6 \mathrm{~d}}$ The enantiomeric purity of the acetonide (e.r. 91:9) was determined by HPLC analysis using a Daicel Chiralpak IA (hexane, $1 \mathrm{~mL} / \mathrm{min})$ : $(2 S, 3 S)$ anti-isomer $\mathrm{t}_{\mathrm{r}}=4.4 \mathrm{~min},(2 R, 3 R)$ anti-isomer $\mathrm{t}_{\mathrm{r}}=6.3 \mathrm{~min}$.

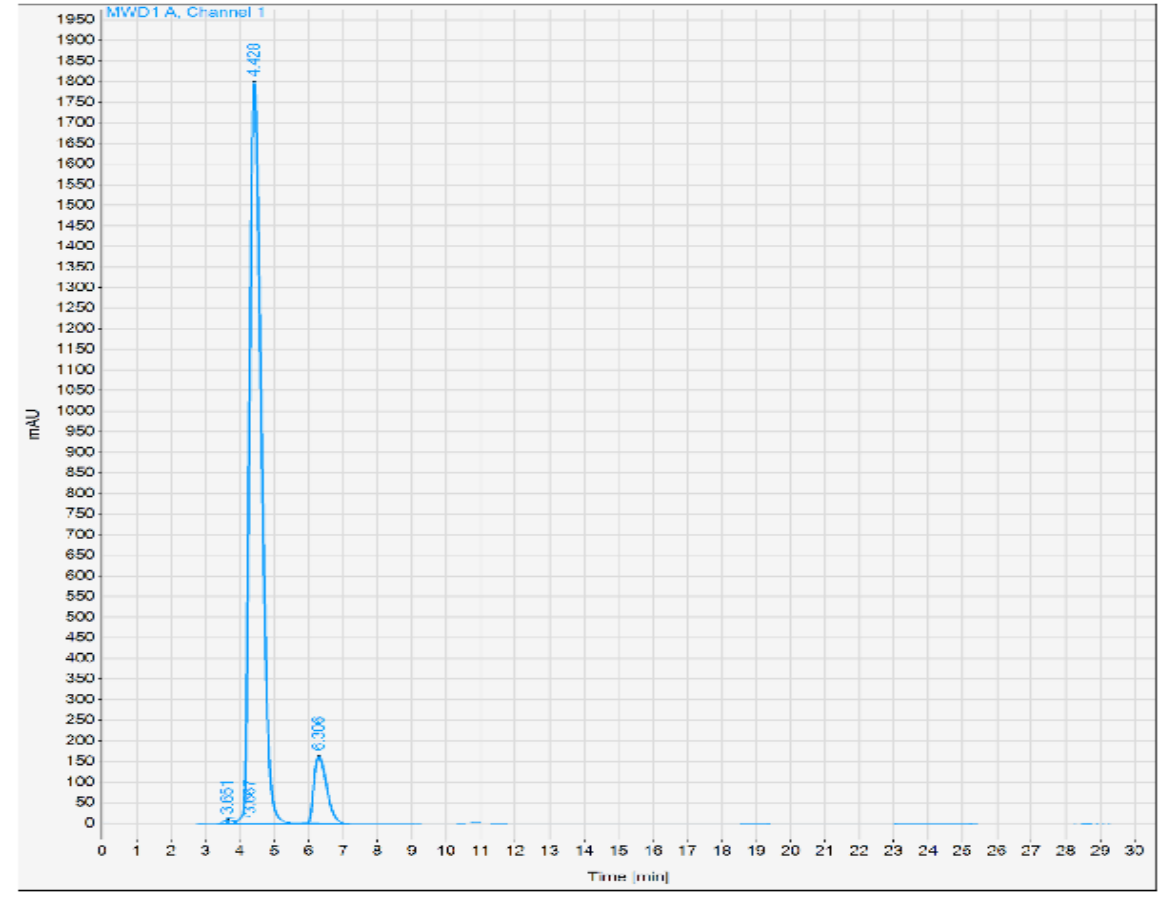

S.I. 6.3.2.1. HPLC analysis of aldol product of 29c.

\section{S.I. 6.4 Synthesis and characterisation data}

S.I. 6.4.1 Synthesis and characterisation data of decapeptides (at U. Ben Gurion, IL) (27-28)

Chemical and reagents were purchased from Aldrich or Merck and used without further purification. Protected amino acids, resins and coupling reagents were 
purchased from Novabiochem. DMF was purchased in biotech grade. Peptides were synthesized on solid phase using MBHA resin. Four-fold excess of Fmoc-amino acids relative to the Rink amide $\mathrm{MBHA}$ resin (loading $0.54 \mathrm{mmol} / \mathrm{g}$ ) was used. Coupling was performed using 1:1:20 amino acid/HBTU/DIPEA in DMF for 45 minutes to 2 hours. Deprotection was performed using 25\% piperidine/DMF twice, for 8 minutes each time. DMF top washes were performed between deprotection and coupling steps. A mixture of trifluoroacetic acid, water and tri-isopropylsilane (95:2.5:2.5) was added to the resin and stirred for 2 hours, to cleave the peptide off the resin and for side chain global deprotection. The resin was removed by filtration and TFA was evaporated out of the peptide mixture by controlled air flow. 8 to 10 times volume of cold diethtyl ether was added to precipitate the crude peptide. All peptides were then purified by preparative HPLC using a C18 reverse phase column (Phenomenex Gemini-NX), with a step gradient of solvent $\mathrm{A}\left(0.1 \mathrm{M} \mathrm{NH}_{4} \mathrm{HCO}_{3}\right.$ in water; $\mathrm{pH}=8$ ) and $\mathrm{B}$ (acetonitrile). Peptides were further analyzed by two methods: (i) reverse phase analytical HPLC (Dionex 1100), using a C18 column and a linear $\mathrm{NH}_{4} \mathrm{HCO}_{3}$ buffer and acetonitrile gradient, and (ii) Mass spectrometry analysis was performed by ESI-MS (LC-MS Thermo Surveyor 355), in order to verify the molecular weight.

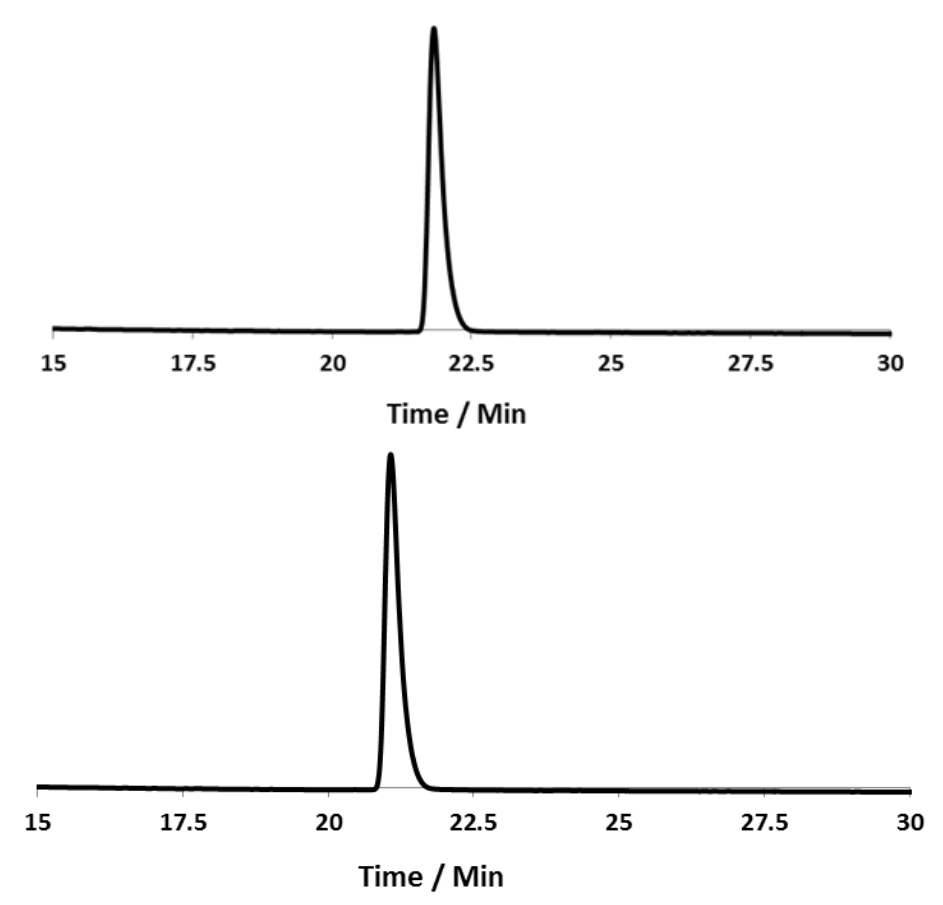

S.I.6.4.1.1 HPLC trace of purified compound 27 (top) and 28 (bottom). 

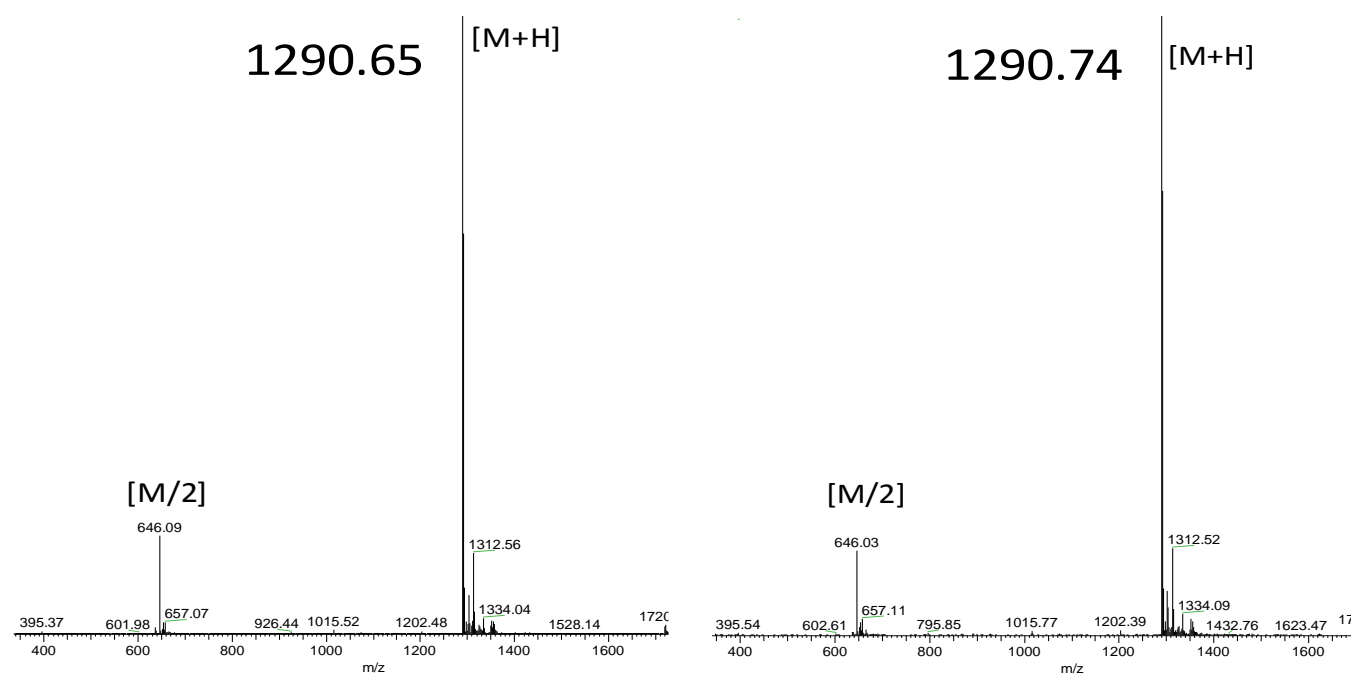

S.I.6.4.1.2 ESI-MS of purified compounds 27 (left) and 28 (right).

S.I. 6.4.2 Synthesis and characterisation data of aldehydes 29-31

Aldehydes 29a, 30 and 31 are commercially available. Aldehyde 29a was used as glycolaldehyde dimer. Compounds $\mathbf{2 9 b}$ and $\mathbf{2 9 c}$ were synthesised as previously reported and ${ }^{1} \mathrm{H}$ and ${ }^{13} \mathrm{C}$ NMR spectra were in good agreement with the published spectra. ${ }^{25}$ 


\subsection{References}

1. a) Raynal, M.; Ballester, P.; Vidal-Ferran, A.; van Leeuwen, P. W. N. M., Supramolecular catalysis. Part 1: non-covalent interactions as a tool for building and modifying homogeneous catalysts. Chem. Soc. Rev. 2014, 43, 1660-1733; b) van Leeuwen, P. W., Supramolecular catalysis. John Wiley \& Sons 2008.

2. a) Lehn, J.-M., Perspectives in chemistry-steps towards complex matter. Angew. Chem. Int. Ed. 2013, 52, 2836-2850; b) Barnard, A.; Smith, D. K., Self-assembled multivalency: Dynamic ligand arrays for high-affinity binding. Angew. Chem. Int. Ed. 2012, 51, 6572-6581; c) Lehn, J.-M., Toward complex matter: Supramolecular chemistry and self-organization. Proc. Natl. Acad. Sci. 2002, 99, 4763-4768.

3. Segarra-Maset, M. D.; Nebot, V. J.; Miravet, J. F.; Escuder, B., Control of molecular gelation by chemical stimuli. Chem. Soc. Rev. 2013, 42, 7086-98.

4. a) Raynal, M.; Ballester, P.; Vidal-Ferran, A.; van Leeuwen, P. W. N. M., Supramolecular catalysis. Part 2: artificial enzyme mimics. Chem. Soc. Rev. 2014, 43, 1734-1787; b) Meeuwissen, J.; Reek, J. N. H., Supramolecular catalysis beyond enzyme mimics. Nat. Chem. 2010, 2, 615-621; c) Gao, Y.; Zhao, F.; Wang, Q.; Zhang, Y.; Xu, B., Small peptide nanofibers as the matrices of molecular hydrogels for mimicking enzymes and enhancing the activity of enzymes. Chem. Soc. Rev. 2010, 39, 3425-3433.

5. Lewandowski, B.; Wennemers, H., Asymmetric catalysis with short-chain peptides. Curr. Opin. Chem. Biol. 2014, 22, 40-46.

6. a) List, B.; Lerner, R. A.; Barbas, C. F., Proline-catalyzed direct asymmetric aldol reactions. J. Am. Chem. Soc. 2000, 122, 2395-2396; b) List, B.; Hoang, L.; Martin, H. J., New mechanistic studies on the proline-catalyzed aldol reaction. Proc. Natl. Acad. Sci. 2004, 101, 5839-5842; c) Northrup, A. B.; MacMillan, D. W. C., Twostep synthesis of carbohydrates by selective aldol reactions. Science 2004, 305, 1752-1755; d) Northrup, A. B.; Mangion, I. K.; Hettche, F.; MacMillan, D. W. C., Enantioselective organocatalytic direct aldol reactions of $\alpha$-oxyaldehydes: Step one in a two-step synthesis of carbohydrates. Angew. Chem. Int. Ed. 2004, 43, 2152-2154; e) Cordova, A.; Engqvist, M.; Ibrahem, I.; Casas, J.; Sunden, H., Plausible origins of homochirality in the amino acid catalyzed neogenesis of carbohydrates. Chem. Commun. 2005, 2047-2049.

7. a) Rodríguez-Llansola, F.; Escuder, B.; Miravet, J. F., Remarkable increase in basicity associated with supramolecular gelation. Org. Biomol. Chem. 2009, 7, 3091-3094; b) Rodríguez-Llansola, F.; Escuder, B.; Miravet, J. F., Switchable perfomance of an L-Proline-derived basic catalyst controlled by supramolecular gelation. J. Am. Chem. Soc. 2009, 131, 11478-11484.

8. Mase, N.; Barbas, C. F., In water, on water, and by water: mimicking nature's aldolases with organocatalysis and water. Org. Biomol. Chem. 2010, 8, 40434050 . 
9. Mase, N.; Nakai, Y.; Ohara, N.; Yoda, H.; Takabe, K.; Tanaka, F.; Barbas, C. F., Organocatalytic direct asymmetric aldol reactions in water. J. Am. Chem. Soc. 2006, 128, 734-735.

10. Hayashi, Y.; Aratake, S.; Okano, T.; Takahashi, J.; Sumiya, T.; Shoji, M., Combined proline-surfactant organocatalyst for the highly diastereo- and enantioselective aqueous direct cross-aldol reaction of aldehydes. Angew. Chem. Int. Ed. 2006, 45, 5527-5529.

11. Duschmale, J.; Kohrt, S.; Wennemers, H., Peptide catalysis in aqueous emulsions. Chem. Commun. 2014, 50, 8109-8112.

12. a) Berdugo, C.; Miravet, J. F.; Escuder, B., Substrate selective catalytic molecular hydrogels: the role of the hydrophobic effect. Chem. Commun. 2013, 49, 1060810610; b) Rodríguez-Llansola, F.; Miravet, J. F.; Escuder, B., A supramolecular hydrogel as a reusable heterogeneous catalyst for the direct aldol reaction. Chem. Commun. 2009, 7303-7305.

13. Mlynarski, J.; Gut, B., Organocatalytic synthesis of carbohydrates. Chem. Soc. Rev. 2012, 41, 587-596.

14. a) Rubinov, B.; Wagner, N.; Rapaport, H.; Ashkenasy, G., Self-replicating amphiphilic $\beta$-sheet peptides. Angew. Chem. Int. Ed. 2009, 48, 6683-6686; b) Bowerman, C. J.; Nilsson, B. L., Review self-assembly of amphipathic beta-sheet peptides: Insights and applications. Biopolymers 2012, 98, 169-184.

15. a) Tena-Solsona, M.; Miravet, J. F.; Escuder, B., Tetrapeptidic molecular hydrogels: self-assembly and co-aggregation with amyloid fragment A $\beta 1-40$. Chem. Eur. J 2014, 20, 1023-1031; b) Tena-Solsona, M.; Alonso-de Castro, S.; Miravet, J. F.; Escuder, B., Co-assembly of tetrapeptides into complex pHresponsive molecular hydrogel networks. J. Mat. Chem. B 2014, 2, 6192-6197.

16. Brogan, A. P.; Dickerson, T. J.; Janda, K. D., Enamine-based aldol organocatalysis in water: Are they really "all wet"? Angew. Chem. Int. Ed. 2006, 45, 8100-8102.

17. Burroughs, L.; Clarke, P. A.; Forintos, H.; Gilks, J. A. R.; Hayes, C. J.; Vale, M. E.; Wade, W.; Zbytniewski, M., Asymmetric organocatalytic formation of protected and unprotected tetroses under potentially prebiotic conditions. Org. Biomol. Chem. 2012, 10, 1565-1570.

18. Anand, U.; Mukherjee, M., Exploring the self-assembly of a short aromatic $A \beta(16-$ 24) peptide. Langmuir 2013, 29, 2713-2721.

19. a) Pashuck, E. T.; Cui, H.; Stupp, S. I., Tuning supramolecular rigidity of peptide fibers through ,molecular structure. J. Am. Chem. Soc. 2010, 132, 6041-6046; b) Cinar, G.; Ceylan, H.; Urel, M.; Erkal, T. S.; Deniz Tekin, E.; Tekinay, A. B.; Dâna, A.; Guler, M. O., Amyloid inspired self-assembled peptide nanofibers. Biomacromolecules 2012, 13, 3377-3387.

20. Davie, E. A. C.; Mennen, S. M.; Xu, Y.; Miller, S. J., Asymmetric catalysis mediated by synthetic peptides. Chem. Rev. 2007, 107, 5759-5812. 
21. Lo Nostro, P.; Ninham, B. W., Hofmeister phenomena: An update on ion specificity in biology. Chem. Rev. 2012, 112, 2286-2322.

22. a) Chadha, G.; Zhao, Y., Properties of surface-cross-linked micelles probed by fluorescence spectroscopy and their catalysis of phosphate ester hydrolysis. J. Colloid Interface Sci. 2013, 390, 151-157; b) Schönbrunn, E.; Eschenburg, S.; Luger, K.; Kabsch, W.; Amrhein, N., Structural basis for the interaction of the fluorescence probe 8-anilino-1-naphthalene sulfonate (ANS) with the antibiotic target MurA. Proc. Natl. Acad. Sci. 2000, 97, 6345-6349.

23. a) Koskinen, A. M. P.; Karisalmi, K., Polyketide stereotetrads in natural products. Chem. Soc. Rev. 2005, 34, 677-690; b) Rohr, J., A new role for polyketides. Angew. Chem. Int. Ed. 2000, 39, 2847-2849.

24. Ruiz-Mirazo, K.; Briones, C.; de la Escosura, A. S., Prebiotic systems chemistry: new perspectives for the origins of life. Chem. Rev. 2014, 114, 285-366.

25. a) Abraham, E.; Davies, S. G.; Millican, N. L.; Nicholson, R. L.; Roberts, P. M.; Smith, A. D., Asymmetric synthesis of vicinal amino alcohols: xestoaminol C, sphinganine and sphingosine. Org. Biomol. Chem. 2008, 6, 1655-1664; b) Barbero, A.; Cuadrado, P.; Fleming, I.; Gonzalez, A. M.; Pulido, F. J.; Sánchez, A., Synthesis of vinylsilanes by silyl-cupration of acetylenes using tertbutyldiphenylsilyl-cuprate reagents. J. Chem. Soc., Perkin Trans. 1. 1995, 15251532. 
CHAPTER 7 CONCLUSIONS 

CHAPTER 7

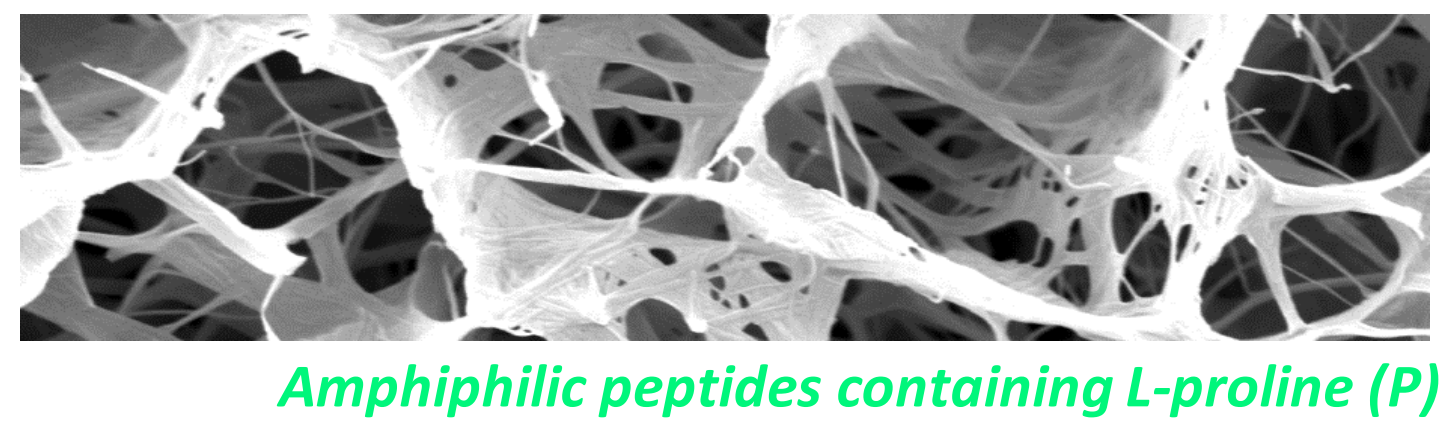





\section{CONCLUSIONS}

Several short amphiphatic hydrogelators derived from amino acids have been designed and successfully synthesised using a step by step procedure in solution. This synthetic route allowed obtaining the compounds in a simple way in good yields and in grams scale without the need of further purification by column chromatography. Besides a solid phase methodology has also been tested for one of the compounds. The comparison between both methodologies set the SPPS as a good strategy to synthesise small amounts of compounds which will be used for an initial screening of hydrogelator properties whereas the synthesis in solution represents a better option to synthesise bigger amounts of those compounds exhibiting the required properties.

Unexpectedly, during preliminary hydrogelation assays the cleavage of benzyloxycarbonyl group in mild basic conditions was detected and studied in detail. A reasonable mechanism has been finally proposed for this unprecedented behaviour highlighting the importance of the anchimeric assistance by $\mathrm{H}$-bonding in a similar way to enzymes perform catalysis with the help of oxyanion holes.

Isomeric acidic tetrapeptides (1-6) containing polar (D) and non-polar amino acids (F) have shown excellent hydrogelation ability by means of GdL hydrolysis. However significant differences among them have been pointed out as a consequence of the amino acid position within the peptide chain. A detailed structural study using $C D$, FTIR, fluorescence and WAXD among other techniques highlighted the key role of hydrophobicity and $\pi$-stacking interactions in the final assemblies. Tentative packing models have been finally built considering the experimental data reported and the presence of segregated blocks of polar and non-polar residues was detected for the best hydrogelators.

Following with the study of these tetrapeptides a more detailed study considering the thermodynamics and kinetics of the fibrillisation process was carried out. Interestingly a general pKa shift was detected due to the aggregation which correlates with the thermodynamics of the aggregation. This pKa shift allows the gel formation around neutrality which is highly convenient for biologically related 
applications. The kinetic study of the aggregation process revealed the presence of an induction time that includes not only the time required for the $\mathrm{pH}$ to reach the thermodynamic aggregation onset but also an extra period where thermodynamically metastable solutions are present. In addition, fluorescence experiments indicated that dimer formation is the rate determining step most likely due to the free activation energy associated to peptide reorganisation. As a consequence of the well-known behaviour of these systems a kinetically self-sorted system was design in which the formation of the least thermodynamically stable aggregate was achieved in a first place. It is known that this kind of kinetic effect could be much more intense in longer peptides such as amyloid proteins and short peptides like the ones we present in this work may be useful in this regard as simple models of amyloid fibrillisation.

Being aware of the role that short peptides play as amyloid aggregation inhibitors a study of the interaction between compounds 1-6 with the amyloid peptide $A \beta 1-40$ was also carried out. Interesting results were found especially for compounds $\mathbf{1}$ and $\mathbf{5}$ which seem to act as seeds for the aggregation of $A \beta 1-40$. In comparison with other previous peptide systems reported, our compounds possess particular features such as the small size (being just four amino acids) and the absence of any $\beta$-amyloid natural fragment.

On the other hand the combination between acidic tetrapeptides and their basic analogues containing $K$ and $F(\mathbf{7}, \mathbf{8})$ allowed the formation of co-assembled hydrogels at neutral $\mathrm{pH}$ by means of charge screening among oppositely charged ionic residues as well as hydrophobic interactions. Such hydrogel formation methodology is particularly interesting for biomedical applications since no external stimulus is required and these hydrogels can be prepared easily by a simple injection methodology using solutions of the precursors at neutral $\mathrm{pH}$. In addition this approach can also be used to create a chameleonic complex system which is able to maintain gel appearance through all $\mathrm{pH}$ range. We have shown then the dynamic behaviour of these networks that allows the switching between a two-component network at neutral $\mathrm{pH}$ to one-component networks at either basic of acid pH. The particular features of these systems can be used in dye-release field exploiting not only the molecular structure of such loads but also the particular features of the network involved leading interesting differences in the release profile. 
Finally the emergence of catalytic activity upon the self-assembly of short amphiphilic peptides in water has been probed by studying the catalytic properties of proline functionalised aggregates in aldol condensation reactions. Besides, a set of experiments have been performed trying to rationalise the catalytic activity according to the supramolecular structures of the aggregates. In this way pKa shifts of the catalytic group as well as hydrophobicity of catalyst and substrates or accessibility to the catalytic site have been considered. In addition more biologically relevant products such as carbohydrate derivatives have been also obtained by using these heterogeneous catalysts. The overall results are of great value in terms of prebiotic chemistry since the current systems are an example of chemical complexity appearance after the selfassembly. 
ANNEXES 



\section{Annex I: Summary in Spanish}

\section{Tema y objetivos de la tesis}

Debido a la estrecha relación entre el auto-ensamblaje de péptidos y proteínas con las enfermedades de tipo amiloide, ${ }^{1}$ entender los principios que gobiernan este fenómeno resulta de gran interés en la actualidad. El uso de pequeños péptidos como modelos o inhibidores del proceso de fibrilación es considerado una de las mejores aproximaciones debido a su facilidad de síntesis, versatilidad y biocompatibilidad. ${ }^{2}$

Se conoce además que la organización jerárquica de estas fibrillas peptídicas da lugar a menudo a redes auto-ensambladas que retienen el disolvente dando lugar a geles supramoleculares. ${ }^{3}$ Estos materiales soportados mediante interacciones no covalentes presentan multitud de propiedades incluyendo reversibilidad, autoreparación o sensibilidad frente a diferentes estímulos físico-químicos que hacen de ellos unos materiales extremadamente útiles en campos tan diferentes como la biomedicina, la catálisis o la ciencia de materiales. ${ }^{4}$

\section{Autoensamblajejerárquico mediante interacciones no covalentes}

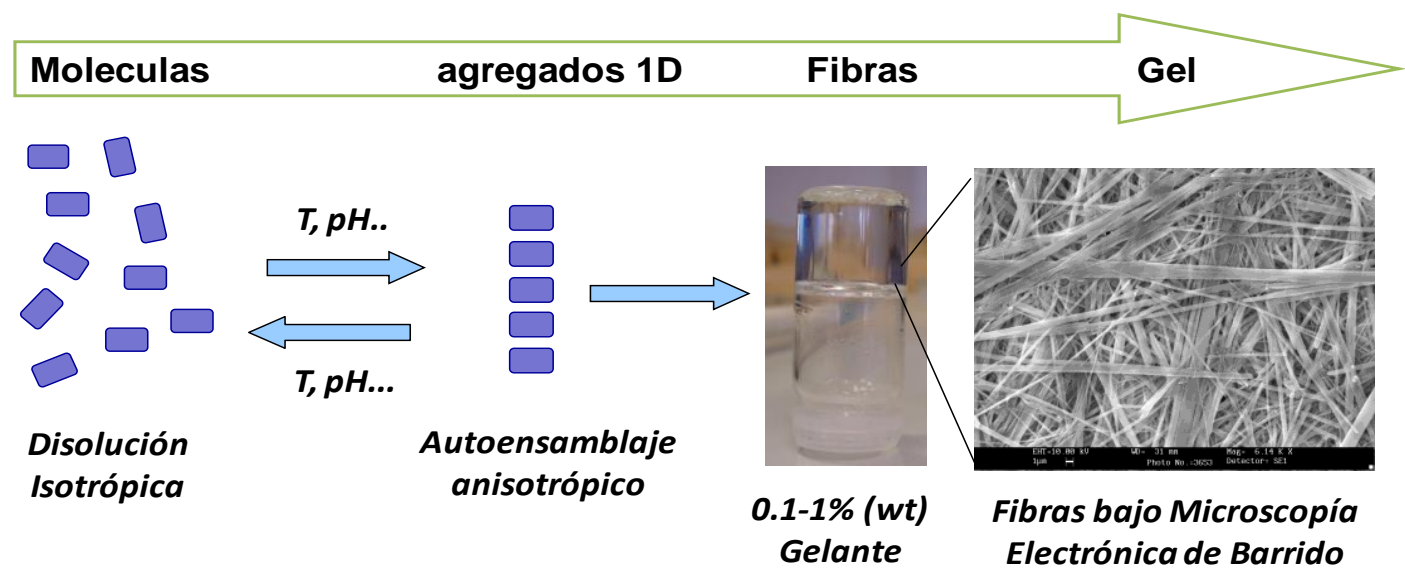

Figura A1 Representación esquemática del auto-ensamblaje jerárquico de los gelantes supramoleculares.

Teniendo en cuenta estas consideraciones durante el transcurso de la presente tesis doctoral se han desarrollado nuevos péptidos anfipáticos con tendencia a la formación de hojas- $\beta$ para:

Profundizar en los fundamentos del auto-ensamblaje proporcionando un mayor entendimiento del complejo proceso de fibrilación.

- Estudiar la habilidad de estos compuestos como hidrogelantes supramoleculares para utilizarlos como catalizadores o materiales que respondan a estímulos. 


\section{Resultados y discusión}

1) Diseño y síntesis de los hidrogelantes supramoleculares

El primer paso para alcanzar los objetivos previamente mencionados consiste en el diseño y la síntesis de los compuestos que posteriormente van a ser estudiados como hidrogelantes. En nuestro caso se han sintetizado tres familias de compuestos anfipáticos derivados de péptidos cuya estructura general se muestra a continuación:

- $\quad$ Tetrapéptidos ácidos formados por L-fenilalanina (F) y L-ácido aspártico (D)

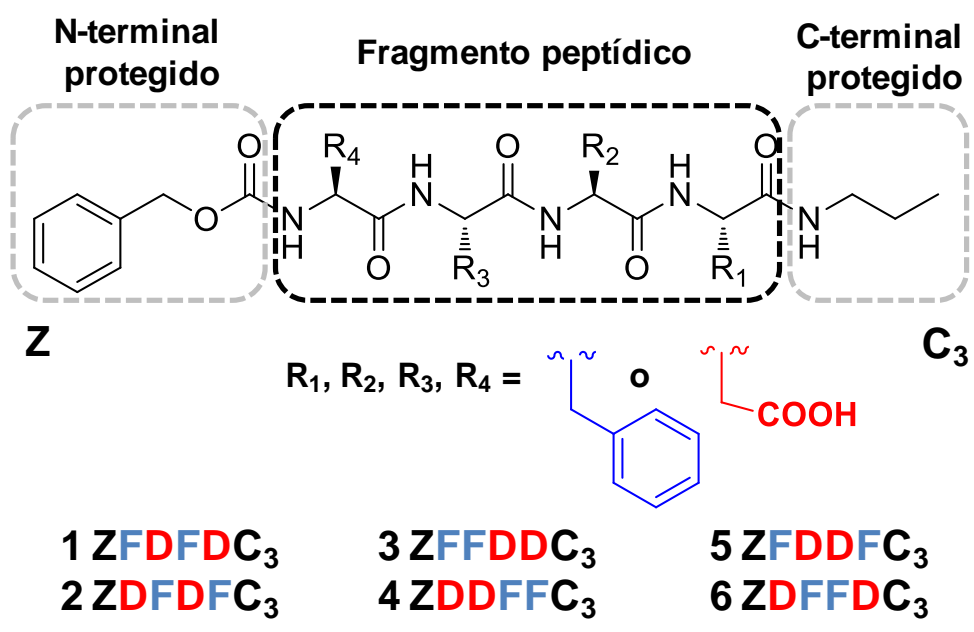

Figura A2 Estructura química de los tetrapéptidos ácidos formados por F y D.

La família de tetrapéptidos isoméricos que se muestra en la Figura A2 combina la presencia de aminoácidos aromáticos (F) y residuos iónicos de aspártico (D). La tendencia de dichos péptidos anfipáticos a la formación de hojas $\beta$ ha sido previamente demostrada en multitud de ocasiones y en nuestro caso, las variaciones sistemáticas en la secuencia de aminoácidos nos permitirán estudiar el papel que desempeña el balance hidrofóbico/hidrofílico en el proceso de fibrilación. Es necesario mencionar que ambos extremos de la cadena peptídica han sido bloqueados usando una pequeña cadena alifática y un grupo protector de tipo benciloxicarbonilo en el extremo $\mathrm{C}$ - y N-terminal respectivamente para evitar ionizaciones adicionales y simplificar de ese modo el análisis del proceso de agregación. 


\section{- Tetrapéptidos básicos formados por L-fenilalanina (F) y L-lisina (K)}

De modo semejante a los tetrapéptidos descritos en el párrafo anterior se han diseñado adicionalmente dos tetrapéptidos básicos que contienen lisina (Figura A3) para estudiar su habilidad como hidrogelantes y posteriormente estudiar su coagregación con sus análogos tetrapeptídicos que contienen aspártico.

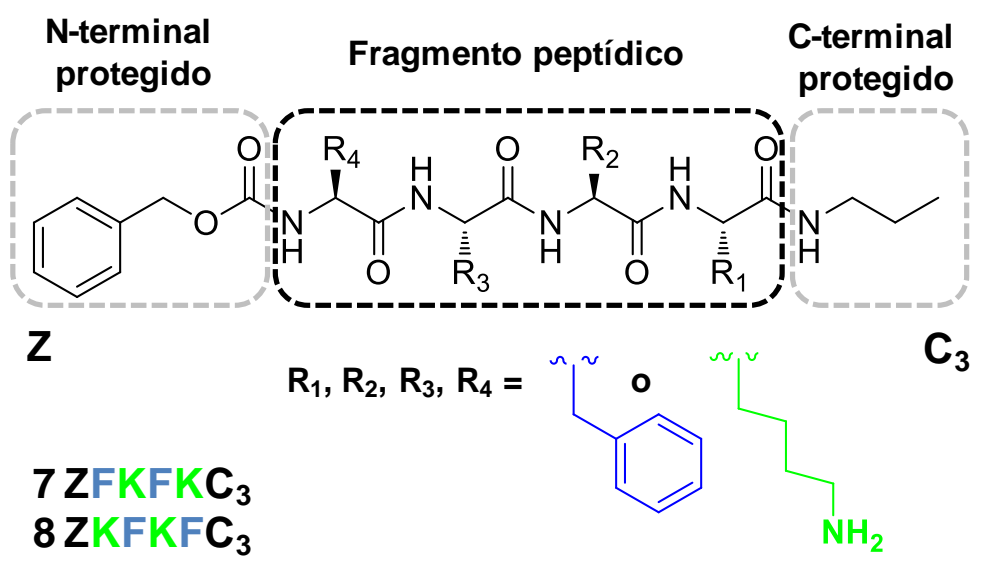

Figura A3 Estructura química de los tetrapéptidos básicos formados por $\mathrm{F}$ y K.

- Tripéptidos anfifílicos formados por L-prolina $(P), L$-fenilalanina $(F)$ y $L$-ácido glutámico (E)

Finalmente una familia de tripéptidos anfifílicos que contienen L-prolina como fragmento funcional ha sido diseñada para su posterior estudio de agregación en agua tamponada y como catalizadores de condensaciones aldólicas.

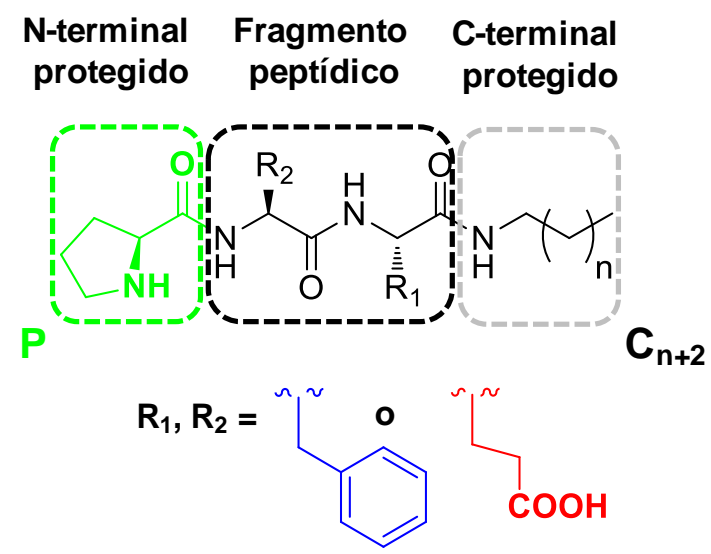

$$
\begin{array}{clll}
9 \mathrm{PFEC}_{3} & 11 & \mathrm{PEFC}_{3} \\
10 \mathrm{PFEC}_{12} & 12 \mathrm{PEFC}_{12}
\end{array}
$$

Figure A4 Estructura química de los tripéptidos anfifílicos formados por $P, F$ y E. 
La síntesis de todos ellos ha sido llevada a cabo mediante una metología por pasos en disolución y los compuestos fueron obtenidos sin dificultad y con buenos rendimientos. Además la purificación se realizó de manera sencilla sin necesidad de cromatografía. Sin embargo, debido a la creciente utilización de fase sólida para la síntesis de derivados peptídicos se ha decidido probar también dicha metodología en la síntesis de uno de nuestros compuestos estableciendo finalmente ventajas e inconvenientes de cada metodología para nuestros propósitos en particular. Así pues se ha establecido que la síntesis en fase sólida podría ser de gran utilidad para fabricar pequeñas cantidades de compuesto destinadas a una evaluación inicial de sus propiedades. La síntesis en disolución sin embargo, podría ser utilizada para la obtención a mayor escala de aquellos que resulten más convenientes en función de dicha evaluación inicial.

También resulta de interés recalcar que durante la síntesis se ha descubierto una inesperada labilidad del grupo Z (benziloxicarbonilo) en condiciones básicas muy suaves. Dicho fenómeno ha sido estudiado para una familia mucho más amplia de compuestos llegándose a la conclusión de que una asistencia anquimérica adicional proporcionada por un puente de hidrógeno entre el carbamato y una amida adyacente resulta fundamental para la desprotección de este grupo. ${ }^{5}$

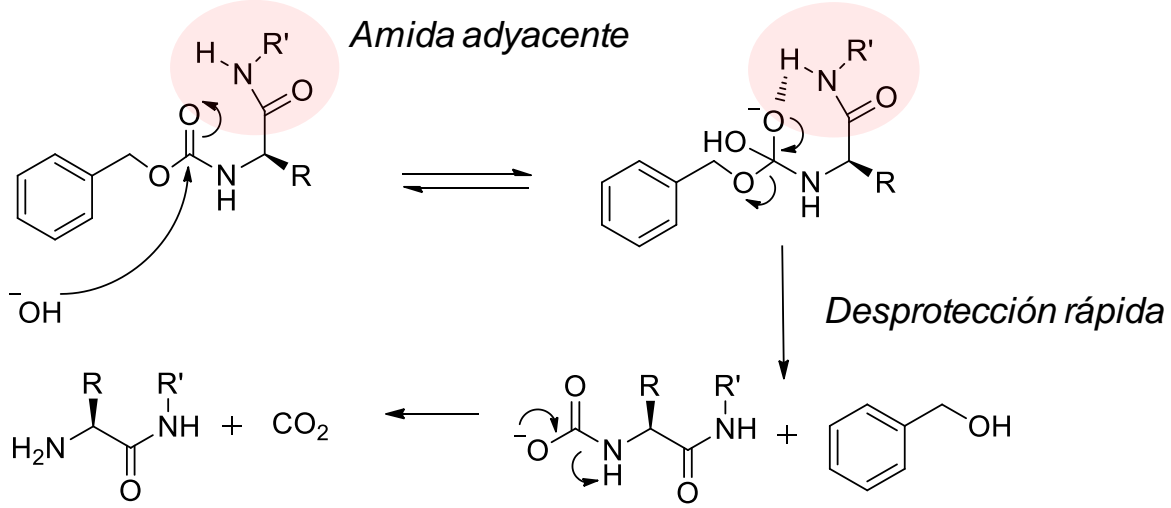

Figura A5 Mecanismo propuesto para la hidrólisis básica del grupo Z en presencia de una amida adyacente que da lugar a un intermedio tetraédrico.

\section{2) Tetrapéptidos ácidos formados por $D$ y $F$}

Afortunadamente todos los compuestos sintetizados han dado lugar a hidrogeles utilizando el cambio de $\mathrm{pH}$ como estímulo externo. Dichos hidrogeles han sido estudiados minuciosamente utilizando técnicas como la resonancia magnética nuclear, 
dicroísmo circular, microscopía de transmisión y de barrido, espectroscopia de infrarojo, fluorescencia, etc. Mediante este completo estudio se comprobó el efecto que causaba la disposición de los aminoácidos en esta cadena ya que dan lugar a redes fibrilares de morfologías y propiedades muy distintas.

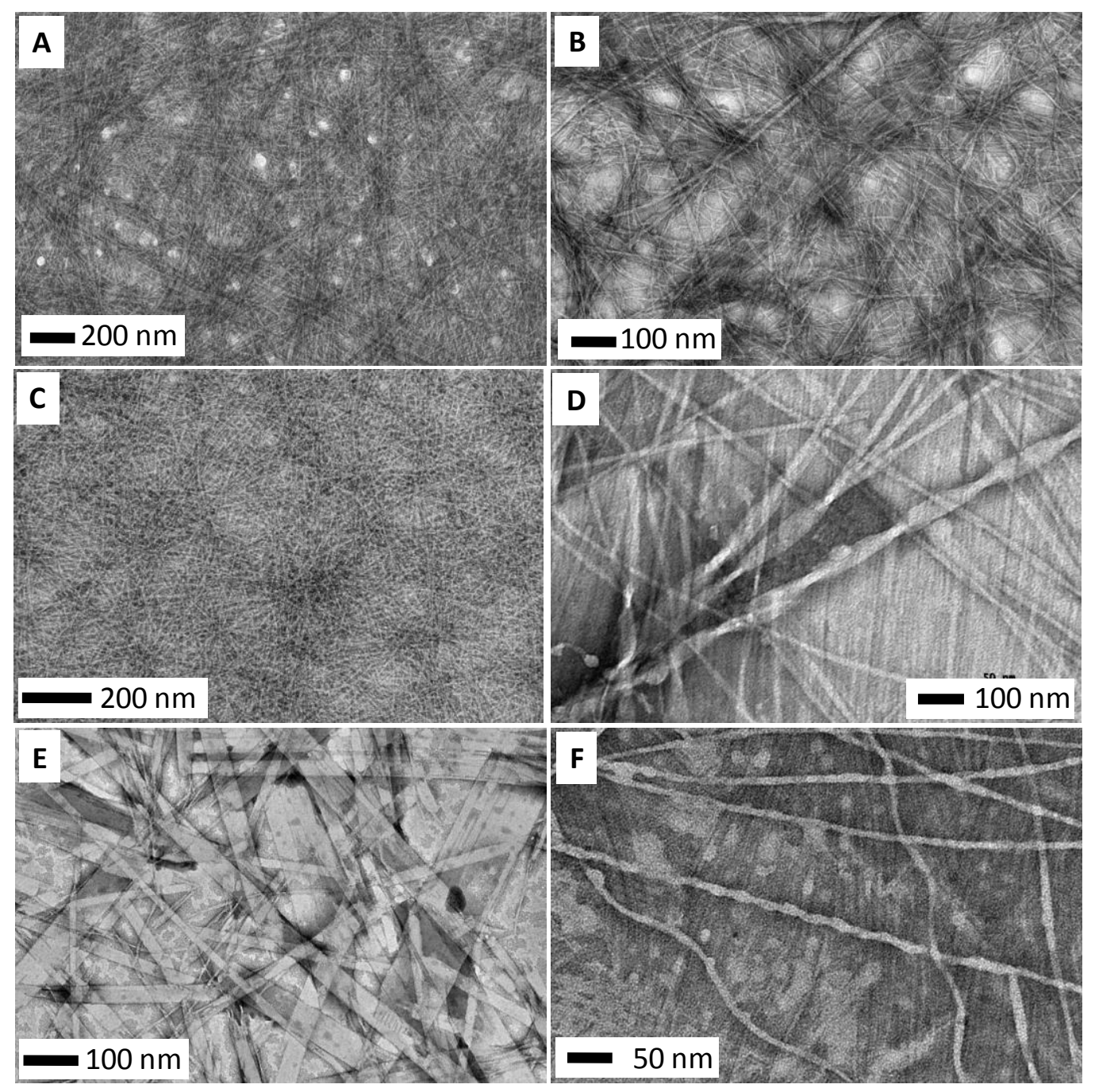

Figura $\mathbf{A 6}$ Imágenes de microscopía de transmisión de los the hidrogeles 1-6 a su concentración mínima de gelación. A) compuesto 1, B) 2, C) 3, D) 4, E) 5 and F) 6.

La combinación de los resultados experimentales con los modelos teóricos propuestos nos ha permitido observar el papel que tanto las interacciones hidrófobicas como aromáticas desempeñan en el proceso de agregación disponiendo bloques segregados de aminoácidos polares y no polares para los mejores hidrogelantes.

Continuando con los hidrogeles tetrapeptídicos se ha llevado a cabo un estudio referente a la termodinámica y cinética del proceso de fibrilación, a menudo aspectos no considerados durante la descripción de nuevos hidrogelantes. Se han determinado para ello constantes de solubilidad y acidez detectándose un aumento general del valor de 
pKa (en comparación con el pKa del ácido aspártico en disolución) a consecuencia de la agregación que permite la obtención de hidrogeles a valores de $\mathrm{pH}$ cercanos a la neutralidad. Estas diferencias de pKa están directamente relacionadas con la termodinámica de agregación. Por otro lado los estudios cinéticos nos han permitido detectar un periodo de inducción previo a la agregación para todos los compuestos aunque con diferencias significativas entre ellos. Dicho periodo contiene el tiempo necesario para alcanzar el valor de $\mathrm{pH}$ que da lugar a fibrilación (termodinámica) y además otro período en el cual se encuentran presentes especies metastables. Mediante experimentos de fluorescencia se ha detectado que el paso determinante en el proceso de fibrilación resulta ser la formación de dímeros probablemente debido a la energía de activación asociada a la reorganización estructural. Como consecuencia del conocimiento tanto termodinámico como cinético de estos sistemas se ha conseguido obtener geles metaestables en presencia de otros compuestos que forman agregados termodinámicamente más estables pero que permanecen en disolución (self-sorting cinético).

Teniendo en cuenta el papel que los péptidos pequeños desempeñan tanto como modelos o inhibidores de la agregación amiloide ${ }^{2 c}$ se ha decido probar la interacción entre los tetrapéptidos ácidos y el péptido amiloide $A \beta 1-40$ obteniendo resultados satisfactorios para al menos dos de los compuestos $(\mathbf{1}, \mathbf{5})$ que parecen funcionar como semillas (núcleos) para la agregación del péptido amiloide. Comparando nuestros resultados con otros previamente publicados resulta importante destacar que nuestros compuestos son de pequeño tamaño (cuatro aminoácidos) y además no poseen ningún fragmento contenido en dicha proteína.

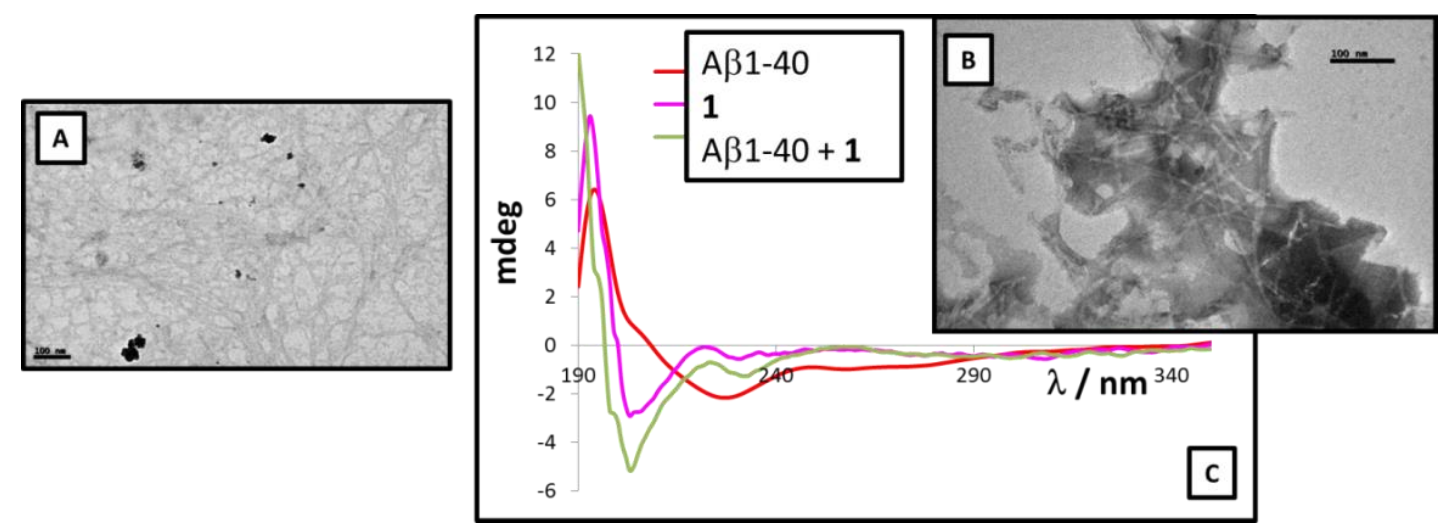

Figura A7 A) Fotografías microscopia de transmisión del A $\beta 1-40$ después de 7 días; B) Fotografías microscopia de transmisión de una mezcla equimolecular de A $\beta 1-40$ y el compuesto 1 . C) Dicroismo circular de los compuestos por separado y su mezcla equimolecular tras 7 días de incubación ( 37 으). 
3) Tetrapéptidos básicos formados por $K$ y $F$

Tras el estudio de los tetrapéptidos ácidos se han sintetizado dos análogos tetrapépticos básicos (7-8) que contienen lisina (K) en lugar de ácido aspártico (D). Además de formar geles en agua básica se ha logrado la coagregación a valores de pH neutros con los compuestos $\mathbf{1}$ y $\mathbf{2}$ utilizando para ello interacciones no covalentes. La metodología utilizada para ello ha sido mediante la inyección de sus componentes por separado en disolución dando lugar a hidrogeles homogéneos y transparentes con características idóneas para potenciales aplicaciones biológicas.

Utilizando el mismo concepto se han desarrollado además geles multicomponente capaces de mantener su estabilidad macroscópica en todo el rango de $\mathrm{pH}$. Dicho comportamiento es debido al intercambio que se establece entre redes coagregadas de dos componentes a $\mathrm{pH}$ neutro y redes formadas por un solo compuesto a valores ácidos o básicos de $\mathrm{pH}$ tal y como se ve reflejado en la Figure A8.

La singularidad de este sistema ha sido aprovechada para la liberación controlada de algunos colorantes teniendo en cuenta por un lado la estructura molecular de dichos compuestos y por otro lado las características particulares que presentan las diferentes redes co-ensambladas. 


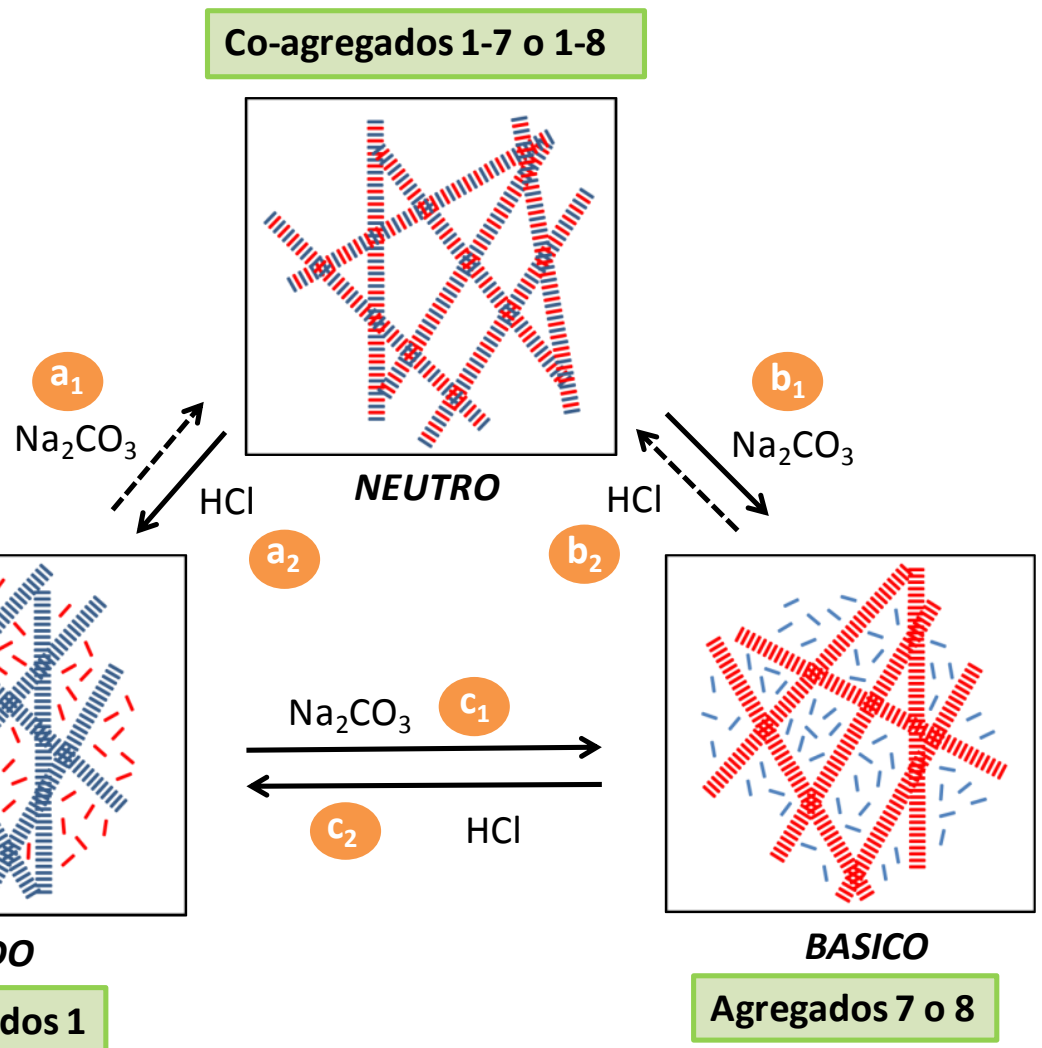

Figure A8 Representación esquemática de los geles multicomponentes sensibles al pH.

- 4) Tripéptidos anfifilicos formados por $P, F y E$

Por último, las propiedades catalíticas de la prolina en sitemas autoensamblados han sido ampliamente estudiadas, en colaboración con el profesor Ashkenasy de la Universidad Ben Gurinon (Israel), atendiendo a los precedentes publicados por el grupo. ${ }^{6}$
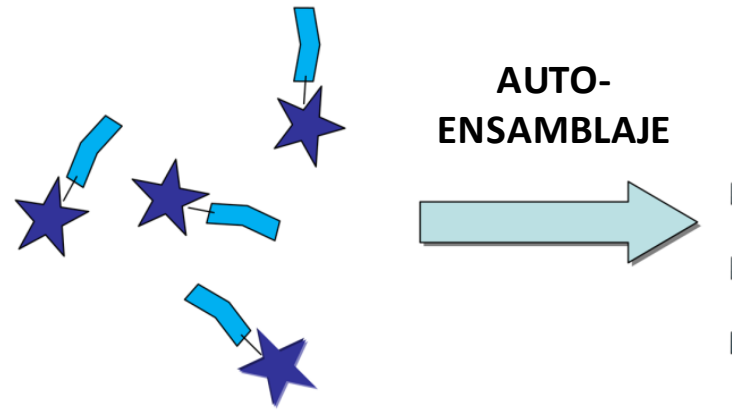

Fragmento funcional

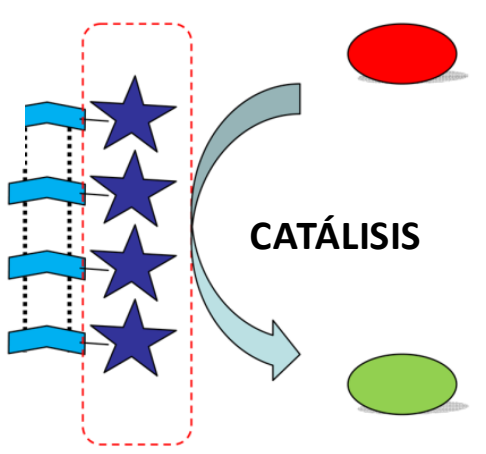

Reconocimiento y/o centros catalíticos

Para ello se han utilizado los compuestos 9-12 (Figure A4) en reacciones de condensación aldólica mostrando una clara influencia de la hidrofobicidad 
proporcionada por la cadena alifática del extremo C-terminal. Aquellos compuestos que formaron redes fibrilares en agua (10 y $\mathbf{1 2}$ ) resultaron activos en la formación de enlaces C-C mientras que los compuestos que permanecieron en disolución (9 y 11) resultaron inactivos. Estos sistemas catalíticos demuestran pues la emergencia de propiedades catalíticas debidas al autoensamblaje. Además el orden en la secuencia de aminoácidos influyó en los resultados obtenidos sugiriendo la formación de sitios catalíticos de diferente accesibilidad. Dichos compuestos sirvieron además de modelos para decapéptidos de secuencia semejante que resultaron también ser activos en reacciones aldólicas. Finalmente y tras conocer las propiedades catalíticas des estos compuestos se probó su efectividad en la obtención de productos biológicamente más relevantes de tipo carbohidratos.

\section{Conclusiones}

En resumen, durante el transcurso de la presente tesis doctoral se han diseñado y sintetizado con éxito nuevos hidrogelantes basados en péptidos anfipáticos de pequeño tamaño. Ambas metodologías empleadas para ello, tanto en disolución como en fase sólida han dado lugar a resultados satisfactorios pudiendo obtener los productos con elevado grado de pureza y suficiente en cantidad.

El estudio del proceso de agregación desarrollado sobre todo para los tetrapéptidos ácidos ha permitido poner de manifiesto lo importante que resulta el balance hidrofóbico/hidrofílico en el modo de agregación y propiedades de los sistemas finales. Profundizar en la termodinámica y cinética de este proceso ha permitido además discernir la etapa limitante del mismo y utilizar dicho conocimiento para la elaboración de sistemas multi-componente más complejos basados en especies termodinámicamente metaestables. Dichos estudios resultan de gran utilidad considerando que los péptidos son considerados buenos modelos de la agregación amiloide y que los fenómenos que aquí se presentan pueden observarse e incluso magnificarse en sistemas proteicos de mayor tamaño.

Por otro lado el co-ensamblaje entre dos compuestos opuestamente cargados ha permitido obtener geles cuya estabilidad se extiende a todo el rango de $\mathrm{pH}$. Dichos sistemas resultan de gran utilidad biológica puesto que pueden formarse a $\mathrm{pH}$ neutro sin necesidad de calentar o aplicar ningún otro estímulo externo simplemente mediante la 
mezcla de sus componentes por separado en disoluciones acuosas. Además se ha logrado modular la liberación de ciertos colorantes atendiendo a la estructura del mismo y de la red fibrilar que lo contiene.

Finalmente la aparición de propiedades catalíticas debidas al auto-ensamblaje ha sido demostrada para derivados anfifílicos que contienen prolina como fragmento funcional. La aparición de nuevas propiedades a consecuencia del autoensamblaje así como el papel fundamental que él mismo desempeña en la formación de compartimentos aislados confiere relevancia prebiótica a estos pequeños sistemas peptídicos agregados.

Los resultados obtenidos contribuyen pues al mejor entendimiento de este complejo proceso que representa la fibrilización.

\section{Referencias}

1. a) Knowles, T. P. J.; Vendruscolo, M.; Dobson, C. M., The amyloid state and its association with protein misfolding diseases. Nat. Rev. Mol. Cell Biol. 2014, 15, 384-396; b) Hamley, I. W., The amyloid $\beta$ peptide: A chemist's perspective role in Alzheimer's and fibrillization. Chem. Rev. 2012, 112, 5147-5192.

2. a) Lakshmanan, A.; Cheong, D. W.; Accardo, A.; Di Fabrizio, E.; Riekel, C.; Hauser, C. A. E., Aliphatic peptides show similar self-assembly to amyloid core sequences, challenging the importance of aromatic interactions in amyloidosis. Proc. Natl. Acad. Sci. 2013, 110, 519-524; b) Gazit, E., Self assembly of short aromatic peptides into amyloid fibrils and related nanostructures. Prion 2007, 1, 32-35; c) Hamley, I. W., Peptide fibrillization. Angew. Chem. Int. Ed. 2007, 46, 8128-8147; d) Gazit, E., Mechanisms of amyloid fibril self-assembly and inhibition. FEBS J. 2005, 272, 5971-5978.

3. a) Dasgupta, A.; Mondal, J. H.; Das, D., Peptide hydrogels. Rsc Advances 2013, 3, 9117-9149; b) Jonker, A. M.; Löwik, D. W. P. M.; van Hest, J. C. M., Peptide- and Protein-Based Hydrogels. Chem. Mater. 2012, 24, 759-773.

4. Escuder, B.; Miravet, J.F., Functional Molecular Gels. RSC 2013; pp 001-319.

5. Tena-Solsona, M.; Angulo-Pachón, C. A.; Escuder, B.; Miravet, J. F., Mechanistic insight into the lability of the benzyloxycarbonyl (Z) group in N-protected peptides under mild basic conditions. Eur. J. Org. Chem. 2014, 3372-3378.

6. a) Berdugo, C.; Miravet, J. F.; Escuder, B., Substrate selective catalytic molecular hydrogels: the role of the hydrophobic effect. Chem. Commun. 2013, 49, 1060810610; b) Rodríguez-Llansola, F.; Miravet, J. F.; Escuder, B., A supramolecular hydrogel as a reusable heterogeneous catalyst for the direct aldol reaction. Chem. Commun. 2009, 7303-7305. 
Compounds 1-8 (Tetrapeptides)

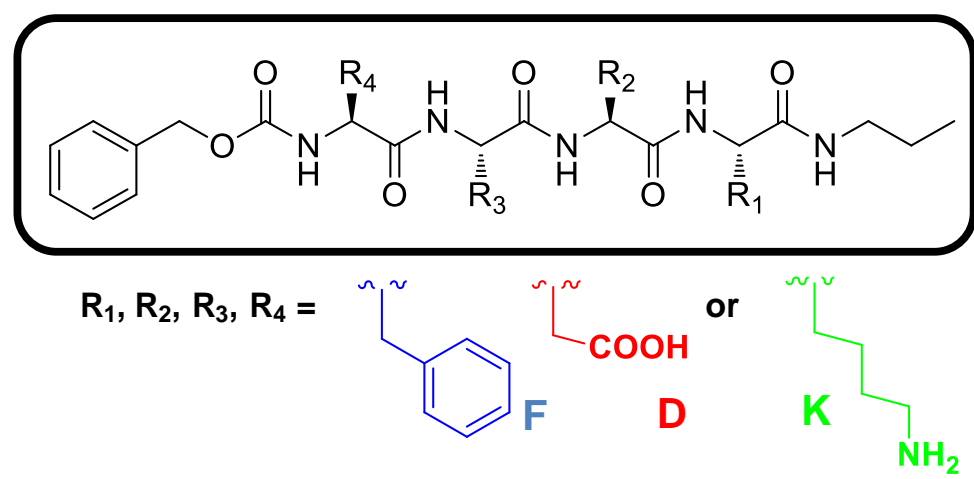

1ZFDFDC $_{3} \quad$ 4ZDDFFC $_{3} \quad$ 7ZFKFKC $_{3}$

$2 \mathrm{ZDFDFC}_{3} \quad \mathrm{5ZFDDFC}_{3} \quad \mathrm{ZZKFKFC}_{3}$

$3 \mathrm{ZFFDDC}_{3} \quad 6 \mathrm{ZDFFDC}_{3}$

Compounds 9-12 (Lipopeptides)

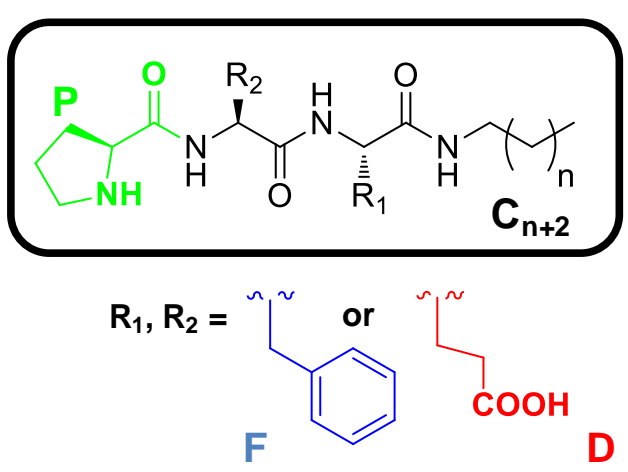

$$
\begin{array}{clll}
9 & \mathrm{PFEC}_{3} & 11 & \mathrm{PEFC}_{3} \\
10 \mathrm{PFEC}_{12} & 12 & \mathrm{PEFC}_{12}
\end{array}
$$

Compounds 27-28 (Decapeptides)

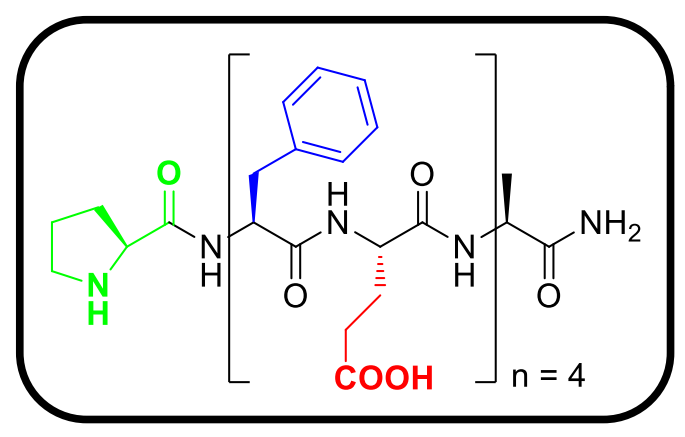

$27 \mathrm{P}(\mathrm{FE})_{4} \mathrm{ANH}_{2}$

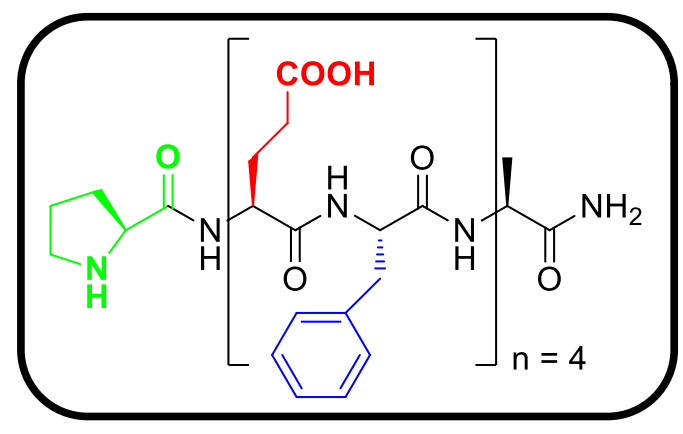

$28 \mathrm{P}(\mathrm{EF})_{4} \mathrm{ANH}_{2}$ 
Compounds 13-26

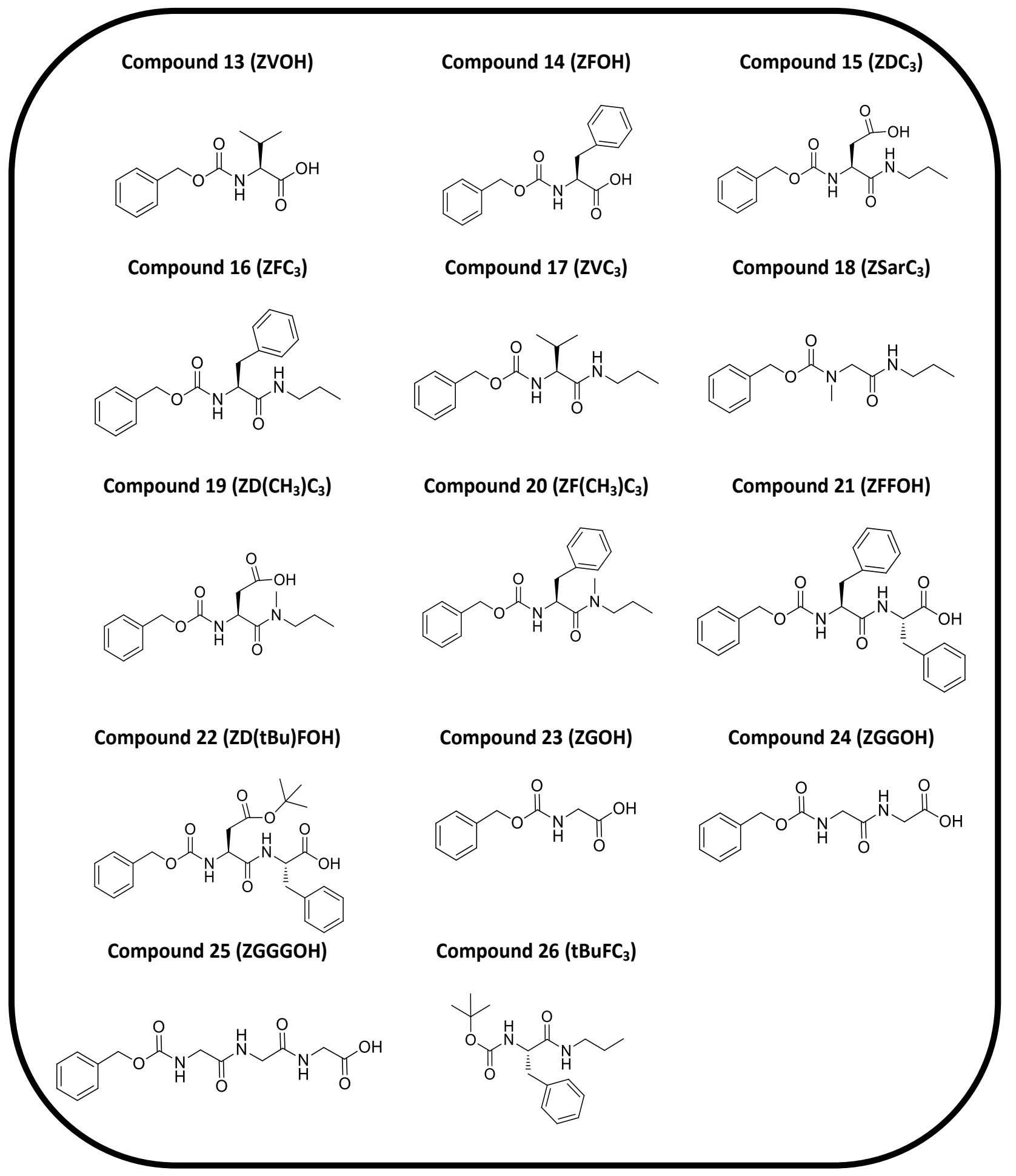

Aldehydes (29-31)

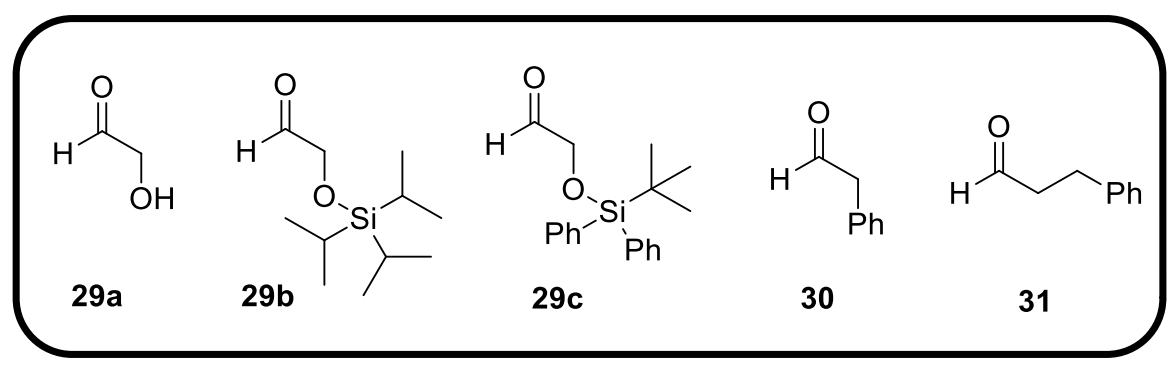



